\title{
Mexican Youth in Canada: A Political Economy Analysis of Motivations for Immigration, Labour Market Integration, and Transnational Practices
}

by

Alejandro Hernández-Ramírez

A thesis submitted to the Faculty of Graduate and Postdoctoral Affairs in partial fulfillment of the requirements for the degree of

\author{
Doctor of Philosophy \\ in
}

Sociology with a Specialization in Political Economy

Carleton University

Ottawa, Ontario

(C) 2019, Alejandro Hernández-Ramírez 


\section{Abstract}

This dissertation investigates and illuminates the factors that led 35 Mexican immigrant and refugee youth in Ottawa and Montreal to develop transnational practices. Among these factors are their class location before migration, motivations for immigration, and type of economic integration once in Canada. I identified three different types of economic integration among my participants, which were central in differently shaping their production of sociocultural, economic, and political transnational practices or lack thereof.

I contextualized these various processes in the historical and politico-economic context of Mexico and its relationship with Canada, a relationship mediated, in turn, by the one sustained between these two countries and the United States. In addition, I locate the particularities of Mexican immigration in the broader context of Latin American immigration to Canada, particularly since the 1970 s.

Making use of Bourdieusian theory, segmented markets theory, and a transnationalism approach, my dissertation responds to the limited scholarship on Latin Americans and transnationalism in Canada. This incipient Canadian literature contrasts to the rich scholarship produced in the United States since the late 1980s around the Mexico-United States migration circuit.

My analysis thus offers a complex account of how transnationalism from below is shaped by immigrants and refugees' pre- and post-migration class location (including migration status, age, and gender). It is also shaped from above under a Canadian immigration model that privileges economic immigration over family and humanitarian immigration, along with the expansion of Canadian, Mexican, and global capital.

The comparison of economic integration among immigrants and refugees living in a small, Anglo-Canadian (capital) city vis-à-vis those living in a sizable French-Canadian city (Ottawa and Montreal respectively) also offered an interesting insight. For instance, I illuminate the effects that the expansion and accumulation of (trans)national and global capital have in shaping national and sub-national models of immigration and integration in Canada.

Finally, my research also contributes to the understanding of the little explored arena of reasons for immigration, types of economic integration, and transnational practices of high-skilled and educated immigrants. The traditional emphasis of Canadian and American literature on lowskilled workers has not assisted us in having a better understanding of the economic integration experiences of (Mexican) skilled immigrants, and the extent to which they generate transnational practices and ties in the North American region. 


\section{Acknowledgements}

I acknowledge and thank the Omàmiwininìwag for my being able to write this article in the traditional and unceded territory of the Algonquin nation.

I thank Dr. Daiva Stasiulis for her continuous support as my supervisor during the $\mathrm{PhD}$ process, as well as Dr. Laura Macdonald and Dr. Xiaobei Chen for their insightful comments and critiques as members of the comprehensive exams and dissertation committees. I also thank Dr. Cristina Rojas and Dr. Marianne H. Marchand for their generosity and willingness to serve as internal and external examiners in the $\mathrm{PhD}$ dissertation examination board respectively. This was despite their continuous international travelling and heavy workload in the summer of 2019.

I thank those young Mexican and Mexican-Canadian women and men in Ottawa and Montreal who generously shared their time and life experiences as immigrants and refugees with me. For some youths, their life stories have been marked by extremely painful experiences, but also by a great deal of agency, resilience, and resistance. Youths also spoke about their re-learning processes in a new milieu, their transformation of identities, and the positive things and advantages that they have found in Canada.

I also thank those who kindly assisted me during the recruitment process, a crucial aspect in any research endeavor: Martha Lucía Chaparro Pacheco (Red Cross), Ledianis Rivero Sosa (World Skills), Dr. Valerie Stam (City for All Women Initiative - CAWI), Sonia Gómez (Punto de Encuentro, CKCU), Félix Grande (Amanecer Ranchero, CHUO), Camila Reimers, Mónica Muraira (Consejo Consultivo del Instituto de los Mexicanos en el Exterior), Dr. Luis Abanto Rojas (University of Ottawa), Dr. Daniel Buckles (Carleton University), Dr. Pablo Mendez (Carleton University), Dr. Luisa Veronis (University of Ottawa), Dr. Victoria Simmons (Mount Royal University), Javier Clavelo Robinson (Catholic Centre for Immigrants), Dr. Gabrielle Etcheverry (Livres Canada Books), Dr. Jacqueline Kennelly (Carleton University), Dr. Helin Burkay (Innovation, Science and Economic Development Canada), Dr. Gerardo Barajas Garrido (CEIMEXCAN), Dr. Francisco Ucán Marín (CEIMEXCAN), Donna Coghill (Carleton University), Emilie Hayes (Somerset West Community Health Centre), Erin Leigh (Ottawa Coalition to End Violence Against Women), Gillian Keefe (South-East Ottawa Community Health Centre), Ana da Silva Soares, Norbert Piché (Jesuit Refugee Service - Canada), Gabriela López (Rogers), Cintia Gillam (Saint Mary’s University), Manuel Ardila (Alliance pour l'accueil et l'intégration des immigrants-es), Ana Daza, María Teresa García (Catholic Centre for Immigrants), Yasmina Proveyer (YMCA Ottawa), Atoosa Adnani (World Skills), Javier Clavelo Robinson (Catholic Centre for Immigrants), Alberto Foncerrada Berúmen (Embassy of Mexico in Canada), Miguel Arévalo (Scalabrini Centre for Refugees and Immigrants), and the team of Montreal Hispano. 
A heartfelt thanks to Paula Whissell (Departmental Administrator), Kim Mitchell (Undergraduate Program Administrator), Darlene Moss (Graduate Program Administrator), and Stephanie LeBlanc (Administrative Assistant) in the Department of Sociology and Anthropology; as well as Donna Coghill (Administrator) in the Institute of Political Economy, Ann Anderson (Departmental Administrator) in the Department of History, and Tammy Tracey (Undergraduate Administrator) in Latin American and Caribbean Studies for their constant support. You are the backbone of Carleton University!

Thanks to Dr. Aaron Doyle (Chair of the Sociology and Anthropology department) and Dr. Alexis Shotwell (Sociology Graduate Program Coordinator) for their valuable advice and dedicated assistance in the final stage of the $\mathrm{PhD}$ program.

I also want to thank those colleagues and friends who belong to the Latin American cluster, and with whom I have shared a great time: Dr. Andrea Carreón, Dr. Laura Macdonald, Dr. Cristina Rojas, Dr. Lucy Lucissano, Dr. Paula Mauruto, Dr. Jill Wigle, Lorena Zarate, Ana Cuesta, José Bustamante, Dr. Daniel Tubb, Jael Mercedes Duarte, Kirsten Francescone, and Vladimir Díaz Cuellar.

I thank those who also supported me along the PhD pathway in different capacities and who have enriched my academic and personal experience: Dr. Luin Goldring, Dr. Tanya Basok, Dr. James Milner, Dr. Alan Simmons, Dr. Valerie Stam, Dr. Evelyn Encalada Grez, Dr. Ajay Parasram, Dr. Victoria Simmons, Dr. Jiyoung Lee-Ann, Kevin Patridge, and Dr. Luisa Veronis.

I also want to acknowledge some members from Metropolis and Migration and Diaspora Studies (MDS), with whom I collaborated in different capacities: Dr. Howard Duncan (Executive Head of the Metropolis Project and Secretariat), Dr. James Milner (Political Science), Dr. Daniel McNeil (History), and Dr. Jeff Sahadeo (Political Science).

I thank Ümit Mustafa Kiziltan (Director General of NHQ - Research and Evaluation), Chu Dou Lynhiavu (A/Assistant Director, Research and Evaluation), and Régine Cirondeye (Research Analyst, Research and Evaluation) from Immigration, Refugees and Citizenship Canada for their support in obtaining IRCC specialized databases.

This work was supported by a Vanier Canada Graduate Scholarship, a Conacyt scholarship, the Graduate Research and Innovative Thinking (GRIT) Award, the Norman Pollock Memorial Award for Latin American Studies, the Indira Gandhi Memorial Fellowship, the Directors of the Institute of Political Economy Prize 2014-2015, and the GSA International Student Award 2013-2014. 


\section{Table of Contents}

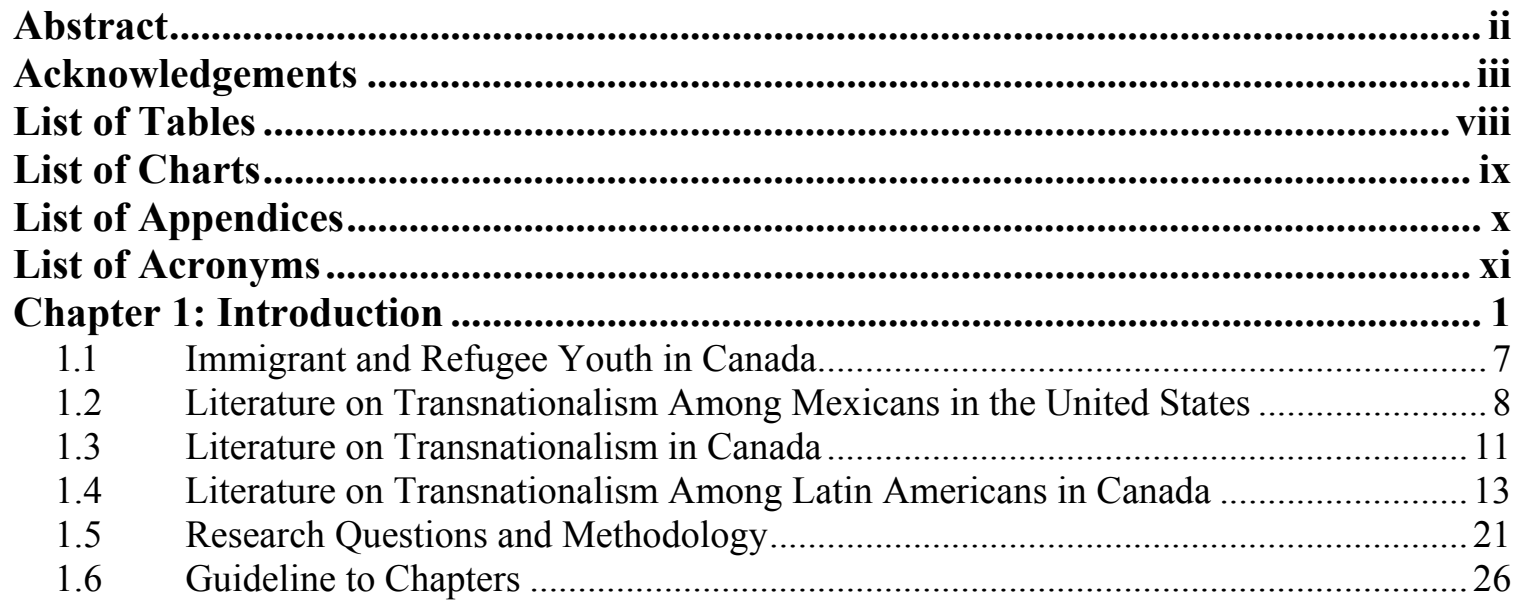

Chapter 2: Theoretical Approaches to Immigrant and Refugee Youth's Economic

Integration and Transnational Practices ................................................................ 28

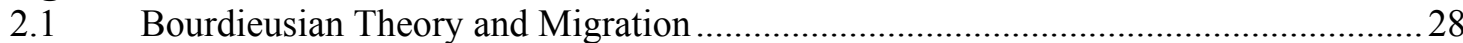

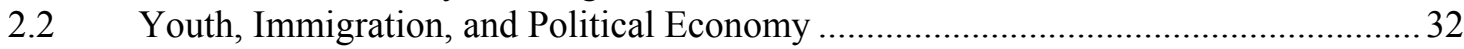

2.3 Perspectives on Transnationalism and Transnational Practices .................................. 41

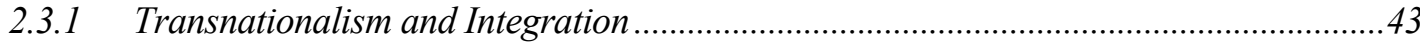

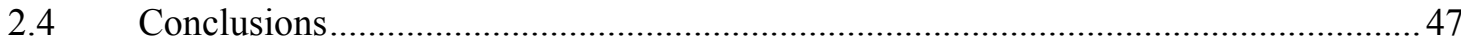

Chapter 3: So Far from Canada, So Close to the United States: Mexico and

Canada's Historical, Political, and Economic Relations ......................................... 49

3.1 Mexican (Im)Migration to the United States: Historical and Politico-Economic

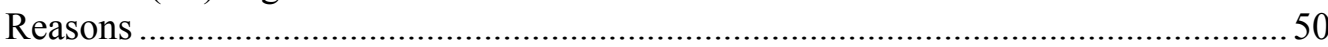

3.2 Mexico and Canada's Relationship: An On-Again-and-Off-Again Thin Relationship...

3.3 Conclusions

Chapter 4: Mexican Immigration to Canada: The Needed Economic Immigrant vs.

the Unwanted "Bogus" Refugee .......................................................................... 79

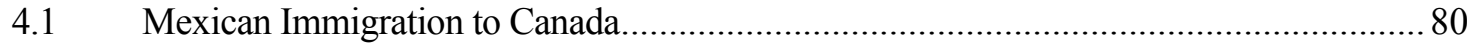

4.1.1 What Do We Know About Mexicans In Canada? .........................................................86

4.2 The Bogus Refugee Vis-à-Vis Multifaceted Forms of Insecurity and Violence in

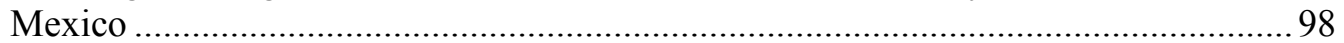

4.2.1 The Mexican State-Criminality Symbiosis .............................................................. 103

4.2.2 The Production of Multifaceted Forms of Violence \& Mexican Refugee Applications......

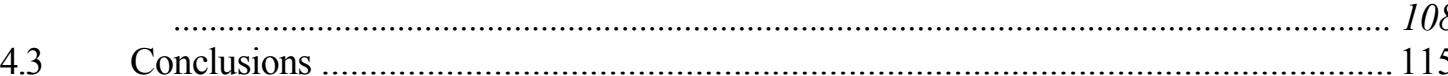

Chapter 5: Mexican Immigrant and Refugee Youth's Micro-Level Motivations for

Immigration ....................................................................................................... 118

5.1 The Myth of all Mexicans in Canada as Middle-Class and Educated People............ 119

5.2 Why Did Young Mexicans Immigrate to Ottawa and Montreal?.............................. 125

5.3 A Desire to Improve Life Conditions Does Not Necessarily Mean Immediate

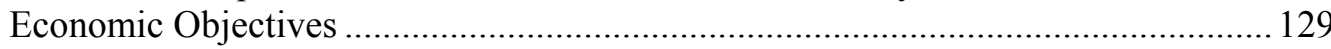

5.4 Making Canada Home: International Students and Skilled Temporary Migrants Putting Down Roots in Canada............................................................................. 136

5.5 Unexpected Immigration by Marriage and Other Relatives Sponsorship Processes . 138

5.5.1 Effect of Gender in Immigration Sponsorship Processes ......................................... 145

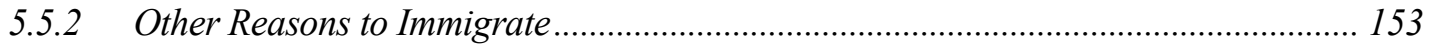


5.6 Discussion: Mexican Youth's Micro-Level Reasons for Immigration to Canada ..... 156

Chapter 6: Mexican Youth's Macro-Level Motivations for Immigration ............... 160

6.1 Mexico-Canada Transnational Connections and Their Effect on Immigration .......... 161

6.2 Escaping from Increased and Multifaceted Forms of Violence in Mexico................ 169

6.3 Escaping from Economic Crises and In Search of Better Opportunities ..................... 177

6.4 Discussion: Mexican Youth's Macro-Level Reasons for Immigration to Canada .... 180

Chapter 7: The Independent Type of Economic Integration.................................. 185

7.1 Mexican Youth's Distribution Across Labour Market Integration Types .................. 186

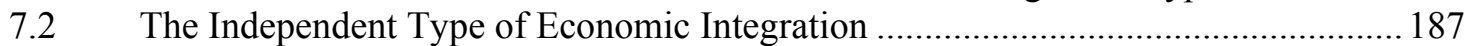

7.3 The Relevance of Language and Canadian Education (Canadian Capital) ................ 188

7.4 Employment Trajectories Leading to an Independent Type of Integration ................ 191

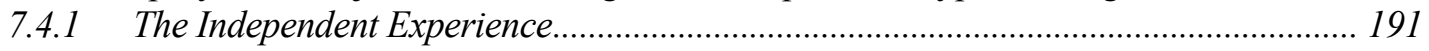

7.4.1.1 The Secondary $\Rightarrow$ Subordinate $\Rightarrow$ Independent Trajectory .......................................193

7.4.1.2 The Secondary $\Rightarrow$ Independent Trajectory............................................................196

7.4.1.3 The Subordinate $\Rightarrow$ Independent Trajectory.............................................................197

7.4.1.4 Independent Economic Integration by Extension .........................................................198

7.4.2 The Role of Gender in the Independent Type of Integration......................................... 200

7.4.3 Canada's Labour Market Configurations and North American Economies in a Global

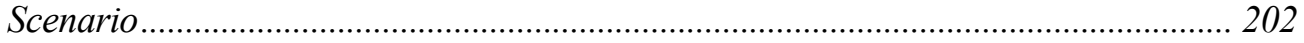

7.5 Discussion: Pre- and Post-Migration Locations Leading to an Independent Location....

Chapter 8: The Subordinate Type of Economic Integration ........................................ 216

8.1 The Relevance of Official Languages and Canadian Education (Canadian Capital) .......

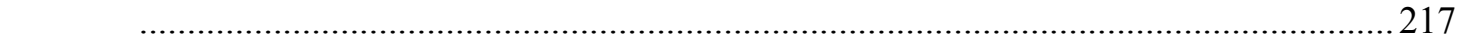

8.2 Employment Trajectories of Mexican Immigrant and Refugee Youth in Canada.....222

8.3 The Role of Gender and Sexuality in the Secondary Type of Integration ................. 235

8.4 Discussion: Subordinate Integration in a Changing Labour Market Landscape ........ 237

Chapter 9: The Secondary Type of Economic Integration ........................................ 253

9.1 Lack of Official Languages and Canadian Education as Downward Economic

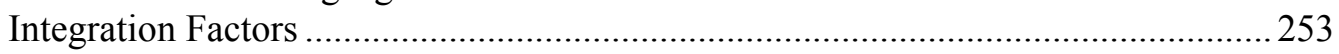

9.2 Employment Trajectories of Mexican Immigrant and Refugee Youth in Canada .....261

9.3 Strategies to Find Jobs Under Limited Possession of Capitals ................................ 270

9.4 Health Risks Within the Secondary Type of Economic Integration...........................2 274

9.5 Discussion: Absence or Misrecognition of Capitals and Secondary Integration........277

Chapter 10: The Shaping of Transnational Practices by Pre- and Post Migration

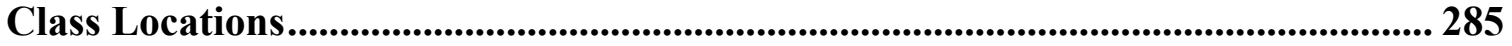

10.1 To Be There and Not to Be There: Transnational Relationships Across Mexico and

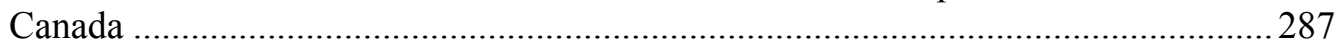

10.2 Systems of Support Among Family Members and Friends Across Borders...............292

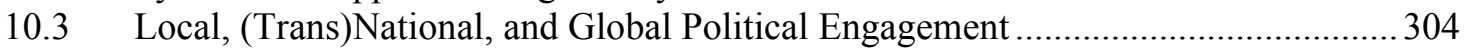

10.3.1 Transnational Political Engagement and the Independent Type of Integration ........... 306

10.3.2 Transnational Political Engagement and the Subordinate Type of Integration ........... 309

10.3.3 Transnational Political Engagement and the Secondary Type of Integration.............. 313

10.4 Discussion: The Shaping of Transnational Participation Among Mexican Youth in

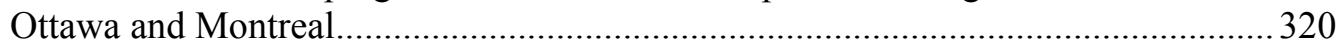

10.4.1 Maintenance of Social Relations and Generation of Support Across Borders ............. 320

10.4.2 Economic Integration in Canada and Political Engagement at Various Levels .......... 327

Chapter 11: Conclusions: Mexican Immigration to Canada: Contexts, Reasons, Economic Integration, and Transnationalism........................................................... 339

11.1 Mexican Immigrant and Refugee Youths' Types of Economic Integration ................ 344 
11.2 The Shaping of Transnational Practices by Pre- and Post-Migration Class Locations....

113 Contributions of the Research

Appendix A................................................................................................................... 365

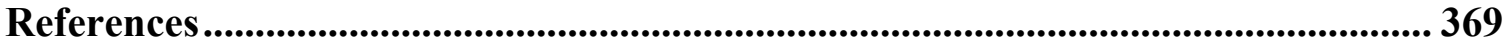




\section{List of Tables}

Comparison of Independent, Subordinate, and Secondary Market Segments

Table 1

After-Tax Low-Income Measure (LIM-AT) For Various Ethnic Groups in Private Households, 2011

Table 2

After-Tax Low-Income Measure (LIM-AT) For Various Ethnic Groups in Private Households, 2015

Table 3

Distribution of Mexican Youth by Immigration Class in Ottawa and Montreal Table 4

Mexican Youth in Ottawa by Sex, Age at Arrival, Immigration Class, and Time to Obtain PR Status

Table 5

Mexican Youth in Montreal by Sex, Age at Arrival, Immigration Class, and Time to Obtain PR Status

Table 6

Types of Economic Integration by City (i.e. Ottawa and Montreal) and Gender Table 7

Mexican Youth in an Independent Type of Integration by Gender, City, and Immigration Class

Table 8

Mexican Youth in a Subordinate Type of Integration by Gender, City, and Immigration Class

Table 9

Mexican Youth in a Secondary Type of Integration by Gender, City, and Immigration Class

Table 10

p. 254 


\section{List of Charts}

Admissions of Mexicans as Permanent Residents in Canada, 1980-2017

Chart 1

p. 3

Refugee Protection Claims by Mexicans, 1998-2018

Chart 2

p. 97

Location of Mexican Youth in Ottawa and Montreal by Type of Integration

Chart 3

p. 187 


\section{List of Appendices}

Appendix A 


\section{List of Acronyms}

\begin{tabular}{|c|c|}
\hline BA & Bachelor of Arts \\
\hline CAIR & Canadian Agricultural Injury Reporting \\
\hline CBSA & Canada Border Services Agency \\
\hline $\mathrm{CCR}$ & Canadian Council for Refugees \\
\hline $\mathrm{CDP}$ & Country Documentation Package \\
\hline CECP & Economic, Canadian Experience Class Program \\
\hline CEGEP & Collège d'Enseignement Général et Professionnel \\
\hline CIC & Citizenship and Immigration Canada \\
\hline CONACYT & National Council of Science and Technology \\
\hline CSQ & Certificat de Sélection du Québec \\
\hline CUSMA & Canada-United States-Mexico Agreement \\
\hline CYB & Canada Year Books \\
\hline DCO & Designated Countries of Origin \\
\hline DFAIT & Department of Foreign Affairs, Trade and Development \\
\hline DGQM & Délégation Générale du Québec à Mexico \\
\hline DHS & Department of Homeland Security \\
\hline EAL & English as an Additional Language \\
\hline FBI & Federal Bureau of Investigation \\
\hline FIDH & Fédération Internationale des Ligues des Droits de l'Homme \\
\hline FSWP & Federal Skilled Worker Program \\
\hline GBV & Gender-Based Violence \\
\hline GCIM & Global Commission on International Migration \\
\hline GDP & Gross Domestic Product \\
\hline GTA & Greater Toronto Area \\
\hline HIV & Human Immunodeficiency Virus \\
\hline HRW & Human Rights Watch \\
\hline ICE & U.S. Immigration and Customs Enforcement \\
\hline IDMC & Internal Displacement Monitoring Centre \\
\hline IME & Institute of Mexicans Abroad or Instituto de los Mexicanos en el Exterior \\
\hline IMP & International Mobility Program \\
\hline IRB & Immigration and Refugee Board \\
\hline IRCC & Immigration, Refugees and Citizenship Canada \\
\hline LGBTIQ+ & $\begin{array}{l}\text { Lesbian, Gay, Bisexual, Transgender, Intersex, Queer, and other sexual } \\
\text { orientations/identities }\end{array}$ \\
\hline LICO-AT & Low-Income Cut-Offs After-Tax \\
\hline LIM-AT & Low-Income Measure After-Tax \\
\hline LMO & Labour Market Opinion \\
\hline M-18 & Calle 18 \\
\hline
\end{tabular}




$\begin{array}{ll}\text { MA } & \text { Master of Arts } \\ \text { MS-13 } & \text { Mara Salvatruchas } \\ \text { NAFTA } & \text { North American Free Trade Agreement } \\ \text { NGO } & \text { Non-governmental organization } \\ \text { NDP } & \text { New Democratic Party } \\ \text { OAS } & \text { Organization of American States } \\ \text { OMCT } & \text { World Organization Against Torture } \\ \text { OPME } & \text { Presidential Office for Mexicans Abroad or Oficina Presidencial para los } \\ & \text { Mexicanos en el Exterior } \\ \text { OSAP } & \text { Ontario Student Assistance Program } \\ \text { PCME } & \text { Mexican Community Abroad Assistance Program or Programa para las } \\ & \text { Comunidades Mexicanas en el Exterior } \\ \text { PGWP } & \text { Post-Graduation Work Permit } \\ \text { PR } & \text { Permanent Resident } \\ \text { PRI } & \text { Institutional Revolutionary Party } \\ \text { QEP } & \text { Quebec Experience Program } \\ \text { QRSWP } & \text { Quebec Regular Skilled Worker Program } \\ \text { SAWP } & \text { Seasonal Agricultural Workers Program } \\ \text { SEGOB } & \text { Ministry of Internal Affairs } \\ \text { SOGIE } & \text { Sexual Orientation and Gender Identity and Expression } \\ \text { TFWP } & \text { Temporary Foreign Worker Program } \\ \text { UNAM } & \text { National Autonomous University of Mexico } \\ \text { UNICEF } & \text { United Nations Children's Fund is a United Nations } \\ \text { UQAM } & \text { Université du Québec à Montréal } \\ \text { WTO } & \text { World Trade Organization } \\ \text { WWII } & \text { World War II }\end{array}$




\section{Chapter 1: Introduction}

In this dissertation, I analyze the involvement of Mexican immigrant and refugee youth, aged 18 to 35 and living in Ottawa and Montreal, in transnational practices. My research placed specific focus on the significance of immigration motivations, pre-migration class location and post-migration economic integration of these youth. This is because I contend that the type of economic integration, along with pre- and post-migration resources, shapes the extent of involvement of youth in border-spanning sociocultural, economic, and political practices. In some cases, however, a combination of these factors accounted for the youths' limited involvement in transnational practices. I contextualize these factors and processes in the historical and politicoeconomic context of Mexico and the relationship between Canada and Mexico, the latter also mediated by the relationship that these two countries have had with the United States. In addition, I situate the particularities of Mexican immigration in the broader phenomenon of Latin American immigration to Canada, particularly since the 1970s.

My research responds to the limited scholarship on transnationalism in Canada, particularly among Latin Americans, which contrasts with the rich scholarship produced in the United States since the late 1980s around the Mexico-United States migration circuit. As Goldring (2006:181) contends, "[f]urther research is needed on Latin Americans in Canada to document their transnational activities more systematically. Such work should contribute to comparative analyses that stress the importance of legal status, migratory history, broader historical context, contexts of departure, and contexts of reception."

The limited knowledge about Latin American transnationalism in Canada - and Mexican transnationalism in particular - is explained by three factors. First, much of the Latin American migration to Canada is a relatively recent phenomenon, originating after Canada's acceptance of Chilean, Salvadoran, and Guatemalan (Mayan and mestizo) refugees in the late 1970s (Díaz 2011; IRCC 2016a; Landolt 2007b; Nolin Hanlon 2000, 2004; Peddie 2014; Snow 2013). For example, Mexican immigration to Canada dates from at least 1875, with registries showing two 
Mexicans living in Vancouver at that time (Berdichewsky 2007). Nonetheless, it is until the 1990s and particularly the mid-2000s when their presence gradually increased, with an average of 1,217 and 2,436 persons arriving per year respectively (between 1918 and 1979, only 8,907 Mexicans arrived in Canada) (IRCC 2016a, 2019b).

Moreover, the imposition of the visa on Mexicans on July 14, 2009 did not seem to immediately influence the number of Mexicans accepted as permanent residents (PR) and landing in Canada (see Chart 1). Indeed, their number increased between 2010 and 2014, with an average of 4,102 persons landing per year (out of an average of 251,000 immigrants landing per year between 2001 and 2015). A slight reduction is observed, however, between 2015 and 2017, with an average of 3,255 persons landing per year (IRCC 2016a, 2019b). A couple of potential explanations for this may be that the effect of the visa, which effectively halted refugee applications, was only visible until most of the refugee applications were resolved and, perhaps, because more immigrants used the economic class to escape from increased violence in Mexico. Thus, the 2015 numbers may show a more regular distribution, where most applications were made by economic immigrants discounting increased refugee applications.

When compared to other national groups, Mexican immigrants landing with PR status ranked 27 among all 219 national groups landing in Canada between 1980 and 2017 (IRCC 2016a, 2019b). Mexico only comes after other Latin American and Caribbean countries such as Jamaica (ranking 14), Haiti (ranking 17), Colombia (ranking 20) and Guyana (ranking 24). India, China, the Philippines, the United Kingdom, Pakistan, and the United States rank 1 to 6 respectively (ibid.).

Second, since the Latin American community in Canada is "an extremely heterogeneous group in terms of national, ethnic/racial, socioeconomic, cultural, political, and even religious backgrounds" (Veronis 2006a:19), it is difficult to do comprehensive studies about this broad and diverse community. In contrast to relatively more 'homogeneous' and 'older' ethnic immigrant groups such as Italians and Ukrainians, about whom numerous studies have been written in 
Canada, Latin Americans come from 17 different countries where Spanish, Portuguese and Indigenous languages such as Quechua, Maya, and Guaraní are spoken. ${ }^{1}$ And third, research about Mexicans in Canada is still sparse. This is a curious lacuna given that Mexican immigration has been constituted as one of the most significant streams of Latin American immigration to Canada since the 2000s (Statistics Canada 2014). Moreover, Mexico is Canada's third largest international merchandise trading partner after China (Embassy of Canada in Mexico 2016; Gowans 2016), a partner in NAFTA and potentially CUSMA, and geographically not so distant.

\section{Chart 1}

Admissions of Mexicans as Permanent Residents in Canada, 1980-2017

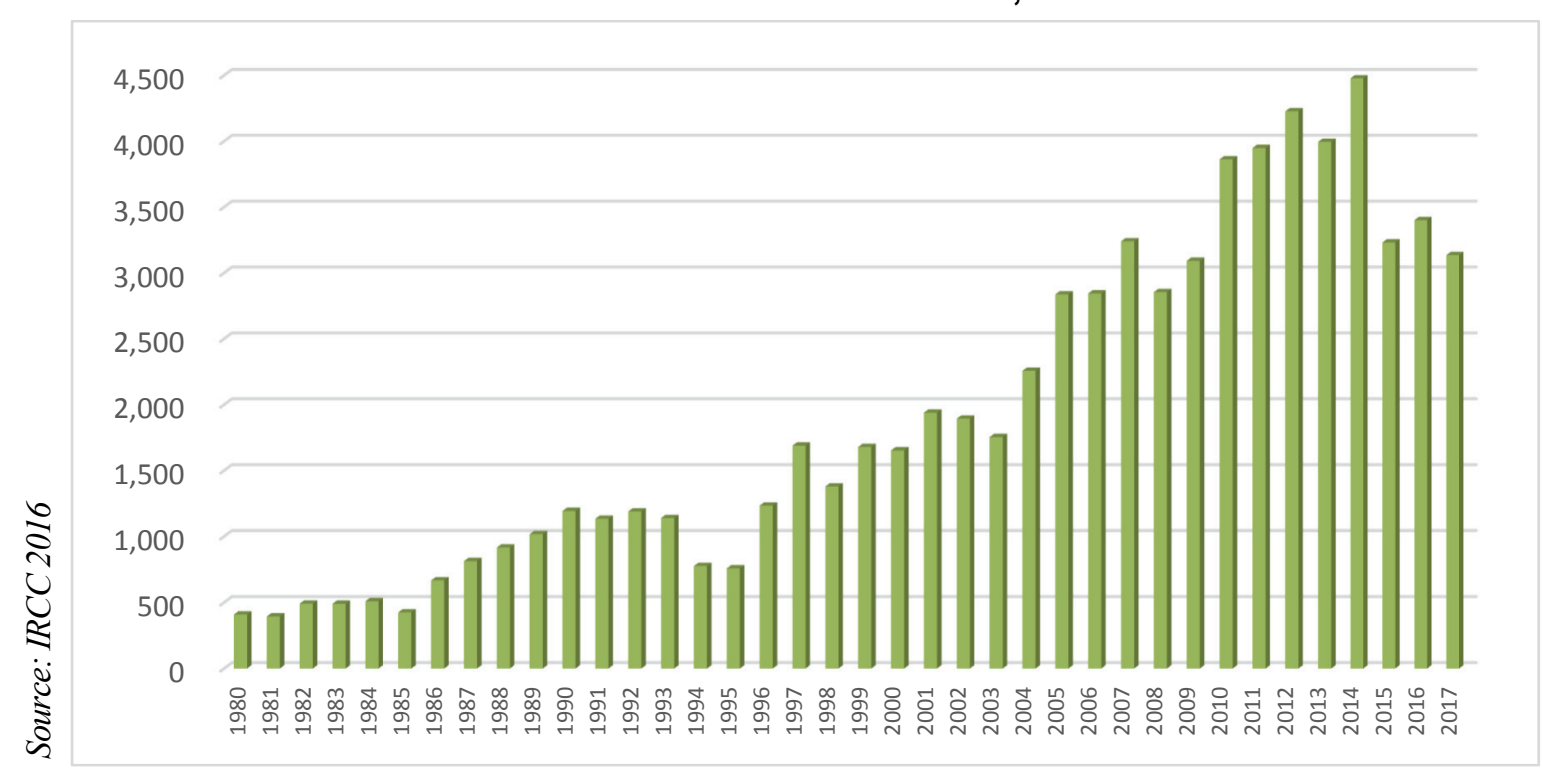

My analysis also highlights the significance of the class location of Mexican youth. As Van Hear (2014) contends, scholars' long-established emphasis on studying social class as the driving factor of migration has led much of the current migration research to favour the analysis of other factors such as ethnicity, gender, and more recently religion, overlooking the effect of social class. However, social class is relevant in understanding how it differently shapes immigrants and refugees' experiences after migration. In Canada, for example, Low-Income Measure After-Tax (LIM-AT) data, ${ }^{2}$ a proxy to measure poverty, indicates that Mexicans had higher poverty levels than Canadians and Québécois(es) in 2011 (see Table 2 in page 86), particularly in Montreal, followed by 
Quebec (i.e. they had low income percentage differences of $28.3 \%$ and $24.9 \%$ vis-à-vis Canadians and $19.3 \%$ and $17.7 \%$ vis-à-vis Québécois(es) respectively) (Statistics Canada 2014).

In addition, in recent years, sparse research has focused on social class and its impact on transnational activities. Norma, a young Mexican woman I interviewed in Montreal, exemplifies the relevance of class location in the construction of Mexican transnationalism in Canada. Along with other Mexicans, she protested at the Día de Muertos $^{3}$ celebration at the Mexican consulate in Montreal:

We took over the altar of the [Mexican] consulate. We decided to intervene because they were going to make a very nice altar dedicated to Octavio Paz and a poet from here, a Québécois. We thought that that was a travesty because everything related to Ayotzinapa was occurring, ${ }^{4}$ so much violence. [They were acting] as if nothing had happened in Mexico, right? Then we made a very beautiful live altar! We arrived all in black, little by little. We started to put on makeup there, [...] we painted our faces with skulls, we [symbolically] put the remains of the Ayotzinapa [Indigenous] youth [in the altar] so as not to forget them. So, we honoured [other] dead people for different reasons, and then we brought a coffin and made a procession there. [...] And in fact, people began congratulating the Consul: 'Wow!' 'How incredible!' 'Is this part of the altar?' Because they had a beautiful altar, right? All the posh Mexicans were there with the Consul. And then the underclass arrived, that's us, ha, ha. And quietly they called the police. The police looked around and said that nothing was happening, that people were having a great time, right? So, police did nothing. And we spoiled their party because we were there for hours. And they wanted us to leave for them to have chocolate and bread. And we were like: 'What's going on with these people?' I mean, the country is falling apart.

Moreover, immigrants' and refugees' ties to the country of origin, such as those displayed by Norma's political protest, have long been regarded with suspicion by various publics in receiving states and even by scholars (cf. Huntington 1996). These bonds to homelands are often read as a threat to the 'host' nation-state and a sign of immigrants being disloyal, unpatriotic, or worse — in certain cases — acting as criminals (Goldring, Henders, and Vandergeest 2003:16). My research challenges these perspectives by examining and accounting for Mexican youth's engagement in transnational practices that stem, to a degree, from a sense of greater belonging to Canada. This makes some Mexican youth feel comfortable and engaged enough to, for example, protest both Mexican and Canadian politics. 
Migration literature also tends to be adult-centric. This is partly because youth has been understood and constructed for too long as a sandbox-like stage towards adulthood, rather than this being recognized as one more of various socially constructed life dimensions that impact broader societal processes. Moreover, much of the 1980's and 1990's literature on youth, particularly in the United States and certain European countries, was influenced by analyses of (male) subcultures and so-called social maladjustment that developed during the 1940s and 1950s, focusing on a risk perspective (see Clinard 1949; Cohen 1955; Rogers 1945; Whyte 1955).

In addition, the heavy emphasis on understanding migration from a purely economic perspective in migration studies erased any societal distinctions generated by age. This did not help to recognize youth's agency and the differences that age creates in immigration and refugee processes. While migration scholarship did not pay much attention to youth, Whittaker (1988) noticed that between 1956 and 1984, Canada considered youths as the prime subjects for its immigration policies, favouring the immigration of (Mexican) youths between 18 and 35 years of age. Between 2011 and 2016, a little more than 489,000 youth, aged 15 to 34, immigrated to Canada (constituting 40.4\% from a total of 1,212,075 immigrants) (Statistics Canada 2017a). In 2016, there were nine million youth aged 15 to 34 across Canada, about one quarter of the country's population. Of these, $27 \%$ identified as visible minority and around $10 \%$ as homosexual or bisexual (Statistics Canada 2018a).

In all societies, however, the frontier between life stages, as Bourdieu (1978) mentioned, is a source of contestation, for which youth or the markers that delimit this age stage are in constant transformation. This is done based on the particularities of the social group and the characteristics of the individual, such as social class and location. Furthermore, economic changes in countries such as Canada, particularly after the recent increase in precarious employment (Vosko 2006), have also led to economic and social reorganization. This reorganization, in turn, is shaping the way in which youth is conceptualized and experienced. Although some youth in Canada tend to 
leave the parental home after acquiring the legal right to do so at age 18 , economic changes are extending the identity marker of who can be considered a young person. For instance, recent data indicates that $35 \%$ of young adults, aged 20 to 34 , still live with one or two parents, up from $31 \%$ in 2001. Of these, 24\% are men and 19\% women (Statistics Canada 2018a, 2019a). And a national survey found that $48 \%$ of parents with young adult children $(\mathrm{N}=1,004)$ still financially support their 30 to 35-year-old children (RBC 2019).

I join Maira and Soep (2005) and Reynolds and Zontini (2016:382) when they contend that "there is still little attention paid to the transnational lives of migrant youths as the sole or primary subjects of investigation." Transnationalism is a process whereby migrants and non-immigrants maintain active ties across national borders through their participation in economic, political, social, cultural, and/or religious networks and processes (Goldring et al. 2003; Levitt 2001b; Levitt, DeWind, and Vertovec 2003; Levitt and Glick Schiller 2004). Using Mexican youth immigration to Canada as an empirical case, I thus demonstrate that the type, frequency, and extent of transnational involvement of youth is shaped by their pre-migration class location (i.e. the total sum of their capitals before migrating, differently distributed by age and gender), the particulars of their economic integration in Canada, and the type and strength of social relations they create and maintain in both Canada and Mexico.

Moreover, I show how youths' economic integration, meaning their location in one of three different labour market segments (Edwards 2015), is the result of a combination of several factors. These factors include their pre- and post-migration class locations and the configuration of various politico-economic fields in the country of origin and reception. My findings thus differ from research on other ethnic minority groups' economic integration and transnational practices. For instance, Filipinxs, who ranked fourth among ethnic minority groups in Canada in 2016 in terms of population (Latin Americans ranked sixth), have a lower incidence of poverty than Latinxs. ${ }^{5}$ Filipinxs and Latinxs had low income percentages of 7.4 and 19.8 respectively in 2016 
(Statistics Canada 2018e, 2019b). Filipinxs also have very high levels of employment, although in less professionalized positions and concentrated in the healthcare, hospitality, retail, and manufacturing sectors (P. Kelly 2015).

At the same time, Filipinxs have high levels of transnationalism. For instance, Filipinxs are the main senders of international remittances in Canada. In 2017, they remitted CAD \$1.2 billion (Dimbuene and Turcotte 2019). However, this transnational behaviour responds to various reasons that depart from the circumstances of Mexicans in Canada. First, the Filipino government "actively promotes the training and the deployment of young adults to work abroad and send back remittances" (17). Second, the number of Filipinxs in Canada is significant. There were 780,125 Filipinxs vis-à-vis 447,320 Latinxs in 2016 (Statistics Canada 2018e). And third, a very large proportion of Filipinx immigrants have been admitted under the temporary Live-In Caregiver Program, most of them women who have left their families behind (Dimbuene and Turcotte 2019). In contrast, as I will show in chapter 4, most Mexican immigrants to Canada have arrived through the family and economic classes. In the following sections, I delve into the literature review regarding immigrant and refugee youth and transnationalism among Latin Americans in the United States and Canada. This is followed by the presentation of the research questions and methodology that guided my work.

\subsection{Immigrant and Refugee Youth in Canada}

Being an immigrant or a refugee youth in Canada shapes the integration experience in particular ways. When we consider both age at arrival and time spent in the country of reception, labour market location and integration divergences arise due to differentials in credentials recognition, official languages knowledge, and social capital (Yee et al. 2003). This occurs irrespective of the entry status and includes professional immigrants coming through the economic class who face unemployment and under-employment (Stasiulis, Hughes, and Amery 2011). Immigrant youth are more likely to achieve better employment outcomes the earlier they arrive in 
Canada and the longer they have held residency (Yee et al. 2003). This is because the acquisition of education, language, and work experience in the country of reception grant them recognized advantages. Nonetheless, immigrant and refugee youth who arrive after their teen ages often face numerous challenges in their integration process, such as language limitations, lack of credential recognition, and/or employment experience in Canada, known as 'Canadian experience.'

In comparison to the general Canadian youth population, immigrant and refugee youth who have obtained foreign education credentials tend to experience a deskilling process, have lower income levels, and less desirable jobs, leading some to start from zero regarding the acquisition of education and/or work experience (Halli and Vedanand 2007; Pozniak 2009; Wilkinson et al. 2010). These circumstances are often more dire for those youths who arrived as refugees, since they are more exposed to "interrupted or no schooling, physical and psychological trauma, and extreme financial and familial hardships" (Gunderson 2004:52). The refugee condition per se, however, is not enough to determine economic integration (e.g. a downward integration). This is because pre-migration social class, education, entrepreneurship experience, etc. strongly shape this process (Hernández-Ramírez 2012).

\subsection{Literature on Transnationalism Among Mexicans in the United States}

Transnationalism scholars, who have mainly focused on the Mexico-US migration circuit (for decades the migration circuit par excellence to study transnationalism), have analyzed a variety of topics at different scales and dimensions. This scholarship ranges from the formation (and conceptualization) of the transnational space to the role of transnationalism in the reformulation of power hierarchies and the modification of social, economic, and political processes and geographies (Cornelius 2009; Goldring 1992a, 1992b, 1997, 1999c; Kearney 1995; Massey 1986; Massey et al. 2006; Massey, Goldring, and Durand 1994; Massey and Aysa 2005; Mines and Massey 1985; Phillips and Massey 2000; Rouse 1989, 1992, Smith 1992a, 1992b, 2000, 2006a). Some of the literature also focuses on the impact that globalization and the political 
economy of the Mexico-US migration circuit have had on the transnationalization of social and political spaces, practices, identity and belonging of Mexican migrants, and the growth of remittances (Alarcón 2002; Guarnizo, Portes, and Haller 2003; Levitt 2001a, 2005, Levitt and Lamba-Nieves 2011, 2013; Marchand 2014b; Pérez-Armendáriz and Crow 2010; Smith 2006b).

Another literature stream has focused on the migration-development nexus and the role and use of so-called 'migradollars' or monetary remittances. These studies analytically range from the cumulative impact of monetary remittances on Mexico's finances to the politico-economic impact of migradollars in rural or semi-urban communities to the effect of remittances on the gendered redistribution of power inside households after migration (Durand 2007; Durand, Kandel, et al. 1996; Durand, Parrado, and Massey 1996; Escobar Latapí 2009, 2012; Escobar Latapí and Janssen 2006; Faist 2008; García Zamora 2007; Goldring 2004; Marchand 2015, 2011; Massey and Basem 1992; Massey and Parrado 1994, 1998, Portes 2008, 2015; Portes, Guarnizo, and Landolt 2003; Taylor 1987; Taylor et al. 1996; Unger 2007).

Other studies have focused on what Goldring (2002) calls "state-led transnationalism" (56), which refers to the varied actions and policies enacted by the state to maintain transnational social spaces (60). This includes movements of global and transnational capital, the effects of global media, actions of emergent supra-national political institutions, and activities of international NGOs, political parties, and transnational corporations. However, this type of transnationalism is seen as weakening the nation-state 'from above' (Goldring 2002; Guarnizo and Smith 1998). In the case of Mexico, state-led transnationalism has included two significant legal reforms that allowed for the tenure of dual nationality and the right to vote from abroad. Mexican state transnationalism has also included the development of various governmental programs and agencies to support and offer certain protection to migrants and promote social development, institutionalizing this relationship. These include the Mexican Community Abroad Assistance Program or PCME, for its acronym in Spanish, created in 1990, and the Presidential Office for Mexicans Abroad or OPME created in 
2000. Both organizations were merged into the Institute of Mexicans Abroad or IME in 2003 (Alarcón 2006; Cano and Délano 2007; Délano 2006, 2009, 2010, 2011, 2012; Goldring 1999a).

Other scholars have focused on the influence that gender has had in the migration and transnational experiences of Mexican migrants, the organizational arrangements of transnational motherhood, and the gendering of transnational migrant networks and political participation in spaces ranging from hometown associations to women's and feminist movements (Donato et al. 2006; Goldring 2003; Hondagneu-Sotelo 1992, 1994, 2009; Hondagneu-Sotelo and Ávila 1997; Mahler and Pessar 2001; Marchand 2014a; Pessar 1999; Pessar and Mahler 2003, 2001). The USbased migration transnationalism literature, however, has had a strong focus on rural milieus and semi- or low-skilled workers. In addition, this literature has not generally considered migration status despite the United States having similar proportions of documented and undocumented persons. In 2017, there were 12.6 million Mexican (im)migrants the United States $(26.6 \%$ of all immigrants in the US), of whom approximately between 4.9 and 5.7 million had an undocumented status (González-Barrera and Krogstad 2018; Guerrero, Giorguli-Saucedo, and Masferrer 2019; Passel and Cohn 2019).

This lack of attention to migration status may be explained by the fact that Mexicans obtain permanent residence in the United States mainly via family reunification or through sponsorship by immediate relatives who hold US citizenship, and also because these programs do not have quotas. For instance, between 2003 and 2012, close to 91\% of Mexicans who received permanent resident status in the United States did so making use of the two mentioned programs, and only $6 \%$ were accepted via economic migration (i.e. employment) (Calva Sánchez and Alarcón 2015). This means that a little more than nine thousand Mexicans were granted permanent residence via employment each year between 2003 and 2012. A lack of detailed data, however, does not permit us to know if these workers were skilled or semi-skilled (ibid.). The remaining $3 \%$ was given to refugee cases and the category of 'other' (ibid.). Thus, differences in the US immigration system 
and the uneven distribution of Mexican immigrants by legal status, which differs from Canada, do not allow us to know the extent to which migration status shapes transnationalism.

In addition, the dissimilar number of Mexicans in both countries does not allow for a neat comparison of the two countries' immigration and transnational experiences. For example, the substantial presence of Latin Americans in certain cities of the United States has led to the use of Spanish as lingua franca in public spaces such as airports, malls, etc. In Canada, although one can frequently hear Spanish being spoken on the streets of Montreal or Toronto, the overall impact of Latin Americans on Canadian society is still limited. Thus, a lack of attention to migration status does not allow us to know much about the effect that migration status, and particularly documented migration, has had on shaping Mexican transnationalism in North America.

\subsection{Literature on Transnationalism in Canada}

In contrast to the United States' scholarship, researchers have only recently begun to pay attention to immigrant transnationalism in Canada. This explains why the available studies are still developing in terms of conceptualization and topics, even when many geographical regions have been included (e.g. East and South Asia, eastern Europe, and the Middle East) (Goldring 2006). For example, the first studies about transnationalism in Canada were done in the late 1990s, most of them qualitative in nature (see Nolin Hanlon 1997, 1999; Winland 1995; Wong 1995, 1997). Since then, the available literature has included some analyses of how refugees and immigrants are involved in political and economic transnational activities around homeland issues. This includes Croatians' and Sri Lankan Tamils' transnational mobilization around their homeland's autonomy and political independence, the engagement of left-oriented Portuguese-Canadians in community organizations, and the human rights organizing of Burmese refugees in Vancouver (Amarasingam 2015; Bloemraad 2009; Cheran 2007; Goldring et al. 2003; Hyndman and Walton-Roberts 2000; Vargscarr 2016; Wayland 2003). This research, however, does not include an analysis of how economic integration and the role of youth shape those transnational practices. 
Other researchers have focused on understanding how downward social mobility, pre-migration distress, and continuing resettlement troubles play a role in Cambodian and Filipinos' generation of transnational practices (Hiebert and Ley 2003b, 2006; P. Kelly 2012; McLellan 2004). For example, political participation has been observed among the Filipino community, which has had a "vibrant, and growing political engagement" since the 1970s (P. Kelly 2007:216). However, ongoing and pressing economic commitment to family members in the Philippines and racialization in Canadian society has also pushed many Filipinx immigrants to find survival-level jobs rather than employment according to their qualifications. This has limited or canceled their possibilities of political participation (ibid.). Scholars have also analyzed the ways in which ethnic groups establish and maintain relationships with co-ethnics in the countries of origin through (extended) family-class migration networks, public cultural activities, humanitarian relief campaigns, commemorative celebrations, and public protests (Drotbohm 2009; Mina 2015; Walton-Roberts 2003). These analyses, nonetheless, do not consider how (successful) economic integration shapes immigrants' development of and engagement with transnational practices.

Research has also focused on how gender shapes transnationalism among some immigrants in Canada. Preston, Kobayashi, and Man (2006) found that Hong Kong women's transnational activities center around family and friendships rather than political or economic ties. This type of research, however, does not address how gender and pre-migration class location shape postmigration economic integration. Scholars have also focused on how transnational practices among some Filipinxs are a response to experiences of Othering, racism, and discrimination. Indeed, some Filipinxs do not engage in transnationalism due to the negative emotional engagement they have with the Philippines as a diasporic homeland (P. Kelly 2015; Pratt 2002, 2010; Pratt, Ugnayan ng Kabataang Pilipino sa Canada, and Filipino-Canadian Youth Alliance 2003; Ticar 2017).

Labelle, Rocher, and Field (2006) found that leaders of social movements associated with 
ethnic, racialized, and immigrant identity groups that face multiple types of discrimination in Quebec identified their use of transnational networks filtered by various immediate concerns (i.e. economic integration, poverty, economic inequalities, sexism, racism, Arabophobia, and Islamophobia). The abovementioned literature, however, does not include immigrants who have not experienced discrimination or have achieved a positive economic integration, and the ways in which these conditions shape their (potential) production and types of transnational practices.

\subsection{Literature on Transnationalism Among Latin Americans in Canada}

Since only a handful of scholars have paid attention to Latin Americans' transnationalism in Canada, I thus engage with this literature in this section. Catherine Nolin Hanlon (1997, 1999, $2000,2001,2004,2006$ ) analyzed the relatively local and immobile, yet highly transnational social relations produced by (non-)Indigenous Guatemalan refugees and immigrants in southern Ontario and those who remained in Guatemala between 1979 and 1999. Although Nolin Hanlon (2004:267) considered Guatemala's genocidal past and political violence as the core feature of Guatemalan transnationalism, she also analyzed how "Canadian foreign and immigration policies, immigration status, socio-economic circumstances, and spatial concentration or dispersal of settlement" factored into the "vastly different experience and form of transnationalism." She found that Canadian foreign and immigration policies "functioned at various times both to facilitate and to impede refugee movements from Guatemala," ultimately cementing "transnational ruptures rather than encouraging transnational flows" (Nolin Hanlon 2000:118). As a result, weak transnational ties among Guatemalans, "infused by the effects of political violence and forced displacement" (Nolin Hanlon 2006:182), played a prominent, gendered role in their everyday experiences (Nolin Hanlon 2000:111). Nolin Hanlon's population, however, did not allow her to include cases where violence was not central to Guatemalans' transnational processes.

Ruth San Martín (1998) examined how the Latin American Women's Collective in Toronto financially and politically supported liberation movements in the women's countries of 
origin (1983 to mid-1990s). This included the numerous personal, local, and transnational struggles they faced. San Martín's research, based upon oral histories with four women plus her own account, did not address, however, transnationalism or economic integration per se, making it difficult to assert the impact of both factors on these women's actions. Mónica Escobar (2000) analyzed the integration challenges and relevance of the transnational political experiences of 11 Chilean women in exile in Toronto. Their location in inferior roles where they could not “"embody' Canada" $(246,248)$, along with their initial intention to return to Chile, nullified their political involvement in Canada and led them to rather focus on Chilean politics, looking to bring down the US-backed military regime. Although Escobar's research included a few cases where pre-migration class location was addressed, her analysis did not cover all cases, making it difficult to assert how economic integration patterns shaped the women's transnational involvement.

Tanya Chute (2004) identified and analyzed three groups of Salvadorans in Toronto regarding political participation: "the non-participants, the transnational participants and the local participants" (73). The non-participants, the largest of the three groups, did not get involved either in solidarity activities or in Canadian politics. The transnational participants, the second largest group, engaged in activities related to El Salvador such as relief and development initiatives that were sometimes connected to political activities. While Salvadorans had a significant involvement in Salvadoran country politics, they had low levels of political participation in Canada. Chute's research, however, did not address how types of economic integration shaped Salvadoran's political involvement or if other types of transnationalism were developed among the 'transnational' participants.

Bernhard, Goldring, and Landolt (2005:i) analyzed how 40 Latin American migrant mothers living in Toronto and the relationship with their children left behind were systematically transformed by transnational, multi-local family structures. These relationships were marked by "unexpected lengths of separation, the spatial dispersal of social reproduction, and post- 
reunification problems." This, in turn, created tension, guilt, isolation, and shame (Bernhard, Landolt, and Goldring 2008:3). This research, nonetheless, does not allow us to know the role that men play in (non)parental immigration experiences or the role of young people in the generation of transnationalism.

Goldring (2006) identified that Salvadorians and Guatemalans developed transnational solidarity as an important form of transnationalism in Canada in the 1980s. In contrast, Ecuadoreans and Mexicans, who came due to economic reasons at the end of the 1990s, developed “cultural and professional organizations” (193). Luisa Veronis (2006a, 2006b:i), analyzing Latin Americans' settlement in Toronto, contends that Latin American immigrants developed a 'local' form of transnationalism in Toronto to "lay claims to equal rights." This transnationalism developed in the form of "public parades, the building of ethnic places, the creation of umbrella organizations, networks of service providers, and partnerships with other ethnic/immigrant groups" (Veronis 2010:189). Veronis' research, however, does not allow us to know about the 'non-local' forms of transnational practices among Latin Americans and the ways in which their economic integration shaped those practices.

Jorge Ginieniewicz (2007, 2008a, 2008b, 2010a) interviewed 200 Latin Americans from 14 countries living in Toronto, most of them with higher educational levels. He found that various factors undermined Latinxs opportunities to attain formal political participation in Canada, even if they had ample involvement in grassroots politics. These factors included basic settlement issues such as job search and housing, limited or accented language skills, Latinx disunity, a short length of residence that led to insufficient knowledge of the Canadian political system, a disadvantaged economic situation, discrimination, and lack of efficient leadership. Nonetheless, education and higher income showed a positive effect on their increased political participation in Canada. One of Ginieniewicz's (2007) analyses considered a few individual cases of economic and political transnationalism among Latinxs, such as fundraising money for solidarity activities, supporting 
Latin American countries' political campaigns in Toronto, raising awareness of human rights violations in Latin America, and selling crafts in Canada to support K'iche' women (Guatemala) who lost their husbands due to political violence. However, he did not address the effect of Latinxs' economic integration in their political involvement.

Patricia Landolt (2007a, 2007b, 2008) compared and analyzed the political transnationalism of Salvadorans in Los Angeles, Washington, and Toronto. In her analysis, she considered their circumstances of exit, modes of entry, dynamic contexts of reception, as well as the "city's political and cultural history, its immigration patterns, and its labour market dynamics" (2007b:191). In the United States, migration was organized around informal social networks among kin and co-villagers, following a pattern of chain migration that became important for resource sharing and patterns of collective action (205). In contrast, the decision of the Canadian government to accept Salvadorans as refugees and the settlement support offered limited the formation of chain migration patterns. Here, it was nuclear family ties and political affinities that led to the formation of small networks of friendship and mutual aid, as well as the organization of small community projects (ibid.).

Goldring and Landolt (2010) did an institutional analysis of Chileans, Salvadorans, Guatemalans and Colombians' transnational political practices and the formation of different types of transnational political fields in Toronto (444). The authors found that there were variations in political culture and political dispositions. This variation depended on what immigrants politically brought to Canada and, at the same time, how the context of reception had already been shaped by the political action and "political culture tool-kits" of previous Latin American immigrants and Canadian activists (2014:123). This finding is similar to that of Levitt \& Lamba-Nieves (2011) among Dominicans in the United States. Their "long history of active community organisation, a robust track record in participatory democracy and a strong sense of responsibility to the collective good" strongly influenced their participation once in the United 
States. Although Goldring and Landolt's research sheds light on political transnationalism among Latinxs, we do not know from this research how economic integration shapes this involvement or what other forms of transnationalism were developed.

Riaño-Alcalá and Goldring (2006:1) found that Colombian immigrants and refugees, by living in different Canadian cities (i.e. Toronto, Sherbrook, and Vancouver), distinctively shaped their patterns of homeland engagement, particularly in relation to "a spectrum of political issues regarding the resolution of the armed conflict and peace building in Colombia." At the same time, not all Colombians were able to be involved in peace-building processes due to fragmentation, division, and a lack of social cohesion within the Colombian diaspora (Riaño-Alcalá and Goldring 2014). Still, some Colombians generated a few minor but significant transnational solidarity initiatives in Canada, "conducted by small, relatively informal, networks of activists with episodic collaboration with Canadian civil society actors" and supported by international pressure. This included promoting refugee rights, "denouncing human rights violations in Colombia, educating the Canadian public, and lobbying Canadian authorities" (18). Nonetheless, similarly to other analyses of political transnationalism among Latin Americans in Canada, we do not know how their economic integration shaped not only political but also other forms of transnationalism.

María Frances Cachón (2013) studied the transnational affect (or “the non-material conditions," such as emotion and affect, "which foster and underpin transnational networks and relationships" [51]). She interviewed twenty Mexicans "who had either permanently settled or were seeking permanent residency in Canada and ten temporary agricultural workers" in Southwestern Ontario (24). Cachón's inclusion of three different streams of migrants (i.e. immigrants, temporary residents, and agricultural migrant workers) makes it difficult to determine the variations and prevalence of transnational activity among these groups. Due to migration status differentials, it is also difficult to establish a relationship between immigrant incorporation and transnational engagement, or identify the extent to which social exclusion or 
racism may factor in the production and development of transnational practices.

Gloria Díaz Barrero (2007) analyzed the experiences of women from six different Latin American countries who came to Canada to work in the adult entertainment industry as exotic dancers. Díaz Barrero found that these women maintained strong bonds with their families in their countries of origin through regular monetary remittances they sent home. These remittances helped in the "daily expenses of the household, to educate younger relatives, to support their children, and to make small investments" (154). After they obtained PR status, they also sponsored their children and provided for their families in Canada.

Kerry Preibisch and Evelyn Encalada (2013:785) analyzed transnational homemaking among Mexican, female Seasonal Agricultural Workers Program (SAWP) workers, or "the set of practices involved in caring for family relationships and maintaining household economies across borders.” Although this process yielded material and economic benefits for women, it was also paired with precarious labour and status in Canada. Thus, the "advantages derived from transnational migration [were] tenuous, limited, and contradictory" (ibid.). Encalada (2017) also found that Mexican women who used the SAWP as a strategy of family survival defied patriarchal norms, since they assumed the role of principal breadwinners. In the same vein, Ofelia Becerril (2007:158) examined how Mexican SAWP workers engaged in "an everyday struggle against extant and emerging forms of inequality." They did so "contesting changes in the transnational work arrangements of the Canadian horticultural sector" through transnational collective acts of contestation (ibid.). These analyses, however, focused on migrants with temporary status, which means we do not know much about transnationalism among Mexicans with permanent status.

What we learn from this literature is that some Latin Americans have not been able to develop transnational practices in Canada. Reasons include Canadian foreign and immigration policies that impede the movement of refugees, thus creating transnational ruptures as well as downward economic integration processes. This hinders, in turn, the generation of a sense of 
belonging to Canada and an exclusive focus on home country issues. In other cases, particularly among economic immigrants in the 1990s, their economic integration difficulties led them to focus instead on developing strategies of social mobility in Canada. Settlement issues along with limited or accented language skills also prevented some others to be politically engaged in Canada. Others generated relief and development initiatives in the home country but, at the same time, showed low levels of political participation in Canada.

Similar to what others have found among immigrants in the United States and the Netherlands (van Bochove 2012; Glick Schiller and Levitt 2006; Itzigsohn and Giorguli-Saucedo 2005), some scholars found that education and higher income led some Latinxs in Canada to increase their political participation. Other factors shaping the degree of disposition and participation in political transnationalism among Latinxs are the extent to which the context of reception was shaped by previous waves of immigrants, what Latinxs politically brought to Canada, and even ethnic fragmentation and division among them. Thus, some were engaged in socio-economic and political transnational activities whereas others were less involved or not at all.

Analytically speaking, however, only a small group of scholars have considered economic integration as a relevant factor in shaping the transnational practices of immigrants and refugees in Canada (i.e. Bernhard et al., P. Kelly, Landolt, and Nolin Hanlon). Still, most of this scholarship has not considered the central relevance of economic integration in shaping Latin Americans' and specifically Mexicans' transnationalism in Canada. Previous research, mostly in the United States, has suggested that downward economic assimilation has collaborated in promoting certain reactive transnational practices among immigrants (Itzigsohn and Giorguli Saucedo 2002). However, we do not know if and how immigrants and refugees who have achieved positive economic integration develop transnational practices, or how different types of economic integration may produce an array of different transnational forms.

For example, many of the analyses of political transnationalism among Latin Americans in 
Canada ignore the underlying effect of economic integration in the generation and shaping of political practices. Based on the literature, it could be assumed that a better economic integration may grant immigrants a higher income and perhaps more spare time, and thus higher possibilities to engage in transnational practices. This would contrast to those who experience a poor economic integration and whose limited income may not facilitate their involvement in transnational practices. However, as I will show below, my findings challenge these hypotheses. There is also scant attention paid to the participation and role of young people in the production of transnational practices. As mentioned before, an adult-centric tendency in migration studies has long overlooked the participation of youth in migration processes. This has not facilitated the identification of potential differences in the creation of transnational practices when taking age into account. For instance, considering that youths are 'digital natives,' it may be expected that they communicate more frequently with family members and friends across borders through their use of new communication technologies such as Facebook and WhatsApp.

Moreover, the bulk of the literature on migration that focuses on youth and transnationalism has mainly directed its attention to the second generation. This is partly because this literature has responded to the challenges that some assimilationist proposals have posited when contending that second and plus generations will assimilate into the culture of the country of reception (see Alba and Nee 1999, 2003; Gordon 1978). Consequently, we find research that illuminates how second generations engage in and participate in the development of transnational practices or even decide to move to their parents' country of origin (see, for instance, Foner 2002; King, Christou, and Teerling 2010; Lee 2011; Levitt and Waters 2002; Quirke, Potter, and Conway 2009; Sanchez 2004; Smith 2002; Wessendorf 2007, 2013).

Nonetheless, this emphasis of studying transnationalism among the second generation has, at the same time, limited the analysis of the participation of first-generation youth in the development of transnationalism. Consequently, this study will examine how pre-migration contexts and 
different types of economic integration shape sociocultural, economic, and political forms of transnationalism among Mexican youth in Ottawa and Montreal. In addition, most scholars begin their immigration and integration analyses only after immigrants and refugees arrived in Canada, following a longstanding Canadian tradition of settlement research since the 1980s. This focus, however, does not allow us to better understand the effect that immigrants' and refugees' contexts of departure (or that of their families) have on their posterior economic integration and development of transnational practices. My methodological incorporation of immigrants' and refugee youths' immigration circumstances, their types of economic integration in Ottawa and Montreal, and the effect of this integration on the generation of sociocultural, economic, and political transnational practices (or lack thereof) thus addresses various unexplored arenas in migration, youth, and Latin America scholarship.

\subsection{Research Questions and Methodology}

My dissertation investigates the reasons for immigration and the impact of economic integration on the diverse practices of transnationalism among Mexican youth in Canada. Four main research questions frame my analysis: first, what are the structural conditions and individual reasons for the immigration of Mexican immigrant and refugee youth to two Canadian cities, namely Ottawa and Montreal? Second, to what extent have pre-migration class location and postmigration circumstances shaped my respondents' economic integration in Canada? Third, in what ways have the types of economic integration experienced by these Mexican youth shaped the extent and type of their involvement in diverse transnational practices? A fourth framing question pertains to the differences in integration and transnationalism of Latin Americans in cities associated with Canada's two linguistically and culturally distinct settler societies.

I located my research in Montreal and Ottawa to allow for a unique comparative analysis between a large, mainly Francophone city and a mid-size, mainly Anglophone city, where both provinces exhibit differentiated colonial histories, governance structures, and immigration/ 
settlement systems (Veronis 2013). Moreover, considering that research about visible minorities has traditionally been done in Toronto, Montreal, and Vancouver, the inclusion of Ottawa offered a fruitful avenue to advance knowledge about economic integration and transnationalism of immigrant populations in a smaller (but capital) city. Due to the dual-sited nature of the project and looking to produce a depth of knowledge, I chose to pursue qualitative methodology.

Using purposeful sampling (i.e. maximum variation and snowball sampling) (Coyne 1997), I conducted 35 semi-structured interviews with Mexican immigrant and refugee youth, 18 to 35 years of age. This age framework corresponds to a now common age framework used in youth research (see for example Reynolds and Zontini 2016). I used maximum variation sampling to include a wide range of profiles that included differences in migration status (i.e. citizenship vs. permanent resident, immigrant vs. refugee status), class location, place (i.e. Ottawa and Montreal), and a similar number of women and men in each city. In addition, I purposely did not include Mexicans who had temporary work permits, such as TFWP workers or international students, since one of my goals was to analyze how documented status shapes economic integration and transnationalism. In addition, I chose maximum variation sampling to avoid sampling on the dependent variable, a frequent critique made by the 'Portesian' school of thought regarding research on transnationalism (cf. Guarnizo et al. 2003; Portes 2001, 2003). This allowed me to seek and interview Mexican immigrant and refugee youth without knowing beforehand whether or not they engage in transnational practices (cf. Portes 2003:877), their type of economic integration in Canada, and the reasons for their immigration. I also interviewed four members of the Mexican community in Ottawa and two settlement service workers in Ottawa and one in Montreal to obtain contextual data.

As in my previous research in metropolitan Vancouver (Hernández-Ramírez 2012), recruitment proved to be a difficult task, particularly finding willing men to participate in Ottawa. I used various strategies to seek participants, the most effective one being Facebook posts linked 
to a webpage that contained my invitation letter. The letter was located in a website that promotes businesses and events catering to Latin Americans in Montreal (i.e. Montreal Hispano). The Latinx company behind the webpage, Hispano City Network, which also covers the cities of Toronto, Calgary, and Miami, kindly agreed to publish the page for free. Although the webpage where my invitation letter was published focuses on Montreal, promoting the link on Facebook also allowed me to connect with people who live in Ottawa.

I continuously created and shared Facebook posts with the link to the webpage and shared them across numerous Facebook 'pages' or groups whose administrators kindly gave me permission to publish them: Mexicanos viviendo en Montreal, Jóvenes mexicanos en Montreal, Asociación Mexicano Canadiense, CONACYT-Canada Fellowship and Becarios CONACYT, Carleton Research Participants, Latinos en Gatineau y Ottawa, and Ottawa Latinos. I also sent emails to my networks in Ottawa and Montreal, which included personal and academic contacts at Carleton University, University of Ottawa, UQÀM, and associations that cater to immigrants (Catholic Centre for Immigrants, Coalition of Community Health Centres, Scalabrini Centre for Refugees and Immigrants, and Alliance pour l'accueil et l'intégration des immigrants-es). The Embassy of Mexico in Canada also published the invitation in one of its monthly bulletins.

Another successful strategy consisted of seeking the direct support of immigrant associations, particularly of Latinx persons who work there, and who shared my invitation through their networks. I thus greatly benefited from the support I received from staff at Ottawa World Skills, as well as contacts in the Red Cross, the Catholic Center for Immigrants, and UNAM Canadá (under the direction of former director Dr. Ramón Peralta y Fabi). I also received the support of Félix Grande and Hada Martínez, from the radio show Amanecer Ranchero (CHUO 89.1 FM), as well as Sonia Gómez from the radio show Punto de Encuentro (CKCU 93.1 FM), both located in Ottawa, who hosted me and constantly promoted my research invitation in their radio shows. Unsuccessful strategies consisted of a \$100 ad in Eco-Latino, a monthly Ottawa-based 
printed newspaper catering to Latinxs, as well as ignored requests by the General Consulate of Mexico's Community Affairs section in Montreal and other Latinx media organizations and immigrant associations in Ottawa and Montreal to share the research invitation (Centro de Atención Inmediata al Latino-CAIL, Pasión Latina Montreal, Hispanos en Canadá, Le Ballet Mexicain de Montreal, Red Global MX Capítulo Montreal, Radio Canadá Internacional, and Alianza de Comercios Mexicanos en Montreal).

I interviewed 35 persons in total, 18 people in Ottawa (twelve women and six men) and 17 in Montreal (eight women and nine men). Sixteen persons immigrated through the economic class (nine in Ottawa and seven in Montreal; of these, ten had citizenship and six had permanent resident [PR] status), thirteen persons via the family class (eight in Ottawa and five in Montreal, five with citizenship and eight with PR status), five immigrated through the refugee class (one in Ottawa and four in Montreal, two with citizenship and three with PR status), and one person was granted temporary stay under compassionate grounds under special considerations in Montreal. My respondents came from 13 of 31 different Mexican states and Mexico City, comprising the north, center, and south of Mexico (Nuevo León, Chihuahua, San Luis Potosí, Estado de México, Ciudad de México, Puebla, Querétaro, Aguascalientes, Jalisco, Michoacán, Guerrero, Oaxaca, Chiapas, and Yucatán). The interviews lasted one hour and 45 minutes on average and were held in a place where youths felt comfortable. Most respondents chose coffee shops, although I also did one interview at a public park and two interviews at the persons' home, and two interviews were done via Skype. Except for one interview conducted in English, the rest were done in Spanish (see questionnaire in Annex 1).

All ethical protocols, as established by Carleton University's Office of Research Ethics and Compliance and Canada's Tri-Council Policy Statement for Ethical Conduct for Research Involving Humans, were followed. An honorarium of \$15 was given to each participant, although in some cases they rejected the money since they indicated they accepted to be interviewed to help 
a co-national. Each interview was transcribed verbatim and then exported to and coded in NVivo 11. I created a codebook based on the themes that were appearing in the interviews and showed a certain level of saturation. The codebook contains 20 parent nodes or main themes and 130 child nodes or sub-themes. Using thematic analysis, I ran queries and extracted content from the parent and child nodes that responded to my research questions. I then identified significant trends and sub-topics, which soon converted into thematic skeletons for the empirical dissertation chapters.

The theoretical framework I used to analyze the data included Bourdieusian theory and political economy and transnationalism approaches. Bourdieusian theory emphasizes how social practices are historically located (constituted) and constructed within (constituting) a particular and practical function. These practices are also related to the very specific social location of the agent, rather than merely being imposed by a structure (Bourdieu 1990a). I complemented this theoretical framework with a political economy approach, which connects the economic, political, social, and ideological moments of social life, contextualizing each with the other (Clement 1997). It is in this conjuncture that a transnationalism approach fitted well, since it is in these economic, political, and sociocultural spaces or fields that immigrants and non-immigrants maintain active ties across national borders.

Many migration scholars use either a transnationalism or a political economy approach to analyze migration. I rather contend that migration, being a complex phenomenon, needs to increasingly be analyzed making use of interdisciplinary and varied theoretical perspectives. Thus, in this dissertation, I analyze transnational practices under a political economy lens, as seen in a macro contextual consideration and analysis of the state and national and regional politics and economies. And also under a transnationalism approach, where varied transnational practices are correspondingly shaped by historical politico-economic processes, and not only by factors at the household or individual level.

Regarding my research positionality, my being a Mexican person assisted me to obtain 
various interviews with Mexican youth who expressed their desire to participate in the research to help a co-national. At the same time, this positionality might have hindered some findings, since some participants may have felt the need to present themselves in a better light in front of a conational. Nonetheless, my impression was that they provided candid answers to my questions.

\subsection{Guideline to Chapters}

The dissertation is comprised of 11 chapters, including this introductory chapter and a Conclusion. In chapter 2, I provide a theoretical framework that informs the subsequent analysis. The historical and politico-economic relations generated between Mexico and Canada since the late $19^{\text {th }}$ century, mediated by their mutual relation with the United States, are addressed in chapter 3. In chapter 4, I focus on the historical (im)migration of Mexicans to Canada and the development of the 'bogus' refugee figure as a Canadian strategy of migration securitization. The structural (or macro) context provided in these chapters is significant in framing my respondents' economic integration processes and transnational formations.

A key element of this structural context is the United States' influence as a hegemonic power, which has historically shaped Canada's and Mexico's circumstances, as well as the conditions of exit and reception and transnational practices of Mexican (im)migrants and refugees. As colourfully conveyed in the metaphorical language of former Mexican foreign minister Manuel Tello Macías, "Mexico and Canada cannot possibly make a sandwich" because "there is too much meat in between" (DePalma 2001:58). My inclusion of a historically rooted, structural politico-economic context also responds to both my sharing of Luisa Veronis' (2006b:2) assessment that some of the empirical literature on transnationalism lacks historical contextualization, and because migration cannot be disengaged from its wider economic, political, and socio-cultural factors (Whitaker 1998).

In chapters 5 and 6, I address a generalized myth in Canada that considers Mexican immigrants as middle or upper-middle class and educated people. I also analyze, at micro- and 
macro-levels, the various factors that led my Mexican young respondents to immigrate to Canada. For most of the youth (and evidently for those who came as refugees), these reasons were not directly tied to economic motives. Rather, these included a desire to change their social milieu, maintain a partnership and/or friendships, obtain foreign education, and stay away from local issues embedded in the Mexican culture such as corruption, nepotism, and homophobia. Other reasons included having put roots down in Canada, unexpected marriage or other forms of migration sponsorship, and because of increasing and multi-faceted forms of violence developing in Mexico (Martin and Lapalme 2014).

In chapters 7, 8, and 9, I analyze how the immigration/refugee fields in Ottawa and Montreal, along with my participants' pre-migration class locations, shaped the youths' integration processes in the two significant integration arenas: education and employment. As will be illuminated in chapter 10, immigrants' types of economic integration are closely tied to their intentions and possibilities for creation of socio-cultural, economic, and political forms of transnationalism. I offer some concluding remarks in chapter 11, where I also provide a summary of the contributions my research has made and suggestions for further avenues of investigation. 


\section{Chapter 2: Theoretical Approaches to Immigrant and Refugee Youth's Economic Integration and Transnational Practices}

This chapter offers a theoretical framework to inform my analysis of the immigration and economic integration processes, as well as the generation of transnational practices of Mexican immigrant and refugee youth in Montreal and Ottawa. The chapter is composed of three sections. In the first section, I present the main tenets of Pierre Bourdieu's theorizing on field, capitals, and hysteresis, and some theoretical applications to migration. The use of Bourdieusian theory aims at facilitating an understanding of how macro-structural factors interact with and shape social process at a micro-level. This section also considers the operational definitions of economic integration. In the second section, I situate the notion of youth, and in particular the notion of immigrant youth, as a product of varying socio-cultural processes and the (re)production and expansion of capital. These processes have shaped and segmented, at a macro-level, the labour market into primary and secondary markets, creating differentiated immigrant labour force needs as well as particular integration conditions for immigrant youth in Canada. In the third section, I focus on the notion of transnationalism, introducing particular perspectives that guide this dissertation pertaining to issues of frequency, intensity, and scope. This section also includes the various social practices that constitute an (emergent) transnational field, and the ways in which transnationalism interacts with economic integration processes, a little explored arena in migration and transnationalism studies.

\subsection{Bourdieusian Theory and Migration}

Bourdieu did not address immigration issues. Nonetheless, his theory has been used in migration studies to understand the dialectical co-relation between agency and structure, and the way in which geographical movement is constituted and developed. Central to Bourdieusian theory are the concepts of dispositions, habitus, hysteresis, fields, and capitals, which I define below. For Bourdieu, a disposition is a propensity to act that assumes bodily dispositions in an unconscious, pre-reflexive, and systematic way. Dispositions are unconscious - although not in a Freudian sense - because agents do not realize the reasons underlying their practices and the way 
in which these are executed, even when they are being performed (Bourdieu 1990a, 1990b).

This disposition, or a practical or common sense, is so instilled in social agents that they tend to correct and adjust either themselves or others to their structured and structuring dispositions to keep reproducing them, obtaining thus a "mastery of a common code" (Bourdieu 1990a:59). Practical sense, however, is never uniform, even among similar social groups. This variation in social practices exists because people are always immersed in fields of power that generate distinctive social relations or "distinction" (Bourdieu 1984:183-84). These distinctive relations, reproduced through habitus, are generated as (in)visible markers that signal someone's belonging to one or more social fields and which, at the same time, imply exclusion from others.

HABITUS: Habitus is an acquired system of structured and structuring generative schemes or dispositions. Habitus has an infinite capacity for generating products (thoughts, perceptions, expressions, and actions) inherent in the particular conditions of its production (and only those), whose limits are set by the historically and socially situated conditions of its production (Bourdieu 1990b:55). Habitus is “"structured' by one's past and present circumstances, such as family upbringing and educational experiences. It is 'structuring' in that one's habitus helps to shape one's present and future practices. It is a 'structure' in that it is systematically ordered rather than random or unpatterned" (Maton 2008:53).

FIELD: A field is an indispensable component in Bourdieu's logic of practice, since it is this element, in conjunction with habitus mediated by the (lack of) possession of diverse capitals, that (re)produces social reality. A field "is a state of the power relations among the agents or institutions engaged in the struggle, or, to put it another way, a state of the distribution of the specific capital which has been accumulated in the course of previous struggles and which orients subsequent strategies” (Bourdieu 1993:73). Fields are never randomly generated, but always (re)configured based on previous and current power struggles and distribution of capitals, for which fields — and therefore habitūs — are always historical. ${ }^{6}$ Since the structure of the field is 
always at stake, the unavoidable struggles taking place within it are about "the conservation or subversion of the structure of the distribution of the specific capital" or power (ibid.).

HYSTERESIS: Since change constantly occurs in social life, there are situations in which the coherence between the logic of practice, habitūs, and fields is out of phase. Practices then, cannot be adapted to their objective conditions since these no longer exist, and agents might lose the dispositions that their objective conditions had previously provided them. When a person faces a case in which their habitus no longer matches its original objective conditions or when "the effect of a social trajectory [leads] to conditions of living different from initial ones" (Bourdieu 1990a:116), through for instance immigration, hysteresis, or out-of-phase dispositions and illadaptation of practices, might appear. Nonetheless, hysteresis does not necessarily lead to an immediate change of dispositions. Rather, it develops gradually, since durable dispositions "can outlive the economic and social conditions in which they were produced" (Bourdieu 1990b:62).

In the transition between hysteresis and the creation of and adaptation to new habitūs in new fields, people might experience different possibilities, such as crises, "misadaptation as well as adaptation, [and] revolt as well as resignation" (Bourdieu 1990b:62). It is also important to note that not all changes in habitus constitute hysteresis. Two different practices, for instance, can be part of the same habitus if both practices originated as a direct response to the generative conditions of the original field. Only when the constitutive, objective conditions of the habitus change or are abandoned, is there hysteresis. Thus, immigration, as a geographical dislocation that implies the movement from some fields to other ones, does not necessarily modify the previous habitūs of immigrants, although it might favour the proper conditions for this to happen.

Immigration also generates new habitūs among immigrants due to their immersion into new fields. Noble (2013) signals how due to hysteresis resulting from immigration, the new habitus acquires elements from both previous and new fields in which the immigrant or refugee finds themselves. Noble, however, did not discuss the fact that, since previous fields do not 
necessarily continue to exist as they did in the country of origin after immigrants depart (because social changes constantly occur), the immigrants' former habitūs may lead them to feel at odds if they return to the country of origin. The resultant experience is then one in which immigrants feel that they do not fully belong to any place.

CAPITALS: For Bourdieu (1983), capitals (in plural) are accumulated labour in materialized, objectified and/or embodied forms that need time to be accrued. They are “fundamental social powers” (Bourdieu 1990a:128) that manifest in three inter-related forms:

... as economic capital, which is immediately and directly convertible into money and may be institutionalized in the form of property rights; as cultural capital, which is convertible, in certain conditions, into economic capital and may be institutionalized in the form of educational qualifications; and as social capital, made up of social obligations, which is convertible, in certain conditions, into economic capital (Bourdieu 1983:16).

The access to/or mobilization of capitals (especially social capital) is influenced by the particular configuration of the fields, along with the networks' structure, composition, intensity, durability, frequency, multiplexity, and density of social capital (Flores-Yeffal and Aysa-Lastra 2011; Ryan 2011). This configuration may operate at different levels. At the micro level, for example immigrant job seekers' contexts determine the valuation of their skills, generating a depreciation of their institutionalized cultural capital (or cultural capital for economy of language), since their skills are not recognized (Thieme and Siegmann 2010). At the macro level, a strong shift in macro-structural conditions can change the dynamics, composition, and access to social capital, for which personal connections in a particular field may change or shape migration (Flores-Yeffal and Aysa-Lastra 2011; McIlwaine 2012).

Moreover, an increased possession and volume of varied capitals also adds to the probabilities of a successful capital conversion among migrants. On the contrary, the lack of capital "can be one of the main barriers preventing migrants from converting and mobilizing other types of institutional cultural capital as well as economic capital' (Flores-Yeffal and AysaLastra 2011:490). Finally, another form of capital is the one that Erel (2010) identifies as national 
capital and that I will call Canadian capital here. National capital is constituted by "resources and assets such as language knowledge, accent or light skin [that] can be converted into 'national capital' to legitimize belonging" to the nation (648). National capital is also constituted by educational and professional institutions that "exercise nationally-based protectionism by not recognizing qualifications acquired abroad." National capital thus reinforces the segmentation of the labour market along national and ethnic/racial lines. Overall, the assemblage of dispositions, fields, habitūs, and capitals generates a person's historically and socially situated "class of conditions of existence" or class location (Bourdieu 1990b:54). Class location is thus different from social class, and changes amid the re-establishment of fields and habitūs mediated by power relations and possession of diverse capitals.

\subsection{Youth, Immigration, and Political Economy}

Youth is a multi-dimensional and socially constructed age category that, varying over time and space, refers to certain characteristics, permissions (to refrain from or engage in a variety of 'adult' activities), and (de)limitations assigned by a particular society to some of its members. Usually, youth is socially understood as " "unfinished', in the 'process of becoming' [adults,] and fixed in marginality" (Mansouri and Francis 2009:14). Immigrant and refugee youth find themselves, by virtue of their crossing of borders, in different fields that assign dissimilar — and sometimes competing - characteristics, permissions, and limits to the notion of youth. A political economy approach to youth helps to unveil "the relationship between a particular socially constructed age stage, an economic mode of production and reproduction (capitalist-patriarchy), and the socio-spatial and cultural forms of life this combination engenders" (Hollands 2003:444).

Rather than seeing youth as an objective biological condition or an 'unfinished' social product, I understand the category of youth to be the result of the interrelation of transnational economic, socio-spatial, and cultural processes. This generates a specific milieu where individuals are ascribed — and also shape — the status of youth (Best 2011; Côté and Allahar 
2006; Reguillo 2000). Recent global changes in occupational and educational structures have also, in turn, refashioned the structure of household arrangements (e.g. years spent in the parental home) and thus reshaped the age span of what is considered as young today, particularly in industrialized countries (Côté and Allahar 1996). Scholars such as Mitchell, Wister, and Gee (2002) have thus identified a transitional stage between the traditional youth stage (18 to 25 years) and adulthood, which they call 'young adulthood,' ranging between the ages of 25 and 34.

Age at immigration is also relevant in the case of families' integration processes, since children of immigrants or refugees, due to their easier acquisition of official languages and the culture of the host country, may acquire power over their parents, which Portes and Rumbaut (2001) identified as role reversal (i.e. becoming the 'parents' parents'). Children in these cases find themselves serving as translators, administering the day-to-day activities of the family in the host country, and taking decisions for adults (ibid.). Moreover, migration scholarship has traditionally conceptualized immigrants as adults, whereby youths have not usually been recognized as central actors of immigration processes (Hernández-Ramírez 2008). Age also relates to gender, since the combination of these two features produces distinctive social outcomes depending on the analyzed group or society. (Doing) gender "involves a complex of socially guided perceptual, interactional, and micropolitical activities that cast particular pursuits as expressions of masculine and feminine "natures"' (West and Zimmerman 1987:126). Gender also relates to the notion of patriarchy, understood as "male domination in an institutional as well as cultural sense.” Thus, patriarchal societies are the "ones wherein, if examined closely, men held positions of power in virtually all decision-making spheres" (Chancer and Watkins 2006:33).

Immigration is defined as a movement characterized by simultaneous changes: a change of residence that implies the crossing of a political or national border, a change in employment if applicable (depending on the life cycle and/or economic insertion of the individual), and a change 
in social relations (Simmons 1991). Diverse theories provide explanations for immigration, such as the neoclassical economics theory, which emphasizes the push and pull macro-structural factors that work towards an equilibrium point in the labour economy (i.e. supply and demand of labour) (Todaro 1969). Under this theory, the (male, heterosexual, adult) migrant is considered as an individual that evaluates, via a rational process (i.e. micro-economic model of individual choice), the benefits and costs of migrating. However, this theory incorrectly assumes that migrants possess complete knowledge of employment opportunities and international wages, thus mainly informing their decisions by rational and economic factors. This theory also ignores broader societal factors that shape migration, such as the influence of familial and communal dynamics, historical events, or the fact that it is not the poorest who migrate but those who possess a diversified set of capitals (economic, cultural, and social) (Castles and Miller 2009; Massey 1999).

Reasons to immigrate are also influenced, at a macro-level, by varying processes of reproduction and expansion of capital such as global trade and investment under post-Keynesian, global, and neo-liberal economies that affect countries, regions, and cities in different ways. These neoliberal practices have generated economic disparities across national, regional, and local North American economies, reshaping capital and labour needs and also labour movement possibilities (Castles 2000; Massey, Durand, and Malone 2002; Portes and Rumbaut 2014).

Moreover, the concentration of capital in global cities such as Montreal, Toronto, and Vancouver, or regions such as the Alberta's oil sands, has led these cities/regions to require a (semi-) skilled immigrant labour force during economic expansion cycles, whilst other cities/regions have found themselves expelling labour force due to the closure of employment sources such as the auto sector in Windsor-Essex (CBC News 2018; cf. Lightman and Good Gingrich 2012; cf. Sassen 1995, cf. 2001; Sorensen 2013; Vosko 2006). Consequently, youth across countries and in various regions have been differently affected by the global reproduction and expansion of capital. Some have faced increased levels of unemployment and economic 
precarity, forcing them to look for local survival strategies, while others, due to their possession of capitals, have been able to (im)migrate.

The effect of globalization processes, neoliberal policies, the orientation of a dominant economic model (e.g. a knowledge oriented economy), and the changing needs of capital and uses of labour thus combine to structurally arrange markets and distribute labour into segments (Edwards 2015; Sassen 2018). Whilst Piore and Doeringer's (1970) original formulation of the labour market segmentation considered only a primary and a secondary market, Wilson and Portes (1980) identified a third segment among immigrants in the United States in the late 1970s based on ethnic solidarity, the 'enclave economy.' This model, however, lends little explanatory power to the Canadian context. The diverse Latin Americans' immigration waves, their scattered and relatively small population size, and their diversity have not led to the development of an ethnic clustering, as we find among other ethnic groups such as Chinese, Arabs, Italians, or Jews, which geographers call ethnic segregation (Qadeer 2003). ${ }^{7}$

I thus use Edwards' (2015) identification of three market segments (i.e. the independent primary market, the subordinate primary market, and the secondary market) to identify how Mexican immigrant youth has been structurally distributed across labour markets in Ottawa and Montreal. My use of Edwards' tripartite scheme, along with Bourdieu's various theoretical notions, allows for the identification of how the interaction between pre- and post-migration economic, cultural, and social capitals granted my interviewees access to and facilitated or impeded their labour mobility between market segments. This scheme also allows for a useful comparison of immigrant and refugee youth's cases regarding their allocation into market segments. This is because each segment is associated with differentiated labour processes and outcomes, where "fundamental differences are not so much among the workers as among the jobs that workers hold" (63). Thus, even if a worker has more education than is required for a particular segment, they might find that their education will offer them very little return in that segment. ${ }^{8}$ 
The first segment, the independent primary market (or 'independent' for economy of language), is defined as one that offers "stable employment with considerable job security, established patterns of career profession, and relatively high pay" (Edwards 2015:69) (see Table 1). Independent jobs "typically require skills obtained in advanced or specialized schooling; they often demand educational credentials; they are likely to have occupational or professional standards of performance; and they are likely to require independent initiative of self-pacing" (ibid.). The average level of pay is significantly higher due to experience or age than in the other two segments, and workers enjoy significant "promotional or career ladders linking prior employment with subsequent jobs" (70). Since this location allows youth to achieve economic stability and thus have, if desired, a more fulsome participation in the social, cultural, and political life of Canada, I consider this to be a positive type of economic integration.

The second segment, the subordinate primary market (or 'subordinate'), includes jobs where tasks are more routinized, the skills required are basic-to-medium level, and the payment is lower than in the independent segment. Here, although workers have little control over their own jobs, their employment mobility is defined by the employing firm and/or union rules (if any), usually based on seniority within the company. The cultural capital required to obtain a job in this segment is lower than in the independent market, but higher than in the secondary market. Thus, some years of college/university, along with age and experience, offer more returns in the subordinate location when compared to the secondary market, but not as many as in the independent location (Edwards 2015:67-68).

This market is composed of permanent production and non-production jobs, which include traditional jobs in the industrial working class such as manufacturing, (unionized) lower-level jobs such as administrative, sales, and clerical jobs or production-type positions in retailing, wholesaling, and utilities or other sectors of the core economy. Subordinate workers, however, face a higher risk of unemployment when economic or business depressions occur, since they do 
not have too much protection against being laid off under these conditions (68-69). Moreover, the possibility of a fulsome participation in the social, cultural, political, and economic life of Canada in this labour segment may be lower when compared to those who experience an independent integration, although higher when compared to those who experience a secondary integration due to differentiated class locations.

The third segment, the secondary market, is characterized by a "lack of any worker rights or elaborate employer-imposed work structures," and constituted by the "preserve of casual labor" (Edwards 2015:63, 66). In secondary market workplaces additional job experience, seniority or education will not lead to higher earnings, for labour here is "treated simply as a commodity." It includes "many different types of jobs, and spans both production and nonproduction work" such as non-union manufacturing, service employment, retail and wholesale trade, lowest-level clerical jobs, seasonal employment, and migrant agricultural labour $(63,65)$. Moreover, secondary market workers might face prompt dismissal for "disciplinary of other arbitrary reasons," since employers find it easy to replace or dismiss workers, even during economic booms, as labour needs change (68). This market location thus leads youths to experience constant job insecurity, low pay, and poor working conditions, making it more difficult for them to participate, if desired, in Canada's social, cultural, political, and economic life vis-à-vis those located in a subordinate or independent type of integration.

In immigration-heavy countries such as Canada, and particularly in cities with a high density of immigrants, it is frequent to find immigrants and/or racialized people in secondary market jobs, since labour market segmentation is also mediated by occupational hierarchies that aim at (re)producing and maintaining non-immigrants' social status and privileges (Calliste 1993, 2000; Massey 1999). In Canada, the secondary market can also be identified in the increasing demand for cheap and flexible labour for specific areas such as agriculture or services such as inhome caregiving, often sourced using temporary migration programs. ${ }^{9}$ This labour is destined to 
serve in jobs that the regular Canadian would not take and/or in isolated regions or towns, such as fast food franchises in small towns. Migrants working in these programs have thus responded to a Canadian labour-capital duality, where capital is a fixed factor that can be idled but not laid off, and where labour constitutes a variable factor of production, manageable according to the specific state of the markets and therefore expendable (Massey 1999). At the same time, the need for labour flexibility and the accumulation and expansion of capital have led to an extension of precarity among broader segments of the non-immigrant population, including youth (Lightman and Good Gingrich 2012; Tremblay 2003).

The main differences between independent and subordinate primary markets reside in their particular mechanisms to provide job security and stability, and in the nature of the actual linkages between successive jobs typically held by workers (66). The main differences between primary and secondary markets are that primary jobs "offer some job security, relatively stable employment, higher wages," "well-defined occupations," and "established paths for advancement" (66), while secondary jobs are rather characterized by low-paying jobs, poor working conditions, little employment security or stability, the requirement of few skills, and the promotion of relatively high voluntary turnover (ibid.).

Moreover, when economic crises arise and unemployment increases, or sometimes even immediately after arrival, some skilled immigrants might be willing to take on low-level jobs as a means to generate an income. This, at the same time, satisfies the employers' needs to have a controlled, docile, and cheap labour force, further reinforcing the labour market segmentation regardless of immigrants' qualifications (Massey 1999). In addition, when immigrants are located in the secondary market, they are more likely to have limited social networks, which restricts their ability to obtain information, funnels their employment access to specific sectors and/or jobs, and curbs their potential for social mobility. This is what Sassen (1995) calls spatial structuration. The structuration of markets and the distribution of labour into segments (Edwards 2015) has also 
been shaped by the increase in precarious work. Precarious work is "employment that is uncertain, unpredictable, and risky from the point of view of the worker" (Kalleberg 2009:2). It affects people not only physically but also psychologically and morally, and "may lead to a lack of social engagement" (9). Even though the recent era of precarious employment began in the mid-1970s in the United States (id.), precarity has been advancing in Canada since the 1980s, promoting the rise of temporary, seasonal, casual, on-call, and contract labour in private and governmental sectors (Kalleberg 2009; Landolt, Goldring, and Bernhard 2011; Zhang and Zuberi 2017). These changing market conditions have led workers to access precarious work not as a choice but as the only alternative to face unemployment, creating a state of permanent temporariness that leaves out protections and benefits (Vosko 2006).

Although the increasing precariousness of the labour market affects Canadians in general, research also shows how recent immigrants, racialized workers, women, and single parents are disproportionately likely to work in precarious forms of work (Zhang and Zuberi 2017:32). As Lightman and Good Gingrich (2012:125) summarize, "whether one is a visible minority - that is, discernible not white — matters in Canada." Visible minority status thus "remains a salient source of economic exclusion in Canada" $(132,134)$. Their quantitative research also unveils that visible minorities have $60 \%$ greater adjusted odds of being below Canada's low-income measure, and $40 \%$ greater adjusted odds of being unemployed over the long-term and have non-permanent employment vis-à-vis their reference categories (i.e. male, non-visible minority, Canadian-born, aged 30-49). They also found that youth (aged 18-29) have more than twice as great the odds of being without the security of permanent employment (133). Location in one of the market segments, however, is not necessarily definitive. Multiple factors intervene for an immigrant to be located in a particular segment. However, the use of Edward's tripartite schema allows us to analytically identify and compare how (Mexican) immigrant youth has been structurally distributed across labour markets. 
Table 1: Comparison of Independent, Subordinate, and Secondary Market Segments

\begin{tabular}{|c|c|c|c|c|}
\hline & TYPES OF JOBS & CHARACTERISTICS OF JOBS & $\begin{array}{l}\text { VALUE OF EXPERIENCE AND } \\
\text { EDUCATION FOR JOB MOBILITY }\end{array}$ & RISK OF UNEMPLOYMENT \\
\hline SECONDARY & $\begin{array}{l}\text { Jobs span both production and non- } \\
\text { production work. They include low- } \\
\text { skill jobs in non-union } \\
\text { manufacturing, service employment, } \\
\text { lower-level positions in retail and } \\
\text { wholesale trade, and seasonal } \\
\text { labour. }\end{array}$ & $\begin{array}{l}\text { Casual employment; the job does not } \\
\text { necessarily require previous training } \\
\text { or education beyond basic literacy; } \\
\text { few skills are required and few A can } \\
\text { be learned. Jobs offer low pay, } \\
\text { virtually no job security, and are } \\
\text { typically dead-end jobs with little } \\
\text { prospect for advancement. }\end{array}$ & $\begin{array}{l}\text { Little reward for seniority or } \\
\text { education in the form of higher } \\
\text { pay or a better job. Turnover } \\
\text { tends to be high, thus job tenure } \\
\text { is small. Jobs offer little } \\
\text { employment security and } \\
\text { stability. Links between one job } \\
\text { and the next are slight. }\end{array}$ & $\begin{array}{l}\text { Workers may face dismissal } \\
\text { even during boom times for } \\
\text { disciplinary or other } \\
\text { arbitrary reasons. }\end{array}$ \\
\hline SUBORDINATE & $\begin{array}{l}\text { Jobs span both production and non- } \\
\text { production jobs. Production jobs } \\
\text { include traditional jobs of the } \\
\text { industrial working class such as } \\
\text { manufacturing, consumer products } \\
\text { assembly, etc., and.also lower-level } \\
\text { jobs such as sales, clerical, and } \\
\text { administrative work found mostly in } \\
\text { retailing, utilities, and manufacturing } \\
\text { corporations. Other jobs include } \\
\text { production-type positions in core } \\
\text { firms in transportation, retailing, and } \\
\text { wholesaling. }\end{array}$ & $\begin{array}{l}\text { Offer some job security, relatively } \\
\text { stable employment, higher wages, } \\
\text { and linkages between successive jobs } \\
\text { with paths for advancement. Work } \\
\text { tasks are repetitive and routinized. } \\
\text { The skills required are learned quickly } \\
\text { and often acquired on the job. } \\
\text { However, jobs provide little } \\
\text { opportunity for workers to have any } \\
\text { control over their own jobs. Jobs are } \\
\text { better paying, and generally involve } \\
\text { long-term work. }\end{array}$ & $\begin{array}{l}\text { Schooling pays off, particularly at } \\
\text { the high school level and the first } \\
\text { few years of university. }\end{array}$ & $\begin{array}{l}\text { Workers may carry with } \\
\text { them substantial risk of } \\
\text { unemployment, but the } \\
\text { risks are different than } \\
\text { those of the secondary } \\
\text { market. The main } \\
\text { unemployment risk comes } \\
\text { from business depressions. } \\
\text { Cyclical unemployment is } \\
\text { not uncommon. However, } \\
\text { there are continuous } \\
\text { connections between laid- } \\
\text { off workers and their jobs. }\end{array}$ \\
\hline INDEPENDENT & $\begin{array}{l}\text { Jobs span middle and professional } \\
\text { layers of the employment structure. } \\
\text { The middle layer is composed of jobs } \\
\text { such as long-term clerical, sales, and } \\
\text { technical staff jobs, bookkeepers, } \\
\text { supervisors, and so on. The } \\
\text { professional positions include jobs } \\
\text { such as accountants, researchers, } \\
\text { scientists, nurses, doctors, teachers, } \\
\text { etc. }\end{array}$ & $\begin{array}{l}\text { Stable employments, with } \\
\text { established patterns of career } \\
\text { progression, and relatively high pay. } \\
\text { The jobs are not centered in } \\
\text { production. }\end{array}$ & $\begin{array}{l}\text { Jobs require skills obtained in } \\
\text { advanced or specialized schooling } \\
\text { (i.e. educational credentials). Jobs } \\
\text { likely to have educational or } \\
\text { occupational standards for } \\
\text { performance, and likely to require } \\
\text { independent initiative or self- } \\
\text { pacing. Education and work } \\
\text { experience pay off. }\end{array}$ & $\begin{array}{l}\text { Workers have longer tenure } \\
\text { and little voluntary } \\
\text { turnover. Job changes } \\
\text { usually mean movement } \\
\text { from one employer to } \\
\text { another, usually within } \\
\text { occupational job ladders. } \\
\text { Professional workers, } \\
\text { however, have a much } \\
\text { greater chance of } \\
\text { unemployment than those } \\
\text { in the middle layer. }\end{array}$ \\
\hline
\end{tabular}

Source: Edwards 2015 


\subsection{Perspectives on Transnationalism and Transnational Practices}

Transnationalism is a process whereby immigrants and non-immigrants, embedded in multi-layered and multi-sited social fields, maintain active ties across national borders with other immigrants and non-migrants through participation in economic, political, social, cultural, and/or religious networks and processes with varying frequency, duration, intensity, strength, impact, formality, and scope (Goldring et al. 2003; Levitt 2001b; Levitt et al. 2003; Levitt and Glick Schiller 2004). Guarnizo (in Levitt 2001b:198) identified two types of transnationalism: core transnationalism, consisting of regular and patterned transnational activities integral to persons' habitual lives, thus being somewhat predictable, and whose strength "varies with regard to their frequency or intensity." In contrast, expanded transnationalism is found among immigrants who engage only occasionally in transnational practices, such as offering support in natural disasters or responding to varied crises in their homelands.

Expanded transnationalism is also close to what Itzigsohn et al. (1999:323) called broad transnationalism, constituted by "a series of material and symbolic practices in which people engage that involve only sporadic physical movement between the two countries, a low level of institutionalization, or just occasional personal involvement." Broad transnationalism is one of "two poles along a continuum of different forms of transnational practices" (317), the other pole being a narrow form of transnationalism. Narrow transnationalism refers to "those people involved in economic, political, social, or cultural practices that involve a regular movement within the geographic transnational field, a high level of institutionalization, or constant personal involvement" (323).

Transnationalism, however, is not a process that develops immediately. Al-Ali et al. (2001), for example, have shown how, at the time of their research, Bosnian refugees in the United Kingdom and The Netherlands and Eritrean refugees in the United Kingdom and Germany had not constituted a transnational community. Nonetheless, their actions clearly indicated a process 
of transnationalism in development. These included economic "remittances, regular contact and visits, the exchange of ideas and knowledge, and the involvement in community associations promoting and upholding social ties and cultural practices[,] as well as organizing charitable collections" (583). They called this process emerging transnationalism, where "transnational activities and social fields are dynamic and fluid, as well as evolving and changing" (594). In emergent transnationalism, opportunities might increase for some immigrants while diminishing for others based on politico-economic and socio-cultural contexts of exit and reception, transnational institutions, and other factors such as class, gender, life stage, etc. (Levitt 2001b).

Moreover, despite being composed of sporadic or limited transnational practices, incipient or emergent transnationalism has shown to have macro-social impacts on the political, economic, socio-cultural, and religious milieus of the sending and receiving locales. This impact is stronger if transnational practices are sustained over time and accompanied by at least a small immigrant group doing core transnationalism and a bigger group engaged in broader transnationalism (Itzigsohn and Giorguli Saucedo 2002). As Portes (2003:878-79) asserts, “[w]hile from an individual perspective the act of sending a remittance, buying a house in the migrant's hometown, or traveling there on occasion have purely personal consequences, in the aggregate they can modify the fortunes and the cultures of these towns and even of the countries of which they are part" (see also Itzigsohn et al. 1999).

Transnational practices might consist of one or various practices such as "regular contact with relatives and friends back home, travel for family occasions, etc.” (social), "celebrating ethnic, religious or national holidays associated with the home country" (cultural or religious), or sending "family [economic] remittances, collective remittances, investment, [or] owning a home or property 'back home”' (economic) (Goldring et al. 2003:5). Economic transnationalism or monetary remittances can be individual, collective, or investor or "“successful migrant' remittances" (Goldring 2004:803). Economic transnationalism also varies by immigrants' class 
(Levitt and Jaworsky 2007), its effect depending on the particular exchange value between the economic capital invested in transnational practices, the use of remittances, and the social capital generated in both contexts of exit and reception. For instance, the owner of a Brazilian bakery in Boston may belong to a lower class in the United States due to a differential racial status, but he may be considered as important as the mayor of a rural town in Brazil (Levitt and Jaworsky 2007). Moreover, in times of economic and/or political crises, monetary remittances acquire more value, both at a macro-level and at the household or individual level (Goldring 2004).

Other transnational activities are political, such as reading newspapers, keeping in touch with politics, lobbying the authorities of one country to influence its policies, acquiring membership in political associations or parties in two or more different countries, electoral participation (either as voters or as candidates), giving or raising money for political parties, organizations, or social movements, or participating in political campaigns or rallies and nation-building itself(Levitt and Jaworsky 2007; Paasche and Fangen 2012). Overall, transnational practices are shaped by immigrants' social and economic status, gender, ethnicity/race, politico-economic contexts, and processes of integration in countries of exit and reception (Goldring et al. 2003:7).

\subsubsection{Transnationalism and Integration}

Immigrants' transnational practices have historically been located under contexts of competing nation-state building projects and demands for assimilation in countries of reception, for which immigrants' allegiances and loyalties to home countries are constantly questioned, delimited, and/or constrained (Glick Schiller, Basch, and Szanton Blanc 1995). In the United States and Canada, for instance, it has been argued that immigrants' transnational practices, such as political involvement in home country affairs, diminish and even act against the expected political and civic commitment to the host country (Goldring et al. 2003). Correspondingly, some political and academic approaches expect immigrants to assimilate into the new country over time, shedding their old customs, values, and traditions, and adopting those of the country of 
reception (see, for instance, Alba and Nee 1999; Younge 1944).

Assimilationist perspectives, however, have failed to recognize that some immigrants' social and emotional lives, connections, and actions are located in transnational social fields. Indeed, as Goldring et al. (2003) found, processes of integration in the country of reception are sometimes positively correlated to transnational activities and vice-versa. For example, Chilean and Canadian transnational political activism in Toronto in the 1970s favourably shaped Canada's context of reception for later waves of Latin American immigrants, such as Central Americans and Colombians (Goldring and Landolt 2014). Thus, rather than simply assimilating into a Canadian identity, Latin Americans' actions exerted a decisive influence in terms of asserting their own identities, the establishment of their political presence in Canada and abroad, and the shaping of their integration processes.

I understand integration as a multi-dimensional process where immigrants and refugees are able to enjoy full and equal participation in the political, economic, social, and cultural life of the country of reception. Integration also offers the possibility of generating multiple forms of belonging, guaranteed under a legal framework, which allows immigrants and refugees to maintain and shape their cultures and beliefs (Ministère des Communautés Culturelles et de l'Immigration in Caplan 2001:2; Melia 2004). In addition, as Berry (in Tonks and Paranjpe 1999) contends, integration implies the possibility of establishing relations with other ethnic groups, identifying with other traditions and values, and engaging in activities from two or more cultures. Integration among immigrant youth is shaped by factors such as age, length of stay in the country of reception, parents' education, and their friends' influence and ethnic background (Melia 2004).

Integration is also mediated by the socio-cultural, religious, ideological, and political beliefs that immigrants and refugees arrive with in the country of reception. For example, Long and Hughes (2003) found that some Latin American immigrants did not want to actively incorporate themselves into the political life of Canada to avoid drawing the alleged potential ire of authority 
figures such as government officials, a common occurrence in some Latin American countries. In this sense, a lack of political integration and depoliticization can occur on the part of immigrants and refugees based on both their previous experiences in their countries of origin and an understanding of their immigration as a gracious concession of the Canadian government. Integration can be identified by a number of variables such as occupational possibilities, mobility or status, attainment (or recognition) of education, language proficiency, income levels, acquisition of property, political and civic participation, access to social services, and sense of belonging (Green 199:8).

Belonging is a central element of integration and means more than just the possibility of occupying a space and a place. It refers to the degree of attachment to a nation-state, region, and/or a particular culture or group, and also requires acceptance and openness on the part of Canadians (Long and Hughes 2003). Immigrants' pre-migration experiences also influence what they envision and do in countries of reception, and consequently shape the degree and types of transnationalism they might develop and/or engage with (Levitt and Lamba-Nieves 2011). For example, Latin Americans' political transnationalism in Toronto in the 1970s and 1980s was strongly mediated by the politico-economic contexts and the grassroots organization and experiences they had in their countries of origin. These experiences shaped the form of their political organization in Canada when looking to improve their type and quality of integration (Goldring and Landolt 2014; Landolt and Goldring 2009, 2010; Landolt et al. 2011; Veronis 2006a, 2010, 2015; Veronis and McAloney 2010).

It is also important to recognize, however, that the relationship between integration and transnationalism is a complex and, at times, contradictory one (Goldring et al. 2003). This implies that there is no direct correlation between, for instance, social exclusion and the development of transnationalism. Certainly, research in the United States and Europe signals how racism, racialization, and discrimination have sometimes contributed to transnationalism (ibid.). This is 
because immigrants who have faced such experiences, while maintaining active ties in their home countries, are able to generate social capital, status, and social mobility in transnational fields (ibid.). This accumulation of capitals compensates for their negative experiences of poor integration in the country of reception (see also Basch, Glick Schiller, and Szanton Blanc 1994). Itzigsohn and Giorguli Saucedo (2002:772) call this type of transnationalism "reactive transnationalism," since this originates as a reaction to certain (negative) social experiences.

Regarding gender and transnationalism, Guarnizo et al. (2003:1229-30) found that political activism was highly concentrated among adult, married Salvadoran, Dominican, and Colombian immigrant males in the United States. Nonetheless, they also found Jones-Correa's "notion that the proclivity of males to engage in home country politics [as] a consequence of status loss," a common argument in the transnationalism literature, was statistically insignificant. What made a difference in engagement in transnational practices among these groups was "greater stability and greater resources brought from the home country" (1230), such as length of residence, education, citizenship acquisition, human capital, strong and enduring social connections, and nationality. Thus, if immigrants have a poor integration in the host country, and since the emergence and development of transnationalism partially depends on the possession of resources, its development may be slow and "resource dependent" (Itzigsohn and Giorguli Saucedo 2002:773).

Research also shows that immigrants who are well integrated into the host society and have acquired local capitals usually develop feelings of belonging to the host country (Bauböck 2003). And in the case of Mexicans in the United States, they also tend to engage more in transnational practices (López Salinas 2016). Consequently, the outcomes resulting from immigrants' type of integration and transnational participation are determined in part by " $[\mathrm{t}]$ he kinds of activities in which migrants participate, the institutional arenas where these activities take place, the class resources to which they have access, and their life-cycle stage" (Levitt et al. 2003:571). As Levitt et al. contend, some migrants participate actively in the economic, political and religious lives of 
their homelands and achieve upward mobility in both contexts, while others engage in transnational practices but advance only in a single setting.

\subsection{Conclusions}

Canada's immigration policy has followed economic and labour market imperatives since the late 1960s, favouring an extensive use of economic migration over family reunification and humanitarian migration. At the same time, neoliberal policies and globalization have refashioned and further segmented Canada's labour markets. Thus, on the one hand, Canada's economy constantly requires immigrants to supply its labour force demand, but on the other hand it funnels the immigrant labour force - even if skilled — into different labour market segments, particularly the subordinate and secondary markets.

Bourdieusian theory is thus useful here to better understand the relationship between youths' habitūs prior to their immigration and the way those habitūs may shape their economic integration after immigration. Their habitūs may also assist them to respond to their structural location in Canada's market segments and reflect on their production of and engagement with transnationalism. The relation between transnationalism and integration, however, is not a straightforward one. Transnationalism can originate as a reaction to certain social experiences (i.e. reactive transnationalism) or evolve as manifestation of a positive integration process which, nonetheless, is dependant on the accumulation of resources (i.e. resource-dependent transnationalism). In other cases, integration processes and transnationalism can be mutually supportive, particularly when immigrants experience an extended length of residence, education, and strong social ties, or they might simply coexist, the two not necessarily constituting a zerosum game.

The overall framework presented in this chapter is devised to offer a set of theoretical and analytical tools to better understand the relationship between the pre- and post-migration location, economic integration, and creation of transnational practices of Mexican immigrant and refugee 
youth in Montreal and Ottawa. These relationships need to be properly situated, however, in a broader historical and politico-economic context. In the following chapter, I analyze the 150-year history of thin, mainly economic Canadian engagement with Mexico, which contrasts with the almost 200-year history of a thick relationship between Mexico and the United States. The relationships that these countries have maintained have functioned as a historical and politicoeconomic backdrop against which the immigration of Mexicans in Canada has developed. 


\section{Chapter 3: So Far from Canada, So Close to the United States: Mexico and Canada's Historical, Political, and Economic Relations}

Although Mexican immigration to Canada has been officially registered since 1918 (Canada Dominion Bureau of Statistics 1924), it is only since the mid-2000s that this immigration stream has become a somewhat meaningful phenomenon. However, to better understand why Mexicans have immigrated to Canada and the types of transnational practices they have developed, one needs to take into consideration the more structural and broader historical and politico-economic contexts that have shaped this immigration. Although Canada and Mexico have maintained on-and-off commercial relations since the $19^{\text {th }}$ century, this relationship has also been mediated - at various levels - by the relation between Mexico and the United States (and the relation between Canada and the United States). Thus, a proper understanding of Mexican migration to Canada needs to be contextualized in a North American framework.

Correspondingly, the goals of this chapter are twofold. First, using a historical and politicoeconomic approach, I show how Canada's politico-economic dependent relations to the United States, along with its foreign policy re-location in the post-War period, have led Canada to maintain historical on-again-and-off-again thin relations with Mexico. Only recently have these relations shown a gradual growth, first with NAFTA and then through both the expansion of Canadian capital to Mexico (e.g. via mining and banking sectors) and an incipient expansion of Mexican capital to Canada. And second, I show how the political, economic, imperialistic, and military relations that the United States has maintained with Mexico have, at the same time, fostered dense, multiple, and varied ties between these two countries that have promoted and sustained thick and longstanding streams of (im)migration to the United States.

The Mexico-US relationship contrasts to the generalized absence of significant networks of various types between Canada and Mexico, a restrictive and shifting Canadian immigration policy that has mainly fostered an economic type of migration, and a geographical location that makes it more difficult for Mexicans to travel across the Canadian border. Thus, even when Mexicans do 
not currently constitute the main migrant group to the United States (Passel and Cohn 2019), Mexicans migrate in large numbers to the United States rather than to Canada. This, in turn, diminishes the possibilities of Mexico and Mexicans developing transnational ties with Canada.

This chapter is divided into two sections. The first section analyzes the political and economic conditions that led Mexicans to emigrate to the United States since the 1820s, thus establishing strong ties with this country. This is paired with an analysis on how the transformation of the United States into an industrial capitalist empire demanded considerable amounts of cheap, flexible, and low- and semi-skilled labour as an inherent condition for the expansion of its capitalist economy. Besides constituting a colossal pull factor for Mexicans, the manner in which they provided cheap labour to the US economy also subjected them to Othering and racialization processes. In the second section, I identify the historical and politico-economic reasons for Canada's lack of engagement with (and knowledge about) Mexico and vice-versa. This limited engagement, in turn, has contributed towards producing low levels of immigration from Mexico to Canada resulting in the production of thin networks between both countries. Contrasting these two historical and politico-economic structural accounts of international relations will serve as a framework to better understand the conditions of production of two dissimilar Mexican migration streams. While this chapter focuses more on various structural conditions of (limited) Mexican migration to Canada, the following chapter will address the particularities of this migration.

\subsection{Mexican (Im)Migration to the United States: Historical and Politico-Economic Reasons}

Although Mexico and Canada are geographically located at opposite sides of the United States and are North American neighbours, they are also situated in historically, politically, economically, and socio-culturally different scenarios that have produced what Macdonald and Gabriel (2004:67) call “asymmetrical relationships.” These asymmetrical relationships, intersected by hierarchies based on nation, gender, and class among others, have also played out to shape Mexican and Canadian relationships. This relationship has been one that we can call an 
on-and-off and thin relationship, and "by far the weakest of the three bilateral relationships within North America” (Macdonald 2003, 2016). ${ }^{10}$ Mexico and the United States, in contrast, have maintained a highly complex albeit asymmetrical relationship that has lasted for almost two centuries. It is characterized by dense and multi-layered networks of political, economic, social, cultural, ideological, and religious systems that bind the histories of both countries.

The historical migration of Mexicans to the United States results from a number of structural and accumulated circumstances. These include Mexico's considerable instability resulting from its human, economic, and political resources invested in trying to achieve independence from Spain (1810-1821), its defence against a first French army invasion (18381839), Tejas' proclamation of independence (1836), and a US military invasion, ${ }^{11}$ which culminated in the surrender of more than half of the Mexican territory (1846-1848) (Merry 2011; Olson-Raymer 2014; The Library of Congress 1848; US Department of Interior 1992; Zoraida Vázquez 2008). Mexico’s territorial surrender would also confirm to other Latin American countries "their view that the United States was a devious, domineering, meddling, arrogant, and aggressive imperialist power, one that threatened the very existence of its hemispheric neighbors" (Henderson 2007:186). Mexico's territory surrender, however, also meant the acquisition of an 'unwanted issue' for the United States, that of dealing with a so-considered "inferior population" (Ibarra 2004) now living in its newly-acquired territory, that is to say, Mexicans.

Despite the obligations stipulated in the Treaty of Guadalupe Hidalgo (1848), and contrary to what Ramírez (2015:95) contends (i.e. that Mexicans who remained in the United States along with their progeny “became a permanent component of the country's citizenry"), Mexicans who stayed on US soil were not given full US citizenship status until the 1930s (Griswold del Castillo 2006). That is more than 80 years after the signing of the treaty. The surrender of the Mexican territory, along with the development of an expansionist, US industrial economy, which demanded considerable amounts of cheap, flexible, and low-skilled labour as an inherent 
condition for its capitalist realization and expansion, (Gutiérrez 1995), led Mexicans to experience downward class mobility.

Furthermore, Mexicans "became alienated from the dominant, Anglo European society" due to Anglo-Americans' ethnic self-segregation. The latter began building up their own stores, institutions, etc., whilst Mexicans were also being politically disempowered. "They [also] became the target of racist violence because whites believed Mexicans posed a threat to the economy of the southwest" (Olson-Raymer 2014). This second-class treatment not only set the pattern for the later treatment of Mexican immigrants in the United States, but also fostered the development of a classed society that functioned with “distinct racial divisions” (García 1981:1, 7).

Soon after the surrender of Mexican territory, Mexicans began immigrating to 'Occupied Mexico' due to a number of push and pull factors that were being generated and accumulated at both sides of the border (more below). Their migration was also stimulated because the new international border did not immediately change the previous trade and social network patterns that existed in the region among Mexicans. Moreover, the border did not have any visible markers or barriers that impeded their access, plus the US immigration policies and practices were lax at the time (García 1981). Thus, Mexicans kept crossing "all along the border with the feeling that in reality nothing had changed" (Martínez 1957:1). On the Mexican side, emigration resulted from a number of structural and accumulated circumstances.

After Mexico was forced to surrender 55\% its territory, along with the symbolic and emotional blow that this meant for Mexicans, the then President of Mexico, José Joaquín de Herrera, found himself reorganizing the country's remaining territory, while also confronting threats of uprisings by some Mexican groups who supported the monarchy and others who supported a federalist system. He also faced Indigenous uprisings in various states, particularly by Mayans in Yucatán who were fighting for better economic and political conditions (Zoraida Vázquez 2008). He also was trying to secure Mexico from armed attacks by both Indigenous 
peoples from the United States - trying to recover their land - and from the "persistent efforts of private American citizens to enter Mexico illegally and incite rebellions in an effort to gain [even more] territory" (US Department of State 2013).

Mexico would also have to confront a second French military invasion in 1862-1867. Due to the poor state of the Mexican economy, then Mexican President, Indigenous Zapotec Benito Juárez, suspended Mexico's external debt payments in 1861. The payment suspension was used as an excuse by the French monarchy to invade Mexico, to advance its plan of building a 'Latin Empire' in the Americas, and impede any other potential US territorial expansion via the acquisition of more Mexican territory (Zoraida Vázquez 2008). After the Union won the civil war against the Confederacy in the United States (1860-1865), the Americans supported President Juárez's fight against the French empire, leading to the defeat, trial, and ultimate death sentence of Maximilian I in Mexico City (1867). His death put an end to the short-lived Franco-Mexican empire (Zoraida Vázquez 2008).

All this political and military tumult had a profoundly negative impact on Mexico's structural conditions, increasing its political and economic vulnerability. Indeed, the second French intervention not only increased Mexico's external debt but also disrupted Mexico's production (Menegus and Tortolero 1999), particularly in the central region of the country, a traditionally rich agricultural area. Moreover, the successful commercial routes that Mexico had developed in Santa Fe and Tejas before Mexico's territory surrender were lost due to the Treaty of Guadalupe Hidalgo and Tejas' independence (Zoraida Vázquez 2008). Mexico’s demographic density and distribution did not help in the generation of a diversified economy. In 1870, its population was still heavily concentrated in the middle and southern parts of the country, totalling nine million inhabitants (ibid.), whilst the United States had a more geographically extended population of approximately 38.5 million people (US Census Bureau 2016) and was invested in developing a fierce industrial capitalism. 
The entrance of coarse textiles from the United States (where cotton produced on slave plantations would play a central role) affected Mexican textile companies and made their workers redundant. The overall panorama caused by the consequences of warfare, land dispossession, and usually deficient administrations was grim for the Mexican population (Zoraida Vázquez 2008). The United States, meanwhile, was transforming its previous territorial growth into an agricultural and industrial capitalist development from the mid-1800s onwards. This transformation, however, was not uniform; it was based on regional characteristics that created differentiated labour needs. Thus, "in the industrialized East and Midwest, for example, immigration gave rise to an industrial[, more skilled-type] working class." In contrast, regions "such as the South, Southwest, and West... supplied agricultural products and industrial metals" that required unskilled labour for the mines, railroads, farms, ranches, as well as other types of menial work (García 1981:2). In Southern California, the sugar beet industry began developing in 1868 and was thriving by 1888 , but since white American labourers refused to do arduous work and European workers were harder to find due to geographic distance, the US demand for labour substantially increased. This attracted thousands of Mexicans and also Japanese and Filipino workers (Martínez 1957).

In addition, the gold rush to California had attracted around ten thousand Mexicans every spring since 1848, many of them already highly skilled in mining production (Martínez 1957; Mora-Torres 2011). Indeed, Americans took advantage of the knowledge that Mexican migrants from the state of Sonora, a mining center established since 1640, brought with them to California and Arizona. For instance, “'[b]y the mid-1920s, Mexicans made up 43 percent of Arizona's copper miners" (Rodríguez 2008:131). At the same time, the construction of the US transcontinental railroad generated a huge demand for labourers in the following decades. Indeed, since 1880, Mexicans had "made up seventy percent of the section crews and ninety percent of the extra gangs on the principal western lines [i.e. the Southern Pacific and Santa Fe lines,] which 
regularly employ[ed] between 35,000 and 50,000 workers in these categories" (Martínez 1957:3).

Furthermore, the east Texas cotton industry, no longer benefitting from chattel slavery due to the Emancipation Proclamation of 1863 and requiring fine hands for the harvest, found itself highly dependent on readily available Mexican labour due to its geographical proximity. These differentiated regional economic developments in the United States, based on diverse industries created an internal "regional division of labor" (García 1981:2). Here, Mexican cheap, racialized, and flexible labour constituted a central element in the (re)production and expansion of US capital. This labour also substituted jobs left open by decreasing numbers of European but mostly Asian immigrants between the late-1800s and the 1920s after the passage of various US migration exclusions (Sadowski-Smith 2008).

Paired with Mexico's context, the overall US geographical expansion and its development of industrial capitalism generated the propitious conditions for the displacement of Mexicans to 'Occupied Mexico,' who were looking for their survival. At the same time, "[ $[\mathrm{t}]$ ogether, industrialization, regional economic specialization, and Mexican immigrant labor launched an economic boom" in many US regions, "and in the process created new and enlarged Mexican communities within the United States" (García 1981:2).

In Mexico, the government of Porfirio Díaz (1876-1911) paid Mexico’s external debt, reinvigorated the public finances that were bankrupt, achieved a surplus in 1894, linked the Mexican economy to international markets, and opened the country's economy to foreign investment. It also offered generous concessions and legislation that guaranteed an ample margin of profits, attracting considerable Canadian, American, English, French, German, and Dutch investments (Speckman Guerra 2008). Many of these resources were invested in the construction of ports and trains, the generation of power, and in oil exploitation and mining extraction. Although the United Kingdom had a vested commercial interest in Mexico as a way to circulate its excess of capital since 1824, and thus made big investments in the country, the presence of Canadian capital 
was also important in modernizing Mexico City's infrastructure under the Porfiriato (GutiérrezHaces 2015). At the same time, however, subsistence agriculture was drastically reduced despite Mexico's significant population increase of $162 \%$ between 1877 and 1910 . This led to both food price increases, particularly corn, the main staple of the Mexican diet, which had now to be imported (Speckman Guerra 2008), and a consequent experience of hunger among Mexicans. Such experiences were also marked by Díaz's authoritarian dictatorship, under which the Mexican population, mainly an indigenous and peasant society (Gutiérrez-Haces 2015), had to find urgent solutions to make ends meet.

The previous historical inequality that Mexico had experienced now took another turn. The contrast between the output of export agriculture and domestic consumption agriculture, as well as the uneven development between light and heavy industry led by foreign investment, generated a geography of irregular economic development. The north of Mexico, for instance, developed a more diversified economy (i.e. livestock, agriculture, mining, and industry), propelling the development of a mainly urban, waged, and more literate population. This northern development was also fostered by an increased contact and commerce between Mexico and US border cities, which boosted Mexico's northern industrialization (Speckman Guerra 2008). The middle part of the country (e.g. Jalisco, Puebla, Veracruz, Mexico City), on the contrary, witnessed the substitution of craft workshops with light manufacturing industries that focused on domestic consumption. The southern regions were the less developed and, at the same time, concentrated most of Mexico's indigenous groups. Moreover, international economic crises would also have a strong impact on the less developed regions (ibid.).

At the same time, hacendados—owners of haciendas — grew "more numerous and powerful” (Martínez 1957:4). Porfirio Díaz’s land policies benefited large and traditional land owners and foreign investors rather than Mexican individuals and communities (García 1981). As the Mexican population increased and the ownership and redistribution of land diminished, 
"conditions became more desperate" (Martínez 1957:4). This forced much of the rural population off of their individual and communal lands (García 1981) and created a vast pool of manual labourers. Between 90 to $95 \%$ of the 15.16 million inhabitants that Mexico had in 1910 were landless and now working as agricultural labourers for hacendados. They worked twelve hours per day and usually were paid in supplies, which limited their possibilities of capital generation, not to mention the repressive and authoritarian character of the Porfiriato, which impeded workers from organizing and facilitated keeping wages low (Martínez 1957:4; Massey et al. 2002). Consequently, migration was a natural answer for many of Mexico's rural residents to temporarily "solve economic problems their families faced at home, problems associated with the market failures of the Porfirian economy and later on of the Revolution" (Massey et al. 2002:31). In addition, the development of railroads financed by the United States allowed uS capital to penetrate Mexico's interior. This also facilitated the movement of labour recruiters from the United States to Mexico and that of Mexican migrants to the northern neighbour, setting up the large-scale migration of Mexicans around 1900 (Durand, Massey, and Zenteno 2001:109).

Wage disparities in Mexico also constituted a migration motor (Gamio 1969). Gamio determined that the mean or "misery wage" of a Mexican worker had to increase eight times to cover only the basic necessities of life (35). Meanwhile, the wages offered in the United States were higher than those offered in the north of Mexico. For example, in the 1890s, the acquisitive power of Mexican peasants (only in regard to corn, wheat, cloth, and other essentials) was considered "to be 1,400 percent less than that of the American farm laborer of the same class and time" (Simpson in Martínez 1957:4). These wage disparities, along with the dispossession and unavailability of land under the Porfiriato, generated a strong current of internal migration that, in many cases, also constituted the first stage for international migration.

The severity of the long-lasting Mexican Revolution (1910-1920), ${ }^{12}$ along with the Cristero war (1926-1929) ${ }^{13}$ that strongly affected traditional Mexican agricultural regions (Garciadiego 
2008), just added to the negative structural factors that Mexico had been accumulating. Mexican migrants in the United States then turned out to be "more spatially mobile than both native and foreign-born whites" as a way of survival (Rodríguez 2008:135). The generated work circuits also allowed Mexican immigrants to expand their geographical presence in the United States. This high labour mobility also created the myth among Americans that "Mexicans were mere sojourners," and that the United States "could avail itself of cheap labor without having to incorporate the laborers themselves into its national life" (Rodríguez 2008:134).

Nonetheless, Mexican immigrants had already begun establishing intra-national and transnational networks of labour-based knowledge and social and symbolic capital that linked migrants, towns of origin, new Mexican communities in the United States, and people who had never migrated. These networks, in turn, began raising the probabilities of migration in Mexico and altered the context in which decisions to migrate were made (Hernández-Ramírez 2008; Massey 1999). By the mid-1920s, Mexicans were already deeply entrenched into the US geography and economy as both low-skilled and skilled laborers: "Mexicans are engaged in every conceivable type of occupation. We have become so dependent upon them in many sections of our agricultural and industrial life that were they suddenly to be withdrawn, these enterprises would at last temporarily collapse" (McCombs 1925:15).

In the long history of US capitalistic economic needs, perpetually in tension with racist ideologies, Mexican labour has been always indispensable for the maintenance of that economic model due to its "very desirable economic qualities:" their geographical proximity, their dire need of jobs regardless of the offered wage, their availability as part of an abundant labour source, and because they have been considered, at various points of time, better workers than Americans and other national groups (Handman 1935:607). For instance, between 1926 and 1930, many US Congressional hearings were held with the intent of restricting or defending Mexican immigration. Mexicans were positioned against Native Americans, Filipinos, Chinese, Japanese, and Puerto 
Ricans in what Aragón (2017:59) identifies as “multiple trajectories of racism.” For example, American "[d]efenders of Mexican labour repeatedly stated their fear that 'the negro' $[\mathrm{sic}]$ would 'spread' if Mexican immigrants were shut out' (61). Detractors typified Mexicans as primitives, classless, poor, ignorant, degraded, foreigners, satisfied with very low social conditions, mentally and physically slow, greasers, and mongrels (Gómez 2007; Rodríguez 2008).

These characterizations were not only based on anti-Mexican prejudice, a continuation of previous American racialization processes, but also on a binary opposition to an alleged American superiority synthesized in the phrase ‘the Mexican problem' (see González 2011). ${ }^{14}$ Nonetheless, the continuous and pressing need for cheap and flexible labour to keep meeting the demands of the US capitalist system led many US regions to keep demanding Mexican workers. At the same time, as Durand (2004) notes, from the late 19th century to 1940, "Mexican emigrants were often considered 'traitors' to the homeland [by other Mexicans] for working for and therefore strengthening their northern neighbor."

This conception markedly changed with the electoral win of Mexican President Vicente Fox in 2000. President Fox saw Mexican emigrants as the "new heroes" (Lizarzaburu 2004), forced to leave the country for economic reasons and, nonetheless contributing billions of dollars to the Mexican economy (Durand 2004). At the same time, Fox encouraged emigrants to return to jobs in Mexico. Nonetheless, Mexico's inadequate employment promotion policies, such as asking emigrants to dial a toll-free jobs hotline to find a job, led many to see their new characterization as 'heroes’ as empty political posturing (FitzGerald 2009).

Overall, since the nineteenth century, many Mexicans have (im)migrated to the United States as a way of survival due to the hardship they experienced in their home communities. Others migrated due to the increasing demand for labour in the agricultural, mining, cattle, and railroad sectors in the United States and its higher wages. And yet other Mexicans migrated as political exiles or religious refugees due to the increasing insecurity and violence experienced 
because of constant revolts, civil and foreign wars, and repeated foreign invasions that Mexico underwent, such as the US invasions of 1914 and 1916.

It would be simplistic to affirm today that Mexican (im)migration to the United States, as Gamio (1969:30) did, is only "an economic phenomenon, the automatic result of increasing demand for labour in the one country and available supply of laborers in the other." Neither is it the result of a "striking coincidence," as Martínez (1957:iv) considered, where the "agricultural development of the United States across the border at the same time required almost limitless numbers of laborers." As the comprehensive historical and politico-economic analysis I have laid out allows us to see, there were no "striking coincidences" in the development and expansion of US industrial capitalism.

Rather, the continuous and multifaceted interventions of the United States in Mexico's matters, as well as the former's diverse strategies of control and dispossession of Mexican resources, "created a virtual economic colony [...] while acknowledging a nominal Mexican sovereignty" (González 2011:29). This, along with Mexico's own history of politico-economic developments that also included a French colonial intervention, allowed for the proper conditions for one of the most significant migration streams to develop in modern times, that of Mexicans to the United States. This migration even turned into a rite du passage among some young people (García 2008a, 2008b). Certainly, the increased securitization of the border after 9/11, an improving Mexican economy, and the long-term drop in Mexico's birth rates have led to a decline of the Mexican immigrant population in the United States since 2010 (Zong and Batalova 2018). Nonetheless, the dense transnational networks created after 40 years of increased Mexican immigration still maintain strong and multiple connections between both countries.

\subsection{Mexico and Canada's Relationship: An On-Again-and-Off-Again Thin Relationship}

Mexican migration to the United States has been constituted and fostered by dense and rich webs of political, economic, social, cultural, ideological, and religious systems that have bound 
the histories of both countries together, sometimes contradictorily. This also means that, between the two countries, numerous transnational fields have been created and are operating at different scales and in different spaces. Whereas the Mexico-US history can be synthesized in Porfirio Díaz's famous saying 'poor Mexico, so far from God and so close to the United States,' the relation between Canada and Latin America — and Mexico in particular — has been sporadic and sometimes insubstantial. It is not strange, then, that Canada and Mexico's relationship has constantly been described as an impossible or contrasting relationship:

One is hot, the other cold... One looks north to the United States across a border bristling with barbed wire erected to stop illegal immigration, one looks south across the world's longest undefended border. One has a history of fierce anti-American nationalism, the other has been a good, if wary, friend of the United States. In most respects, Mexico and Canada are as different as night and day (The Globe and Mail 1996).

Moreover, when Mexico discovered that the Canadian government had spied on Mexican trade representatives during the NAFTA negotiations, some people saw this as "bitter proof that it is not only the US, but Canada too, that considers Mexico not as a trading partner, but as their backyard and employee of their economies" (Mayans in Viveros 1997:126). This relationship has thus not facilitated the fostering of basic knowledge of Canada in Mexico and vice versa (Tigau and Ucán Marín 2013).

What are the reasons, then, for which Mexico and Canada have had a continuous on-againand-off-again relationship, in turn shaping the level and nature of Mexican immigration to Canada? Part of the answer lies in the lack of shared borders between both countries, but mainly in their differentiated historical and politico-economic circumstances, which have not led them to develop rich networks of various types. A few years before Mexico began fighting its Independence War against Spain (1810), Canada had just founded the city of York (now Toronto) (1793). Anglo and French settlers were still actively implementing the settler colonial system and the corresponding dispossession of Indigenous peoples' lands. Canada's staples economy — central up to today (cf. Stanford 2014; Watkins 2007)—was still developing, 
although under a strong economic dependence on the US economy. Furthermore, Quebec's transition into industrial capitalism had just begun with the launch of Canada's first steam vessel in 1809. In addition, a war between the United States and Britain would be waged (1812-1814), and the national borders between Canada and the United States would not be defined until 1818 and not ratified until 1846 .

In 1865, the men who were crafting Confederation considered Mexico (along with Brazil, Cuba, Haiti, and Puerto Rico) as a "possible alternative market to the United States" (Ogelsby 1976:66). This new expansionist, international approach, however, was more a reactive response to the United States' intention of eliminating the Reciprocity Treaty of 1854 - which had benefited British North Americans with "a readily accessible market for their fish, grain, and lumber" (10) - than a real desire to establish new relations with Latin American countries. Although Canada's Confederation occurred in 1867, Canada still had strong colonial ties with the British empire, with Britain still representing Canada abroad and shaping its international role and foreign policy, something that would only cease after wWII.

The Canadian government thus sent a trade mission to the abovementioned Latin American countries, but the delegation decided not to go to Mexico since the colonial French army was occupying the country at the time (Ogelsby 1976:15). It would be 22 years until, in 1887, Canada would send its first commercial agents to investigate potential markets in Brazil, Argentina, Puerto Rico, and Cuba. Later, during the 1890s, Conservative governments would expand those exploratory commercial trips, which then included Mexico and Central America (Ogelsby 1976). After failing to establish trade relations during these trips, it would be another 18 years until the Canadian government sent A.W. Donly to Mexico in 1905 as the first Canadian Trade Commissioner, a permanent civil servant position but without diplomatic status.

Donly's responsibility was to report on trade opportunities in Mexico, meaning that he was not authorized to buy or sell. Nevertheless, Donly's presence led to the first agreement between 
Mexico and Canada in 1905 (and renewed in 1909 and 1912), which aimed at developing and equally subsidizing a steamship route that would promote direct commerce and trade between both countries (Ogelsby 1976). The Canadian Department of Trade and Commerce even produced a survey of economic activity between both countries in 1911 (Demers 2010). At the same time, Canadian capitalists began investing in Mexico's power generation, railways and tramways, mining, and the banking system, with a total investment of almost $\$ 50$ million (19051911). Nonetheless, the Mexican Revolution (1910) put a halt to the steamship project, affecting Canadian investment. Donly retired in 1911 and the Canadian government never sent his replacement, ending the short-lived Canadian relationship with Mexico (Ogelsby 1976).

The Mexican Revolution and its economic nationalism took Canadian dealers and government officials aback (Demers 2010:68). Indeed, still relying on the British government's analysis of the situation rather than Canada's, PM Sir Robert Borden called upon US President Woodrow Wilson, at the Allied Conference of Versailles in 1919, to stop the 'anarchy' in Mexico and close ranks with British hard-liners. Although the United States rejected the demand, the case unveiled the "Canadian inability_ _ or unwillingness — to imagine a truly independent stance from the two main neo-colonial powers" (69) (i.e. the United States and Britain). Mexico and Canada, nonetheless, would re-establish commercial contacts and reciprocal visits almost ten years later (1920-1921), once the Mexican Revolution was about to end. However, these efforts wouldagain — significantly diminish in the following years due to the business uncertainty that the recent conclusion of Mexico's Revolution and the development of the Cristero war generated.

By 1931, some trade had been re-established between both countries and Mexico was now exporting oil and minerals to Canada, a possibility inherited from Mexican president Porfirio Díaz's foreign policies. Nonetheless, these exports were owned and controlled by British and American investors rather than by Mexicans (Ogelsby 1976). Canada then determined that any imports from Mexico would be limited to agricultural products and began importing Mexican 
coffee, tomatoes, mahogany, oranges, and bananas (the latter controlled by the US United Fruit Company). As a protectionist measure, Canada rejected the import of Mexican sugar to avoid competition with Canadian producers (72).

In Mexico, Canadian utility groups still controlled a significant portion of power and transportation facilities, as well as subsidiary companies between 1911 and 1930. However, the capacity of Canadian capital markets to provide the required funds for the companies' investment and expansion was small. Consequently, even if the companies were nominally Canadian, the capital control had switched to Europe, from where the initial financial capital had been procured (Demers 2010:66-67). These novel commercial relations between Canada and Mexico, which may have facilitated the increased contact between both countries and the development of other types of networks, would soon face another complication.

By 1931, Canada had secured 70\% of the overall Us import market, 9\% of Great Britain's import market, and only 3\% of the Mexican import market. However, Canadian manufactured goods being exported to Mexico were $10 \%$ to $20 \%$ higher in cost than those of the United States (Ogelsby 1976). This was not only because the geographical distance added a premium, but mainly because most of the goods had to be shipped via the United States, administered by the US commercial system, and handled by American brokers who were reaping the economic benefits by charging commissions of between $25 \%$ and $30 \%$. Thus, the United States was placed in between Mexico and Canada not just in geographic terms but also as a result of its economic hegemony over both countries. Despite these economic obstacles, Canada was able to send around $\$ 2.85$ million in exports to Mexico, while buying only $\$ 812,000$ worth of Mexican goods in 1937. In addition, the Canadian government added a tariff to Mexican tomatoes as a way of protecting Canadian tomato producers, and it also doubled the duty on Mexican bananas (Ogelsby 1976:75,77-78). In the end, it was perhaps not that "Mexicans were not by instinct exporters" (72), as Canadian government representatives claimed when they produced an economic profile of 
Mexico (ibid.). Rather, Mexicans were not allowed to compete with Canadian producers.

In January 1944, Canada and Mexico established diplomatic relations (SRE 2015). There were also other lesser known attempts to establish relations with Mexico at the sub-national level. As Demers (2010) showed, French Canadian nationalists and Mexican Catholic militants lobbied for a political rapprochement between Canada and Mexico at the turn of the 1940s. This was a strategy to advance their own political and sociocultural agendas in a transnational field. The process went against Canada's disposition to only maintain economic relations with Latin America, this time as a result of the changing international political environment due to WWII. Since this political environment was threatening the preservation of the British empire at that moment, one in which Canada still heavily relied upon, Canada began favouring US interests. Thus, when Mexico invited Canada to join the Pan American Union in the 1930s (as a way for Mexico to gain more leverage with the United States), many Canadian politicians feared that “joining the US' neocolonial network would ultimately weaken Canada's British identity" and open the door to a US annexation (Demers 2010:63, 64-65). Consequently, Mexico’s invitation was rejected.

French Canadian nationalists made use of the notion of latinité as an identity discourse that aimed at establishing a link between Mexicans and Québécois(es).${ }^{15}$ Mexican Catholic militants promoted a stance on democracy and economic modernization under politico-religious tenets. In doing so, they aspired to achieve in Mexico what they considered was a harmonious state-church relation in Quebec that allegedly was lost in Mexico due to its political liberalization and secularization (Demers 2010:257). The resulting transnational activities and networks developed by these Québécois and Mexican minority groups did not lead to a change in course in the overall Canada-Mexico relation, especially after Canada aligned its foreign policy on a North Atlantic axis rather than on a Pan-American one at the beginning of the Cold War (ibid.).

After WWII, Canada's newly appointed Trade Commissioner to Mexico advised Ottawa to dispose of the United States as a commercial intermediary and to promote a direct maritime route 
with Mexico as a way to avoid US soil, the same proposal made by Donly 35 years earlier. Canadians had sensed a commercial opportunity in Mexico, since this country was looking to obtain goods from nations other than the United States due to the loss of European markets. Nonetheless, even when the suggested maritime commercial route was not pursued (Ogelsby 1976), and despite the fact that Canada had decided in 1944 that "it was better to keep its links with the Americas thin [since] fuller engagement meant being locked into a region that was dominated by the US to an unchecked extent" (Cooper 2012:688), Canada reached a commercial agreement with Mexico in 1946. Whereas the trade balance had favoured Mexico between 1944 and 1945 (\$26.6 million to \$14.32 million), Canada would have the upper hand two decades later, between 1964 and 1965 (\$116.1 million to \$50.8 million) (Ogelsby 1976:78-79).

In the case of Mexico, a small exception has occurred in relation to tourism. Canadians markedly began visiting Mexico in the 1950s, especially after the opening of direct air routes connecting Vancouver and Montreal with Mexico City in 1953. By 1965, Canadians were already ranked as the second most important national tourist group after Americans. This was also aided by Mexico's opening of two tourist delegations in Canada (as Mexico also did in other countries) and the promotion of Mexico as an international tourist destination (Vézina 2019). By the late 1970s, Canadians already constituted an important source of tourism income for the country. For example, Canadian tourists spent \$26 million in travel services in Mexico in 1971 (Ogelsby 1976). In 2014, the most recent year for which data are available, Canadians spent $\$ 2.1$ billion compared to the $\$ 250$ million that Mexicans spent in Canada as tourists (Gowans 2017).

In 1967, businessmen and academics met at the Second Canada-Mexico Colloquium in Mexico to discuss potential trade and ways to increase the bi-national relationship. Nonetheless, things had not changed much. Mexican and Canadian exports were still being handled by US brokers, and Canadian exports to Mexico were now facing difficulties due to Mexico's high tariff rates and its import licensing system (Ogelsby 1976:79). The colloquium had preceded and then 
run parallel to a policy shift towards Latin America powered by PM Pierre Trudeau. As Macdonald (2017) signals, Trudeau had previously expressed affinity to the idea of latinité between Québécois(es) and Latin Americans, as well as concern about certain social and economic issues occurring in the region. Once in power, and in preparation for the Canadian government's 1970 Foreign Policy review, the Trudeau government sent five ministers on a one-month mission to nine Latin American countries in 1968, including Mexico. The resultant analysis, contained in the 1970 publication of Foreign Policy for Canadians, established Latin America as a priority. One of the reasons for this policy change was the intention to diversify — once again — Canadian ties away from the United States, while recognizing "the growing importance of the region in the context of a move away from the Cold War bipolar system" (ibid.).

Parallel to this mission, government ministries of Canada and Mexico held the first Canada-Mexico joint committee meeting in Ottawa in 1968. They agreed to study_once more - the issues that both countries had been dealing with for a period of 42 years (since 1926). These included transportation issues as well as different grading standards in agricultural products and divergences in trade statistics (Ogelsby 1976). In 1972, 70 Mexican officials and businessmen travelled to Canada, constituting the largest trade mission ever to visit Canada from Latin America (ibid.), but not much resulted from these meetings.

Despite the on-and-off exchanges and trade research in a period of slightly more than 80 years, "Canadians and Mexicans still know little about each other, and this ignorance dogs Canadian-Mexican trade relations. These relations are also [still] affected by the pressure of the United States on both countries" (Ogelsby 1976:81). And although Canadians and Mexicans "have recognized this for almost a century," "it has been easier to recognize it than to do something about it" (ibid.). On the political side, and besides being heavily influenced by the hegemonic and imperialist drives of the United States, Canada's lack of engagement with the Americas after WWII was also a reaction to protect its interests during a rapidly post-war changing 
context and due to its compartmentalized and segmented foreign policy (Cooper 2012; GutiérrezHaces 2015). Cooper (2012:687-88) identified three reasons for which Canada detached from an engagement with the Americas under this context: First, foreign affairs officials thought that if Canada embraced a regionalization within the Americas, this would have seriously challenged its diplomatic advantage as a traditional mediator on the international stage.

Second, since the various countries that tended to work with Canada at the time were not firmly attached to a single regional home, a push for a wide Latin American regionalization would have closed off Canada's one-to-one way of relating to other countries. And third, the regionalization of the Americas would have limited Canada's international status-seeking instincts and its ability to win posts in the international sphere. This was because countries such as Brazil, Argentina, and Mexico were seen by Canada not as allies but as rivals who were seeking increased international positions. Thus, Canadian government officials concluded that it was too 'complicated' and too 'unimportant' to maintain relationships with the Americas (Cooper 2012).

Canada's decision also constituted both a withdrawal and a geo-political strategy (Cooper 2012; Macdonald 2016). It was a withdrawal strategy because Canada preferred not to meddle with its southern neighbour that was becoming a hegemonic power through the post-1945 era, except for the Cuba case. ${ }^{16}$ Thus, Ottawa seemed to have identified more gains maintaining a distant position regarding US interests than being thrown into the middle of US affairs. It was also a geo-political strategy because, in not engaging with the Americas, Canada aimed at protecting itself from what could have been a diminished location in the new world scenario (Cooper 2012). The resultant irrelevance of Latin America for Canada was also inversely reflected in the irrelevance of Canada for Latin America, both in commercial interests, which can be described as “cultivated in a piecemeal" fashion (689), and in terms of building potential political networks.

In the late 1970s and 1980s, Canada's minimal engagement with the Americas thinned out again. The United States was still heavily intervening militarily, economically, and politically in 
Central and South America as part of its geopolitical and imperialist expansion (see Doyle 1996; Doyle and Osorio 1999; Grandin 2007). These multiple interventions consisted of supplying arms, capital, and military advisers to right-wing military and civil factions in several Central and South American countries. The United States also created the Escuela de las Américas in the Panama Canal (renamed the Western Hemisphere Institute for Security Cooperation in 2000), a military training structure for Latin American dictators and covert militias (Abramovici 2001). Thus, since Canada "has been a good, if wary, friend of the United States" (The Globe and Mail 1996), Canada mostly stepped aside from the Americas.

A second exception to this was the acceptance of Chileans (from the political left) and Salvadorans and Guatemalans (from the left and right political spectrum) as refugees in the late 1970s and 1980s. Certainly, as Simmons (1993:287) contends, Canada has had "limited but important policy independence" from the United States. However, in this case, the decision to allow in Latin American refugees was the direct result of organized political pressure exerted by non-governmental and religious groups, a few Parliamentarians, and a few Latin Americans who were living or studying in Canada, rather than this being a principled decision on the part of the Canadian Government (Foster 2013; Peddie 2014; Snow 2013; Tomic and Trumper 1994).

Canada would re-engage with the Latin American region in the late 1980s due to a number of reasons: "democratization and economic liberalization in most countries of Latin America; the end of the Cold War; the [gradual] decline in Us hegemony; increased Latin American independence; and a move towards regional economic integration" (Macdonald 2016:5). Indeed, Conservative PM Brian Mulroney (1984-1993) decided to join the Organization of American States in 1990 "to advance Canada's credentials as 'a nation of the Americas." And Liberal PM Jean Chrétien (1993-2003) pushed the so-called "more amigos the better" approach, seen in his support to the Free Trade Area of the Americas, the summit of the Americas process, the targeting of Team Canada's activities in the region (Cooper 2012:685-86, 697-98), and NAFTA. 
These institutional initiatives, excluding NAFTA, began to decline by the late 1990s. Macdonald (2016:4-6) identified six reasons for this: first, the failure of the Free Trade of the Americas Initiative; second, the identification of Africa as a priority in Canada's direct development assistance by Jean Chretien and particularly Paul Martin's Liberal governments. Third, the decline of the US hegemony manifested in decreased levels of (direct) political, economic, and military interventions in the region; fourth, the rise of new actors such as Japan and China (which would become Canada's top export destinations after the United States and also top exporters to Canada in recent times [Simoes 2007]); fifth, the creation and reinvigoration of regional trading blocs in the Latin American region that purposefully excluded Canada and the United States; and sixth, the creation of a post-hegemonic Latin American region where new regional groups and alliances, as well as new forms of politics and contestation began to emerge.

Although NAFTA has maintained Canada and Mexico closer compared to other Latin American countries, at least in the economic arena, Canada's support for NAFTA was not immediate. As Dawson (2014) mentions, considering that the majority of pre-NAFTA Canadian exports were being sent to the United States (around 80\%), Mexico was not seen as an important market. The real business for Canada has been trade with the United States. Not surprisingly, Canadian officials "worried that [in] adding Mexico to the [Canada-U.S. Free Trade Agreement, it] would erode Canada's preferential access to the U.S. and distract American officials from issues of concern to Canada" (5). Nonetheless, since the United States hinted to Canadian officials that they would proceed with a Mexican free trade agreement with or without Canada, "as a defensive action, Canada became a somewhat reluctant convert to NAFTA" (ibid.). The signing of NAFTA, however, would not be achieved without opposition from Canadian unions and civil society groups, since they considered that Canadian jobs would we transferred to Mexico as a way to decrease local business costs and, at the same time, increase Canadian shareholders' profits (Katz 2015). And although Mexico wanted to include labour mobility in the agreement as 
a strategy to manage migration, the United States rejected this proposal.

NAFTA brought various benefits to Canadian capital, however. For example, Mexico is one of the largest metal producers in the world and ranks in the world's top ten (and first among Latin American countries) in terms of mining foreign investment attraction (Deloitte 2012). This is not gratuitous, however. Under the auspices of the privatization and economic liberalization in Latin America in the 1980s and 1990s, and as a way to attract foreign investment, governments across the region did not levy mining-specific taxes (Cornelissen 2016). Nonetheless, "[w]hile all other Latin American countries changed their mining tax policies as the commodity boom brought higher metal prices throughout the 2000s, Mexico maintained its taxation rates until 2014" to keep attracting international investment (6-7).

By $2012,73 \%$ of the total foreign mining companies in Mexico were Canadian, representing 44\% of Canada's total investment in Mexico (Deloitte 2012). Since then, the percentage of Canadian mining ownership in Mexico has oscillated between 64\% and 72\% up until August 2018 (Auditoría Superior de la Federación 2017a; Hernández 2018; Subsecretaría de Minería 2018). And although Canadian mining companies in Mexico obtained elevated revenues during the global commodity boom (2003-2012), the generated level of local employment was "trivial," for which “Canadian mining production was not a very significant driver of economic development in Mexico" (Cornelissen 2016:109, 110). Moreover, at least 12 Canadian mining companies were identified by the Mexican Audit Office "as alleged tax evaders" in the 2015 fiscal year (Auditoría Superior de la Federación 2017b:16; see also El Correo de Oaxaca 2017; Ramírez 2017).

At the same time, whilst Canadian capital increased in Mexico's mining sector, violence related to the presence of Canadian mines appeared and expanded at some of the mines' locations in the form of threats and acts of intimidation from company representatives, armed mine workers, and unidentified people against protestors and activists. Homes were raided, people were shot or assaulted, land was illegally occupied to locate a company's massive open-pit gold 
mine, fraudulent land use contracts were enforced, and corruption and murders become common (Moore 2015; Moore and Colgrove 2013). There have also been violations of people's right to self-determination and serious environmental, health, and social impacts in various communities. These include the location of a cyanide heap-leach pad only hundreds of metres away from the centre of a community, a high incidence of eye, skin, respiratory, and gastrointestinal problems, and a significant increase in premature births, as well as leach ponds overflowing into water sources used by a community (ibid.).

On the Canadian side, under the Conservative government of Stephen Harper, the coupling of the mining industry and finance was championed in more open and direct forms than by previous Liberal governments. This despite increasing and open concerns about the social, economic, environmental, and human rights costs of mining projects in Latin America (Gordon and Webber 2016; Macdonald 2016:9). Moreover, the so-called corporate social responsibility policy, "as practiced by the Canadian government[,] has been ineffective at mitigating abusive practices by Canadian mining companies in Mexico" (Bocking 2012:3). This has gone hand in hand with the former Conservative government's transformation of Canadian missions abroad into commercial outlets that instrumentalized foreign aid (Brown 2016). In addition, the Canadian government has directly promoted and protected "the interests of Canadian mining companies to the detriment of the individual and collective rights of affected communities" in Mexico (Moore 2015:1).

Canada's protection has included the active assistance of bureaucrats from the Canadian Embassy in Mexico — from the Ambassador to the staff-and senior bureaucrats from DFAIT (now called Global Affairs Canada) in supporting Canadian mining companies. Canadian bureaucrats also lobbied key Mexican officials and accepted, by omission, Mexican state repression to be used against peaceful protesters, despite having detailed and previous knowledge about potential serious human rights violations. One trade commissioner even wished the 
Canadian mining company's owner well the night before the Mexican army and police were to forcefully evict protesters who were camping at the mining site, demanding that their signed contracts with the Canadian company were respected (Moore 2015). Hence, the Conservative government put Canadian tax-payer resources to the service of "the short-term commercial interests of this small Canadian mining company over the wellbeing and rights of workers and the community" in Mexico (3).

In 2003, the Standing Senate Committee on Foreign Affairs examined the Canada-US and the Canada-Mexico trade relationships once again, looking to secure access for Canadian goods and services to the United States and Mexico, as well as develop effective dispute settlement mechanisms (Senate of Canada 2003). However, there were no specific outcomes from the corresponding Senate recommendations. In 2007, Conservative PM Stephen Harper launched the so-called Americas Strategy in Chile, which aimed at creating "a new beginning" with the region (Government of Canada 2009:3) and make it "a top international priority" (DFAIT 2011). This new beginning had a strong thinly-veiled commercial objective, since under Harper's tenure the globalization of 'Corporate Canada' became one of the main goals of Canada's foreign policy (Klassen 2015). The Americas strategy thus was accompanied by the appointment of a Minister of State of Foreign Affairs with special responsibility for the Americas and Consular Affairs in October 2008 (DFAIT 2009). The position, however, was suspended in November 2015 with the arrival of the Liberal government.

Although the official evaluation of the Americas Strategy indicated as major results the signing of new bilateral free trade agreements and high-level visits from Canadian officials to the region, Macdonald (2016:6) signals how the announcements made during those bilateral visits, even when they "raised expectations," made Canada appear as "“silent' and indecisive to local partners and country governments," particularly due to the "lack of follow-up." According to Daudelin (2013), this transformed Canada's diplomacy in the Americas into a "hyperactive, 
hamster wheel diplomacy"-type, which "looks at best irrelevant, and at worst counterproductive." Daudelin's characterization, however, seems to simplify the complexities and contradictions of Canada's foreign policy, which are most often strongly linked to us foreign policies. As Cooper (2012:700) exemplifies, Canada's “commitment to multilateralism [at the OAS, the region's most important multilateral organization,] often clashed with Canada's desire to help the United States achieve its objectives in the hemisphere, even when pursued by unilateral means. [For instance, t]hroughout the Honduran crisis, Canada moved in lockstep with the United States, even as US policy diverged from the hemispheric consensus" (see also Shipley 2017).

Canada's foreign policy contradictions in Latin America, arising mainly from broader politico-economic interests, are also seen in the differing value that Mexico has recently acquired in various arenas. For example, Canada has recognized at various forums the relevant role that Mexico has achieved as one of its most important trading partners after the United States. Indeed, Mexico became Canada's third largest international merchandise destination for exports in 2016 only after China (the fifth one between 2009-2015), with the largest provincial exporters being Ontario, Quebec, and Alberta. Mexico is also Canada's third most important source of imports worldwide, Canada's largest export market in Latin America, and the largest source of imports in Latin America (Embassy of Canada in Mexico 2016; Gauthier 2012; Gauthier and Meredith 2011; Gowans 2015, 2016; Holden 2010; Lambert-Racine and Benatuil 2014; Sydor 2003; Tremblay 2013). At the same time, defying Canadian tourism industry objections, the Harper government imposed a visa on Mexicans in 2009, limiting their mobility.

In the political realm, "Canadian policy-makers want to distance Canada from Mexico in order to ensure that the United States does not treat our respective borders- and the countries beyond them - in a similar fashion" (Cooper 2012:697). This position diverges from the one that the Senate (2015:vii) suggested to foster with Mexico in a 2015 report. The Senate examined, once again, "the potential for increased Canada-United States-Mexico trade and investment, 
including in growth areas in key resource, manufacturing and service sectors." One of the conclusions was that the Canadian government needed to recognize that "Mexico is not merely our 'other' NAFTA partner, but rather of fundamental importance to our relations bilaterally and with neighbours across the Western Hemisphere."

The Senate recommended that the government "pursue closer ties and engage strategically with Mexico on issues of mutual concern, such as those affecting the movement of goods and services in North America, North American competitiveness, and advocacy of North American positions in international fora" (id. 1). Once again, however, the focus here was the economic side, even when the Committee recommended "address[ing] all outstanding visa issues" between both countries (19). Indeed, the real objective of recommending the removal of "remaining barriers with a view towards the full elimination of the visa requirement" was to eliminate a "major irritant in a relationship that is important for Canada's future growth and prosperity" (20).

In 2017, four Senators undertook a two-day fact-finding mission to Mexico City to "hear the most up-to-date analysis of the possible political, economic, and social implications for Mexico and the North American relationship that could result from such policy changes" (Senate of Canada 2017:4). In their report, they again insisted that "Canada needs to engage more strategically with Mexico," particularly because of the "period of flux" brought on by the US 2016 presidential election (id. 11). They also reiterated Canada's (five-decade history of) good wishes regarding a more strategic, meaningful engagement with Mexico, which would "hold tremendous potential benefit not only mutually, but also for North America” (4).

The tendency to maintain an on-and-off type of relationship, however, has recently —and momentously — changed due to the 2017-2018 NAFTA re-negotiation and signature of the new Canada-United States-Mexico Agreement (CUSMA) in November 2018 (still to be ratified). Certainly, Canada's tendency to favour the United States unapologetically appeared at the beginning of the CUSMA negotiations in February 2017: 
'We love our Mexican friends. But our national interests come first and the friendship comes second,' a source said on the sidelines of a [Liberal] cabinet retreat in Calgary, Alberta. [...] 'Our negotiating positions are totally different. Mexico is being hung out of a skyscraper window by its feet' [by the United States], said a second government source. 'Mexico is in a terrible, terrible position. We are not,' said another Canadian person involved on the trade file (Ljunggren 2017).

The conditions and style of negotiation imposed by the United States, however, along with words of precaution from people close to the Liberal government and even former (Conservative) PM Brian Mulroney (in McGregor 2017), forced Canada to change its strategy: “Throwing friends and neighbours and allies under the bus is a position for a weak leader. [...] This is not the Canadian tradition." However, as I have shown, this has been, indeed, the general Canadian tradition.

Recent political changes brought about by the triumph of Andrés Manuel López Obrador (AMLO) in the Mexican presidential elections of 2018, along with shifts in the US internal and foreign policies under the 2017-2021 presidency, may bring changes to the historical relation between Canada and Mexico. There were some signs of this in the unprecedented meetings between then Mexico's President Peña Nieto and President-elect López Obrador with a group of top Canadian officials in Mexico that included the Ministers of Foreign Affairs, Finance, and International Trade Diversification (Contramuro 2018). Time will only tell if Mexico and Canada's relationship breaks the spell of the historical on-again-and-off-again thin relationship. ${ }^{17}$

\subsection{Conclusions}

Mexican migration in general has strongly been shaped by an almost two-centuries long history of dense political, economic, social, cultural, ideological, and religious networks with the United States. This has bound together the histories of both countries and facilitated the creation of numerous and diverse transnational fields. Much of the Mexican migration to the United States, however, has been constituted as a 'forced' migration. This resulted from the accumulation of external and internal factors such as French colonial interventions, AngloAmericans' imperialist and expansionist ambition, the different conflicts in Mexico, and the economic consequences of the loss of more than 55\% of Mexico's territory, which threatened the 
livelihood of Mexicans and constituted strong migration push factors. Mexican President Porfirio Díaz's political, economic, and land policies also had a considerable impact on the movement of the Mexican population, leading to an uneven Mexican geography of economic development. This, in turn, generated a regional division of labour and fostered several streams of internal migration, constituting the first stage of international migration for many Mexicans.

Meanwhile, the development of the United States as an industrial capitalist hegemon consistently demanded substantial amounts of cheap, flexible, and low-skilled and semi-skilled labour. The geographical closeness of Mexicans, the abundance of their low-cost labour, and their economic needs posited them as the ideal source of labour. At the same time, the uneven expansion of capital in the US territory also led to regional divisions of labour. This capital expansion created regional circuits of unskilled labour and thus the constitution of numerous social networks and the creation of transnational fields. These networks and fields, in turn, raised the probabilities of migrating to the point that migration was even turned into a rite du passage among young people.

In contrast, Canada's 130-year relationship with Mexico has been characterized as an onagain-and-off-again relationship, where thin and primarily economic relations have prevailed. Despite Mexico's various attempts to expand this relation to other dimensions such as the political, post-war Canadian relations with Mexico have been mainly shaped by the former's politico-economic decisions of siding with the United States, preserving its middle-power identity, and a recent drive to globalize Corporate Canada under the former Harper regime. This thin relationship has not facilitated the fostering of basic knowledge of Canada in Mexico and vice versa, or the development of dense networks of political, economic, social, cultural, and/or religious systems that may bound together the histories of both countries and promote varied exchanges at various levels.

In addition, Canada's immigration policies, which strongly favour selected, economic 
immigration over family or humanitarian immigration streams, as well as the geographical distance and the lack of shared borders, have contributed towards limiting Mexican migration to Canada and the creation of more transnational fields between both countries. Nonetheless, Mexicans are welcomed if they fit 'designer immigrant profiles' (Simmons 2010) or if their temporary labour is needed in areas that would serve Canada's economic needs. In the following chapter, I thus situate recent Mexican migration to Canada as part of a broader Latin American migration stream. I also identify the different profiles of Mexicans and their reasons to immigrate as found in the literature, and briefly analyze the transformation of the Mexican state and the increased production of violence in Mexico that has generated numerous refugees. This group in particular, which has been identified by some immigration officials and politicians in Canada as 'bogus refugees,' reflects the volatile and unequal nature of Canada's relationship to Mexico. 


\section{Chapter 4: Mexican Immigration to Canada: The Needed Economic Immigrant vs. the Unwanted "Bogus" Refugee}

In the previous chapter, I established that in order to better understand Mexicans' immigration to Canada and their transnational practices, one needs to locate those in a North American context of historical, transnational, and politico-economic relations. However, besides including the almost 200-year history of a thick relationship that has bound Mexico and the United States (sometimes with unfortunate outcomes), and the 150-year history of thin, mainly economic Canadian engagement with Mexico, there are other national and institutional factors that help account for Mexican immigration to Canada. These other factors include, first, Canada's and Quebec's immigration policies and the ways in which these have historically shaped Latin American and in particular Mexican immigration since the late twentieth century. ${ }^{18}$ A second factor is Mexico's modern economic conditions, which some people allege constitute the reason why growing numbers of Mexicans requested asylum in the mid-2000s. A third influence pertains to the symbiosis between the Mexican state and criminality, which has led to a corresponding increase of violence in the country.

This chapter is divided into two sections. In the first section, I comprehensively explore Mexican immigration to Canada starting a few years after Confederation, and later as part of broader Latin American immigration waves. I also focus on Mexican immigrants' diverse profiles and their reasons for immigration since the 1970s. A second section presents an analysis of the 'bogus' asylum claimant narrative created by the Harper Conservative government between 2009 and 2015 (see Köhler 2009), where Mexicans were prominently featured as negative 'child posters.' Here, I first analyze how the 'bogus refugee' narrative, which also operates as a politico-economic strategy, has purposefully ignored the symbiosis between the Mexican state and criminality in Mexico. Second, I explore the production of what Martin, Lapalme, and Roffe Gutman (2013) identify as multifaceted forms of violence and human insecurity in Mexico. These conditions are reflected within Canada's historical repertoire of 
migration securitization and border control, which has served to keep at bay Mexican migration while still shaping the experiences of current refugee claimants and migrants.

\subsection{Mexican Immigration to Canada}

Latin American immigration to Canada, even if small in numbers, dates from at least 1875, eight years after Confederation. Berdichewsky $(1990,2007)$ found that a small population of 20 males that included two Mexicans, "more than a dozen of Chileans", and some Peruvians were living on the north shore of Vancouver (Berdichewsky 2007:36). The Canada Year Books (CYB) (1867-1990) registered for the very first time, since the first edition of 1867, the arrival of Latin Americans to Canada in 1914: 10 Cubans and five Brazilians (Canada Dominion Bureau of Statistics 1921). And the 1922-1923 edition, also for the first time, included the category of "nonEuropean nationalities or races," which included the immigration of Mexicans (first recorded in 1918) (Canada Dominion Bureau of Statistics 1924:iv). It is quite possible that even before 1875, and despite some opaque statistics and categorizations contained in the CYB, Latin Americans were immigrating in small numbers not only to Vancouver but also to other Canadian cities such as Montreal and Toronto. Between 1918 and 1979, a total of 8,907 Mexicans immigrated to Canada (Canada 1968, 1969, 1970, 2008).

Berdichewsky (1990) grouped Latin American immigration to Canada into five waves. ${ }^{19}$ The first wave began some time before WWII and ended immediately after it. A few Mexican families, for instance, were accepted by the Quebec in the 1940s (Burgueño 2005). The second wave evolved during the 1960s and included a small number of Mexicans (1,689 persons between 1960 and 1969 [Canada 1968, 1969, 1970, 2008]), Argentines, Uruguayans, and Colombians (Berdichewsky 1990). This wave was possible because the Canadian government discarded its non-written country-of-origin immigrant selection process in 1962, which had favoured white people from the United Kingdom and Europe, and adopted a points-based system in 1967 (Simmons 2010). The change did not result from a gracious Canadian government concession. It 
was rather one more of various politico-economic manoeuvres that Canada developed to attract much-needed immigrants to confront the lack of investment and return migration to Europe. This was also a strategy to counteract an increase in the number of vacancies in professional, skilled, and service areas (ibid).

Moreover, although Canada began shaping and securitizing immigration since 1823 through various Immigration Acts and Orders-in-Council (Hernández-Ramírez 2019), some of which were markedly racist policies, ${ }^{20}$ these did not target Latin Americans or Mexicans per se. Nevertheless, the non-written, white-only immigration policy that had developed in Canada (Simmons 2010), partially shaped the acceptance and reception of some Latin Americans in the 1970s. For instance, while Hungarian refugees were readily accepted by Canada and considered as European, white, anti-communist, and highly skilled, Chileans were considered by government bureaucrats too political, Hispanic, non-white (Tomic and Trumper 1994:167, 168, 170), and some even subversive and dangerous to Canada (Bangarth 2015).

The third wave developed during the 1970s due to a combination of political, economic, and social crises in Central and South America. This resulted from local and US interventions ${ }^{21}$ that aimed to dismantle democratically elected social-democratic and socialist governments, prevent the expansion of communism (Wheelon and Graybeal 1961), and expand capitalism as the only international economic model (Harvey 2005). One of the direct results of this US interventionism in the region, besides the multiple horrors inflicted on the population, was that a significant number of people from Chile, El Salvador, Nicaragua, Guatemala, Peru, Colombia, Ecuador, Argentina, and Uruguay (IRCC 2016a) — particularly from the political left—sought refuge in Canada as well as in other countries. Since many left-oriented people escaping from persecution knew that they would not be welcomed in the United States, they chose other countries to make their asylum claims, including Canada (Simmons 1989). ${ }^{22}$ Between 1970 and 1979, 5,725 Mexicans immigrated to Canada (Canada 2008). 
The fourth wave developed during the 1980s (Berdichewsky 1990, 2007). It was composed by a significant number of refugees from Central America who were escaping from military and guerrilla conflicts, both from the right and left of the political spectrum, processed under a special immigrant class (Mata 1985). Central Americans constituted 47.2\% of this wave while Mexicans only $8.5 \%$ or 6,130 people (IRCC $2016 a$ ). The fifth wave, according to Berdichewsky (1985), was comprised of a large number of Mexicans entering during the mid1990s under economic and family migration classes. However, the number of Mexicans entering was not as large as he suggested. Rather, it was a small wave of 6,739 people (1995-1999) that was following the bigger Salvadorian wave of the 1980s and 1990s. What perhaps caused Mexicans to be seen as immigrating in big numbers was the dramatic decline of Salvadorian immigration in the mid-1990s. But whereas 12,170 Mexicans immigrated to Canada during the 1990s, the number of Salvadorians was 24,334 (IRCC 2016a). Simmons (2015) noted that during this wave, due to immigration policy changes introduced in 1996, the composition of the immigrant population in Canada shifted considerably. Whereas before 1996 almost half of the immigrant population was arriving via the family class followed by economic migrants, the opposite was true after 1996. This explains why Veronis (2006) observed that this wave was composed of Latin American professionals who immigrated under the Skilled Migrant Program and, to a lesser extent, some business class immigrants.

There are two more waves that the literature does not register. A sixth wave mainly consisted of Colombians and 45,813 Mexicans who immigrated between 2000 and 2009 (constituting $33 \%$ and $17.5 \%$ of the total Latinx immigrant population respectively; a total of 50.5\%). And a seventh wave, developed between 2010 and 2017, with (30,274) Mexican immigrants ranking first and Colombians second among the total Latinx immigrant population (constituting 27.5\% and 24.2\% respectively, a total of 51.7\%) (IRCC 2016a, 2019b). Overall, a total of 429,392 persons from Latin America were accepted as permanent residents between 1980 
and 2017, and from these, Mexicans constituted the second most numerous Latin American national group (17\%) after Colombians (19\%).

The last 2016 Canadian census indicates that there were 80,585 immigrants born in Mexico, 37,530 males and 43,055 females. Of these, 1,290 are in Ottawa (545 males, and 750 females), and 9,155 in Montreal (4,205 males and 4,955 females) (Statistics Canada 2017b). ${ }^{23}$ If measured by permanent residence status, 72,940 Mexicans were granted PR between 1980 and 2017 (IRCC 2016a, 2019b). If measured by ethnic origin, however, the census identifies 128,485 Mexicans (62,890 males and 65,590 females). From these, 73,195 belong to a first generation, 44,075 to a second generation, and 11,210 to a third generation (Statistics Canada 2018c). Between 1980 and 2015, almost 40\% of Mexicans came through the economic class and 41.5\% through the family class, whilst refugees constituted only $15 \%$ and other immigrant categories 3.5\% (IRCC 2018c). In addition, between 1980 and 2015, 32,105 Mexicans between the ages of 20 and 34 landed in Canada, of which 17,640 were women (55\%) and 14,465 men (45\%). This contrasted with the 18,055 Mexicans who arrived at the age of 35 or more, of which 9,595 were women (53\%) and 8,460 men (47\%). When analyzed by periods of two decades, however, we observe that between 1980 and 1999, youth represented 28\% of the total Mexican immigrant population (of which 55\% were women and $45 \%$ men; the population aged $35+$ represented $22 \%$ ) and $49 \%$ between 2000 and 2015 (of which 52\% were women and 48\% men; the population aged $35+$ represented $29 \%$ ). This indicates that the Mexican immigrant population in Canada has been increasingly getting younger across time (IRCC 2018d, 2018e). ${ }^{24}$

Parallel to these seven waves, there has also been a less visible but steady wave of temporary Mexican migration under the Seasonal Agricultural Workers Program (SAWP), a subprogram of the Temporary Foreign Worker Program (TFWP). The SAWP's main objective, which applies to Mexicans (since 1974) and Caribbean agricultural workers (since 1966), is to provide a temporary and flexible, but also cheap, captive, and expendable labour force as a rapid solution to 
labour shortages in Canada's agricultural sector. Although the TFWP is intended to "hire foreign nationals to fill temporary labour and skill shortages when qualified Canadian citizens or permanent residents are not available" (IRCC 2017a), the program has proven to be a permanent fixture, and therefore a structural component of the Canadian economy (see IRCC 2017b) ${ }^{25}$ Between 2007 and 2016, Mexico ranked second among 171 countries in sending workers under the TFWP (207,930 workers), only after the Philippines (278,074 workers) and followed by the United States (97,850 workers) and Jamaica (81,361 workers) (IRCC 2018g, 2018h).

Thus, whereas in the United States this type of labour has been obtained through undocumented migration and the deskilling of Mexican immigrants, as shown in chapter 3, in Canada this labour has been regulated and made temporary through the TFWP. The Latin American population in Canada is "an extremely heterogeneous group in terms of national, ethnic/racial, socioeconomic, cultural, political, and even religious background, as well as demographic characteristics (age, gender)." This also includes "unequal relations of power, divisions along class lines, and ethnic/racial discrimination, which are a legacy of Latin America's history of colonialism" (Veronis 2006a:19).

Although Canada does not have an immigration policy targeting specific ethnic/racial groups as it did with its previous non-spoken, white-only policy (Simmons 2010), its current policies favour an economic type of immigration. These policies aim at reaping the economic benefits of selected immigration while decentralizing immigration decisions and their associated costs (Simmons 2015). However, the white settler/colonial particularities of Canada, where Quebec asserts its own (sub-)national identity vis-à-vis Anglo-Canada, have also shaped immigration policies. As Barker (2010:12-13) contends, "policies on immigration and management of diversity are in turn [strategically] used as a means of asserting nation-building projects.” Thus, Quebec $(2017 \mathrm{a}, 2018)$ is the only province that promotes its politico-economic, socio-cultural, and immigration interests abroad through a network of 31 bureaus located in 18 countries, which 
include general delegations, delegations, offices, and offshoots. In the case of Mexico, Quebec opened a délégation générale in Mexico City in 1980 and created a Quebec-Mexico Working Group in 1982. The latter has facilitated more than 250 Quebec-sponsored cooperation projects with Mexico in numerous areas that range from art to research to innovation (Quebec 2017b). ${ }^{26}$

The opening of délégations was framed by Quebec's response to the neoliberalization of its economy, a push for the decentralization of the state, and the establishment of partnerships aiming to modernize its regional economies and correct economic territorial disparities in the late 1970s (Simard 1996). In this framework, attracting selected immigrants would help Quebec to develop its regions and, at the same time, create a favourable and attractive environment for immigrants to settle outside Montreal (ibid.). Thus, the Immigration and Temporary Admission of Aliens or the Canada-Quebec Accord, signed between Canada and Quebec in 1991, led to Quebec being "responsible for the selection of immigrants destined to that province" and for their integration "in a manner that respects the distinct identity of Quebec." This selection is done through various evaluation mechanisms that also favour an economic type of immigration, the provincial labour market needs, and knowledge of French. If positive, Quebec grants a Certificat de sélection and refers the selected immigrant "to federal authorities for assessment relating to the admission," security and health screening, and the issuance of permanent residence (PR) (Quebec and Canada 1991).

Whereas Canada establishes relations with (prospective) immigrants under the policy of multiculturalism (established in 1971 and 1988), Quebec does so through its interculturalism policy, understood as "a reciprocal engagement between the Quebecois majority and cultural communities" (i.e. ethnic groups). Here, Quebec "must in turn manifest their appreciation for the contributions of immigrants" and assist in their integration. But in exchange, Quebec expects from immigrants the obligation to "know and respect Quebec's common values" and “develop a feeling of belonging and a comprehension of Quebec society" (Chiasson 2002:2). 
This differentiated Québécoise approach to immigration stems from Quebec's old "subordination [as] the 'other' settler society," after the "British won the imperialist war with New France in 1760"' (Stasiulis and Jhappan 1995:96).

The French "were treated not as equal but as subordinate partners" in Canada's nationbuilding process, and the Québécois(es) resisted British and Canadian elites' efforts to assimilate them. This, in turn, "fuelled a sense of national oppression" that led Québécois(es) to strongly preserve their attachment to their language, culture, traditions, and Catholic religion (Stasiulis and Jhappan 1995:98, 99). The resultant "fragile national identity" of Quebec (Stasiulis 2013:192) led Québécois(es), then, to generate their own acculturation processes as a mechanism of societal 'protection' against some Others who could diminish their national standing. This includes, as Stasiulis argues, the development of a matrix of 'common values' that privileges the French language (and Québécoise culture) over (sometimes) racial criteria to be embraced by minority Canadians and immigrants alike. The main objective is thus "to seek and retain homogeneity, racial purity and immutability in the name of 'common values"' (192-193, 204).

\subsubsection{What Do We Know About Mexicans In Canada?}

The relative novelty of Latin American and particularly Mexican immigration to Canada (when compared to other non-Latinx national groups) has also resulted in a sparse although growing academic literature focused on this population. Indeed, only a handful of scholars have focused on Mexican immigration to Canada. Gosseling (1984) noted that in comparison to other Latin Americans such as Chileans, Argentinians, Uruguayans, and Colombians, who immigrated to Quebec for political reasons during the 1970s, Mexicans immigrated in low numbers to that province even when Quebec had sent a representative to the Canadian embassy in Mexico. For example, between 1974 and 1979, only 3,824 Mexicans immigrated to Quebec in comparison to 13,609 Chileans. Mexicans preferred to immigrate to English-speaking provinces (ibid.).

Armony (2014:12), based on data from Statistics Canada from 2011, found that more 
Mexicans and Colombians (30.7\% and 25.2\% respectively) had a lower income level in Canada than, for instance, other Latin American national groups that had been in Canada longer, such as Chileans and Salvadorans (16.9\% and 18.2\% respectively). He also noted that in "Quebec, all groups show higher levels of poverty than in the rest of the country, but the gap is even wider among Colombians and Mexicans." Similarly, the unemployment rate for Mexicans was 10.7\% and $15.6 \%$ in Canada and Quebec respectively. This led him to conclude that although all minority groups have lower levels of income in Quebec when compared to the national average (e.g. "they earn about 17 percent less"), "Latin Americans in that province are somewhat worse off than others," something Armony calls the unfavorable "Quebec effect." This has occurred despite "a growing migration stream from Latin America to Quebec that comprises a higher proportion of qualified economic immigrants" (p. 13).

By 2015, the situation had changed (see note for a relevant methodological observation). ${ }^{27}$ Mexicans were slightly better off than Québécois(es) at the Canada, Quebec, and Montreal levels in that order. Nonetheless, they were significantly disadvantaged in Ottawa and Ontario in comparison to Québécois(es), and still disadvantaged vis-à-vis Canadians in the five geographical sites (see Table 3) (Statistics Canada 2018c). Thus, across time, and particularly in comparison to Québécois(es), the economic situation of Mexicans improved. The statistical data, however, does not allow us to know the reasons for this improvement.

Table 2: After-Tax Low-Income Measure (LIM-AT) For Various Ethnic Groups in Private Households, 2011

\begin{tabular}{|l|c|c|c|c|c|}
\hline \multicolumn{1}{|c|}{2011} & Ottawa & Montreal & Ontario & Quebec & Canada \\
\hline Canadians & 8.7 & 13.3 & 13.1 & 14.3 & 14.1 \\
\hline Québécois(es) & 12.6 & 22.3 & 12.7 & 21.5 & 21.1 \\
\hline Mexicans & 21.5 & 41.6 & 20.3 & 39.2 & 25.4 \\
\hline
\end{tabular}

Source: Statistics Canada 2014

Table 3: After-Tax Low-Income Measure (LIM-AT) For Various Ethnic Groups in Private Households, 2015

\begin{tabular}{|l|c|c|c|c|c|}
\hline \multicolumn{1}{|c|}{2015} & Ottawa & Montreal & Ontario & Quebec & Canada \\
\hline Canadians & 9 & 11.1 & 12.8 & 12.3 & 12.7 \\
\hline Québécois(es) & 8.2 & 20.1 & 14.8 & 20.3 & 20 \\
\hline Mexicans & 15.5 & 19.7 & 18.9 & 19.1 & 18.6 \\
\hline
\end{tabular}

Source: Statistics Canada 2018 
In the late 1980s, Whittaker (1988:30), while interviewing "more than twenty-five Mexicans" who had settled in Vancouver, found that $75 \%$ of the Mexican immigrant population to Canada at that time (i.e. $\mathrm{N}=10,078$ [Canada 2008]) was composed of young adults between 18 and 35 years of age. This age range, she found, was the result of targeted Canadian immigration policies. A second Canadian policy favoured the promotion of family reunification, especially for so-called "holiday brides" or young females between 20 and 24 years who met and later married Canadian citizens on vacation in Mexico (Whittaker 1988:34). The Mexicans Whittaker (1988) interviewed came either under the professional-entrepreneurial category (economic immigration) or through family reunification (i.e. holiday brides), "presumably [from a] comfortable middle class" (36). Their profiles contrasted to the characteristics of most Mexicans who migrate to the United States. Indeed, her respondents mentioned that rather than following what they considered the traditional Mexican migration pattern, where "the Mexican is supposed to migrate [to the United States] to gain financial and material advantage," they "decidedly declare[d] themselves as not seeking this" (38). Instead, they chose Canada due to its "quality of public life," and never considered the United States as a possibility for migration due to its "negative image" (37).

Whittaker's (1988) respondents' narratives led her to conclude that theirs was not necessarily a migration motivated by economic gains. Rather, it was the search for a different lifestyle. "Allusions are made to political graft, to the excessive wealth of a few, to inefficient bureaucracy, [...] to dangerous driving conditions, to bribery of police and so on" (39). Her respondents implied that these abuses did not occur in Canada and they thus considered this country a preferable option to living in Mexico. Although Whittaker did not delve into a critical and/or class analysis of her respondents' narratives, it can be inferred that those who came under the professional category did so supported by their economic status in Mexico and a Canadian policy that favoured economic immigration. Some of her respondents, however, decreased their economic standing after having immigrated to Canada (38). 
Samuel, Gutiérrez, and Vázquez (1995) hypothesized that the low levels of immigration from Mexico to Canada in the 1990s had to do with the physical distance between Canada and Mexico, the fact that the United States blocked a constant stream of immigrants to Canada due to the former's "good [employment] opportunities" [sic] (59), the lack of Mexican networks in Canada, and the fear of the Canadian winter. Nonetheless, Mexicans have immigrated to US cities of similar distances as Canadian cities, such as New York. ${ }^{28}$ They have also migrated to cities with cold winters such as Chicago, Wisconsin, or Syracuse, where they have formed sizeable ethnic communities. In addition, the argument that the United States offers good employment opportunities is relative and does not consider a number of issues such as health risks, job security, migrant status, exploitation, etc. Samuel et al. (1995) are correct, however, when they affirm that the lack of social networks has limited Mexican immigration to Canada.

Goldring (1999b) identified five distinct groups of Mexicans in Canada in the 1980s-1990s:

1) Middle- or upper-class professionals who immigrated looking to enhance their professional or economic opportunities and improve their children's opportunities. Many of these immigrants were proficient in English and came with their families.

2) Middle-class immigrants with tertiary education (professionals, technicians, certified people) without much proficiency in English or French, with little knowledge about Canada, and more likely to include single people or couples without children.

3) Mennonites who returned or immigrated to Canada from Mexico in the mid-1980s and early 1990s (according to Janzen [2004], return migration began in 1977). They did so for three reasons: first, as a response to economic difficulties in Mexico due to NAFTA's negative impact (Janzen 2004). Second, due to a severe drought in the north of Mexico (1997-1999), which adversely affected Mennonite agricultural production. And third, due to the desire to improve their children's opportunities (see also Castro 2004; Driedger 1973; and Klassen 2008).

4) 'Holiday' spouses, a label that, expanding Whittaker's notion (1988), also includes males and international students who married Canadian citizens and subsequently decided to obtain landed status. This group incorporates people from a wide range of socio-economic backgrounds. And, 
5) some Mexicans who overstayed their student or visitor visas rather than crossing the border undocumented, and now have a less than full status in Canada.

In addition to the five immigrant groups that Goldring mentioned, there are three other migrant groups she did not identify: NAFTA migrants, international students, and refugees. NAFTA migrants are "business visitors, traders and investors, intra-company transferees, and professionals" who have temporarily migrated and operate between Canada, Mexico, and/or the United States (George and Young 2006:10). This group was created with the aim of facilitating the movement of trade, capital, and labour in North America and is regulated by chapter 16. Nonetheless, NAFTA only grants a working permit rather than PR status. Mueller (2005) signalled that the number of Mexicans who obtained a NAFTA permit was minimal, increasing only from 34 to 101 between 1994 and 2001.

From 2003 to 2013, the number of foreign nationals working in Canada under the NAFTA visa increased substantially, particularly after 2008 , totalling 182,222 persons for the period in question. This number, however, also includes US citizens (Canada 2015). Open source data indicates that Mexicans ranked 13 among all foreign nationals receiving International Mobility Program (IMP) permits, and 23,274 Mexicans held a work permit via the IMP between 2006 and 2016 (IRCC 2015a, 2018b). However, IMP permits not only include NAFTA visas, one of four Canada-International Agreements work permits, but also other programs (with their own subprograms), such as the so-called Agreements, Canadian Interests, Significant Benefit, Reciprocal Employment, and Competitiveness and Public Policy work permits (IRCC 2015a). The advantage of having a NAFTA visa is that it grants its holder so-called Canadian (work) experience, an element that greatly facilitates the procurement of PR status under current Canada's immigration policy. ${ }^{29}$

The second group constitutes Mexicans who came to Canada as international students, applied for PR and were allowed to stay after completing their studies. This has been possible due to varied — although on-again-and-off-again — federal and provincial immigration programs catering 
to international students. Since diverse levels of government frequently amend these program requisites, scope, restrictions, and the annual number of places available to candidates, these also shape the list of potential applicants. In contrast to those Mexican students who stayed because they were sponsored by a Canadian partner (Goldring 1999b), these students remained in the country for a number of reasons, such as the desire to obtain international work experience (Lu and Hou 2015), for economic gains, and/or because of socio-cultural motivations. Some of these motivations reflected an appreciation of and desire to continue enjoying some Canadian values, like openness to other cultures and diverse gender and/or sexual identities (Hernández-Ramírez 2012).

The number of international students from Mexico is relatively small compared to other national groups due to, presumably, a lack of economic resources and/or English or French proficiency, as well as the favouring of the United States or European countries as a destination among those with the resources or scholarships to study abroad. Nonetheless, these numbers have increased over time. Between 1990-2001, "the flow of Mexican students into the country increased by 465\%, from 856 entering in 1990 to 4,847 in 2001" (George and Young 2006:27). This number kept increasing for the period 2006-2015. Current figures rank Mexican international students in tenth position (although this ranking also includes language or exchange courses for all ages) (Statistics Canada 2017). The number of Mexicans who came to obtain postsecondary education gradually increased between 1999 and $2015(n=24,366)$, except for a 9.3\% decrease for the 2007-2008 period (relative to the previous year) that coincided with the global financial crisis. In contrast, between 2010 and January 2019, only 524 Canadians went to Mexico to study as international students (SEGOB 2017, 2019).

IRCC's Open Access data does not contain information yet about the number, citizenship, sex, age, and/or level of study of international students who transitioned to PR status after finishing their studies in Canada. However, we know that ten years after international students received their first student permit, $25 \%$ of the early 2000 s cohort members became permanent 
residents in comparison to $20 \%$ in the late 1990 s cohort, and $27 \%$ in the early 1990 s cohort (Lu and Hou 2015). We also know that between $74 \%$ and $80 \%$ of international students are under the age of 25, and the majority are concentrated in the cities of Toronto, Vancouver, and Montreal following the pattern of new immigrants (ibid.). International students who obtained PR status shared the following demographics: they were 25 years and over $(56.9 \%$ of those who applied in the $1990-1999$ period and $70.8 \%$ of those who applied in the $2000-2004$ period), studied in Canada for between three and four years (52.7\% for 2000-2004), their level of study at first permit was above a bachelor degree (49\% for 2000-2004), and they spoke English only (62.6\% for 2000-2004). Those who spoke French only represented a very small percentage (2\%), whilst those who spoke French and English constituted $11.3 \%$ of the total population for the same period (Lu and Hou 2015).

Moreover, $47.7 \%$ of international students who applied as principal applicants and obtained PR status between 2000 and 2004 used the Economic Class stream, while another 22\% constituted spouses or dependants. This means that close to $70 \%$ of this group immigrated through the economic stream. The rest of the students were granted PR status through family reunification (22.5\%) and refugee streams (7.7\%) (Lu and Hou 2015). Lu and Hou, however, do not provide data about Mexican or Latinx international students transitioning to PR status. Presumably, this is because most of the transitioning students are from Southern and Eastern Europe, Asia, and Africa. However, we can observe in one of their graphics that around $9 \%$ of Mexicans who came as international students between 1990 and 2013 obtained permanent residence in the ten years following the receipt of their first study permit.

One of the reasons for the low percentage of status conversion among Mexican students is the fact that some of them belong to upper-middle or upper classes in Mexico. Thus, after finishing their studies, they return to Mexico and reintegrate into family businesses and/or other lucrative ventures. This may be further enhanced by the fact that studying abroad generates 
considerable social capital in Mexico. This capital can be easily exchanged in profitable labour markets whose entrance is highly regulated by belonging to select social networks, and to which these students may belong even before coming to study to Canada. Other students, for whom it would be impossible to study abroad without a scholarship, have come sponsored by the Mexican or Canadian government. However, if sponsored by Mexico, they are required to go back for at least six months to avoid paying back the scholarship they received. This, paired with constantly changing Canadian immigration policies focused on international students and the elevated cost of the process of immigrating to Canada (between $\$ 2,000$ and $\$ 3,500$ for one-person application in 2017 , plus $\$ 12,475$ for subsistence money for one person), may also help to explain the low number of Mexicans who gain PR status after finishing their studies.

Finally, the third and largest group of Mexicans in Canada constitutes refugees. By the late 1990s, Mexicans began applying for asylum in Canada escaping from persecution related to diverse types of violence (e.g. gender and/or sexuality violence and state violence). These asylum requests dramatically increased between 2006 and 2009 (more about state violence below). The precise number of claims based on sexual and/or gender identity/orientation persecution is hard to track before the late 1990s. This is because the Immigration and Refugee Board (IRB) did not keep track of "claims based on gender persecution (i.e. domestic violence) or sexual-oriented persecution" (Escalante 2004:211). Although the IRB opened the door for lesbian and gay refugees in 1995, pressured by LGBTIQ $+{ }^{30}$ Canadian groups (The Globe and Mail 1995), the lack of scientific information, the way in which the AIDS crisis in North America was understood at the time, the fear of HIV contagion, and the concern regarding potential tax-payer expenditures if HIVpositive immigrants were accepted, shaped the way in which their applications were processed (Calgary Herald 2000; Merriam and Birchard 2000). Indeed, after the IRB granted refugee status to seven HIV-positive applicants from "Mexico, Chile, and countries from the Caribbean and Africa" in 1995 (Escalante 2004:214), the media brought the issue to the public's attention and 
public resistance to admit HIV-positive immigrants was generated in Canada. ${ }^{31}$

Recent data from the IRB (2011-2015) shows that 371 Mexicans submitted an asylum claim under the category of Sexual Orientation and Gender Identity and Expression (SOGIE) from a total of 5,815 SOGIE refugee claimants (including all national groups) or from a total of 16,547 refugee claims made by Mexicans. The SOGIE claims made by Mexicans thus represent $6.4 \%$ of the total SOGIE claims and $2.2 \%$ of the total refugee claims made by Mexicans for the period in question (the total number of refugee claims made by Mexicans constituted $13.7 \%$ of the total 120,620 claims made in Canada during the same period). Of these, 73 self-identified as lesbians, 257 as gays, 34 as bisexuals, and seven as trans, intersex or queer persons. However, only 61 claims or $0.37 \%$ were granted landed status (16 lesbians, 38 gays, three bisexuals, and four trans, intersex or queer persons) (Robertson 2017). ${ }^{32}$

These numbers, nonetheless, need to be understood in a context where the disclosure of sexual/gender orientation and identity by an LGBTIQ+ person during the admission hearings, particularly if they come from a conservative and/or repressive local sub-culture in Mexico, is a difficult thing to do. Another point to consider is that the Canadian immigration system has long demanded "additional evidence in order to be able to administer such a claim. LGBT refugees are required to provide documentation not only of persecution but also 'proof' of their sexual orientation and/or gender identity. To do so they may provide police reports, medical files or other forms of testimonies, all of which can be extremely difficult or impossible to obtain" (Envisioning Global LGBT Human Rights 2015:21).

In addition, because Mexicans belonged to a Designated Country of Origin (DCO) between 2013 and 2019, as per the Protecting Canada's Immigration System Act (Canada 2012), claimants had only 15 days to file their Basis of Claim, something that complicated the process for LGBTIQ+ persons (the DCO policy was suspended by the Liberal government on May 17, 2019, with the expectation that the policy be repealed through posterior legislative changes 
[IRCC 2019a]. The suspension does not retroactively change, however, a 180-day bar on applying for a work permit for citizens from formerly DCO countries [IRCC 2019c]). In the process, asylum claimants need to overcome stigma, embarrassment, and fear in order to be able to obtain refugee status (Jordan and Morrissey 2013:40-41). However, in the case of LGBTIQ+ refugee claimants many come from a local or national socio-cultural context where, in order to survive violence and stigma, they learned how to deny, cover, or hide their sexuality and/or gender identity, for which obtaining evidence to corroborate their claim is a complicated or sometimes an even impossible endeavour (ibid.).

This is compounded by what Cloutier (2015) calls the "illusion of progressive legislation." This is the rejection of asylum claims under the argument that Mexican cities or states' legislations had already legalized same-sex marriage and/or approved legislation against LGBTQ+ discrimination, demonstrating state protection, even if the reality is different. After constant critiques about how the IRB has been conducting hearings and determining LGBTIQ+ refugee applications, the IRB published a new guideline in May 2017 on proceedings involving sexual orientation and gender identity and expression. Its aim is to recognize the challenges that LGBTIQ+ individuals face in presenting their cases, and for IRB members to have ad hoc principles when determining those cases (IRB 2017). The outcome of this change remains to be seen.

By the mid-2000s, Mexicans ranked first among national groups who were applying for asylum. Whilst Mexicans submitted 913 refugee applications in 1996 (951 according to Escalante [1998]), they submitted 2,656 applications in 2004 (George 2008). Nonetheless, only 25\% of those 2004 refugee claims were accepted (ibid). George considered that "this may be due to the perception that Mexico is not a 'refugee-producing country,' and that asylum seekers from the country are primarily economic refugees" (464). George, however, did not delve into a critical analysis of the notion of Mexico as a non-refugee producing country. By 2008, Mexicans already "accounted for more than 25\% of all refugee claims filed in Canada" (CIC 2009). That year, "the 
IRB reviewed and completed 5,654 Mexican refugee claims, of which 606 were accepted. This represents an overall acceptance rate of $11 \%$ for Mexican refugee claims. In 2009, the number of claims $[\ldots]$ increased, while the acceptance rate [...] decreased further still”' (ibid.).

The correlation between the sudden increase of Mexican refugee claims and their low acceptance rate led the Conservative government (2006-2015) to argue that this correlation was neither efficient nor financially sound. Jason Kenney (2009), former Minister of Citizenship, Immigration and Multiculturalism, affirmed that Mexican asylum claimants were jumping "the immigration queue," and thus were "illegitimate," "bogus" claimants. Mexicans were not seen as being in need of refuge, but rather as taking advantage of the "generosity and compassion of [Canada's] immigration and refugee programs" (ibid.), while, at the same time, "[t]oo many tax dollars [were being] spent on bogus refugees" (Baluja 2012). A visa was thus imposed on Mexicans on July 13, 2009 to reduce the number of refugee claimants.

Former Conservative Mexican President Felipe Calderón, following this discourse when addressing Parliament members as part of his state visit to Canada in 2010, said: "[w]e definitely reject the abusive use of any legal principle, in this case, the abuse of an admirable legislation from Canada that gives refugee status to anyone who has been persecuted in any part of the world." He considered that those Mexicans exploited "Canada's compassionate policies by making bogus refugee claims," and acted "on 'false pretence' to enter Canada" "for economic reasons" (Harris and Payton 2010). PM Stephen Harper added to this saying that "[t]he visa is our sole method of control when we face a torrent of bogus applications" (ibid.).

Between 1998 and 2018, 52,998 Mexicans sought asylum in Canada (CIC 2008, 2012; IRB 2019). However, the significant reduction in their refugee applications between 2010 and 2016 is noteworthy; it resulted from the Conservative government's imposition of a visa and the DCO policy (see Chart 2). The reduction in asylum and humanitarian applications, nonetheless, is not unique to Mexicans, even if they were branded as a poster child of bogus, abusive applicants, as I 
will show below. This reduction, rather, bows to drastic changes in immigration, refugee, and humanitarian policies implemented by what Carlaw (2018) identifies as 'authoritarian populism' during Canada's neo-conservative decade (2006-2015). In the case of Mexicans, after the decline in the number of their applications and once the Liberal government rescinded the visa on December 1, 2016 (Canada 2016), their refugee applications increased again, particularly in 2018. Chart 2: Refugee Protection Claims by Mexicans, 1998-2018 12,000

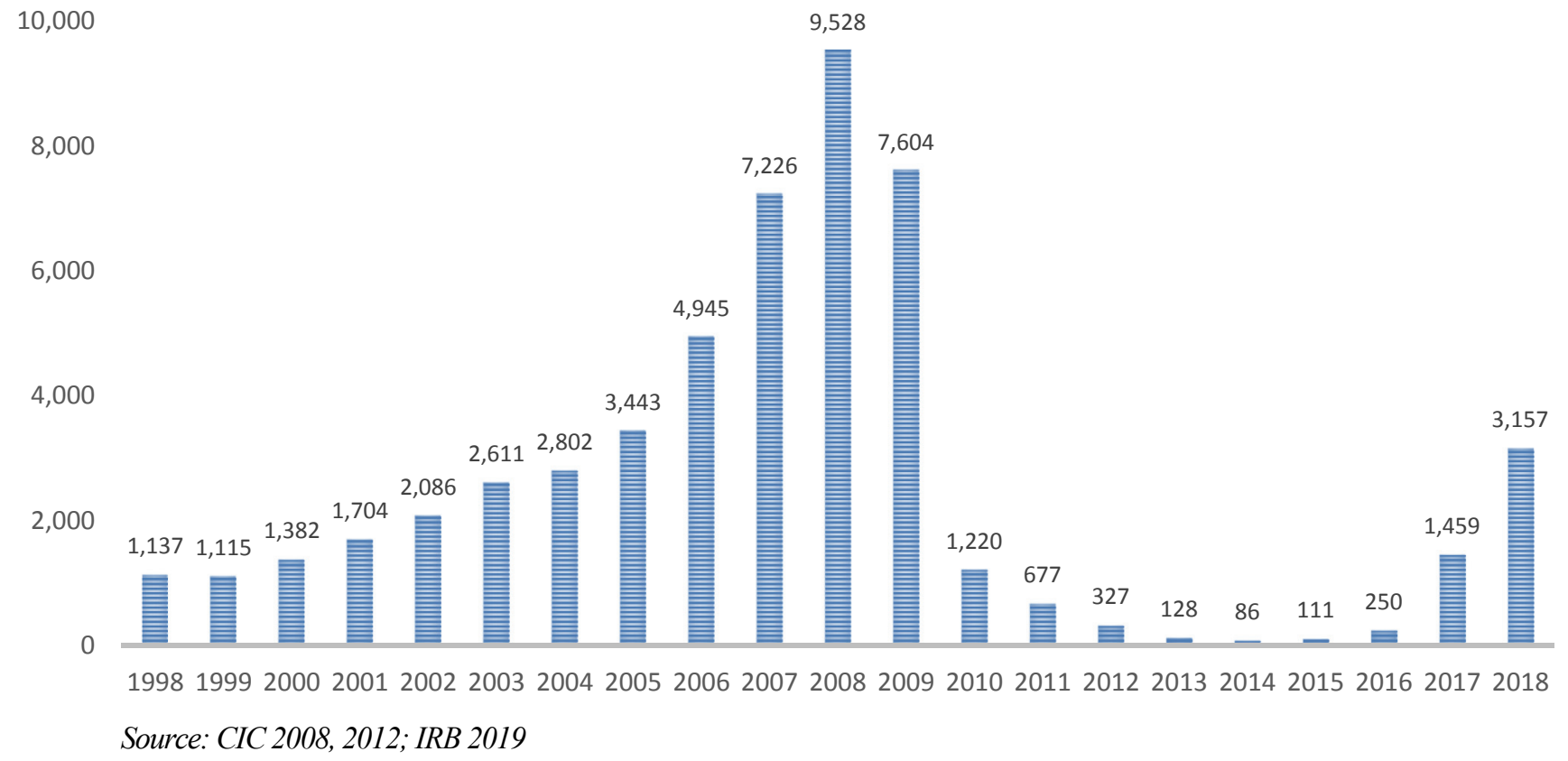

Carlaw (2018), drawing from Stuart Hall, identifies authoritarian populism as politics and policies that aim at achieving "an electoral and social hegemony by mobilizing a law and order narrative involving the manipulation and generation of 'moral panics' and fears of social anarchy. The ultimate aim of such hegemonic power is the normalization of the policies and practices of neo-liberalism and neo-conservatism" (785). One of the effects of this authoritarian populism was "a drop of greater than 28\% from 2006 to 2014 in terms of refugees admitted as permanent residents, while the number of claims made within Canada per year declined more than $40 \%$ from 2006 to 2014" (802). These politics and policies reinvigorated the narrative of the bogus 
refugee developed in the 1980s in Canada (see for example Glenn 1981). This narrative still permeates the attitudes of some Canadians and government officials as of today, as I examine in the following section.

\subsection{The Bogus Refugee Vis-à-Vis Multifaceted Forms of Insecurity and Violence in Mexico}

Between 2006 and 2015, Mexico ranked first among countries with the most refugee claims, followed by China, Colombia, Hungary, Haiti, and the United States, in that order (IRCC 2015b). Martin and Lapalme (2014) contend - following Betts - that Mexican immigration to Canada (also) needs to be understood as a "migration flow [that] might be best categorized as a form of 'survival migration,' or mobility caused by an existential threat to the personhood of individuals, families, or communities." In these circumstances, people "have no access to a domestic remedy or resolution" (Betts 2010:365) and, consequently, face "multifaceted forms of human insecurity, both political and economic" (Martin and Lapalme 2014). Nonetheless, these multi-faceted forms of insecurity are ignored by those who argue in Canada that Mexicans' refugee claims are, rather, of an economic nature.

Since 1998, Escalante (1998, 2004:209) signalled how Mexico was not "characterized as a country that creates refugees" in Canada. This occurred even when "an extensive violation of human rights and a lack of protection of essential rights by the Mexican state led Mexican nationals to seek international protection.” Ignoring this context, and alleging that so-called 'bogus' refugees from "democratic countries that respect human rights" significantly increased their asylum petitions, Jason Kenney (2012) mandated his Ministry to restructure and amend some of Canada's immigration regulations. This resulted in the development and Royal Assent of the Protecting Canada's Immigration System Act in 2012 (Parliament of Canada 2012). One of its outcomes was the inclusion of Mexico in the DCO policy in February 2013.

The DCO's policy objective was to "deter abuse of the refugee system by people who come from countries generally considered safe," and includes "countries that do not normally produce 
refugees, but do respect human rights and offer state protection" (CIC 2014a, my emphasis). The imposition of the visa and the inclusion of Mexico in the DCO policy, however, revealed a threepronged process that has functioned both as a politico-economic strategy and as a narrative imposed by Canada to control immigration. First, Mexico is publicly (and politically) recognized as a state that respects human rights and offers state protection, something that has historically proven to be inconsistent. As Escalante (2004:217) mentioned, referring to the 1990s, Mexican "[m]igration based on human-rights violations and persecution also has to be acknowledged."

Second, the visa and the DCO policy have served (and were meant) to create a legal boundary to halt the increase of Mexicans' refugee claims and consequently their immigration. And third, the 'bogus' refugee narrative feeds another associated (even if inaccurate) discourse that situates Mexico as a chronically under-developed country, with an overall failed economy, that pushes its citizens out. The interlocking of these politico-economic processes, strategies, and narratives has created a generalized mischaracterization of Mexican refugee applicants as 'economic' or 'bogus' refugees in Canadian Conservative parlance.

More importantly, the 'bogus refugee' narrative has purposefully been fostered by both Mexican and Canadian governments (Escalante 1998, 2004). On the one hand, the Mexican government has keenly embraced this narrative since the 1990s to avoid any state responsibility in terms of its human rights obligations (and failures) (ibid.). On the other hand, the Conservative Canadian government, while fostering the narrative of the proliferation of the 'bogus' refugee, politically justified its strategy of mobility control and constituted a new stage in the long history of Canadian immigration securitization (Hernández-Ramírez 2019).

The bogus refugee causality established by the Conservative government (i.e. an increase in Mexican refugee applications vis-à-vis their lower acceptance rate, allegedly revealing their 'bogus' nature) does not, however, consider the reasons for which IRB members do not grant asylum to Mexican applicants. Indeed, odd variations in refugee adjudications have been found to 
be significant, such as those of former IRB member David McBean, who, (re)appointed by Harperites for a total of eight years, only granted refugee status in 18 of 361 cases between 20082014 (i.e. 4.98\%) (Reehag 2017b). In his first mandate (2008-2010), McBean denied all asylum claims, including those of 82 Mexicans. Reehag found that "the probability of a decision-maker deciding eighty-two negative cases and zero positive cases from Mexico from 2008-2010 is approximately one in 70,000” (47).

Abogado (2014), in a legal analysis of Mexican asylum claims, identified four key decision-making aspects that "may themselves be contributing to the denial of Mexican would-be refugees: credibility assessment, the application of the doctrine of state protection, inaccuracies in the Mexican [Country Documentation Package] CDP, and the selective use of parts of the CDP in the IRB's decisions" (151). Reehag (2008, 2011a, 2011b, 2017a) has also found numerous elements that play out in the decision to grant or deny refugee applications, which constitute strong counter-arguments to the 'bogus' refugee narrative/strategy. Among these are the number of claims that adjudicators are assigned, the types of claim and the region in which members specialize, the IRB office to which members belong, as well as the personal characteristics of the IRB member reviewing the case, such as their gender.

Bonisteel (2010), while analyzing how Jason Kenney’s much publicized ‘bogus refugee’ pitch may have created institutional bias among IRB members when evaluating Mexican asylum claimants, concluded that they may have compromised their independent decision making. As Abogado (2014:156) concluded, the probability that Mexican asylum claims be rejected by the IRB is high due to a "whole set of argumentative tools" awaiting the claimant. Among these arguments are the "high level of democracy in her country and the use of isolated parts of the CDP that prove that [the applicant] is lying and Mexico is safe." It is not surprising, then, that Beaudoin et al. (2015:57) found that some countries designated as 'safe' under the DCO policy are, indeed, producing "many positive refugee determinations" every year. 
In the case of Mexico, "the acceptance rate for Mexican refugees rose from 18.8 percent to 28.8 percent" in 2014, just one year after the implementation of the DCO policy. And although this is good news for refugees, "the high acceptance rates of claims from the safe countries contravene the government rhetoric that these countries are safe" (Dench in Keung 2015). The IRB explains these discrepancies due to "the nature of the claims that the member hears and the countries of origin involved" (Reehag 2008:343). However, Reehag's various statistical analyses and Abogado's legal analysis reveal that these arguments are unsatisfactory to explain the constant disparities in asylum claims outcomes.

There is also a lack of attention paid to gender-based violence (GBV) in policy decisionmaking around refugee issues. Data obtained from the IRB signals that GBV is the top reason for which women seek asylum in Canada (Carman and Elash 2018). ${ }^{33}$ Open data from CIC (2008) indicates that Mexican women refugee claimants represented the largest group of female claimants in Canada between 2005 and 2007 (see also Boyd and Nowak 2013). This data also echoes refugee applications made in the United States, where even unaccompanied girls aged 12 to 17 have fled Mexico and the Northern Triangle as a result of rape, physical violence, and the threat of human trafficking (Pope 2016:20).

Martin and Lapalme (2014) and Martin et al. (2013) have greatly advanced the analysis of interrelated factors that have forced some Mexicans to apply for asylum in Canada. These authors suggest the need to consider a transnational, North American governance space, where Mexican mobility is "not simply driven by economics[,] but is also deeply political in nature" (604). This space has been marked by an "increased North American economic integration, the transformation in the nature of the state and social violence in Mexico, and radical policy reform that renders political asylum increasingly and durably inaccessible, particularly for peoples of the Global South" (Martin and Lapalme 2014).

Thus, whilst liberalization and free movement of capital has usually been promoted 
through North American (and international) borders from North to South, barriers to commerce and trade have also been erected, negatively affecting those located on the receiving end. Tariffs, bans, regulations, and embargos are representative of the illusory notion of a liberal and free trade doctrine or the 'more integrated' North American economy. ${ }^{34}$ At the same time, while 'free' circulation of capital is strategically and selectively promoted, usually from North-to-South, human mobility becomes more regulated.

In addition, the North American governance project is not only an economic project, but also an identity project, where 'North American' people imagine themselves as a community (cf. Anderson 2016) that can benefit from a market 'without borders' (Martin et al. 2013).

Paradoxically and purposefully, this also erects commercial, physical, and symbolic borders that exclude Mexicans. Mexicans, then, are seen as shadow figures, as undesirables, as the Others of North America who need to be kept on the other side of the 'North American' fortress (Gilbert 2007; Martin et al. 2013). Except, of course, when their skills and abilities make them desirable to supply Canadian (and to a lesser extent US) skilled labour market needs, or when their cheap, flexible, and expendable labour force is needed to fill permanent Canadian "labour gaps" with temporary labour force (42nd Parliament 2016:31; see also Harvesting Freedom 2017).

For Martin et al. (2013:607), the (uneven) development and expansion of capital in the North American geography is also manifest in the securitization of the region, which is accompanied by the production of new and structural forms of social, economic, and political violence in Mexico. Nonetheless, whereas the mentioned authors consider that the Mexican state has strategically 'retreated,' allowing for the development of criminality and new forms of violence (ibid.), a more critical look at Mexico since 2006 precisely when the number of refugee applications by Mexicans began soaring in Canada—reveals a more complex scenario. Thus, unlike Martin et al., I do contend that it is not that the Mexican state has strategically retreated, allowing for violence to multiply. Rather, the state has undergone a profound symbiosis 
with criminality in Mexico, being still quite present in Mexicans' daily lives.

\subsubsection{The Mexican State-Criminality Symbiosis}

In contrast to other perspectives that explain the Mexican state as detached or retreated from the citizenry's lives under growing levels of violence in Mexico, I contend that the Mexican state is more present than ever, although in new and more complex ways. I explain this transformed Mexican state presence using the metaphor of conjunctive symbiosis (or symbiosis for economy of language), where two entities have bodily union, even if I agree that no metaphor is perfect to fully describe a phenomenon. I use the notion of Mexican state-criminality symbiosis to identify and understand politico-economic processes and outcomes wherein members of the state and criminals' identities are blurred to the point of generating a symbiosis. These symbiotic figures then play intertwined roles in the production of multifaceted forms of violence and new geographies and grammars of insecurity from/in both state and criminality fields. This symbiosis has resulted from internal politico-economic processes in Mexico and from international, ongoing politico-economic systems that geographically include the United States, Canada and, increasingly, other Central American countries.

My understanding of a Mexican symbiotic state contrasts to other scholars' notions about the Mexican state, since I contend that such descriptors no longer suffice to explain the role of the state in the growing violence that Mexico experiences. Corona-Cadena (2008), for example, considers that the narco became a parallel state and thus a rival of the Mexican state. Bonilla (2014:110) argues that the Mexican state became a narco-state, i.e. a state whose institutions and legislative, executive, and judicial officers have been "smeared" by the narco. And Vidal de la Rosa (2009) argues that the Mexican state became a failed, weak state because it has not yet faced institutional disintegration or a generalized failure of its institutions. As I will demonstrate further below, however, the narco is no longer a parallel state, exerting pressure from the outside due to its accumulated power, as Corona-Cadena contends, but rather an element that not only infiltrated 
significant areas of the Mexican state but became part of the state. And although the notion of a narco-state was useful some time ago (Bonilla Castro 2014), this definition does not say too much about how the Mexican state has currently (although partially) modified its capacity and institutional roles to transform into a different entity from the very inside.

As Correa-Cabrera (2017) and Correa-Cabrera and Gutiérrez-Mannix (2019) have pointed out, criminals such as Los Zetas have expanded their fields of action beyond the drug trafficking realm to also include the trafficking of natural gas, gasoline, and crude oil, migrants and weapons smuggling, as well as kidnapping for ransom. In addition to these other 'commercial' areas, there is also the traffic of organs and the kidnapping and sexual exploitation of women and children of both sexes, many of them migrants from Central America. ${ }^{35}$ The notion of a narco-state, then, is not helpful to describe the current multifaceted forms of violence occurring in Mexico. Even when some political scientists argue that the Mexican state became weak and thus failed (e.g. Vidal de la Rosa 2009), I contend that it is not necessarily that the state is weak, even if some urban and rural areas have been dominated by criminal groups and the access of the state (i.e. police and authorities) to these areas has been banned. Rather, the Mexican state has undergone a symbiotic process/outcome wherein some of its members are simultaneously state members and criminals. Thus, state agents from diverse levels, from governors to police members to judicial clerks, act to achieve specific illicit goals as part of criminal groups (see Alonso 2016; Malkin 2017; Proceso 2016; Redacción AN 2017). This occurs even if, at the same time, other state or even the same security divisions combat these groups.

The symbiotic transformation of the Mexican state is also related to the production of new geographies of insecurity. These geographies have been created by " $[t]$ he flow of arms from the United States into Mexico and the return flow of drug money; the increasing repression of unauthorized migrants in the United States; and the destruction of livelihoods and environments in urban and rural areas linked to neoliberal and economic policies, including the very notable 
presence of Canadian mining companies on Mexican soil” (Martin and Lapalme 2014).

Combined with the criminalization and repression of social movements and journalists, and the harsh, far-reaching, and expanding conflict among narco-trafficker cartels and the Mexican and United States governments' war on drugs, these processes have produced multifaceted forms of violence and human insecurity. Violence has spread throughout classrooms, public spaces, small villages, and big urban centers in Mexico (ibid.).

These processes have not only created a sense of (ontological) insecurity that has become a fundamental reality of contemporary Mexico (Martin et al. 2013), but have also been constituted as migration push factors. Moreover, these multifaceted forms of violence and human insecurity have an origin in highly complex, multi-located, and inter-related developments, evolving across different geographies of the American continent. One of the entry points to understand these developments, and perhaps a central one, is the massive demand for drugs in the United States and the elevated profits that it has generated since the late 1960s (US Senate 2015). This co-relation is still not fully recognized as a central issue in the United States (ibid.), even if President Obama conceded that the opioid overdose epidemic was "a priority" for his administration (House 2016).

The historical US drug demand has also led to the development and expanded use of semisynthetic drugs such as hydrocodone and oxycodone, and synthetic drugs such as fentanyl and methadone. Half of the opiates needed to create these highly demanded semi- and synthetic drugs, along with cocaine (260 tons. annually) and marijuana (16,000 tons. annually), are produced in Mexico and the rest in Central and South America (Nájar 2009). Drug production has also partially been induced by conditions of social exclusion and poverty in these countries. Moreover, the US shift and increase in drugs demand led Mexican gangs to refurbish themselves into complex global organizations in the 1990s. These groups, mirroring the configuration of transnational enterprises, expanded their operation centers and money laundering activities as far south as Argentina (Contreras Velasco 2010). This commercial conversion has run parallel to the emergence of new 
drug trafficking groups, such as the Zetas, the Familia Michoacana, and Cartel Jalisco Nueva Generación who, along with local drug traffickers, constantly dispute power, territory, and "control over the valuable smuggling corridors" along Central America's isthmus over older criminal groups (Harrigan 2011).

Since the isthmus became "a key transit route for cocaine, heroin, and methamphetamine precursors heading to Mexico and the United States," the region has, correspondingly, experienced significantly increased levels of violence. For example, "[i]n both Guatemala and El Salvador the rate of killing is now higher than during their civil wars, and Guatemala's government estimates that at least two-fifths of murders are linked to the drug trafficking" (Harrigan 2011). It is not surprising, then, that the North American politico-economic space is increasingly being tied to further developments in the Northern Triangle (i.e. Guatemala, Honduras, and El Salvador) (Chávez and Ávalos 2014; see Jacobson 2011; J. F. Kelly 2015), and that migration from this region towards the North American space (i.e. Mexico, USA, and Canada) is being constituted as a central issue for years to come.

The region's lack of social inclusion, healthcare, social services, and educational opportunities, as well as the high levels of income inequality, is now paired with elevated levels of violence, murder rates, crime, impunity, and insecurity (Chávez and Ávalos 2014). Part of the violence increase in the Northern triangle is also related to the deportation of tens of thousands of Mara Salvatruchas (MS-13) and Calle 18 (M-18) gang members from the United States (FBI 2008; Winton 2007). Their origin can be traced back to Los Angeles, in the mid-1980s, when the Maras offered Latino immigrant and displaced youth social "referents and a sense of belonging; ways of responding to the inability of modern institutions (schools, churches, work, the family) to offer alternatives to crises, both structural and of meaning, which started the spiral of precariousness in the late 1980s" (Reguillo 2005:72). The deportation of Maras to Mexico and Central America translated soon into inflicted violence, forced gang recruitment, and extortion 
(Renwick 2016). Consequently, the Maras' presence and actions in the region has contributed towards a massive exodus of Central Americans since the 2000s - including numerous unaccompanied children — seeking refuge in Mexico, the United States, and more recently Canada (Hernández-Ramírez 2018). ${ }^{36}$

The transnational character of the Maras posited them as a highly attractive group in the geographical expansion of the Cartel de Sinaloa and los Zetas gangs in Mexico. MS-13 currently supplies "crucial manpower" to these cartels in Central America and helps "sell drugs in the local market, intimidate rivals, and carry out executions" (InSight Crime 2017). But the association between MS-13 and los Zetas also indicates a common origin in the United States, besides their use of violence and extortion. This is because the Zetas were founded by between 31 to 67 deserters of the Mexican elite Grupo Aeromóvil de Fuerzas Especiales (GAFE), an elite army unit created in the mid-1990s to combat drug trafficking organizations along the US-Mexico border. They were specially trained in tactics and weapons at the infamous School of the Americas at Fort Benning, Georgia, and by the Kaibiles, the "Guatemalan Special Forces unit responsible for grave atrocities in that country's civil war" (Evans 2015; see also Silva Ávalos 2013). Los Zetas developed a violent, heavily armed, and highly structured organization (FBI 2005b:2, 2005c:1) that started a gang warfare in Mexico.

What has made los Zetas distinct from other cartels in the history of criminality in Mexico, however, is the unprecedented and extreme degree of violence that they impinge not only on other rival gang members, but on anyone they deem necessary. Human heads and dismembered body parts lying on the streets became a too frequent feature of Mexican cities and towns as incarnated messages to rivals, constituting a new calligraphy and grammar of violence (Reguillo 2012). More importantly, the Zetas — as other drug trafficking groups would do later-infiltrated the Mexican state in new ways to the point that the state became deeply entrenched within a renewed and expanded drug trafficking realm and vice-versa. Members of diverse police corporations at all 
levels, the military, the judiciary system, and even municipal departments such as Civil Protection, Firefighters, and Urban Development would work in different capacities for Los Zetas (Balderas and Janowitz 2016; Univision.com 2013). Public servants and politicians who opposed the encroachment of drug traffickers died at the hands of police officers (Osorno 2011).

The infiltration of the state by criminals subsequently reached novel levels. Rather than merely coercing and/or corrupting public office candidates, politicians, and state officials into supporting drug traffic and other related commercial activities as in the past (Nieto 2012), criminals are now promoting their own (gang member) candidates in democratic local processes. They now also follow normal hiring processes at state institutions to become part of the state from the inside, a symbiotic process (Expansión 2012; Padgett 2013; see El País 2016).

\subsubsection{The Production of Multifaceted Forms of Violence \& Mexican Refugee Applications}

The symbiosis between the narco/criminality and the Mexican state has led to the development of new and multifaceted forms of violence in Mexico. For example, between 2006 and 2012, under the tenure of President Felipe Calderón, there were 121,669 registered homicides, or more than 55 people being killed in Mexico per day (Heinle, Rodríguez Ferreira, and Shirk 2017). In contrast, Mexico's homicide rate "generally declined from the 1930s into the mid-2000s" (6). Moreover, after 2008, the year in which the Plan Mérida was signed between the United States and Mexico, homicides increased dramatically. There were "year-over-year increases [in homicides] of more than 58\% in 2008, $41 \%$ in 2009, 30\% in 2010, and 5\% in 2011" (Heinle, Molzahn, and Shirk 2015:vi). Criminal violence also led to the internal displacement of 287,430 people as of December 31, 2015 (IDMC 2015a, 2015b).

Disappearances also constitute a widespread situation within Mexican territory, many of which may be classified as enforced (United Nations 2015). Mexico's National Registry of Missing or Disappeared People registered 37,435 disappearances between 2007 and 2018 (up to April 30) (SEGOB 2018a, 2018b). This number signals, however, a probable low estimate because 
of potential underreporting due to fear of repercussions against partners, family members, neighbours, and/or friends of the disappeared. It is also probable that some of the disappeared people have unfortunately been killed and placed in a mass grave, since the number of known mass graves in Mexico has increased since 2009. And although federal and state authorities know about the location of more mass graves, they have not publicly disclosed them (Expansión 2012).

The Mexican state-criminality symbiosis has also been further developed by the increase in "killings, disappearances, and torture by the military and police" (IDMC 2015a:18), as well as by a frontal attack on "[p]olitical activists, human rights advocates and journalists who expose officials' abuse of power, embezzlement and criminal activities" (17). Moreover, activists and human rights defenders — of whom the majority are women—-find themselves between a rock and a hard place, since they face numerous local, institutionalized obstacles and generalized impunity to bring justice (FIDH \& OMCT 2009). The attacks they face include harassment and threats via email or cellphone, as well as personal surveillance, patrols, and unlawful searches of their homes and offices, many times accompanied by the theft of computers, data, money, and personal effects (IDMC 2015a). Activists also face state espionage via both traditional and advanced and expensive technologies (Article 19, R3D 2017; Fierro 2017), persecution, repression, and, since 2006, increasing homicides (ibid.; see as an example Villegas 2017).

Perhaps one of the most terrifying aspects of the new and multifaceted forms of violence generated by the state-criminality symbiosis is an increasing sense of one's life disposability and its lack of worthiness. In this process, human agency plays a crucial role. For instance, Evans (2015) considers that the Zetas are not only "creatures of the state" due to its origins, but that they also have an unmatched ability to compromise state and local security forces and to entice, coopt, and coerce government officials into compliance. Although these descriptions certainly fit into the Zetas' profile, Evan's account dismisses the agency of those state agents or, in other words, the capacity of state representatives to act on their own behalf and agree on being part and 
parcel of both the Mexican state and criminal groups. In doing so, they transform the Mexican state from the inside and further advance the state-criminality symbiosis.

As Human Rights Watch (HRW) (2013) correctly points out, the 'war on drugs' launched by President Felipe Calderón "led to a dramatic increase in grave human rights violations committed by the security forces sent to confront them. Rather than strengthening public security, these abuses had exacerbated a climate of violence, lawlessness, and fear" (1). Indeed, more than 140 of the nearly 250 disappearances documented by HRW since 2007 have been enforced disappearances. This means that:

state agents participated directly in the crime, or indirectly through support or acquiescence. These crimes were committed by members of every security force involved in public security operations [i.e. the Navy, the Army, and the local and federal police], sometimes acting in conjunction with organized crime. [...] In nearly all of these cases authorities failed to promptly and thoroughly search for the victims or investigate the cases" (ibid.).

The US Department of State (2014:1) summarizes these conditions as "[s]ignificant human rightsrelated problems [that] included police and military involvement in serious abuses, including unlawful killings, physical abuse, torture, and disappearances" (my emphasis). It is evident, then, that the development of the state-criminality symbiosis began since President Calderón started his 'war on drugs,' generating new and multifaceted forms of violence and human insecurity that are now constant features of modern Mexico (Martin and Lapalme 2014).

There is also another aspect linked to the processes mentioned already that influence patterns of emigration from Mexico. This is the United States' presence and intervention in Mexico's affairs. On the one hand, the United States has been constantly aware of the complex processes that Mexico has experienced, both through formal channels (i.e. consulates and embassies) and diverse (overt and covert) intelligence operations (Archibold and Schmitt 2012; Thompson 2011). On the other hand, the United States continues to be central in Mexico's current state of affairs in at least two other areas: the southern US economic dependence on revenue generated by the trade arms with Mexico, which in turn feeds and increases violence in 
Mexican territory, and the US-Mexico Plan Mérida. As McDougal et al. (2013) state, "Mexico is experiencing a surge in gun-related violence since 2006. Yet [...] Mexico has some of the most restrictive gun legislation in the world." Still, ninety percent of confiscated arms to drug traffickers in Mexico comes from the United States (Castillo García 2008).

The Mexican demand for arms, which is related to the high us demand for drugs, has also had an impact on the economic development of the US arms sector, since $46.7 \%$ of US Federal Firearms Licensees now depend "for their economic existence on some amount of demand from the U.S.-Mexico firearms trade to stay in business" (1). This dependence has thus fed an increase in arms sales to Mexico, particularly between 2006 and 2008, placing Mexico as the largest consumer of arms in Latin America only after Colombia (Currier and Franzblau 2015). This also points to a process of militarization that coexists within the development of Mexico's statecriminality symbiosis, and feeds on the Plan Mérida. The Plan Mérida (2008) was allegedly borne of an explicit request by the administration of then Mexican President Felipe Calderón, who "expanded [the previous cooperation system with the United States] and offered to work with [them] in an unprecedented collaborative and coordinated fashion” (Shannon 2009). Through the US delivery of \$2.6 billion to Mexico, the Plan Mérida, part of the US Four Pillars strategy, ${ }^{37}$ is meant to build "a new architecture for bilateral security cooperation" (Gortney 2015). As of March 2017, the US Congress had delivered \$1.6 billion to Mexico through the Plan Mérida, including some \$20 million above the budget requested for the Fiscal Year 2016 (for a total of \$139 million for FY2016) (Ribando Seelke and Finklea 2017:ii).

Paradoxically, despite the Plan Mérida’s influx of billions of dollars, Mexico's “security situation remains highly volatile" according to high ranked American officials. Violence has even expanded to "more than 1,200 American cities where these ruthless criminal networks now operate" (US Senate 2015). Moreover, there are indications that the Plan Mérida funds are feeding the development of the Mexican state-criminality symbiosis. For example, and as 
referenced by Paley (2015), members of the Mexican army massacred 22 young people, some of them children, in the town of San Pedro Limón, Tlatlaya, in 2014 (SinEmbargo 2014). The US Embassy in Mexico (2015) mentioned in an internal unclassified memo that none of the "alleged perpetrators [in the Tlatlaya case] previously received us-funded training." Currier and Franzblau (2015), however, obtained an anonymous declaration from a US State Department official that confirmed "that five individuals in the unit had received training from Northern Command, but that none of those specific trainees had been charged in the killings."

The multifaceted forms of violence and insecurity to which Mexicans are exposed in one way or another know no gender, age, or social class. These also lead Mexicans to claim refugee status in Canada, such as 24-year-old Grise, her mother, and sister, who requested refuge in Canada in 2004 and 2008. Grise was found dead in Mexico, in 2009, "with blows to her body and a bullet in the forehead, a classic revenge from drug trafficking." The men thought to have kidnapped and killed young Grise are also thought to be the same men who previously "attacked and raped [her], leaving her pregnant. She came back to Canada [in 2008] but was deported in December [of that year]." This left "the fate of her baby unknown after she was forced back to Mexico," when her second refugee claim was rejected:

The [IRB] board said [in 2005], among other things, that the family hadn't made enough effort to seek help from Mexican authorities. "I changed my residence 10 times to avoid our attackers. Every time, they found us," said a grieving Nuemi. "Canada has to recognize that Mexico is a war zone run by drug cartels. The government just can't protect its own citizens." [...] FCJ Hamilton House persuaded the federal government to issue a visitor's visa so the surviving mother and sister could return to Canada earlier this month. "I am happy and sad to be back," said a tearful Nuemi, the dead woman's mother. "I'm sad because my daughter had to be killed in order for Canada to believe in our story. The price is just too high" (Keung 2009).

There have also been other cases of women, made public only by the media's efforts, who found a terrible fate after their refugee claims were rejected in Canada, such as Lucía Vega Jiménez (see BC Ministry of Justice 2014; and Burgmann 2004) and Verónica Castro (see Sheppard 2012).

Whilst these women belonged to a lower-middle class in Mexico, other cases refer to 
wealthy Mexicans, such as that of Daniel Balcorta and his family, who fled from Cancún due to extortions made by los Zetas:

Balcorta had "developed a thriving business catering to well-heeled snowbirds from the U.S. and Canada. "I even had a private jet I'd rent to fly around my clients viewing properties," says the 34-year-old ruefully. "We lived a very comfortable life." [...] It was Aug. 14, 2009, and the man with the raspy voice on the other end introduced himself as a representative of "the Company"-gangster-speak for Los Zetas [...] The time had come for Balcorta to pay, the man said, and the price was 500,000 pesos (about \$50,000). [...] and on Sept. 13, they boarded a plane for Calgary, where they claimed asylum under Canada's refugee protection laws. With their Louis Vuitton clothing and laptop computers, the Balcortas are not your stereotypical refugees. Rather, they typify a wave of asylum-seekers whose flight from their home country has been dubbed the "Mexodus"- a mass withdrawal of monied, skilled Mexicans whose wealth has made them targets for narco-gangs back home (Gillis 2012).

Gillis (2012) notes that many rich Mexicans who were victims of extortion initially applied for US visas "under provisions admitting people willing and financially able to start new businesses [see also Becker 2009 and Masferrer and Rodríguez 2019]. But as the gangs turned to extortion and kidnapping for income," many began seeking asylum.

Balcorta's refugee claim, as other similar cases, was rejected by the IRB since it concluded that "Mexicans don't qualify for asylum because all Mexicans face gang crime, and the Immigration and Refugee Protection Act offers no protection against 'a risk faced generally by other individuals"” (Gillis 2012). This argument, however, would make it impossible to obtain a positive resolution in any refugee claim presented by a Mexican citizen who faces violence and insecurity. Indeed, Balcorta's IRB rejection followed a similar pattern to that of Alejandro Blando's claim. Blando was “a distributor of wireless network plans who in 2008 came under threats from men claiming links to Mexico's Federal Investigation Agency. In Blando's case, the callers didn't want money but undocumented phone lines through which — presumably — they could conduct illegal business" (Gillis 2012).

Balcorta's economic background allowed him to apply for a judicial review to the Federal Court. Justice Shore (2012:13-14), who presided over the case, determined that: 
The risk of an individual who is being targeted is qualitatively different from the risk of an individual who has a strong likelihood of being targeted. As such, the former cannot be faced generally. [...] It is irrational for the [Immigration and Refugee] Board to accept the principal Applicant's allegations that he was specifically targeted by Los Zetas and, yet, conclude that his particular risk was faced generally by other Mexicans. The risks of those standing in the same vicinity as the gunman cannot be considered the same as the risks of those standing directly in front of him.

Justice Shore's reasoning properly contextualized and contested the Conservative government's argument that "risks are not personal when faced generally by a large subgroup" (5). The apparent irrationality of the Canadian government's argument, as stated by Justice Shore, unveiled the Conservative government's double standard in relation to Mexico. On the one hand, the government declared Mexico as a generally safe country that should not produce refugees, placing Mexico in the DCO policy. On the other hand, it argued in federal court that Mexicans face a general insecurity risk, for which refugee applications cannot have merit. In the middle of both positions, there has been a frequent understanding among some IRB members that exposure to danger or threats can be mitigated by the applicant's geographical relocation within Mexico, for which a refugee claim may not be recognized if the person does not demonstrate that relocation could have resolved the matter of their refugee claim.

However, as others have pointed out (e.g. Martin and Lapalme 2012; Martin et al. 2013), the fact that the Canadian government maintains regular security advisories for Mexico signals an implicit recognition that "high levels of criminal activity, as well as demonstrations, protests and occasional illegal roadblocks throughout the country" are a constant in the country (Government of Canada 2017). Thus, if Canada issues travel advisories to its citizens about the risks of travelling in Mexico, the rationale for Mexico being safe for Mexican nationals and therefore a non-refugee producing country is weak to say the least. Moreover, it also has been demonstrated that the degree of violence that Mexico is experiencing does not stop with geographical relocation within Mexico when it threatens people, as in the case of Grise (Keung 2009). The narrative of the 'bogus,' economic refugee then, purposefully ignores or hides the strong correlation between the increase in Mexican refugee claims between 2006 and 2009 and Mexico's increase in multifaceted forms of 
violence and insecurity that has resulted from the state-criminality symbiosis since, precisely, 2006. Thus, rather than being an irrational stance implemented by the former Conservative government, the narrative of the 'bogus refugee' constitutes and conceals a strategy of securitization and border control, where Mexicans have been used as scapegoats.

\subsection{Conclusions}

Although small in numbers, Mexicans have immigrated to Canada since at least the latenineteenth century and later as part of various Latin American immigration waves. Since 2000, they have constituted the second largest Latin American national group in Canada after Colombians. Mexican immigration to Canada has been facilitated by both Canadian immigration policies that favour an economic type of immigration and Mexicans' profiles that match the requirements of Canadian immigration policies. Thus, middle- or upper-class professionals, holiday spouses, and international students and their families (i.e. family reunification) have comprised much of Mexican migration to Canada. However, an increase in Mexican asylum claims since 2006 and their low acceptance rate led the Conservative government to argue that Mexicans were 'bogus' refugee claimants looking to improve their economic status and, in doing so, were abusing the generosity of Canadians.

The increase in Mexican refugee applications and even those of economic immigrants needs to be located, however, in a more complex matrix of inter-related phenomena in an increasing transnational space that includes more and more Central America. This matrix consists of various factors, such as the high and sustained demand for drugs in the United States and its multi-billion derived profits, the refurbishing of Mexican gangs into complex transnational organizations, the emergence of new criminal and trafficking groups with a transnational scope, and the increased geographical relevance of the Central American isthmus for criminality. Other factors are the deportation of Maras and Calle 18 gang members from the United States and the corresponding increase of violence in Central America, Mexico, and the United States, the 
implementation of the Plan Mérida, and the southern US economic dependence on the traffic of arms to Mexico, the latter based on the increasing demand for arms by Mexican criminals.

Fundamental in these developments has been the presence of the Mexican state that, rather than retreating, still constitutes a central element in the lives of Mexicans. What is distinctive in the current state-citizenry relationship is the new ways in which the narco and the state have come together in a symbiotic process. Here, state agents, making use of their agency, use their state roles and positionality to advance criminal activities. This symbiosis has been central to the development of new and expanded forms of criminality that have, in turn, developed multifaceted forms of violence and insecurity. This violence manifests in a new embodied grammar, increasing rates of homicides, enforced disappearances, mass graves, torture, espionage, trafficking of natural gas, gasoline, and crude oil, trafficking of migrants, sexual exploitation and enslavement of women and children, and the traffic of organs.

The consequences of these processes have affected Mexicans of all social classes, some of whom have applied for refuge in Canada. Whereas some asylum claimants have been killed after returning to Mexico due to unsuccessful refugee hearings, a few others have had successful hearings at the IRB and even the federal court, although this is mediated by social class.

Considering this panorama, the contention that Mexicans are 'bogus,' economic refugees reveals rather a strategy and narrative — fostered by the Canadian and Mexican governments — to achieve political purposes. On the Canadian side, the goal has been the advancement of border and securitization control. On the Mexican side, it has been more about justifying and concealing its human right violations derived from its state-criminality symbiosis, particularly after 2006.

The historically strong and mutually dependent (even if unequal) relationship between Mexico and the United States, along with the thin and on-again-and-off-again relationship with Canada, as shown in Chapters 3 and 4, has mostly directed Mexican emigration to the United States. Nonetheless, Mexicans have gradually increased their presence in Canada across three 
periods: between 1997 and 2003, between 2004 and 2009, and particularly between 2010 and 2014. This recent growth in immigration is partly related to the increase in violence in Mexico, originated by the Mexican state-criminality symbiosis and the expansion of multifaceted forms of violence and insecurity. However, whereas the imposition of a visa and the DCO policy strongly deterred the refugee applications of many Mexicans since 2009, this did not prevent some of those who possessed various capitals to apply for and obtain permanent residence through the economic class as a strategy to escape from that violence.

Moreover, since aspiring economic and family reunification immigrants or family members need to have a considerable amount of money and other capitals to be able to immigrate to Canada, and considering the stringent process to acquire refugee status, Canada's immigration and refugee system tends to fragment the immigration of extended family members. This, plus the lack of ampler Mexican social networks that facilitate migration and a lack of shared borders, reduces the possibilities of immigration for other family members, as it happens in the United States.

Correspondingly, the fragmented character — although of a growing size — of Mexican immigration in Canada, along with reasons to immigrate, should also impact the type, degree and frequency of transnational practices that Mexicans develop in Canada. Mexicans' reasons to immigrate are varied and complex, and they also include individual motives as well as more structural causes that operate as push and pull factors. In the next chapter, I thus present and analyze the reasons for which my participants decided to immigrate to Canada and the impact that their class locations have had in their immigration experiences. 


\section{Chapter 5: Mexican Immigrant and Refugee Youth's Micro-Level Motivations for Immigration}

In the previous chapter, I showed how Mexicans have immigrated to Canada, even if in small numbers, since at least the late nineteenth century. Their presence in Canada, however, has significantly increased since 2000, currently representing the second largest Latin American national group in Canada after Colombians. The immigration of most (skilled) Mexicans to Canada has been facilitated by Canada's emphasis on economic immigration and to a lesser extent family reintegration and humanitarian assistance. This stream thus contrasts to the Mexican migration stream going to the United States, mainly composed of low-skilled and undocumented people. This stream is estimated to be composed of 11.3 million persons, of which six million were undocumented in 2016 (Zong and Batalova 2018). ${ }^{38}$

Moreover, and for comparison purposes, only 3\% of Mexican immigrants to the United States obtained permanent residence (i.e. green card) via an employment pathway in 2017 visà-vis $12 \%$ of the overall immigrant population (Zong and Batalova 2018). In Canada, most Mexican immigrants arrived in Canada as permanent residents via the economic stream. Since 2006, however, there has also been an upsurge in Mexican asylum claims in Canada, stemming from the increase in new and multi-faceted forms of violence and human insecurity occurring in Mexico. Although the growth in refugee applications has been attributed by Canada and Mexico's governments to economic factors (i.e. the 'economic' refugee), I rather demonstrated how the political use of the so-called 'bogus' refugee as a metonymical figure was meant to obscure Canada's securitization of immigration and Mexico's human right violations.

Making use of Bourdieusian theory and a politico-economic perspective, in this chapter I aim to illuminate both the general profile of Mexican immigrants in Canada and the backgrounds of the Mexican youth I interviewed in Ottawa and Montreal. This includes their pre-migration circumstances, their reasons for immigrating, and the role that their various capitals, age, gender, and sexuality had in their immigration processes. I also analyze the extent 
to which different Canadian immigration policies at the federal and provincial levels differently promote or impede immigration depending on the applicants' profiles, thus stratifying immigrants by pre-migration class location as part of broader institutional and political processes. Understanding immigrants' pre-migration class location and the effect of Canadian immigration policies is relevant to elucidating the extent to which these factors shape immigrants' subsequent economic integration and their formulation of transnational practices.

The chapter is divided in six sections. In the first section, I demystify the profile of Mexicans in Canada, challenging the widespread perception that they are all middle-class and educated people. In the second section, I describe the profiles and class immigration of the 35 Mexican youth I interviewed in Ottawa and Montreal. In the third section, I address how the circumstances (and desires) of the youth who came under economic and family classes to improve their life conditions constituted strong motives to immigrate to Canada rather than the United States, although this did not necessarily or only mean achieving economic objectives. In the fourth section, I analyze how the pre-migration class locations of some youth allowed them to come as international students to Canada, and how relatively favourable Canadian immigration policies allowed them to obtain PR status as economic immigrants after they established roots in the country. In the fifth section, I examine unexpected immigration processes among youth due to marriage/partnership and other relative sponsorship processes. In the final section, I present the analytical conclusions of the chapter, where, drawing on Bourdieusian theory, I show the extent to which my participants' pre-migration class locations shaped their reasons for immigration.

\subsection{The Myth of all Mexicans in Canada as Middle-Class and Educated People}

Most of the existing literature about Mexican immigrants in Canada supports the idea that Mexicans constitute a uniform group in terms of social class and education (see Cachón 2013; George 2008; George and Young 2006; Mueller 2005; Samuel et al. 1995; Tigau 2011; Whittaker 1988). Iturralde (in Tigau 2011:193), for example, an IRCC official, considers that 
Mexicans with permanent residence or Canadian citizenship "tend to be educated and have an upper social status.” Luján (in Notimex 2015, my translation), based on his doctoral research about Mexicans in Toronto, asserts that Mexicans "live in Canada as a middle class, they are educated, and inculcate in their children the relevance of education." Indeed, "ninety five percent [of his respondents] were university-educated professionals and enjoyed significant social capital" (Luján 2017:6). Francisco Rico (in Estévez 2015:17), from the FCJ Refugee Centre, mentioned that Mexicans applying for refugee status are "middle-class people who come from the biggest cities in the country — DF, Guadalajara, Monterrey — who can no longer continue their lives in an ordinary way because of drug trafficking violence, machismo (crimes because of misogyny and homophobia), impunity and judicial corruption that takes away from them life opportunities...."

However, the pre- and post-migration class locations of Mexicans in Canada are more varied than the descriptions provided above, making assertions such as that of Iturralde, Luján or Rico problematic. Certainly, Mexicans' post-migration class locations variation is generated, in part, by the effect of Canada's immigration policies and programs, which structurally stratify the entrance of immigrants based on their pre-migration class location. As Elrick and Lightman (2016:356) assert, there is a realist perspective in Canada that understands immigration categories as reflecting “preexisting differences among immigrants. Thus immigrant outcomes [will] vary by entry category by virtue of fundamental differences between people denoted by each category." Following this realist logic, if most Mexican immigrants have arrived in Canada as economic migrants, they 'must' belong to a middle or upper-middle and educated class.

Certainly, among my respondents, those belonging to a middle or upper-middle class in Mexico were accepted by one of the various economic immigration programs, either at the federal or provincial level. However, there were also respondents who were admitted through the family class and showed more class variation, being populated by youth who belonged to middle, uppermiddle, or working-class locations. This is because the family class program requirements do not 
demand a specific set of education, skills, and work experience. And the refugee and humanitarian streams were almost entirely populated by young people (or their families) with a working-class background. Moreover, it is unwise to conclude that possession of economic capital in Mexico is maintained once in Canada, or that just because some Mexicans had a positive economic background in Mexico this automatically indicates the possession of a number of skillsets and thus an advantageous post-migration class location. For example, among the youth I interviewed, I found that some of the children and/or partners that came along with the main economic applicant, usually a male breadwinner, did not know either of the official languages upon arrival.

When Orlando's ${ }^{39}$ father lost his job and some Canadian contacts got him a job in Ottawa, "the plan [for the rest of the family] was to come for two years to learn English and see how things were in Canada." Although Orlando's family had access to a private sports club in Mexico, a sign of their good economic standing and possession of symbolic capital, this economic location did not translate into the acquisition of more cultural capital (i.e. knowledge of additional languages) among the family members but only for the pater familia. In Deyanira's case, her parents came as international students to Montreal years before they immigrated to Toronto. However, when they returned to Mexico, they "always spoke to me in Spanish, they never wanted me to learn another language. So, when I arrived here, I didn't speak any English [or French] whatsoever." Thus, in Orlando and Deyanira's cases, although their families' total sum of capitals allowed them to immigrate to Canada through the Federal Skilled Worker Program, the lack of official languages knowledge among the rest of the family members was remarkable.

From an outsider perspective, it could be argued that Mexican immigrants in Canada belong to a middle or upper educated class if we only focus on those who are more visible due to their participation in public events, for instance. However, once we take a closer look at pre- and postmigration processes, even among those who came from middle or upper-middle class locations via one of Canada's economic classes, we observe that the process of assigning a social class to 
Mexicans is a more complicated one. Rather, diverse types of capitals are unevenly distributed by age and gender among family members before immigrating and even among those using the economic class (e.g. wives usually lacked knowledge of any of the official languages). Certainly, as I have shown elsewhere (Hernández-Ramírez 2012), the refugee condition among Latin Americans in Canada does not necessarily imply that the person belonged to a lower class location in their country of origin. The cases of rich Mexicans fleeing violence in Mexico and claiming refugee status in Canada, the so-called narco-refugees (Gillis 2012), also exemplify this point.

Nonetheless, there are other Mexican refugees or even sponsored Mexicans (i.e. family class) in Canada who do not fit into the urban, educated, and/or middle- or upper-class categories. In fact, among my participants, some of those who came under the family class via a partner sponsorship or most of those who came as refugees or under the humanitarian compassion program, belonged to a lower-middle or working pre-migration class location. Moreover, except for three participants who studied English at private schools when they were children or teenagers, all the youth who came through a non-economic class had a (self-disclosed) basic or low-to-medium level of proficiency in English or French on arrival.

There are at least two reasons for which this inadequate idea of Mexicans as urban, educated, middle- or upper-class immigrants seems to be generalized in some academic, government, and non-governmental sources. One reason refers to the type of data available about Mexicans. As I mentioned in chapter 4, there are few studies about Mexican immigrants in Canada and most support this idea, which derives, in turn, from their narrow methodologies. Here, researchers selected only certain types of Mexicans, sampling on the dependent variable and thus pre-determining the results. For example, Luján (2017) only interviewed Mexicans in Toronto who have post-secondary studies ( $95 \%$ of his sample), mainly came from two of the biggest cities in Mexico, Mexico City (67\%) and Monterrey (15\%), and have professional backgrounds in Canada associated with middle, upper-middle, or upper social classes such as 
entrepreneurs, academics, artists, and scientists. These educated and salaried Mexicans have thus the luxury of leisure time to spare in cultural and community activities in Toronto, such as posadas and the Mexican Independence Day (September 16), where their visibility is higher.

The second reason refers to the structural invisibilization to which some Mexicans are subjected after immigrating. This invisibilization results from the interplay between their premigration class location and their post-migration economic integration processes. For example, one of my informants in Ottawa (a Mexican man in his forties who immigrated at the beginning of the 2010s, but not one of my youth respondents) mentioned how there are some Mexicans who fit the description of the middle-class, educated immigrant in Ottawa:

...it's people who has education, they attended [expensive, private] universities such as La Salle, Tec de Monterrey, uh, some even came with a developed career and hired by huge companies. Others... ${ }^{40}$ they sold some properties they had in Mexico and came to live here, to live placidly, without too much hassle. They know English, they didn't have to go through the [immigrant] system of learning English, and they know some other languages. They had already some social connections with some people [in Canada]. So, it wasn't that difficult [for them]. [...] Uh, they don't know what it is to be a refugee. [...] They are the elite; they are the elite. They're seen as the elite [among Mexicans in Ottawa].

However, my informant also mentioned how due to the recent increase in violence in Mexico there has been an influx of Mexican refugees in Ottawa, both with and without economic resources:

The other side of the coin is the underprivileged people who have arrived [...]. [Immigrant] poor people are the people that we don't notice. [Or] those who arrived because they had a tiny business in Mexico and organized crime threatened them, or they wanted to kill their children, or this and that. They come here all humbled, like deer caught in the headlights... where should I go, right? [...] Uh, people who are under the government system, receiving the government's support. They're surviving day by day, looking for casual, midnight cleaning jobs, forced to go and study English because, well, they must, right? But they don't have education.

Another Mexican informant, a man in his forties and an entrepreneur who immigrated through the economic class due to increased violence in Mexico, also talked about how there are some Mexicans in Ottawa who have succeeded and obtained good jobs, but they are few in number. Rather, he said, most Mexicans he had met have jobs which are low level and low wage. This 
was also confirmed by a Latina settlement worker in Ottawa, who told me that it was very probable that Mexicans would not participate in my research "because they have this issue of status." Since many immigrated as doctors, lawyers, etc. and "han venido a menos" after their arrival, a phrase in Spanish that signals their downward economic mobility, they have been forced to end up cleaning floors and do not want to speak about "esa intimidad" or that very personal experience. Although I did not directly encounter someone who rejected being interviewed due to their downward economic mobility, this line of argumentation is consistent with Mexicans' cultural emphasis on generating symbolic capital and guarding their status.

My research also unveiled how the invisibilization of some Mexicans in Canada results as an extension of their pre-migration class location, maintained after immigration, rather than because of downward mobility. Rodolfo, for example, came from a small town at age 18 to Montreal as a refugee. Without education beyond high school and a basic knowledge of English, he did not have any other option but to look for a job through employment agencies. He thus worked the full gamut of casual, precarious jobs that gave him no respite to do anything else but work and try to learn French in his scarce spare time. Cases such as that of Rodolfo, where- due to a lack of various capitals - the refugee/immigrant or their family's survival depends on their work in secondary markets, force immigrants and refugees to follow and remain in an invisible, precarious integration pathway, with little possibilities of upward social mobility. This also separates them from the more visible, middle- or upper-class Mexican 'community.'

Moreover, if we consider that almost $40 \%$ of Mexicans came through the economic class and $41.5 \%$ through the family class between 1980 and 2015 (IRCC 2018c), the weight of the economic class might disguise the nuances occurring among members of this class, as I detailed earlier. And even if some Mexicans arrived via the economic class, it is their total amount of capitals and their integration experiences in Canada, rather than the program used for their immigration, which determine their post-migration class location. Thus, Mexican immigrants in 
Canada do not constitute a homogeneous group in terms of pre- and post-migration possession of economic and cultural capital since these are differentially distributed based on factors such as gender, age, location, and sexuality. Consequently, immigration through the economic class cannot be used as a synonym for belonging to a middle or upper-class and/or the possession of cultural capital after immigration. A more detailed analysis is needed to determine the extent to which immigrants and refugees' pre-migration and post-migration class processes interact along with other factors at the micro, macro, and transnational levels to shape their particular economic integration pathways, as I do in chapters 7 to 9 . In the remainder of this chapter, I focus on the profiles of the Mexican youth I interviewed in Ottawa and Montreal, their pre-migration circumstances, their (or their families') reasons to immigrate, and the programs used.

\subsection{Why Did Young Mexicans Immigrate to Ottawa and Montreal?}

I found certain continuity in some of the profiles of the youth I interviewed with those Mexicans who immigrated to Canada in the late 1990s. As mentioned in Chapter 4, Mexicans in the 1990s were a) middle-class professionals who immigrated with their families to enhance their professional or economic opportunities and improve their children's opportunities, b) middle-class, single or immigrant couples without children, with tertiary education, and without much proficiency in English or French, and c) holiday spouses, which included also males and international students coming from a wide range of socio-economic statuses (Goldring 1999b). I also found some differences. For instance, all my respondents who immigrated via the economic class as single persons or as couples without children had a medium-to-advanced knowledge of one or two of the official languages (and in the case of those who first immigrated as international students, they had already improved their language skills at the moment of their immigration application). This is because the Canadian immigration system has increased language proficiency requirements for prospective immigrants. And although some of my respondents faced language difficulties after immigrating, they certainly came with better language skills than the Mexicans 
Goldring identified. I also distinguished other profiles that Goldring did not identify, such as NAFTA migrants, international students who became permanent residents, and refugees, all of whom were also part of my research.

Looking at the immigration streams through which my participants came to Canada, one still finds empirical validation of how the structuration of the Canadian immigration system, strongly shaped by an economic imperative and the somewhat discretionary power of visa officers, determines who is allowed to come to this country (cf. Reehag 2008, 2011a, 2017a, 2017b; Satzewich 2015). Data from the 2016 census signals that about six in 10 recent immigrants were admitted to Canada under the economic category (whom Simmons [2010] calls 'designer immigrants'), three in 10 were accepted under the family class to join family members already in the country, and roughly one in 10 were admitted as refugees (Statistics Canada 2017c). From my two non-representative samples (Ottawa $n=18$, Montreal $n=17$ ), $46 \%$ of the youth came through the economic class, $37 \%$ via the family class, and $17 \%$ through the refugee/humanitarian and compassionate grounds under "special considerations" class (see Tables 4, 5, and 6).

Among the youth I interviewed in Ottawa, seven arrived in their teens and seven in their twenties, whereas among those I interviewed in Montreal, 12 arrived in their twenties and three in their thirties. Some of the implications of this in terms of their education, economic integration, and sense of belonging in Canada is, in general, that the younger they were on arrival, the easier it was for them to obtain Canadian capitals and perhaps more quickly develop a sense of belonging to Canada. These themes, however, will be further analyzed in chapters 7, 8, and 9 .

Those participants who immigrated through the economic class used different sub-programs to do so, reflecting the variability in their pre-migration class locations and differently responding to the various requirements that Canada's and Quebec's economic programs create (see Tables 4 and 5). The most frequent immigration class used by Mexican youth was the economic class (16 of 35 persons or $46 \%$ ). This also includes family economic migration (e.g. some of my respondents 
came with their parents, one of these being the main applicant and who, in four of five cases, was the father). The second-most used immigration class was the family class (13 of 35 persons or $37 \%$ ). The family class consists of two sub-programs, the Spouse or Common-law Partner Sponsorship and Undertaking stream, and the Adopted Child or Orphaned Family Member or Another Relatives stream. One participant also came through the family class under the Canadian citizenship by birth outside Canada to a Canadian citizen parent procedure (i.e. citizenship by descent or jus sanguinis). The rest of the respondents came through the Humanitarian and Compassionate Considerations stream, the Refugees Landed in Canada stream, and Compassionate Grounds under the "Special Considerations" option (6 of 35 persons or 17\%).

Table 4: Distribution of Mexican Youth by Immigration Class in Ottawa and Montreal

\begin{tabular}{|c|c|c|c|c|c|c|c|}
\hline $\begin{array}{l}\text { Immigration } \\
\text { Class }\end{array}$ & Ottawa & $\begin{array}{c}\text { Percentage } \\
\text { of Ottawa } \\
\text { sample }\end{array}$ & $\begin{array}{c}\text { Percentage } \\
\text { of } \\
\text { population }\end{array}$ & Montreal & $\begin{array}{l}\text { Percentage } \\
\text { of Montreal } \\
\text { sample }\end{array}$ & $\begin{array}{c}\text { Percentage } \\
\text { of } \\
\text { population }\end{array}$ & $\begin{array}{c}\text { Percentage of } \\
\text { population } \\
\text { (Ottawa \& } \\
\text { Montreal) }\end{array}$ \\
\hline $\begin{array}{l}\text { Economic } \\
\text { class }\end{array}$ & 9 & 50 & 26 & 7 & 41 & 20 & 46 \\
\hline Family class & 8 & 44 & 23 & 5 & 29 & 14 & 37 \\
\hline $\begin{array}{l}\text { Refugee/ } \\
\text { Humanitarian } \\
\text { class }\end{array}$ & 1 & 6 & 3 & 4 & 24 & 11 & 14 \\
\hline $\begin{array}{l}\text { Special } \\
\text { Consideration }\end{array}$ & 0 & 0 & 0 & 1 & 6 & 3 & 3 \\
\hline Total & 18 & 100 & 52 & 17 & 100 & 48 & 100 \\
\hline
\end{tabular}

Table 5: Mexican in Ottawa Youth by Sex, Age at Arrival, Immigration Class, and Time to Obtain PR Status

\begin{tabular}{|c|c|c|c|c|c|}
\hline Participant & Sex & $\begin{array}{l}\text { Age at } \\
\text { arrival }\end{array}$ & $\begin{array}{l}\text { Years in } \\
\text { Canada }\end{array}$ & Program & $\begin{array}{l}\text { Time to obtain PR status } \\
\text { after initial application }\end{array}$ \\
\hline Myrna & $\mathrm{F}$ & 21 & 13 & $\begin{array}{l}\text { Economic, Family Migration, Federal } \\
\text { Skilled Worker Program (FSWP) }\end{array}$ & 2 years \\
\hline Andrea & $\mathrm{F}$ & 6 & 12 & Economic, Family Migration FSWP & Unknown \\
\hline Deyanira & $\mathrm{F}$ & 17 & 5 & Economic, Family Migration FSWP & $\mathrm{N} / \mathrm{A}$ \\
\hline Alberto & M & 15 & 6 & Economic, Family Migration FSWP & 1 year \\
\hline Orlando & M & 13 & 13 & Economic, Family Migration FSWP & 1 year \\
\hline Teresa & $\mathrm{F}$ & 6 & 29 & $\begin{array}{l}\text { Economic, Family Migration, Quebec } \\
\text { Experience Program (QEP) }\end{array}$ & 2 months \\
\hline Ivette & $\mathrm{F}$ & 15 & 14 & Economic, CECP & 1 year and 6 months \\
\hline Griselda & $\mathrm{F}$ & 22 & 9 & $\begin{array}{l}\text { Economic, Canadian Experience Class } \\
\text { (CECP) }\end{array}$ & 2 years \\
\hline
\end{tabular}




\begin{tabular}{|c|c|c|c|c|c|}
\hline Participant & Sex & $\begin{array}{l}\text { Age at } \\
\text { arrival }\end{array}$ & $\begin{array}{l}\text { Years in } \\
\text { Canada }\end{array}$ & Program & $\begin{array}{l}\text { Time to obtain PR status } \\
\text { after initial application }\end{array}$ \\
\hline Ildefonso & M & 18 & 7 & Economic, CECP & 6 months \\
\hline Verónica & $\mathrm{F}$ & 29 & 5 & Family, Marriage Sponsored - MX* & 1 year and 3 months \\
\hline Gilda & $\mathrm{F}$ & 27 & 4 & Family, Marriage Sponsored - MX* & 2 years \\
\hline Artemisa & $\mathrm{F}$ & 23 & 4 & Family, Marriage Sponsored - CAN* & 1 year and 2 months \\
\hline Gabriel & M & 24 & 9 & Family, Marriage Sponsored - CAN & 8 months \\
\hline Mauricio & M & 24 & 6 & Family, Marriage Sponsored - CAN & 10 months \\
\hline Erika & $\mathrm{F}$ & 18 & 10 & Family, Sponsored Member & 2 years \\
\hline Román & M & 8 & 18 & Family, Adoption & $\mathrm{N} / \mathrm{A}$ \\
\hline Nadia & $\mathrm{F}$ & 1 & 23 & Family, Citizenship & $\mathrm{N} / \mathrm{A}$ \\
\hline Aurora & $\mathrm{F}$ & 19 & 13 & Humanitarian & 2 years \\
\hline \multicolumn{2}{|c|}{ MEDIAN AGE } & $\begin{array}{l}18 \\
17\end{array}$ & $\begin{array}{l}9.5 \\
11\end{array}$ & & \\
\hline
\end{tabular}

*MX means that the sponsorship application was submitted from Mexico, and CAN that the application was submitted from Canada.

Table 6: Mexican Youth in Montreal by Sex, Age at Arrival, Immigration Class, and Time to Obtain PR Status

\begin{tabular}{|c|c|c|c|c|c|}
\hline Participant & Sex & $\begin{array}{l}\text { Age at } \\
\text { arrival }\end{array}$ & $\begin{array}{l}\text { Years in } \\
\text { Canada }\end{array}$ & Program & $\begin{array}{l}\text { Time to obtain PR status } \\
\text { after initial application }\end{array}$ \\
\hline Patricia & $\mathrm{F}$ & 29 & 6 & $\begin{array}{l}\text { Economic, Quebec Regular Skilled } \\
\text { Worker Program (QSWP) }\end{array}$ & 1 year and 6 months \\
\hline Karina & $\mathrm{F}$ & 28 & 7 & Economic, QEP TFW & 1 year and 6 months \\
\hline Diana & $\mathrm{F}$ & 23 & 10 & $\begin{array}{c}\text { Economic, QEP Temporary Foreign } \\
\text { Workers (TFW) }\end{array}$ & 2 years \\
\hline Miriam & $\mathrm{F}$ & 25 & 10 & Economic, QEP TFW & 2 years \\
\hline Roberto & M & 23 & 3 & $\begin{array}{l}\text { Economic, QEP Graduates or Future } \\
\text { Graduates }\end{array}$ & 2 years \\
\hline Joaquín & M & 24 & 9 & Economic, QEP Graduates & 1 year and 8 months \\
\hline Carolina & $\mathrm{F}$ & 31 & 4 & Economic, QSWP & 1 year \\
\hline Jimena & $\mathrm{F}$ & 30 & 5 & Family, Marriage Sponsored - QUEB* & 2 years \\
\hline Jaime & M & 25 & 10 & Family, Marriage Sponsored - QUEB* & 1 year \\
\hline Javier & M & 22 & 13 & Family, Marriage Sponsored - QUEB* & 1 year and 6 months \\
\hline César & M & 23 & 10 & Family, Marriage Sponsored - QUEB* & 7 years \\
\hline Eduardo & M & 22 & 12 & Family, Marriage Sponsored - QUEB* & 1 year and 8 months \\
\hline Lorena & $\mathrm{F}$ & 23 & 9 & Refugee & 2 years \\
\hline Marco & M & 22 & 8 & Refugee & 2 years \\
\hline Gonzalo & M & 11 & 16 & Refugee & Unknown \\
\hline Rodolfo & M & 18 & 9 & Refugee & 4 years \\
\hline Norma & $F$ & 30 & 5 & $\begin{array}{l}\text { Compassionate grounds under special } \\
\text { considerations }\end{array}$ & $\mathrm{N} / \mathrm{A}$ \\
\hline \multicolumn{2}{|c|}{$\begin{array}{l}\text { MEDIAN AGE } \\
\text { AVERAGE AGE }\end{array}$} & $\begin{array}{l}23 \\
24\end{array}$ & $\begin{array}{c}9 \\
8.6\end{array}$ & & \\
\hline
\end{tabular}

*QUEB means that the immiaration application was submitted from Quebec. 
Among those who immigrated through the economic class, I identified five reasons and/or circumstances in order of frequency, which compelled and allowed them to immigrate: 1) a desire to improve their life conditions, which did not necessarily or only refer to economic motives; 2) their possession and use of social, cultural, and economic capitals and networks in an expanding transnational economic space between Mexico and Canada; 3) a desire to maintain the personal relations they had created in Canada while being international students, signalling how they had already put down roots in the country; 4) to escape from increased violence in Mexico (a reason also mentioned and experienced by those who came via the refugee and humanitarian and/or compassionate streams and some of those who came under marriage sponsorship), and 5) to escape (potential) unemployment and economic crises in Mexico, as well as looking to offer more opportunities for children in the case of economic family migration (these last two reasons will be explored in the next chapter).

Among those who came to Canada under the family class, they did so to stay with their Canadian/Québécois(e) partner/spouse, to be reunited with family members, due to adoption, or because the family returned to Canada from Mexico. It was also noticeable that, except for two persons, Mexican youth who came via marriage sponsorship had never thought of immigrating to Canada until they formed their relationship with a Canadian or a Québécois(e). And those who came as refugees did so to escape from different types of persecution. I also interviewed another person who came as an international student but was unexpectedly forced to stay in Canada after an accident, and thus obtained a stay permit. In the following six sub-sections, I contextualize and analyze the abovementioned reasons for Mexican youth to immigrate to Canada.

\subsection{A Desire to Improve Life Conditions Does Not Necessarily Mean Immediate Economic Objectives}

Almost half of Mexican youth (16 of 35) manifestly expressed a desire to improve their life conditions as an important reason to immigrate. This did not necessarily (or not only) mean improving their economic circumstances. Rather (or also), it meant changing their social milieu, 
maintaining a partnership and/or friendships made in Canada, obtaining foreign cultural capital, staying away from local issues embedded in the Mexican culture, such as corruption, nepotism, and homophobia, as well as avoiding Mexico’s growing violence. For example, Patricia and Ramiro immigrated as a couple, and ever since they had started dating, "we said, 'We don't want to live in Mexico City, so where should we go?' And like no other place in Mexico caught our attention, so we said, 'We can try outside Mexico.' The most obvious choice was the United States, but we didn't want to because they're racists. The other options were Canada, Australia... We chose Canada because it was closer, and we saw that the migration process wasn't too difficult at that time" (i.e. 2009).

Joaquín "noticed during the time I was [living] here [in Montreal]... I noticed that the quality of life is better. Where I am from, [name of small city], it's a place... at that time it wasn't that good and now it's much worse. I was reading in Proceso that this is one out of the two cities with lower quality of life in Mexico. So, I noticed while living here, as I said, that there was a better quality of life and I felt safer.” Miriam, "by hazards of destiny, [...] began working in a political campaign of a municipal president [in Mexico], and then I began witnessing a lot of things. I got disappointed about many issues I witnessed. [I saw] the reality that our country faces. So, I said, "This is definitively another reason for me to concretize my decision to live abroad."'

These non-economic reasons to immigrate reveal the limitations of some theoretical approaches to migration, such as the neoclassical economics theory, which favours an understanding of migration as the resultant equilibrium point generated between the supply and demand of labour among countries (Todaro 1969). Certainly, some of my respondents who came through the economic class evaluated the costs and benefits of migrating, as posited by the microeconomic model of individual choice (Massey 1999). For instance, Patricia and Ramiro took four years to evaluate their immigration options and prepare their process of immigrating to Canada, which included one-year stay in Paris, where they improved their French. And Carolina and her 
partner developed a strategy to maximize their points in their QRSWP application, which included waiting for two years for her partner to do her MA degree in Mexico and researching employability and credential recognition options in Montreal. They also hired a French language consultant to improve their French language exam scores, and another consultant to advise them on how to better answer questions during the immigration interview, besides taking a course on Quebec history. This case of intense preparation, however, was unique in my sample. In addition, Patricia and Carolina used the orientation services of the Délégation Générale du Québec à Mexico (DGQM), in Mexico City, to obtain better guidance regarding the Quebec immigration process.

However, for Carolina and her partner, the main reason for engaging in this timeconsuming, intensive, and expensive process to maximize their points and be able to immigrate through the economic class was to avoid being subjected to the homophobia they encountered in Mexico: 'because I don't have to get [to a workplace] and say: 'Nice to meet you, I'm Carolina and I'm lesbian. I like women.' No! I mean, my introduction [should be]: 'I'm Carolina, I'm an [administrator], and this is what I can do." The explicit emphasis that some of my research participants made on improving their life conditions was somewhat similar to the emphasis made by the Mexican immigrants that Whittaker (1988) interviewed in Vancouver in the late 1980s, and who were looking for Canada's "quality of public life" (38).

It is important to note, however, that even when some of my economic class respondents mentioned non-economic factors as reasons to immigrate to Canada, it was precisely their premigration class location or total sum of capitals which provided them with the necessary information, skills, and capital (convertibility) to be able to emigrate. Joaquín, for example, did not know what to do after he finished his bachelor's degree in Mexico, so he decided to travel abroad. Once he returned, he decided to volunteer for a research laboratory in the United States, and once in Mexico, but again still not knowing what to do, he decided to do a post-graduate degree in Montreal. For Joaquín, the economic factor was not relevant to his decision to migrate. 
However, his pre-migration class location allowed him to chart a provisional life pathway, and, while doing so, find about the possibility of immigrating to Canada and thus being able to fulfil all the necessary requirements to do so.

In Carolina's case, as described above, she was able to spend/invest economic capital to immigrate due to her previous class location in Mexico, her high-income level, and her partner's various capitals. But in the cases of other LGBTIQ+ persons (and despite the historical violence inflicted on this community), it is not always possible for them to immigrate due to, precisely, their lack of economic and other types of capitals, thus becoming 'undesirables' under Canada's economic immigration policy. Parallel to this absence of capitals, Canada's generalized lack of recognition of LGBTIQ+ persecution cases when applying for asylum (as detailed in chapter 4), along with the previous limitations imposed by the DCO policy, renders many cases ineligible for humanitarian assistance (Abogado 2014; Egale Canada 2013; and Global Rights et al. 2010).

At the same time, however, a favourable pre-migration class location is not necessarily enough to make immigration easier. The economic immigration programs created by the federal government, the provinces, and the Northwest Territories have created different pathways, each containing distinctive requisites that can constitute obstacles for someone looking to immigrate. Roberto and Joaquín represent successful cases since they had already lived in Montreal, had Québécoise education, and a good level of French knowledge — all of these requirements in Quebec's immigration policy (cf. Quebec 2015). For them, it was only a matter of applying to the QEP for Graduates, paying the associated fees for them to obtain their Certificat de Sélection du Quebec (CSQ), and then applying for their PR status to Canada.

In contrast, and despite their young age and favourable pre-migration class location, other Mexican youth faced a more complicated scenario to obtain their PR status due to the requirements of other immigration programs. For example, those who wanted to apply to the CECP or QRSWP were asked to provide qualified, full-time prior employment experience. Under the first program, 
the employment experience must be held in Canada to count as valid work experience (i.e. Canadian capital), whilst under the second program, the employment experience can be held in any country, although in both cases it must be in a technical, management, or professional level position. Ildefonso, who finished high school and a bachelor's degree as an international student in Ottawa, obtained his Post-Graduation Work Permit (PGWP) immediately after graduation and transitioned from a non-supervisory, part-time job to a supervisory, part-time position:

In fact, [the process] was not too difficult for me, [...] and I decided to take that job not because of the money, because the first thing that I needed to check was that the job was valid for migration [purposes]. Because I remember that I had classmates [i.e. international students] who got a job, but that job didn't count for the national list of occupations. And if this [job] didn't count in that classification, it was pointless to take it, independently of the payment, because then those three years of the work permit became invalid, and then it's about starting the process all over again [but now from Mexico].

Had Ildefonso not found qualified employment, he would have had to return to Mexico and obtain at least one year of qualified work experience to be able to apply to one of Canada's economic immigration streams. Thus, although pre-migration class location was a central factor for my economic class respondents to come to Canada, this did not necessarily translate into an easy possibility for some to immigrate due to the particularities of Canada's immigration fields. Moreover, had Ildefonso lived and studied in Quebec and learned French rather than English, he would have been able to immediately apply to the QEP for graduate students and easily obtain his PR status. Consequently, the different economic immigration scenarios created by the federal government and/or the provinces/territories' programs ${ }^{43}$ also pre-determine the immigration possibilities and outcomes of prospect applicants, irrespective of their middle-to-upper premigration class locations or their experience as international students or workers in Canada.

Canada's economic immigration policies (including those of its provinces/territories), thus not only stratify immigrants by their pre-migration class location, as mentioned before, but they also (and usually) require from prospective immigrants a highly qualified previous participation in the labour market, either in their country of origin or in Canada. The exception to this is the 
QEP for graduate students (Quebec 2016d) and other provincial nominee programs catering to graduate students, such as the Ontario Immigrant Nominee Program (Ontario 2018). In this sense, the possession of pre-migration economic capital, which can facilitate the acquisition of Canadian cultural capital (as in the case for international students), is generally not enough for immigration purposes if the configuration of the Canadian immigration field requires, in addition, other types of capital, such as (Canadian) work experience at management, professional or technical levels (i.e. Canadian capital), which in Bourdieusian terms constitutes an entry fee. ${ }^{44}$ Moreover, the varying entry fees that the provinces/territories and Canada demand (i.e. their immigration policy requirements) also reveal their internal economic and political competition as institutional actors, which in turn shape the immigration field.

At present, for example (i.e. 2018), the Liberal federal government does not have an immigration pathway for international students despite the latter's constant portrayal, since 2015, as: a more fertile ground for which to look for new Canadians [...] They are educated, by definition. They speak English or French, or they wouldn't be at our universities. And they know something about the country. [...] So for all those reasons, they're the best source for new Canadians, so we should court them actively (McCallum 2016).

In contrast, Quebec has been quite active in promoting the retention of international students as part of its political efforts to reposition itself in economic and identity terms vis-à-vis AngloCanada. Thus, when compared to other federal or provincial programs, being an international student in Quebec currently offers an easier pathway to acquiring PR status. Nonetheless, this is in exchange for knowing “and respect[ing] Quebec's common values" and developing "a feeling of belonging and a comprehension of Quebec society" (Chiasson 2002:2). Accordingly, competing politics between Canada and the provinces/territories shape the immigration policies and therefore the overall degree of easiness (or difficulty) to acquire PR status. This only applies, however, to those who have the minimum amount of economic and cultural capitals to apply. Among my economic class respondents, another element that shaped their decision to immigrate, besides their middle or upper-middle pre-migration class location — and sexuality in 
the case of Carolina — was gender. In seven of nine cases where Mexican youth came as part of family immigration or with a partner via the economic class, the main applicant was the father/husband (except Karina). In Karina's case, her husband would have been the main applicant in their immigration process had he not been fired from his job and subsequently lost his one-employer-only work permit, for which Karina ended up being the main applicant using the open work permit given to her as the accompanying wife.

In most of these cases, the male figure, playing the role of breadwinner even before immigrating, was constituted as the active individual who looked to prevent negative economic outcomes against the family in the face of economic uncertainty. It was also the male figure who searched for a job in different countries and used his transnational social capital to contact friends and acquaintances to obtain information about immigration possibilities. It was he who also tried to protect the family from increasing violence in Mexico, and/or favourably responded to transnational labour markets that connect Mexico and Canada (as I will show in chapter 6). In contrast, the role of the female partner in six of these cases was that of family caregiver and/or wife. Hence, the configuration and social dynamics of these economic immigrant families corresponded to the traditional Mexican gender division of labour, a close connection to extended families and kin relationships, and in most cases to the Catholic religion (Esteinou 2004). Here, the male figure functioned as the epicenter of the family around which all members' activities, plans, and pre-migration distribution of capitals revolved.

Overall, the desire to improve their life conditions constituted a strong reason for many Mexican youths to immigrate to Canada. This notion did not necessarily (or only) mean improving their economic circumstances, but rather referred to expanded notions of wellbeing, and a strategy to avoid negative elements of the Mexican culture. These reasons, however, were strongly mediated by the youths' pre-migration class location, the particular role that gender and sexuality played in their families' and personal lives, the configuration of Canada and the provinces' 
immigration fields, in particular that of Quebec and its historical and political location vis-à-vis Anglo-Canada, and in some cases their pre-migration access to the Canadian labour market.

\subsection{Making Canada Home: International Students and Skilled Temporary Migrants Putting Down Roots in Canada}

Another reason for which some Mexican youth from the economic class decided to immigrate was because they had already been living in Canada for some time and had put down roots here (i.e. Ivette, Ildefonso, and Griselda from Ottawa and Roberto, Joaquín, Diana, and Karina from Montreal). Most of these respondents (six of seven) came as international students, either to obtain a high school certificate and/or a post-secondary degree, or to participate in an exchange program, but then decided that they wanted to stay and started their immigration process. Griselda, for example, came first to Ottawa to participate in a summer exchange program, went back to Mexico for a year, and then returned to Ottawa to apply for a job:

[it was] in part because of the guy I was dating [since the first visit], and in part because I studied [name of program] and I didn't see myself [working] in Mexico City or Washington. And Ottawa, like it offered me like a good balance between this being a capital, [being able to] use [my] English and French, [...] and this being a little town. In terms of lifestyle, [Ottawa] is not Mexico City. [...] Like Mexico City is like wow! Spooky! Like... be careful! And here, I feel super safe and now also... as a woman to come [here] and being able to be a professional, by myself, I felt that it was safer and quieter than living in Mexico City. Washington, maybe, but the difference with Washington is that... I feel they're more racists.

Roberto had initially come to Montreal to study French in a co-op program for six months, and after going back to Mexico he decided to return: "I didn't want to stay in Mexico anymore because... well, I missed a lot being here, I missed the friendships that I had made; I had left my girlfriend here, so all of those things [weighted on my decision to return]. [...] My family was financially supporting me, so I didn’t have the need to work." Joaquín went through a similar process: "I have friends from all over the world. [...] My girlfriend, she was born in [South East Asian country], but she grew up in Toronto [...] So, I like this very much, that I can meet people from all over the world, so that gives me like, like this [...] different perspective, I guess... a more open mind." And Ivette, after she finished her high school and technical career in Toronto, 
and since "I had been making my life here," decided to apply for PR status.

Gender was also relevant among Mexican youth from this sub-section, since three of four respondents experienced differentiated immigration processes due to the fact that they were women. Diana met a lot of resistance from her father, who was barely able to accept the fact that, as a woman, she was staying longer in Canada than the initial six months her English course demanded so as to keep studying. It was Diana's mother who firmly supported the continuation of her technical studies in Montreal. After Ivette went to Toronto to study, her relationship with her younger sister deteriorated to the point that they stopped communicating. The latter felt that Ivette had abandoned her after having immigrated to Canada. And Griselda did not face family opposition to her immigration, although she had to hide the fact that she was also moving in with her boyfriend once in Canada. Her father, who was aware of her relationship and perhaps somewhat suspicious of Griselda's intentions, was clear in telling her before her departure that he was not expecting an unplanned pregnancy from her. The father's warning thus revealed a somewhat conservative position that was meant to influence Griselda's ability to decide over her own person. For him, the only option in the case of an unwanted pregnancy was for his daughter to give birth and face a difficult situation as a prospective single mother, a common assumption among Mexican social conservatives. In contrast, my male respondents did not face any issues regarding their immigration processes on the part of family members in Mexico. These relations unveil how traditional, patriarchal ideologies shape migration trajectories_-particularly for women - in the context of the family unit, a central institution in Mexican culture. Roberto, for example, mentioned how he "always had my family's support."

Overall, for this group of Mexican youth, five factors are notable in shaping their immigration process: first, the amount of their capitals before immigrating allowed them to temporarily come to Canada to study. Second, after some time living in the country and having established meaningful friendships and/or significant other relationships and having obtained 
Canadian capital (i.e. Québécoise/Canadian education, [improved] knowledge of any of the official languages, and work experience) they decided to begin their immigration process. Thus, their positive experiences in Canada, paired with their affinity for the city where they were living, and compared to some of their previous experiences in Mexico, led them to consider that they would obtain more advantages if they stayed than if they returned. Third, except for Griselda, none of these youths had the intention to immigrate to Canada; they had only come to study or work temporarily. Thus, the weight of having put down roots was significant in their immigration decision-making processes. Fourth, they found a favourable configuration of Canada and Quebec's immigration policies, which matched their profiles and intentions to stay, facilitating their immigration. And fifth, gender expectations differently shaped the immigration process of these respondents, since most women faced opposition to or backlash against their immigration by family members, whereas men did not face any negative reactions, reflecting traditional and patriarchal Mexican attitudes.

\subsection{Unexpected Immigration by Marriage and Other Relatives Sponsorship Processes}

Although many Mexicans have immigrated via the economic class, the family class has a slightly higher weight among Mexican immigrants (i.e. $40 \%$ and $41.5 \%$ respectively between 1980 and 2015). Moreover, when we compare the weight proportion of the economic and family classes for the total population of immigrants vis-à-vis that of Mexicans, we notice that the Mexicans' family class weight is higher (41.5\%) than for the general immigrant population (31.2\%), and that the economic class weight is lower among Mexicans than for the general immigrant population ( $40 \%$ vis-à-vis $53.4 \%$ respectively). The proportion of refugees for both groups is quite similar (15\% and 13.4\%) (IRCC 2016b, 2018c). The higher weight of the family class among Mexican immigrants thus points toward the relevance of marriage/partnership sponsorships between Mexicans and Canadians/Québécois(es).

Between 1980 and 2015, 77.5\% of the Mexicans who obtained PR status via the family 
class did so because they married or partnered with a Canadian/Québécois(e), while the remaining $22.5 \%$ consisted of sponsored family members (i.e. children, parents, grandparents, or extended family members) (IRCC 2018c). It is important to consider here that for someone to sponsor a relative from Mexico, the former needs to be either a permanent resident or a Canadian citizen, have enough funds to meet set income guidelines, and agree to provide the sponsored person with financial support for up to 20 years depending on their age and how they are related, among other requirements (IRCC 2018f). The economic demands slightly change for sponsoring spouses, partners, or dependent children, since sponsors are required to provide for the basic needs of the sponsored person (and in some situations even to meet Canada's low-income cutoff) (IRCC 2018i). Thus, although the family institution is central in Mexican culture, family reunification in Canada is strongly regulated by the high economic requirements set up by the Canadian government. This, plus the changing and stringent grandparent sponsorship regulations, partially helps to explain the low percentage of Mexican family sponsorship.

Among Mexican youth sponsored by spouses or partners, it was noticeable that, except for Jimena and Jaime, none had thought about or had had the intention of immigrating if it had not been for their marriage to/ partnership with a Canadian citizen (or their sponsorship by a parent in Erika's case). This also echoes Whittaker's (1988:40) findings among the sponsored-by-marriage Mexicans she interviewed in the late 1980's, since they "did not choose immigration with determined conviction, or Canada as its object." Considerations regarding the acquisition of capital of potential children as immigration motives (i.e. education and life chances in Canada) did not came up among these interviewees. Among these youths, however, two different types of experiences developed depending on where they submitted their application (i.e. Mexico or Canada).

For those who submitted their application from Mexico, a separation of the couple occurred for a period of between a year and three months and two years and a half. Jimena, for example, was 
living in Montreal when she met her now ex-husband. They had already been living together for a while and had a child who was born in Montreal. Since her previous permit was about to expire and they did not have time to marry in Canada and begin the sponsorship process, Jimena went back to Mexico. After five months, her then fiancé went to Mexico to visit her, so they could marry and start the sponsorship process there. From that point forward, the ex-husband travelled back and forth every three months and stayed in Mexico for 15 days per visit (this considering that they had already a child and that they would be expecting a child again in Mexico). "It was a very long, long process" that lasted for two years until Jimena received her PR status.

Gilda, who had come to Ottawa as an international student on a scholarship, returned to Mexico the day after she married her fiancé because her student visa was about to expire. They thus began the sponsorship process from Mexico. However, she was not able to return to Canada while the process was pending because her chances to obtain a tourist visa were minimal due to her lack of funds. Her husband, who "has a good salary when converted to pesos, and a good salary here [in Canada] as well, I mean, like average, but not something that you could say, okay, he's going to be able to come and visit me in Mexico every month, still made the effort to come and see me at least twice a year." Gilda also contemplated the idea of having her husband immigrate to Mexico, so they could be together, but:

he doesn't speak Spanish, he's white, I mean, I'm going to expose him to security issues in Mexico, to be kidnapped or something like that. He's a chef; and working as a chef in Mexico he's not going to make much money, he's not going to make even half of what he's making here [in Canada], and we're going to have problems. Instead, if I go there [to Canada], we aren't going to have [problems], we're going to be much better.

Verónica went through a similar experience: "when we started the relationship, he began looking for a job in Mexico. But then I thought that it was going to be difficult for him... because he didn't study at the university here [in Canada], he studied a course in construction. So, you know that in Mexico construction isn't well paid, it's not even respected. So, I began thinking about all this, and I thought that it would be easier for me to come here.” In Gilda's and Verónica's cases, although 
the option of their Canadian partners immigrating to Mexico was considered, their partners' lack of Spanish knowledge, the potential insecurity that they could attract in Mexico as white foreigners, and their employment backgrounds, which would deliver few economic benefits in Mexico due to the different valuation given to trades, made this option unattractive. Thus, the Canadian partners' total sum of capitals was not enough for them to respond to the particularities of the labour market configuration in Mexico and be able to make ends meet if they immigrated there.

Considering the couple as a unit, the potential loss of economic value if any of the partners immigrated to a new country was minor if the female partner immigrated, meaning Mexican women had more capitals in a transnational field, granting them adaptability, even if other capitals were to be devalued in the short and long term (e.g. education). For example, Verónica had already obtained a bachelor's degree, work experience, and was also in the process of obtaining a certificate in Mexico when she met her Canadian partner. However, after doing some research, Verónica found out that her educational credentials were not going to be recognized in Canada due to her educational background, which meant it was pointless for her to finish her certificate while waiting for the marriage sponsorship resolution.

Since the couple had already determined that it was not viable for him to immigrate to Mexico and she had vacationed in Ontario before, it was easier for her to renew her tourist visa and travel back and forth between Mexico and Canada to stay with her husband. Moreover, despite the fact that her Mexican education was not convertible in the Canadian employment field, Verónica was quite pro-active regarding their financial situation: "I sold my car, everything, I did everything, I sold everything to leave everything in order in Mexico and have a fresh start here, and not being a[n economic] burden for my husband, right? [...] This love proved to be very expensive, ha, ha!" Although Verónica experienced a devaluation of her education after immigrating, she was still better positioned to respond to the various demands of the immigration process (i.e. entry fees) than if her husband had immigrated to Mexico (e.g. language 
improvement, acquiring a different type of education, etc.).

As seen in the abovementioned cases, the separation caused by the sponsorship application from outside Canada forced the couples to elaborate varied strategies to stay together. Thus, depending on their amount of economic capital and personal circumstances, one partner was travelling back and forth to visit the other partner. In the rest of the marriage/partnership sponsorship cases, the application was submitted from Canada. And whilst this strategy simplified things in terms of the couples being able to stay together, in some cases this also created other types of difficulties, particularly when the couple did not have enough economic resources and/or the sponsorship process got complicated.

In Eduardo's case, “it's a well-known story. We met each other travelling [...] and one thing led to another, right? We got pregnant, and then, like after travelling together for six months we decided to come here, no? and try to start a family and have our child. She didn't believe in abortion and me neither, so uh, that's it!" When Eduardo came to Montreal in 2005, immigrating to Canada was easier. He entered as a tourist with a six-month visa, married his partner, and began the application process. Quebec gave him the CSQ in a period of one year, ${ }^{45}$ and then Citizenship and Immigration Canada (CIC $)^{46}$ gave him PR status after a further eight months.

Eduardo, however, had not “even realized that this wasn't... a place where people speak English. [... I I jumped like blindly to the ship, I sailed, and suddenly I saw myself here, and like I said 'shit, they don't even speak English here."' He did not take the francization course immediately: "it took me a year because I arrived and... well... I had to start working, no? As everyone I think, ha, ha. And then, after working and being somewhat stable, my son was born, I had an apartment, ah... my ex-wife was more... relaxed with my son, no?” In César's case, after CIC denied his sponsorship application because they did not accept their partnership proofs, he experienced "fatalism, totally. I said: 'they're going to take me out, deport me, what's going to happen?"' His then partner “told me, 'No, don't worry. We're going to make another petition 
with more proofs as it says there [in the CIC letter]. We had pictures of the girl, everything [...], and I could've done that from Mexico, but I wasn't going to come back here, and I was going to miss my daughter's childhood, so I stayed because of her. And it's hard, winters are hard, right?" César and his then partner thought that the process would take a year, but in fact it took seven years. César was not able to return to Mexico during that time: "I mean, I lost hope." Without access to a work permit until he received a positive resolution, César was forced to work the full gamut of casual jobs, ranging from cleaning to demolition to washing dishes to cooking: "I've gone through everything."

Class location was then relevant not only among sponsored Mexicans but also among Canadian sponsors regarding the way in which the sponsorship process evolved. While César experienced difficulties in his sponsorship application that further complicated his and his family's economic situation once in Montreal, in other cases the difficulties arising from the immigration process were eased by the possession of various capitals. Mauricio, for instance, was living with his girlfriend in Canada (whom he met in South East Asia) under a tourist visa. But despite his upper-middle class location in Mexico and having studied English in the United States and Canada, he was denied his latest tourist and student visa applications (two strategies he used to stay with his Canadian girlfriend). He was forced to return to Mexico, and it was not until his girlfriend sponsored him that he obtained PR status and could be reunited with her.

During the application process, Mauricio also received the support of his father-in-law, since he "knows a guy who works at the [Canadian] embassy, so he helped him to check that our file was... that they were working on it. And then they realized that our file had been sitting there for months, and just because he asked: 'oh!'. Then they took it and began processing it! But we didn't have any idea [that the file was sitting on a desk]." After four months, their sponsorship approval arrived, the overall process taking only ten months. Immediately after his arrival, Mauricio underwent a smooth integration process. He began studying French, and although he 
was studying a bachelor's degree in Mexico, "I wanted to study here in Canada, so once in Canada I applied to and began studying [name of BA program].” During those first days, he also “went to my in-laws' chalet, super cute. My wife taught me how to ski because in New Zealand I was with some Mexicans and we did some snowboarding, but we didn't want to pay for the lessons, so we fell to the ground many times."

Mauricio's case thus contrasts with those of Eduardo and César, the latter who had a premigration working class location. But their cases also differ because although they met Québécoises in Central America or South East Asia, partnered with them, and were later sponsored by them, Mauricio's partner's class location was different than that of Eduardo, César and their respective Québécoises partners. Their pre-migration class locations collaborated in differently shaping their immigration and settlement experiences. This even was reflected on the time it took them to receive their PR status. César's and Eduardo’s partners belong to a Québécoise working class, strongly connected to the summer fruit picking labour market in British Columbia. ${ }^{47}$ Thus, while the sponsorship process was running, these women invited their partners to come and pick fruit with them. César, for example, mentioned how his partner "was an expert. She had done that job to [get money and] travel to Mexico and Central America. She gave me the tip. I mean, [she said] 'the season is coming, let's go to pick cherries, to make some money."'

The immigration processes of Eduardo and César thus seemed to have arisen not only due to the personal relations they had developed in a transnational space (i.e. romantic relationships and/or pregnancies that occurred between these Mexicans and Québécoises while travelling together across Central America), but also because of the confluence of similar class locations. For Bourdieu (1990a), classes are generated by the confluence of cultural affinities, tastes, etc. in a space of power relations that lead to the development of habitūs. Thus, despite coming from different countries, the similarity in the class locations/habitūs between these Mexicans and Québécoises, such as sharing certain Latinité, facilitated their partnering and the Mexicans' 
subsequent sponsorship and immigration. These cases also contrast with that of Jaime, who, coming from an upper-middle class family in Mexico, also met a Québécoise while travelling. However, this woman belonged to a Québécoise middle-class and was vacationing in a trendy touristic Mexican city, frequented by North American immigrants and tourists. They would date and meet intermittently not only in Canada but also around the world (e.g. Africa, Mexico, Central America), facilitated by the type of job she got due to her Canadian education and class location and by Jaime's economic background. His frequent visits to Montreal also opened Jaime's possibility to later meet another Québécoise in Montreal, who eventually married and sponsored him.

Thus, the total sum of capitals that sponsors and sponsored persons possessed shaped the circumstances of how they met their future spouses, how the dating process evolved, the experiences in and length of their partnering sponsorship, and their initial settlement experiences. Whereas César had to wait seven years for his overall sponsorship process to be approved and receive his PR status, thus lacking the opportunity to visit his family in Mexico or even be able to legally work in Montreal, Mauricio only had to wait for ten months to obtain his PR status, was immediately able to begin studying not only French but also study for a bachelor's degree, and was also immersed in Canadian, middle-class leisure activities, such as vacationing in cabins and practicing winter sports. Moreover, in Mauricio’s immigration process, economic capital was not the only relevant capital, but also his extended social capital. Namely, the social capital that his father-in-law has in the Canadian government field. This capital proved quite useful for the young couple to find out about the state of their sponsorship application and, allegedly, to push it forward. These cases then, illustrate the complex ways in which class locations and the total amount of capitals of both the Canadian and Québécois(es) sponsors and sponsored Mexicans intersect to shape their immigration experiences.

\subsubsection{Effect of Gender in Immigration Sponsorship Processes}


The experiences of my sponsored-through-marriage/partnership respondents also revealed three other facets of the process directly related to gender: first, the sponsorship by marriage processes altered young women's family social relationships based in Mexico. Second, the reasons for which a female participant decided to partner with a Canadian man also constituted a rejection of Mexican patriarchal attitudes. And third, the relationships between Mexican women and Canadian/Québécois men were negatively understood by some Canadians. As mentioned before, Gilda and her then boyfriend got married in Ottawa a day before she had to return to Mexico. Only his close family members were present at the civil ceremony because Gilda did not tell her family in Mexico that she was getting married. Rather, she decided to proceed cautiously. When Gilda returned to Mexico and told her mother that she had a boyfriend she met in Ottawa while studying and that he had proposed, "she almost had a heart attack. She didn't take it well. On the contrary, it was like... What?? I mean, to be honest, it was really, really difficult. I thought she would be happy, but she wasn't at all, nobody in my family was."

Since Gilda's (secret) husband would be visiting her in Mexico every six months until she got her PR status, Gilda told her mother that the wedding plans were still ongoing and that her boyfriend was coming to Mexico to meet her and her other siblings. Her family "met him, they liked him and, just imagine, I mean, he's like blond, blue eyes, so my mom liked him [...] but not [like a lot.] Okay, [she said,] you're leaving [home,] but not with a nobody." When Gilda received her PR status, her mom told her that for her to leave home and go to Canada, she needed to be married. Thus, Gilda agreed to 'marry' her (secret) husband in Mexico to appease her mom, but after they got married and she was about to move to Canada, "it was kind of traumatic for my family, the fact that, yes, I'm leaving with him. [...] I had saved some money and I came [to Canada] and well... my family got very angry with me, they stop talking to me for a while."

Even before this, however, Gilda's decision to marry her Canadian boyfriend was not an easy one. First, Gilda had come to Canada as an sponsored international student for a year and was 
not planning to stay. Second, after the boyfriend asked her to stay with him rather than going back to Mexico, Gilda told him, 'I don't have the means to stay here. And if I stay it's illegal, so... [it's not an option]. And he said, 'okay, you know what?' And it came from him, it was not even my idea. He told me, 'Marry me and you can stay here.' And I was like, 'This is quite surrealist. This is much like a Mexican soap opera.' Yep, he proposed at the sixth-month of the relationship." And third, Gilda "was really nervous to be honest because [...] he's a white Canadian, it's a different culture in relation to one's [culture], I mean, I'm not really part of the country. [His parents] might think that I just came to look for someone, marry him, and stay here, which is like the popular belief [in Canada], so I had like my concerns." Verónica also encountered this 'popular Canadian belief.' She mentioned how “it bothers me so much the ignorance of many people, people who think that, for instance, I met my husband through the Internet and that I came [to Canada] just like that, without knowing him. Things like that. They don’t even know! A lot of people think like that. What they don't know is that if it weren't because of my husband, I wouldn't even be here."

The idea of 'abusive' to-be-immigrants looking to obtain Canadian permanent residence via marriage is not new. The notion of marriage fraud became generalized in North America since at least the 1990s (Medina 1997). This was fostered by the idea that countries such as the United States and Canada were 'rightfully' seen as magnets by to-be-immigrants, who were eager to move from a so-called 'third world' to a 'first world' country. Scholars of marriage migration, however, have noted how the legal framework that was established around transnational marriages in North America (i.e. marriages in which the partners have different nationalities), has been marked by political ideologies where immigrant women became legal subjects (Wang 2013). That is, "an invention of law that defines the subject of fraud as one who desires citizenship rather than the 'bona fide' love of a citizen spouse” (1224). In both the legal framework and the sponsorship marriage process, generated by a "heteronormative white subject against fraud," "[i]mmigrant women are innocent of fraud only if they can match their love to that 
of their spouse and deny any articulation of self-love." That is, if they "can prove an absence of desire for citizenship or legal status" $(1224,1249-1250)$, something difficult to do.

However, once the immigrant partners have successfully crossed the high standards of marriage sponsorship policy in Canada, some must face a second scrutiny process by a more diffuse public opinion, which doubts the veracity of their love and by extension their marriage or partnership. In this interpretation, women are seen as PR status seekers, looking to acquire Canadian capital, rather than people who fell in love and/or decided to marry/establish a partnership in a transnational field. In this understanding, what separates immigrant from nonimmigrant women is their citizenship status. And Canadian underlying notions of national superiority (i.e. Canada is posited as an attractive and desirable first world country) and Manichean discourses of development/underdevelopment, innocence/malice, and generosity/abuse.

Regarding the decision of dating/partnering with a Canadian man, Gilda mentioned how her experiences with patriarchy in Mexico collaborate in her marrying her Canadian boyfriend:

because in all the relationships I had in Mexico, always, always they ended up with the same pattern, which was, well... they were jealous, and in fact, in one of the latest relationships I had, it almost ended like violently because he tried to hit me. [...] So, I was left with a very bad experience of machismo, of how things are in Mexico. My older brother, the same thing. I mean, I still live this and it's horrible. In his case, when he finished high school, they [Gilda's parents] gave him driving lessons as a present, and my mom bought him a car, so he could drive to the university. I finished high school and I didn't get the driving lessons, much less a car. [...] When the opportunity arose, they bought my brother an apartment, and I was already working. When I came here, nobody helped me with a peso, [...] [but] they've paid all his debts in banks, services, and departmental stores. He's going to get married in December, oh, okay, they're gonna pay him his honeymoon. We didn't have a honeymoon [...] So, I have that feeling that there's always been that preference towards him for being a man.

Even though her father died 15 years ago, Gilda's family relationships were strongly marked by a patriarchal dynamic to the point that this constituted one of the reasons for Gilda's decision to date and marry a Canadian man, i.e. to avoid discriminatory and sexist circumstances. Still, when Gilda accepted to marry her Canadian husband in Mexico on the request of her mother (and the 
boyfriend accepted to do so), Gilda's family severed relations with her after she departed for Canada. This seemed to have occurred because by leaving the house, Gilda broke the family's rules of the game, or her family subjection, and thus threatened the household's balance of power.

Artemisa's unexpected decision to marry a Canadian had a different effect on her mother and sisters. Artemisa's original plan was to go and work in Alberta for one year only. However, since she had delayed her return to Mexico because she had met and decided to marry her boyfriend:

talking to her I said, 'Well, it's just that [name of boyfriend] wants to marry me,' and my mom was like, 'All right.' Because my mom 'knew' him already [since] I had talked to her about him, and I don't know, I guess it's the way in which you talk about the other person that you can see that that person is good for your daughter. Well, that your daughter feels good with that person. So, my mom was really nice in that respect because she listened to me and she knew that I was taking the right decision, I guess.

The families' initial reactions, and the way in which their social relations were altered after my female respondents announced that they were marrying a Canadian, were thus determined by each family's particular configuration in terms of class location, ideological orientation (i.e. a more conservative or progressive stance), and understanding of gender roles. It was noticeable that these young women, using their agency, both decided to stay in Canada and not break their connections to their families in Mexico. In doing so, they had to negotiate their gendered locations in a transnational field and deploy various strategies. This allowed them to maintain those relationships, even if fraught with conflict at times. At the same time, they also pursued their own lives in Canada and faced new challenges due to their Othering as sponsored women.

Moreover, the way in which some sponsored women were treated by their families in Mexico clearly contrasted with the ways in which the sponsored men were treated, signalling a gender division dictated by patriarchal values. Eduardo, for instance, who comes from a workingclass background, mentioned that he is:

literally the representative of masculinity in my family because I had two sons, no? And my two sisters, they had daughters; I had sons. And I don't know, for my family I think it 
was a shock that... this side of masculinity was a fruit that fell far away, right? Especially for my mom, and well she doesn't say anything because well... she respects my pathway and she's proud of the fact that I decided to stay with my children [in Canada] rather than staying with her. But I can see that it's a heavy weight on her shoulders, no? Like seeing that I went far away, and, like, she has never verbalized this, right?

Eduardo identified his masculinity and gender location—relative to his family in Mexicoaligned to patriarchal values, based on his perception of his mother's undeclared expectations and his own upbringing. He would later turn his personal understanding of masculinity and gender into a more progressive understanding due to his lived experience in Montreal.

Eduardo's notion of masculinity, explained with the metaphorical use of "a fruit that fell far away," reveals the underlying value that masculinity represents in traditional Mexican, patriarchal families, where the reproduction of the family (i.e. the tree) is dependant on the seeds (or semen in Latin) of the male figure (i.e. the fruit). In his metaphor, it is not his two sisters and their daughters who are expected to carry on with the family name and/or values of the family (i.e. its symbolic capital or symbolic power), but rather Eduardo as the male figure. Eduardo's emigration, then, changed his family's rules of the game in terms of its social reproduction, displacing “far away” as a so-considered essential component of this process (i.e. his masculinity, the seed, the semen). Since in this type of configuration "the masculine principle is posited as the measure of all things" (Bourdieu 2001:14), the "fruit that felt far away" symbolically disempowered Eduardo's family in their field.

Moreover, the silent burden that his mother carries on her shoulders unveils the way in which this particular understanding of masculinity is extrapolated to a transnational field. Under this patriarchal construction, it is the duty of the male partner to provide for the family and remain as the center of the household, financially taking care of the dependent children, wife, and in some cases other extended family members, such as the mother and/or other siblings. But since Eduardo precisely did this when he opted to immigrate to Canada with his Québécoise pregnant partner, the mother is forced to 'proudly' accept this complex situation. This is because he is, indeed, fulfilling the social expectations placed onto him as a 'man,' even if in a distant land, and 
even if physically distancing himself from his other family and thus restricting the latter's possibilities of social and symbolic reproduction, as expected by their field's configuration. Although the potential loss of economic support from the mother due to the son's departure was not mentioned in the interview. Eduardo's sending of monetary remittances after immigration has not lessened the mother's emotional and symbolic experience of loss.

In the case of Gabriel, who comes from an upper middle-class family, his immigration was not seen as disruptive to the family's cohesion. This was because his parents were divorced and his father "was never too present in the relationship." His father always said: "“You have to travel! 'You have to travel!' Like they [i.e. parents] really got into our heads that message, and now my brother lives in [European country] and my sister in [Mexican city], and I'm here [in Ottawa]. [...] Like there's other people who are like, 'No, we're family, we have to stay here [in Mexico]." In fact, because Gabriel, like his brother, independently moved to Mexico City when he was 17 or 18 years of age, the children's immigration was not seen as a novelty by the parents. For Mauricio, his family's reaction evolved over time. Although he was sent by his parents to the United States and Canada to study English as a teenager, when he wanted to go to New Zealand at age 18 , they refused to pay for this trip, so he worked and paid the expenses for himself. Once in New Zealand, he got a European girlfriend and "my mom noticed. I told my dad not to tell her, but my dad did so anyway. And he told her that I was going to travel with her across South East Asia, so she got mad: 'how's it possible? You're going to travel with a girlfriend! I expected this from everyone except you. Is this the way I've educated you?' Pure drama. She wasn't sleeping for days [because of this]." His parents, being conservative Catholics, disapproved of what they understood as Mauricio's alleged moral licentiousness. The mother assumed that dating and travelling with a girlfriend would imply sexual activity between them, something that contradicted, for them, the expected moral behaviour of a young and unmarried person, regardless of gender. 
Thus, whilst Eduardo's immigration process constituted the loss of symbolic capital for his working-class family, irrespective of his previous travelling around Mexico, dating, or sexual life (i.e. an alleged exercise of his masculinity), in Mauricio's case the infringement of the family's moral code, derived from a conservative, Mexican upper-middle class position, threatened not only the social symbolic capital that the family had acquired by observing, precisely, those conservative moral codes (i.e. honour), but also the social capital that they had generated among their social circle. For example, having a teenaged son who is travelling around the world with a girlfriend, breaking various class-specific moral codes and norms, reflects 'badly' on the family and questions their adherence to the habitūs of their field.

In fact, the threat of breaking habitus among some Mexican families (habitūs that vary in terms of their constitutive elements across classes), is synthesized in the saying 'iqué va a decir la gente?'/ 'What will people say?' signalling the symbolic power that moral codes and norms as expressions and regulators of class, gender, race/ethnicity, sexuality, religion, and ideology have in Mexican culture. As Wacquant (2018:10) asserts regarding Bourdieusian theory, the diversification of capitals and their grade of objectification can exist in a practical state as [social] mechanisms or they can be codified under the guise of norms and explicit rules. By the time Mauricio was dating his Canadian girlfriend (five years after the New Zealand incident), his parents, however, had changed to the point that Mauricio's girlfriend visited him in Mexico and stayed at his parents' house, even before they decided to remain in a long-term relationship.

Gender, class location, and ideology then, played a significant role regarding the ways in which some of the Mexican youths' sponsorship processes were understood by their family members and, correspondingly, shaped their social relationships in Mexico. It was also noticeable that these factors particularly affected the experiences of young women, who were compelled to elaborate varied strategies to navigate at least three different fields in their new transnational space: first, that of their families in Mexico; second, that of their new partnerships in Canada, 
which included not only their relationships with the Canadian or Québécois partner, but also with the latter's families, and third, that of their new social location in Canada's gender/immigration field. Here, women are additionally subjected to scrutiny over their 'real' reasons to immigrate, implying that, as immigrant women, they have pursued a marriage for convenience rather than a genuine relationship. In contrast, Mexican men—irrespective of their class location— did not have to establish any kind of strategy for their families in Mexico to accept their relationships with their Canadian/Québécoise partners, even if, as in Eduardo’s case, the partnership and corresponding immigration process changed the local, family fields.

\subsubsection{Other Reasons to Immigrate}

There are four other cases, those of Erika, Román, Nadia, and Norma that do not easily fit into the categories consistent with most of my respondents' reasons for immigrating, and which are reflected in the type of programs they used to immigrate. One of Erika's parents was already living in Canada and thus she had frequently come to visit during various summers. Once Erika finished high school in Mexico, "I was struggling to decide... like to choose what I wanted to study at the university." She studied for a year at a university in Mexico and "then, I came [to Canada] for a year" to keep studying English, to be able to decide what subject to study, and then return to Mexico. "And then when I came here, I met a lot of people, and thus I decided to apply to the university [here].” Her mother told her, “'Why don't you stay?' Even if you decide to go back to Mexico it's a good experience having studied English and... like have... foreign credentials" (i.e. acquiring symbolic capital). Thus, Erika stayed and was later sponsored as a family member.

Román's mother passed away when he was six or seven years of age. She had moved to Mexico as a refugee, escaping religious violence she experienced in her country of origin, and would meet Román's father later, on a missionary trip to the Caribbean. Román’s parents moved to Mexico, but after his mother passed, the father disappeared. Román's maternal uncle took 
charge of him, and since Román's mother had always told him that if anything happened to her, he needed to go to her sisters who were living in the United States, Román asked his uncle to send him to his aunts. The uncle tried to send him to the United States, but:

I guess the United States thought it was fishy, so they didn't let me into the States, so rather I had another aunt in Canada and moved to Canada to hopefully be able to get... to the States from Canada. Then, when I got here and we tried to get me into the States and it still doesn't work... I decided to stay here. Like... I ask them 'can I just stay here instead of trying to go to the States? They clearly don't want me.'

Román was now eight years old and his aunt agreed to adopt him. "The first two years were really, really frustrating. Even up until I got here at eight years old, until like 15... I was like, very clearly an outsider.”

Norma initially came to Canada to work for a year in a specialized area and then returned to Mexico. Half a year later, she returned as an international student, but near the end of her stay Norma suffered a serious accident, for which she had to spend a considerable amount of time at a hospital and then on medical follow-ups. Due to the particularities of the accident, Norma was granted a stay under compassionate grounds under special considerations by CIC. In Nadia's case, her European/Canadian father met her Mexican mother while he was vacationing in Mexico, and soon took her to Toronto, married, and sponsored her. Nadia's mother got pregnant, and looking to stay closer to her family, they moved back to Mexico, where Nadia was born. The father had a hard time finding a job in Mexico, and the family moved back to Canada a year later, registering Nadia as a Canadian citizen. Since his family “didn't like too much my mom because she was Mexican,” they moved to a different city. After five years, the family went back to Mexico again and Nadia's father opened a small business along with a maternal uncle, but two years later they again returned to Canada. A couple of years later Nadia's parents divorced, and her mother sent Nadia to Mexico while the mother took care of her other two children. After a year and a half, Nadia returned to Canada and has mainly been here since, although she has also spent a few summers in Mexico.

Overall, marriage/partner sponsorship by a Canadian/Québécois(e) was an important 
immigration pathway for some Mexican youth, even if many did not initially intend to immigrate. This process forced some of the couples to undergo physical separation and consequently deploy varied strategies, based on their total sum of capitals, to tackle this separation. My respondents' cases also revealed that the interaction between Canada's family immigration policies and determination processes (see Satzewich 2015) and my participants and their partners' circumstances (i.e. their pre-migration class locations and their possession of varied capitals in a transnational field, such as social capital) led them to either experience a speedy sponsorship process or a lengthy one.

I also found that some of the partnerships between Mexicans and Québécoises were reflective of similar locations in the field of power relations (i.e. classes). As Grenfell (2008) describes when addressing Bourdieu's understanding of formation of classes, individuals who share similar positions in social space will tend to generate a degree of personal proximity. Similarly, because of their social location, they "are inclined to develop similar lifestyles, outlooks, dispositions and a tacit sense of their place in the world or 'class consciousness'; that is, class habitus" (93; italics in the original). My interviewees' partnerships, then, were not only characterized by romantic love, but also by shared habitūs, even if they belonged to geographically separated fields, denoting the production and embodiment of some transnational fields.

In addition, in this immigration sub-set, gender appeared as relevant in terms of the ways in which traditional and/or patriarchal attitudes, mediated by class location and ideology, were deployed by family members in Mexico to control women's movement or support men's immigration. In Canada, gender was relevant in the way in which immigrant women were Othered due to their sponsored condition. The four other separate cases of family sponsorship indicate the varied profiles of Mexicans immigrating to Canada and the complexities that their pre-migration class locations generate. 


\subsection{Discussion: Mexican Youth's Micro-Level Reasons for Immigration to Canada}

The presence of Mexican immigrant and refugee youth in Canada responded to multifaceted factors that accounted for their immigration at the individual and collective levels (the latter in the case of family immigration). Although previous research has shown that the configuration of Canada's immigration and refugee policies established since the 1970s has favoured an economic type of immigration, little attention has been paid to the ways in which these programs have stratified Latin American immigrants - and Mexicans in particular - by premigration class location. Here, I have shown how the favouring of an economic type of immigration as a central immigration policy has positively attracted some Mexicans who belonged to a medium to upper pre-migration social class.

Nonetheless, the prevalence of the economic class as an entry point for Mexican immigrants to Canada has led some people to believe that Mexicans comprise a homogeneous group of middle-class and educated immigrants. My research revealed, on the contrary, a more nuanced and complex variability in the profiles of Mexicans shaped by at least four factors. One factor refers to the effect of Mexicans' varied pre-migration contexts in their migration decision processes. This is mediated by gender, age, sexuality, and possession and/or distribution of various capitals at the individual and/or family level. A second factor refers to the circumstances under which they immigrated (i.e. purposeful and planned economic immigration, refugee claim, unexpected marriage or family sponsorship, or transition from an international student status to PR).

Third, these factors are further shaped by the effects of Canada's (and Quebec's) immigration policies, programs, and processes and by the immigrants and refugees' integration experiences once in Canada. Moreover, since various capitals such as education are differentially distributed by gender and age among family members even before immigrating (this in the case of family economic immigration), intra-familial disparities in terms of possession of capitals are created. A fourth factor is the devaluation of Mexicans' various pre-migration capitals after arrival and their general lack of social and Canadian capitals. This has pushed some youths towards a downward economic pathway, 
forcing them to undergo a social invisibilization process (see chapter 9). This latter process contrasts with the experiences of other Mexicans who, due to their favourable pre- and post-migration class locations, are able to be more socially visible (see chapter 7). A fifth factor, that of the effect of transnational economic fields, will be analyzed in the next chapter.

Regarding my economic class respondents, I found five reasons or circumstances that led them to immigrate to Canada. The most important reason was the improvement of their life conditions, even if this was not economic in principle. Other reasons were to maintain social relations already established in Canada, obtaining Canadian institutionalized cultural capital, avoid certain local issues embedded in the Mexican culture such as corruption, nepotism, and/or homophobia, and/or the growing violence in Mexico. However, it was these immigrants' premigration class location, including economic capital, which allowed them to fit into Canada's immigration policy_ particularly the economic class — and be able to immigrate in the first place. Nonetheless, the possession of capitals is, in some cases, not enough to immigrate. Possession of economic and Canadian capital (in the form of education and work experience) is not enough to apply to any recent economic immigration program if the immigrant does not have the entry fees requested by Canada's immigration field, such as work experience.

This case thus reveals the complexity of Canada's economic immigration policies, since, on the one hand, Canada demands the possession of various types of capitals and high requirements for someone to be able to immigrate, even for those who came as international students. On the other hand, the structuration of the immigration programs does not easily facilitate the status transition from international student to permanent resident if the applicant does not obtain a job with certain requirements in an already challenging Canadian labour market. What may seem contradictory, i.e., an immigration system that seeks international students as perfect PR candidates but subsequently closes its doors on them, reveals rather an immigration stratification process mediated by what Bourdieu called entry fees. Considering that the Canadian 
labour market is saturated or depressed in certain areas but burgeoning in others, and that selfsufficiency has been a Canadian immigration imperative since the $19^{\text {th }}$ century (HernándezRamírez 2019), the requirement that international students have at least one-year of specialized Canadian work experience ensures that only those seen as providing already tangible economic benefits can stay.

The requirement of varied entry fees among institutional actors such as provinces, territories, and the federal government also speaks to political competition regarding the attraction and retention of the 'ideal' immigrant. In this field, Quebec has played a significant role since, as part of its political strategy to reposition itself in sub-national, cultural, and identity terms vis-à-vis Anglo Canada, has facilitated the immigration of those who already speak French and have Québécoise education. Quebec's reduced entry fees, however, come with strings attached, since it requires that prospective immigrants develop a feeling of belonging to Quebec society under an intercultural framework, that is, allegiance to the Quebec sub-nation.

Putting down roots in Canada among those who had already come as international students constituted a second prevalent reason to immigrate. Here, putting down roots meant having significant others and close friendships, as well as having a wider appreciation for the Canadian or Montreal lifestyle when compared to the youths' experiences in Mexico. It is important to note that most of the youths in this category did not have the intention to immigrate when they came as international students, but the abovementioned reasons, plus a favourable configuration of the Canadian or Quebec immigration systems and their 'right' fit (i.e. a sufficient sum of capitals), persuaded them to stay. In addition, gender strongly shaped the immigration processes of my female participants in this sub-sample. Other Mexican youth made use of the family class to immigrate even if most had never thought of immigrating before. Even in these cases, however, the shifting configuration of immigration policies at federal and provincial levels shaped the possibilities and experiences of these youth, stratifying them by pre-migration class location as 
part of broader Canadian institutional and political processes.

Overall, among my economic respondents, their pre-migration contexts and capitals positively aligned with Canada's/Quebec's immigration systems, allowing them to immigrate. For those who came via family migration, different pre-migration class locations generated variation in how easily they navigated their sponsorship process. And for all Mexican youth, their class location, age, gender, and sexuality, as well as particular reasons to immigrate, strongly determined how they experienced their immigration processes. The various profiles and immigration cases of Mexican youth I presented, then, show the relevance of understanding migration at diverse scales and fields, as well as considering how the different distribution of capitals and class location before migrating shape the migration experience. In the following chapter, I address the macro-structural factors that, along with their pre-migration class locations, led other young Mexicans to immigrate, including those who came as refugees. 


\section{Chapter 6: Mexican Youth's Macro-Level Motivations for Immigration}

In chapter 5, I analyzed the pre-migration circumstances and micro-level reasons that led some Mexican youth to immigrate to Canada, both in the economic and family classes. Central to these contexts, processes, and decisions was their pre-migration class location, which functioned as a springboard for them to be able to migrate and obtain PR status. Other important aspects shaping their migratory experiences were age, gender, and sexuality, as well as Canada and Quebec's immigration policies. These operate as part of broader institutional and political fields where certain economic immigrants are sought after under economic terms. In this chapter, I focus on the extent to which broader politico-economic factors and transnational fields across North America (and increasingly expanding to Central America) motivated and shaped Mexican youths' decisions (or their families) to immigrate to Canada. Analyzing the interaction between structured and structuring transnational fields and my participants' pre-migration social locations will assist us in producing a nuanced understanding of how Mexican youth negotiated their location in macro-structures that derived from their decisions to immigrate to Canada (i.e. agency). Moreover, analyzing how immigrants navigate and negotiate these broader social processes will also offer us the possibility of better understanding how conditions of exit and reception impact their subsequent economic integration, and whether and how this generates transnational practices.

The chapter is divided into four sections. In the first section, I show how pre-existing broader, transnational economic connections between Canada and Mexico operate as push and pull factors for some Mexican youth to immigrate. In the second section, I analyze how the expansion of Canadian capital to Mexico and the decisive support of the Canadian state to Canadian companies led other youths to immigrate under the refugee and humanitarian system. In the third section, I analyze how other macro-economic and transnational dynamics, manifesting in processes of unemployment and economic crises across the Latin American region, and particularly in Mexico, operated as push factors for some Mexican youths' parents to 
immigrate through the economic class. The final section, informed by Bourdieusian theory, presents an analysis of how youths' pre-migration class locations, along with broader macrostructural processes, led them to immigrate or claim asylum in Canada rather than in another country, such as the United States.

\subsection{Mexico-Canada Transnational Connections and Their Effect on Immigration}

The immigration decisions of my economic class respondents (or their parents) were also framed in the broader context of the Mexico-Canada relationship. This relationship, as explained in chapter 3, has historically been characterized as on-again-and-off-again, usually limiting the creation and development of transnational connections and, consequently, contributing to a limited presence of Mexicans in Canada and Canadians in Mexico. However, I found that transnational connections are increasing between Mexico and Canada at a macro-level due to increased direct foreign investment and commercial ventures between both countries, even if at a slow pace. This, in turn, is fostering the temporal migration of skilled Mexicans, who can later apply for permanent migration (e.g. via the Canadian Experience Class or marriage sponsorship). These possibilities are mediated, however, by the configuration of Canada's federal and provincial economies and the type of relationships these establish with Mexico.

Since Ontario and Quebec are the main export provinces to Mexico, the probabilities for Mexicans to establish transnational connections there and create social capital with Canadians via trade, commerce, and labour market relations are higher than in the rest of Canada. For example, Ontario exported 3.7 billion worth or $48.2 \%$ of Canada's exports to Mexico in 2016 (an increase from $\$ 3$ billion in 2015), and Quebec exported 1.7 billion or $22.7 \%$ of Canada's exports (an increase from $\$ 1.3$ billion in 2015). As a point of comparison, Alberta, exported 944 million or $12.3 \%$ of Canada's exports, a decrease from $\$ 15.3$ billion in 2015 (Gowans 2016, 2017). Active trade sectors between Mexico and Canada also determine the areas in which some Mexicans, whose professional or technical backgrounds respond or relate to those trade and commerce 
areas, might establish transnational contacts and develop social capital in Canada.

For example, since 2012, Canada has been exporting mainly resource-based and manufactured goods such as motor vehicle parts, machinery and equipment, and oilseeds to Mexico. And Mexico has been exporting motor vehicles and goods-transporting trucks and vehicles, electronics, and machinery and equipment to Canada. Thus, industrial sectors that revolve around the multifaceted North American car industry are opening economic transnational fields between both countries and corresponding possibilities of transnational employment (e.g. the hiring of employees who need to work in Mexico and/or Canada and who constantly travel back and forth between the two countries to do their operations). Given that Ontario and Quebec are the two larger provincial economies with two of the largest cities in Canada, these provinces function as strong employment/labour magnets, and also have attracted the largest number of Mexican immigrants and refugees. For instance, between 1980 and 2015, Ontario attracted 23,335 Mexican immigrants and Quebec 19,720, whilst British Columbia attracted 11,035, and Alberta 8,460 (as per their declared intended destination at landing) (IRCC 2018c). A similar process has recently developed with the de-nationalization of Mexico's energy sector (2013-2014) and the active interest of Alberta's oil and gas sectors to do business or expanding their operations to Mexico (Harlow 2016; Hussain 2014; see v.gr. The Canadian Council for the Americas, Alberta 2019), as well as projects focused on the commercialization of technology (McCuaig-Boyd [Alberta Minister of Energy] 2017). This, in turn, has also generated a certain demand of skilled Mexicans with legal, administrative, or technical knowledge in oil and gas production, who may facilitate the expansion of Canadian capital in the extractive and technological industry sectors in Mexico.

Although the tourism industry is not prone to open economic spaces where transnational labour is required, it nonetheless has opened a transnational field of interpersonal relations. Since many Canadians go on vacation to Mexico, the probabilities of Canadians meeting, dating, and partnering with Mexicans (and potentially sponsoring them) are higher than for Mexicans 
meeting Canadians/Québécois(es) in Canada. In 2017, for instance, 1.92 million Canadians visited Mexico (Notimex 2018), but only 366,639 Mexicans visited Canada (Statistics Canada 2018d). In addition, data from the Canada Border Services Agency (CBSA) indicates that between January 2012 and January 2017, 5,291 Mexicans were turned back from the Canadian border, with their numbers increasing after May 2015, seven months before the Liberals arrived to power (Stargardter, Díaz, and Paperny 2017).

The probabilities for Canadians meeting Mexicans slightly increase if we consider that some Canadians have (im)migrated to Mexico. Available data signals that between January 2009 and September 2018, 16,549 Canadians were granted temporary residence permits (called FM3 visas), which allow them to stay between six months and less than four years, and 14,046 Canadians were granted permanent residence (called FM2 permits) (SEGOB 2017, 2019). ${ }^{48}$ As a snapshot, in 2009, 10,869 Canadians were living in Mexico, 30\% of whom did so for workrelated reasons, $44.3 \%$ were pensioners, $2.4 \%$ were students (i.e. 257 persons), and $23.3 \%$ belonged to other categories (Rodríguez Chávez and Cobo 2012). ${ }^{49}$

Because of the economic transnational fields opened by the increased trade and Foreign Direct Investment (FDI) between Canada and Mexico, some of the Mexican youth or their parents were able to establish transnational social connections even before immigrating, since they worked for or dealt with Canadians in Mexico. These transnational relationships facilitated their subsequent immigration, since their generated social capital made it possible for Mexicans, for example, to obtain a job in Ontario or a recommendation letter from a Canadian employer (i.e. Canadian capital). For instance, Orlando's father "lost his job precisely the same year that we came to Canada, and he was lucky that he got a job with a Canadian company. He had clients in Canada when he was working in Mexico, so he befriended them, $[\ldots]$ and once the opportunity [to immigrate] arose, well he took it without thinking twice about it."

When Myrna's father was looking to immigrate to the United States or Canada, he began 
working for a Canadian automotive company. He was the Canadian contact with manufacturing plants in Mexico. “And the more he came the more he liked it here.” Myrna’s father was also worried about the automotive industry declining in Mexico and how this could affect him. Thus, after Myrna's father applied for and obtained PR status for him and his family through the FSWP, he told his Canadian employers "that he had gotten his PR [status] and was bringing his family to Canada. And the Canadian company told him 'OK, but we don't have a job for you here. You were useful for us in Mexico, with our customers there, but we don't have a position for you here."' They offered him good references, instead. The father quit his job, the family immigrated, and with those references in hand he began looking for a job in the Tri-Cities region (i.e. Kitchener, Waterloo, and Cambridge in Ontario), and immediately found one.

Social networks and social capital between Mexican immigrants in Canada and family members or friends in Mexico were also important to foster and facilitate immigration and settlement processes. Social capital greatly facilitated the access of some youths' parents to certain Canadian fields. The access to these fields was possible because the Mexican contacts were already well positioned in some Canadian fields and thus able to provide my respondents' parents with valuable advice or endorsements (i.e. Canadian social capital). Andrea's mother, for example, came to Canada invited by her brother — who had been living in Canada for 30-plus years - to work making use of the TFWP. "The conversation about him retiring came out, that they had a [type of business] in Ottawa... they [i.e. the uncle and his wife] wanted to retire and wanted my mom to be the coordinator. So, this is how the idea of moving to Canada came out." When Alberto's parents decided to immigrate, they chose to move to Ottawa because "my mom had a friend who was living here in Ottawa, and my mom was also doing some research about schools we could attend, and she read in various places that [name of high school] was quite good, and she said, "I think that school in Ottawa is very good."'

Cumulative causation theory signals that social capital is one of the main factors that 
promote migration (Massey 1990). However, I found that social capital is insufficient when we consider its relation to broader social structures and processes, such as the behaviour and segmentation of local and transnational labour markets, and the specific location of players in those fields. Myrna's father, for example, "had been looking to immigrate to the United States [using his contacts] [...], but in the United States he was definitively told "no!"' since there were no positions available to him. Moreover, for someone to transform social capital into Canadian national capital in favour of a player on the other side of the transnational field (e.g. someone in Mexico), the holder of social capital (e.g. someone in Canada) needs to be located in a certain position of power in their local field. If that person does not have the power, for instance, to write recommendation letters for a (prospective) Mexican immigrant looking for a job, the social capital existing between both parties may not produce the desired results. Thus, the amount of power possessed by an agent in any given field shapes the potential of social capital for this to be effective in that field.

In addition, for social capital to be successfully used in obtaining a job in a transnational field (which would offer the possibility of later immigrating to Canada, for example), the state of the labour market needs to be attuned or receptive to the capitals the person has, such as cultural capital (i.e. education and knowledge of official languages), work experience, and economic capital. Because of the high-level requirements needed for social capital to be successfully converted into advantages in a transnational field, pre-migration class location turns out to be highly relevant for immigration to Canada. That is to say, access to the transnational fields being opened by trade and commerce between Mexico and Canada are limited to those few who are already in possession of various capitals and can easily respond to the demands of mobile capital. However, if certain Canadian labour markets are constrained or not propitious to the (prospective) immigrant's total sum of capitals at certain point in time, their immigration possibilities will also diminish accordingly, irrespective of their pre-migration class location. 
For a Mexican person to be able to access a transnational space connected to Canada, where social capital can be created, that person needs, first, to have a minimum amount of economic capital to pay for the acquisition of cultural capital, which would allow them to access specialized employment fields. Second, the possession of cultural capital (granted by the previous possession of economic capital), might also grant them knowledge of and possibilities to access other (potential) transnational employment fields. Karina's husband, for instance, was unexpectedly offered a job transfer from Mexico to Montreal by a Montreal-based, transnational printing and publishing company. In fact, it was not only Karina's husband who was offered to relocate, but his full administrative department in Mexico. Initially, these employees had acquired the education and experience necessary in their field to be employed by this Canadian company in Mexico. When the company considered that a propitious Canadian migration policy, which allowed for the import of temporary and perhaps cheaper Mexican labour and expertise, offered cost reductions that might increase its profits, it offered its Mexican employees the opportunity to migrate via the TFWP. Once in Canada, Karina and her husband learned about Canada's immigration programs and, after one year of Karina's qualified employment, she applied for and obtained PR status for her and her husband.

This case also signals how the broader confluence of transnational economic processes (i.e. the expansion and accumulation of capital in a transnational and/or global fashion) can also open spaces for the movement of skilled, although sometimes temporary, transnational labour, where the use of social capital is not necessary to migrate. At the same time, however, the company's need for some Mexican employees to temporarily work in Canada created a small niche of potential networks and social capital that now linked these Mexican employees living in Montreal with their family members and friends in Mexico. The restructuration of transnational labour to increase profits thus opened new immigration possibilities for a broader group of people via the potential generation of social capital. As Massey et al. (1987) found among Mexicans in the 
United States in what Gunnar Myrdal had initially called circular and cumulative causation (Massey 1990), a constant stream of immigration might reduce migration costs over time, create social capital among people, raise the probabilities of immigration, and alter the context in which future decisions to immigrate are made (i.e. this immigration might modify the cultural perception about immigration to Canada in Mexico). The potential cumulative causation effect that Mexican immigrants generate in Canada is heretofore unknown, since cumulative causation does not equally contribute to all migration streams, and its principal generative mechanisms might not (equally) function in large urban settings as it does in rural milieus (Fussell 2010; Fussell and Massey 2004).

The possession of transnational connections (i.e. social capital), paired with (and resulting from) the pre-migration class location of some Mexican youth, also allowed them to have diverse immigration options at their disposal. For example, eight youths had the option of immigrating to Australia, Europe, the United States or Canada. They chose Canada for reasons such as, first, greater proximity to Mexico (excluding the United States) and thus greater ease and lower costs of visiting family and maintaining transnational connections. Immigrating to a country closer to Mexico also resonated with at least one of Whittaker's (1988:37) Mexican respondents, who declared that he immigrated to Canada instead of Australia because the latter is " $[\mathrm{t}] \mathrm{oo}$ far from part of the family, from friends, from everywhere." Second, the main applicant in the case of family migration, using his social capital and transnational connections, obtained an immediate or a better job offer in Canada than in the other countries. Third, in some cases of economic family migration, and since they were facing pressing economic circumstances and increased violence in Mexico, immigrating to Canada was the first or only option that opened up for them among their other international options. Deyanira, for example, mentioned how after being dismissed from his job, her father "contacted people from his $\mathrm{PhD}$ [at his former Montreal university], and they recommended him to different companies that were looking for people from abroad." Although 
the father had hoped to receive an offer from the United States, he instead got job offers from Canada and Australia. Thus, Canada "was the first option that we found, and we immigrated."

Other youth chose Canada because they considered it to be a less expensive country than Australia or Europe, or because it is a multicultural and cosmopolitan place, or because they heard more positive things about Canadians than Americans. Others immediately rejected the idea of immigrating to the United States because they considered it to be a racist country to be avoided, a country with an uninteresting culture, or one that would not defend a person from narco-related threats. Some of Whittaker's (1988:37) Mexican respondents also rejected immigrating to the United States in the late 1980s. However, in contrast to my respondents, they did so for political reasons: "It is a country that is very important in wars and things like that. We said - if we had children, they would go to the war. We didn't want this. Maybe they would even send me. We didn't choose the United States because one reason for us is political."

When Ivette was thinking of studying English abroad, she thought that studying in the United States would not help her, since she would have to go to California with family members "where everybody speaks Spanish," and rather decided to come to Canada. Ivette thus ignored the advantages offered by her transnational networks and social capital in the United States, even if this meant having no social capital in Canada. Rather, she focused on immigrating to Montreal. Moreover, for six of my respondents, their choice of Canada occurred even when they had family members in the United States who could have assisted them in their immigration process and/or their parents were green card holders. Three other youths tried first to immigrate to the United States. ${ }^{50}$ However, this was not possible because neither one of Myrna's and Deyanira's fathers received a job offer, or because that country rejected an adoption application (i.e. Román's case).

Overall, increasing trade between Canada and Mexico has facilitated the creation of transnational connections and the generation of social capital among some people in both countries, which in turn has facilitated the immigration of skilled Mexicans. Comparatively 
speaking, this constitutes one of the reasons why it is easier for some qualified Mexicans to immigrate to Canada than to the United States, plus immigration policies place fewer barriers for skilled immigration. At the same time, this is one of the reasons why Canada is, in general, not a widely used option for Mexicans to migrate undocumented, since the transnational connections generated between Canada and Mexico are more attuned to labour market fields that require (changing) specialized skills (besides the distance and lack of ample social capital networks). Moreover, the transnational connections created between Mexico and Canada around the latter's need of unskilled or low-skilled labour are rather regulated via the TFWP, which not only collaborates in reducing seasonal labour shortages, but also limits the possibilities for creation of social capital and potential transnational connections among temporary migrants.

\subsection{Escaping from Increased and Multifaceted Forms of Violence in Mexico}

Some participants, from all immigration classes, also mentioned the increase in violence in Mexico as a compelling reason to migrate. Their experiences of violence, however, were not of a uniform type. Rather, youths' life stories unveiled a widespread scenario that ranged from narcoviolence to violence generated by the presence of Canadian mining companies in Mexico to domestic violence. Despite the classification of Mexico as a safe country by former Conservative Immigration Minister Jason Kenney, increasing or direct violence, insecurity, and a lack of official protection affected some of the youths' and their families' lives and contributed to their decisions to leave Mexico. Joaquín and Griselda, who initially came as international students and then transitioned to PR status via the economic class, mentioned that one of their reasons to immigrate was because they felt safer in Canada, a comment also echoed by most women from the economic and family classes. And Deyanira said that:

we heard friends mentioning that people were being kidnapped and all of that, so my dad began to be afraid. Especially because [the kidnapped people] were working people, people that aren't related [to crime]. [...] So uh, one day my parents, I don't know, we sat at the table and they said, 'What do you think if we look for an opportunity abroad?' 
Orlando’s family went through a similar experience: “there was a time in Mexico that was kinda ugly with the issue of violence, the narcos. Especially in [name of medium-size city] there were various kidnappings. The situation turned pretty ugly, and well, having the opportunity of living in a country such as Canada, which offers you quality of life, our parents took the decision [of migrating to Canada] at the end.” In Ildefonso's case, “after I graduated from high school in [name of a small city in Ontario], my parents told me that, well, Mexico is unsafe, because, actually, I was going to do my BA in [name of private university] in [medium-size city in Mexico], but they told me, 'If you want to stay, choose a university in Canada," as a way to avoid violence.

In the abovementioned cases, violence occupied a significant place in their immigration narratives, but the possibilities of immigrating and bypassing violence in Mexico were favourably mediated by these youths' pre-migration class location, their or their families' possession of transnational connections, and a propitious configuration of the Canadian immigration system. These cases also signal how "survival migration," one in which persons migrate "because of an existential threat for which they have no access to a domestic remedy or resolution" due to livelihood failure and state fragility (Betts 2010:365), is only possible for those who possess the various and necessary capitals to migrate. Increased violence in Mexico, touching upon all social classes and across different regions and scales (i.e. rural areas and mid-size and big cities), also came out in the narratives of other youths who came through non-economic programs. Gabriel, for example, who was sponsored by his Québécoise partner but was initially not sure of remaining in Canada during the sponsorship process, was thinking that in "[name of his state] things were heating up very badly, and I didn't see how, at that time [things could get better]... and then a bomb [exploded] in [name of a Mexican city], and I said, 'Nope, you know what? Let's stay [in Canada]."”

Other cases in which violence motivated the immigration of Mexican youth were related to transnational violence. Namely, violence generated by the close inter-connection between 
Canada's and Mexico's politico-economic processes. Eduardo, for example:

was actively participating in some campaigns against the mining company [name], which is a subsidiary of [Canadian mining company]. And this mining company, well, it began [operating] in the hill. [...] It's like if [...] a Mexican mining company arrives to Mont-Royal and begins [operating in the] hill to take away the gold and silver. And the Canadian government says, uh, okay, sure, but first, share some of the money. Just imagine what would happen! [...] But since it was Canada the one who made it and not Mexico, well, nobody said anything, everybody stood quiet. [...] A friend of mine, they tried to kill him. But he survived. They tied him up with iron cables and throw him into a dam, and miraculously he freed himself and came out. A politician friend gave him a plane ticket for Montreal and told him, 'Get out of here, they're going to kill you, they want you dead, go away!"”

The regular persecution of social activists by actors ranging from state to criminal actors, forced Eduardo to abandon his city to keep his family safe: "I left the city and began travelling around the country. Later, for very different reasons [i.e. a partnership sponsorship], I came here [to Montreal], no?' The presence of Mexican immigrants and refugees in Canada escaping from violence generated by Canadian mining companies also speaks to the gradual but increasing development of complex, transnational connections between both countries and the (re) production and expansion of Canadian capital in Mexico, including its negative consequences.

It is in this context that Eduardo's immigration experience (as well as those of others who have sought refuge, ironically, in Canada due to problems related to Canadian mining companies [see Lapalme 2013]), acquires a more structural, transnational connection intimately related to violence. Thus, Mexican immigration to Canada has also been the result of violence generated by Canadian capital invested in mining operations in Mexico. These investments, in turn, have been promoted and protected by the active assistance of some senior and middle-ranked bureaucrats with the Canadian government, despite their knowledge of this violence (see Moore 2015; Moore and Colgrove 2013), and paid by unsuspecting Canadian taxpayers. This has thus further dislocated Mexico's social fabric in a transnational fashion, since "repression and violence are the norm for those that challenge Canadian interests in Mexico" (Gordon and Webber 2016:280).

Another type of violence faced by another of my respondents, Marco, was also mediated by 
broader, transnational processes. Marco arrived in Montreal escaping from narco-threats he received in Mexico. His family's relationship with members of the Mexican military automatically put him on one of the various sides of the ongoing narco conflict and made him an easy target: “There's a high risk [for me to] be kidnapped there, of [experiencing] violence [...] And that stops me from moving freely in some places or being in those places [in Mexico], no? [Because of certain people being afraid of] me seeing something and saying something.” As mentioned in Chapter 4, the increased symbiosis between the Mexican state and criminality, along with geopolitical and socio-economic changes in the North and Central American regions, radically transformed Mexico's structure. This provoked social dislocations that changed, in a Bourdieusian sense, the rules of the game in communities, towns and cities, leading to people's class re-location and re-valuation of alliances and various capitals among family members, friends, and neighbours. In certain cases, these re-valuations meant life or death, as in Marco's case.

In another case of transnational violence, Rodolfo arrived in Montreal, escaping from gang violence with roots in the United States. As described in chapter 4, the development of gangs in the United States among Latinxs, initially created as social buffers against inequality, racism, and social ostracism among young people, continues its transnational expansion. This expansion has resulted, in part, from immigration policies initiated under the George W. Bush administration that were continued and reshaped by the Obama administration's immigration enforcement priorities. Under President Obama, priorities focused on border and national security and the identification and removal of those who broke criminal laws, threatened public safety and national security, and/or were repeated violators of immigration law (ICE 2012, 2015a). The resultant effect was an increase in removal orders (whilst the Bush administration had focused on returns), ${ }^{51}$ for which Latinx activists, beginning with the prominent National Council of La Raza, named Obama as “deporter-in-chief” (Kaplan 2014). However, when we consider both removals and returns, we can observe that there were 5.26 million deportations under Obama as compared 
to 10.32 million under the Bush administration (DHS 2017a). ${ }^{52}$

Obama's widespread use of removals rather than returns was intended to fingerprint, file and record charges against and expel criminals and/or so-identified threats to national security (Bennett 2014). This generated a double effect in relation to the profiles of those who were being deported. On the one hand, it was mostly Mexicans and people from the Northern Triangle, many of whom had not committed a crime, who were being expelled. For example, only about half of deportees had a prior criminal conviction in the 2016 fiscal year (DHS 2017b). And up to two thirds of deported people between 2009 and 2014 were young Mexicans under the age of 35 who had committed minor infractions such as traffic violations or had no criminal record at all (Thompson and Cohen 2014). On the other hand, the number of gang members detained in and deported from the United States has also been increasing (FBI 2005a, 2009; ICE 2017a).

Since 2005, 57,000 gang-related arrests have been made in the United States through Operation Community Shield. In 2017, 4,818 gang-related criminal arrests were made, of which 796 were Mara Salvatrucha or MS-13 arrests (ICE 2017b). These gang members were involved in activities such as murder, extortion, narcotics and weapons trafficking, human smuggling/ trafficking and prostitution, and other crimes with a transnational nexus (ibid). While the number of deported gang members from the United States has increased, with 17,167 gang members deported between 2014 and 2018 (ICE 2014, 2015b, 2018), their deportations have paradoxically fostered their undocumented return and their expansion into new US areas (López, Connell, and Kraul 2005). This has created, in turn, a migration circuit of gangs in the Central and North American regions. Thus, when a tattooed gang member who had been recently deported from the United States and a couple of local gang members physically attacked Rodolfo and his wife on a Mexican street for no apparent reason, Rodolfo's ordeal had just begun.

During the attack, Rodolfo defended himself and his wife with a metal tube he found, and they were able to flee the scene. He asked some friends to help him confront the gang members, 
but when he told them the name of the gangster he overheard during the altercation, they got scared and told him, 'Oh no! don't you know that that guy tried to kill his cousin? No! Don't do anything [against him!],' so I was left speechless." When the police arrived and found the gang members, they did not intervene because "they were afraid of him [i.e. the recently deported gangster], that's why they didn't want to do anything against him, because they were afraid of him.” Rather, they asked him what had happened, “and they didn't even handcuff him.” The next day, some gangsters' family members filed a complaint with the police, alleging that Rodolfo had taken advantage of the gang members, who were high, and had attacked them with a pipe. Rodolfo, however, received the support of some local authorities, who were friends of his family, and the charge did not proceed. From that moment, the gang members "began chasing me. They harassed me. I was driving my car and they were behind me, chasing me. And I speeded up and they kept chasing me. 'Come here, come here,' [they yelled at me]. And that became very common, but now more gang members were chasing me.” Rodolfo was forced to relocate to avoid the gangsters, and afterwards he sought refugee status in Montreal.

Rodolfo's story, even if it can be identified as a relatively 'simple' albeit unexpected case of aggression by a deported gangster, can thus be situated in a broader geo-political, social, and economic transnational intersection, as mentioned above. The attack against Rodolfo also unveiled a vacuum of state legitimacy, where police, as part of the state, are incapable of defending the local citizenry and/or might be part of organized crime. In this context, the recently deported gangster, through his deployment of physical and symbolic violence, along with the silence and inaction of police, claimed his stake for control over the town, showing his selfproclaimed legitimacy to others and changing the rules of the local fields. His deported presence in a small rural town in Mexico thus represents the transnationalization of criminality that operates along state and institutional structures throughout the region. This has, in turn, contributed to the development of even more complex landscapes of violence at micro-levels that 
further propel immigration (Winton 2012, 2014). Consequently, immigration under this scenario of cumulative transnational violence is constituted as a survival strategy and as "a complex balancing act of different kinds of harm" (Winton 2017b:131).

Nonetheless, escaping from violence is a possibility only granted to those with enough capitals to do so. As Winton (2017b:132) found in Central America and the south of Mexico, "[v]iolence as it relates to mobility is to do with how the places we live in are fundamentally structured in a violent way, such that how we experience and move through them, where we can and cannot pass through or stay, to a large extent depends on our relative position within these structures.” In Rodolfo's case, had his family not had good relations with the local authorities (i.e. social capital), he would not have received support against the legal accusations that were made up by the gangsters' family members and his story might have been different. This is particularly true in a culture where corruption and nepotism are largely unchecked and/or controlled by criminality. Certainly, it was not easy for Rodolfo to obtain the money for his ticket to Montreal (and later that of his wife), but without the possession of social capital and not only economic capital, his escape would not have been possible. Thus, while Rodolfo was able to claim asylum in Montreal due to his possession of capitals, those experiencing violence but lacking various types of capitals are located in a precarious position and thus forced to experience what Winton (2017a:5) calls a “forced immobility:" the impossibility of moving even when one's life is in danger.

The Maras, however, are just one of the many visible faces in the full gamut of pernicious, rooted, institutionalized types of violence occurring in Mexico and Central America (Winton 2017a). Gender violence, for instance, a more invisible type of violence, also generates mobility and displacements from the Northern Triangle to Mexico (ibid.), and from Mexico and the Northern Triangle to the United States (Estévez 2016). The statistics regarding migration from this region to Canada due to gender violence are, however, unclear. Aurora, for example: never thought of leaving the country! Never in my life it occurred to me [...] We were very, very poor. My dad was a fisherman and my mother prepared tamales to 
sell, she did raffles, did everything. She sold Avon, Füller, things like that. Since I was nine, she took me to an orphanage and left me there. [...] I always knew that she didn't love me, she told me that herself. She told me, 'You should've never been born, you ruined my life.'

After Aurora left the orphanage, she was taken by a Christian pastor to his home. Unfortunately, she faced sexual abuse by this man "and I couldn’t say anything because I feared that if I said anything, I was going to be kicked out to the street and I didn't know what I could do." When Aurora finally got the courage to denounce the Pastor to his secretary, Aurora was immediately sent back to her mother. Soon, she moved away to live with her grandmother and began studying computing and English. It is here when Aurora met a young Canadian man who was teaching English in her city. "I was going through a very strong depression [due to her past], so, he was like a lifesaver. So, I strongly hold, hold onto him thinking that this was love. And when he returned to Canada in June, I came [to Canada two months later]. [... . My visit was scheduled for one month only, I was going to go back to Mexico, to school, as if nothing else had happened. Then, uh... we found out that I was pregnant. So, all my plans changed."

Soon after, Aurora found herself subjected to psychological and emotional violence at personal and institutional levels: "he was very possessive, too insecure. He didn't want me to go outside because men would see me and think that I'm pretty, they would try to talk to me, make me fall in love with them, and then I would abandon him because they'd be better than him." $\mathrm{He}$ also prohibited Aurora from going outside the house without him or his mother. Some time after their child was born, he began ignoring her and even stopped looking at her. Aurora was thinking of returning to Mexico with her child, even if she had no economic means to pay for the tickets or even legal knowledge of the requirements to leave Canada with her child. After an altercation, the man obtained a restraining order against her, alleging that he was afraid of being physically assaulted. Soon after, Aurora lost the custody of her child. After some years of battling the justice system and without English knowledge or even migration status, Aurora —under the advice of social workers and lawyers - applied for and obtained PR status via humanitarian and 
compassionate grounds, so she could fight for her child's custody. Aurora's experience thus unveils the complex interrelations between citizenship, gender, social class, the emotional and sexual violence she experienced as a child/teenager, and her subsequent immigration.

Overall, violence operated as either the main push factor for some Mexican youth's cases (i.e. refugee or humanitarian compassion streams) or as an added push factor among those respondents from the economic and family immigration streams. In all these cases, however, it was my respondents' and/or their families' possession and use of various capitals before immigrating that allowed them to escape from new and multifaceted forms of violence occurring in Mexico. In some cases, violence was also connected to broader transnational and politicoeconomic processes being generated between Canada and Mexico, or processes with a more regional scope (i.e. including the United States and Central America).

\subsection{Escaping from Economic Crises and In Search of Better Opportunities}

Economic crises and/or unemployment, paired with the desire of offering better opportunities for their children, also constituted some of the reasons for which five of my respondents' families decided to immigrate to Canada under the economy class. In these cases, Mexico's economy operated as a push factor when the families' total sum of capitals was not enough to maintain their class location, or it was directly threatened. Deyanira's father, for example, "lost his job because there was that devaluation [in Mexico]. So, obviously we needed to find [an immediate solution]." The devaluation Deyanira mentioned refers to the one that happened in 2011, when the peso devalued $13 \%$ in comparison to the previous year. This devaluation occurred in the context of President Felipe Calderón's government (2007-2012), discussed in Chapter 4. In fact, under Calderón's tenure, the peso had an accumulated devaluation of $19.4 \%$ compared to the previous accumulated devaluation of $13.7 \%$ under President Vicente Fox's tenure (2001-2006) (Aguirre Botello 2017). Moreover, when Deyanira's family immigrated to Canada, Mexico's economy was still experiencing the negative effects of the 
2008-2009 global crisis. For example, inflation had increased from 3.8\% in 2007 to $6.5 \%$ at the end of 2008, while the GDP decreased 4.7 points in 2009. The unemployment rate under President Fox's tenure was of 3\% and under Calderón's tenure, $4.4 \%$.

By the time Deyanira's father found himself unemployed in 2011, unemployment had reached almost 5\% in Mexico. And although inflation had decreased from 4.4\% to 3.8\% from the previous year, the effects of the evolving economic crisis in Europe, particularly in Spain and Greece, were still affecting Mexico's economic growth. The negative economic impact of the global crisis, however, was not uniform in Mexico. As mentioned in Chapter 4, the crisis had different impacts upon the various sectors of the Mexican economy and the people working on those sectors. Moreover, Mexican migration to the United States, rather than increasing as a result of the economic crisis, astonishingly diminished by almost $60 \%$ between $2007-2010$, while at the same time return migration increased by 18\% between 2005 and 2009 (Canales 2012; Ramírez García and Meza González 2011). The latter was because (would-be-) migrants deployed a strategy of crisis containment, that is, they remained in the United States or Mexico to avoid increasing potential economic risks. If there was no significant migration of Mexicans to the United States during the global crisis, one may assume that the probabilities for Mexicans to migrate to Canada were even smaller.

However, IRCC (2016a) data shows the opposite. Before the economic crisis (2004-2007), $36 \%$ of Mexican immigrants came via the economic class and $26.4 \%$ via the refugee class (of a total of 11,175 people). During the economic crisis years (2008 to 2011), $42.6 \%$ came via the economic class and $16.4 \%$ via the refugee class (of a total of 13,750 people), and during the postcrisis period (2012 to 2015$), 41.2 \%$ came via the economic class and $14.9 \%$ via the refugee class (of a total of 15,930 people). Thus, during the (global) economic crisis, more Mexicans with enough economic capitals immigrated making use of the economic class, probably to maintain (a potentially deteriorating) or improve their economic stance. We also need to consider that this 
period coincides with the changes to immigration, refugee, and humanitarian policies implemented by the Conservatives between 2006 and 2015, which increased economic immigration and decreased humanitarian and refugee assistance.

In the case of Myrna, her father decided to immigrate with his family "looking for a better life for them as a couple, and [...] well, also looking for the chance to offer more opportunities for their children.” But her father's decision, as in other cases, was also based upon several considerations:

My dad and my mom being in his 50s... he said, 'Right now I'm working for Canadians in the automotive industry, but the automotive industry is going down, so it's having a [bad] streak, and once they begin dismissing personnel, I'm going to be the first person they'll fire. I'll be left without a job and being over 50 years of age here in Mexico, nobody is going to hire me.' Because at that time, I don't know if it's still the same, but they always used to hire new people to pay them less. The older the person, the lesser their possibilities to be hired, so he was afraid of that happening to him.

But Myrna's father was afraid of being dismissed not only due to ageism, but also because the family had a precarious economic position despite his having a good job (even if in a declining industry): "well, they had a house [her parents], but it was the only thing they had. They didn't have a single peso in a savings account. So, had they found themselves without a job, they would've faced extreme hardship."

Moreover, Myrna's family situation in Mexico and subsequent immigration to Canada were linked to broader economic processes occurring in a transnational space. Despite the automotive industry being one of the strongest industries in the North American market, one that has most benefited from NAFTA, and the second most important economic sector in Mexico (due to its deregulated commercial environment, qualified workforce, and an ample production infrastructure), it was also negatively affected by the 2008-2009 global economic recession (Vicencio Miranda 2007). This negative impact was compounded by a diminution of automotive exports since 2001, the weakening of the industry despite the injection of 50 billion in FDI in Latin America in 2003 (particularly in Mexico and Brazil), and the lack of appropriate responses by the Mexican government (ibid.). 
Thus, the fear of Deyanira's father was more than justified when he thought that the contraction of the automotive industry might lead to his dismissal, along with a deeply embedded ageism in the Mexican labour culture, which could have resulted in further complications due to the family's lack of economic assets. In this scenario, it was Deyanira's father's transnational connections and social capital that allowed him to successfully apply for immigration to Canada rather than his (lack of) economic capital. Thus, when the macro-economic scenario evolved and threatened Deyanira's father's fragile position, and despite his location in a primary labour market, immigration was seen as the most viable alternative to preserve his family's class location and offer better opportunities to his children. The objective of better opportunities for the children also played strongly in Alberto's case. “[My parents] wanted to offer us a better life experience for when we grew up. And yes, that was really the reason, for us to be able to have a career that we like and yes, a better house, right?" In Teresa's case, her parents were also looking for better opportunities for their children in the late 1990s. They "went to work [to the United States] for a year," but they disliked the experience and moved to Canada.

Overall, sudden unemployment or a forecasting strategy before a grim economic scenario, which resulted from macro-structural changes constraining certain labour markets in Mexico, led some youths' parents to look for better options for them and their families. Whereas Whittaker (1988) did not mention or find among her respondents the desire among (future) parents to offer better opportunities for their children in the late 1980s as reasons to immigrate, Goldring (1999b) did so among Mexican middle-class professionals who immigrated with their families in the late 1990s. As some of my respondents mentioned, this is still one of several reasons why some Mexicans immigrated in the late 2000s and early 2010s.

\subsection{Discussion: Mexican Youth's Macro-Level Reasons for Immigration to Canada}

In this chapter, I have focused on structural and transnational causes that have shaped and/or motivated Mexican youth's immigration (or their parents'). Whereas all my respondents 
from the previous chapter immigrated through the economic and family immigration classes, the youth mentioned in this chapter did so making use of the various immigration classes. I found three macro-structural reasons for them to immigrate. First, some youths directly responded to the interaction of various politico-economic factors that produced, on the one hand, a transnational space linking Mexico and Canada, and on the other, a growing transnational space that has been increasingly including the United States and Central America. Second, some other youths from across all immigration classes immigrated to escape from increasing and multifaceted types of violence happening in Mexico, connected to broader politico-economic transnational processes. And third, unemployment generated by economic crises tied to global and financial processes was constituted as an immigration push factor among middle and upper-middle class Mexicans. Due to the variability in the impact of these economic crises, certain economic and employment sectors are affected more than others, for which some people with certain profiles are being affected more than others.

The generation and growth of an economic transnational space between Mexico and Canada allowed some of my economic class respondents (and their parents) to immigrate. This space has resulted from an increase in direct foreign investment and commercial and trade relations between Mexico and Canada, particularly Ontario and Quebec, facilitating the parallel constitution of transnational networks and the generation of social capital among some Mexicans and Canadians. Whilst this space has responded to the global expansion and reproduction of capital from Canada to Mexico and from Mexico to Canada, it has also facilitated the temporary and permanent migration of skilled Mexicans. I found two different types of skilled labour movement among Mexican youth. One type constituted skilled Mexicans who directly applied for and obtained permanent residence under Canada's economic programs. In order to do so, however, Mexican skilled immigrants had to exchange their social capital generated with Canadians for Canadian capital, such as contacts in Canada, recommendation letters from 
Canadian employers, or job offers. It was these immigrants' pre-migration total sum of capitals that facilitated their access to this transnational field, and which then allowed them to use their social capital as an immigration passageway.

The other type of labour movement I found operating in the Mexico-Canada transnational space constituted skilled Mexican workers who were temporarily transferred to Canada under the TFWP as part of a broader South-to-North labour movement. In contrast to other low-skilled streams of temporary and precarious labour, such as the one generated by the SAWP, these skilled workers generated Canadian capital once in Canada (i.e. skilled Canadian work experience, language practice in any of the two official languages, and immersion in the Canadian culture). This Canadian capital would constitute a valuable resource that allowed them to apply later for PR status. Moreover, this temporary movement of skilled labour, as a product of the transnational operations of capital, unintentionally converted these workers into potential nodes of social capital in a transnational space. After having immigrated, these workers are now in the position to form transnational networks with family members and friends in Mexico. They can now open the door to the development of a perhaps limited, but still cumulative causation process.

It was also noticeable that in this latter type of labour movement, social capital did not play any role in the immigration process. It was rather the migrants' previous possession of education and economic capitals that allowed them to be located in a Mexico-Canada transnational space. Consequently, when transnational labour fields, driven by the expansion and accumulation of capital, required a skilled but cheap labour force, some skilled Mexican workers were able to respond to the job relocation offer. The experience of Mexicans in both types of skilled labour movement also showed that the capitals of prospective immigrants need to be attuned to the configuration of the local and/or transnational labour markets for them to be able to enter this field. If a labour market is constrained and/or there is a mismatch between the market's requirements and the aspiring immigrant's capitals, their possibilities to immigrate via the 
economic class will accordingly diminish to the point of these being null.

I also found another reason to immigrate tied to transnational and macro-level factors among economic immigrants' families. Here, the male breadwinner was actively looking to avoid an economic crisis and/or unemployment in Mexico, partly induced by the 2008-2009 global recession, and both parents were looking to offer better opportunities to their children (i.e. my respondents). Since these families' total sum of capitals was not enough for them to maintain their class location in Mexico, or was threatened by macro-structural factors such as the constriction or disruption of transnational or global markets, economic immigration was the only alternative they foresaw to stay ahead. Once again, it was the total sum of their capitals, including transnational networks and social capital, which allowed them to promptly respond to macrostructural changes and take advantage of the transnational economic field operating between Canada and Mexico.

Other youth also found themselves in a broader politico-economic and transnational space, but one where they had to confront increasing and multifaceted forms of violence developing in Mexico, and thus make use of Canada's refugee and humanitarian classes. These ranged from transnational violence generated, ironically, by a close politico-economic relation between Canada and Mexico, particularly regarding the effect of the Canadian extractive sector (i.e. mining), to narco-related violence to transnational gang violence to gender violence. All these different forms of violence propelled migration in one way or another, and in few cases, they also led to immigration as a form of survival. Nonetheless, whereas my economic and family class respondents were active in evaluating diverse scenarios, pulling out resources (some even at a transnational level), and taking the necessary and appropriate measures to immigrate to or stay in Canada, my other respondents who came via the refugee stream were met with limited options.

Nonetheless, in these latter cases, it was also their pre-migration total sums of capitals (even if different from those who came via the economic and family classes), and not only the 
possibilities offered by the Canadian refugee policy, which allowed them to immigrate. That is to say, rather than being forced to experience a forced immobility in Mexico due to a lack of resources (Winton 2017a), they were able to mobilize certain economic and non-economic capitals (i.e. social and cultural) to travel to Canada and make their refugee claim to escape from violence in Mexico. Overall, politico and economic transnational fields developed between Canada and Mexico, and increasingly with the United States and some Central American countries, thereby shaping the decisions of my respondents to immigrate to Canada. In each decision, and independent of the immigration program used, it was their pre-migration class location that allowed them to immigrate. My focus on and emphasis in understanding politicoeconomic and transnational processes as push factors have served to unveil the connections between macro-level processes and my respondents' circumstances at the micro-level. These relationships will be useful to better understand their type of economic integration and their participation in the social, cultural, and political life of Canada and/or Mexico (i.e. transnationalism). In the following three chapters, I thus analyze the types of economic integration processes that Mexican youth have undergone in Ottawa and Montreal (i.e. independent, subordinate, or secondary). 


\section{Chapter 7: The Independent Type of Economic Integration}

In chapters 5 and 6, I showed how the Canadian immigration and refugee system structured the entry points of the Mexican youth I interviewed (or their families). I also showed how their motives for immigration were based on several factors, in many cases not limited to economic reasons, and how their pre-migration class location, gender, age, and sexuality (at least) allowed for and shaped their immigration experiences. However, in each case, it was their total sum of capitals or their particular location in their pre-migration fields which allowed them to immigrate or seek refuge in Canada, which also assisted them in matching one of Canada's or Quebec's immigration policies. Moreover, broader transnational processes operating between Canada and Mexico and across the North and Central American regions, including commerce, tourism, and violence, also collaborated in promoting and/or facilitating the immigration of some youth. After having immigrated, they faced diverse settlement and integration processes. Nonetheless, for the purposes of this dissertation, I will only focus on their economic integration. This is because I consider economic integration to be a strong condition that shapes the type and extent of immigrants' participation in the social, cultural, and political life of Canada and Mexico (i.e. transnationalism), as I will illuminate in chapter 10.

In the following three chapters, I thus analyze the ways in which the pre- and postmigration class locations of Mexican youth coalesced for them to be located in one of three different types of labour market segments and their corresponding economic integration: independent, subordinate, and secondary (Edwards 2015). I also analyze the extent to which other factors, such as labour market orientation and market configurations, have shaped their economic integration experiences. In this chapter, I focus in particular on the conditions and reasons that led 14 of my 35 respondents to be located in the independent type of integration. The chapter is divided into six sections. In the first section, I briefly present my respondents' location in the three different types of economic integration. In the second section, I introduce the independent location, as well as the relevance of language and Canadian education (i.e. Canadian capitals) for 
some youths to be located in this type of integration.

In the third section, I delve into various types of employment trajectories that led my participants to an independent location, and I also include the independent type of location by extension (i.e. a location granted by the capitals obtained from a relationship with a significant other or a family member, rather than by one's own possibilities). In the fourth and fifth sections, I analyze the role that gender and Canada's labour market configurations have played in facilitating Mexican youths' location in the independent type of integration. And in the final section, using Bourdieusian theory, I present an analysis of how the interplay between pre- and post-migration class locations, as well as more structural and politico-economic factors, facilitated my respondents' economic insertion into the independent location.

\subsection{Mexican Youth's Distribution Across Labour Market Integration Types}

As mentioned in Chapter 2, Edwards (2015) considers three different types of labour market segmentation, which I use as proxies for immigrants' types of economic integration: independent, subordinate, and secondary. Among my respondents, eight of the 18 youths I interviewed in Ottawa and six of the 17 youths I interviewed in Montreal are located in the independent location (see Table 7 and Chart 3). Eight of the 18 youths in Ottawa and four of the 17 youths in Montreal are located in a subordinate location. And two of the 18 youths in Ottawa and seven of the 17 youths in Montreal are located in a secondary location.

Table 7: Types of Economic Integration by City (i.e. Ottawa and Montreal) and Gender

\begin{tabular}{|c|c|c|c|c|c|c|c|c|c|c|c|c|}
\hline $\begin{array}{c}\text { Type of } \\
\text { integration }\end{array}$ & $\begin{array}{l}\text { Ottawa } \\
\text { Women }\end{array}$ & $\begin{array}{l}\text { Ottawa } \\
\text { Men }\end{array}$ & \multicolumn{2}{|c|}{$\begin{array}{c}\text { Ottawa } \\
n \%\end{array}$} & $\begin{array}{l}\text { Montreal } \\
\text { Women }\end{array}$ & $\begin{array}{l}\text { Montreal } \\
\text { Men }\end{array}$ & \multicolumn{2}{|c|}{$\begin{array}{c}\text { Montreal } \\
\mathrm{n} \%\end{array}$} & Wome & Men & \multicolumn{2}{|c|}{$\begin{array}{c}\text { Ott \& Mtl } \\
\quad \mathrm{n} \%\end{array}$} \\
\hline Independent & 3 & 5 & 8 & 44.5 & 4 & 2 & 6 & 35 & 7 & 7 & 14 & 40 \\
\hline Subordinate & 7 & 1 & 8 & 44.5 & 2 & 2 & 4 & 24 & 9 & 3 & 12 & 34 \\
\hline Secondary & 2 & 0 & 2 & 11 & 2 & 5 & 7 & 41 & 4 & 5 & 9 & 26 \\
\hline Total & 12 & 6 & 18 & 100 & 8 & 9 & 17 & 100 & 20 & 15 & 35 & 100 \\
\hline
\end{tabular}


Chart 3: Location of Mexican Youth in Ottawa and Montreal by Type of Integration

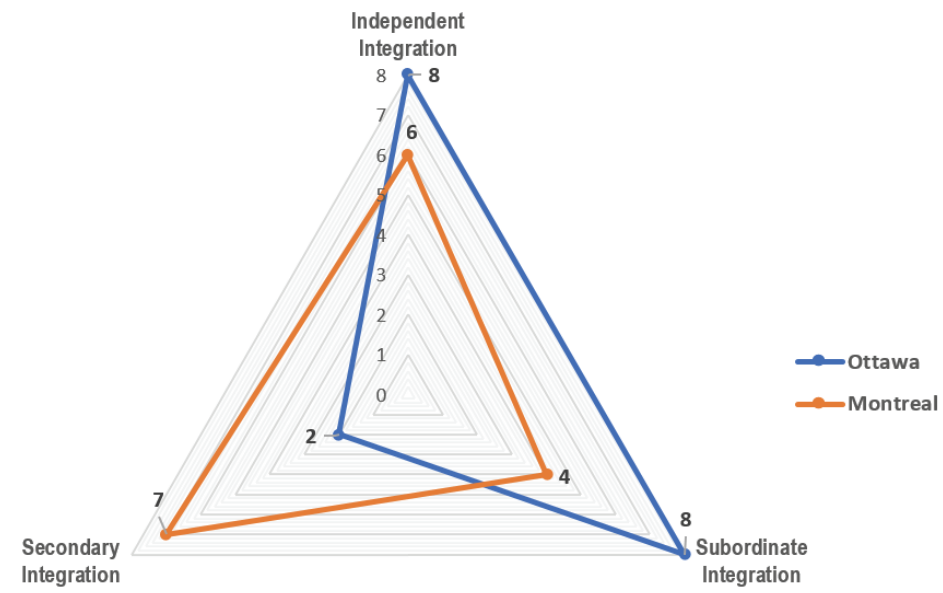

\subsection{The Independent Type of Economic Integration}

A positive correlation between pre-migration class location and the generation of social and Canadian capitals (i.e. education, knowledge of any of the two official languages, and work experience) was decisive for 14 respondents to achieve an independent economic integration. Their average age when they arrived in Canada was 23.5 years (although this average does not refer to their age when they obtained PR status). All came either through the economic class (i.e. eight people in total, three of whom came as part of economic family immigration) or the family class (i.e. six people, five of whom came via marriage sponsorship and one sponsored as a family member) (see Table 8). None arrived as asylum-seekers.

Table 8: Mexican Youth in an Independent Type of Integration by Gender, City, and Immigration Class

\begin{tabular}{|l|c|c|c|l|}
\hline Respondent & Sex & City & Years in Canada & \multicolumn{1}{|c|}{ Immigration Class } \\
\hline Myrna & F & Ottawa & 13 & Economic, Family Migration FSWP \\
\hline Alberto & M & Ottawa & 6 & Economic, Family Migration FSWP \\
\hline Orlando & M & Ottawa & 13 & Economic, Family Migration FSWP \\
\hline Ildefonso & M & Ottawa & 7 & Economic, CECP \\
\hline Verónica & F & Ottawa & 5 & Family, Marriage Sponsored \\
\hline Gabriel & M & Ottawa & 9 & Family, Marriage Sponsored \\
\hline Mauricio & M & Ottawa & 6 & Family, Marriage Sponsored \\
\hline Erika & F & Ottawa & 10 & Family, Sponsored Member \\
\hline Patricia & F & Montreal & 6 & Economic, QSWP \\
\hline Karina & F & Montreal & 7 & Economic, QEP TFW \\
\hline
\end{tabular}




\begin{tabular}{|l|c|l|c|l|}
\hline Respondent & Sex & City & Years in Canada & \multicolumn{1}{|c|}{ Immigration Class } \\
\hline Diana & F & Montreal & 10 & Economic, QEP TFW \\
\hline Roberto & M & Montreal & 3 & Economic, QEP Graduate \\
\hline Jimena & F & Montreal & 5 & Family, Marriage Sponsored \\
\hline Jaime & M & Montreal & 10 & Family, Marriage Sponsored \\
\hline & & Mean & 7.9 & \\
\hline & & Median & 7 & \\
\hline
\end{tabular}

\subsection{The Relevance of Language and Canadian Education (Canadian Capital)}

Knowledge of one of the two official languages was an important factor for these participants to be located in an independent economic integration. Ten of my 14 respondents in this location arrived in Canada with a medium-to-high level of proficiency in English and/or French, which reflects their middle or upper-middle social class locations in Mexico. The exceptions were Jimena and Diana in Montreal, and Gabriel, Orlando, and Alberto in Ottawa. Among my respondents from Montreal, most had already studied English and/or French in Mexico, and in a few cases also in Canada, the United States or France. Patricia and Ramiro (QRSWP) were told at the DGQM that "to come here, you need to learn French, [...] so we began learning it at the Alliance Française" (private school) in Mexico. They also studied French because Ramiro, Pilar's partner, became captivated by what he had learned about Quebec's cultural resistance through language, which he identified as “the combative resistance." Both were studying towards a master's degree at the moment of the interview. Jaime (spouse sponsorship program) had been studying English since primary school at private schools, "and my dad used to take us to the United States. He's an American resident. [...] So, it was mandatory to learn English. [...] I [also] lived for a while in the United States. I studied high school for a semester in [name of city], Texas.”

Jaime opted to immigrate to Montreal rather than Quebec City because "in Montreal they speak English. [...] To be honest, I'm almost 100\% sure that speaking English is better for making business here." Jaime also studied French at the Alliance Française in Mexico at the wish of his parents, given that Jaime's grandmother was a French immigrant in Mexico:

But when I came here it was pointless! I had to learn Québécois. And I went to France, 
and I can perfectly understand them. But a Québécois(e), sometimes, still it's hard for me to understand them. But I speak [French] like 80, 85\%. I speak it well.

Among my Ottawa respondents, except for Gabriel, Orlando, and Alberto, all had acquired a medium-to-upper proficiency in English at school in Mexico and/or abroad. Ildefonso (CECP) mentioned how, besides learning English at the private schools he attended in Mexico, "my parents used to send me and my sisters to Canada to study English during the summers and winters, so I've been coming to Canada since I was 15 years old.” Ildefonso also studied the last year of high school and a bachelor's degree in Ontario, which helped him to improve his language abilities. Mauricio's parents (spouse sponsorship program) sent him, at age twelve, "first to Florida, then to Canada at age fifteen for a month," for a summer course, and he also obtained a BA in Ottawa. Mauricio also practiced his English while travelling and working in New Zealand at age eighteen.

For other youth in Ottawa, learning English was easier since they arrived with a medium level of language proficiency. For example, Myrna (family economic migration via FSWP) obtained a medium level of English proficiency at the private schools she attended in Mexico, "and after like three years of working in Canada," she improved not only her English but also learned "how things work in here." Myrna also did an MA program and learned French since her job later required her to work in West Africa: "I realized that French was going to be quite useful for me. So, I began taking classes at a community centre. [...] I can't say that I was super fluent in French, but I could speak it more or less, and functionally speaking it was very useful for me at my job." Her case was, indeed, only one of two in which knowledge of the two languages was useful for achieving an independent location. The other case is Roberto (Montreal, QEP graduate), whose company's global orientation valued his knowledge of both official languages. Among those who faced difficulties were Verónica (spouse sponsorship program), who had already studied English for some years at private schools, at university, and then took a course to teach English in Mexico. But:

it took me like a year [here] where 'oops! Maybe I didn't learn what I thought I had learned. And then I began to feel sick, like at the beginning I had headaches [when trying to speak English]. At [my husband's] family reunions, everything was in French and English [...] because he's French [i.e. Québécois]. They try to speak in English, but 
obviously it isn't natural, no? So, it was really hard for me, I felt like a shock. [...] It was really difficult for me that change, to begin thinking in English.

Gabriel (Ottawa, marriage sponsored) also experienced that language shock, but his circumstances were different. He arrived with only a basic level of English and thus learning the language was a challenge. This also threatened his relationship with his partner, who had sponsored him: "my English wasn’t, like, quite good. [...] I even had strong discussions with [name of partner]... at that moment I said... enough! I'm going back to Mexico!' It took Gabriel a year and a half to learn English. However, he did not take any English courses after immigrating. Rather, he learned it while volunteering at an association and talking to people. In the cases of Orlando and Alberto (FSWP), learning the language was a relatively easy experience because they immigrated as teenagers, and it was only a matter of time for them to acquire the language once they were fully immersed in Ottawa's education system. Years later, after Orlando finished his BA, he took subsidized French classes because he always liked the language and also as a way "to open more opportunities in Montreal and in Quebec. [The French language is] very useful for work, and if I want to work in the government, it's always an asset that gives you an extra [push]."

Another characteristic that most youths in this category shared is that they obtained a high school certificate and/or a post-secondary degree in Canada (i.e. 11 of 14 youths or $83 \%$ of the subsample). Exceptions are Verónica from Ottawa and Jaime and Karina from Montreal. Verónica has not studied anything in Canada because she focused on taking care of her newborn after immigrating, and then began working at her husband's business. Nonetheless, she expressed her desire to study in Canada in the near future. Jaime has not needed more education beyond his BA in Mexico to be a successful entrepreneur in Montreal. And Karina began working at her current full-time job shortly after her arrival and has not needed more education. At the moment of the interviews, three of my participants knew both official languages, two had an advanced knowledge of one language and a medium level of knowledge of the second one, and two others 
had an advanced knowledge of one language and a basic level knowledge of the second one.

Overall, knowledge of one or both official languages and education in Canada, understood as Canadian capital in the employment field, facilitated accessing employment trajectories that would lead them to acquire an independent type of job. It was noticeable that knowing both official languages did not necessarily assist youths in moving towards an independent type of integration except in two cases. Moreover, location did not have a meaningful impact on knowing both official languages. Rather, it was the particular needs of the employment fields which were more significant to determine the requirement and value given to any official language, irrespective of living in Montreal or Ottawa.

\subsection{Employment Trajectories Leading to an Independent Type of Integration}

\subsubsection{The Independent Experience}

Although 14 youths were located in the independent location at the moment of the interview, the majority of their trajectories were neither straightforward nor uniform. Thus, besides a direct trajectory to an independent location, I found three other types of trajectories that included different combinations of employment market segmentations, all resulting in these youths taking up positions in the independent labour market: 1) Secondary $\Rightarrow$ Subordinate $\Rightarrow$ Independent, 2) Secondary $\Rightarrow$ Independent, and 3) Subordinate $\Rightarrow$ Independent. Only one of my 14 respondents, Diana in Montreal, immediately obtained a job that falls under the category of an independent location. In addition, Jaime, from Montreal, opened two small businesses soon after having immigrated.

After studying English, Diana studied for a technical career at a CÉGEP and generated social capital with some of her professors. This, along with the fact that CÉGEPS are closely connected to companies' needs in Quebec as part of the former's mission, led Diana to obtain a paid internship after finishing her courses as an international student, which was later converted into a full-time job: “I think it's very important how each person does at school. I did well, I always had good 
grades, and my instructors at CÉGEP helped me to get a job, which even was a permanent job. Since I began doing my practicums, I was paid. And well, I worked for five years at that company." Moreover, Diana's previous engineering studies at a private university in Mexico “began to be noticed. So, my own bosses began to realize that I can do more, and thus I began to get promotions until I got three different positions at the company" (all independent types of jobs).

Diana quit her job once she obtained her PR status and Canadian citizenship because she wanted to have some respite after all the bureaucracy that these two processes entailed, and also to take some time off so that she could decide what to study for her master's degree. She returned to Mexico for a visit, and on her return to Montreal, the company she is currently working for contacted her. 'It's an opportunity that I wouldn't have gotten if I hadn't had the 5-year [work] experience with the other company." The company she is currently working for "is the biggest company in the world in [name of industry]. It's one of the most important companies in Canada." Currently, Diana is looking to obtain a technical certification rather than a master's degree, and she hopes to eventually work for the federal government in Ottawa, where her partner lives.

Ever since he was a child in Mexico, Jaime has always had an entrepreneurial spirit. While waiting for his PR status, he decided to open a cleaning company, hired three Mexican workers, and got six contracts with bars and restaurants in Montreal. At the same time, he began working for a craft shop using the craft knowledge he acquired during a previous stay in Vancouver. Jaime had already had the idea of opening his own craft store, and thus asked two Québécois acquaintances to invest with him in the opening of the store. Once they opened the small business, Jaime quit his job, and although the partnership dissolved some time later, Jaime kept the store and hired his own personnel. "The business is standard. I pay my bills every month, but I'm not making myself rich, no? I save money but it's hard. But at least the rent is paid and now it's paid with the work of others [i.e. employees], so it's not directly [coming from] my money, you know?"

Jaime closed the cleaning company after four years because "I was fed up" with cleaning. 
He sometimes thinks about opening his cleaning business again, but then he also mentions that "at the end of the day, the owners [of the restaurants/bars] are abusers" because they ask you to clean beyond what the contract stipulates. "They begin changing the rules, and if you don't follow them, then you're the abuser." Although Jaime never finished his bachelor's degree in Mexico, he mentioned that he has never felt the need to keep studying beyond what he did in Mexico, even if he would like to keep studying in Canada. "But what for? To ask for a job? I already went through that, you know? I'd rather like to grow my company and be able to open another store.”

While Edwards' (2015) reformulation of the segmented market theory focuses on differentiated labour processes and outcomes considering the types of jobs that workers hold, his theory does not address those who possess certain means of production and who are located at the other end of the spectrum, such as the self-employed and small business owners. Wright (2000) identifies cases such as that of Jaime as being shaped by a particular distribution of rights and powers over productive resources embedded in social relations. This distribution generates class relations that locate people in different, temporal, multiple or even contradictory class locations. Since Jaime is the owner of his own businesses, hires labour, and has not been in the paid labour force, except when he was a recent immigrant, he would be identified as a capitalist in Wright's (2000) scheme. ${ }^{53}$ In this sense, Jaime would be an exception to the rest of my respondents in terms of his location regarding the segmentation of the labour market.

\subsubsection{The Secondary $\Rightarrow$ Subordinate $\Rightarrow$ Independent Trajectory}

The rest of the youth followed different pathways in terms of the market segmentation jobs they acquired until arriving at an independent location. For example, seven of them followed the route secondary $\Rightarrow$ subordinate $\Rightarrow$ independent (i.e. Erika, Alberto, Orlando, Gabriel from Ottawa, and Jimena, Patricia, and Roberto from Montreal). In some cases, this was because they arrived quite young and, while studying either at a high school or post-secondary level, they began working in secondary types of jobs. They would only move onto subordinate type of jobs 
after they finished school and accumulated more Canadian work experience, allowing them to obtain an independent type of job later. Erika, for example, after enrolling at a university as an international student, got a job as a server at a restaurant where "all servers were Latinxs and Asian." Then she obtained a job as a customer service assistant at the student services centre of her university, as a babysitter of a Canadian-Mexican child for two years, and, after a couple of years after her arrival, as a research assistant.

Once Erika finished her BA, she decided to take a year off from school and began "looking for a job at the provincial government. Super basic jobs, and it was only business and engineering students who were taking all the jobs [in my area], which included planning and research. So, I ended up working in cosmetics, in retail! I was earning enough money, but I was too demoralized because I had just finished five years of education and had good job experience and... I end up working in retail" (i.e. secondary jobs). Erika stayed there for six months and decided to apply for a master's degree. While waiting for school to start, Erika began working for the City of [name of city] in customer service (a subordinate job), and then moved to Ottawa.

After her postgraduate courses finished, Erika did a co-op in the government, but once her program was over, she had trouble finding a job in Ottawa and decided to move to [name of city], where she found a short-term contract job at the City of [name of city] (subordinate job): "Look, the conditions for youth, even in Canada, are too precarious. I mean, nobody has a permanent job [anymore]. Everything is done through short-term contracts. Nobody gets benefits. [...] In four months, I'm going to be looking for a job again, and one invests too much money, time, and effort asking for a job that you're not going to get." At the moment of the interview, Erika had just obtained a full-time, permanent, independent type of job in her area of expertise at a nonprofit organization.

While Gabriel was waiting for his PR status (via a marriage sponsorship), he began working in furniture delivery with a Latino employer (i.e. secondary job). Once he learned 
English, and four years after having immigrated, Gabriel applied to a master's degree program. His experience was disappointing since the quality of the education he obtained was lower in comparison to the public, undergraduate education he received in Mexico. Besides, it was also Canadian- and US-centric, despite the international orientation of his field. Moreover, when Gabriel entered the program, "I felt it quite clear. I was seen like, 'Congratulations, you made it! You are in the first world! I felt like if they were saying, 'You don't know too much, but we'll teach you."”

Because of these experiences, he decided to trace his own route independently of the school's system. Gabriel began networking and obtained a paid internship at the most influential organization in his field. His school peers and teacher "suddenly said, 'What happened?' [...] How is it possible that he is so... [capable]? Gabriel also applied to and obtained a three-month teaching residence in the United States (a subordinate job): "I was working as a primary school teacher in neighbourhoods where everyone is Black and Latinx. It was a very enriching experience." Once Gabriel returned, he obtained a full-time permanent position at a school (an independent job). Parallel to his case, and before Gabriel immigrated, his Canadian partner had spent various years living in Mexico. But when she "got back [to Ottawa, she did so] without any network." She obtained a job at the federal government and worked "for seven years without a permanent contract. Every six months she had to renew it [...]. It was not until two years ago that she got a permanent contract and didn't have to be worried about looking for another job." Thus, in Gabriel's case, his class location ran parallel to that of his partner, being both located in subordinate types of jobs and then in an independent type location.

Roberto arrived in Montreal as a co-op French language student. This gave him the possibility of working for six months after he finished his course. Since his family owns a distribution company in Mexico, Roberto found a temporary job working in logistics for a company, covering someone on maternity leave (a subordinate job). However, because his 
student visa was about to expire, Roberto went back to Mexico and then returned to Montreal, enrolling in a college to study a logistics course. Roberto's parents were paying for his tuition fee and maintenance costs, but since he felt "bad that, just imagine, being a 23-, 24-year-old and still receiving money from my parents, like... it really bothered me." So, after eating at a Mexican restaurant and chatting with the owner, he was offered a job at the restaurant. The owner told him, "I want to organize my work team, and what better than having my working team with Mexicans that I know are hardworking" (secondary job).

Roberto began working as a dishwasher but was shortly promoted to waiter because he spoke English and French. Soon after, he was offered the position of manager (secondary job). Once Roberto finished his one-year course at the college, his name was entered into the school's pool of graduates and he was contacted by a transnational company that was looking to hire a logistics agent. Roberto, unbeknownst to him, competed against 14 other people, among them Québécois(es), Chinese, Indian, and Latinxs, but he obtained the job (independent job). He faced backlash from Québécois(es) co-workers later "because, 'Why? We have the best universities, the best schools. Why someone from outside comes and takes away the opportunity to work from someone that has obtained Canadian education, that has lived in Canada, that knows Canada?' For them it's quite hard to understand this, but as I tell them, it's not my fault to be better prepared." This apparent inequity was especially hard to understand for Québécois(es) who have worked for the company for many years, while Roberto had been in Canada for only three years.

\subsubsection{The Secondary $\Rightarrow$ Independent Trajectory}

Ildefonso from Ottawa and Karina from Montreal followed a shorter, secondary $\Rightarrow$ independent employment route. Karina came accompanying her husband who was offered a job transfer by his company to Montreal. Meanwhile, Karina volunteered for an NGO for four months to obtain the work experience that employers were asking for. "I noticed that many of the accounting processes [in Canada] are done in the same way that they're done in Mexico, although 
there were few things I didn't know about and I learned them there.” Karina and her husband never applied for a managerial position despite their management experience in Mexico. Rather, they worked as accounting assistants since they wanted to acquire some accountancy experience in Montreal first. And also because "they never hire you as a manager, you need to start from the bottom. [...] It's very easy to find Latinxs in cleaning jobs, they hire you to do that. But if you look for something else, like a manager position or something like that, it's going to be harder." Karina obtained a weekend job counting bills for a bank for a minimum wage, via a Manpower agency (secondary job), but her boss began asking her to speak French, which she did not know very well. At the same time, Karina developed an allergy because of her constant contact with the bills, and after consulting with a doctor, Karina was advised to quit that job for her own health.

Karina then found a job at a subsidiary of a Mexican media company. The company was looking for someone with accounting experience who spoke Spanish. Although she fit the job description, initially they did not want to hire her because "if I hire you right now, with the experience that you have, you'll get bored and you'll quit in a month." After promising them that she would not quit, they hired Karina and she has been working there for almost six years. She works as an accountant's auxiliary for an "average salary" (independent, middle layer job), and hopes to be promoted as a manager once her Canadian boss retires. But if that does not happen, "I'd still be happy because I like the job, it's close to my place, so I have many advantages."

\subsubsection{The Subordinate $\Rightarrow$ Independent Trajectory}

One more youth, Myrna from Ottawa, followed a subordinate $\Rightarrow$ independent employment route. After she finished her bachelor's degree and moved to a small Ontario city with her parents, Myrna obtained a job as a receptionist because:

you arrive at Canada and you are a nobody! I mean, you're an immigrant at the bottom of the social scale, the social hierarchy. And I wanted to have a real job, acquire work experience in a company, you know? Something related to what I studied. And I had to swallow my pride many times, and I ended up as a receptionist (subordinate job).

The job helped her, nonetheless, to practice her English and "learn how Canadian life worked in 
general: boyfriends, social relationships, the Canadian personal space! That we Mexicans don't have! The barbecues, um, well, the Canadian social code.” Myrna’s father, who spoke English and had acquired Canadian work experience working for Canadians in Mexico, immediately found a job in his field with a very good salary after immigrating. Myrna's mother had always been a housewife, but once in Canada, she learned English for a year and then took courses on anything related to job acquisition at a settlement agency. This helped her to obtain a job as a receptionist, and then as a community advisor (independent job). After two and a half years as a receptionist, Myrna applied for a master's degree, moved to Ottawa, finished school, and then got a job at an organization as instructor. It was a "professional [job]. I was earning my 60 thousand dollars per year"' (independent job).

Although the organization's job ad had requested fluency in French and Myrna was not that fluent, she got the job because they were also looking for someone who spoke Spanish for the "Latin American portfolio. So, it wasn't because of the French language, but because of the Spanish language that they gave me the job." Myrna then got another job at an NGO that sent her to Africa for three years, after which she came back to Ontario. At the moment of the interview, Myrna had just moved to another province, where her boyfriend obtained a full-time job.

\subsubsection{Independent Economic Integration by Extension}

Two other youths, Verónica and Mauricio, are located in the independent integration location, but by extension. This means that they have not had any independent job in Canada but are nonetheless located in an independent location because of their Canadian partners' class location. Verónica, for example, finished her undergraduate studies in Mexico and worked for the Mexican federal government for one year, then for a municipal government for two years, and then as an English teacher at a university due to connections her father had there. However, after "I knew that I was coming [to Canada], I started doing some research online and realized all the certifications [and credentials recognition] they were asking for [to obtain a job]. And then I 
began to realize like, 'Oh no! I need to start [my education] all over again!'”

When Verónica obtained her PR status, she was five months pregnant "and it seemed a little bit dishonest for me to get a job when I was going to work for four months, and then I would ask for a maternity leave. So, I waited to give birth to my child, but meanwhile, I began working as a bookkeeper. [...] My father-in-law has a family company along with my husband. So, I'm in charge of accounting." Verónica decided to take care of her newborn rather than keep looking for a job "because I'm not that much [into using] childcare services.” And although Verónica applied for various jobs once her child grew older, they never called her back. Her lack of Canadian work experience and the impossibility of obtaining credential recognition for her field of study did not facilitate her potential hiring. Nonetheless, since Verónica has a subordinate type of job for which she was not trained, but to which she has access due to the possibilities that her husband's location in an independent market segment has granted her, Verónica enjoys an independent economic integration by extension. Although Verónica has been learning a new profession, that of assisting in the company's accounting, her lack of a Canadian certification in this area does not allow her to look for a job as, for example, an auxiliary accountant. Thus, without the support of her new Canadian family, it is probable that Verónica's integration experience in Canada would be one of a secondary type of integration.

In Mauricio's case, after obtaining his PR status, he and his Québécoise wife moved to Ottawa because she wanted to study for a respected and high-earning profession outside of Quebec, and also because Mauricio does not speak French. After obtaining a bachelor's degree, he began studying for a master's degree. One of his friends, who used to work for an agency, helped him obtain casual jobs as a server at various events and as a mystery-shopper, but in this last job "I did it one day and I said, 'No, this is not my thing."” Mauricio has been looking for and applying for customer service jobs, but he has not been hired. Thus, whilst Mauricio's postmigration capitals and employment experiences in Canada locate him in a secondary type of 
integration, his Québécoise partner's upper-middle class location, intimately connected to her parents' same class location, situates Mauricio in an independent type of integration by extension. Mauricio's acquisition of Canadian capital (i.e. education and knowledge of official languages), along with his potential access to social capital by extension (i.e. that of his wife's family), might help him to be located in an independent category in the future.

\subsubsection{The Role of Gender in the Independent Type of Integration}

The interaction between the youths' pre-migration capitals and those they were able to acquire and/or convert in the Canadian fields, allowed them to follow different labour trajectories. And whilst gender played a significant role for some young women at the beginning of their immigration processes (see chapter 5), it did not have a marked influence for those respondents who came to be located in an independent location, except for Jimena (Montreal). Jimena's economic integration pathway is one characterized by a secondary $\Rightarrow$ subordinate $\Rightarrow$ independent employment route. After Jimena endured years of domestic violence by her Québécois partner and decided to get help from social agencies to deal with her situation, she also received support from the province of Quebec to acquire a short but useful technical education that landed her a subordinate type of job at a health and social services centre.

However, when Jimena realized that this job was emotionally affecting her, she once again obtained the support of Quebec's social agencies to identify another potential employment niche, acquire the necessary education to access that niche, and obtain the financial means to pay for this new credential. (i.e. economic and cultural capitals). It is here where gender was relevant for Jimena to access an independent type of job. Despite her lack of experience in her new knowledge area and an unsatisfactory performance during her internship, the female business owner agreed to hire her in a full-time capacity “because I believe in women's strength.” Thus, a grassroots, gender-equalizing process allowed Jimena to transition from a subordinate type of integration to an independent one, where she has been thriving. 
Among the rest of my female respondents, gender did not appear to play a major role in their transition to an independent integration. For instance, the social capital that Diana generated with professors during her studies, and which allowed her to obtain a full-time independent position, was not generated by her being a woman, but rather due to her own merits and previous Mexican education. However, in cases of family immigration, the mothers of my respondents were the most negatively affected, since their lack of capitals, such as knowledge of any of the official languages or social capital, put them in a more dependent and fragile position vis-à-vis the male breadwinner after immigration (the exception being Myrna's mother).

In the mid-1980s, scholars showed that Canadian settlement and immigration admission policies that identify women as dependents of males have negative consequences in terms of both their integration and personal accomplishment outcomes. For instance, Estable (1986) and Boyd (1986) found that these policies contributed to the socioeconomic stratification of immigrant women, their exacerbated problems of isolation, particularly for women who lack knowledge of any of the official languages, and further reinforced female dependency on the male figure. I still find evidence of these processes occurring among some of my participants' mothers thirty years later. Although women can apply as principal applicants to any of Canada's immigration programs such as the economic class, Canada's immigration policy still forces applicants to identify a main applicant or primary migrant, while the rest of the accompanying members (if any) are identified as secondary or dependent migrants.

Today, secondary or dependent immigrants are still overwhelmingly female (Elrick and Lightman 2016). Moreover, when one considers official language knowledge, one of the main drivers of economic and sociocultural integration, men are still:

more likely to be proficient in an official language than women, most of whom enter as spouses or dependents of principal applicants, or as sponsored family-class members or refugees. Adult male immigrants, who are usually heads of households, receive the major advantages of Canada's language training programs so that they can enter the workforce quickly. Programs for female immigrants who are not heads of households have a focus on "practical" rather than advanced or professional English (Kilbride et al. 2008:13). 
Research has also found that disparities in women's integration, particularly regarding their "failed attempts to obtain work and in limited social interactions" (Adamuti-Trache, Anisef, and Sweet 2018:29), are produced by their post-migration context: "[I] solation and lack of information; family obligations; and cultural barriers, including patriarchal practices and the expectation of women that they carry the main responsibility for the cultural socialization of children"' (ii), still constitute key barriers for immigrant women to learn, for instance, any of the official languages.

These disparities affect the balance of power in women's personal and family lives and intensify their multiple burdens as wives, mothers, and workers (see also Abu-Laban 1998; Agnew 2009; Boyd 1984, 1992, 1997; Boyd and Pikkov 2005; Creese 2011; Creese, Dyck, and McLaren 2008; $\mathrm{Ng}$ 1990). However, what this previous research has sometimes overlooked is the various ways in which pre-migration family configurations and the differentiated distribution of capitals among its members (and thus power) are already pre-determining the location of women inside the family, thus shaping the roles and possibilities that women may have after immigration. Namely, in the case of some Mexican immigrants, the way in which traditional and patriarchal values are deployed among family members before immigrating, along with Canada's immigration and settlement structuring fields, strongly collaborate in the post-migration, downward location of some wives/mothers inside and outside of the household.

\subsubsection{Canada's Labour Market Configurations and North American Economies in a Global Scenario}

There are other two important aspects that allowed some of these youth to be located in an independent location, and which relate to the generation of transnational fields from above: first, the articulation of some Canadian labour markets with the broader global economy, and, second, the intensification of transnational commercial ties between Canada and Mexico. For example, the articulation of certain global consumption demands that involve digital visual design with Canada's digital animation market niche favoured Alberto's economic integration in Ottawa. After his family immigrated to Ottawa, Alberto decided to study digital animation, and since his 
college has direct links to the needs and development of that industry, his education allowed him to be on the right track for future employability. "Ending my second year, two teachers recommended me to two different jobs, and I chose the one where I'm still working at."

The pairing of these global markets' needs with Alberto's cultural and social capitals acquired in Canada opened the doors for him to find a job even before graduating. However, he began working on commission during the summer (subordinate job), doing piecework, earning a dollar and some cents a piece in an industry where workers are usually commissioned 800 pieces per week. And although he initially made fewer pieces, his productivity increased over time. Nonetheless, Alberto decided to quit and finish his education even when a credential is not necessary in this industry but rather work experience. Moreover, he witnessed firsthand how recent graduates who have no work experience but are more qualified are not hired, with jobs going instead to those who already have work experience in the industry. Nonetheless, he considered that acquiring cultural capital could help him access other similar markets in the future. "My bosses told me, 'It's your decision. We have an open space for you. You can come back whenever you want." Thus, once Alberto finished his technical career, he was immediately hired by his former company and, due to the quality of his work, was shortly promoted to supervisor and made part of the permanent staff at age 21 (independent job).

The needs for a particular set of skills and knowledge of some global consumption markets are thus closely connected to Canadian companies that feed this market. At the same time, these Canadian companies are connected to local academic institutions that cater to the former's needs through the delivery of updated, specialized curricula and the training of human resources. In addition, Alberto's pre-migration field, where acquiring cultural capital is an important, constitutive part of his class location, allowed him to generate cultural and social capitals once in Ottawa. These capitals, in turn, facilitated his entry into a specialized labour field where he was able to easily exchange his newly acquired capitals for an independent job. In contrast to his 
successful economic integration experience, Alberto's parents' integration has been problematic, since their profiles do not necessarily match the needs of the Canadian labour market. His father, for example, who had a very good administrative job in Mexico, "was trying to find a job with the same position for almost a year, but he couldn't find it, so he had to work on other things, like insurance and that kind of stuff, like sales jobs" (subordinate jobs).

Alberto's mom, besides being a housewife, also used to teach wellness courses in Mexico. Once in Ottawa, she remained a housewife until she was able to obtain an administrative assistant position (a subordinate job). Despite their independent, upper-middle class location in Mexico, Alberto's parents' economic integration corresponds to a subordinate type of integration in Canada. Their lack of Canadian capitals (i.e. education and Canadian work experience), the father's medium level of English knowledge, their lack of use of settlement services on arrival, and the depletion of their savings due to differential exchange rates and higher prices in Canada did not permit them to be located in an independent location. Moreover, their pre-migration employment areas are not connected to local, transnational, or global markets, which also limit their post-migration economic integration.

At the same time, however, Alberto's family's subordinate integration context offered him an economic springboard to access certain Canadian fields and acquire diverse local capitals. This eased his transition to his current independent location. Namely, since Alberto still lives with his parents, he has not had to worry about paying for housing, services, and/or food. This is because, in Mexican culture, children are not expected to pay their parents for any of the house-related expenses or even leave the parental home until they get economic independence and/or start their own families. Moreover, Alberto also received the support of his high school counsellors, who presented him with post-secondary education options and helped him decide what was best for him based on his expectations and likes. They also offered him guidance to obtain Ontario Student Assistance Program (OSAP) support to pay for his education, ${ }^{54}$ since “my parents' weren’t able to 
pay for my college" (another Mexican cultural expectation is parents paying for the children's postsecondary education whenever possible, especially among middle and upper classes).

The scant literature about young Latinxs in the Canadian education system points out some negative experiences they undergo due to their Latinness. These include being suspended or expelled from school, being identified as problematic, being placed by teachers on a trajectory of low expectations that might lead to low academic achievement, achieving low grades and, consequently, producing a higher rate of high school drop outs, as well as a perception that teachers prefer students from ethnolinguistic and socioeconomic groups other than Latinxs (Bhattacharjee 2003; Creese, Ngene Kambere, and Masinda 2011; Daniel and Bondy 2008; Gaztambide-Fernández and Guerrero 2011; Guerrero 2009; Schugurensky, Mantilla, and Serrano 2009). In contrast to these experiences, Alberto had a positive experience in high school that also helped him to jump into an independent type of economic integration.

I have already mentioned some of the micro-level conditions that led Diana to be located in a successful, independent location. But there was another structural factor that facilitated her quick economic integration in the independent category, namely her company's industry profile and its location in the global economy, which necessitated and matched Diana's education in Mexico and Canada. Indeed, Diana's experiences at her company reveal how the strong global orientation of the company also dictates the 'official' language at work, which is English, despite the company being located in Montreal. This preference for the English language, however, is also located at a historical point of contention between Anglo-Canadian and Québécois(es) capital owners. This is because language has played a more relevant role in politico-economic terms than just being limited to a specific form of communication due to their different settler-colonial histories (see Dickinson and Young 2008; and Linteau et al. 1989, particularly chapter 31).

Diana's company's orientation and its Anglophone system of communication also led Diana to not feel a need to learn French in Montreal: "I speak a very basic French, a medium level. 
Honestly, French is not my forte. That's one of the reasons for which I work in this company; here, everything is in English. And the French is for the street, something I've learned from my friends, coworkers, the TV or radio.” Thus, Diana's successful integration has also been shaped by global processes of expansion and accumulation of capital. While these processes (and outcomes) have facilitated her independent location, they have also shaped her linguistic integration in Montreal and, consequently, the limits to which she can relate to the Québécoise culture and thus socioculturally integrate in Montreal.

Language was also relevant in Karina's integration in Montreal. When Karina's husband accepted a job transfer from Mexico to Montreal, offered by his Canadian company, the transfer also shaped the labour culture inside his company. This was because many of the transferees were Mexicans and spoke Spanish among themselves at the workplace and English with other coworkers or the bosses, but not French. In Karina's case, she was hired by a Mexican company in Montreal, where "almost everyone speaks Spanish but the bosses; they speak English and French, but more English. So, since my English is good, I'm okay.” Karina learned English and some French at private schools in Mexico, and then she took a few French courses after moving to Montreal. However, in Karina's daily life "almost everything is in Spanish, and when I buy something it's in English," but little to no French. Her company's orientation, which has a continental scope (i.e. from Mexico to the Southern cone) is composed of around $80 \%$ Latinx employees, while management is composed of only Canadians, mostly Anglophones.

Thus, the expansion of Mexican transnational capital to Canada, while granting Karina an independent type of job, also shaped her linguistic and sociocultural integration in Montreal and the extent to which she relates to the Québécoise culture. In Diana and Karina's cases, then, their independent economic integration, shaped by a transnational expansion of capital, has structurally distanced them from the Québécoise culture, even if they live in Montreal. Consequently, despite Quebec's intention of promoting and reinforcing immigrants' allegiance to Quebec, the 
orientation and deployment of capital in global cities such as Montreal shape the internal configuration of the companies in which capital operates. This is seen in terms of both an ethnic division of labour and the development of an institutional culture within the companies, including language, irrespective of the geographical site where capital is deployed. This also has a spillover effect on other immigrant integration arenas, such as "the street" or the more general integration process within Quebec society. Canada's labour markets' articulation with the global economy, along with the expansion of capital in a transnational space between Mexico and Canada, thus collaborated in opening opportunities for some youth to acquire an independent location.

\subsection{Discussion: Pre- and Post-Migration Locations Leading to an Independent Location}

I found four key areas where Mexican youths' pre-migration location interacted with their post-migration location and capitals, assisting them in achieving an independent type of economic integration: 1) language, 2) education, 3) social capital, and 4) work experience. Regarding language, two-thirds of my respondents immigrated with a medium-to-high level of proficiency in French and/or English. The acquisition of this cultural capital in Mexico and/or abroad, reflects a pre-migration class location closely related to a medium or upper-medium economic stratum in Mexico. Thus, even before immigrating, some of these youths were able to acquire one of the key Canadian capitals for economic integration (i.e. language). Once in Canada, they were subsequently able to exchange this capital in the labour market.

Although migration may facilitate the dislocation between the logic of practice, habitūs, and fields, consequently producing hysteresis (Bourdieu 1990a), this dislocation does not necessarily lead to (im)migrants' immediate change of disposition. Certainly, my independently located respondents spoke, for instance, about how they had to learn to navigate their new fields and acquire some new habitūs, which took them some time. However, at a more structural level, it was noticeable that their pre-migration class location and capitals, an expression of their social location in specific Mexican fields, partially facilitated their independent integration in Ottawa or Montreal. 
For some of these youth (or their families), economic capital allowed them to pay for and thus attend private schools and language schools in Mexico or other countries even before immigrating.

This cultural (and economic) capital granted them symbolic capital and distinction in their Mexican fields. But their class location in Mexico also collaborated in their acquisition of more cultural and social capitals in the Ottawa and Montreal fields after (im)migration. For example, some youths came fully sponsored by their parents as international students either to study one of the official languages, attend high school, or pursue a technical career. This transportability and exchange of capitals that happened between Mexico and Canada indicates (even if not all capitals can be exchanged or be portable in every field) that the capital obtained by these youth responded to fields that are not necessarily delimited by national borders. Rather, their acquisition of capitals partially responded to and are developed by the expansion and accumulation of capital at transnational and global levels. This accumulation and expansion of capital assign some value to certain capitals (e.g. knowledge of English language), which are then sought by some of those who already have the necessary capitals to acquire (even more) capitals.

LANGUAGE. Variation in pre-migration social location also shaped the experiences of other youth when accessing and obtaining various capitals once in Canada. For instance, among a few participants who immigrated with a basic knowledge of any of the official languages, it was their immersion in the local Canadian or Québécois day-to-day activities that helped them to improve their language knowledge. In these cases, it would take them at least a couple of years to achieve a language level appropriate for a better job. In two other cases, some youths learned French for political or family reasons, and in one of these cases ideological reasons also shaped their decision to immigrate to Quebec rather than to any Anglophone part of Canada. Thus, the learning of a second and even a third language (i.e. French and English) stemmed, besides from their social class, from previous transnational connections that arose from familial or more ideological reasons. 
I also found some respondents who never learned a second or third language or did not do so at an advanced level before immigrating to Canada, even if their pre-migration class location could have easily allowed them to do so. This was because these youths had not thought about immigrating and/or because the distribution of capitals inside their households restricted their access to certain capitals (as shown in chapter 5). Thus, since the acquisition of capital directly responds to a person's location in certain fields, the acquisition of capital that responded to Canadian fields was not on the horizon of these respondents. This lack of capital created some complications in their initial settlement process and navigation of Canadian fields, since, for instance, the language learning curve was substantial.

Moreover, the difficulties in acquiring any of the official languages led these youths to experience a psychosomatic process characterized by frequent headaches, a general physical experience of being unwell, and also a sense of social rejection. In Gabriel's case, for instance, his lack of English knowledge led him to experience constant problems with his partner to the point that he thought about returning to Mexico for good, even though he had come sponsored via marriage. A few other respondents also studied the other second official language some time after having immigrated. They did so because they were now fully immersed in the Canadian fields and realized that learning another language, particularly French (i.e. Canadian capital) would increase their employability in Canada. This strategy also signals how these youths had already increased their level of mastery in their new Canadian fields, and thus deployed a strategy seeking social mobility.

EDUCATION. Education obtained in Canada constitutes the second arena where youths' pre- and post-migration locations and capitals interacted to locate them in an independent location. Two-thirds of my respondents who immigrated as young adults had already finished their bachelor's degrees in Mexico when they immigrated, thus bringing with them some cultural capital. In a couple of cases (i.e. Diana and Gabriel), my respondents considered — based on their 
experience - that the education they received in Mexico (either at public or private schools) was about the same or of a superior quality than that obtained in Canada at post-secondary and postgraduate levels. This is something I also found in Vancouver among some Mexican youth who studied in private schools in Mexico (Hernández-Ramírez 2012). In addition, almost $80 \%$ of my respondents acquired (or are acquiring) Canadian education, either starting at high school or at a bachelor's or a master's degree level. Indeed, Mexican education (along with other postmigration capitals they acquired, such as social and Canadian capital) was relevant for some of my respondents to obtain an independent location once in Montreal and Ottawa, since it accorded them knowledge that was valued by employers. Moreover, for these youth, recognition of foreign credentials was not an issue since most obtained a Canadian credential.

In the case of those youths who came at younger ages, their entrance into the Canadian education system since high school helped them not only to learn English, but also learn about Canadian fields and acquire (and even complement) some other habitūs. However, knowledge of both languages or even Spanish had little relevance among three respondents, since the value of this capital was rather determined by the needs of capital and the economic orientation of the companies that hired them, irrespective of the major language spoken in Montreal or Ottawa. Thus, as theorized by Bourdieu (1990a), the value of certain capitals is determined by the configuration of the specific field and the recognition of those capitals as having certain symbolic power.

Social CAPITAL. A third area where pre- and post-migration locations interacted was in the generation and use of social capital in Canada. The type of relations that some of my respondents (i.e. Diana, Alberto, and Jimena) built with professors or acquaintances were in part facilitated by their previous class locations and habitūs in Mexico (e.g. attending private schools and obtaining good grades, which in turn facilitated their relations with professors once in Canada, and thus the generation of social capital). These Mexican habitūs thus collaborated in their getting acquainted with important Canadian gatekeepers and navigating the school fields. 
Although the generated social capital in these three cases was short in duration because it was not further cultivated, it was fundamental for these participants to later have access to Canadian/ Québécois economic fields and obtain an independent location. The relevance of social capital as an entry fee to independent fields was revealed in cases such as that of Alberto, who discovered that more qualified applicants did not get jobs in his area of digital animation, but only those with more social capital. Thus, even if some young people are better prepared than some of those who are already working in certain global industries, the former are disadvantaged because of their lack of social capital in that field. Here, again, the high value given to social capital over cultural capital was determined by the configuration of the specific field.

In other cases, the way in which jobs are allocated to youth signal, on the one hand, that possession of cultural capital is not enough to access certain fields if their gatekeepers also consider other elements in their hiring decision process, such as social capital or other characteristics of the capital holder (such as race, age, and able-bodiedness). Moreover, gender, age, or city did not seem to be major factors that influenced the acquisition of Canadian and social capital. For example, Alberto obtained a full-time, independent job at age 21 with the social capital he generated at age 20 in Ottawa. And Diana obtained a full-time, independent job at age 25 with the social capital she generated at age 24 in Montreal. Certainly, the types of markets available in each city also shaped the possibilities to access certain types of jobs. In my sample, some of the youth located in Montreal obtained jobs at global companies, whereas other youth obtained jobs that responded to one of Ottawa's employment markets, such as technology. Nonetheless, as demonstrated before, social capital (derived from the interaction between pre-migration and post-migration class locations) showed itself to be a significant factor in the type of employment acquisition.

WORK EXPERIENCE. A fourth element where pre- and post-migration class locations interacted to obtain an independent location, and which applied to most of these youth, was previous experience in secondary and/or subordinate jobs. In some cases, this reflected age at 
arrival, since some youth arrived quite young and, like other young Canadians, obtained their first jobs in the secondary market. In other cases, their pre-migration lack of knowledge of any of the official languages and lack of Canadian work experience did not help them to obtain either subordinate or independent types of jobs sooner. Rather, they were funnelled into a secondary location.

Secondary and subordinate experiences (along with their pre-migration capitals) nonetheless allowed these young immigrants to acquire familiarity with the ways in which job expectations, rules, and norms are deployed in various Canadian employment fields. And for those who immigrated at an older age, this also helped in their integration processes, since the Canadian workplace assisted them in learning some of the broader Canadian habitūs. Moreover, their secondary and/or subordinate jobs, besides facilitating their learning of new habitūs, constituted valuable Canadian capital that they exchanged in subsequent jobs since now they could behave, to a certain extent, "like fish in the water." This means not engaging "in rational computation in order to reach the goals that best suit their interests [in the workplace]. All they have to do is to follow their dispositions, which, being adjusted to their positions, 'naturally' generate practices adjusted to the situation" (Bourdieu 1990a:108).

Thus, depending on the type and amount of social capital they generated in Canada, and the value that the diverse Ottawa and Montreal employment fields assigned to my respondents' pre- and post-migration capitals (i.e. education, knowledge of any of the official languages or Spanish, as well as Canadian work experience), the probabilities for their capitals to be considered as entry fees and grant them access to independent jobs increased or decreased accordingly. In addition, the inter-relationship between the types of pre- and post-migration capitals a person had, her age at arrival, along with the particular state of employment markets, also shaped their economic integration possibilities.

It is important to note that although some young immigrants shared the same types of 
capital, each of their capitals was assigned a different value in their Canadian employment field, revealing how the latter's configuration also modifies the rules of the game and grants differentiated access to that field. For instance, an overvaluation of (Canadian) social connections in the Canadian employment field funnels immigrants and refugees without social capital into secondary types of jobs, leading them to a deskilling process (as initially happened to Erika). This is because, once in a secondary integration pathway, it is harder to keep developing skills and education or acquire more professional experience that may facilitate their social mobility, further devaluating their capitals. This process may also be exacerbated by higher unemployment rates among youth, particularly when compared to the general population in Canada, what Chung, Lauer, and Chan (2009) call the 'hidden deficit'.

An independent location can also be achieved by extension in Canada's immigration fields if the immigrant or refugee's Canadian or Québécois(e) partner belongs to an independent location, extending the effect of their class location to the partner. This occurs irrespective of the former's type of economic integration. One of the advantages of being located in an independent location by extension is that the immigrant or refugee can benefit from the partner's capitals, such as economic and/or social capital, to potentially use them to acquire Canadian capital, facilitating their individual achievement of an independent location. Nonetheless, this can also be a doubleedged sword, since it forces the immigrant or refugee to depend on the partner's capitals to be located in that type of economic integration (i.e. economic dependency), particularly when the type of integration of the non-Canadian partner is of a secondary type.

Although gender was an element that shaped some young women's initial immigration processes (in contrast to men), gender was not recognized as a relevant factor among my female respondents for them to be located in an independent location. Rather, it was their own merits and circumstances that allowed them to experience this social mobility. The only exception to this was Jimena, who was offered an informal, grassroots equity measure by her female boss after she 
finished her second technical career and her one-month co-op.

The articulation of capital's needs and its development in transnational and/or global economies also led some companies or organizations in Montreal and Ottawa to require certain non-Canadian capitals from their new hires, such as knowledge of Spanish or Latin American cultures. Under these conditions, immigrants' capitals acquired a new valuation. Rather than these capitals being devalued for being Mexican, as one might expect, the global and transnational demands of the expansion and accumulation of capital (re)valued them (i.e. they became transnational capitals). This is an apparent contradiction because non-Canadian capitals are usually seen as having little or diminished value in Canadian employment fields.

Nonetheless, for these Mexican capitals to be converted into transnational capitals in a Canadian field, the immigrant had to previously acquire a minimum of Canadian capitals to guarantee their entrance into that Canadian field (i.e. Canadian work experience, education, and knowledge of one of the official languages). And for someone to acquire these capitals, the person needed to have a number of pre-migration capitals to be able to immigrate and unlock various national and transnational doors once in Canada. Thus, the interaction between pre- and postmigration capitals and class locations in a transnational field is not only a complex and subtle one, but one that also extends across time.

Moreover, the articulation of capital at the local, transnational, and global scale has also shaped the employment culture of some companies, such as some of those located in Montreal. Here, English is constituted as lingua franca, shaping the extent to which their employees integrate in Montreal not only in linguistic terms, but also in broader social and cultural terms at the sub-national level. This is because their need to learn and use French is almost non-existent. Consequently, whereas Quebec is intent on securing a cultural allegiance from immigrants as part of its immigration policies (see chapter 5), the effect of global and transnational capital and its Anglo orientation hampers this intention, furthering the historical settler/colonial division in 
Canada. Finally, as mentioned in chapters 5 and 6, for some of my respondents, part of their consideration in their decision to immigrate to Canada (or that of their parents) was because they were looking to improve their social and cultural conditions, and only sometimes their economic circumstances.

Among those families who immigrated to maintain their pre-migration economic class location, threatened by macro-structural circumstances, their children were indeed able to achieve an economic independent location (i.e. Myrna, Alberto, and Orlando). Thus, the parents' goals for their children were accomplished via immigration, even if in two cases they were not able, as parents, to achieve an independent location themselves, but rather, a subordinate one. The children's independent location would have been more difficult to achieve, nonetheless, if they had not had their parents' subordinate location support, which operated as a safety net and springboard in Canadian fields. Thus, in some of these cases, economic integration has been a family and generational achievement rather than solely an individual one.

Although previous research has unveiled the positive effect of the acquisition of Canadian capitals in the integration processes of immigrants (even if in the long term), my research has unveiled less explored arenas in migration studies. I have shown here how there is a constant interaction, across time, between immigrants' and refugees' pre-migration and post-migration class locations and capitals. This interaction, which shapes their (independent) economic integration in Canada, occurs not only in their new Canadian fields but also in newly created transnational fields. These fields, in turn, are shaped by the expansion and accumulation of capital at local, transnational, and global scales. In the following chapter, I analyze how the relation between pre- and post-migration class locations led other youth to be located in a subordinate type of integration. 


\section{Chapter 8: The Subordinate Type of Economic Integration}

In Chapter 7, I showed how pre-migration capitals, age at arrival, the acquisition of new Canadian capitals, and family support in cases of family migration or the partners' location (i.e. integration by extension) shaped the post-migration location of some Mexican youth once in Canada. This, paired with the needs of transnational or global markets that required or strongly value some of their capitals, facilitated their transition into an independent type of integration. In many cases, it was shown that having Canadian or Québécois social capital, even if it was not further developed, ended up being essential. Nonetheless, not all my respondents are located in an independent location.

Literature on immigrant integration in Canada has unveiled the inner contradiction of Canada's immigration policies since the 1970s. On the one hand, they promote the immigration of those considered the 'best and brightest' from around the world. This has been done under "economic and demographic terms, [since immigrants are seen] as a component of 'building the nation,' [a] pillar of economic prosperity, and an antidote to declining fertility" (Hiebert 2016:5).

On the other hand, some of the 'best and brightest' face difficulties in obtaining a job that corresponds to their pre-migration cultural capital and/or work experience. For example, Carolina, a well-paid administrator in Mexico, working for an American company, mentioned how:

when we went to the talks that the Délégation offered in Mexico [City], they told us that [Quebec] was a land full of opportunities, that there was plenty of work, that it was easy to get a job and all that. So, I came with that idea; my partner thought the same thing, right? She came with that very same idea. That this is a land of opportunities. That we'll do very well. And when we came here, [we faced] reality.

In this chapter, I focus on the reasons and conditions that led 12 of my 35 respondents to be located in a subordinate type of integration. The chapter is divided into four sections. First, I analyze the relevance of having official language knowledge and Canadian education and, second, I delve into two employment trajectories for some Mexican youth to be located in this location. Third, I analyze the role of gender and sexuality in some of my respondents' employment trajectories. And fourth, I present an analysis of how the interplay between pre- and 
post-migration class locations, as well as changing labour market conditions, collaborated to locate some of my respondents in the subordinate location.

\subsection{The Relevance of Official Languages and Canadian Education (Canadian Capital)}

Twelve youth (seven women and one man from Ottawa, and two women and two men from Montreal), or one-third of my participants (34\%), are located in a subordinate location. The average age when they arrived in Canada was 19 years, although this average does not refer to the age when they obtained their PR status. Similar to my respondents in the independent location, these youth came either through the economic class (eight people, three of whom came as part of family economic immigration) or the family class (four people, three of whom came via a marriage sponsorship and one by adoption) (see Table 9). None arrived in the refugee class.

Table 9: Mexican Youth in a Subordinate Type of Integration by Gender, City, and Immigration Class

\begin{tabular}{|l|c|l|c|l|}
\hline Respondent & Sex & City & $\begin{array}{c}\text { Years in } \\
\text { Canada }\end{array}$ \\
\hline Ivette & F & Ottawa & 14 & Economic, CECP \\
\hline Griselda & F & Ottawa & 9 & Economic, CECP \\
\hline Andrea & F & Ottawa & 12 & Economic, Family Migration FSWP \\
\hline Deyanira & F & Ottawa & 5 & Economic, Family Migration FSWP \\
\hline Teresa & F & Ottawa & 29 & Economic, Family Migration QEP \\
\hline Gilda & F & Ottawa & 4 & Family, Marriage Sponsored \\
\hline Artemisa & F & Ottawa & 4 & Family, Marriage Sponsored \\
\hline Román & M & Ottawa & 18 & Family, Adoption \\
\hline Joaquín & M & Montreal & 9 & Economic, QEP Graduate \\
\hline Carolina & F & Montreal & 4 & Economic, QSWP \\
\hline Miriam & F & Montreal & 10 & Economic, QEP TFW \\
\hline Javier & M & Montreal & 13 & Family, Marriage Sponsored \\
\hline & & Mean & 10.9 & \\
\hline & & Median & 9.5 & \\
\hline
\end{tabular}

LANGUAGE: Two of my 12 respondents arrived with a medium-to-high level knowledge of one of the two official languages (Gilda from Ottawa and Javier and Carolina from Montreal), and three knew both languages (Griselda from Ottawa, and Joaquín and Miriam from Montreal). These respondents were young adults on arrival, but I also found other youths who arrived as children (i.e. Teresa, Román, and Andrea from Ottawa) or teenagers (Ivette and Deyanira from 
Ottawa). They arrived with no knowledge of either of the official languages but quickly learned one of them. Artemisa and Carolina, who arrived as young adults, had only a basic knowledge of one of the official languages (Artemisa is also currently studying French).

Those youths who came as part of family economic immigration or through the family class, and as children or teenagers, learned English and/or French at school after having immigrated. Ivette's parents had initially suggested that she come to Canada and study English, but then she convinced them that it was better for her to learn English while doing her last two years of high school. Ivette registered at a high school in a small Ontario city, at age 15, and took English as an Additional Language (EAL) courses. But since she stayed at a Latina homestay and they spoke Spanish, her English did not improve much. This was later reflected when she moved to Toronto to study at a college because "I still struggled [with the language] a little bit." However, since much of the college schoolwork was done in teams, she found it easier to bypass the English language demands. Hence, despite having been in Canada for thirteen years, Ivette considers that her English is currently at an $80 \%$ level.

Deyanira, who arrived at age 17, never learned a language other than Spanish even though her parents came to Montreal to do their PhDs years before. 'I didn’t know any English whatsoever, nothing. My siblings knew the basic words, what you are taught at school [in Mexico]. The language was an additional shock [after immigrating], one of the first ones... it was tough.” Deyanira took EAL courses at her high school to compensate for her lack of English knowledge. After his aunt adopted him and he moved to Montreal at the age of eight, Román: ... basically, ended up going to a French school, so I was basically learning French and English at the same time. [...] And I didn't have the easiest time, like, adapting to school here [in Montreal] because I had such a thick accent. [...] the kids were like literally making fun of my accent. I think that lasted until high school in Quebec. In Quebec it's like Grade 8, and then I started losing my accent, and it got better from that point. Um... but I did find that having like that [Mexican] accent, it didn't help.

Román mentioned that he did not feel that French was a language of his own, and "as odd as it sounds, I don’t identify as [...] French [i.e. Québécois] in any way.” And since "I never quite... I 
don't identify with the Quebec culture, the French culture at all," he did not want to keep studying in French, thus Román moved to Ottawa to obtain his bachelor's and MA degrees.

Other youth acquired a high-level knowledge of one or occasionally both Canadian official languages in Mexico or in other countries even before immigrating, signalling in most cases their middle or upper-middle class location. For example, in Griselda's case, "my parents registered me at a bilingual school since second grade. Half of the day was in English and the other half in Spanish. In the north [of Mexico] having English is quite common, not common but it's like an advantage." Griselda then studied French during her last two years of high school. "And after high school I went like for a year to France with a family as an au pair [...]. So, I lived with a family and there... I even perfected it, no?"

Joaquín's parents went to study to the United States when he was nine years of age, where he took EAL courses and after a year became fluent in English. Years later, when he finished his bachelor's degree in Mexico, he took an immersive French language program in France for three months, and then went back to the United States to volunteer at a research laboratory, where he kept studying French for a year "with a gringo accent." However, after moving to Montreal to do his master's degree at an anglophone university, mastering the English language "was a little difficult. I'd never taken courses at an advanced level in another language.” Moreover, working and living in an anglophone environment also reflected on his experience, since he rarely needed to speak French in Montreal.

Miriam studied English and French at her university in Mexico, and since she wanted to immigrate to Montreal, she registered for extra French courses. Once in Montreal, she also took all the francization level courses, and "up to now I'm still trying to improve my French. I read in French, I watch TV in French, I socialize in French, but it's true that, depending on the employment sector, the French language [requirements] can be more demanding than in other sectors." Miriam also found that speaking Spanish was an asset in the service sector: Any place you go you have the need to speak in English and French. It's true that, as 
Hispanic persons, Spanish gives us a plus. There're more people settling down here, people who speak Spanish, so that gives you an extra value. But it's [also] true that, in employment matters, [speaking French] is a total challenge. It's not easy at all.

For some participants in Montreal, the particularities of the Québécoise French brought some difficulties in their learning of the language. As Miriam mentioned, "one of the challenges is the local [Québécois(e)] clientele because they have their own jargon, their own accent and ways of expressing themselves. And that's where you find the challenge, because it's also a cultural one. You didn't grow up with those physical or language expressions, so you must understand or adapt to what people are trying to say." At the moment of the interviews, four of the twelve participants knew the two official languages (Griselda, Teresa, and Román from Ottawa, and Miriam from Montreal), two more knew one language and had a medium proficiency level in the other one (Gilda from Ottawa and Joaquín from Montreal), and the rest knew only one language. EDUCATION: Like those located in the independent type of integration, most participants in the subordinate position studied or are studying in Canada (10 of 12 participants or 79\%). This is partly related to the fact that five participants arrived as children or teenagers, and thus were incorporated into the Canadian education system from primary school (Andrea, Teresa, and Román from Ottawa) or high school (Ivette and Deyanira from Ottawa). Two other participants initially came to obtain a master's degree in Canada before acquiring PR status (Gilda from Ottawa and Joaquín from Montreal). And Miriam successfully received two certificates in Montreal after obtaining her PR status.

Two other participants who came via the economic class started their post-secondary studies in Canada after they got PR status, but they interrupted them for various reasons. Griselda applied for a master's degree whilst working full-time in Ottawa. But since she was offered a scholarship and teaching assistantships, she quit her job when she realized that the school workload was too much for her. Nonetheless, she left the master's program later because when the time arrived for her to apply for a co-op, she was told that because she was not a Canadian citizen (even though she had PR status) they could not guarantee her the co-op she wanted at the 
federal government. Griselda ended up doing her co-op in the United States. Once in Ottawa and disenchanted with the program, Griselda withdrew and found an administrative job.

Carolina, despite her good pre-migration economic stance, did not have a strong knowledge of French. But because she pooled resources with her partner, who was the main applicant in the immigration process, this helped her to limit the potential negative impact of her basic knowledge of French in their QSWP application. Once in Montreal, however, Carolina went through a slow language learning process, and thus was not immediately able to look for a job. After Carolina obtained her recognition for her certificate and started looking for a job in Montreal, she also enrolled in a certificate program at a prestigious school, but, "Oh surprise! The way of studying here is quite different [than the one in Mexico]. It was really hard for me to understand [this way of studying], and in the middle of the process I said, 'No, I can't deal with this." Carolina quit the program and enrolled in a shorter, technical course in her professional area at the Commission Scolaire de Montréal. However, she abandoned the course because she got a full-time job at a small business.

Two people, Artemisa from Ottawa and Javier from Montreal, were the only respondents who had not studied in Canada. Artemisa is a relatively new immigrant who studied for a technical career in Mexico with limited employability scope. She is currently volunteering for an organization to obtain work experience as per the recommendation of an immigrant agency. After Artemisa and her partner moved from Alberta to Ottawa, he obtained a secondary job at an entertainment organization, which allowed him to obtain other secondary jobs until he got a fulltime, subordinate job at the same organization. Thus, it is Artemisa's partner's location that situates her in a subordinate type of economic integration rather than her own trajectory, since her own integration experience would put her in a secondary location. Javier was studying a bachelor's degree when he decided to pause his education because "I wanted to travel." His first destination was Vancouver, and once there he met his partner who married and sponsored him. 
Since then, Javier has not furthered his education in Canada. When I asked him if he would like to keep studying, he mentioned that "life has taken me through other paths," pathways where he has not needed education for him to be happy or do what he likes, which is working as a chef.

Two other people were quite young at the moment of the interview and thus were at the beginning of their post-secondary education. Andrea recently finished high school and was saving money to study film in another city. And Deyanira, after she finished high school in Toronto, applied to the seven best health sciences schools in Canada. She moved to Ottawa because a university offered her the highest scholarship. However, Deyanira's decision to do a BA, even when this was expected due to her family's Mexican class location/habitūs, brought a lot of tension to her family because of their precarious economy despite their previous pre-migration middle-class location. And although her parents could not financially support her, something that would have been different had they stayed in Mexico, they did support her goal of studying. Deyanira was only able to keep studying because "someone told me about OSAP, which is the miracle of every student."

\subsection{Employment Trajectories of Mexican Immigrant and Refugee Youth in Canada}

A common experience among youth in the secondary location is that they have followed a secondary $\Rightarrow$ subordinate trajectory, although I also found the secondary $\Rightarrow$ subordinate $\Rightarrow$ secondary $\Rightarrow$ subordinate trajectory. In both cases, however, the subordinate location is the maximum level they have achieved. For those who immigrated at younger ages, a young age at arrival and age at the moment of the interview explain why their employment trajectories are still in development and why they are located in a subordinate location. However, their integration processes have been strongly influenced by those of their parents.

For example, in Andrea's case, her mother's employment experiences in Ottawa have been characterized by a precarious insertion into the labour market. Andrea's mother, who was a professor at a private university in Mexico, "has worked in almost anything but as a professor" 
(secondary jobs). Although initially she came invited by her brother to take care of his business in Ottawa, the agreement soon dissolved due to business management differences. In addition, due to a lack of funds and a missing document, she has not been able to request her credential recognition. In contrast, Andrea's father, who was an artisan and a sports coach in Mexico, immediately took charge of maintenance at Andrea's uncle's business after their arrival. A few months later, he also started working as a sports coach at a small private business (subordinate jobs).

Thus, Andrea's father has had an easier time economically integrating than his wife despite the cultural capital differential between them. This is not only because he found jobs in Canada related to his previous work experience in Mexico (the first job he obtained was due to the social capital he had with his Mexican brother-in-law). It was also because these jobs do not require that he speak much English (e.g. Andrea's brother, who attended the father's coaching sessions as a user, used to translate for his father). Andrea's mother "has really been frustrated because she can't work in her field. Or sometimes because of the language or something else, employers don't give her a chance to demonstrate her capacities, and that's really frustrating for her." Thus, the mother's economic integration experience has been "exhausting."

Andrea's parents' divergent cases illustrate how the particular requirements for immigrants to enter the Canadian labour market vary in terms of entry fees and capitals demanded by each field. These requirements not only influence the immigrants' type of economic integration, but also generate imbalances inside immigrant households that affect their members in personal, economic, and even mental health terms. The jobs that Andrea's father has had require only a semi-skilled specialization, have less competition, and require lower access fees to enter the field than those required of his wife in Ottawa's education sector. Consequently, Andrea's father was not only able to keep his first job, but with the support of a small amount of social capital he generated in Canada, and despite his limited English knowledge, he also obtained a second job.

In contrast, Andrea's mother's lack of credential recognition and social capital, her basic 
level of English, and her work experience in only secondary types of jobs have not helped her to find a job even in the subordinate segment. Rather, using her pre-migration social capital, she was able to find an online job in Mexico that she can do from Canada. Thus, even if Andrea's family arrived via the economic class, their case helps to demystify the notion that Mexicans belong only to middle- or upper-middle classes in Canada (see chapter 5). Moreover, the diverse economic integration pathways occurring inside Andrea's household also exemplify the complexity that immigrant children experience regarding economic integration.

Andrea's parents' economic integration processes have partially marked her own economic integration experience in Ottawa. Because she immigrated at age six and went through an early English learning process and introduction to the Canadian culture via the school system, she became her 'parent's parent' (Portes and Rumbaut 2001), answering the phone for them, etc. (i.e. role reversal):

Even if I didn't want to, I was the one who had to learn how the system works in Canada. Even my parents call me 'Mamá Andrea' [...] Well, I've turned into a second mother, particularly because my parents have had to work too much, [so] I've had to take care of my sister. I mean, I had to mix Canadian rules [in her sister's child care], like how everything worked in here, along with how my parents educated us, with Mexican ideals of care.

Andrea's role reversal forced her to only be able to work sometimes as babysitter (secondary job). This is because Andrea had to focus on school in the mornings and take care of her younger sister during the afternoon, leaving her with little time for a job. At the moment of the interview, Andrea had just finished high school, was working at the federal government in a temporary position that one of her father's bosses helped her to obtain (following the secondary $\Rightarrow$ subordinate route), and was saving money to move to another city to do a film course. Considering Andrea's future area of studies, a socially recognized and well-paid career area, it is highly probable that if she finishes this course, she will follow an employment pathway similar to that of Alberto from Ottawa and Diana and Roberto from Montreal, who immediately found an independent type of job after finishing their technical careers (see chapter 7). 
In Deyanira's case, the economic integration of her parents has also been mixed.

Deyanira's father's knowledge of French, English, and Spanish, along with the recommendation of a friend who works in Australia, allowed him to obtain a job in one of Canada's extractive industries that has operations in Mexico (independent job). The company that hired Deyanira's father took care of the family's immigration process and, in four months, they got the clearance to immigrate. However, once they moved to Toronto, their savings were almost fully depleted due to Toronto's high living costs and the currency exchange rate. In a short period of time, their habitūs also drastically changed due to this economic standing change (i.e. hysteresis).

Deyanira's mother always worked in Mexico as a professor in the mornings and took care of the children in the afternoon, taking them to after-school activities such as swimming classes, etc., characteristic activities of the upper-middle class in Mexico. Once in Toronto, she studied English and was a housewife. But once she realized that her husband's income was not enough to maintain the family, she decided to look for a job. However:

...she didn't get a job. She had to go back to school again [...] so my mom was very depressed the first two, three years [after immigrating]. [...] She applied like to 100 jobs and got very few interviews [...] and small jobs. For example, she worked at banks or began working at an office. I think that that caused her a lot of depression because she had a $\mathrm{PhD}$ and then she was funnelled down [to secondary types of jobs]. I believe she was making $\$ 12$ per hour, so this emotionally... we couldn't take her out of bed, so we started talking to her and she decided to keep studying.

Deyanira's mother used some of her previous $\mathrm{PhD}$ credits and had to study more courses to receive another $\mathrm{PhD}$ in a similar area, but nonetheless it has been very difficult for her to obtain a job. At the moment of the interview, the family was experiencing some anxiety because the mother's six-month-contract as a store assistant was about to end, and they did not know if it would be renewed and, if not, how this would affect her mental health.

The differentiated entry fees demanded by various labour market fields, Deyanira's parents' dissimilar backgrounds, and their unequal, gendered possession of social capital even before migrating led them to experience disjointed economic integration pathways after having 
immigrated. This happened despite their possession of cultural capital and proficiency in at least one of the official languages. However, whilst the father worked in an industry in Mexico related to the $\mathrm{PhD}$ he obtained in Canada, the mother focused on teaching and taking care of the family. In addition, the father generated some social capital in Canada and other countries, which facilitated the immigration of the family in the first place, whilst the mother did not.

These experiences granted them with different (and gendered) pre-migration types of capitals that, once entered into different post-migration fields, acquired diverse values. Thus, Deyanira's father's capitals allowed him to obtain a job in Canada even before immigrating, in a company with a global orientation, and whose economic interests span a Mexico-Canada transnational space. In contrast, her mother found that Canada's entrance fees are higher and more competitive in the education area, for which her capitals were significantly devalued. Along with her lack of social capital derived from her pre-migration role as mother/wife, this has impeded her access to the employment field. At the same time, these circumstances have shaped Deyanira's economic integration context and positioned her in a subordinate location by extension.

Soon after having immigrated, a high school teacher told Deyanira about swimming certifications, and since she attended swimming lessons in Mexico as part of her previous class location/habitūs, Deyanira obtained aquatic and first aid certifications shortly after her arrival. This allowed her to work as a lifeguard during her first summer in Ottawa, whilst also taking some high school courses at night. Her pre-migration class location then, allowed her to transform the capital she had previously generated as a mark of distinction in one of her Mexican fields (i.e. symbolic capital) into cultural capital in Canada. This new capital, valued in one of Canada's fields (i.e. that of summer activities), allowed her to obtain her first job, some economic capital, and Canadian capital in the form of work experience.

Deyanira is also studying health sciences, doing an internship at a health institution (i.e. a subordinate type of experience), and volunteering as a teaching assistant at her university in order 
to boost her CV. Because her family does not support her economically due to its precarious economic situation, and because the father frequently travels to Mexico as part of his job, he brings Mexican food back on each trip with him, which reduces the cost of purchasing Mexican food in Canada. He sends some to Deyanira ("you [as a student] save some money with that"), and this helps her to maintain her class location. Until now, Deyanira's trajectory has been entirely located in a subordinate location, whilst Andrea's trajectory has followed the route secondary $\Rightarrow$ subordinate. In both cases, an increase in their Canadian capitals, and particularly their education orientation, may assist in achieving an independent type of economic integration in the future.

Other youths who immigrated at older ages are situated in a subordinate location because they had an initial poor insertion into the Canadian labour market, lacked social capital that might have connected them to various markets, because their Canadian employers did not recognize the value of their Mexican credentials even if they had gone through the Canadian accreditation process, or because of a lack of post-graduate education. Ivette, for example, decided to get a job while studying in Toronto, since many of her classmates were already working in the service sector. She obtained a job as a cleaning staff supervisor, where most of her co-workers were Latinxs and the owners Canadians. But Ivette resigned from that job because it was too demanding (i.e. she needed to drive back and forth in Toronto) and was not fully committing to school.

Once Ivette finished college, she wanted to obtain permanent residence, but "I was a recent graduate, didn't have too much work experience, and Toronto is too big. So, I decided to start from below, cleaning rooms at a hotel and looking to move upwards. So, I spent three years there but without any possibility of advancing to a [managerial] job position." Since Ivette needed a managerial position to be able to apply for permanent residence, some Latinx friends she had in Ottawa invited her to move there "because it was smaller and perhaps I could have more 
[employment] possibilities." Those friends also helped her to deliver resumes to potential employers. Because of Ivette's previous experience, she obtained an interview and a job at a hotel, and also later acquired her PR status. However, her company closed soon after and Ivette could not immediately find another job. After some time, she found two part-time jobs cleaning hotel rooms (secondary jobs), where she worked for a year.

Ivette then found another job as room supervisor at a hotel (a subordinate job), but fed up with that job, she quit. A friend found her a part-time job cleaning houses (secondary job), where later one of the clients offered her a job at his company as housekeeping supervisor (subordinate job). Ivette has been working there since then. Overall, various elements have negatively affected her economic integration process in Canada. First, although she arrived at age 15 and was enrolled at high school in an Ontarian town, she did not improve her English skills as mentioned before. Once Ivette moved to Toronto, "I kept communicating with people who speak Spanish, particularly Mexicans. [...] Where I work now, everybody speaks Spanish, the majority, 80\% speaks Spanish. And... I just got married; he speaks Spanish as well. So, at home it’s Spanish. It's a lot of Spanish. [...] And I know that I have a really strong accent, still, because I still speak Spanish every single day." Ivette's social relations with mainly Latinxs have also led her to have limited social networks outside this ethnic group, and thus a narrow form of class-based, ethnic social capital. This has also reduced her opportunities to obtain information about other types of jobs and has funnelled her employment possibilities to the cleaning sector, in a process that Sassen (1995) calls spatial structuration. Ivette's employment trajectory has thus been characterized by a secondary $\Rightarrow$ subordinate $\Rightarrow$ secondary $\Rightarrow$ subordinate route, without a real possibility of acquiring an independent type of job.

When Teresa's family arrived in Quebec, she was six years old. Her father, an instructor at a college, had to take extra courses at a local university to be able to obtain certificate recognition for his degree. However, unable to find a job in his area, and because:

...we needed to eat, pay rent, [my parents] started working in cleaning. And I 
remember that on Fridays we had our family activity: all of us went to clean offices [secondary job]. And I remember that at the beginning I used to say, 'Oh no, what an embarrassment, I hate this.' [...] But now I'm grateful because, thanks to that, we've reached the point where we're at now.

Her mother, who was a secretary in Mexico, joined her husband in the cleaning activities once in Canada (secondary job), but she also took care of the children. Teresa finished her primary, secondary, and CÉGEP education in a small city in Quebec, and when she was 19 years old her parents "decided that they'd spent enough time living in Quebec, that we've learned French, completed part of our education," and decided to move to British Columbia.

Once in BC, Teresa's father tried to find a job in his former professional area. He got a job, but because he was struggling with the English language, this caused him anxiety, "like he experienced that loneliness, he [mentally] blocked himself. He said, 'You know what? I can't deal with the language, we need to pay for stuff, I'm going to work in construction' [secondary job]. So, my father works in construction and my mom went back to school. She did a course on health care aid [in Quebec] [...] and works on care aid" in BC (subordinate job). The mother was able to upgrade her skills because her children had already grown up and moved away, freeing some of her time. However, the economic integration of the parents has been mixed. Teresa's mother's acquisition of Canadian cultural capital helped her to obtain a subordinate job, both in Quebec and BC, whilst the immediacy of the family's needs forced the husband to obtain secondary jobs. At the same time, although his credential recognition helped him to obtain a subordinate job after having emigrated to BC, his lack of English proficiency made it difficult for him to keep the job and again funnelled him into a secondary market segment.

Meanwhile, while living in BC, Teresa did a double undergraduate degree at a private university that she paid for with the support of a government student loan and working part-time at a club (secondary job). She also received indirect economic support from her parents, since she did not have to pay for accommodation, services, or food while staying at her parents' house as part of a Mexican habitus. One term before finishing her studies, Teresa applied for a co-op 
placement and moved to Ottawa. A friend who was also doing the same co-op recommended her to a government employer as an assistant. Teresa's knowledge of French was decisive in her hiring: "At the moment that they know that you speak French you jump five people in the queue. You are now number two or three. It definitively opens the doors for you."

After a year in that job, Teresa's employer recommended her to another person, and that person to another person: "they know each other and support each other. It's easy to change offices because the work is very similar." The social capital that Teresa was generating was tied, however, to her informal political affiliation to the party in power. Thus, when the Conservative party was rejected in the last federal elections, Teresa could not maintain her job. Due to her previous work experience, she was able to obtain a three-month contract in another sector of the federal government, and then found a job at an international NGO, where she has been working as a mid-level administrator. Although Teresa aspires to be a manager, she mentioned that she would need a master's degree to be able to apply for such a position, something she intends to do once she knows what she wants to do in the future. Her employment trajectory has thus followed the secondary $\Rightarrow$ subordinate route. If Teresa continues acquiring cultural capital, and also considering her Canadian capital, her possibilities to move forward to an independent type of economic integration may increase.

In contrast, other youths found that their educational credentials, either Canadian or officially recognized foreign credentials, were not useful for them to find a job commensurate with their education. After Carolina took francization courses in Montreal, she began the process of obtaining her Mexican certificate recognition, a process that lasted one year. Nonetheless, Carolina realized soon that her Mexican education, even if recognized, was not enough for her to be hired due to her background as an accountant, which requires accreditation with a professional Quebec Order. To obtain this accreditation, Carolina needs to pay for and write two different exams, as well as pay an annual premium that amounts to more than $\$ 400$ before obtaining the 
accreditation, plus increased dues after obtaining membership in the Order. ${ }^{55}$ Due to these costs, Carolina renounced the idea of applying to the Order and rather opted to study for a diploma. When she started looking for a job, she realized that "it's quite complicated. You arrive with your CV and say 'look, I have all this experience.' But at the beginning they didn't even call me back for an interview. [...] It was very, very complicated.” Before immigrating, Carolina was expecting to work in her area, where she had an independent location.

While she was taking a short course, a Latino friend recommended Carolina to a small business owner who was looking for an employee. She was hired and began working part-time while still studying full-time. But after her boss asked her to take full responsibility for the business portfolio, she decided to withdraw from school and fully focus on her job. Carolina's salary was then raised from $\$ 13$ to $\$ 25$ per hour. However, her boss and the husband, a Québécoise and a Central American man respectively, used to make a lot of homophobic comments in her presence without knowing that she was a lesbian. "And they found out, I don't know how, but they found out and began making even more homophobic comments. [...] They didn't retract but it was the opposite. So, wow! That really shocked me.” In the summer, when the business wasn't doing as well due to its business orientation, her boss used the low-sales argument to force her to choose between reducing her wages from $\$ 25$ to $\$ 18$, to work only three days a week, or be fired. Carolina chose the wage reduction, but increasing frictions led to her dismissal without full payment. Her dismissal "was also a shock [for her] because to find again a job is complicated." This time, however, due to her previous work experience, Carolina obtained some interviews and found a part-time job as an administrative assistant.

Carolina also mentioned that when she was attending the francization and the recherche d'emploi courses, the instructors told participating immigrants that the best way to find a job in Montreal is by looking at the "hidden market." "They don't have a page with job offers, they never announce it. Rather, it's hidden, it's, 'Oh, you know what? I need someone.' 'Oh, look, I 
know someone that knows an accountant. I'm going to recommend this person to you.'” However, Carolina's network is small and limited to few Latin Americans in Montreal:

I got this job [i.e. her first job] because, again, an acquaintance, my friend's partner knew this man and that's why he put me in contact [with him]. He interviewed me, he liked me, and well I was hired, no? But, in this respect, I still feel a little bit excluded [in Montreal]. Still. I'm sure there's something else that is missing for me to do [i.e. find a job], no?

Carolina has thus not been able to associate the fact that lacking in Canadian education and social capital (i.e. entry fees) has not helped her to obtain an independent type of job. In a more structural sense, it is not that she needs to do "something else" to obtain a job. Rather, it is the way in which the particular Montreal employment field is configured, demanding certain types of entry fees to access it, while not recognizing her pre-migration capitals. Carolina's employment trajectory in Montreal has thus always been constituted by subordinate, precarious types of jobs. Despite her pre-migration capitals and her independent location in Mexico, she currently supplements her income with social assistance and is still looking for a full-time, independent job. Carolina is considering continuing her studies because "everybody tells you that it's really important to have a local certificate. The [local] certificate is worth a lot because your certificate from Mexico is of no use even having the [credential] recognition."

The possession of a local certificate, however, does not unto itself secure a positive exchange in Canada's employment field. For example, after Gilda finished her master's degree in a field of humanities and obtained PR status via marriage sponsorship, she started looking for a job:

I told myself: 'OK, I have a degree from Canada, that's going to help me and give me an advantage, and I also have international experience that will help me.' And it certainly didn't. It was really, really hard to find a job. My savings were almost depleted, my [Canadian] husband was also draining all his savings, and he had to look for a second job. He was working day and night. We were about to give up because we were running out of money. I even asked for a job at a Tim Horton's and I couldn't get it.

Gilda also went to various settlement organizations in Ottawa looking for assistance, but she felt that "I lost my time with them." She knew already how to integrate into the Canadian culture having lived here as an international student, but she was not offered a list of potential jobs that 
matched her education and work experience. Meanwhile, Gilda also began studying French. After some time, her mother-in-law sent her an email with information about a short-term job contract with an NGO, funded by Ontario through a youth program, and she got the job. However, "I had to start from zero. Forget that you previously were research coordinator and you were in charge of other type of projects. Here it was like: 'okay, you are going to program content on Twitter, and I'm still going to check the posts to see if they're okay."' Gilda's job experience lasted only a few months because, due to governmental budget cuts, the program closed. But then she was transferred to another organization, where she even got a small raise working in a subordinate type of job. At the same time, Gilda was offered and took an online job at her previous workplace in Mexico.

Soon, Gilda's second job in Ottawa was also cancelled due to budget cuts, but she was offered an assistant position at a different organization, which included a wage increase. During the time that Gilda was looking for a job, her partner, who has a subordinate job as a chef, was unable to share her potential social capital due to their different backgrounds, and which might have helped Gilda to enter a local social network. Moreover, his working two jobs helped Gilda to survive economically during her job search, which located her in a subordinate type of economic integration by extension. After obtaining a job, Gilda underwent a deskilling process, where her pre-migration work experience and even possession of Canadian capital (i.e. education and English knowledge) were discounted, whilst her lack of Canadian work experience and social capital were emphasized.

The possession of Canadian capitals (i.e. education, knowledge of official languages, Canadian accents, and Canadian work experience) and an early age at arrival have not helped Román to be situated in an independent location. As a teenager, Román obtained various secondary and subordinate jobs, which helped him to obtain Canadian work experience. While in high school, Román worked as a counsellor at a Jewish summer camp for three summers 
(secondary job). But being gay:

and a bit flamboyant as a teenager [...] they very clearly didn't like it, and they tried to bully me about it, like not the kids, the staff. [...] One of the instructors had instructed all his kids to attack for fun and they did. [...] They fired the person and reprimanded everyone, but I do remember that that was like a sore point at that job, plus I wasn't Jewish.

Román's sexual orientation and ethnic identity thus operated as negative elements in his personal experience and economic integration as a teenager. When Román moved from Montreal to Ottawa, he obtained a part-time job in an educational program. He has been working there for the past four years. Román also enrolled in a master's program, which he paid for with his own work as a research and teaching assistant, as well as with the support of a scholarship (his parents could not afford to pay for his master's degree as they had done with his BA). After graduation, he obtained a temporary job as contract instructor at a university. However, obtaining a full-time, independent type of job has not been easy for him: "I was definitely frustrated when I was hunting for jobs 'cause I sent applications for six months and I felt I'm like, I dunno, I'm qualified, and I have all these degrees, I have work experience... but maybe it's the saturation of my field. There's so many, so many young people [in my area] that it's hard for people [i.e. employers] to choose."

Román also recognized that a couple of other factors might be playing against him. One of these is his youthful appearance:

I find... there's a lot of ageism, ageism in the workforce. Or like, being young is, maybe a bad thing for like... cause like the jobs I was applying for were relevant with my educational background, like I have seven years of schooling behind me, I have a master's degree, and I was applying for jobs that I think I should have gotten as an undergrad student, and I was getting comments like, 'Oh, you're too young.' Like I went to a job fair, and I'd shaved and gotten myself all nice and clean and I regretted that, because I looked much younger than I am. Like, the second I shave this off I look five years younger. And that actually worked against me at that work fair 'cause I looked green, right? [...] 'cause I went up to some people and they outright turned me away and they're like 'we're not looking for junior [employees].'

The other element Román identified as a potential cause for not getting a full-time, subordinate or independent job is because: "I wonder if my name was John, if it would be easier for me to get a 
job. [...] So... I'm the only ethnic person [i.e. non-white] on my team, at work, where they're all white." In Román's perspective, hidden racism might be a possible factor playing against him.

\subsection{The Role of Gender and Sexuality in the Secondary Type of Integration}

Most participants located in this type of integration are women (i.e. seven women and one man in Ottawa, and two women and two men in Montreal). Nonetheless, the marked presence of women in this type of integration is derived from the recruitment process, as mentioned in Chapter 1. Although I did not find that gender was a factor that correlated with my respondents' economic integration in their answers, quantitative data indicates that there is a clear correlation between unemployment rate and gender in Canada. Immigrant women aged 25 to 54 "are more likely to face persistent challenges becoming employed" (Yssaad and Fields 2018). Indeed, the unemployment-rate gap has been consistently higher for immigrant women aged 25 to 54 when compared to immigrant men and Canadian-born women between 2006 and 2017, particularly for female newcomers, i.e. those who have been in Canada for less than five years. The average gap between newcomer and Canadian-born women is 9.3\%, whereas that of newcomer and Canadian-born men is 4\% (computed from Yssaad and Fields' data 2018). For immigrant men who landed more than five to 10 years earlier and those who landed more than 10 years earlier, this gap is reduced to $0.9 \%$ and $0.3 \%$ respectively in comparison to Canadian-born men. For immigrant women, this gap is reduced to $4.6 \%$ and $1.7 \%$ respectively when compared to Canadian-born women (ibid.).

On average, for the 2006 to 2017 period, immigrants of both sexes have never achieved parity with people born in Canada regarding their unemployment rate (Yssaad and Fields 2018). Nonetheless, immigrant men who landed more than 10 years earlier have not only achieved parity but slightly improved their unemployment rate vis-à-vis Canadian men by an average of $0.4 \%$ between 2015-2017 (ibid.). Thus, cases such as those of Carolina and Gilda, who have been in Canada for four years, are thus confronted with additional disadvantages due to their limited time 
spent in Canada and possibly because of gender discrimination.

I also found a strong gender effect in the experiences of my respondents' parents, since it usually was their mothers who faced a more difficult scenario to get ahead once in Canada (as it occurred among the mothers of some of those in the independent location). This happened even when in most cases they had come from an upper-middle, pre-migration class location in Mexico. At a structural level, this is partly because the economic or independent class is usually masculinized in Canada's immigration legislation based on the applicants' expected economic contribution to Canada. In contrast, the family class, based on family ties, is feminized and constructed as a non-economic, dependent category (Thobani 1998:4). Thus, the fact that the majority of my respondents' fathers (in both independent and subordinate categories) were the main applicants and self-identified as heads of the family and breadwinners in their immigration processes speaks, on the one hand, to Canada's gendered construction of immigration, even if women can apply for any immigration program. On the other hand, it reveals how traditional, patriarchal Mexican values harmonized with Canada’s immigration configuration.

As mentioned in chapter 5, the gendered, pre-migration distribution of various types of capitals inside the households favoured the male breadwinner, whilst the wives played the role of housewives or worked part-time and then spent the rest of the day as housewives and taking care of the children. Once in Canada, however, these mothers spent their first year learning one of the official languages, since their partners knew at least one of the languages already. This experience contrasted to the experiences of some immigrant and refugee women who belong to lower class locations (or due to their cultural backgrounds) and whose husbands usually are the first or the only ones to study any of the official languages using the government's support (Boyd 1990; Kilbride et al. 2008). This latter experience also occurs because, as Kilbride et al. (2008:13) contend, "adult male immigrants, who are usually heads of households, receive the major advantages of Canada's language training programs so that they can enter the workforce quickly. 
Programs for female immigrants who are not heads of households focus on 'practical' rather than advanced or professional English."

Thus, in contrast to these experiences, my respondents' mothers' pre-migration class location allowed them to access the government's language training immediately after arrival. However, once they finished this process, they went through a difficult time finding jobs according to their pre- and newly acquired post-migration capitals. The exception was Teresa's mother, who, after having studied French and who, years later, after having worked in cleaning along with her husband and raising her family, also studied a technical career that put her ahead of her husband in economic integration terms.

Regarding sexuality, my sample included two youths who self-identified as gay and for whom their sexual identity has been a significant factor at certain moments in their employment experiences. In Román's case, the verbal attacks he received from summer camp children following one of his colleagues' orders unveiled the way in which hatred and homophobia may easily be replicated in one of Canada's fields. In Carolina's case, the homophobic slurs she continuously faced at her job, and which increased after her Québécoise and Central American bosses knew that she was a lesbian, assist in demystifying the notion of Canadian metropolises as totally progressive places, particularly when compared to rural locations. This case also suggests how homophobia, as a discriminatory and oppressive socio-cultural system, can be reproduced across transnational fields, since a man from Central America and a woman from Quebec joined each other in discriminating against Carolina due to her sexual orientation. Carolina thus correctly stated that the notion of Canada being a more advanced society in terms of accepting other sexual identities needs to be situated "in brackets."

\subsection{Discussion: Subordinate Integration in a Changing Labour Market Landscape}

I identified six factors where the pre-migration location of some youth interacted with their post-migration location and capitals to situate them in a secondary type of integration: 1) age at 
immigration, 2) time spent in Canada, 3) labour market conditions and valuation of their capitals in employment fields (i.e. language skills and Canadian and/or Mexican education), 4) absence or limited possession of social capital, 5) difficulty in obtaining Canadian education or work experience for those who arrived as young adults, and 6) the post-migration location of the parents in cases of family immigration.

Certainly, all these factors do not fully account for each of the labour market experiences of those who persistently find themselves in a subordinate type of job. Moreover, even the same factor sometimes had opposite effects from one case to another. However, the two factors that appear to have a strong effect in allocating Mexican immigrant youth to subordinate locations were the configuration of the employment fields and lack of social capital. Then, depending on the existence and arrangement of the other mentioned factors, youths went through a different integration experience. The subordinate location thus resulted in a 'messy' space that positioned participants in a location closer to either the independent or the secondary location. At the same time, broader changes such as government defunding or discrimination, along with a lack of social capital, resulted in labour precariousness or unemployment, and thus some youth remained in a subordinate space.

Age at ARrival ANd Time Spent in Canada. Age at arrival and age at the time of the interview shaped the results I found in a couple of cases, since my respondents were between 18 and 21 years of age. Because they were still acquiring education in Canada, their employment experiences were few and mainly of a secondary type. In other cases, such as those of Gilda, Artemisa, and Carolina, the time they have spent in Canada (i.e. four years) has not provided them, statistically speaking, with increased opportunities to, first, obtain a job soon after arrival and, second, obtain employment possibilities closer to those of Canadian-born youth. Indeed, compared to the early 1980s, "proportionately fewer young immigrants [aged 25 to 34] have employment income two years after landing" today (Morissette 2016). On average, $88 \%$ and $73 \%$ of men and 
women respectively, aged 25 to 34, obtained employment income two years after landing between 1981 and 1989 . These rates decreased to $82.2 \%$ and $63.6 \%$ for men and women respectively between 2000 and 2011 (personal calculations using data from Morissette 2016). Thus, recent immigrant women are more affected in terms of obtaining employment income than men.

If we consider time spent in Canada, between 2006 and 2017, immigrants aged 25 to 54 who landed five or less years earlier had an employment rate of $66 \%$ vis-à-vis people of the same age born in Canada, who had a rate of $83.2 \%$, thus a negative difference of $17.2 \%$ (personal calculations using data from Yssaad and Fields 2018). The percentage gap between both groups decreased to $8 \%$ for those immigrants who landed more than 5 to 10 years earlier and $2.5 \%$ for those who landed more than 10 years earlier. Moreover, immigrants who landed five or less years earlier had an unemployment rate average of $11.7 \%$ vis-à-vis people born in Canada who had a rate of $5.3 \%$, thus a negative difference of $6.4 \%$. This percentage was lowered to $2.7 \%$ for those who landed more than 5 to 10 years earlier and to $1 \%$ for those who landed more than 10 years earlier (ibid.). Time spent in Canada, on average, increases the employment possibilities and decreases the unemployment rate of immigrants, bringing their rates closer to the employment experiences of those born in Canada, but only after the 10-year mark. Among my respondents, the negative outlier to these statistics, based on time spent in Canada, would be Román, who has been in Canada for 18 years.

Moreover, the possibilities of employment and unemployment among immigrants are shaped not only by time spent in Canada, but also by province of residence (i.e. labour market conditions). Between 2014 and 2017, immigrants aged 25 to 54 who landed five or less years earlier in Ontario and Quebec experienced decreases of 19\% and 23.2\% in their average employment rates respectively when compared to people born in Canada (immigrants had rates of $64.3 \%$ and $61.6 \%$ respectively and Canadian-born had rates of $83.3 \%$ and $84.8 \%$ respectively) (personal calculations using data from Yssaad and Fields 2018). The gap between those groups 
was reduced to $9.5 \%$ and $7.8 \%$ for those who landed in Ontario and Quebec more than 5 to 10 years earlier respectively, and to $2.6 \%$ and $4.9 \%$ for those who landed more than 10 years earlier respectively. This data clearly indicates that recent immigrants were highly penalized in Quebec's labour market, closely followed by those who lived in Ontario. Although time spent in Canada favoured those immigrants who lived in Ontario in comparison to those who lived in Quebec, this mainly applied to those who have lived in Canada for more than 10 years.

Regarding the unemployment rate, immigrants who landed five or less years earlier in Ontario and Quebec between 2014 and 2017 experienced average unemployment rate increases of $5.9 \%$ and $9.8 \%$ respectively when compared to those born in Canada (immigrants had average unemployment rates of $7.8 \%$ and $15.5 \%$ respectively and Canadian-born people had rates of $4.9 \%$ and $5.3 \%$ respectively). Unemployment percentages went down to $2.9 \%$ and $3 \%$ respectively for those immigrants who landed more than 5 to 10 years earlier in Ontario and Quebec respectively, and $0.6 \%$ and $2.8 \%$ respectively for those who landed more than 10 years earlier (personal calculations using data from Yssaad and Fields 2018). Thus, although the unemployment rate similarly affected immigrants in both provinces, especially recent immigrants, the effect of unemployment was harder on those who lived in Quebec longer. Location, however, as shown in the various cases of my respondents, is not enough to shape by itself the economic integration of immigrants.

For example, in the case of one of my respondents (i.e. Andrea), the parents experienced a mixed type of economic integration (one being a secondary and the other one a subordinate location). Since the parents were able to only find jobs belonging to different class locations after immigration, a class restructuration occurred within their household. This was because the objective conditions which had granted them an independent economic integration in Mexico, and which had (re)produced a number of habitūs, no longer existed. Thus, out-of-phase dispositions and ill-adaptation of practices appeared (i.e. hysteresis) (Bourdieu 1990a, 1990b). The family's 
class restructuration also shaped Andrea's experiences of economic integration. For instance, while some other teenagers Andrea's age began working in secondary types of jobs in Ottawa, acquiring valuable work experience and perhaps social capital as part of their class location, she had to stay home to babysit her sister and do some chores while her parents were working.

Despite this initial disadvantage, Andrea's father's limited social capital in Ottawa was useful for her to obtain a subordinate type of job at the federal government after she finished high school (i.e. social capital by extension). Moreover, this job is allowing her to save the necessary money to pay for an expensive college course that might grant her an entry to an independent location due to the orientation of her desired studies (i.e. the film industry). A similar pathway, although a lengthier one, might await Deyanira, who is studying health sciences and enriching her CV to obtain an independent type of job after finishing school. Although Andrea and Deyanira's parents have experienced downward mobility, these young women have taken indirect advantage of their parents' finances and Mexican culture as a springboard to acquire various Canadian capitals (i.e. they do not have to pay for rent, utilities, and food while living with their parents). These capitals may prove useful for them to get a different type of economic integration than those their parents achieved, as happened among some of the youth in the independent location.

These cases also reveal that the generation and accumulation of capitals in a transnational field are not necessarily an individual but can also be a collective endeavour. Although immigration led to both hysteresis and a class relocation, the family unit functioned as a safety network where material and non-material resources were also redistributed. In the case of my respondents, they benefitted from both the material support that their parents offered them and the reproduction of a Mexican habitus in Canada that allowed them to not to have to pay rent or leave the house after they turned 18. In these cases, although the families' previous class location could no longer been reproduced in Canada, still some of their habitūs endured, facilitating an improved economic integration for their offspring. As Bourdieu (1990b:62) contended, dispositions "can 
outlive the economic and social conditions in which they were produced."

VAlUATION OF CAPITAlS AND LABOUR MARKet CONDITIONS. Regarding knowledge of any of the official languages, whilst $71 \%$ of my participants from the independent location immigrated with a medium-to-high level of English and/or French knowledge, $42 \%$ of those in the subordinate location did so. In addition, similar to some youth located in the independent location, some respondents in the subordinate location had already obtained an advanced knowledge of one or two of the Canadian official languages in Mexico or abroad even prior to making plans to immigrate to Canada. As mentioned in chapter 5, studying a second or a third language is indicative of a person's class location in Mexico, both in economic and symbolic terms, since this operates as a marker of distinction.

Four of my participants knew both official languages (in contrast to three of those located in the independent location), and two had an advanced knowledge of one language plus a medium-level knowledge of the second one (similar to those in the independent location). Nonetheless, in some cases, this cultural capital has not been enough for them to acquire an independent job since, as it happened among those located in the independent location, the value given to knowledge of the two official languages derives from the employment fields' needs, irrespective of the city. Official language knowledge, then, is a relational factor that acquires value based on the needs of the local, regional, national, transnational, or global employment fields and capital, rather than having a value unto itself.

Joaquín, for example, needed only to speak English at his laboratory in Montreal. His partner and most of his friends also speak English, and he rarely speaks French in his daily life: “my life is in English.” Joaquín's employment field orientation also shaped his socio-cultural integration in Montreal despite having used one of Quebec's economic immigration programs. Thus, as it occurred among some in the independent location, and despite Quebec's efforts to attract immigrants to reinforce its French character, global capital, through the opening of 
economic spaces that require no French knowledge, shapes the socio-cultural integration of immigrants in these spaces, overriding sub-national immigrant integration policies. Correspondingly, in fields where language knowledge is overvalued, immigrants obtain extra value for such capital. Thus, Teresa obtained various jobs in Ottawa because her knowledge of the two official languages is highly sought by Canadian government agencies and NGOs. And Miriam easily obtained customer service jobs in Montreal not only because of her knowledge of the two official languages but also of Spanish.

Similar to youth in the independent location, among whom $79 \%$ studied high school and/or a post-secondary degree in Canada, most participants in the subordinate location had studied or are studying in Canada (83\%). In a couple of cases, it was their pre-migration class location that facilitated, first, their international mobility across North America or Europe and, second, obtaining Canadian education as international students before applying for PR status. The Canadian cultural capital that the youths have obtained has helped some of them to access the subordinate labour market. This means that the employment fields have recognized their Canadian education as an entry fee. Indeed, this capital recognition has granted them with an advantage when compared to those immigrants whose foreign credentials, particularly those coming from developing countries, are not recognized by employers, even if those credentials have been already accredited in Canada (i.e. their prior learning and work experience is discounted and devalued [Andersson and Guo 2009; Guo 2009]).

In other cases, access to Canadian education has been facilitated by scholarships, as in the case of Gilda, who came to Canada to obtain a master's degree with the support of a Canadian government scholarship. Without this economic support, aimed at fostering relations between Canada and Mexico, she would not have been able to study here and later meet her now husband who sponsored her. This type of case also shows how transnational connections, either at the state or professional level, are being created between Mexico and Canada, further facilitating Mexican 
immigration. Nonetheless, official language knowledge and Canadian education, either obtained as part of one's pre-migration class location or through a scholarship, are not enough to obtain an independent job or even secure a subordinate job. Rather, it is the required entry fees of each employment field, which strongly determine the access to and amount of time youth remain employed in a subordinate type of employment.

For some other youth in this sub-set, the acquisition of post-migration Canadian education was a strategy they developed to respond to the stringent local employment conditions they faced after having immigrated. The changing circumstances of the labour markets in Canada and the way in which these are being locally configured, more oriented towards its casualization and consequent precariousness, forced some Mexican youth to elaborate complex strategies to survive these changes. Among these are perfecting the language and a further post-migration investment of diverse types of capitals, such as time and money to acquire more education. As Miriam mentioned, the changes in the labour market oblige "you to be constantly adapting depending on the circumstances." She herself obtained two different certificates in Montreal just to be able to get a subordinate job despite having her Mexican certificate recognition, French knowledge, Québécoise work experience, and having been in Canada for 10 years. Although her second post-migration credential allowed her to obtain a full-time, subordinate job at the time of the interview, she is still looking to take one more year of on-line courses to convert this second certificate into a Diplome d'Études Collégiales. This will offer her extra symbolic value that, she hopes, can easily be exchanged in the employment field for an independent job.

Miriam's case also shows how despite her pre-migration class location, which allowed her to immigrate to Canada via the economic class, she still needs to constantly reinvent herself in terms of her career orientation and the acquisition of more Canadian capital to just 'not drown.' For example, the first certificate she obtained in Montreal and the community services area in which she worked for five years is not related to her Mexican education. The same applies to her 
more recently acquired certificate, which allowed her to obtain a full-time job, but this time in the customer services area. After immigrants invest time and economic capital in acquiring local education (i.e. an entry fee), which facilitate their inclusion into a particular labour niche, their investment might not yield constant results if a particular market is no longer propitious to the type of education acquired and/or shrinks.

Thus, the way in which some employment fields are now being reconfigured is increasingly generating scenarios of precariousness not only in the secondary market, but also in the subordinate market. Here, certain types of cultural capital and Canadian work experience are no longer enough to secure a job, forcing some immigrants (i.e. those who can afford it or obtain the means to do so) to constantly acquire an assortment of education credentials just to be able to obtain the next precarious, even if subordinate job. Moreover, as Kalleberg (2009:10) argues, "the growth of precarious work has made educational decisions more precarious too," making it hard to even plan the 'right' education.

The temporality of some of these subordinate jobs generates certain precariousness, although one of a different kind when compared to the one found in the secondary market. This is because subordinate jobs require a specialized education to fulfill their functions and roles, as well as an initial set of capitals (i.e. economic, social, and cultural) to acquire that education. In both types of precariousness, however, immigrants might need to find multiple jobs or are being forced to get involuntary part-time work just to make ends meet (Hira-Friesen 2018a). Cases such as that of Miriam, where the accumulation of Canadian education credentials is constituted as a strategy to obtain precarious jobs, partially substantiate Hira-Friesen's (2018b) quantitative findings regarding precarious work in Canada:

the "effect of immigrant status on temporary employment [...] was substantial in females as they were almost 1.4 times as likely to be employed in temporary jobs compared to their Canadian-born counterparts. Similar significant odds ratios greater than one were found for the 20-29-year-old respondents for both sexes. With respect to education, males with a university certificate are more than one and a half times as likely to be employed in temporary jobs and females are slightly less than one and a half times as likely. The 
trend continues with males and females with a bachelor's degree and is most pronounced in those with graduate degrees (p. 55).

However, the type of education that Hira-Friesen considered was non-Canadian education, whereas my research unveils how even the acquisition of post-migration Canadian education (even including multiple Canadian certificates) is further discounted in the Canadian market for some immigrants, even if paired with knowledge of at least one official language and work experience.

The experiences of some of these Mexican youth also embody the expectations and experiences of Chinese-descent Canadian-born youth and immigrant youth from Hong Kong in Toronto and Vancouver. Some of these youth believed "that their chances of fulfilling employment matching their [Canadian] educational qualifications are considerably lower than those of their white Canadian counterparts.” Others experienced being “"dead-ended' in Canadian companies in positions that did not take advantage of their Canadian education" (Kobayashi 2006:30). Pendakur and Pendakur (2016) found that, from 1990 to 2005, visible minority male immigrants faced significant earnings disparity regardless of their age-at-migration, and that immigrants who arrived after age 17 performed much worse than those arriving at this age or earlier.

The experiences of increased precariousness and deterioration of job quality are also associated with being a young person in Canada (Morissette 2016). Between 1976 and 2014, $66 \%$ of males and $54 \%$ of females aged 17 to 24 were employed full time in Canada (full-time students excluded). This contrasted to $84.1 \%$ of males and $53.5 \%$ of females aged 30 to 54 who were employed full time (personal calculations using data from Morissette 2016). One can argue that the youths' employment percentages are lower than those of the older group because the former lack work experience and some of them perhaps education.

However, having these low percentages in an age range that includes youth aged 21 to 24 , when youth usually finish post-secondary education for those who are able or decide to pursue such pathway, is telling. The employment rates improved for men in the 25 to 29 age range, since 81.8\% were employed full time between 1976 and 2014, getting quite close to the percentage of 
men aged 30 to 54 already mentioned (personal calculations using data from Morissette 2016). In contrast, young women aged 25 to 29 only achieved a meagre improvement of $5.4 \%$ when compared to youth aged 17 to 24 . This improvement, nonetheless, disappeared for women aged 30 to 54 , who had an employment rate almost equal to that of women aged 17 to 24 . Thus, being young and a woman in Canada brings some penalizations in the labour market.

Statistics Canada data also show that youth with full-time jobs (students excluded) were more likely to be in temporary jobs in 2014 than in previous years since 1989 . The percentage of full-time, male employees aged 15 to 24 and 25 to 34 working in temporary jobs, from 1989 to 2014, changed from $7.4 \%$ and $4.8 \%$ to $24.1 \%$ and $10.3 \%$ respectively. This contrasts to men aged 35 to 54 , whose percentages moved from $2.1 \%$ to $6.7 \%$ (Morissette 2016). Among women aged 15 to 24 and 25 to 34 , their percentages moved from $7.8 \%$ and $3 \%$ respectively to $26 \%$ and $10.7 \%$ respectively. This contrasts to women aged 35 to 54 , whose percentages increased from $3.4 \%$ to $6.2 \%$. Women between the ages of 15 and 24 thus experienced a slightly higher rate of being in a temporary job than men the same age, while male and female youth aged 25 to 34 experienced almost identical increases. Still, there is an increase of $3.6 \%$ and $4.5 \%$ for men and women aged 25 to 34 working in a full-time, but temporary job when compared to people aged 35 to 54 .

Another factor that may deter some of my educated participants in the secondary location from obtaining a job is the fact that the average employment rate distance between Canadianborn and immigrants who landed five or less years earlier, despite having a university degree, was $22.6 \%$ between 2006 and 2017 (the employment rate of immigrants who landed less than 5 years earlier was $68 \%$ and the Canadian-born $90.6 \%$ ). The average gap for those immigrant youths who landed more than five to 10 years earlier and those who landed more than 10 years earlier was $11.3 \%$ and $4.7 \%$ respectively. If we consider age, we observe that the average rates of youth who had a full-time job, even when having a university degree, decreased from 1976 to 2014 
(full-time students excluded). Men aged 17 to 24 and those aged 25 to 29 with a university degree experienced a drop of 16.6 and 9.6 percentage points respectively, and women aged 17 to 24 with a university degree experienced a drop of $16.2 \%$ in their full-time employment rates. Only women aged 25 to 29 experienced an increase of 8.7 percentage points for the same period (Morissette 2016). Thus, being immigrant, young, and a woman in Canada, even when having a university degree (except for women aged 25 to 29 ), decreased the possibilities of first, finding a job, second, finding a full-time job, and third, finding a permanent job.

For example, despite her knowledge of English and having obtained Canadian education (i.e. a master's degree), Gilda's lack of Canadian work experience and social capital, in part due to her having been in Canada for only four years, was emphasized in Ottawa's employment fields, which meant she was not able to obtain a job. As others have signaled before, Canadian work experience is usually required by employers in order to access the paid labour force (Wilson-Forsberg and Sethi 2015). At the same time, lack of Canadian work experience, a common occurrence among recent and racialized immigrants, is operationalized as an individual deficit, forcing some into precarious employment relations (Slade 2008). In Gilda's case, the fact that her studies are in the field of humanities might also have influenced her lack of employability, since employers might have considered this education to have a poor labour market valuation and her lack of other capitals became more prominent. Moreover, her four years spent in Canada and her being a young immigrant woman fit into the unfavourable pattern already described.

While the local configuration of the labour market fields in Ottawa closed the doors for Gilda due possibly to her lack of other capitals such as social capital, while discounting the capitals she already possessed, her belonging to other Mexican fields and her Mexican social capital assisted her in obtaining an online job in Mexico. This shows how the possession of preand post-migration capitals, such as education and social capital, can be deployed in a 
transnational field and constitute part of broader, transnational strategies of survival. Gilda's strategy was thus similar to that of Andrea's mother, who was forced to obtain an online job at a university in Mexico due to her inability to find a job as a professor in Ottawa. These women transformed their Mexican social capital into economic capital once in Canada. Moreover, as a strategy to avoid losing Mexican economic capital if converted to Canadian currency, they left their earned wages in a Mexican savings account to be used only for (Mexican and Canadian) family emergencies, thus creating a transnational safety net.

Furthermore, Gilda and Artemisa are the only participants who have been located in a subordinate type of economic integration by extension. Gilda fell into this category when she received her PR status and was unable to obtain a job even at Tim Horton's, thus necessitating that her husband take on two jobs. Artemisa, being a new immigrant who is still learning the two official languages, having a Mexican certificate with limited employability scope, and lacking Canadian work experience, is still dependant on her husband's secondary location to make ends meet. In both cases, if it were not for their partners' subordinate location, these women would possibly be located in a secondary type of economic integration. Andrea and Deyanira have been in a mixed type of economic integration by extension, since their parents each have other different locations.

Being located in a subordinate location can offer certain possibilities to move to an independent location if certain conditions that fulfill the entry fees of the respective labour market fields are met. For example, if Teresa pursues graduate studies and pairs this education with her Canadian, subordinate work experience and knowledge of both official languages, her probabilities of finding an independent type of job may increase. Gilda's accumulated Canadian capital (i.e. education, language skills, and now subordinate work experience) can help her to move towards an independent integration if the labour market opens more opportunities. Carolina, Griselda, Miriam, and Joaquín have also accumulated partial or full Canadian cultural 
capital, at least one of the official languages, and important subordinate experience in terms of type of employment, for which their possibilities of acquiring an independent type of job may be higher if the labour conditions permit. However, this is also dependent on their acquisition of more Canadian and social capitals.

For those two participants who withdrew from school once in Canada, they further limited their access to valuable Canadian capital in the form of cultural, social, and symbolic capitals, which could have assisted them in obtaining an independent location. In the case of Ivette, and despite her having Canadian education, her Latinx social network has collaborated in maintaining her employment options in an enclosed sector, limiting her possibilities for future social mobility. Moreover, her close relationship with mostly Spanish speakers at work, at home, and in her social life does not assist her in improving her English language skills. Under a Bourdieusian perspective, Ivette has, indeed, been reproducing her post-migration class location, first in Toronto and now in Ottawa. Her continuous employment in a small niche where some Latinx immigrants in Canada are found (i.e. the cleaning sector), her continuous socialization with Latinxs, her constant use of Spanish in different fields, and her minimal social mobility have (re)produced a specific social class. The (re)production of this class has been constituted not only by the sharing of a social location, but more importantly by the identification of a group of individuals with one another, their continuous socialization, and the actions that they deploy that (re)produce them as an entity (Grenfell 2008).

Finally, other factors that located two youths in a secondary location were possibly related to age or language discrimination. Although lack of proficiency in French was portrayed as a 'legitimate' discriminator in Montreal's employment field to dismiss Miriam, the argument flies in the face of the numerous years she has spent formally learning the language in Mexico and Montreal. Román, despite having all alleged necessary capitals to succeed in the labour market (i.e. knowledge of both official languages, a Canadian accent, Canadian education since primary school 
up to post-graduate studies, and subordinate work experience), has not been able to achieve a position similar to those of his white peers. Moreover, his profile does not correspond to the profile found by Banerjee (2009) among immigrants, where pre-migration education, work experience, and first language play major roles in disadvantaging them. Hence, other concealed factors that the literature on immigrant integration has uncovered and amply analyzed, such as veiled or 'educated' racism and age discrimination might be playing a strong role for some Mexican youth in not attaining an independent job (Calliste 2000; Lightman and Good Gingrich 2012; Oreopoulos 2011; Oreopoulos and Dechief 2011; Pendakur and Pendakur 2016). And although I have already mentioned how the increased precarization of the labour market affects both Canadian-born and immigrants alike, I have also illustrated how there are significant differences in employment and unemployment rates and the characteristics of the jobs obtained when we consider these two groups separately.

Overall, even when some Mexican youth possess enough types and amounts of Canadian capital to qualify for an independent location, they have been funneled into subordinate locations. Various factors are at play and there is no single pattern that explains each of the youths' cases. Undoubtedly, the ways in which employment conditions in various labour market fields are configured, generating increasingly precarious jobs and restricting the job access, have played a strong role in this process. This is despite some youth's considerable capital investment to acquire more education. In addition, a lack of social capital in Canada has a strong effect on individual outcomes. This is particularly true when this lacuna intersected with other factors, such as a poor valuation of immigrants' capitals by the labour market (even if some of these capitals were acquired in Canada), the difficulty in obtaining Canadian education, and time spent in Canada.

In other cases, specifically among those who immigrated as children or teenagers, it seems to be rather a matter of obtaining more capitals for them to move to an independent type of integration, although this will depend on the labour market conditions, type of chosen education, 
and social capital they obtain. However, when these cases are contrasted to cases such as that of Román, who is the perfect example of an early immersion in the Canadian milieu as a 1.5 generation member, the traditional economic integration factors do not suffice to explain why someone with such 'good' qualifications is still located in a subordinate location, suggesting other factors such as a combination of market saturation, ageism, discrimination, and racism.

This structural incongruity, where the possession of factors that allegedly facilitate the obtention of a job in Canada do not lead to a better job, also reveals how the same factors can have contradictory effects on immigrants' integration, particularly when compared to the cases of those who are situated in an independent location. What may make or break this situation is the possession of social capital and how this capital is connected to specific, independent employment fields that overvalue certain capitals at specific points in time based on capital's needs. Otherwise, the possession of social capital connected to small or closed circuits of labour will only perpetuate the location of the immigrant in subordinate or even secondary locations, as it happened among a few of my respondents. In general, however, education and work experience are more or less paying off for these young people, facilitating their access to a subordinate integration. This contrasts to some other Mexican youth who, despite their ample possession or lack of Canadian capitals, are still located in the secondary location, as I show in the following chapter. 


\section{Chapter 9: The Secondary Type of Economic Integration}

In Chapter 7, I showed how pre-migration capitals, age at arrival, the acquisition of new Canadian capitals, family support, and its positive correlation with capital's needs led some of my participants to obtain an independent location after immigration. I also showed in Chapter 8 how the difficulty in obtaining Canadian education, a lack of social capital, a modest valuation of immigrants' (Canadian) capitals, and the reconfiguration of the labour market, which has generated increasingly precarious jobs, have led some other respondents to be located in a subordinate position. In this chapter, I examine the reasons that lead nine of my respondents to be located in a secondary type of integration.

The chapter is divided into five sections. In the first section, I introduce the Mexican youth located in the secondary location. I also analyze how the reasons for a lack of French and/or English knowledge and pre- and post-migration education has led my participants to downward economic mobility. In the second section, I analyze how their employment trajectories, connected to their pre-migration class locations, post-migration circumstances, and migration status have resulted in a disadvantageous labour market position. In the third section, I analyze the strategies they resorted to in order to find jobs, strategies due in most cases to their lack of capitals. Here, I also place emphasis on their agency and resistance to get ahead in their new Canadian fields. This section is followed by an analysis of heightened work risks and health hazards to which they are subjected due to their position in a subordinate location. The final section presents an analysis of the interaction between immigration status and absence or misrecognition of capitals, which led my participants toward a downward economic integration.

\subsection{Lack of Official Languages and Canadian Education as Downward Economic Integration Factors}

Nine of the 35 people I interviewed (two women from Ottawa and two women and five men from Montreal) are located in the secondary location. Their median age at arrival was 22 years, with one participant who came with her parents at the age of one. All the youth came either through the family class (i.e. three people, two of whom came via marriage sponsorship and one 
by citizenship by birth outside Canada) or the refugee/ humanitarian stream (five people). One more person has a permit to stay under special considerations (see Table 10).

In contrast to my respondents located in the independent and subordinate types of integration, many of whom arrived in Canada with a medium-to-high level knowledge of English and/or French, eight of nine respondents located in the secondary type of integration arrived in Canada with little or no knowledge of French and/or English. This is because those who came under refugee or humanitarian streams were not expecting to immigrate and also were from a working-class in Mexico, which meant that their knowledge of official languages was basic. The other participant, Nadia from Ottawa, who was born in Mexico and accompanied her parents to Canada when she was one year old, learned English by growing up in Canada. She also learned Spanish from her mother and during her various stays in Mexico. When people hear Nadia speaking, she is usually told, "Wow, your English is amazing!" To which she replies that she grew up here.

Table 10: Mexican Youth in a Secondary Type of Integration by Gender, City, and Immigration Class

\begin{tabular}{|l|c|c|c|l|}
\hline Respondent & Gender & City & Years in Canada & \multicolumn{1}{|c|}{ Immigration Class } \\
\hline Aurora & F & Ottawa & 13 & Humanitarian \\
\hline Nadia & F & Ottawa & 23 & Family, Citizenship \\
\hline César & M & Montreal & 10 & Family, Marriage Sponsored \\
\hline Eduardo & M & Montreal & 12 & Family, Marriage Sponsored \\
\hline Marco & M & Montreal & 8 & Refugee \\
\hline Gonzalo & M & Montreal & 16 & Refugee \\
\hline Lorena & F & Montreal & 9 & Refugee \\
\hline Rodolfo & M & Montreal & 9 & Refugee \\
\hline Norma & F & Montreal & 5 & Humanitarian under special \\
\hline & & Mean & 11.7 & \\
\hline & & Median & 10 & \\
\hline
\end{tabular}

Gonzalo arrived as a refugee in Montreal at age eleven, along with his mother. He joined primary school and was sent to accueil:

which is where they receive you and where, in that class, there're only immigrants [that need to learn French]. [...] And that's where I really felt a shock, because it's there 
where you really live... where you really learn how people treat you when they learn

that you're Mexican, because that's when I felt racism, really. Not only by the children; there're many teachers that... I understand them today, that they get bored, no? [...] because you don't speak the language well [...] For instance, in secondary 2 , someone who should've had a little bit of culture because this is very cultural, he didn't understand what I said and told me 'speak white!' [...] They used to tell the Québécois(es): 'speak white.' Speak white, speak English, speak well, speak the superior language if you will.

Gonzalo's childhood experiences of encountering racism while he was learning the language and the culture were also marked by the fact that he arrived at a time when Quebec and Anglo Canada were grappling with broader politico-economic and identity issues.

As Mezei (1998) asserts, the poem "Speak White," by Michèle Lalonde, reflects how Québécois(es) nationalists in the 1960s promoted the preservation of the French language and culture while seeking independence from Canada. Thus, the semantic reformulation of "Speak White" by one of Gonzalo's classmates, a Québécois who demanded that Gonzalo speak a "français pur et atrocement blanc" (Lalonde 1970), paradoxically re-appropriated the symbolic violence exerted by the Anglo settler-colonial system against Québécois(es) and used it against Gonzalo. This signalled (and demarcated) his minoritized and Othered status in Quebec, even if this came from a previously subordinated, but nonetheless settler-colonial Québécois(e) identity. Thus, in Quebec's settler-colonial field (Stasiulis and Jhappan 1995), and in terms of the establishment of ethnic/racial hierarchies (i.e. symbolic power), in the land of the blind, the oneeyed man is king:

... parlez un français pur et atrocement blanc

[...] speak white

c'est une langue universelle

[...] be civilized... (Lalonde 1970, my emphasis).

For Lalonde, to 'speak white' signified Anglo linguistic, cultural, and economic imperialism (Mezei 1998). However, the request that Gonzalo speak a white, Québécoise French implies ethnic minorities' assimilation and subordination, via language, in a complex settler-colonial structure. Indeed, Gonzalo's encounter took place in 1993, some years before religious, cultural, and ethnic elements became overtly politicized in Montreal, such as the accommodation debates 
regarding the right of female Muslim students to wear the hijab (Stasiulis 2013). Quebec's immigration policy, that of interculturalism, is understood as "a reciprocal engagement between the Quebecois majority and cultural communities.” Here, Québécois(es) “must in turn manifest their appreciation for the contributions of immigrants" and assist in their integration. But the policy also expects that immigrants "know and respect Quebec's common values" and "develop a feeling of belonging and a comprehension of Quebec society" (Chiasson 2002:2).

Moreover, underlying Gonzalo's classmate's demand was a notion of Quebec as "a distinct yet 'fragile' nation" (Stasiulis 2013:184). Namely, since under the “dominant historical narrative of Quebec's fragility as a conquered settler colonial nation [...] the major threat is defined as the cultural otherness of racialized immigrants and religious minorities" (183), symbolic violence is imposed (Bourdieu 1990a). This symbolic violence demands, then, "cultural assimilation as the price of entry into Quebec citizenship" (Stasiulis 2013:183) starting with language: speak white. Gonzalo's basic French skills and Mexican accent as a recently arrived refugee are thus read as a symbol of non-belonging to Quebec, for which his assimilation is demanded in secondary school.

Among youth who arrived as young adults, the learning of one of the official languages was something they could not do immediately after their arrival because they were facing a precarious economy and/or due to the uncertainty of their refugee determination or marriage sponsorship process. In Aurora's case, after she got pregnant, stayed in Canada, and experienced domestic abuse by her Canadian partner, she was not allowed to leave her ex-partner's house without him or his mother. She thus continued to learn English by watching cartoons and movies and listening to music. After her child custody was taken away, she kept learning English at the sexual assault centre she was attending: "Uh, sometimes I have even better grammar than [locals] [...] So, I feel like [in noticing these errors,] this is like a rebellion to certain extent. Like a rebellion in saying no, I'm not a piece of shit. I'm someone, I'm something, I'm competent, I can." Aurora also took six months of EAL before being admitted to a university to do her bachelor's degree. 
In Marco's case, he spoke little English when he arrived in Montreal to apply for refugee status. Although he could have taken Francization courses, he did not do so because:

I was in a crisis; I didn't have the motivation. It was like... being in limbo, you don't know what to do. It was a stage in my life... I lived those years as if I were blind. And I imagine that many of us who came as refugees experienced that. [Initially] it's a crisis, then it's poverty, it's something that... you live like at the margins of everything. You don't speak the language, you don't work.

Once Marco obtained refugee status, he began his Francization process, "and like I felt better, I felt more included in society, no?" Sharing a house with Québécois(es) also helped Marco to improve his French. He later learned some English while "working on the anglophone side of Montreal."

Rodolfo, who arrived at the age of 18 , found out that he had cancer after undergoing his refugee application medical examination. He began a medical treatment that further weakened him, but, "as much as I could, I was studying French because I realized that I really needed to study French. [...] So, I realized that I had the ability to say, hey! I'm not going to let myself down because of this illness." Although it was not easy for Rodolfo to learn French, he also began practicing the basic English he had learned in high school in Mexico while working for employment agencies. Lorena, a refugee who arrived in Montreal at the age of 23, was able to take only the first basic level of Francization "because I needed to have economic solvency, so I needed to work." Lorena learned French while working in a chicken processing plant where everyone spoke French only: "I spoke a little bit of English, the basic stuff that I spoke at the university, uh... I didn't know French at all, and when I began working, I was working for an African man that only speaks French." Lorena is currently studying English at an employment training center "because it's beneficial."

Among Mexican youth who came via a marriage/partnership sponsorship, César found it difficult to learn French due to his precarious economic situation in Canada. He did not take francization courses "because I was busy with work and with my child, so this wasn't an option 
for me. I chose to be self-taught.” It took him between three to four years to understand everything in French, and five to six years to "write some things and have more profound conversations." Similar to César, Eduardo was only able to take francization courses a year and a half after his arrival because:

I had to start working, no? Like everybody. [...] And then I began working at a fruit store, in Côte-des-Neiges. It was cool in there. That's where I began speaking French because I had contact with the public, no? [...] I think I speak it well. I mean, I have an accent, but I think that that accent is going to stay forever.

And Norma took French courses in Mexico, but "here I continued taking conversation classes, because the French is super different than the one you learn in Mexico" (i.e. a Parisian French).

In contrast to youth located in the independent and subordinate types of integration, few of those located in the secondary location have education beyond high school in Mexico and/or Canada. Those who interrupted their education in Mexico have not been able to continue studying due to their precarious migration status. César had to wait seven years to obtain his PR status, and was thus able to do post-secondary studies without being charged international student fees. A year before the interview, he began studies in a technical career, although "yes, I made a pause because it also requires a lot of time, working and studying is hard. I did it last year, and it was a very hard year to do both things, the same day studying and working." Norma, who has a compassionate grounds under special considerations status and had come to Montreal to take a short, specialized course, has not been able to keep studying due to her accident and her continuous need to go to her appointments at a hospital in Montreal. At the same time, without PR status, she cannot request provincial support to keep studying.

Other youth found it very difficult to continue studying beyond their Mexican high school degree due to the economic pressures they faced after immigrating, or their domestic arrangements with partners, or their lack of knowledge of Canadian employment fields. For example, before being sponsored via marriage, Eduardo had interrupted his studies in Mexico because "I never liked too much the school, and... well, I was quite skilled with my hands, I'd 
been always a craftsman." Thus, Eduardo worked in the craft business and was also an activist in Mexico. After immigrating, he began working to help his partner with the household economy and prepare the birth of their child: "I always found it quite difficult: working and studying and having children. It demands a lot of time, it's a lot of pressure. I was too young. I couldn't stand it." Rodolfo comes from a rural background, and when he finished high school in Mexico "I didn't have more options. To be honest I never thought about other possibility [of studying]." Once in Montreal, Rodolfo did not consider studying because "I didn't know if I was going to stay [i.e. if his refugee claim was going to be approved], I couldn't aspire to more, because... I used to say, 'Either if I go back or not, well I have to work' [to survive]. Besides, I didn't have [my school] equivalencies.”

After Rodolfo obtained his PR status, and despite his illness, he wanted to keep studying. But he asked his wife, “'Do you want to work or study? Whatever you want.' 'No, I want to study to finish my high school.' 'OK, you study, I'm going to get better and work as much as I can, no?" Rodolfo kept working while his wife kept studying. In 2013, Rodolfo received his high school certificate equivalence, which included one year of études pré-universitaires (i.e. a pre-certificate that counts for the diplôme d'études collégiales), "so I can attend a CÉGEP with this, or even a university, or something, or get an easier [technical] education, no?" At the moment of the interview, Rodolfo's wife was about to finish high school, but he did not have concrete plans to keep studying.

Marco, who comes from a rural background in Mexico, whilst waiting for his refugee determination:

tried to study agriculture to work in [places such as] the botanical gardens and all that, but since I didn't have the [required] education level, I'd have to do high school again, no? [So,] to revalidate all that [i.e. his Mexican high school courses] was like going back a little bit, no? I tried, but my certification was denied because I didn't have PR status [at that moment, so] I didn't have access to an education a little bit more professional. I had to study French first. First, French, then secondary school, and then I could [continue my education]. So, uhm, I lost the motivation to study, besides the fees are a little bit expensive and no, I just ditched this." 
After Marco obtained his PR status, he began working as a mechanic, and "the very same boss wanted me to study [automotive] mechanic, they [offered to] pay [for the tuition fee] and I told them, 'No, I don't want to' [...]. But that was because this [course] didn't appeal to me. [...] I have an idea, it might be wrong, but I used to say. 'Okay, he wants me to work for him [in the future], no? and I might stay here all my life, no? making him rich."' Marco has not considered continuing studying.

The rest of my participants, Aurora and Nadia from Ottawa, and Lorena and Gonzalo from Montreal, have studied in Canada, although the type of studies they have pursued vary depending on their time spent in Canada and their personal circumstances (i.e. relative poverty, violence, or lack of support). Aurora could only resume her high school education eight years after having immigrated to Ottawa due to her experience of domestic and institutionalized violence. A social worker connected her with a couple of programs catering to women, which assisted Aurora in paying for and obtaining her high school degree in Canada. And then "my best friend told me, 'Why don't you go to school? Do something."' With the support of a scholarship, Aurora took a university course about gender issues. "And I liked it, and I said, 'Screw the college, I want to go to university." Aurora was accepted into university, "so I was happy about that. I applied to OSAP and I got OSAP, I was super happy." At the moment of the interview, Aurora was still doing her bachelor's degree, and her studies have also helped her to re-interpret her difficult life situations.

Nadia was brought to Canada by her parents when she was one year old, but also spent some years in Mexico: "I studied like three years of primary school, two years of high school, and I went there every summer." After Nadia's parents divorced, her family's economic situation (her mother and two younger siblings) become dire. When she returned from Mexico to finish high school in Canada, Nadia decided to work full-time to support her family and have some pocket money: "I worked from 4 pm to 11-12 pm, so I got home to eat and then do school stuff." Nadia also faced problems at school. For instance, a teacher asked her to reconsider her career choice 
because "Hispanics tend not to do well in those academic areas, so I left the place crying." And she also was constantly bullied: "Oh god! They bullied me a lot. [...] They made fun of me or they passed me notes saying that they were going to hit me." This happened even when "I don't look like 'a piece of minority,' as they said.” Indeed, Nadia changed high school five times trying to avoid the bullying:

And yes, I think that my economic status was also a reason for which they bullied me. You know that kids are like 'look what my dad bought me,' 'look at this,' 'look what I have here,' and 'I went here, I went there!' And I could never participate in that, so I think that that also caused this. That didn't matter to me [i.e. her economic situation], but that was another reason for which I was not inside the circle. I didn't have money to go to the cinema, to go to the food trucks, I didn't have [money] for new shoes or what was [fashionable]."

Once Nadia finished high school, she attended college for a year under a university transfer program that facilitates entrance to university. Thus, after a year, Nadia applied to a university and moved to Ottawa, supported by various scholarships and OSAP. At the moment of the interview, she was applying for admission to a master's program in Montreal.

After finishing his secondary school in Laval, Gonzalo did three years of pre-university preparatory studies at a CÉGEP in Montreal. He also was told by an advisor that "“No, Mr. [surname], you will never attend the CÉGEP.' And I remember that when I got accepted, they accept almost everyone, I took my acceptance letter with me, went to see this teacher, and told her, 'Look lady, they accepted me, and I won't come back to your course!' And I never went back to her course." When Gonzalo finished his CÉGEP, he enrolled in a BA program and later in a master's program, funded by some university scholarships and loans from the Quebec government. At the moment of the interview, he was about to finish his MA.

\subsection{Employment Trajectories of Mexican Immigrant and Refugee Youth in Canada}

The lack of a medium-to-advanced knowledge of any of the official languages and secondary or post-secondary education in Mexico and/or Canada, derived — in turn — from their immigration conditions and pre- and post-migration class location, was a strong determinant for 
some Mexican youth to be located in a secondary location. This is not a novelty, since previous research has shown that most refugees and those who come under humanitarian streams struggle in terms of economic integration, in addition to immigrants requiring a minimum of between 10 to 11 years to achieve economic parity with Canadian-born people (Boudarbat and Grenier 2017; Guo 2013; Hiebert 2009; Hiebert and Sherrell 2009; Li and Xiaoling Li 2013; Lightman and Good Gingrich 2012; Raza, Beaujot, and Woldemicael 2013; Yee et al. 2003).

However, as mentioned earlier, there were also a couple of cases where my respondents had accumulated a significant amount of Canadian capitals (i.e. they immigrated quite young, are fluent in one of the official languages, and have studied in Canada since at least secondary school) and are still located in a secondary location. These two cases thus contradict positive integration outcomes found among immigrants who arrive up to the age of 12 , known in the literature as members of a 1.5 immigrant generation (Pendakur and Pendakur 2016; Rumbaut 2008). As in the cases of a couple of my 1.5 generation respondents positioned in the independent and subordinate locations, Nadia's parents' economic integration also shaped her own economic integration process. Before immigrating, Nadia's mother worked in the arts industry in Mexico, for which her skills were not transferable to the Canadian labour market. Thus, after Nadia's parents divorced, her mother found herself in a precarious situation.

Nadia's mother had to support herself and her three children without having access to enough economic capital or other types of Canadian capital, such as an advanced level of proficiency in one of the official languages or cultural capital (i.e. a credential accreditation or education). This led the family to experience poverty, and under these circumstances they did not have access to what would be considered luxuries, such as buying certain types of food, or paying for everyone's flights to visit their family in Mexico (with whom the mother maintains a close transnational relationship). Nadia also spent some years in Mexico as a child and teenager, which helped her mother to reduce the family's expenses in Canada. 
The last time that Nadia returned from one of her long stays in Mexico, she decided to work full-time while also studying secondary school to help "to reduce the expenses for my mom, because my dad did not pay child support for four years, he didn't want to. And my mom was accumulating too much debt, she [even] had to claim bankruptcy." Indeed, Nadia's mother went to court trying to force her ex-husband to pay for the child support he owed for years, but the judge sided with the father: "He didn't have to pay the 40 thousand dollars. The only thing he [was ordered] to do was to visit my siblings more frequently."

Living in Mexico for two years while studying high school did not allow Nadia to acquire secondary jobs in Canada as other Canadian youths her age did, so she missed out on some work experience and potential social capital. Once in Canada, Nadia had a variety of secondary jobs, such as working as a babysitter and as an employee at clothing stores. Nadia's (family's) economic strategy while looking to confront an economically difficult situation, including the use of a transnational field, hampered her early acquisition of Canadian capital (i.e. work experience and potential social capital). After Nadia moved to Ottawa to do her undergraduate degree, Nadia obtained a job as teaching assistant (subordinate job). However, after graduation and unable to find a job in Ottawa, she moved to Montreal, where she could only get some cooking and baking jobs at restaurants (secondary jobs). At the moment of the interview, Nadia was still looking for a subordinate type of job, but “the only thing I've been finding is marketing jobs, and I don't want a marketing job, I don't know anything about marketing."

In addition, Nadia's constant experiences of moving from one Canadian city to another and to Mexico, along with her precarious insertion in the labour market, have not facilitated her acquisition of social capital, which could help her to tap into social networks and be aware of better jobs. Thus, despite her possession of rich Canadian capital (i.e. a Canadian education, a Canadian English accent, some Canadian secondary work experience, knowledge of the local culture, and even skin fair enough to sometimes pass as white), her lack of social capital has been 
a strong factor behind her not being able to enjoy further social mobility. Thus, so far, Nadia has had a secondary $\Rightarrow$ subordinate $\Rightarrow$ secondary trajectory.

Gonzalo, who came to Canada at age 11 and has studied here since secondary school, has not found any job that might help him to be permanently located in at least a subordinate location. He started working at age 15 , first at a burger restaurant and then picking strawberries during the summers with other Mexicans who came via the SAWP. Since then, Gonzalo has worked in many secondary jobs. Before arriving as a refugee in Montreal, his mother used to work as an administrative technician for a global company with offices in Mexico. Once in Canada, "and I'm not lying, for a year she worked packing chicken [at a factory] despite having a master's degree, no? Not anymore. Currently, my mom is again an [administrative technician] in an [industry] export company [independent job], but... well, nothing is rosy when one immigrates to Canada. And I feel like the first three years are the hardest ones."

Gonzalo's mother's economic independent integration, however, has not facilitated Gonzalo's development of social capital, which could help him to obtain other types of jobs. Indeed, it was not until he moved to a smaller city in the province of Quebec to do his master's degree that Gonzalo obtained a subordinate type of job as a research assistant. When his short contract finished, Gonzalo began working for a year and a half as a specialized guide at a museum (subordinate job). Currently, and now back in Montreal and living on his own, Gonzalo is working as a server at a restaurant while he finishes his master's degree (secondary job). Thus, as in Nadia's case, and despite his possession of rich Québécois capital (i.e. a Québécoise education, knowledge of French, Québécoise work experience, and knowledge of the local culture), Gonzalo's lack of social capital in Montreal has not helped him to get a job that might locate him in a different type of economic integration. So far, then, Gonzalo has had a secondary $\Rightarrow$ subordinate $\Rightarrow$ secondary employment trajectory.

Gonzalo's possibilities of acquiring an independent job, once he obtains more advanced 
cultural capital (i.e. finishing his master's degree), seem not to be as high as those of my other participants who are also students (or were students) and are located in a subordinate or independent type of integration. This is because in his and Nadia's case, their area of studies (i.e. social sciences) has a more limited value in the labour market and thus reduced possibilities of generating social capital. Their cases contrast to those of the youth located in an independent location, who studied for careers directly connected to the needs of global, transnational, or national labour markets, and where the possibilities of generating social capital were an added component to their institutions' programs.

In the other two cases where my respondents studied or are studying in Canada (i.e. Lorena and Aurora), their acquisition of cultural capital has not translated into significant job opportunities. This is because their lack of other Canadian and social capitals, life challenges, and even physical limitations, have acted as deterrents to an improved economic integration, furthering the reproduction of their linear trajectory of secondary jobs. Lorena did a bachelor's degree and had a technical career in Mexico before requesting refugee status in Canada. After Lorena moved from Vancouver to Montreal, a Salvadoran friend recommended her for a one-onone interview with the owner of a chicken factory, and she got a job immediately:

I had to cut chicken. Later, they saw that I was quite agile and transferred me to packing. Then they transferred me to labelling, with the supervisor, who was an African man. My [last] task was quite simple, but then I decided to quit because I got pregnant, I had my child, and once my child was born, I decided not to go back [to work] anymore [to take care of her].

Once her child grew up, Lorena took a short technical course in childcare and then in French, which in theory should have secured her access to continuous employment and a pathway to an independent location due to the high demand for childcare in Canada.

However, the outcome was different. This is because, on the one hand, Lorena did not like the course and did not look for jobs in this area, and on the other hand, as a single mother, she lacks support from a partner or a family member to take care of her child while she works. 
Although Lorena recognized that she receives economic support from the Quebec government: at the same time this isn't everything. [...] Because I've gone back to Mexico to visit my family, so here I've felt like, a little bit alone, in the sense that there's no family. So, I've compared the two environments, [one where there's] myself among my family [in Mexico] and here myself with my daughter. We do have many friends [here] and everything, but it's not the same.

Lorena is currently unemployed and studying English at an employment center. This is because she was told that her Mexican bachelor's degree might help her to obtain a job in Montreal if she also speaks English. Nonetheless, she is thinking of returning to Mexico for good. The experience of being by herself with her child in Montreal, with no family connections, lacking close relationships and social capital that might assist her as a single mother, plus Latinx, Christian friends that pity her for being a single parent, have pushed her boundaries and let her think that it is better to let all Montreal things go. Lorena would not be the first Mexican immigrant to do so. Ramiro (i.e. Patricia's partner) mentioned how while they were doing research about immigrating to Montreal, they met with a close friend who had obtained PR status in Canada and decided to return to Mexico for good because "he did very badly" in terms of integration.

Aurora was living in a women's shelter and sorting out her legal situation when she also started working: "my first job [in Canada] was at a coffee shop. It was like my refuge from the shelter." Aurora could not work anymore because she suffered an accident that caused her a certain disability. Currently, she is still fighting for her child's custody, wants to finish her bachelors' degree and work for an NGO or the refugee cause. Among my other respondents, a number of factors have led them to be located in a secondary type of economic integration. These factors include their initial precarious insertion in the labour market, their lack of Mexican education and Canadian capital (i.e. post-secondary education, knowledge of official languages, a marked accent, and lack of knowledge about the local employment culture), a limited or restricted possession of social capital in Canada, and the immediacy of their social reproduction needs after arrival. In the case of those who came as refugees, attending their social reproduction needs 
meant making use of any strategy available to get a job, and in the case of those who came under marriage sponsorship, it meant helping their partners with the day-to-day costs of their social reproduction and preparing for the arrival of their child.

Rodolfo, for instance, while waiting for his refugee hearing and having no knowledge of French, was told that the way to get a job in Montreal was through an agency. His first job was distributing printed material for Publisacs, involving going door-to-door dropping off plastic bags filled with ads:

For a long time, I worked with employment agencies. At that time, there were a lot of agencies. They closed afterwards because they used to hire tourists or refugees and didn't pay taxes, and [the government] caught them. That's why there aren't as many agencies as before, when you saw hundreds of people outside the metro stations waiting for the buses to take them to their workplaces!

Despite having cancer, Rodolfo kept working whenever possible in secondary jobs, showing an extraordinary resilience and agency: unloading trucks, packing, cleaning washrooms, picking fruits and vegetables, serving at restaurants, etc. 'This was because I don't have education, because I didn't know if I was going to stay [in Canada], because I couldn't aspire to more [due to his circumstances]." Rodolfo mentioned that one of the worst jobs he had was at a kayak factory. At the employment agencies, they called it "the kayaks and plastic," which was "a place nobody wanted to go because it was really a hard job!"

Rodolfo left that job (and the employment agencies) because he got a weekend job at a market based on the recommendation of an acquaintance, taking care of a stall of household products. There, he did not have to carry objects around and he could practice his French and English (he had already attended courses for both languages). Rodolfo also met a Latino friend at the market who invited him to work in plumbing, and an Arab man who employed him to tend his market stall on weekdays selling clothes. The social capital that Rodolfo has generated in Montreal has been limited to the opportunities he has obtained in the market, mediated by his contact with people from different ethnic backgrounds, thus limiting his possibilities of being 
employed in a different type of job (i.e. spatial structuration). Moreover, despite his acquisition of some Canadian capital (i.e. intermediate knowledge of both official languages), his lack of education and his narrowed employment experiences have limited his possibilities of advancing to a better type of economic integration.

After Marco claimed refugee status, he received welfare support and then found a job at a Chinese restaurant in Montreal, washing dishes on weekends for $\$ 10$ per hour, meals included. One day, he was approached by a man at a Tim Horton's who offered him a job in greenhouses picking vegetables for $\$ 8$ per hour, Monday to Friday. For this job, Marco was picked up by a van outside a Metro station, along with 11 other people, and had to commute for one hour to get to the greenhouses: "[I experienced there] a terrible loneliness and like the migrant illness, that experience of only working, and I said, 'This is not what I want,' right? [...] There was a lot, a lot of exploitation." After this job and having obtained refugee status, Marco got a job as an automotive mechanic, "changing winter tires and I stayed there for four years. I started there with a broom and ended up being a mechanic." Marco earned more money there, and thus stopped receiving social support. Marco mentioned that the lack of studies and an advanced knowledge of both French and English "makes it hard to find a good job" in Montreal. Due to his lack of education, and because work is scarce at the mechanic shop during the summer, Marco has been working in the Okanagan Valley picking fruit during summers for three seasons already. At the moment of the interview, he was still following this pattern.

Norma, who is an atypical case due to her migration status and her reason for staying in Montreal, has also remained in a secondary trajectory due to a combination of factors. Because her accident forced her to stay in Montreal, she generated a considerable amount of social capital among Latinxs and other ethnic groups. However, this capital, along with her basic knowledge of French and Mexican education, has not helped her much with respect to moving toward another type of economic integration. Thus, Norma obtained her first job in Montreal: via an agency. That's how you generally get a job, via agencies. So, you go to an 
exploitative agency, whose owners can be from Mexico, Puerto Rico, Peru, Quebec, whatever. Many agencies are Latinxs, but they work with Québécois(es), so they operate in the same way, right? [...] Besides, the scums of the agencies retain your wages for three weeks! So, you go to work and no one pays you anything, right? And I was earning $\$ 8$ per hour, but they [the agency] were paid $\$ 12$. So, $\$ 4$ for the agency and $\$ 8$ for you, so it's the perfect business, because the guy [i.e. the agency owner], the Québécois, has people he exploits, right?

Moreover, Norma's accident generated elevated costs due to her non-permanent resident status:

"I had to resort to the strategy deployed by everyone: to work." Norma's first job was at a clothes

factory, where she was assigned to the final stage of the production line to:

take off the [previous] label from the garment. It's easy, no? But the label turns out to be 500, 1,000, 1,500, 2,000 labels. Then, [you have to] change the plastic cover, take off the old label, put the correct size label, put the right clothes hook because it comes with the wrong clothes hook. And because here [in Canada] people are taller, the coats are bigger, right? So, you have to do a lot of manual labor, and then move the racks with the 500, 300 coats, 200 coats, and you are being watched all the time. That for me was like... a horror story. And I was like, 'excuse me,' and I brought a chair close to my station, and everybody was like 'how dare you to bring the chair close to you!?' But I'm not going to be standing up for seven hours there. One day I almost fainted because of the work pressure and the lack of ventilation. So, the dust, the garments, a lot of dust, I had already issues with my throat... and my boss treated me really bad. [...] My supervisor... from Pakistan, was like super... she abused me: 'you're an idiot,' 'you're stupid,' among other things she told me. So, it was a crazy world [...] there were also Chinese people working there, Québécois(es). One hour to eat, a five-minute break, you can't use chairs, so it was super... [Alejandro: And did she treat the Québécois(es) in the same way?] Oh yeah! Because they [the owners] were anglophones, so for the anglophones the Québécois(es) belong to certain class, Latinxs to a $3^{\text {rd }}$ class, Arabs to a $4^{\text {th }}$ class and so on, right? [...] You become a... machine. After doing the same thing 20 times you stop thinking.

Norma left that job because "what I was earning was being spent on therapeutic massages" due to

the physical toll that the job took on her. Norma was then assigned by the agency to work:

in a chalk factory, which is, indeed, a horror story. And since quite often people think that I'm Pakistani, or from Bangladesh, or India, I was sent with [South East Asian] women. So, [in my first day] they [i.e. the managers] simply saw me and told me, 'Welcome, you have to go there.' [pointing towards the Pakistani women...].

Moreover, Latinxs discriminate against Pakistanis a lot. [...] I saw in that factory that Latinxs didn't eat with them and made fun of them. So, it was a real shock to me because... we're here in the middle of the shit.... and the [Pakistani] ladies felt it. They didn't understand what [the Latinxs] were talking about, they just felt it. So, to eat lunch, they [i.e. the Pakistani women] just stayed there! Alongside the gases [emanating from the chalk], no? And they also stayed there making extra hours and... it was horrible. 
Reflecting on her employment experiences and the experiences of other immigrants she met in Montreal, Norma concluded that "most people who work in the toughest jobs are migrants, and the ones with a higher risk of accidents are, of course, migrants." Although Norma mentioned that the majority of the maquilas are located outside of Montreal, "there are other ones hidden here [in the city]. [...] And I got to work to [that] factory, and it was in the middle of the city, there, in downtown. And it was alongside places that are now art galleries. But inside, there are Chinese people working and... I mean, it's a crazy world here. But you don't see it.” An overall lack of capitals, then, forced these youth to make use of a couple of main strategies to find a job, as I show in the next section.

\subsection{Strategies to Find Jobs Under Limited Possession of Capitals}

Among the youth from this sub-set, I found two widely used strategies for them to find a

job in Montreal, particularly considering their lack of capitals. One was a word-of-mouth strategy and the other one was resorting to private employment agencies. The word-of-mouth strategy represents the development of the only capital they could access considering their pre- and postmigration locations, which is social capital. This strategy led several of my respondents to work in cleaning services. This is not surprising since cleaning is, "in fact, central to the functioning of the contemporary global(izing) economy" (Aguiar 2006:24). Moreover, this service is also mediated by subcontracting processes and the use of racialized labour force. The intersection of pre-migration precarious situations and a poor economic integration in Canada led most of my participants to undergo a depletion of capitals. Indeed, the creation of social capital among these youths was strongly characterized by its limited scope.

Since the people they were able to meet and create social capital with were mainly other Latinxs or immigrants facing similar conditions to theirs, their possibilities of potential employment were reduced to other secondary jobs. Consequently, what matters most in terms of immigrants' social mobility in Canada is not necessarily the size or duration of the network but its 
quality. This means that the types of fields to which its nodes are connected, and the strength and/or relevance of these connections, are what create potential value to access a field (i.e. entry fees). Thus, although social capital was the main or only possible post-migration capital they could have, its scope and effect has been limited, thus funneling their employment access to specific sectors and/or jobs, and reducing their potential for social mobility (i.e. spatial structuration [Sassen 1995]).

The second widely used strategy to obtain a job among this sub-set of participants was that of resorting to a private employment agency. Shortly after their arrival, many of my respondents were told that the way to obtain employment in Montreal was by making use of these agencies. Employment agencies are not new in Canada. Their existence can be traced back as early as the 1880s (Vosko 2000). However, their relevance has increased since the late 1970s due to capital's demand for a flexible, cheap, and casual labour force (Bernier et al. 2014). Hence, companies have found creative ways to decrease their labour force responsibility whilst increasing their net profits through the use of private employment agencies, which, at the same time, have proliferated both legally and illegally. Ownership of these agencies in Montreal, as indicated by Norma, is varied in terms of ethnicity, ranging from Québécois(es) to Latinxs, as well as in terms of legality.

As Rodolfo mentioned and has been confirmed by other research, there have been illegal employment agencies or agences clandestines shut down in Montreal whose ownership is identified as Latinx and Arab (Bernier et al. 2014). However, Norma's personal knowledge of the agencies unveiled a more complex network of ownership and collaboration among people from diverse ethnic groups including Québécois(es): "So, you go to an exploitative agency, whose owners can be from Mexico, Puerto Rico, Peru, Quebec, whatever. Many agencies are Latinxs, but they work with Québécois(es), so they operate in the same way, right?’ Norma's insight, then, signals how capital and labour exploitation knows no boundaries regarding nationality/ethnicity, even in an immigration field. 
The boom of private employment agencies also responds to the easiness with which these agencies facilitate the hiring, managing, and remuneration of workers, even if the agency has no control over the employment workflow. Agencies also facilitate the client company's temporary assignment of agency staff to specific tasks, but without being officially recognized as the employer and the responsibilities of that status (Quebec 2016). In Quebec, so-called 'atypical employment' types, such as part-time, temporary, autonomous, occasional, at home, on-call jobs, and jobs obtained via agencies represented 38.1\% of the labour force in 2012 (Bernier et al. 2014). Moreover, $32 \%$ of agency workers in Quebec were born outside Canada, and among the latter, 37\% were born in the Americas (Quebec 2012). In addition, the employment agencies' revenues have also doubled since the 2000s, reaching \$13.3 million for Canada and \$1.4 million for Quebec by 2014 (Quebec 2016). It is clear, then, that the evolution to a post-Fordist economic model, the increase of temporary and casual labour use, and the high transference of surplus value from agency workers to employers in Canada has generated huge dividends for both employers and private employment agencies.

The conditions in which youth from this sub-set arrived in Canada thus made them easy prey for private employment agencies. Precarious, hard, and sometimes dangerous work, at times managed by employment agencies, remains the only option for many refugees and immigrants who lack enough capitals to exchange in the Canadian labour market. For instance, after the upsurge of refugee claimants coming from the United States in 2017, various companies and community organizations co-organized job fairs. They offered the jobs that few Canadians are willing to take, either because of their geographical location, difficulty, or low pay, such as meat packing companies or a canoe and kayak manufacturer (Ross 2018). It is no coincidence then, that among youth from this sub-sample, the first or second job that Lorena, Eduardo, and Gonzalo's mother had to resort was working in a chicken processing factory. Or that "the kayaks and plastic" job, as Rodolfo mentioned, constitutes a job offered to immigrants and refugees since 
it is "a place nobody wanted to go because it was really a hard job," one that demands exhaustive physical and mental work.

The lack of Canadian capitals also forced some youth to remain longer at certain jobs despite the low pay, demanded extra work hours, and in some cases involved associated health risks. At the same time, these experiences were frequently contested by a strong resilience and agency. For example, even when Lorena had developed early symptoms of arthritis due to the mechanical repetition and work stress inherent to her job, she only left her chicken factory job once she got pregnant. And Rodolfo, despite his debilitating illness, worked in the gamut of secondary types of jobs to support his family. Marco was also forced to do his job at the greenhouses as often as possible, despite there being "a lot, a lot of exploitation," due to economic reasons and because he needed to send remittances back to Mexico (more in Chapter 10). And César had no other option but to endure working at "dirty jobs" due to his seven-year period of uncertainty regarding his migration status, and also so he could stay with his daughter.

I found two other employment characteristics among my participants located in the secondary location that were almost exclusive among them. One was an increased labour control and surveillance, and the second one was the presence of work hazards and risks at their job places that caused them health issues. Regarding labour control and surveillance in the workplace, Norma's employment experiences in Montreal showed how regulatory labour and management practices, as documented in the labour literature, also occur in 'first-world' countries: strict control over going to the toilet, (im)possibility to sit at one's station (or the 'struggle for chairs' using Lugo's notion [2008]), health and environmental issues, as well as a hyper-strict supervision of individual production processes were continually reproduced (see Kamel and Anya 1999; de la O and Quintero 2002; National Interfaith Committee for Worker Justice 1998).

Norma's experiences also uncovered the minoritization and racialization of ethnic groups inside Canadian maquilas, but also the discrimination that is being (re)produced among 
minoritized ethnic groups, such as Latinxs discriminating against South Asian women, even if they do the same type of job. This points toward inter-ethnic dynamics playing out at the workplace, where labour, rather than establishing solidarity networks, breaks down potential ties that ultimately benefit the company and the reproduction of capital. In addition, while discriminating against people of other ethnic groups, Latinxs are, on the one hand, deploying a cultural trait where ethnic/racial hierarchies are continuously (re)configured via Othering. On the other hand, the (re)production of this cultural trait, even if in a distant field, finds its origin in a colonial habitus, where Othering was constituted as a central mechanism of (symbolic) social mobility. This habitus is deployed in a precarious employment situation where all workers, despite their ethnic/racial identity, face the same hazards and health risks derived from dangerous jobs, as I show in the next section.

\subsection{Health Risks Within the Secondary Type of Economic Integration}

The hazardous experiences and health risks that Norma witnessed and was subjected to at the maquilas in Montreal, unveiled a characteristic that I only found among some of the youth located in the secondary location, that of serious health issues caused by the types of jobs they have had. Certainly, Karina, from the independent location, developed a strong allergy that resulted from the first job she obtained, counting thousands of bills for a bank in Montreal (via a private employment agency). But this type of work was precisely one of a secondary labour market nature, and - as explained in chapter 7-Karina's pre-migration capitals and the needs of a transnational market led her to later achieve an independent location. For my respondents located in the secondary type of integration, however, it has been their limited amount of pre- and post-migration capitals, along with their immigration motives and status, which have led them to only obtain secondary types of jobs and thus be exposed to increased health and security risks.

For example, when Nadia finished her bachelor's degree, she could not obtain a job. “All the jobs were for students, [...] [besides] I couldn't apply to those jobs, or museums, because 
anywhere here [in Ottawa] you need to know French, so I was on welfare like for two months, because I depleted all my savings." Nadia then moved to Montreal and got a job at a bakery that was expanding, for which she was soon transferred to their new industrial kitchen. The job implied a change of schedule, without a salary raise, and added labour: "I was already carrying big bags of flour, I mean it's heavier, and I was by myself, making a thousand cookies every day, twenty cakes, that's the hardest thing I've done in my life, so I had to resign." Nonetheless, Nadia was only able to find jobs at restaurants, and at her last restaurant job, which she got by recommendation of her boyfriend, she began working eight hours, but these soon "increased to between 16 to 18 hours per day, and I got a hernia in my back. I was at the hospital for a week. [Then] I returned to work with a really strong pain in my back."

In Norma's case, when the agency sent her to work at the chalk factory and she was ordered to work along Pakistani women:

I went there, and they [i.e. the Pakistani women] had very bad health issues: holes here in the nose [i.e. internal cartilage], in the mouth, facial blemishes. [...] And the job seemed quite simple: put the chalk in a box, right? But you are smelling the toxic gases emanating from the chalk. There isn't a separation [i.e. protection] system. A Mexican guy, who got permanent residence, burned his arm [because of the toxic elements]. Myself, once, I almost didn't wake up because I got intoxicated. I had to go to the doctor, I was totally intoxicated with the gases that I inhaled in there. So, I only lasted there four days and decided that I would never get another job like that one.

Norma decided to quit this job fearing for her health after she fainted, but before leaving, she decided that because of the "horror stories" she had witnessed in a short period of time, she needed to do something. "So, in all the small boxes that I filled with chalk... I left small pieces of paper saying that those boxes had been filled by two ill Pakistani women and a Mexican." From there, Norma worked cleaning houses and earning $\$ 10$ per hour, but she also had to quit due to the chronic back pain she got from her previous accident: "it was too much for my back."

In Lorena's case, once she got a job at the chicken factory and was being promoted, her wages also increased slightly. But she was working from Monday to Saturday, doing more than 80 hours per week. This caused her hands not only to hurt but become paralyzed. A doctor told 
her it was early symptoms of arthritis due to mechanical repetition and work stress. However, she did not want to quit because she "needed the job and be okay with my boss. Show him that I was willing [to work] for me not to lose a job that everyone - perhaps — wanted, because it was a covered job [i.e. inside a building rather than outside, especially during winters], and without too much pressure, [compared to] the last position I had." Lorena left the job after her daughter was born and because the latter got constantly ill: "it's very difficult here [in Montreal]. Children get sick here because of the cold." Lorena also moved to social assistance, which helped her to improve the condition of her hands.

Similarly, Eduardo, who worked as a tree planter in BC, left that job:

because it's too heavy, too harsh for the body. I began developing problems in my joints, in... my hands. There's this thing they call the 'claw,' which is tendonitis in the hand. You wake up in the morning and you can't even close or open your hand. [This is] because of the shovel, due to... repetitive movements, tendonitis, juvenile arthritis. Yeah, it's a hard job. Generally, this type of job is done like... people begin [working] around their twenties, and eh... in five, six years they retire. I started at age 30, so, I was a very old planter when I started. But I could only handle this for two years. I wiped my body out.

Eduardo mentioned that the job was "super well paid. They pay you 10 cents per tree, so it's based on volume. Based on your production it's what you get paid, no? I used to make an average of 2,000 trees per day, and I was one of the slowest [workers] because of my age, no?” But despite the good wages, the physical demand of the job and health-related issues led Eduardo to quit. Similarly, the physical demand of the job and the generated stress led Marco to leave his job as an automotive mechanic before something more serious occurred to him. Marco was:

working every single day. I didn't have any day off, I was working from 7am to $6 \mathrm{pm}$. So, I finished my shift and I made an hour to get home, I got there, and I couldn't do anything: too much physical work and my body isn't as physical [i.e. strong] let's say, so I was worn out. And, uh, I was thinking on going back to that job, but a friendnot long ago - a Filipino friend due to so much stress, he had been working there for 10 years, [he was] young, but he was working too much, he was too stressed out, half his body got paralyzed because of that job, and now he cannot do anything else. He has a family and four children. [...] I also suffered a lot of stress in that job. I didn't have a social life, I worked 69 hours per week.

This was not, however, the only experience Marco faced regarding health issues at work. When 
he was working at the greenhouses, he realized that "there's money in there, but there are pesticides, carcinogens, you can become sterile or you can get liver cancer. [...] I was poorly fed and with headaches." Besides, "it was also like playing with fire, because you're [driven] in those vans, vans with more than 12 people inside, and if police arrive and ask us where we're heading to, we say we're going to a picnic, ha, ha, because everyone was bringing their own lunch, but we were heading to work." Marco's precarious experiences were similar to those experienced by SAWP workers, who are driven around to get to their workplaces and are thus exposed to potential accidents. Indeed, between 1990 and 2008, 392 rollovers and 354 runovers occurred among agricultural workers in Canada (CAIR 2011), affecting more temporal workers (Porter 2019).

\subsection{Discussion: Absence or Misrecognition of Capitals and Secondary Integration}

The fact that my respondents who came through the refugee/humanitarian streams are located in the secondary location is not surprising. Research about young and Latin American refugees in Canada has consistently shown that a number of factors lead them to downward economic mobility (Hernández 1984; Israelite et al. 2004; Shields, Rahi, and Scholtz 2006). Among these are low levels of psychosocial adaptation (i.e. strong feelings of depression, guilt, lack of choice in leaving their countries, and extreme losses) (Meredith 1992) and a lengthy refugee determination process, which situates them in "a holding pattern of financial hardship and dependence upon government support" (Shields and Rahi 2002:2-3). There are also "linguistic barriers, acculturation difficulties, adaptation challenges, and experiences of social isolation." This forces them "to settle for jobs which pay little, challenge them less, and are completely unrelated to their foreign work experience or education" (Rummens and Sefa Dei 2010:4).

At the same time, broader structural processes that have increased employment precarity in Canada, particularly among youth, have led youth with no university degree to experience a drop in their full-time employment rates from 1976 to 2014 (full-time students excluded), except for women aged 25 to 29 . Men aged 17 to 24 and those aged 25 to 29 with no university degree 
experienced a drop of 18.1 and 10.9 percentage points respectively for the mentioned period. Women aged 17 to 24 with a university degree experienced a drop of $11.9 \%$, and only women aged 25 to 29 showed an increase of 17.7 percentage points in their full-time employment rates (Morissette 2016). Other factors that may be involved, although not explored here, are racialization and discrimination processes among immigrants and refugees that permeate their labour market integration (Abu-Laban 1998; Fuller and Vosko 2008; Stasiulis 1997; Thobani 2000).

However, not all Mexican youth located in the secondary location had a refugee/ humanitarian immigration status. Three participants came via the family class (i.e. two of these under marriage sponsorship) and one more participant has a special considerations status (i.e. she can stay in Canada but without PR status). Although immigration through marriage sponsorship requires the sponsor to have enough funds to maintain the partner for at least a year, in the case of two of my family class respondents, their economic pre-migration stance and that of their Canadian partners were not enough for them to do well after immigrating to Montreal. Their relatively limited possession of capitals before and after immigration strongly shaped their postmigration experiences, as well as the long time it took to obtain PR status via marriage in César's case. Moreover, in two other cases (i.e. Gonzalo and Nadia), despite having arrived as children and possessing plentiful Canadian capitals, they are still located in a secondary location.

Although those participants' contexts differ, some of their post-migration experiences echo certain experiences of Salvadoran and Guatemalan refugees in Montreal and Toronto between the 1980s and 2000s. After having immigrated, the latter were only able to find mostly menial jobs (Beausoleil 1998, 2001; Juteau 1989; Smith 1986). They remained "concentrated in industrial niches that are characterized by low wages, poor working conditions, and uncertainty" due to "subcontracting and temporary work arrangements" (Landolt 2007b:197). Moreover, those who entered the labour force worked under a traditional gendered division of labour. Women work as housekeepers, caregivers, cleaners, labourers, in restaurants and as labour-intensive assembly 
workers. Men performed “dangerous and backbreaking work — cleaning high-rise windows, removing asbestos, landscaping, et cetera" (ibid.) In almost all cases, their pay levels were close to the minimum wage irrespective of pre-migration education (Beausoleil 1998, 2001; Juteau 1989).

A similar downward economic experience was found among Ghanaian and Somali youth in the Greater Toronto Area (GTA), who worked part-time and in low-end jobs such as fast food restaurants, call centres sales, and warehouse jobs because they were not been able to find full-time positions (Gariba 2009). These youths identified as barriers to their labour market access a "lack of educational qualifications; discrimination due to race and ethnicity; discrimination due to religion, language and accent; lack of appropriate work experience; stereotypes about youth on the part of employers; criminal backgrounds of youth; and lack of motivation by youth" (207-208).

For seven of nine of my participants, lack of French and/or English knowledge was a strong reason for them to be located in the secondary location. Their lack of language knowledge was shaped by their pre-migration class location, migration status, and their (lack of) possibilities of learning an official language once in Canada. For most of those who came under refugee and humanitarian streams, and despite being able to make use of the government's support to learn a language, the feeling of uncertainty regarding their refugee claim led them to experience a "crisis" or a "lack of motivation" to study any language. This liminal space created a temporal process of hysteresis. Since refugee applicants did not know if their claims would be recognized by the IRB, they could not fully begin a sociocultural and economic integration process. Thus, although they had changed fields and were experiencing new fields in Canada (which, in turn, demanded new habitūs), their temporary status led them to not fully commit to an immersion in those new Canadian fields. In other cases, their immediate economic needs after immigration, which included in some cases raising newborn children, led them to immediately join the secondary market and begin learning the language 'on-the-go.' 
Other youths' post-migration conditions also shaped the speed at which they could learn an official language. Aurora's circumstances of domestic violence at the hands of her Canadian partner did not help her to learn English, despite having already spent some time in Ottawa. Her imposed, quasi-slavery conditions effectively hindered her contact with anyone. Nonetheless, her resilience would allow her, supported by social organizations, to learn English later. I also found this resilience in Rodolfo. Despite finding out he had cancer shortly after requesting refugee status in Montreal, he decided to learn English and French because he realized that this would bring him a valuable capital he could exchange later in Mexico or Montreal's labour market. César's lengthy partnership sponsorship did not allow him to access the government's support to learn French; it took him around six years to feel comfortable speaking and writing in French.

The noticeable lack of education among most youths who arrived in their late teens or early twenties in this sub-set also strongly collaborated in locating them in a secondary location. With the exception of two participants (i.e. Norma and Lorena), the rest had only finished high school or had some high school credits as part of their pre-migration class location. Migration status and postmigration economic integration experiences, where the immediacy of social reproduction became an imperative, also made it difficult for these participants to keep studying in Canada. These varied factors, some more structural, others more individual but nonetheless intersecting, led these participants to find themselves reproducing their class location in a transnational space. Their limited economic and cultural capitals on both sides of the border, and despite their use of social capital as a strategy to overcome their other capitals deficit, reinforced their social immobility.

In contrast, Nadia and Gonzalo, who arrived in Canada as children, acquired Canadian cultural capital while growing up in Ottawa and Montreal respectively. Still, Gonzalo's experience of learning French was harsh (as it was for Román from the subordinate location). His Mexican accent led him to experience what he considers was racism in grade 6 . This experience unveils some of the added complexities that immigrants have to navigate when dealing with the 
power relations between Anglo-Canada and Quebec's settler-colonial and immigration fields. The entry fees required from immigrants in Canada then, are shaped not only by a demand for knowledge of any of the official languages or their economic self-sufficiency, but also by historical and structural factors that locate immigrants in the middle of a colonial field of power. In this field, Quebec expects immigrants to show allegiance to its French character and its interculturalism policy, which contrasts with Anglo-Canada's multiculturalism policy. At the same time, the demand some Québécois(es) place on immigrants is that of assimilation rather than the development of interculturalism.

Moreover, whereas most of the youths in the secondary location lack most capitals required to access other Canadian employment fields, Nadia and Gonzalo have numerous Canadian capitals and are, nonetheless, located in a secondary location. Their lack of adequate entry fees and/or social capital to access particular employment fields have deterred their access to a subordinate or an independent job, and has negatively determined their economic integration irrespective of the city. For example, it was noticeable that Nadia, despite having finished her BA and very actively looking for a job in Ottawa and Montreal, could find no job except in a bakery. Her case then, contrasts to those of my participants located in the independent location, whohaving been in Canada for not more than four years and having only a technical career —obtained an independent job due to their field of study and social capital. As mentioned in Chapter 7, the difference lies in that the latter's educational background directly responded to a transnational/global demand for their labour, the connection created between these labour markets and the schools where they studied, and the social capital they created with professors/professionals who acted as gatekeepers of those employment fields as part of their premigration habitūs.

Thus, despite Nadia and Gonzalo having accumulated significant amounts of Canadian capital and having lived for many years in Canada, their total sum of capitals is not enough to 
compete with the value given to capitals in other employment fields (not to mention the saturation of certain labour markets). Add to this that research on visible minority youth has found how racialized youths, when compared to youth with an European background who possess the same education and training, find it more difficult to find a full-time job (Shields and Rahi 2002). Whilst this might partially respond to the experience of Gonzalo, who has brown skin, this does not apply to Nadia, whose Canadian English accent and skin colour make her pass as a non-Latina or not being regarded, as she was described at one of her high schools, as a "piece-of-minority."

In this sense, the frequent conclusion one finds in the Canadian literature on integration, which indicates that it is the acquisition of Canadian capital (i.e. official languages, Canadian education, and work experience) that can help immigrants to access a subordinate or an independent job, is insufficient to explain certain cases. This notion does not fully explain why 1.5 generation immigrants, who have plenty of Canadian capitals, are unable to find at least a permanent subordinate type of job and are, consequently, streamlined to the secondary market, where they face heightened health risks. A more structural answer to this resides in the increasing precarization of labour at global and local levels which is occurring at an accelerated pace. This disproportionately affects certain 'vulnerable' populations, including migrants with temporary or precarious status and youth and visible minorities, as mentioned in chapter 8 (Goldring and Landolt 2009a, 2009b, 2011; Vosko 2006).

Some of the youths' experiences in the secondary location have also been characterized by what Silver (2014:3) calls "relative poverty," in which "people's income is such that they can acquire some or most of the bare necessities of life, but are excluded from anything resembling a 'normal' life" in the society in which they live. Moreover, this relative poverty does not facilitate the acquisition of different types and quantities of capitals, which may otherwise facilitate the break of the relative poverty cycle in which some of these youth find themselves. Rather, this poverty assures the continued reproduction of these youths' class location and an economic 
model that deprives them of surplus value, and in many cases, also increases their health risks, turning them into a flexible and disposable labour force. This experience also echoes Goldring and Landolt's (2009b) findings, who found that Latin American and Caribbean precarious immigrant workers in Toronto live in poverty. Relative poverty was particularly telling in Nadia's case despite her living many years in Canada and having numerous Canadian capitals.

At the same time, however, the youth in this market segment have shown a great amount of resilience and agency when navigating, surviving, and even trying to sporadically subvert the harsh conditions imposed by their inhabitūsng of secondary market fields in Montreal and/or Ottawa. For Bourdieu (1993), there are two strategies that are in constant tension to maintain the existence of a field, conservation and subversion strategies. Conservation strategies are those that look to maintain a determinate state of power relations. Subversion strategies refer to those promoted by "those least endowed with capital (who are often also the newcomers [to any given field], and therefore generally the youngest)." These usually operate in the form of "heresy, heterodoxy, [and] functioning as a critical break with doxa (and often associated with a crisis)" (73).

Many of the Mexican youth located in the secondary location, as mentioned before, underwent a reproduction of their class location across a Mexico-Canada transnational space. This class location has included limited economic and institutionalized cultural capitals, which have located them in precarious and even hazardous positions. Nonetheless, and despite these circumstances, they have also articulated various subversion strategies that have aimed at rejecting, protesting, and disarticulating the configuration of some of the employment fields in which they have found themselves. Although these strategies, on their own, do not necessarily change the field (e.g. employees working under dangerous conditions putting small notes inside chalkboard boxes explaining their labour conditions), they nonetheless amount to subversion strategies that, together with other practices, may transform the perception of the workers about their conditions and those of the customers reading the notes. These practices also indicate that, 
despite their lack of certain capitals, immigrants variably deploy their agency in the field of power relations and thus demonstrate certain empowerment in the face of adversity.

Overall, pre-migration class location, migration status, lack of English or French knowledge, lack of post-secondary education, and lack of social capital beyond their limited Latinx or immigrant networks coalesced for most of my participants of this sub-set to be located in a secondary trajectory. Moreover, in many cases, their modest and precarious post-migration class location was a continuation of their pre-migration location, further exacerbated by micro and meso-level factors. In the next section, I analyze how Mexican youths' type of economic integration shaped their participation in transnational activities or lack thereof. 


\section{Chapter 10: The Shaping of Transnational Practices by Pre- and Post Migration Class Locations}

In chapters 5 and 6, I analyzed how multi-faceted factors accounted for my participants' immigration to Ottawa and Montreal. While the interaction of various politico-economic factors has produced various transnational spaces linking Mexico and Canada, it was my respondents' class location that determined the ways in which they navigated and made use of those spaces. In some cases, their class location (or that of their families) allowed them to respond to the expansion of Canadian capital in Mexican territory and vice versa, as reflected in their acquisition of jobs in Canada. In other cases, they were rather escaping from increasing and multifaceted types of violence occurring in Mexico. Some of the resultant economic integration experiences contrast with those of many Mexican (im)migrants in the United States who have been economically funnelled down and thus homogenized by the United States' political economy, the configuration of its labour market, and its racial/ethnic hierarchy (Brownell 2017; Massey 2007, 2009, Massey et al. 1987, 2002). Although there are some exceptions (Cobas and Feagin 2008; Delgado 2016; Vallejo 2012), these factors have located many migrants, even middle-class Mexicans, in the lower economic echelons of the United States, incorporating them into the lowwage service or even agricultural sectors (Loaiza 1989; Massey et al. 1987; Massey, Durand, and Pren 2016; Massey and Gentsch 2014; Roberts, Frank, and Lozano-Ascencio 1999).

In Canada, various factors shaped the type of economic integration that my participants achieved, such as their pre-migration class location, the configuration of the labour market, the market valuation of their capitals, age at arrival, level of education, knowledge of official languages, their possession of social capital, and in cases of family migration, also their parents' type of integration. The particular combination of those elements led my participants to be situated in independent, subordinate, or secondary locations. My research, then, contrasts to those other studies that assert that Mexicans constitute only an educated, middle-class immigrant group, thus unveiling differentiated and complex economic integration trajectories among youth. 
Certainly, Canada's immigration policy regulates and shapes the profiles and quotas of those admitted under economic, family, or humanitarian categories, creating different immigrant populations than the ones we find in the United States due to its more restrictive immigration system. However, as shown before, there is not a straightforward correlation between the program used to immigrate and the immigrants' type of economic integration once in Canada. While in some cases the youths' pre-migration class location and post-migration experiences assisted them in achieving an independent type of integration, in other cases this led them to be located in a subordinate location. This occurred even among those participants who came through the economic stream and belonged to the middle class in Mexico. Others faced a continuation of their secondary pre-migration location in Canada.

A handful of scholars have clearly signaled that transnational practices are shaped by factors such as context of departure and reception, class, immigration status, urban or rural background, and experiences as immigrants in the host country (Bernhard et al. 2008). However, age is rarely considered. Thus, a relevant question that arises is, how does the type of economic integration, along with gender and city of settlement, shape the development and types of transnational practices of Mexican youth in Ottawa and Montreal? To answer this question, I will focus on three different types of transnational practices: sociocultural, economic, and political.

These practices were part of a set of five transnational practices that my participants engaged with the most (i.e. communication with family members and friends, economic support and gifts exchanged among family members and friends, political involvement in global, Canadian, and/or Mexican affairs [or lack thereof], travelling back and forth between Canada and Mexico, and maintenance of language, culture, and traditions). They also engaged in other transnational practices, such as reading news, lobbying governments and organizations, etc., but their participation was scattered. As mentioned in Chapter 1, my sample is not representative and therefore its value is in providing a variety of suggestive insights into how immigration motives 
and diverse types of economic integration shape the development of transnational practices or lack thereof.

This chapter is divided into four sections. The first three sections focus respectively on each of the three different types of transnational practices: communication with family members and friends, support to family members and friends across borders, and (trans)national, multiscalar political engagement. While the first two sections include an analysis of how the type of economic integration relates to each transnational practice, the third section is divided into three sub-sections, each addressing the way in which youth located in the three different types of economic integration (i.e. independent, subordinate, and secondary) engaged differently (or not) in transnational political activities. The final section presents the overall analysis of these youths' transnational engagements. Its emphasis is on the factors and type of intersections that determined the generation and development of the various types of transnational practices among participants.

\subsection{To Be There and Not to Be There: Transnational Relationships Across Mexico and Canada}

Communication with family members and friends in Mexico, a sociocultural form of transnationalism, stood out as a practice engaged in by all my respondents. However, there were variations not only in terms of their communication frequency or the persons they interact with in Mexico, but also in relation to the characteristics of that communication. Overall, $37 \%$ of my participants maintain daily communication with nuclear or close family members or friends in Mexico, $40 \%$ communicate once per week with nuclear or extended family members or friends, $20 \%$ communicate between two to three times per week to once every two to three months with close extended family members and friends, and one youth (i.e. $3 \%$ ) communicates with extended family members and friends only two to three times per year.

In contrast to Hiebert and Ley's (2003b) research that included Latinxs in Vancouver, who found that $45 \%$ of immigrants communicate on a daily to a weekly basis, I found that $77 \%$ of the youths I interviewed communicate on a daily to a weekly basis. Undoubtedly, this higher level of 
communication has been facilitated by technological advances and increased use of social media, since Facebook, WhatsApp, Skype, and Facetime are the main vehicles all my participants use to communicate across borders. In contrast, only seven people use the phone and one person uses email. Similar to Hiebert and Ley, I also found no differences in terms of communication frequency when considering economic integration: "there is little differentiation between high and low income households when it comes to maintaining social contact” (p. 10). Moreover, I did not observe gender differences in frequency of communication.

For those Mexican youths who immigrated as part of family immigration, communication with friends or extended family in Mexico is still important, irrespective of the time spent in Canada. This contrasts with Goldring's (2006) finding among Latin Americans in Canada, where generation and length of time lessened contact with family members abroad. Teresa (Montreal, subordinate location), for instance, who has been living in Canada for 22 years, sends messages via WhatsApp to her extended family members once per week (her family created a WhatsApp group to facilitate immediate communication). She also calls extended family members once per month. In cases where respondents migrated individually as economic migrants or refugees and their nuclear family members live in Mexico, social media has helped them to bridge distance and time and fulfill their need to have an emotional connection with their families. Andrea (Ottawa, subordinate) mentioned how there was a period in which she and her cousins connected to Skype every day "even if we were not talking, I mean, we were both connected, just doing our homework, but connected to Skype.” And Artemisa (Ottawa, subordinate), who maintains daily contact with her mother and sisters, said that "of course it's not the same than with physical contact, but I've never felt alone. Be it WhatsApp, Skype, phone calls, Facebook, all these channels have helped me to be there and not to be there at the same time."

Similarly, constant communication via Facebook or Skype has assisted those youth who have children born in Canada to provide their family members in Mexico (and vice versa) with 
immediate visual access to their lives. As Verónica (Ottawa, independent) mentioned, seeing their grandchild via Skype "helps [her parents] a lot" in emotional and connection terms. And Lorena (Montreal, secondary) mentioned how "my parents, my sisters, my mom, everybody is in contact all day long via WhatsApp. They send me pics all the time: 'look at this event,' 'look! The spring day, the children marching.' So, this is like nourishment for me. I think that this has made me like keep feeding my [cultural] roots, no? Like being closer [to Mexico].”

Regarding the content of communication with family members, it varied depending on the type of relationship youths had with them before immigrating. Usually, participants who have a strong connection to family members in Mexico have a very fluid and rich communication in terms of frequency and content, sharing instances that range from daily occurrences to relationship issues in Canada. But whenever there were problems with specific family members before migrating, these usually persisted through time and distance, being reflected in the type and quality of transnational communication (or lack thereof) my participants maintained. Moreover, only five participants maintain a constant and strong contact with friends in Mexico or in other countries (some friends also immigrated somewhere else), usually with between two to three friends. Patricia (Montreal, independent), for example, mentioned how she maintains close ties to a few of her primary school friends: "one lives in the United States, another one used to live in England and now lives in New York. My best friend from university lives in Washington." In general, however, it was very common among most of the youth, irrespective of the immigration program they used, their type of economic integration, or their gender to experience a deterioration of the relationships with their friends in Mexico to the point that many friendships vanished. They explained this as an effect of the emotional distance generated by their immigration process. That is, due to the lack of constant communication and in-person visits, but also a reflection of the mutual lack of understanding of the new fields my participants were experiencing in Canada vis-à-vis their friends' evolving fields in Mexico. Verónica (Ottawa, 
independent), for instance, after four years of living in Canada, mentioned how she now has little contact with their friends: "everyone, at this point in our lives, everyone is quite immersed in their jobs or having families, so it's not easy [to stay in contact] anymore.” Rodolfo (Montreal, secondary), who has been in Canada for nine years and comes from a small town, where relations are usually tight-knit, said that:

for me, communication was lost with the people from where I come from. Those friends from secondary school, well from primary, secondary, and high school, well, I understand that everyone follows their own path, but my communication [with them] was lost to the point that, sometimes, there was zero messages, even when one has Facebook, WhatsApp and all those kinds of social networks today, where you can easily [say], 'Hey, how are you?' It's over.

And Deyanira's (Ottawa, subordinate) communication with her two best friends in Mexico stopped: "they kept with their life, I kept with mine."

Other breaks in communication occurred due to idiosyncratic differences between my respondents and their family members (either in Mexico or those living in other countries), or because of the negative effect that the exchange of information about what is happening in Mexico regarding violence has in the youth. In the first case, Román (Ottawa, subordinate):

actively reduced my exposure to [my aunt] because she's so bigoted. And her sons are equally bigoted. Like, [my cousin] was [visiting] in my house and he was making arguments about how gay marriages lead to people having sex with their toasters. I thought it was a joke you'd find on the internet, that nobody would actually make that argument seriously. I was proved wrong in my own kitchen. And then he made HIV jokes, and I was like automatically done with him in every way, shape and form.

Norma (Ottawa, secondary), who is very close to her extended family in Mexico since she spent various years living there, was blocked on Facebook by some cousins five years ago after gossip spread among her extended family saying that she had had pre-marital sex. An aunt even prohibited her daughter to talk to Norma because the aunt considered that the latter was being 'promiscuous' and would 'pervert' her daughter: 'My family likes to judge whatever they can judge, so I was the first target, my cousin who is gay is a target, [...] so we ceased our trust and support, and a little bit of our love and respect as well.” In the second case, after Norma 
(Montreal, secondary) underwent her accident and recovery, she became disconnected from family members and friends in Mexico: "months passed [without contacting my mother] for mental health reasons, [...] [because] everything that is occurring in Mexico [was] making me feel depressed, a lot." After a while, Norma re-established communication, and now she talks with her mother once per week.

I also found five participants who have very limited communication with Mexico due to various reasons. Among these, Alberto (Ottawa, independent), who "has never liked social media," prefers to talk in person, for which "I think I talk with my friends or cousins twice or thrice per year, maximum.” Aurora (Ottawa, secondary), due to her personal story marked by violence, maintains sporadic communication with friends or family members back home. And Gonzalo (Montreal, secondary), whose nuclear family has been in Canada for 15 years says, "I don't keep too much contact with Mexico, only with [extended] family and that's it, [...] [but] not very frequently. We call each other on Christmas, New Year, the celebrations, and whenever they come here, or I go there.” Gonzalo's experience is thus closer to the experiences of 1.5 and second-generation Somali youth in Canada, for whom the lack of face-to-face and lack of affective ties made these relationships become distant, "and telephone contacts were not enough to create a sense of belonging" (Tiilikainen 2017:67). Type of economic integration and gender did not show any impact on the frequency of renewal of social bonds and emotional connection with people in Mexico and its culture via communication.

Overall, most of the youth maintain a strong communication across borders with family members and a few friends supported by social media, constituting a core feature of Mexican transnationalism in Canada (cf. Guarnizo in Levitt and Jaworsky 2007:133). This helps them to connect with those living in Mexico and other countries, and to nurture their need for emotional contact and information. At the same time, I found some deterioration of social relationships with extended family members and friends due to various factors. These include a lack of constant 
communication despite the possibilities offered by new communication technologies, and differences due to idiosyncrasies related to, for example, diverse understandings of gender and sexuality and types of personalities. More significant in this deterioration was the differences that living in different immigration fields created regarding previous and new habitūs, making it difficult to develop common transnational understandings and thus maintain previous relations.

\subsection{Systems of Support Among Family Members and Friends Across Borders}

The second type of transnational practices that Mexican youth engaged with is the sending of remittances, gifts, or support across borders, an economic type of transnationalism that, in turn, creates and reproduces social capital. Hiebert and Ley (2003b) found that 30\% of Latin Americans in Vancouver sent money to family and friends, ${ }^{56}$ one position below South East Asians (35.9\%) and one above Arabs and South Asians (19.4\%). They also concluded that the relationship between level of transnationalism and socio-economic status was relatively weak, since there was little differentiation among high or low-income immigrant households that maintained transnational economic relations. Goldring (2006:186) found in the Longitudinal Survey of Immigrants to Canada that the percentage of Spanish speaking immigrants who sent remittances to family and friends was $24 \%$. She hypothesized that this low percentage may be due to immigrants still adjusting to Canada and trying to find employment, meaning that they did not have enough surplus income to send remittances. However, recent data indicates that permanent residents who arrived more recently to Canada are more likely to remit money. For example, the percentages of residents in Canada born in the Americas who sent monetary remittances ranged from $31 \%$ for periods before 1980 to $53 \%$ for the 2010-2017 period (Dimbuene and Turcotte 2019).

Among my respondents, their ability to engage — if needed or desired — in the sending of remittances and gifts or the offering of personal support was determined first and foremost by the sender's possession of economic capital, the type of economic integration, and the recipient's economic location. And secondly, by the type and strength of the relationship they maintained 
after immigration, which included not only nuclear family members but also extended members as well as a few friends. These factors also shaped the generation of social capital among family members and/or friends in a transnational space. I thus identified three types of transnational support among respondents: sporadic, meaningful, and engaged.

Sporadic support consists of small, occasional gifts that may involve the sending of money or material objects across borders that foster feelings of mutual connection, affection, and interest among involved parties. While Goldring (2004) contends that money sent to family members and friends is mainly used to support poverty reduction or human development efforts, even if "these monies may also be spent on conspicuous consumption" (819), sporadic gifts are not normally aimed at addressing the recipient's economic needs. Rather, on the surface, their goal is to mainly use such remittances for conspicuous consumption, and more profoundly to feed and sustain the reproduction of social capital across borders at a smaller scale, which can later be transformed into economic capital. This type of remittance is also different from the types of remittances that many Mexicans send from the United States to Mexico (i.e. remittances as wages or salaries, as a form of savings to buy land or a home, or as a type of investment in productive ventures [Durand 1994; Goldring 2004]).

Moreover, the characteristics of the gifts are determined by the giver's intention and the amount of economic capital possessed (on any side of the border), as well as the type of relationship that they have with the recipient. It was also common to find this type of sporadic engagement happening in both directions rather than in a unidirectional Canada-to-Mexico way only. However, monetary gifts sent from Canada to Mexico allowed the recipients, in some cases, to generate or renew their social and/or symbolic capitals in their local fields, something I did not find in the Mexico-to-Canada direction. Examples of this capital generation or renewal in Mexico are when recipients are out with friends and transform the received gift into social and/or symbolic capital, as in 'I'm paying for our lunch with...' or 'I bought this item with the money 
that... my granddaughter sent me from Canada,' which generates distinction in the Mexican fields, or when they invest the gift received in their local community (e.g. when a gift recipient buys toys for the children of the garbage collectors of her neighbourhood at Christmas with the money received from Canada). ${ }^{57}$

In these cases, there is a local multiplier effect of the sporadic support received. This multiplication of capital did not happen, however, in the Mexico-to-Canada circuit. This is because currency exchange differences between both countries increase the price of gifts sent from Mexico to Canada, for which more economic capital is needed to send a gift. This is also because the symbolic value of those gifts is smaller in Canada due its to dissimilar fields and economy scales that differently value the gift economy. For example, someone saying in Ottawa that she is paying for her friend's lunch with a monetary gift sent by a family member from Mexico has less symbolic value than if she does the same thing in Mexico City with money received from Canada. Sporadic support is then a form of expanded transnationalism, where immigrants occasionally engage in transnational practices (cf. Guarnizo in Levitt and Jaworsky 2007:133).

Meaningful support consists of intermittent economic or personal assistance that goes beyond the occasional gift, since its aim is to have certain impact on the lives of those who receive it. Engaged support refers to constant economic support or personal assistance aimed at having a strong impact on the recipient's (and sometimes the sender's) life and their immediate context. In contrast to meaningful support, engaged support strongly reinforces trust and commitment among those involved in the exchange of capitals and strengthens the underlying social bonds that sustain social capital across borders. This support may also have social and/or symbolic capital spillover effects, since the remittance or support is sent to someone who is usually emmeshed in a broader network of family and/or friends who are also connected to the sender. This generates extra social and/or symbolic capital for the sender in Mexico, and thus helps to reshape both local and transnational fields (cf. Beserra 2003; Levitt 2001a). 
Meaningful and engaged support diverge from each other in terms of their frequency and scale, as well as in relation to the scope of their implicit, non-disclosed generation of social capital. Moreover, when compared to sporadic support, meaningful but especially engaged support requires the sender to possess an elevated quantity of economic capital, in Mexico or in Canada, for this to exist. Due to currency exchange differences, the economic weight of sending meaningful and particularly engaged support is more substantial in Mexico than in Canada. Engaged support is also part of immigrants' core transnationalism, while meaningful support is located somewhere between core and expanded transnationalism (cf. Guarnizo in Levitt and Jaworsky 2007:133). This tripartite typology of remittances provides a nuanced understanding of the generative conditions, goals, and characteristics of individual or family remittances that were developed by Mexican immigrant and refugee youth.

SPORADIC SUPPORT. Among my respondents, eight of 35 engaged in sporadic support, three of whom have an independent type of integration, four a subordinate one, and only one person a secondary type. For example, Verónica (Ottawa, independent location) only sends gifts to her parents on Mother's or Father's Day, usually in the form of a $\$ 100$ remittance, so they can go out for a special dinner or to the movies. Mauricio (Ottawa, independent) receives money from his grandmother who lives in Mexico at Christmas, and when Mauricio and his Canadian partner graduated from university in Canada, his dad organized a graduation party for each in Mexico. In turn, Mauricio gifted his parents with plane tickets to come and visit them in Canada, as well as a beach trip in Mexico.

Griselda's mother (Ottawa, subordinate) gave her an extension of her credit card when she moved to Ottawa in case of an emergency, but she has rather been using it (with her mother's consent) to occasionally buy gifts for herself such as shoes. Miriam (Montreal, subordinate) sends money as a gift to her parents in Mexico on important dates, such as birthdays and at Christmas, but only when she is employed: "Whenever I'm not working, I don't. [Sending money] is hard 
because I can barely cope with my expenses.” And Aurora (Ottawa), the only respondent in a secondary location who participates in sporadic support, buys inexpensive gifts such as t-shirts and underwear, little by little, for her best friend and her children in Mexico. Once Aurora accumulates some items, she mails them to Mexico and sometimes adds $\$ 20$ or $\$ 30$, although it takes her a while to do so ("last time it took me six months"). This is because sending the package is much more expensive (around \$60) than the total value of the gifts. Aurora has sent these packages only thrice and sends them every two to three years. More frequently, she sends her friend money for her birthday or for Mother's Day, so she "can buy herself something cute. And I know that she [also] goes and buys something for her children." Aurora's transnational involvement is then resource dependent (cf. Itzigsohn and Giorguli Saucedo 2002).

MEANINGFUL SUPPORT. Seven of 35 respondents are involved in meaningful support. Of these, one is located in an independent type of integration, two in a subordinate one, and four in the secondary location. For example, Andrea (Ottawa, subordinate), after a trip the family did to Mexico, became cognizant of the economic disparity between her and her cousins, and has been asking her parents not to give her any presents at Christmas but to send the equivalent in money "to any of my cousins who may need that money the most." Andrea's parents also engage in meaningful support. Her father travelled to Mexico to take care of his ailing mother when his other two siblings got ill and could not take care of her, and Andrea's mother also paid for her mother-in-law's necessary surgery with the money she earns and saves from her online job in Mexico. And Javier (Montreal, subordinate) sent money to her sister twice, so she could buy school materials for her children and a tablet for one of them.

It was noticeable that among all participants in the secondary location and one in the subordinate location, meaningful support was only offered when the respondent's economic situation in Canada allowed them to do so (i.e. resource dependent transnationalism). This makes sense considering that the secondary location is one characterized by constant employment 
precariousness, job instability, and relative poverty. For example, Nadia (Ottawa, secondary) has not "sent money [to Mexico], I don't have much [money in Canada], but I give some to my mother" (who is also in Ottawa). And the latter sometimes sends money to a sister in Mexico. Following Norma's (Montreal, secondary) accident, and due to the debt her family in Mexico acquired to pay for her hospital bills and her subsequent inability to do heavy work in Montreal, she stated: "whenever I can, I send [remittances]! I now know what it is to become a migrant; it's really hard. [Because of the accident,] we run out of money [as a family]!"

At the same time, after her accident, Norma's Latinx friends in Montreal organized a fundraiser and obtained enough money for her father to come to Montreal and take care of her, and for him not to worry about money for a month. These friends also got him proper winter clothing and housed him during his stay. Once the money ran out, the father used his Mexican credit card to pay for his expenses and to be able to take care of Norma, while another friend sent her \$5,000 pesos (CAD \$350) from Mexico. Norma also mentioned that some Mexicans in Montreal "created a family [among each other] because we realized that, being away from our family, we are our own family [here].” Thus, whenever any real family member of this group needs economic support, they organize and collect money to send it to Mexico. Here, social capital generates a collective and locally rooted—but transnational in scope — safety network through which (economic) risk is confronted by pooling resources. Eduardo (Montreal, secondary) mentioned how after he immigrated, he used to send monthly remittances to his mother (i.e. engaged support), but since he got divorced and as he has two kids, it became much harder for him to do so. Now, he only sends money to his mother sporadically.

ENGAGED SUPPORT. Eight of 35 youths are involved in engaged support. Of these, five are located in an independent location, two in the subordinate one, and one in the secondary. Diana (Montreal, independent), for example, decided to obtain Canadian citizenship because:

I'm the older of my siblings, and since things settled for my being here [in Montreal], this also turned out to be a great opportunity for my siblings. So, I decided that my work life 
would be in Canada, and whenever they want to come or decide to study here, I now can do what my mother did for me. Now I'm helping my siblings, [...] I pay for their [Mexican, private] university fees. So, it's here where all what my mother did [for me to be in Canada] is being repaid, and whenever I can help, I do help: airplane tickets, special things, plane tickets for someone who needs it. Because this is too expensive, we help among each other.

Diana mentioned that, in exchange, her siblings help her not in economic terms but in slowly convincing her father that it is better for her to stay in Canada than return to Mexico, since the father still opposes the idea of her having immigrated to Canada (see chapter 5): "I'm not alone anymore, I have my brothers' [support] and now that of my sister. I can say that I have removed that weight from my shoulders.”

Teresa (Ottawa, subordinate) sends her parents, who are in BC, $\$ 100$ per month, so this money can be added to the monthly remittance they send to one of Teresa's grandmothers in Mexico (and the parents also send money to one of her aunts). Teresa sends this money "because my grandfather is not with [my grandmother] anymore," and "because I know that she needs [the economic support] for her medicaments. So, this may sound odd, but... if I cannot be physically there with her, at least I can be of some help [from afar]." And Marco (Montreal, secondary) used to send around $\$ 800$ every fifteen days to his family in Mexico because "there was an economic crisis in my town. Chinese companies arrived and the economy of my town came down. [...] So, I had to economically support [my family] for like three years. [...] The [family] business went bankrupt and that's also why I had to work a lot [after having immigrated]."

Among those who came as part of family economic migration or reunification, I found some cases where it is not my respondents themselves who send support to Mexico, but rather their parents. For instance, Erika's mother (Ottawa, independent) periodically sends money to her mother in Mexico and for special events such as family weddings, where all family members are expected to contribute, or whenever Erika's grandmother's house, which functions as the extended family meeting center, needs home improvements and all the children are expected to support. "And every time that my parents go to Mexico, they [also] give money to the family." Orlando's parents (Ottawa, independent), since they immigrated 12 years ago, send money to one 
of Orlando's grandmothers every month "to help her with her medicine expenses, so she can complete her treatments. And they have also lent money to my uncles whenever they need it." And Myrna’s father (Ottawa, independent) only began sending monthly economic support to Mexico once his parents moved to a nursing home and the three brothers organized splitting the costs. It was also noticeable that half of the people involved in engaged support targeted their assistance toward women (i.e. mothers or grandmothers), which may find an explanation in the Mexican culture, where the role of the mother and support to elder family members are central. This also speaks to the reproduction of certain Mexican habitūs in a transnational space, regardless of time spent in Canada, and where hysteresis does not apply.

This type of women-centered support I found, however, is different from the type of economic support that many immigrants send to women in rural areas or cities to benefit households (Meyers 2002), based on the assumption that women "make the most effective use of remittances" (GCIM 2005:28). ${ }^{58}$ In the latter case, it is assumed that women will spend the remittances on education, poverty alleviation, and social development (i.e. health, nutrition, and shelter) (cf. Goldring 2004:817). But the type of support the youth I interviewed send to specific female family members such as mothers, grandmothers, aunts, or sisters, on the contrary, is meant to promote or exclusively maintain that person's human development without the intention or expectation that this support be shared with the rest of the household members. Only in two cases was part of the remittance sent to the matriarch meant to be used for the extended benefit of other family members due to local cultural and kinship norms.

Four of 35 respondents do not engage in sending any type of support because their economic possibilities at the moment of the interview, independent of their economic integration, did not allow them to do so. Of these, two are in the independent location, one in the subordinate location, and one in the secondary location. Patricia and Ramiro (Montreal, independent) mentioned that "we still cannot send money" since their business is still growing. However, when 
they moved from Paris to Montreal, they sent some money to acquire and furnish a small apartment in Mexico: “that wasn't money that our family needed, but it was a lodging that we needed whenever we go to there. [...] Right now, my in-laws use that apartment whenever they go to [name of city]. [...] So, this was like our economic contribution to the family, one which they use now." Alberto (Ottawa, independent) mentioned that "we'd like to send money, but to be honest our [family] economic situation is not like good.” Deyanira (Ottawa, subordinate) said that her family does not send remittances “because 'it's been difficult in here.” And Lorena (Montreal, secondary) has only sent money to her mother three times since her arrival eight years ago. Currently, Lorena's daughter is attending a private school "and I really economize, I don't have enough money [to send remittances anymore]."

I also found eight of 35 respondents who do not send remittances to Mexico because the nuclear family immigrated to Canada and they do not send remittances to extended family members or friends, or because both immigrants and family members have a good economic position and there is no need for economic support. Among the latter, three belong to an independent location, three to a subordinate one, and two belong to a secondary location. Gabriel (Ottawa, independent), for instance, does not send remittances to his family “because they don't need the extra money, they're academics and do well." Artemisa (Ottawa, subordinate) mentioned how when she immigrated "it was not agreed to send remittances" to her parents because "we didn't have economic problems." And Gonzalo and Rodolfo (both in Montreal, secondary) do not send remittances because all the members of their nuclear families immigrated with them to Montreal, and in Rodolfo's case also his parents and siblings, as well as his wife.

Certainly, transnational research has found that some immigrants establish transnational practices to compensate for the effects of discrimination and/or racism they experience in the country of reception, such as sending remittances to their home countries (Labelle et al. 2006; McLellan 2004, 2009). This, in turn, generates transnational symbolic capital that compensates 
for those negative experiences (Foner 1997; Goldring et al. 2003; Levitt 2001a, 2002; Levitt and Lamba-Nieves 2011). However, little has been explored about the deployment of transnational strategies to economically survive in the country of reception making use of, precisely, resources located in the sending country, as I found in my research.

Transnational support has notably flown from Mexico to Canada, since fourteen of 35 participants have received support from Mexico. This support was aimed at assisting family members or friends in Canada who experienced a temporary, difficult economic situation, and included three people located in the independent location, seven in the subordinate one, and four in the secondary location. Alberto (Ottawa, independent) mentioned how due to his family's type of economic integration in Canada (i.e. a subordinate one for the parents), they have sought the economic assistance of extended family members in Mexico. Indeed, Alberto also sometimes gives money to his father, so the latter can afford to pay for the rent or buy food for the family. Patricia (Montreal, independent) mentioned how after their business did not take off as expected, her parents sent them money twice to support them with their daily expenses. When Carolina (Montreal, subordinate) was unemployed, her parents sent her a credit card extension, so she could receive money this way since "I don't even have money to eat."

Nadia (Ottawa, secondary) mentioned how a nun who lives in Europe and an aunt in Mexico have sent her and her family some money "whenever they can, for food, stuff like that." César (Montreal, secondary) said how there was a moment in which he did badly in terms of employment and income generation, and thus his mother had to help him twice with remittances: "a few pesos became almost nothing [here], but yes, a couple of times they helped me to pay the rent.” And Marco (Montreal, secondary), who used to send \$800 to Mexico every fifteen days, went through a similar experience as César: "I found myself without a job and without money, and they [i.e. his family] had to send me [money]!" The specific reasons to receive money from Mexico among participants differed depending on their settlement stage, as well as the particular 
needs of the person who received the money (e.g. money to acquire food or pay the rent vis-à-vis temporary settlement expenses among international students before getting PR status).

Immigration status and type of economic integration (shaped in part by the participant's premigration class location) were also two key factors for which some youth, mainly those in the subordinate location followed by those in the secondary one, received economic support from Mexico. Among those in the subordinate location, the existence of this support indicated their relative advantage in having access to transnational economic and social capital when needed, and which now operates in a transnational space. Moreover, whereas most of those located in the subordinate location received economic assistance to support their migration status transition (i.e. five passed from a student or a NAFTA visa to PR status), two did so- despite having come through the economic class - due to the difficulties they faced in economically integrating in Canada, a sign of their downward economic integration. Among those in the secondary location, the transnational support sent from Mexico, even if subjected to differential exchange rates and thus suffering a significantly diminished economic value, signalled the tough economic situations that some participants faced in Canada. Here, however, their transnational connections assisted them in converting social into economic capital, collaborating in re-establishing their standing in Canada.

Overall, the participation of youth across each type of transnational economic support was very similar. Eight people engaged in sporadic support, seven in meaningful support, eight in engaged support, eight did not send any type of support, and four cannot send support. In contrast to Goldring's (2006) hypothesis, where the limited remittances sent by Latinxs is due to their initial adjustment process to Canada, I found that the sending of not only remittances but also other types of support such as gifts or personal assistance from Canada to Mexico is due to various factors. These include the sender's type of economic integration, possession of economic capital (and that of the recipient), their settlement circumstances, the type and strength of personal relationships they maintain across borders, and the particular needs or objectives among the 
people involved in the exchange. Since transnational communication is limited to nuclear or close extended family members and a few friends among youth as shown before, the type of transnational support, when offered, is also confined to these small networks. Nonetheless, the different types of transnational support generated serve to reproduce social capital among those who participate in such exchanges and collaborate in creating a transnational field.

The amount of economic capital invested in these social exchanges is determined by the type of support offered, and thus reflects the type of economic integration of the sender, their settlement stage, their amount of available economic capital at certain point in time, and the type and strength of their social relations across borders. These components constitute a transnational circuit of economic and social capital, although this is susceptible to modifications due to variations in any of its components (i.e. changes in social relationships, unemployment, acquisition of new economic responsibilities such as childbearing, etc.). Transnational support also runs in both directions (i.e. Canada-to-Mexico and Mexico-to-Canada). However, its effects differ depending on the field of destination. If the destination of the transnational support is Mexico, it will probably generate distinction and symbolic capital in the recipient's local field, besides the economic benefit and social capital created between the sender and recipient. If the destination is Canada, the support will have an economically small but nonetheless significant generation or renewal of social capital between the sender and recipient.

This is because the Mexico-to-Canada support is more expensive due to currency exchange differentials. Although this support also generates social capital between the sender and recipient, it does not mean that just because the Mexican sender invested more money, they will correspondingly generate more social capital. As Bourdieu (1983) said, the effectiveness of social capital is dependant on the fulfilling of its social obligations by the members involved. Two other characteristics I found are that among some of those who immigrated as part of economic family migration, it is the parents who are actively engaged in sending transnational 
support rather than the children. Also, half of the persons sending engaged support target their assistance to women, particularly mothers or elderly women such as grandmothers. This microtargeting of support reflects an active, albeit sometimes subconscious, maintenance of a Mexican habitus across borders regardless of time spent in Canada.

\subsection{Local, (Trans)National, and Global Political Engagement}

The few scholars who have studied Latin American political transnationalism in Canada found that although Latinxs in Ontario (i.e. Chilean, Salvadoran, Guatemalan, and Mayans) had an active political participation in homeland politics in the late 1970s and 1980s, their political participation in Canadian issues was low (Escobar 2000; Ginieniewicz 2010b; Landolt 2007b; Landolt and Goldring 2009; Nolin Hanlon 2000, 2001, 2004; Veronis 2006a). This configuration was generated by Canada's somewhat welcoming context of refugee reception before the 1990s, which allow them to exert their pre-migration political socialization, activism, and agency in Canada (Landolt 2007b; Landolt and Goldring 2010; Peddie 2014; Snow 2013). This configuration changed, however, with the arrival of new Latinx economic immigrants in the 1990s, mainly professionals (Veronis 2006b), and the effect of politico-economic changes imposed by a neoliberal agenda in Canada, such as cutbacks and the reorganization of social services (Garay 2000; Veronis 2006b).

In addition, immigrants faced discrimination that prevented them from formally joining political organizations due to their non-Canadian accent, "even for those who were able to manage 'the standardized language of politics"' [Ginieniewicz 2010:511]). This, along with "their daily struggle for survival," impeded a "majority" of Latinxs from being politically active (Veronis 2006b:38). Under these circumstances, new Latin American immigrants turned "their attention to their position within Canadian society and away from the homeland" (ibid.), distancing themselves from the transnational participation of those other Latin Americans who came as refugees in the 1970s and 1980s (Veronis 2010). For example, Mexican professionals 
created business networks and professional associations in the 1990s to assist them with accreditation processes and thus improve their employment market access (Landolt and Goldring 2009). As Landolt and Goldring argue, creating professional organizations does not constitute per se part of a political culture in the host country, but rather forms part of "migration networks, social capital, class, etc., that determine organizational patterns" (1229).

Their organizing, nonetheless, led them to be "engaged in activities that directly sought to transform Canadian society," unveiling "a new civic consciousness" and a desire to acquire substantive citizenship (i.e. inclusion as full and equal citizens) (Veronis 2006b:38). This slowly constituted a political type of engagement and a new political consciousness that, according to Veronis (ibid.), originated from three conditions. First, Latinx immigrants' pre-migration middleclass facilitated their organizing. Second, their long-term commitment to Canada as economic immigrants, particularly when compared to the desire for return among Latin American refugees, made them look inwards toward their own circumstances in Canada. And third, since they experienced post-migration, downward economic integration, they were aiming to overcome such circumstances (40). This context differs from the one my participants experienced two decades later as shown in chapters 4 and 5. Moreover, although issues of economic integration are still common among some visible minority immigrants, particularly youth (Anisef et al. 2008; Biles and Lafrance 2009; Halli and Vedanand 2007; Oreopoulos and Dechief 2011; Pozniak 2009; Yan et al. 2009), my research unveiled different economic integration processes among Mexican youth that include positive economic pathways. These, in turn, differently shaped their type (or lack) of political involvement, as I will show below.

The literature on political participation usually identifies two types of political involvement: 1) civic participation, which refers to participation in voluntary, non-governmental associations, and 2) formal political participation, a more narrowed definition that refers to electoral politics (Theiss-Morse and Hibbing in Landolt and Goldring 2009:1230). However, 
these definitions limit the scope and variation of political engagement among migrants. As Breton (in Armony, Barriga, and Schugurensky 2004:23) argues, political participation among immigrants can take different forms, ranging from following events in the media to direct actions in social movements, to participation in political campaigns. Moreover, political participation can be enacted via formal organizations or informal networks, and it can also be pursued to accrue private benefits or for more altruistic reasons (ibid.).

I thus identified three types of civic and political activities among Mexican youth based on their degree of institutionalization: institutional political activities (e.g. voting, involvement with political parties, discussion of and participation in public policy issues), semi-institutional activities (e.g. participation in student, NGO, or neighbourhood associations), and noninstitutionalized political activities (e.g. activities that deal with anything that affects a person's daily life due to social agents' exercising of power in varied settings) (cf. Painter and Jeffrey 2012). These activities can be situated beyond the nation-state framework as multiscalar social practices, "located in multiple, overlapping socio-spatial entities" (Nagel in Veronis 2006b:30) such as transnational and global fields.

I also identified three levels of political involvement among some of my respondents: limited participation, engaged participation, and a lack of political participation. Limited participation refers to occasional and limited political engagement regarding Mexico, Canada, and/or global issues, such as voting in Canada or Mexico, participation in a few protests, or involvement in fundraising whenever a natural disaster occurs in Mexico. Engaged participation refers to an active and constant involvement in political matters regarding Mexico, Canada, and/or global issues, such as participation in and/or organization of rallies, demonstrations, cultural activities that touch upon political issues, participation in groups with civic and/or political goals, creation of support networks, etc.

\subsubsection{Transnational Political Engagement and the Independent Type of Integration}


Among my 14 respondents located in the independent type of integration, seven do not participate in any sort of political activity (with an average of 8.3 years residence in Canada), six have limited political engagement (with an average of 8 years residence in Canada), and only one participant, Erika, has engaged participation (with ten years in Canada). These participants had a very similar profile to that of Colombians in Toronto described by Landolt and Goldring (2009:1233), who had a "quite dispersed and apolitical agenda," and thus showed an expanded form of transnationalism (cf. Guarnizo in Levitt and Jaworsky 2007:133).

Among those who have no political participation, Alberto (Ottawa, PR, seven years in Canada) has not voted in Mexican elections from Canada even if Mexicans can vote from abroad. Alberto migrated at the age of 15 , and since the minimum age to register and vote in Mexican elections is 18 years, there have been no Mexican elections in which he could have voted. He is interested, however, in voting in Canada once he obtains his citizenship “because I think it's quite important to vote." Among those with a limited political engagement, Orlando (Ottawa, citizen, 12 years) has voted in Canadian but not Mexican elections, does not have much contact with Canadian politics, participated once in a fundraiser to support a Latin American community, and participated once in a protest with friends in Ottawa, when Mexican Indigenous students were kidnapped in Ayotzinapa. He attended the protest because of the "feeling of injustice. Looking to bring about justice makes you be supportive."

Roberto (Montreal, PR, four years), after donating money for a homeless shelter on the street, was invited to volunteer and see how his money was being used. He volunteered by serving food and washing dishes in the shelter's kitchen, "but I did it only twice because that's very time consuming." He also participated once in a rally, supporting some Venezuelan friends, “but I don’t like to be involved in political issues.” Diana (Montreal, citizen, nine years) volunteered in the last federal campaign for the Liberal candidate and voted for that person, since she thought that the candidate would support her area of work. Patricia and Ramiro (Montreal, 
citizens, seven years) voted for their first time in Canada in the last national election and made use of strategic voting to bring about political change (i.e. they voted for the Liberals instead of the New Democratic party to oust the Conservatives). Data from an April 2019 survey among youth aged 15 to $30(\mathrm{~N}=1,000)$ showed that only $38 \%$ of Canadian youth voted in an election, $32 \%$ volunteered for a charity, and 6\% volunteered for a political party in the last 12 months (Coletto and Kishchuk 2019). Thus, low political participation among Mexican immigrant youth situated in the independent location is not dissimilar to the general youth population in Canada.

Only Erika (Ottawa, citizen, 10 years) has an engaged type of political participation. This is, in part, because of her sense of social justice but also because her family has always been involved in political matters in Mexico, so she continued this activism in Canada. Moreover, Erika's engagement has focused not only on Mexican but also Canadian and global matters, ranging from indigenous issues to city, provincial, and national Mexican and Canadian political issues to global gender issues. For example, she continually attends and supports Canadian indigenous causes and events, votes in Canadian provincial and federal elections, and attended the activities organized around the Ayotzinapa case.

The similar time spent in Canada among my independently located participants with different types of engagement suggests that time spent in the host country did not increase their (political) transnational engagement, as some scholars have found (Itzigsohn and Giorguli Saucedo 2002; Portes 2015). Moreover, when compared to other youth who have lived in Canada for fewer years and have a more active political involvement (more below), the influence of time spent in the country of reception is insufficient to explain their type of transnational political involvement. Gender also did not have a significant effect, since a roughly similar number of women and men do not engage in politics (three women and four men) or have limited participation (three men and three women).

Likewise, immigration status was not shown to have a noteworthy impact. Among those 
who do not engage in politics, four have permanent residence and three have citizenship status, and among those with limited participation, two have permanent residence and four have citizenship status. But it was notable among those with limited participation that their engagement was mostly related to institutionalized politics, i.e. casting their vote in Canadian elections (something that permanent residents cannot do), and only in two cases was their involvement in semi-institutionalized or non-institutionalized activities (one person with citizenship and one with permanent resident status). Similarly, location was not shown to have any significant effect, since the total number of people with limited political participation (three people in Ottawa and three in Montreal) was very similar to those with no participation (four people in Ottawa and three in Montreal).

\subsubsection{Transnational Political Engagement and the Subordinate Type of Integration}

Among the 12 youths located in the subordinate type of economic integration, five have limited political participation (with an average of 14.8 years living in Canada) and two have engaged participation (with an average of six years living in Canada). In this location, I found a mix of expanded (or occasional) and core (regular and patterned) transnationalism. Among those who have a limited political participation, Teresa (Ottawa, citizen, 22 years in Canada) volunteered for the Conservative party during the last Canadian federal campaign because her values and political principles align with that party's principles. She has always voted in Canada because "I feel like voting matters [...] and my democratic duty was to go and cast my vote [...] because it's my right." Teresa also helped once to fundraise money for an organization that deals with sexual exploitation in Canada.

Andrea (Ottawa, citizen, 12 years) has only participated in fundraising whenever natural disasters have occurred in Mexico, or in fundraisers organized by her high school to benefit UNICEF, Relay for Life (a festival-like fundraising event centered on cancer issues), etc. Her mother has organized disaster-relief, and she also took her to the Mexican embassy once she 
turned 18 to obtain her Mexican identification, so she could cast her vote in the 2018 Mexican elections from Canada. However, Andrea acknowledged that she is not involved in Mexican politics “because it's a little bit difficult [to do so] from here," nor is she involved in Canadian politics. Román (Ottawa, citizen, 18 years) only votes in Canadian elections: "other than voting, no. I try to stay pretty detached [from politics]" due to a lack of interest. However, he considers that voting is important in terms of political participation among young people: "if you don't vote, you can't complain about the government."

Joaquín (Montreal, PR, eight years) participated twice in \#YoSoy132 demonstrations in Montreal, a Mexican student-based social movement. ${ }^{59}$ This movement opposed the biased coverage of the 2012 Mexican federal election by Mexico's mainstream media, which favoured the Institutional Revolutionary Party’s (PRI) candidate, Enrique Peña Nieto. “Obviously, [our demonstration] didn't have any effect whatsoever," but he did so "to express that I was not happy with what had happened." Joaquín also intends to vote in the 2018 Mexican elections. And Javier (Montreal, PR, 14 years) only participated in a few students' printemps érable demonstrations in 2012. ${ }^{60} \mathrm{He}$ did so to show solidarity with Quebecois(e) post-secondary students and their cause of fighting post-secondary tuition increases. He did not vote in the 2012 Mexican elections from Canada because he lost his Mexican identification card and has not renewed it since.

Among youth who have an engaged political participation, Carolina (Montreal, PR, four years) was already an activist in Mexico before immigrating. She got involved in human right issues "to be able to defend myself. I felt vulnerable as a woman and as a lesbian in Mexico, and that made me to identify with other people, to fight [against discrimination,] so people change their mentality [that goes against human rights].” Because her ex-partner was also involved in activism in Mexico, they tried to join lesbian, feminist organizations once in Montreal. However, they had to pay a participation fee per meeting "and we had just arrived without much money," thus they were unable to join. Carolina also participated in the Ayotzinapa protests organized in 
Montreal 'because it's [about] Mexico and it's my duty. Anything related to human rights is my duty, especially if it's about deaths." She also wanted to show the Mexican government "that there are people [i.e. Mexicans] here [in Montreal] and [that] we're [politically] visible." She also thought of attending a demonstration against Mexican President Peña Nieto during his visit to Montreal, in 2016, to protest electoral fraud and the lack of democracy in Mexico. However, she had to work that day and was thus debating whether to attend or not: "work... yell at him... I better go to work."

Miriam (Montreal, citizen, eight years) also has an engaged political participation. She participated in the Ayotzinapa demonstrations because "you feel connected to what's happening, with [Mexico's] reality," even if Mexicans in Montreal "are not really involved" in political matters. She described how when an Ayotzinapa caravan went to Montreal as part of an international tour to let the world know what had happened in Mexico, the event "had a lukewarm reception. I imagine that the [Mexican] community, besides being small, isn't quite focused on what's happening." Miriam also volunteered in three fundraisers for an NGO working for Southeast Asian children, but she stopped doing so due to lack of time, since she was also working and studying at the same time. In addition, Miriam participated in some printemps érable protests. Although she was initially affected by the protests because she had a loan contingent on being registered as a student, and thus was against the movement, once she knew that protesters were fighting for a tuition-free education "I said okay, I'm in, and I went to protest with them."

Miriam has also gone to Ottawa to protest pipelines and "against many things that are also happening in Canada, which are affecting the flora and fauna, the indigenous regions. [...] So, because all those things are like unjust things to me, I join the rallies and I like to participate." Among my five participants who do not engage in politics, Deyanira (Ottawa, citizen, four years in Canada), for example, did not vote in the last Canadian national elections "because I missed the date. All my [non-Latina] roomies and myself missed the date." 
Variation in years spent in Canada among youth with a subordinate location might suggest that time spent in Canada could slightly increase political engagement among my participants: those with no political involvement have an average of six years living in Canada and those with limited involvement 14.8 years. However, when compared to those with engaged participation and who have an average of six years living in Canada, we observe that time spent in Canada does not help much to explain the type of political involvement in this small sample. Regarding gender, only two women have a pattern of engaged political participation, five women do not have any type of participation, and two women and three men have limited participation.

These numbers, however, are more the result of my recruitment than an indication of a potential intersecting effect of the secondary location and gender on political participation (I was able to interview nine women and three men who are located in the subordinate location). Neither did migration status seem to influence political involvement in this subgroup. Among those who do not engage in politics, three have permanent residence and two have citizenship status. Among those with limited participation, two have permanent residence and three have citizenship status. And among those with engaged participation, one has permanent residence and one has citizenship status.

Compared to those located in the independent location, however, youth in the subordinate location showed a wider variety of engagement in political activities, even if limited. Those with citizenship status, besides voting in Canadian elections, also participated in fundraising to benefit Canadian and Mexican causes and one person volunteered in a political campaign. Those with PR status (and one person with citizenship) attended demonstrations and rallies for Canadian and Mexican causes. Thus, a better economic position does not necessarily leads to increased political (transnational) participation. Location was shown to have more influence regarding the type of political involvement among participants. It was quite clear that those youths in Ottawa either did not have any type of political participation (five people) or were involved in activities that 
consisted mostly of voting and/or occasionally fundraising for organizations (three people). In contrast, those located in Montreal (two persons with engaged participation and two with limited participation) had a more active participation in Canadian, Mexican, or global causes, which required them to spend time and effort beyond their usual activities and obligations (i.e. working and/or studying). I also found this more engaged political activism in Montreal than in Ottawa among those in the secondary location (more below).

\subsubsection{Transnational Political Engagement and the Secondary Type of Integration}

Among the nine youths located in the secondary location, three have limited political participation (with an average of 10.3 years living in Canada) and six engaged political participation (with an average of 11.5 years living in Canada). I did not find anyone who does not engage in political activities. In this location, core transnationalism is dominant (cf. Guarnizo in Levitt and Jaworsky 2007:133). Among those with limited participation, Gonzalo (Montreal, citizen, 15 years) mentioned that it was not until he attended university that "my perception and eyes opened [regarding politics].” Gonzalo began attending Quebec independentist coffee chats because:

I'm quite interested in politics." However, "little by little, when I began to get more information about them and seeing their politics, and witnessing what they say in the campaigns and what they do, especially [regarding] all political issues, I changed my electoral profile. [...] When they chose Pauline Marois, ${ }^{61}$ there was a very difficult political campaign where the Liberal party lost, and it was at that moment that I said 'No! I now want to collaborate, I want to help, I want to be informed about what's happening.' Because they [i.e. the Parti Québécois] arrived with the flag of reasonable accommodations against... not openly against immigrants, but you understood that they wanted to 'clean' the Quebec culture. Although I see myself as a Québécois, that's not the Quebec I want.

Although Gonzalo is a paid member of the provincial Liberal party, he does not attend its congress, has never volunteered to be a candidate, nor has he volunteered at any of their events. His participation has been limited to attending some party events and coffee talks. He also votes in Canadian elections "because it's important, I think. Although the Canadian political system is dysfunctional, for me it's a right, a civic duty. I fundamentally believe in democracy. I consider myself a social democrat. I believe that if people get educated and understand the power they 
have, they can change things." Gonzalo is more interested in Quebec's political culture than that of Canada because he sees himself as mostly Québécois and Mexican. He also wants to fully engage in a political party in the future. Gonzalo's limited political participation in Canada also contrasts with his perception of how getting involved in politics in Mexico may play out for him:

[In Canada], if you want to get involved in politics, you can become a member of a party. Not like in Mexico, where maybe you appear dead one day; you try to protest your mayor, and you know what's going to happen to you, no? Not here. Here, you have that freedom of expression. [...] Here, people listen to you; the government listens to you. You complain, there are ways... you have in fact the power to change the situation and make improvements. Even if you want to change, [there's] the issue of corruption in Mexico.

Gonzalo, then, represents the one in four youth in Canada who participate in a forum, conference, or discussion of issues that they care about according to a recent national youth survey (Coletto and Kishchuk 2019). Lorena (Montreal, citizen, eight years) is not involved in any political activity except for voting in Canada 'because it's like an obligation, no? That every Canadian has to vote." Although legally voting in Canada is not an obligation, unlike in various Latin American countries such as Brazil, Ecuador, Peru, and Uruguay, Lorena sees this as a civic duty comparable to an obligation.

Among those with an engaged political participation, Nadia (Ottawa, citizen, 21 years in Canada), mentioned that she engages in various semi-institutionalized and non-institutionalized political issues because "although we've been always in a very poor and low economic situation [as a family in Canada], the truth is that we never lacked anything [due to the support of others]. [...] There are many problems, and if we as a community help [others], numbers help." Nadia has thus participated in demonstrations defending Indigenous and animal rights, in rallies opposing the Olympics in Vancouver, and has protested the disappearance of Indigenous women. She has also volunteered as coordinator of an undergraduate student group for various years, as a representative of a Canadian political party's university group, and supporting Amnesty International. Nadia has also consistently voted in Canadian elections because "nobody casts their vote. Young people don't vote, they should vote." Because of her activism, Nadia has also been 
the target of attacks, "especially with the issue of animal rights. People spit on your face. They swear at you, they tell you to 'keep your issues to yourself."' At the same time, Nadia dislikes the fact that Canadians “don't fight [for their rights]." She would like to see Canadians be more active in political terms.

Aurora's (Ottawa, PR, 13 years) personal experiences of abuse and domestic violence in Mexico and Canada have led her to participate in numerous non-institutionalized political activities, despite her not being a Canadian citizen. These activities include demonstrations, rallies, and fundraisers in favour of (non-)Latinx immigrants, Indigenous peoples in Canada and the United States, and the Ayotzinapa case. She also protested the visit of former Mexican President Enrique Peña when he came to Ottawa in 2016. Aurora's engagement with and fight for human rights in a transnational field also stems from her recognition of Canada's involvement in mining exploitation in Latin America, including Mexico. "This country [i.e. Canada] says, 'We're the best in human rights.' Nooo! They're the worst!'

Despite her activism, Aurora mentioned that she is afraid of keeping engaged in political activism after a negative experience she had with the Ottawa police. After being detained in a demonstration, she was allegedly strip searched by a male officer despite her request for a female officer. Her resistance led a group of male officers to closely surround her while laughing at her. "So, that makes me to be even more angry." This occurrence was added to her experience with the Canadian judicial system when dealing with her white Canadian ex-partner, where, "because of his nationality and skin color... it gives him a privilege that I don't have. [...] [So,] there was a moment in which I said, 'No, the system cannot be so corrupt, it can’t be so... so... racist!’” Despite her fears, Aurora has channeled these negative experiences into being more involved in activities that oppose injustice. This keeps her politically active: 'I'm happy to finally know that my destiny is to work for human rights, for children and women, and not only in Mexico or here [in Ottawa]." 
Marco (Montreal, permanent resident, seven years) befriended some Mohawks because "I identify myself with them a lot." "I have a more ritualistic connection with them, a feeling with them in Kahnawá:ke" (the Mohawk settlement across from Montreal). When I asked Marco why he identified with them, he mentioned that it was because of the "Indigenous identity, yes. We, as Mexicans, still have an Indigenous feature, we still have a little bit of that... you keep the Indigenous feeling a bit, no? Because we come from the same continent and they, knowing that we're Mexicans, well, they give us a warm welcome, no?" Marco has also politically participated around Mohawk and citizenship issues: "Last year, when [the City of Montreal] contaminated the [St. Lawrence] river, we did a political act in front of the City, and we did a small ritual there, with them [the Mohawks], with the elder, because the government has been contaminating the water." 62 (Alejandro: "And what motivated you to participate in those activities?"). "Dunno. The sensibility that one has, no? Like by participating in those events, you begin to generate a feeling, that sensibility that we have as human beings, to protect each other and support people as well."

Norma (Montreal, special considerations status, five years on and off), after her accident and despite her migration status, got involved in semi- and non-institutionalized political activities regarding human rights and networks of support of Mexican, Latinx, and non-Latinxs with undocumented status or immigrants with precarious economic status: "I was surrounded by a lot of people who had work accidents and are migrants, no? So, I could [closely] see how the system works. [...] 'Look, you need to check a health issue? Go with Médecins Sans Frontières.' 'You need to speak with a psychologist? I know this women's association." Norma also organizes events and solidarity networks for migrants: "You know that many people get depressed here, so let's talk, don't get depressed, let's do something. So, we have like a small network, no? We help each other." She also attends demonstrations and rallies both in Canada and Mexico around a variety of issues, ranging from demanding a \$15 per hour minimum wage in Quebec to supporting an organization that focuses on fighting sexual abuse in Montreal to defending 
teachers' rights in Mexico. She also fundraises for various causes in Mexico, such as the reconstruction of Indigenous schools: "I want to be involved with Mexico, and we do activities here for Mexico."

Norma also attended the Ayotzinapa events organized in Montreal "because it's a priority, but also because the Mexicans who live here, well, this is Mexico, no?' Norma's political sensibility and civic consciousness come from her family's political activism in Mexico, since they have always been engaged in the defence of Indigenous, workers, and peasants' rights, "so, it's like natural for me.” Indeed, Norma used to do some volunteer work around labour exploitation issues in Mexico, particularly among women, "and I thought that I'd never find something worse than Mexico's [labour exploitation system], and then I came here [to Montreal...] and got a job at the factory" (see chapter 9).

My respondents in the secondary location with limited political involvement have been in Canada for an average of 10.3 years, while those with an engaged involvement have an average of 11.5 years, or 9.6 years if I discount Nadia, who is an outlier (i.e. she has been in Canada for 21 years). Thus, the similar duration of residence in Canada among these sub-groups does not support the idea that time spent in the host country increased their political transnational engagement, as Ginieniewicz (2008b) found among some Latinxs in Toronto. Moreover, gender did not show a significant effect on their transnational political participation, since a similar number of women and men engaged in limited participation (two men and one women) and engaged participation (three women and three men).

Regarding immigration status, I found that participants who had permanent residence status (four) were more politically engaged, as was one person with special considerations status, compared to those with limited participation (two citizens). This is an interesting finding not only in terms of the overall needed costs to be politically active (e.g. time and resources), but also because the political cost in terms of accessing future citizenship status. That is, permanent 
residents risk having their status rescinded and being deported from Canada if they are charged with serious crimes and denied any right of appeal (e.g. being sentenced to more than six months in prison, such as in cases of common nuisance when stopping people from exercising/enjoying their rights or endangering the safety or health of the public, which can be punishable with up to two years in prison) (CCR 2018; PEN Canada 2016).

This does not mean that my respondents were involved in any illegal activity, but rather that their political involvement, although legitimate under Canadian law, hypothetically could lead them to higher personal risks than those having citizenship status. The expectation that these permanent residents would lessen their political involvement so as not to jeopardize their ability to remain in Canada was not suggested in my interviews. Moreover, PR status means these youth are not able to vote in any type of elections in Canada, for which it follows that if they were to politically participate in Canada, their participation would be mostly in semi-institutionalized and non-institutionalized activities, as confirmed by my participants' political involvement.

Comparative studies of political participation in Canada consistently show an "essential sameness in participation rates between those born outside and inside the country [...] and, in fact, is received wisdom, supported by research that stretches back approximately 25 years" (Black 2011:1166). However, my investigation reveals variation in degree and type of political participation when considering type of economic integration, migration status, and location. This constitutes valuable and suggestive insights for future qualitative and quantitative research. Moreover, when compared to the general Canadian-born population, immigrants participate slightly more when "communicating views to government through protest, working with other like-minded people, and engaging in lawful demonstrations. For example, $30 \%$ of immigrants had taken part in lawful demonstrations compared to $22 \%$ of the Canadian born" (ibid.). In addition, data from a national Canadian youth survey shows that only $12 \%$ of youth have participated in a political demonstration, rally, or march, and also that youth "who face greater challenges to getting 
involved (like poverty, or low education) are less likely to get involved" (Coletto and Kishchuk 2019:21). Thus, the participation of some of these Mexican youth in engaged political transnationalism considerably departs from political involvement of Canadian youth.

That those respondents living in Montreal had a more active political participation may be explained by the fact that Montréalais(es) are politically more active and nonconformist than Anglo-Canadians, and thus some immigrants and refugees adopted some of their habitūs by living in more politized fields. This was also shaped by some respondents who were already politically active in Mexico, and who found a new transnational space from which to expand their political activity. The increased political participation of Montréalais(es) finds a partial explanation in their historical, sociocultural and politico-economic relationships with AngloCanadians. Key moments in this relationship are Quebec's nationalist and sovereignty movements in the 1960s and 1970s, a more visible political participation of the LGBTQ+ community fighting for their rights in the 1990s, women's and feminists' movements from the late 1960s to the 1990s, an increase in non-white, immigrant groups that brought with them different types of political engagement, and the printemps érable (Barney 2012; Dickinson and Young 2008; Dyck 2011; Sorochan 2012).

Canada's capital city of Ottawa, by contrast, with most of its population working for different levels of government, technology-focused companies, education, and the service sector, has a lower politicization, and protest movements are smaller and less public. The effect of place in political engagement can also be seen in voting intention. For instance, $64 \%$ of Canadian citizens aged 15 to 24 and living in Quebec were very likely to vote in the next election vis-à-vis those in Ontario (58\%) or New Brunswick (34\%) (Turcotte 2015).

In general, participation in institutionalized types of politics, such as voting and belonging to a political party, was exerted by those youths with limited political participation. In contrast, those who had an engaged participation often partook in all three different types of political activities: 
non-institutionalized, semi-institutionalized, and non-institutionalized. Time spent in Canada and gender did not generate differences in types of political participation among respondents, although more permanent residents than citizens were politically engaged, as well as those located in the secondary type of economic integration. I now turn to a focused examination of youths' transnational patterns of social relations, remittances and support, and political participation. 10.4 Discussion: The Shaping of Transnational Participation Among Mexican Youth in Ottawa and Montreal

\subsubsection{Maintenance of Social Relations and Generation of Support Across Borders}

Living in different fields — across Mexico and Canada — led the Mexican youth I interviewed to experience social relations in different ways. This was seen in the type and frequency of communication they maintained across borders. On the one hand, their transnational communication was very frequent due to technological communication advances, particularly when compared to previous generations. For instance, new visual mobile applications allowed youth to offer family members and friends in Mexico and other parts of the world immediate visual access to their lives (and vice versa). In contrast to previous immigrant generations who used to establish contact by mail, fax, phone or even email, this possibility has changed, quantitatively and qualitatively speaking, the type of connections that migrants establish.

On the other hand, and despite these technological advances, the frequency and type of communication that Mexican youth maintained was still mediated and shaped by the type of social relationships they had before immigrating. Thus, whenever there was a strong connection to family members or friends in Mexico, communication was very fluid and rich in terms of frequency and content. Nonetheless, the advancement of technology does not strengthen per se the type of social relations immigrants and non-immigrants maintain with each other. Indeed, the geographical separation caused by migration tested those relationships, and many amicable relations ended. A second important aspect that led to this outcome was the effect of living in different fields and the consequent mismatch between previously shared habitūs. 
Bourdieu (1990a) spoke about hysteresis as a mismatch in the coherence between the logic of practice, habitūs, and fields. This mismatch often produces out-of-phase dispositions and a poor adaptation of practices among those who change fields. However, what I found among Mexican youth is that this mismatch or hysteresis also occurs, to certain extent, among those who do not necessarily change fields, i.e. those who do not immigrate. Whenever a person in Mexico is informed by an immigrant of the properties of different fields that the immigrant is experiencing, and which are different from the latter's fields and habitūs, such as differences in gendered practices, the person was confronted with a brief experience of hysteresis. However, that person usually interpreted reality through their own habitūs and saw the new habitūs as alien to them.

The lack of shared habitūs, a reflection of their living in different fields, thus led them to find less commonalities among them and created social distance. I did not find this effect whenever the youths' friends were also immigrants living in another country. This speaks to the way in which migration, by confronting (im)migrants with different ways of living, facilitates the exposure and — to a certain extent — the potential acquisition (and reshaping) of habitūs beyond those acquired at 'home.'

The transnational type of communication and ties that Mexican youth generated are thus different from the type of transnational ties that other immigrant youth in Canada develop. For example, Hong Kong Chinese youth who immigrated to Toronto with their families in the 1990s and who later were left behind (known in the literature as satellite or parachute children), "took the lead in maintaining transnational ties and expanding the transnational social space of their immigrant families" (Shik 2015:82). Differences in transnational communication and the (re)production of social ties are thus also generated by diverse contexts of exit and reception and type of migration.

Some transnationalism scholars have also identified that social class, migration status, gender, and education shape immigrants' types and levels of transnational engagement (Al-Ali et 
al. 2001; Goldring and Krishnamurti 2007; Hiebert and Ley 2006; P. Kelly 2003). Some other authors found, particularly among Latinxs in the United States, that more educated immigrants and those with a better economic integration are more engaged in transnational practices (Glick Schiller and Levitt 2006; Itzigsohn and Giorguli-Saucedo 2005; Portes 2015). Guarnizo, Portes, and Haller (2003), for example, identified that Latinxs' transnational practices in the United States were positively mediated by various factors.

These factors included length of residence, education (particularly high school level, with post-secondary education exerting only a marginal difference), greater stability and experience in the receiving society, and larger networks and strong social connections. When comparing these scholars' findings with the experiences of my respondents, I found some differences. For example, I found variations in the relation between length of residence in Canada and type of transnational support sent to family members and friends (e.g. gifts, monetary remittances, or personal support). Since those who sent a more engaged support had lived in Canada for a shorter time ( 9.5 years) than those who sent meaningful support (12 years) and those who did not send any type of support (11 years), we can safely assume that, for these youth, time spent in Canada cannot alone determine the type of transnational support offered or its lack thereof.

Level of education shaped to some extent the type of transnational support offered. Thus, when compared to other findings where it was more educated immigrants who engaged in transnational practices, I found that participants with more years of education had an engaged type of support, but some did not send support at all. Moreover, in cases where youth sent support, it was not education per se which generated the creation of transnational support. Rather, it was the person's class location that facilitated their acquisition of education in the first place. Later, that education was exchanged in the labour market for a type of job that provided them with economic capital, which in turn assisted them in their sending of transnational support when the sender's and receiver's circumstances merited and were possible to achieve. 
Regarding my participants' social connections, their networks are limited in Mexico and small in Canada, except for some of those located in the secondary location, whose networks are more extended even if of a similar nature, thus limiting their impact of their social capital. However, the type of social relationships that youth maintain with people in Mexico, even if important, did not determine in itself the sending of transnational support. Rather, this support was in part shaped by the sender's and receiver's economic position in Mexico and Canada. Consequently, those who cannot send remittances still have strong relationships with family members and some friends in Mexico, but their type of economic situation and in some cases economic integration did not allow them to send that support, even if they wanted to.

The impossibility of sending support turned out to be in some cases independent of any initial settlement period, contrary to what Goldring (2006) hypothesized. In her view, this happens because immigrants are still adjusting to the new society and thus have limited economic resources to send support abroad. I found that some youths in the secondary location were not able to send any support due to their long-term precarious economic integration, which in some cases was one of relative poverty, despite their time spent in Canada. Moreover, in contrast to those who could not send support, there were other youth in the independent location who did not send support because their family members or friends did not need such support. Among those who could send support, and whenever there was a specific need or objective to be addressed with people with whom they had significant relationships in Mexico, meaningful and engaged types of transnational support were established (e.g. independent located youth sent more engaged support and secondary located youth more meaningful support). Although social networks are usually small among those who send these two types of support, the strength of their transnational social connections, along with their type of economic integration and economic stance in Canada, turned out to be a determining factor for the type of transnational support offered in the Canada-to-Mexico route. 
A different process operated for those who sent support via the Mexico-to-Canada route, since there were two different cases. In one case, economic support was sent to Canada to sustain family members for them to study as international students and then transition to be permanent residents (even if the latter was not an initial goal after immigration). This support was sent despite its elevated cost due to currency exchange rates differentials. However, in these cases, parents have an independent location in Mexico and can send South-to-North remittances. In the second case, the remittance, sent by family members with varied economic locations in Mexico, was meant to assist family members or friends who were struggling in terms of economic integration in Canada.

After the 2007-2008 global crisis, Mexican migrants in the United States developed various economic strategies to weather the financial crisis. These included borrowing money to survive unemployment, looking for jobs within the migrant community, pooling resources by, for example, moving in with family members or friends, and relying on savings to compensate for losses in personal earnings (Marchand 2014b; Orozco 2009). However, once those possibilities were exhausted, some family members in Mexico wired money to the United States to help their migrant family members (Lacey 2009; Marchand 2014b). The decision to support a family member to remain on the other side of the border is not surprising, since this is part of household strategies to reallocate resources at regional and (trans)national levels (Moser 1996). What is new is how such strategies were shaped by an increase in the securitization of the US border after 9/11 and the corresponding rise in the costs of migration (Marchand 2014b; Walters 2008, 2010).

In comparison, among some of my respondents in Canada, South-to-North remittances were used as an immediate strategy, even if insufficient, to cope with already fragile circumstances, such as relative poverty. These also helped to overcome sudden unemployment while making use of other alternatives (e.g. social security and Employment Insurance or l'assurance-chomage), even if the amount of money received was minimal due to foreign 
exchange rates. What is common among the US and Canada cases is that family members or friends supported immigrants for them to stay in the country of reception, as long as possible, rather than for them to return. As Marchand (2014b:294) contends, there is a cost-benefit calculation underlying the Mexico-United States remittances that takes into consideration the securitization of the border, the increased dangers to travel undocumented among cases in the United States, and the violence in Mexico that create a permanence of temporariness.

In Canada, and considering that my participants have documented status, the South-toNorth support also aimed at supporting immigrants to stay in Canada, but the reasons were not only economic. As mentioned in Chapter 5, some youth immigrated to Canada not for direct economic reasons but as a way to obtain international education, live and express their sexuality, escape from violence, or live in a social milieu where machismo is not as prominent as in Mexico. Thus, the South-to-North remittances also assisted immigrants who were experiencing economic difficulties in Canada to maintain those non-economic immigration objectives. In both types of South-to-North remittances (i.e. for [non]economic reasons), however, the underlying mechanisms that led to the generation of support were the strength of the relationship between people involved in the exchange and their possession of economic capital, even if in some cases the economic capital possessed was meagre on both sides of the border.

It was not strange to observe then, that whenever there was positive economic integration in Canada, a strong relationship with the recipient, and a particular need or objective to be achieved, engaged support was to be found more frequently, as it was the case for those situated in the independent location. In contrast, meaningful support was mainly offered by those situated in the secondary location, a precarious type of economic integration. Indeed, the latter's high participation in meaningful support speaks to the creation of support networks and the relevance of social capital as a transnational strategy of survival for those who immigrated and those who did not. Economic integration seemed to have little effect insofar as a very similar proportion 
among two groups of respondents, those who do not and those who cannot send support, were located across the three different types of economic integration.

The latter case indicates that even for those located in the best possible type of economic integration, the independent one, the circumstances of immigrants in terms of income disposability at certain point in time also shape the possibilities of generating transnational support. In terms of migration status, having citizenship status was no more likely to shape the support offered from Canada-to-Mexico than having permanent residence status. But as mentioned before, there were some cases where Mexico-to-Canada economic support was fundamental in the process of status conversion (where some youth passed from being international students to permanent residents) or to compensate for the lack of status (as in Norma's case).

Regarding gender, it was difficult to identify a pattern considering also the type of transnational support offered, location, and type of economic integration, since my sample size scaled down when considering these elements. For example, only one woman and one man from the independent location engaged in sporadic support in Ottawa but none in Montreal, and only two women from the subordinate location in Ottawa and only one man in Montreal had an engaged type of support. However, if we consider both meaningful and engaged types of support, women are, in general, more supportive. The generation of transnational support, however, is still in an embryonic, more individual-type stage in comparison to the transnational support that other ethnic groups develop from Canada.

For example, Ghanaians in the GTA provide financial support for local economic development through churches that have projects in Ghana, including medical clinics, schools (e.g. one Toronto church established a university in Ghana), and water projects. They also maintain links with local branches of Ghanaian sports fan clubs (Gariba 2009). Filipinos in Canada have one of the highest levels of international remittances when compared to other ethnic groups. This 
transnational economic support also includes sometimes supporting the postsecondary education of relatives in the Philippines, even if this support may in some cases put a strain on the finances of the family in Canada (P. Kelly 2015:290). Overall, type of economic integration, the economic stance of my respondents in Canada and people in Mexico, the type of relationship they maintained, and the objectives or needs to be addressed determined the type or lack of economic transnational support offered, and thus the constitution of an incipient transnational field.

\subsubsection{Economic Integration in Canada and Political Engagement at Various Levels}

My respondents' political engagement departed from the usual findings among Latinxs and other immigrants in the United States and Canada regarding transnationalism. Reitz (1980), for instance, found that immigrants with lower socioeconomic status in Canada had stronger ties to ethnic identification and lower political Canadian participation rates. And higher socioeconomic status immigrants showed lower ethnic cohesion and a higher Canadian political participation (i.e. voting, attendance at political meetings, and familiarity with public affairs). Recent poll data at the national level shows that, although there is a generalized political disengagement in many countries around the world, there is a strong correlation between higher levels of education and political participation, including among Mexicans (Wike and Castillo 2018).

Kazemipur (2008), analyzing data from the Canadian General Social Survey (2003, $\mathrm{N}=25,000$ ), found that the only area where immigrants and Canadian-born had close similarities was in their political party activism. Canadian-born scored higher on voting, non-political volunteering, expressing political views, and creating social networks. Most of the dimensions in which immigrants fall behind were voting and political expression, as well as those which involve social interaction with other people in Canada, such as trust, neighbourliness, social networks, group activities, volunteering, donating to charities or organizations, or belonging to youth groups while in grade or high school (ibid.).

Finn and Momani (2019) found that Canadian-Arab youth born in Canada were 
significantly more likely to be politically active than Canadian-Arab youth born somewhere else. Ginieniewicz (2008b) found a correlation between a moderate level of political involvement in Latin America or Canada and higher educational levels among Latinxs in Toronto. In addition, as mentioned earlier, Guarnizo et al. (2003) identified that transnational participation among Latinxs in the United States was strongly correlated to length of residence, education (particularly high school level, with post-secondary education exerting only a marginal difference), greater stability and experience in the receiving society, larger networks and strong social connections, and enduring moral ties with their home communities.

LENGTH OF RESIDENCE. Thus, when analyzing how these factors related to my respondents' transnational political participation, I found some differences. In this qualitative sample, length of residence was not shown to be relevant in generating a specific type of transnational political involvement or lack thereof. This also contrasts to Black’s (2011:1166) literature review of immigrants' political incorporation in Canada (e.g. voting and participating in lawful demonstrations), where "as the foreign born spend more years in Canada, their participation rates decidedly converge toward those of the native born and in some cases even surpass them." Data on institutionalized political participation among youth in Canada, however, points to more nuanced scenarios. Here, youth are shown to be less likely than adults to consider electoral participation as a civic duty, and immigrant youth are less likely to vote in the next election than non-immigrant youth (Turcotte 2015). Among my independent and subordinate located participants, voting intention in Canada was high. However, rather than time spent in Canada, other factors were more relevant to determine their political participation, such as citizenship acquisition and the possession of a political habitus that led participants go beyond a limited institutionalized participation in politics. It remains to be seen if more years in Canada lead Mexican young people to be more politically engaged. My research, however, indicates that there is no one pathway to political engagement among immigrant and refugee youth, and that we 
need to also consider their type of economic integration, shaped, in part, by their pre-migration location and previous political participation.

EDUCATION. Regarding education, it was those with lower levels of education who had a higher level of political participation in local, transnational, and/or global issues. This also relates to economic integration, since those Mexican youths who have more education (i.e. postsecondary education) are those located in the independent location, among whom seven have no political involvement, six have a limited involvement, and only one person has an engaged political participation. In contrast, among youth located in the secondary location, where more than half have only completed high school and the rest have a bachelor's degree, all are politically involved. Six of them have an engaged political participation and three a limited participation. This finding contradicts the traditional finding in (immigrant) political participation scholarship, where "political participation is low for socially marginal persons" (Reitz 1980:226). This finding is also similar to that of Guarnizo et al. (2003), who found that Mexicans in the United States with a high school education level were more engaged in (general) transnational practices. By itself, however, education is not enough to explain my participants' political engagement.

NETWORK SIZE AND SOCIAL CONNECTIONS. In terms of the size of immigrants' networks and their social connections, those in the secondary location have long-term connections with other immigrants in the same class location. In contrast, those in the independent location have more varied networks whose nodes have ampler and better positioned connections, but the social capital granted by these connections is short-lived and occasional (see chapter 7). Moreover, those located in the independent location had a relatively easy access to social capital, embedded in their educational and/or professional employment fields in Canada, but only after they were able to access that field via their pre-migration class location. Those in the secondary location found themselves involved in networks that facilitated their initial settlement process, but these have - at the same time - limited their economic integration process in Canada (i.e. spatial structuration). 
Thus, the benefits derived from being located in an independent field led most of those youths to be located in a good economic position. However, this also gave them access to networks that did not necessarily compel them to be very politically engaged in local, (trans)national, or global fields. In contrast, those in the secondary location, by the nature of their economic integration processes and networks, focused more on the struggles that immigrants face daily. Pre-migration class location also shaped this involvement, since, in contrast to middle-class Mexicans who immigrated in the 1990s (Veronis 2006b), these youths did not focus on creating immigrant professional support associations to facilitate their economic integration. Their secondary integration also led them to develop empathy toward other persons and partly compelled them to become active in political issues of various types and at different levels.

It was noticeable that despite their precarious economic integration and, consequently, less spare time and economic capital to engage in political activities as compared to those youths located in the independent and subordinate locations, youth with a secondary type of integration showed higher levels of political socialization, awareness about, and engagement with Mexico, Canada, and/or global matters. This was also a proxy for feelings of belonging to Canada and the world (i.e. a form of global citizenship). These cases also depart from other scholars' findings, which indicate that the better the integration of immigrants, the higher their feelings of belonging and engagement in political transnational practices (see Ginieniewicz 2008b). My findings also differ from those of Long and Hughes (2003). They found that some Latin American immigrants did not want to actively incorporate themselves into Canada's political life for fear of awakening the potential ire of authority figures, such as government officials, or negatively affecting their employment possibilities, as they had experienced in their countries of origin (see also Long 2002, 334).

The differences in political engagement are also partly the product of living in new sociocultural and political fields and acquiring new habitūs, particularly for those residing in 
Montreal. And for four respondents, this was also the continuation of their Mexican political habitus despite their disadvantageous economic integration and possession of only PR or special consideration status. These cases, then, partially contrast to research done by Black, Niemi, and Powell $(1987: 76,77)$ with recent European and British West Indian immigrants to Canada in the 1980s. The authors identified that immigrants' partisanship, interest, and political activity in Canada increased with the age of the respondent and previous political experience (see also Armony et al. 2004). In the case of these Mexican youth, although their previous political experience certainly led them to be more politically involved, being young did not deter their political involvement. I also found that the rest of the secondary located youth became politically active after witnessing how political and economic processes affected people in Canada, Mexico, transnationally, or globally, and thus decided to do something about it. Their immigration experience allowed them to 'open' their eyes to a new reality and possibilities.

RACISM. Other authors have also found that negative integration experiences among immigrants, such as racism and/or discrimination in the host country, lead to their involvement in transnational practices, what Itzigsohn and Giorguli Saucedo (2002) call reactive transnationalism (see also Beserra 2003; Chute 2004; Ginieniewicz 2007; Glick Schiller and Fouron 1999; Goldring et al. 2003; Itzigsohn et al. 1999; Landolt, Autler, and Baires 1999; Portes 1999, 2015; Portes, Guarnizo, and Landolt 1999). For instance, first and second-generation Filipino-Canadian youth have actively embraced transnational practices as a reaction to their experiences of being marked "by many Canadians as perpetual outsiders" (Pratt 2010:345). Nonetheless, when I inquired about the existence and possibility of these negative experiences, which may in turn be shaping my participants' transnational involvement, the outcome was almost negative. Only Aurora identified such experiences (see chapter 9) to the point of making use of transnational activities to fight against or cope with those situations.

SEXUALITY. In the cases of Norma and Román, the only two participants who self- 
identified as homosexual and are both located in a subordinate type of integration, their political involvement diverged. Whereas Román has a limited and institutionalized political participation in Ottawa, only casting his vote in Canadian elections, Carolina, who went through a previous political socialization in Mexico, showed an engaged, non-institutionalized involvement in Montreal despite her economic precariousness. This precariousness also helps to explain why Carolina and her ex-partner were not able to join an LGBTIQ+ feminist group in Montreal shortly after their arrival, as they intended (i.e. they needed to pay a fee per meeting). Their potential involvement with this group might have helped them to better identify the experiences of LGBTIQ+ persons in Canada, particularly those with an immigrant and racialized background, and shape, in turn, their political involvement in Canada, also oriented towards LGBTIQ+ issues. As Grundy and Smith (2006:394) found in Toronto, LGBTIQ+ politics in Toronto intersect with other collective identities and politics, such as those related to youth and ethnic groups, and where issues such as racism and poverty are also relevant.

Some of my Montreal participants developed their multilevel political engagement by developing diverse social intervention strategies or engaging with organizations that generated social capital for them. Some of these strategies consisted of participating in events of ethnic organizations or groups that included Mexicans, Latinxs, Filipinxs, and Mohawk Indigenous peoples. Their participation, sustained by and at the same time generating more social capital, later transmuted into some economic and/or cultural capital. The social networks they created both eased their secondary economic integration and sometimes expanded into transnational safety nets that even benefited some of my participants' family members in Mexico.

Some Mexican youths' political participation in Montreal has partly been mediated by their class location and their secondary economic integration. This type of economic integration has led some participants to generate what P. Kelly (2012) identifies as individual or collective political strategies or solidarities arising from (and at the same time defining) their class location. 
Joining other Québécois(es) to fight for a \$15 per hour minimum wage in Quebec, donating money to build an indigenous school in Mexico, or protesting the contamination of the St. Lawrence river unveil their "positional class" or the "emergence (often in a functional way) of politics out of a consciousness of a collective class positioning” (P. Kelly 2012:161). However, the engagement of some youth in multilevel, engaged, and non-institutionalized political transnationalism has not only been developed as a result of their positional class in a secondary type of integration. It has also been transformed after immersion in the Montréalaise society, shaping their cosmovision and subsequent development of transnationalism. Thus, their class location is not the finish line (i.e. a fixed position in the broader set of class relations), but the 'starting' point (i.e. class location as a process) of a deeper and broader politization and political activism after immigration, shaped by a strong ethical commitment expressed as dissident citizenship (more below).

The type of political transnational organization I found among some of my Mexican participants, however, differs from that of other ethnic groups such as Filipinxs, which has become strongly semi-institutionalized. This semi-institutionalization seems to originate from the substantial (im)migration of Filipinxs to Canada, since the Philippines is "a major exporter of human labor, both for temporary contract work and permanent migration" (P. Kelly 2012:164). For instance, many immigrant youths have come as children of Live-In Caregiver Program workers who, eventually and after many struggles, were able to obtain permanent residence. In addition, Filipinxs have shown to have a greater degree of local, national, and transnational organization derived from the establishment of associations in cities such as Montreal, Toronto, and Vancouver since the 1960s (Damasco 2013; Tungohan 2013).

The semi-institutionalization of Filipinx-Canadian politics in Canada has thus facilitated some Filipinx youth groups, such as the Filipino-Canadian Youth Alliance, to promote exchanges to the Philippines among their members “for extended periods of 'integration' into political 
organizations there.” These organizations also allow Filipinx youth to explicitly locate their struggles, such as systemic racism in Canada, "within a longer history of youth mobilization in the Philippines" (Pratt 2010:345) and to develop activities "geared towards exploring Filipino identity in Canada through positive engagements with the Philippines” (P. Kelly 2015:294). Thus, whereas some Filipinx youth have developed semi-institutional forms of political organization due to the abovementioned reasons, some of the Mexican youth I interviewed in Montreal have mainly participated in or established non-institutional organizations. ${ }^{63}$

Whereas Filipinx youth have identified the Philippines as "an imaginative national space that inspires and expands youth organizing" in Canada (Pratt 2010), the Mexican youth I interviewed do not see Mexico under similar terms. On the contrary, as shown in chapter 3, the on-again-andoff-again relationship between both countries has not generated numerous and profound, visible linkages (excluding those of the extractive sector such as the mining industry) that may stimulate the generation of transnational political connections among Mexican youth.

As I have demonstrated here, the combination of various factors such as type of economic integration, size and type of networks in Canada and Mexico, previous political engagement, citizenship status, and interest in civic and political activities intersect to generate a specific outcome regarding political transnationalism. These factors, nonetheless, do not fully explain why my participants in the secondary location, despite being located in a precarious structural position, are very politically engaged. Some scholars signal that immigrants' limited career prospects, a proxy for downward economic integration and an experience widely shared by youth in the secondary location, lead to the development of transnational practices (Goldring et al. 2003; Loaiza 1989). These practices, however, are mainly of an economic type, such as remittances, which create a safety net for immigrants and social capital for the sender of support back home. Among youth in the secondary location, however, their engaged political involvement cannot be fully explained only by their precarious economic situation. This is because the transnational 
support they send is limited to a meaningful type of support, as mentioned above, which does not provide them with a strong safety net in Mexico (i.e. no generation of savings, property purchase, or investments).

In addition, the participants who had an engaged political participation explained such participation as a desire to 'do something' or to 'demonstrate' something in the face of political issues happening in Mexico, Canada, or globally. Thus, as Finn and Momani (2019:29) argue, youth who do this "violate long-standing stereotypes about youth as indifferent to their political realities." But then again, what can explain that those Mexican youths who have experienced a disadvantaged economic integration and have the lowest levels of education in my sample are more politically engaged than those who are doing economically better and have more education, as the literature has indicated for too long?

Guarnizo, Portes, and Haller (2003:1233) mentioned in passing that "enduring moral ties with sending communities" among Latinxs in the United States was another reason for their transnational participation, but they never defined the term. Zhou (2004:1058) developed that notion and defined it as "ties dictated by a common ethnicity or a cultural heritage - origin, religion, and language." However, Zhou's definition falls short of describing the reasons for which these respondents were deeply engaged in varied types and levels of political and civic activities. Sparks' (1997:75) notion of dissident citizenship, however, casts light on:

the practices of marginalized citizens who publicly contest prevailing arrangements of power by means of oppositional democratic practices that augment or replace institutionalized channels of democratic opposition when those channels are inadequate or unavailable. [...] Dissident citizenship, in other words, encompasses the often creative oppositional practices of citizens who, either by choice or (much more commonly) by forced exclusion from the institutionalized means of opposition, contest current arrangements of power from the margins of the polity.

Adding to Spark's notion, I understand practices of dissident citizenship as forged not necessarily or only by those sharing a common ethnicity or a cultural heritage, as Zhou's notion of moral ties implies, but mainly by a personal, ethical compass based on the recognition of a shared humanity. 
This underlying ethical commitment, manifested in practices of dissident citizenship, includes, as Sparks affirms, "a discourse and practice of courage," i.e. "a commitment to resolution and persistence in the face of risk, uncertainty, or fear" (76). Practices of dissident citizenship and courage can thus be enacted by or directed towards members of various ethnic/racial groups at various levels: a region, the country of origin, the host society, and/or the global arena.

I found among my participants in Montreal that their dissident citizenship practices can be short or lengthy, and they can also lead to a group-based or a more individual-based type of activities, or even its constitution into an organization. This is because the existence and development of dissident citizenship practices is dependant on a number of factors, such as the immigrants' contexts and circumstances in Mexico and Canada, the type and strength of connections (real or imagined) that they maintain with varied people, their immigrant status, and their type of economic integration.

In the particular case of political transnationalism, I found that dissident citizenship practices originating from, for example, feelings and notions of (in)justice and a sense of community orientation rather than an individualistic one (the latter being a common orientation found in Canada), compelled some Mexican youth to actively participate, develop, or be involved in political activities. These activities then, can be of an institutionalized, semi-institutionalized, or non-institutionalized form, as described above. Thus, although some of my secondary located participants do not even have formal citizenship, their dissident citizenship practices not only unveil their profound, ethical commitment to others, but also their expanded feelings of belonging to Canadian, Mexican, transnational, and global fields. Moreover, in politically intervening in their old and new fields, they also shape the Canada-Mexico transnational political field.

When compared to other immigrant youth who feel pulled in multiple directions given their identification with two or more homes/homelands, such as Canadian Arab youth (Finn and Momani 2019), my respondents did not mention experiencing this divergence. On the contrary, 
many of my politically engaged participants located across various types of economic integration (one in independent, two in subordinate, and six in secondary locations) were skilfully involved in various transnational (and sometimes global) fields and practices that did not generate conflicts regarding feelings of belonging. Rather, their sense of belonging became expanded and even more inclusive through their multilevel political engagement. Those other youths who had a limited or a more institutionalized political participation also did not express such sense of having to identify with one or the other nation-state. In these cases, however, their limited political participation may not have provided them with many occasions in which to be confronted by this quandary of identification.

In the 1990s, some Mexicans who came via the economic class organized to address their poor economic integration in Toronto through the creation of professional associations, thus developing a desire to acquire substantive citizenship in Canada (Veronis 2006a, 2006b). In contrast, the youth situated in the independent location I interviewed acquired higher education in Canada and did not have to go through an accreditation process, or are located in this type of integration by extension (due to their partners' economic type of integration), or they obtained good jobs due to the social capital they were able to tap into. Consequently, they did not have to face the hurdles that limited the integration of some Mexicans into the Canadian economy in the 1990s, and thus have not demanded substantive citizenship since they already enjoy it. This, in turn, has reduced their possibilities of being confronted with the need to exert certain types of political engagement.

In contrast, those in the secondary location have had to deploy several strategies in order to get ahead in Canada. Nonetheless, their political involvement has not focused on a desire to acquire substantive citizenship due to their downward economic integration, even when many do not have state-sanctioned, formal citizenship. Rather, their involvement derives from an ethics of political courage and dissent. This involvement has also been broadened to include local, 
transnational, and sometimes global affairs despite their risk of jeopardizing their status in Canada due to their involvement in non-institutional and sometimes disruptive politics. Thus, despite their economic precariousness in Canada and Mexico, their political transnational activities have been of a more substantive type and thus show an ampler and richer citizenship commitment than that of some Mexicans living in Canada in the 1990s or the independently located youth I interviewed. This variation in transnational practices, generated by pre-migration class location and types of post-migration economic integration, thus signals a little-explored arena in migration and transnationalism studies. In the final chapter, I offer some overall conclusions about Mexican youth immigration to Canada, their contexts and reasons for departure, and their effect on their economic integration and transnationalism. 


\section{Chapter 11: Conclusions: Mexican Immigration to Canada: Contexts, Reasons, Economic Integration, and Transnationalism}

My dissertation explored the various ways in which the pre-migration class locations and post-migration circumstances of Mexican immigrant and refugee youth shaped their economic integration in Canada, locating them in three distinct market segments. I then analyzed how economic integration and class locations shaped the youths' production of sociocultural, economic, and political transnational practices (or lack thereof) in Ottawa and Montreal. Informed by a politico-economic perspective, I also historicized and contextualized the migration of Mexicans, first to the United States and later Canada. My goal here was to demonstrate how Mexican migration to Canada has been partly shaped by the on-again-and-off-again CanadaMexico relationship (despite the latter's recent attempt to expand this relation to the political level), which contrasts markedly with the almost two-hundred-year relationship between Mexico and the United States.

The Mexico-US relationship has generated dense political, economic, social, cultural, ideological, and religious processes and networks between both countries that, in turn, have transformed into push and pull factors. Some of these factors have, in turn, produced and maintained various levels of marginalization among many Mexican (im)migrants that have fostered the generation of migration circuits. These circuits have been altered only recently due to the securitization of migration after 9/11 and the effects of the 2008-2009 global financial crisis. Still, the strong presence of Mexicans and Mexican-Americans in the United States, along with their continued reproduction of fields and habitūs, constitutes a solid magnet that keeps attracting Mexicans. For instance, a member of the US Border Patrol recently reported that an "increasing" number of mostly Mexicans, Romanians, and to a lesser extent Haitians (i.e. 165 people in 2017 and 548 in 2018) were arriving in Canada to later enter undocumented to the United States (Larouche 2019).

The substance and historical 'thinness' of the Canada-Mexico relationship have also 
produced a modest knowledge of one country about the other. Thus, although Mexicans know little about Canada, this knowledge is mostly positive when it exists. In contrast, the generalized lack of knowledge about Mexico among many Canadians is reflected in their limited narratives that focus on holiday resorts and/or violence. The immigration of Mexican youth to Canada has also been mediated by Canada's need for skilled immigrants and, to a lesser extent, by its refugee and humanitarian programs. Thus, Canada's economic imperative has generated various immigration pathways through which Mexicans have immigrated to Canada, facilitating the movement of Mexicans, particularly those who possess various types and quantities of capitals.

At the same time, the low acceptance of Mexicans as refugees partly stems from Canada's securitization of immigration and a nineteenth-century notion of some immigrants seen as potential economic burdens to the country (Hernández-Ramírez 2019). For instance, in an interview given to The Ottawa Citizen (1997) in the late 1990s, former Canadian Ambassador to Mexico, Marc Perron, assured that "Mexicans are intelligent, astute." "The problem is not with illegal immigration. What occurs is that the Mexicans abuse the Canadian system. They go to Canada and declare themselves political refugees. [...] It is a good deal for them and they can visit the country for free. [...] Consequently, the Parliament will begin to discuss the possibility of demanding a visa from all Mexicans."

This line of argument, revitalized by the Harper government, led Mexicans to be labelled as 'bogus' refugees. As I demonstrated, however, this notion purposefully ignores the growing interrelationship of North American and even Central American geo-politics and economics, as well as the Mexican state symbiosis with criminality that has produced expanding multifaceted forms of insecurity and new grammars of violence in Mexico. In a Bourdieusian sense, the construction of fortress Canada, a reflection of a historical field that has highly regulated immigration, constitutes a strategy of preservation. Namely, strategies that look to maintain a determinate state of power relations that "more or less completely monopolize the specific capital, 
the basis of the specific power or authority characteristic of a field" (Bourdieu 1993:73). The emphasis on economic immigration thus corresponds to one of Canada's strategies of power preservation (i.e. not everyone is welcomed). At the same time, economic and cultural capitals have constituted treasured capitals under Canada's immigration policies and thus capitals that are highly sought after.

It is in this broader, historical scenario that I interviewed 35 Mexican immigrant and refugee youth aged 18 to 35 who settled in Ottawa and Montreal. Drawing from these interviews, one of the contributions of this research is a nuanced understanding of how Canada's and Quebec's immigration policies have differently promoted or inhibited the immigration of Mexicans depending on their profiles, thus stratifying immigrants by their pre-migration class location. Even among some refugee and humanitarian cases, which are not linked to the possession of economic capitals as in the case of economic immigrants, I found through the stories of my participants that class location was an important factor in making a (successful) refugee claim. This was because class location provided claimants with various capitals that allowed them to travel to Canada and make an in-person refugee claim. Pre-migration class location and intended entry class were also important to determine how easily my participants navigated the immigration process or the difficulties they faced to be admitted as immigrants in Canada. This was particularly true for some of those who were sponsored via a marriage or partnership, or those who came as international students and had put down roots in the country.

Canada's structuration of immigration by class location has also led some scholars and bureaucrats to think that Mexicans in Canada are middle-class, educated immigrants. However, I demonstrated here how immigrants' pre-migration class location variably changes after immigration, for which class location should not be assumed to be constant in the immigrants' trajectories. I also showed how even among those who immigrated via the economic class, particularly those who came as dependents of economic class applicants, distribution of capitals 
was unevenly distributed before immigrating by age and gender, creating different post-migration integration processes. Thus, not all Mexican immigrants and refugees fit the urban, educated, and middle- or upper-class categories that some attach to them.

The variation in the profile of Mexicans in Canada has led, on the one hand, to a structural invisibilization to which some are subjected after having immigrated. This invisibilization results from the interplay between their pre-migration class location and their post-migration economic integration processes, which led some of my respondents to a downward assimilation pathway. Since some are unable to obtain jobs that allow them to have spare time and socialize in the Mexican and Canadian communities, they remain invisible. In other cases, their invisibilization was only an extension of their pre-migration class location, which was maintained after immigration. In contrast, those with a positive economic integration are able to socialize and be more visible, but they also reflect a skewed image of Mexicans in Canada. The change of fields due to immigration and the resultant hysteresis is thus managed in different ways depending on immigrants' and refugees' pre-migration class location and type of economic integration. Namely, those immigrants who, due to their possession of varied capitals are able, for instance, to achieve an independent integration, are better situated to navigate their new fields once in Canada and thus have a more visible participation in social activities.

My research also unveiled how relatively recently created economic transnational fields between Mexico and Canada, part of the expansion and accumulation of Canadian and to a lesser extent Mexican capital, have been operating as pull factors. These fields promote the temporary migration of skilled Mexican workers to Canada who, after acquiring Canadian capitals, may take advantage of Canada's or Quebec's economic immigration programs to obtain permanent residence status. Other Mexicans, working in Mexico for Canadian companies, develop transnational social capital that they later use, along with their other capitals, to immigrate via the economic stream. The expansion of Canadian capital to Mexico through different commercial 
ventures, such as that of mining industries and with the decided and strong support of the Canadian state, has opened transnational spaces. However, this has also brought violence to some Mexican communities. This, along with increasing levels of violence generated by the symbiosis between the Mexican state and criminality, has operated as a push factor for those who came as refugees and some others who came via the economic class.

Agency also played an important role while interacting with broader structural factors to prompt the immigration of Mexicans to Canada. For instance, previewing the impact of the ups and downs of certain markets in Mexico, which would modify the employment fate of some of my respondents' fathers, they found a way to immigrate with their families such that they could maintain both their economic and social standing. In these cases, however, it was the immigrants' pre-migration class location that allowed them to, first, access the transnational employment fields, and second, fulfill all the requirements to apply to one of Canada's or Quebec's economic programs. This also means that although Canada's immigration programs structure immigrants by their pre-migration class location, some aspiring immigrants also make use of their agency and capitals to access certain immigration fields. These capitals and agency grant them the possibility of shopping around in search of the country that best suits their interests. Here, considerations such as geographical distance from Mexico, implying the proximity and ease of traveling back and forth to visit family and friends, and possibilities of personal or family development are factored into the decision.

Aspiring immigrants then, also partake in a self-structuring immigration process - even before departure - based on their total sum of social, cultural, and economic capitals in an expanding transnational, economic Mexico-Canada space. In the case of family migration, this self structuring process is also mediated by the effect of pre-migration distribution of capitals among members by gender, age, and ideology. Here, the main head of the household turned out to be the main actor in the family immigration process, being the father/husband who had more 
capitals before immigrating. This role switched after immigration, however, since some of the children acquired more capitals due to their young age at the moment of immigration and a faster sociocultural incorporation.

Moreover, although it is known in the migration literature that it is not the poorest who migrate, I demonstrated here that it is only those with a set of various capitals who can effectively immigrate and be accepted by a country's immigration policies, even in refugee cases. Nonetheless, considering that immigration fields are constantly changing, aspiring immigrants' total sum of capitals may not squarely fit into the requirements of immigration programs or the employer's demands for particular types of labour despite their skills. The synchronization of these macro and micro factors turns out to be essential, then, for immigration to occur even among those who came to Canada as international students.

\subsection{Mexican Immigrant and Refugee Youths' Types of Economic Integration}

Bourdieu never developed a theory of social class or considered 'social class' as it is usually understood in traditional sociological terms (Grenfell 2008). Rather, he developed a theoretical framework to understand, first, how social classes are devised (i.e. "where the boundaries around specific classes should be drawn" [98]). And second, to understand how the social location of individuals may or may not constitute a social class (i.e. class formation), and how once such a class is constituted, it may be reproduced through habitūs (ibid.). Thus, for young immigrants to constitute a social class in a Bourdieusian sense and then reproduce it through habitūs (i.e. class reproduction), they would need to get together in "particular positions in social space to take on board an identity and mobilize around it" (98). Identification and mobilization in the field of power then, are two of the main requisites for class formation.

As such, in this dissertation I do not make the claim that the Mexican youth I interviewed constitute a specific 'social class' in the fields of power relations in Ottawa and Montreal. Rather, I focused on the specific social locations of youth in some of their fields before and after 
immigrating, including their post-migration social location movement regarding economic integration. Here, I showed how their total sum of pre- and post-migration capitals (i.e. economic, cultural, and social) shaped their economic incorporation once in Ottawa or Montreal (or initially in other Canadian cities), locating them in three different employment market segments (independent, subordinate, and secondary).

The literature on economic integration in Canada has strongly focused on identifying the type of Canadian capitals needed for youth to achieve good or poor employment outcomes, such as knowledge of official languages and Canadian work experience (Boyd 1990; Gunderson 2004; Lauer et al. 2012; Pozniak 2009; Wilkinson et al. 2010; Yee et al. 2003). Little attention has been paid, however, to the varied trajectories that immigrants and refugees follow in their quest for economic integration, making use of their capitals or lack thereof, including their pre-migration class location. Thus, although only one of my participants obtained an immediate independent type of integration (and one in a capitalist location), it was common for most of the youths to undergo diverse employment pathways that included subordinate and secondary experiences.

INDEPENDENT LOCATION. This location offers stable employment, increased job security, higher pay than other market segments, and thus more economic stability. The arrival of youth to this type of economic integration responded to their types of pre- and post-migration capitals (i.e. education, official language knowledge, Canadian work experience), the validation of those capitals in the Canadian employment fields, and more importantly their possession of Canadian social capital. Most of the youths located in this labour market segment belonged to upper or upper-middle classes in Mexico. Some of the habitūs they developed as part of those social classes facilitated their posterior generation of social capital once in Canada. This is significant because the relevance of social capital sometimes even surpassed the possession of education or work experience in opening the doors of independent employment for them. Thus, the overvaluation of social capital as a mechanism to obtain a job despite the possession of 
Canadian or Mexican certified qualifications puts immigrants at a disadvantage. Even if some immigrants come via the economic class and have skills and capitals or acquire more capitals, once in Canada, if they do not have those social connections, it would be more difficult for them to obtain a job.

A second factor that strongly determined the overvaluation of some of my immigrants' capitals in Canada was the expansion of Canadian capital to Mexico and, to a lesser extent, Mexican capital to Canada. Under this context, the possession of cultural capital that fulfill the needs of companies (either in Canada or Mexico) was strongly valued. This also facilitated both the youths' immigration and their later transition to an independent type of economic integration. In this context, Montreal presented a particular case vis-à-vis Ottawa. Despite Quebec's longstanding policy to favour immigration with a French-Québécois character, the presence of global or Anglo economic capital in Montreal, which demands specific cultural capitals, also shaped the socio-cultural integration of immigrants 'independently' of Quebec's assimilation objectives. Because of the type of work needed by Canadian, Mexican, or global companies in Canada, (Mexican) immigrants need not learn or even speak French or socialize with Québécois(es). This constitutes a paradox considering Quebec's political and socio-cultural immigration policies, strongly shaped by global capital imperatives.

Moreover, even if Ottawa is to an extent a bilingual city due to the strong presence of the federal government, and whose linguistic mandate is to be bilingual, I did not find this contradiction present in Ottawa due to the dominance of an English Canadian culture and language there. Indeed, the demand for the English language that I found among Mexican youth in Ottawa is similar to that experienced by Mexican and Colombian youth in metropolitan Vancouver (Hernández-Ramírez 2012). Certainly, as mentioned by some of my respondents, knowledge of French in Ottawa greatly helps to obtain certain jobs in the federal government or some NGOs, and knowledge of Spanish (besides English) in Montreal greatly helps to obtain jobs 
in the customer service area.

However, lack of French knowledge does not impede immigrants from obtaining jobs in Ottawa in the government, NGOs, or other areas. Certainly, there is much less pressure to learn French in Ottawa than, evidently, in Montreal or Gatineau (the latter being the neighbour city across the river from Ottawa that belongs to the province of Quebec). But as Veronis (2015) found among Latin American immigrants who live and work between Ottawa and Gatineau, the demand for French is lower in Ottawa because this language is not usually required for employment purposes. Indeed, “immigrants in Gatineau feel more pressure to become bilingual to access employment since the majority of jobs are in Ontario compared to those immigrants residing in Ottawa, who may more easily obtain employment by speaking English only” (55).

I also found that some youths achieved a certain type of economic integration by extension, namely, through a Canadian partner or a parent sharing their resources with one of my respondents rather than through their own enterprise. Moreover, to the best of my knowledge, this is the first study that explores this type of relationship by extension in a transnational field. A location by extension also functioned in some cases as a springboard for the respondent to achieve an independent or subordinate location due to the economic structure put in place by the other person. However, as mentioned before, several factors are continuously at play to shape immigrants' economic integration, such as in the case of youth located in the subordinate location.

SUBORDINATE LOCATION. The skills required in a subordinate location are basic-tomedium level, and thus the jobs are more routinized, the pay is lower than in the independent location, and the risk of unemployment, particularly during economic depressions, is higher. Most of the youths located in the subordinate location studied or are studying in Canada since $42 \%$ of them arrived as children or teenagers, and thus were incorporated into the Canadian education system from primary school. Thus, among those who are about to acquire postsecondary education, an increase in their Canadian capitals, particularly the education orientation 
they choose and their acquisition of social capital, may assist them in achieving an independent location in the future. Other youth are located in the subordinate location because they had an initial poor insertion in the Canadian labour market, lack social capital that may connect them to various markets, or because their Canadian employers do not recognize their Mexican credentials, even if they obtained credential accreditation. Although some youth in the subordinate location had an independent location in Mexico, this has not helped them once in Canada. Rather, they have had employment trajectories that include secondary and subordinate experiences, such that their immigration resulted in a downward economic integration pathway.

Other factors that led some youth to be located in the subordinate location were being a recent immigrant, having a Mexican degree with limited employability scope in the Canadian field, their sexual orientation, ethnic identity, youthful appearance, and discreet racism. Although the Canadian literature on integration has already uncovered some of these findings (Hiebert and Ley 2003a; McLellan 2004; Pratt 2002, 2010; Pratt et al. 2003; Ticar 2017), the influence of sexual orientation in the immigrants' economic integration has only been explored minimally and requires more attention.

Moreover, contrary to other findings where a young age at arrival offers a premium in the labour market (Yee et al. 2003), I found that some of those who arrived at an early age and accumulated plenty of Canadian capitals (i.e. education, English and French knowledge, and work experience) were able to obtain no more than a subordinate location. Certainly, this finding needs to be contrasted with the general employability outcomes of youth in Canada. But as I also demonstrated, the statistics of employment and unemployment tend to favour non-immigrant, older, and male persons. Moreover, the visible minority condition of some immigrant youth, which sometimes is transformed into an Othering process, cannot be taken out of the equation when exploring immigrant youths' economic integration outcomes. In other cases, age played a determinant role in some of my participants' subordinate locations, since some youth are still too 
young to have post-secondary education and employment experience to achieve an independent type of integration. Rather, they have achieved a subordinate location by extension via their parents and the use of Mexican habitūs.

The cases of younger respondents in the subordinate location also unveiled how the differentiated entry fees demanded by various labour market fields shape the immigrants' households' economic experiences. Having parents with dissimilar backgrounds regarding education and work experience, and unequal possession of social capital in Canada and Mexico, led them to experience disjointed economic integration pathways. These differences were also increased by the effect of gender. This is because it was usually mothers who, following the traditional patriarchal division of household labour in Mexico, were less able to obtain various capitals, such as social capital, before and after having immigrated. Had these mothers had more capitals before and after immigrating, it is possible that they could have achieved a subordinate or even an independent location. Some of these findings partly echo those of other scholars who have analyzed the role of gender in the economic integration of women in Canada (Boyd 1986; Elrick and Lightman 2016; Estable 1986). What this research has usually missed, as I demonstrated in this dissertation, is how individual household members undergo differentiated economic integration experiences at the household level, usually affecting women but also youth.

SECONDARY LOCATION. Other youth are located in a different, secondary position, which has led them to experience constant job insecurity, low pay, and poor working conditions. In this location, employment pathways are usually flat, consisting of secondary jobs only, and if they obtain a subordinate job, my respondents usually go back to work in secondary jobs. Some youths (including those sponsored by marriage and humanitarian streams) are situated in this location because of their initial precarious insertion in the Canadian labour market, a continuation of their pre-migration class location, a limited or restricted possession of social capital in Canada, and their lack of Mexican education and Canadian capital (i.e. post-secondary education, 
knowledge of any official language, a marked accent, and lack of knowledge about the local employment culture).

Among refugees, their lack of official language knowledge originated due to the uncertainty regarding their refugee claim. This uncertainty also led them to experience a crisis or a lack of motivation to study any language immediately after arrival. In other cases, such as those who came via marriage sponsorship, raising young children made them face economic pressures, forced them to immediately join the secondary market, and learn the language 'on-the-go.' Other youths' post-migration conditions also shaped their language acquisition process and consequently limited their ability to obtain a job. These include domestic violence and problems with CIC's determination of partnership sponsorship claims, which did not grant them access to any type of government support, including official language learning support. In other interviewees' cases, lack of Canadian and social capitals, illnesses, and even physical limitations have acted as deterrents to an improved economic integration, furthering a secondary location.

For most of those youths who arrived in their late teens or early twenties and who are in the secondary location, their lack of post-secondary education and their economic impossibility to acquire it once in Canada due to their relative poverty, even years after having immigrated, also collaborated in situating them in that location. This also impacted their possibilities of future social mobility. Indeed, except for two participants, all youth in the secondary location had only finished high school or had some high school credits when they immigrated to Canada.

Although all refugees in this study are located in the secondary type of integration, a common finding in the literature (Cécile, Mekki-Berrada, and Moreau 2001; Hernández 1984; McLellan 2009; Meredith 1992; Sarma-Debnath and Kutty 2006; Smith 1986), there were also two other youths who came via the family class and ended up in the secondary location. They immigrated quite young, are fluent in one of the official languages, have studied in Canada since at least secondary school, and are still located in the secondary type of integration. Even if the 
Canadian literature on economic integration frequently concludes that it is the acquisition of Canadian capital that can lead immigrants to a positive integration (Boudarbat and Grenier 2017; Hiebert 2009; Hiebert and Sherrell 2009), the experiences of these youth reveal the unsatisfactory explanatory power of this argument for those participants.

In these cases, their single parents' economic integration process and capitals, the participants' choice of studies, the devaluation of their capitals by employers, and lack of social capital have mostly collaborated to keep them in the secondary location. Thus, when compared to youth in the independent location, whose post-secondary studies are directly connected to the needs of global or national labour markets and who obtained social capital while studying in Canada for a maximum of three years, these other respondents' possibilities have been quite limited. Another potential explanation for the limited economic prospects of these youths resides in the increasing rate of labour precarization, which chiefly affects those less connected to national, transnational or global circuits of capital, and where certain types of education become redundant.

In many cases, Mexican youth's precarious post-migration class location was only a continuation of their pre-migration class location. However, in contrast to their experiences in Mexico, their poor economic integration in Canada forced them to obtain jobs that exposed them to health and security risks. Their precarious conditions also led most of them to obtain jobs either through private employment agencies or their small personal networks via word-of-mouth, the only capital they could access. These networks, nonetheless, connected them to secondary jobs only, further reproducing their secondary location, what Saskia Sassen (1995) calls spatial structuration. The use of co-ethnic or immigrant social networks that maintain immigrants in an inferior type of economic integration was also found among some Filipinos in Canada by P. Kelly $(2007,2012)$. However, he found that this process occurred among Filipinos located in a pre-migration independent location, who, once in Canada, occupied a subordinate location.

The use of private agencies also increased my respondents' exposure to precarious, hard, 
and sometimes dangerous work. Their labour is thus used by a post-Fordist economic model that uses temporary and casual labour to create high levels of surplus value. This value is then transferred from these workers to Québécois(es) and Latinxs agency owners in Canada, while the risks are left to the workers to deal with, including job insecurity, low wages, lack of benefits, and increased health hazards that impact them and also their families in Canada and Mexico. In addition, working under these conditions further exacerbates immigrants' and refugees' lack of capitals, impeding their generation of other capitals that may help them to obtain better jobs, thus entrenching them in a circuit of precarity, relative poverty, and dependence.

Precarious work is also emmeshed in broader politico-economic relations in Canada, since I found that ethnic ownership of capital also determined the type of relations created inside some workplaces in Montreal. For instance, one of my respondents found that if the owners of the company were Anglo-Canadians, Québécois(es) workers would be assigned to lower employment ranks, followed by other groups such as Latinxs and Arabs in a rigid racialized order. Nonetheless, youth in the secondary location have also shown high levels of resilience and agency when overcoming the many difficult situations they have faced. These have ranged from acquiring Canadian capitals despite undergoing trying illnesses, such as learning one of the official languages, to taking advantage of their job as a conduit to educate the general public about their exploited labour.

\subsection{The Shaping of Transnational Practices by Pre- and Post-Migration Class Locations \\ SOCIO-CULTURAL TRANSNATIONALISM. I found that Mexican youth were engaged in} various forms of transnational practices. This contrasts to other ethnic groups in Canada, such as immigrant women from Hong Kong, who focus their transnational practices on specific arenas, such as the family milieu (Preston et al. 2006). Moreover, pre-migration class location and type of economic integration once in Canada had diverse impacts in shaping these young people's generation and type of engagement with transnational practices. Three of their most frequently 
generated transnational practices focus on sociocultural, economic, and political dimensions. Sociocultural transnationalism, as seen in communication established across borders, unveiled the ways in which youth maintain relationships with people in Mexico or other countries across time and space. All respondents maintain a strong communication with family members and friends making use of social media and other applications, and with a higher frequency than those Latinxs interviewed by Hiebert and Ley (2003b) in Vancouver. This transnational communication responds to their emotional needs for contact and renewed information about the whereabouts of family and friends. However, I also found that many of their non-family social relations deteriorated to the point of disappearance, a not-so-well explored topic in the literature.

A number of factors explain this deterioration. These include a lack of constant visits to Mexico, differences in idiosyncrasies, and overall changes in their habitūs/fields resulting from the immigration process and their contact with other cultures, traditions, and perspectives in Canada. Violence in Mexico also shaped the frequency and type of transnational communication that one respondent developed. Having constant updates about violence in Mexico led this respondent to cut all communication with her family as a form of taking care of her mental health. Moreover, living in other Canadian fields and confronting diverse habitūs led Mexican immigrant youth to experience hysteresis and revaluate some of their previous habitūs, discarding some of their former dispositions around gender, sexuality, and politics. Consequently, hysteresis impacted their pre-migration personal relations and created social distance, despite the facilities offered by communication technology advances. Thus, I found that changes in habitūs (stemming from different, evolving fields in both Mexico and Canada) may not necessarily conduce to the generation of an ampler transnational field from below, as other scholars have found in other settings (Levitt 1998, 2005; Levitt and Lamba-Nieves 2011), but they rather fragment social relations to the point of their disappearance.

ECONOMIC TRANSNATIONALISM. A second transnational practice I found among 
youth was constituted by economic and social support, which assists youth in reinvigorating their social relations across borders. This support was also intimately connected to the generation and reproduction of social capital. This type of transnationalism manifested in the sending of gifts, monetary remittances, or support across borders under three different levels: sporadic, meaningful, and engaged. The level and frequency of economic support sent was determined by the immigrant's type of economic integration, pre- and post-migration class location, type and degree of the relationship established across borders, economic stance at a particular point in time, and specific objectives to be fulfilled.

Moreover, sending support created a transnational circuit of economic and social capital that assisted not only those located in Mexico but also almost half of my respondents in Canada, since the support was bi-directional. Much of the support sent from Canada to Mexico was in the form of monetary remittances, although their objectives and function varied across class locations and types of economic integration. I found that this type of support also departed from the support that other Latin Americans in Canada have sent to their countries of origin, more attuned to assisting political or non-governmental organizations, or to help with development initiatives in Canada and abroad (Chute 2004; Ginieniewicz 2007; Goldring 2006; Goldring and Landolt 2014; Landolt 2007a, 2007b, 2008; Landolt and Goldring 2010; Riaño-Alcalá and Goldring 2006, 2014; San Martín 1998). This economic support also departs from the more regular monetary remittances sent from Canada, particularly by women, to help with daily household expenses, support children, educate younger relatives, or generate small investments (Bernhard et al. 2005; Díaz Barrero 2007; Encalada Grez 2017; Preibisch and Encalada Grez 2013).

The support sent from Mexico to Canada also varied. This included treating some youth with small and occasional gifts such as shoes or a laptop, assisting them in their transition from temporary to permanent resident status (a more long-term economic endeavour), helping them to pay for food or rent, or traveling to Canada to take care of them when ill. The types of economic 
transnational practices that youth engaged in were also shaped by their pre-migration class location and type of economic integration. For instance, I found that many of the MexicanCanadian youth in the independent location do not send transnational support because their family members or friends do not need it. This is also a little-explored arena in migration studies.

Nonetheless, depending on the particularities of the settlement process, even a few of those youth located in the independent integration did not send economic support, even if some family members could have benefited, because they were, for instance, investing economic capital in a business in Canada and did not have surplus capital to send abroad. These circumstances differed from the ones confronted by those youths located in the subordinate and particularly secondary locations, who sent economic support more frequently due to their desire to construct transnational social capital or because family or friends needed the economic support. These latter cases generated expanded (i.e. sporadically) and core (i.e. habitual) forms of transnationalism. Within these two sub-groups, it was also more common to find that economic support was sent from Mexico to Canada, even if the economic cost was higher. This signals how this type of 'reverse' economic transnationalism deals with precarious or emergent circumstances in the immigrants' country of reception, and also creates an emergent transnational safety net. In these cases, however, the generation of economic transnationalism was dependent on the possession of surplus or available economic capital on either side of the border.

Political TransnationalisM. Type of economic integration in Ottawa or Montreal was also important in determining the transnational political involvement of my respondents. Whereas scholarship on transnationalism in the United States and Canada has shown that it is those immigrants who are more educated and better integrated in the country of reception who are more engaged in political (and other types of) transnational activities (Ginieniewicz 2008b; Guarnizo et al. 2003), I rather found the opposite. It was youth in the secondary location living in Montreal, with low levels of education and constituting the "preserve 
of casual labour" (Edwards 2015:66) who were quite engaged in institutionalized and semiinstitutionalized political (trans)national and global activities. Those located in the independent location in both cities, and to a lesser extent those in the subordinate location, had little and mostly institutionalized political forms of participation.

Despite the constant hardship among those in the secondary location in finding jobs and putting bread on the table, their more insecure migration status (i.e. PR and special consideration status) and precarious, low-paid, and hazardous employment, they are nonetheless more engaged with and connected to other people at the local, national, transnational, and even global levels. Traditional explanations found in the literature regarding (lack of) immigrant political involvement (Ginieniewicz 2007, 2008a, 2008b, 2010a) usually do not account for the reasons why my participants situated in the secondary labour market were highly politically involved. For instance, P. Kelly (2007) found that pressing economic commitments among Filipinos in Canada pushed many to take survival-level jobs, cancelling their possibilities of political participation.

I identified a personal closeness and human connection that transmutes into an ethical commitment as an explanation for the development of this transnationalism. This ethical commitment manifests in practices of dissident citizenship and courage, which, at the same time, reflect an active feeling of belonging to Canada, Mexico, and to a global citizenry. The notable political involvement of these youths at various levels also responds to their integration in (subnational) Québécois political fields, where they adopted some of Quebec's habitūs. This sociocultural integration led them to be closely immersed in Quebec's politically active fields when compared to those other immigrants who, despite living in Montreal, do not fully socioculturally integrate in the Québécoise culture.

These youths' location in an independent location in Montreal, which is closely related to global circuits of capital, pulls them away from socialization practices with Québécois(es) and consequently away from other more political forms of engagement. Mexican youth located in the 
secondary location also politically distance themselves from those other immigrants and refugees living in Ottawa in terms of political transnationalism. Among the latter, the influence of living in a smaller Anglo-Canadian capital city, with a high percentage of its population working for various levels of government, education, and technological sectors, and characterized by low levels of politicization, seem to be shaping their political habitūs. Certainly, I found a couple of exceptions among those respondents living in Ottawa and who were highly involved in political transnationalism that focused not only on Mexico's but also Canada's issues. These exceptional cases rather obey to a previous political conscientization in Mexico or the generation of a reactive transnationalism occasioned by experiences of violence and racism in Canada.

Overall, I have shown in this dissertation how the production of sociocultural, economic, and political forms of transnationalism among Mexican immigrant and refugee youth in Ottawa and Montreal are shaped by their pre-migration class locations, type of economic and sociocultural integration, as well as by the expansion of global, Canadian, and to a lesser extent Mexican capital, which in turn creates economic transnational fields between Canada and Mexico. Goldring (2006:199) concluded that "diverse forms of transnationalism associated with the maintenance of family ties over time and space, such as communication with family and friends abroad, the intention to sponsor relatives, migration to Canada based on family and friendship ties, and so forth," have configured a "basis for potential transnational activity" among Latin Americans. This is what Al-Ali (2001) considers to be emerging transnationalism.

My respondents' transnational practices show that diverse sociocultural, economic, and political transnational activities are currently being developed and slowly creating an incipient transnational field from below. It is, then, an emergent form of transnationalism (Al-Ali et al. 2001). In contrast to other ethnic groups in Canada who maintain transnational relationships through family-class migration networks, cultural activities, churches, and community organizations (Amarasingam 2015; Bloemraad 2009; Cheran 2007; Mina 2015; Walton-Roberts 
2003; Wayland 2003), I found that the Mexican youths' development of transnationalism is focused on smaller transnational networks and narrowed social groups. The exception is among those highly involved in political transnationalism in Montreal, who develop local, regional, transnational, and sometimes global connections.

For Mexican transnationalism to keep developing from below, it would necessitate an increase in Mexican migration to the point that there is more of an institutionally developed Mexican community, as has happened in the United States through the establishment of community associations, or in Canada with other 'older' ethnic groups. However, for this to happen, another hurdle that would need to be removed is a certain lack of trust and support among some Mexicans. In addition, an increase in temporary visits of family members and friends from Mexico would also facilitate the increase of social connections and the sharing of habitūs, avoiding the rupture of relationships. Nonetheless, this is something that seems somewhat complicated considering that the CBSA keeps returning Mexican travelers. This occurs either before departing from Mexico, even when Mexicans have previously purchased their airplane tickets and obtained an Electronic Travel Authorization (ETA) (a necessary permit to enter Canada in lieu of a visa) and which is rescinded even a couple of hours before their flights depart (as pointed out by anecdotal evidence on Facebook). Or they are allowed to fly to Canada but then are denied entry by CBSA agents at the port of entry. Thus, only in 2018 , " 1,860 of the rejected passengers were from Romania, followed by Mexico $(1,767)$ and India $(1,080)$ " (Keung 2019).

Other exogenous factors that may further this incipient transnationalism is a steady increase in violence in Mexico or a strong negative economic development. This is because violence or an unstable economy would push more people, particularly those with plenty of capitals, to mainly use Canada's economic class to immigrate. Furthermore, making use of the refugee stream may become even more difficult if proposed changes to the Canada-United States Safe Third Country 
Agreement are realized (see Corrigan 2019; Rehaag 2019). The expansion of Canadian and Mexican capitals in the North American space and their requirement of highly skilled Mexican personnel, supported by the Canadian state, may also further the Mexico-Canada transnational field from above. Overall, an expansion of transnationalism from below and from above may herald a stronger relationship between Mexico and Canada in the future, mainly mediated by economic relations and skilled and semi-skilled migration. This, however, remains to be seen.

\subsection{Contributions of the Research}

Transnationalism is a process whereby immigrants and non-immigrants, embedded in multi-layered and multi-sited social fields, maintain active ties across national borders with other immigrants and non-migrants through participation in economic, political, social, cultural, and/or religious networks and processes (Goldring et al. 2003; Levitt 2001b; Levitt et al. 2003; Levitt and Glick Schiller 2004). Much of the transnationalism literature, however, has focused on analyzing the varying frequency, duration, intensity, strength, impact, formality, and scope of migrants' and non-migrants' transnational practices. And although a handful of scholars have signaled that transnational practices are shaped by a number of factors including immigrants' demographics, social and economic status, and processes of integration in countries of exit and reception (Goldring et al. 2003), the effect of pre- and post-migration class location and economic integration on (youth) transnationalism is still sparse.

My research has thus filled a void in the literature offering a complex account of how transnationalism from below is shaped by immigrants and refugees' pre- and post-migration class location (shaped by age, documented migration status, and gender). Class location, understood in a Bourdieusian sense, broadly refers to a "class of conditions of existence" (Bourdieu 1990b:54). I thus demonstrated how the particular configuration of my respondents' pre-migration class location (i.e. the total sum of their capitals before migrating, differently distributed by gender and age) collaborated in situating them in specific post-migration class locations. 
These locations shaped, in turn, the youths' employment trajectories and consequently the type of economic integration they achieved (i.e. one of an independent, subordinate, or secondary type). Subsequently, each type of economic integration and the effect of type and strength of social relations they maintained between Canada and Mexico differently fashioned the type, frequency, and extent of their transnational practices. My study also demonstrated how traditional research findings regarding the effect of social location in the development of transnationalism (e.g. education level, time spent in the country of reception, etc.) did not neatly apply to my respondents, for which alternate explanations needed to be sought, such as an ethics of political courage and dissent regarding political activism.

Class location, however, includes not only individual but also institutional and structural factors. My research thus illuminated how in the Mexican youths' processes of immigration, those factors have included Canada's immigration policies, which have privileged economic over family and humanitarian immigration since the 1960's, and the expansion of Canadian, Mexican, and global capital. Other factors include considerable tourism of Canadians in Mexico and Central America, which has facilitated the contact between Mexicans and Canadians and the development of personal relationships, increased multifaceted forms of insecurity and violence in Mexico (along with the Mexican state-criminality symbiosis), and historical factors derived from the close relationship between Mexico and the United States, which contrasts with the on-again-and-offagain relationship between Canada and Mexico. These structural factors have been constituted, then, as push and pull factors at different points in the life trajectories of my respondents.

The comparison of economic integration among immigrants and refugees living in a small, predominantly Anglo-Canadian (capital) city vis-à-vis those living in a sizable French-Canadian city (Ottawa and Montreal respectively) also offered an interesting insight. This location comparison illuminated the effects that the expansion and accumulation of national and global capital have in shaping (trans)national and sub-national models of immigration and integration in 
Canada. Thus, in Quebec's case, immigration is not only promoted as an economic strategy to attract a qualified labour force. It is also as a political strategy to foster socio-cultural and identity components seen as defining the Québécoise culture (e.g. knowledge of French and allegiance to Quebec) relative to a broader geopolitical stance regarding Anglo-Canada. Nonetheless, Quebec's political intention is trumped by the presence of global companies that seek highly qualified immigrants, foster an English-oriented environment, and lead immigrants to not relate to or interact much with the Québécoise culture. Thus, although Quebec also seeks investments as part of its economic development agenda, the Anglo-orientation of capital diverges from Quebec's political stance.

My research also contributed to the understanding of the little-explored arena of immigration motivations, types of economic integration, and transnational practices of skilled immigrants. As Gabriel and Macdonald (2004:68) contend, "[i]n the North American context, much of the debate on international migration and continental regionalization has focused on the documented and undocumented movement of 'low- skilled' workers from Mexico to the United States." The Canadian and American emphasis on low-skilled workers in the literature has not assisted us in having a better understanding of the economic integration experiences of (Mexican) skilled immigrants and the extent to which they generate transnational practices and ties in the North American region.

Moreover, as Goldring and Krishnamurti (2007) contend, since the United States and other European countries have different immigration contexts (i.e. "not only in terms of policies, but also in terms of 'who gets in' and under what conditions" [21]), a nuanced understanding of who gets in and under what conditions in Canada can help us to better understand the differentiated pathways of economic incorporation and transnationalism generated in the Canadian context. My research then, while including and comparing diverse immigration statuses and individuals' backgrounds in the immigration process (i.e. people who immigrated through the economic, 
family, or humanitarian classes with varied skills obtained in Mexico and/or Canada), illuminated the differences created around immigration, economic integration, and transnationalism in two different Canadian cities (Ottawa and Montreal). These differences are shaped by pre-migration class location, entry class, the various capitals possessed by immigrants and refugees (i.e. economic, cultural, and social capitals), the diverse transnational fields created between Mexico and Canada, and in some cases gender and sexuality.

My qualitative methodology also offered the possibility of obtaining a rich description of economic integration processes occurring among Mexicans in Canada that other more quantitative instruments do not offer in the Canadian context. For example, Statistics Canada's Labour Force Survey, a monthly survey which measures the state of the Canadian labour market since 1945, does not consider entry class, for which it is difficult to determine how immigrants and refugees do in economic terms (see Hira-Friesen 2018b). Similarly, the Longitudinal Survey of Immigrants to Canada, "a survey designed to provide information on how new immigrants adjust to life in Canada and to understand the factors that can help or hinder this adjustment" (Statistics Canada 2016), only run from 2001 to 2002, with a follow-up in 2003 and 2005. My research also contributes to the limited but growing research on Latin Americans and in particular Mexican economic integration and transnationalism in Canada, broadening the scope of analysis to the particular ways in which different types of economic integration shape this transnationalism. This is particularly true considering that research on transnationalism started with and is still strongly focused on Latin American and Caribbean people in the United States (even if some research has also been extended to Europe, Africa, and South East Asia).

This emphasis on transnational analyses conducted mainly in the United States, as Goldring (2006:183) mentions, is due to the "geographic proximity of Mexico and other Latin American and Caribbean countries, the comparatively high proportion of immigrants from this region in the United States, and the long and well-documented history of economic integration 
and international migration in the hemisphere." But this is also because of long-standing US political, economic and military interventions in the region, which have produced not only regional displacements but also immigration to the United States. As a middle power in the international scene, and considering its on-again-and-off-again relationship with the Americas, Canada has fewer although growing regional connections. My research thus shines some light on a particular moment in the history of Canada, where transnational connections from above and below are increasingly being developed regarding a Latin American country.

Moreover, since transnationalism has largely been analyzed as if generation is unimportant and youth have usually been understood as "by-products of the parents, families or households" (LeFrançois 2013:1), another scholarly contribution is the analysis of the particular forms of agency among youth and the roles they play in the immigration and transnational fields. My comparison of different immigrant and refugee groups in different cities also unveiled how some differences are created in terms of economic integration, location, and the generation of transnational practices, although in other cases, such as those of people situated in the independent integration, location was not that relevant. At the sub-national level, I also showed how some Québécois(es)'s high levels of politicization were also shared and, in some cases, adopted by some youth living in Montreal as part of a new habitus acquisition. In other cases, they found Montreal to be more of a prolific springboard from which to continue the political activism they had begun in Mexico. This finding also allowed me to provide a nuanced explanation of how those immigrants with a more precarious immigration status and economic integration were highly involved in local, transnational, and global political activities. It was their pre- and post-migration class location that led them to develop dissident citizenship practices, showing their profound, ethical commitment to others and their expanded feelings of (Canadian, transnational, and global) belonging.

Finally, although my research focused on the correlation between types of economic integration and the generation of multiple forms of transnational practices between Canada and 
Mexico, and sometimes other countries, I did not include in my methodology a measurement method to determine the frequency with which youth developed each of those practices. Doing so would have required a methodology more attuned to a quantitative or mixed methods model, along with increased research resources. Another fruitful avenue to keep developing transnational studies in Canada would be to focus on the extent to which transnational practices are developed as part of households' dynamics and the roles that each member plays considering their particular type of economic integration. As I demonstrated with some of my family economic migration cases, members of a single household, based on age at arrival, pre-migration class location, and even gendered pre-migration distribution of capitals developed different types of household dynamics and ways in which they confronted settlement and economic integration processes in Canada. This, in turn, shaped the types and degree to which transnational practices were created inside the households and their impact on the creation of broader transnational fields. Finally, a qualitative longitudinal study could also provide richer insights as to how the creation of transnational practices evolve based on how differences in economic integration develop at individual and household-based levels. 


\section{Appendix A}

\section{INTERVIEW GUIDE}

1. Demographics:

-Age Gender $\mathrm{M}$ F___ Other Birthplace: country

city/town

-Maximum education level (if employed) Occupation(s)

-Before migrating to Canada where did you live?

\section{Immigration and Settlement Processes}

2. Context of departure

a. How is it that you and/or your family decided to immigrate to Canada?

i. When did you first come to Canada?

ii. Was Canada your first choice (if not, which country was your first choice)?

iii. Did you have previous knowledge about Canada before you immigrated?

iv. Did you feel that you were losing certain things in coming to Canada? (i.e. cultural, social, economic, religious, weather, landscapes, etc.).

v. Did you think you were gaining certain benefits? Which ones?

b. What did you do before immigrating to Canada (i.e. school, work, not working/studying, at home)?

c. How did you end up coming to Ottawa or Montreal?

d. Under which immigration status did you or your family immigrate (e.g. independent, employment-related, student visa, refugee, etc.)

\section{Integration Processes}

3. Context of arrival

a. After you immigrated:

i. What was your experience regarding...? a) housing, b) mobility in the city, c) values and traditions, d) being young, e) other relevant information for the interviewee's case study.

ii. What level of English/French did you arrive with in Canada?

1. (For how long) did you take ESL/FSL classes (if any)?

2. How easy or difficult has it been for you to learn English and/or French?

3. By how much do you feel you improved your proficiency?

4. How often do you speak Spanish/French/English? Where? With whom? Under which circumstances?

iii. Did you receive any support or assistance from anyone in helping you/your family to settle in Ottawa or Montreal? (explore government agencies, non-governmental organizations, Latin American groups or organizations) What kind of support did you receive? Were there any conditions attached?

\section{Integration processes}

a. (If applicable) What have your experiences been in terms of accessing education in Montreal or Ottawa? (contexts, processes, funding, networks). 
b. What have your experiences been in terms of accessing employment in Montreal or Ottawa? (contexts, processes, types of jobs, wages, networks).

i. How did you learn about the particularities of the Canadian education/work culture (i.e. students' roles at school, how to apply for a job, how to conduct oneself in a work environment, etc.).

ii. Do you consider that your English/French language ability is sufficiently fluent to attend or progress in (post)secondary education or get a desirable job?

c. Have you had any difficulties as a Latin/Mexican person in getting access to the education/employment levels you previously had and/or want? (Which type of job/education is that one? Please elaborate).

i. What were the reasons for the difficulties or barriers you faced? (e.g. Credential recognition? Language? Accent? Discrimination based on your skin colour/ethnicity? Lack of economic capital? Lack of information/knowledge? etc.).

ii. Have you been able to surmount those difficulties? How?

d. You mentioned that you finished , would you like to continue studying?

i. What are the reasons for that?

ii. How do you plan to fund your education?

iii. Are there any strategies or arrangements you need to implement for you to keep studying?

iv. Do you anticipate any difficulties for this to happen?

e. In five years, where do you think you will be as far as jobs/the labour market are concerned?

\section{Identity}

\section{Identities/Ethnicity/Race}

a. How do you self-identify in terms of ethnicity? (i.e. as a Mexican, Mexican-Canadian, Latinx, Quebecois(e), Hispanic, Canadian, Indigenous person, etc.).

i. Do you think that your identity changes depending on your location? (i.e. being in Mexico or Ottawa or Montreal, being at school, the workplace, church, etc.).

b. How do you self-identify in terms of skin colour?

i. Would your answer be different had you stayed in Mexico?

c. How do you feel about living in a country with diverse cultures and ethnic groups?

\section{Belonging}

a. In which area of life do you feel most integrated? And in which area do you feel most excluded? (i.e. employment, education, Canadian society, Latinx community, church, friends, etc.).

i. On a scale of 1 to 4 , where 1 is mostly integrated and 4 mostly excluded, where would you see yourself in each of the areas you mentioned? (explore other potential areas not mentioned):

\begin{tabular}{|c|c|c|c|}
\hline 1 & 2 & 3 & 4 \\
\hline $\begin{array}{c}\text { Mostly } \\
\text { integrated }\end{array}$ & $\begin{array}{c}\text { Fairly well } \\
\text { integrated }\end{array}$ & $\begin{array}{c}\text { Not very } \\
\text { well } \\
\text { integrated }\end{array}$ & $\begin{array}{c}\text { Mostly } \\
\text { excluded }\end{array}$ \\
\hline
\end{tabular}


b. Have you experienced discrimination in Ottawa or Montreal? Can you please tell me about the circumstances?

i. (In case of a positive answer) What was your reaction? Did you take any action (e.g. did you complain or file a grievance)? Did you get any support (and from whom) in dealing with this discrimination?

c. How often do you go back to Mexico?

i. What are the main reasons why you go back to Mexico? (e.g. family and/or friends visits; because you have property or businesses there, holidays, activism, etc.).

ii. What length of time are your stays in Mexico?

iii. Have you ever thought about going back to live in Mexico?

iv. Do you intend to retire there?

d. Which values and traditions have you/your family maintained that you would identify as

Mexican? (e.g. national festivities, family norms, gender norms, close-knit relationships, etc.)

i. Which values/traditions have you/your family abandoned, rejected or changed (negotiated)? (e.g. changes in ways of seeing the world, cultural tastes, women's role, sexual identities, etc.).

e. Do you feel you are part of an ethnic community or group in Ottawa or Montreal?

f. Do you belong to or regularly attend the events of any community or organization? Please elaborate.

\section{Transnational practices}

7. Non-political transnational practices

a. How often and in which ways do you maintain contact with a) family members, b) friends, c) other people in Mexico? Please elaborate

i. Do you/your family share ideas with your family members/friends in Mexico that may oppose or differ from the ones they have, for instance regarding family, gender or sexuality norms, close-knit relationships, etc.? Please elaborate.

b. Do you make efforts to keep up with Mexican culture (e.g. food, music, art exhibits, dance, films, etc.)? Please elaborate.

c. Do you or your family send money (monetary remittances) or physical goods to Mexico?

i. Reasons? (e.g. are you supporting any of your family, relatives, friends, neighbors in Mexico)?

ii. To whom do you send money or goods and how often?

b. Do any of your family members or friends in Mexico send you money or goods? Please elaborate.

i. Do they share ideas with you that may differ from or oppose the ones you currently have or have acquired while in Canada, for instance regarding family, gender or sexuality norms, close-knit relationships, etc.? Please elaborate.

c. Do you think that when you/your family return to your community(ies) in Mexico you have an impact on changing how your family and friends see the world? (e.g. cultural tastes, women's role, sexual identities, etc.).

i. Do you feel that money sent back home has made a difference to your family/friends and communities? 
ii. Do you perceive that your family/friends/community regard you in a different way after you immigrated? Please elaborate

8. Political transnational practices

a. Can you tell me if you have taken part in any political activities in Canada related to Mexico and/or Canada/the world? Please elaborate.

i. Are there particular causes or issues that you actively support?

b. (If applicable) How is it that you decided to take part in political activism in Canada?

i. Since when?

c. How often do you:

i. Read newspapers? (Are they Mexican, Canadian or other?)

ii. Participate in demonstrations, political campaigns, and/or rallies?

iii. Raise funds for causes?

iv. Lobby host and local governments regarding Canadian, Latin American, Mexican and/or world or other issues?

v. Engage in online activism?

vi. Participate in activist groups?

d. Have you voted in Canadian elections? (please elaborate)

i. Have you voted in Mexican elections since you arrived in Canada? Why did you decide to vote?

e. Have you participated in the \#YoSoy132 and/or Ayotzinapa social movements in Ottawa/Montreal (or other movements)? How? Please elaborate (e.g. attending meetings, writing letters to government authorities or departments, going to demonstrations, doing online activism, keeping or contributing to political blogs, etc.)

f. How does your participation in these activities connect you to Mexico?

i. How frequently do you engage in these activities?

g. What kind of difficulties have you experienced in doing political activism in Canada?

\section{Youth}

a. Would you say that being a young person or "youth" shapes your experiences in Ottawa/Montreal/Mexico in particular ways? (please elaborate)

b. Do you think that your role as a young person is different in Mexico than in Canada? Has it changed due to immigration?

i. If you were to go back to Mexico, would you "know" how to be a young/adult person there in terms of work/education/culture/politics?

c. What kind of opportunities/disadvantages do young people like you face in Ottawa/ Montreal/Canada/Mexico?

Is there anything else that you consider important in your life experience and about being Mexican in Canada that you would like to mention? 


\section{References}

37th Parliament. Immigration and Refugee Protection Act, 5665Justice Laws Website (2015). Canada. Retrieved from http://laws-lois.justice.gc.ca/eng/acts/I-2.5/page-1.html

42nd Parliament. (2016). Temporary Foreign Worker Program. Report of the Standing Committee on Human Resources, Skills and Social Development and the Status of Persons with Disabilities. Ottawa.

Abogado, A. (2014). Mexican refugee claimants: Cheating the system? University of British Columbia. Retrieved from https://open.library.ubc.ca/cIRcle/collections/ubctheses/24/items/1.0103616

Abramovici, P. (2001, August). Operation Condor explained. Latin America: The 30 years' dirty war. Le Monde Diplomatique. Retrieved from https://mondediplo.com/2001/08/12condor

Abu-Laban, Y. (1998). Keeping 'em out: Gender, race and class biases in Canadian immigration policy. In V. Strong-Boag, S. Grace, A. Eisenberg, \& J. Anderson (Eds.), Painting the maple: Essays on race, gender and the construction of Canada (pp. 69-82). Vancouver: UBC Press.

Adamuti-Trache, M., Anisef, P., \& Sweet, R. (2018). Differences in language proficiency and learning strategies among immigrant women to Canada. Journal of Language, Identity \& Education, 17(1), 16-33.

Agnew, V. (2009). Racialized migrant women in Canada: Essays on health, violence and equity. Toronto: University of Toronto Press.

Aguiar, L. L. M. (2006). Janitors and sweatshop citizenship in Canada. In L. L. M. Aguiar \& A. Herod (Eds.), The dirty work of neoliberalism. Cleaners in the global economy (pp. 16-36). Malden, Oxford, Carlton: Blackwell Publishing.

Aguirre Botello, M. (2017). Súper tabla Bicentenario México 1810-2016. Retrieved April 5, 2017, from http://www.mexicomaxico.org/Voto/super.htm

Al-Ali, N., Black, R., \& Koser, K. (2001). The limits to "transnationalism": Bosnian and Eritrean refugees in Europe as emerging transnational communities. Ethnic and Racial Studies, 24(4), 578-600.

Alarcón, R. (2002). The development of home town associations in the United States and the use of social remittances in Mexico. Manuscript, Tijuana, Mexico: El Colegio de la Frontera Norte. Retrieved from https://s3.amazonaws.com/ssrccdn1/crmuploads/new_publication_3/\%7B9A85A432-3555-DE11-AFAC001CC477EC70\%7D.pdf

Alarcón, R. (2006). Hacia la construcción de una política de emigración en México. In C. González Gutiérrez (Ed.), Relaciones Estado-diáspora: aproximaciones desde cuatro continentes (pp. 157-179). México: Miguel Ángel Porrúa.

Alba, R., \& Nee, V. (1999). Rethinking assimilation theory for a new era of immigration. In C. Hirschman, P. Kasinitz, \& J. DeWind (Eds.), The handbook of international migration: The American experience (pp. 137-160). New York: Russell Sage Foundation.

Alba, R., \& Nee, V. (2003). Remaking the American mainstream: Assimilation and the new immigration. Cambridge, Mass.: Harvard University Press.

Alberta. (2019). Alberta Mexico Office. Retrieved February 15, 2019, from https://investalberta.ca/international-offices/mexico/

Alonso, L. F. (2016). Texas trial sheds light on Zetas' brutal reign in Mexico. Retrieved May 22, 2017, from http://www.insightcrime.org/news-briefs/zeta-leader-stands-trial-in-texas Amarasingam, A. (2015). Pain, pride, and politics: Social movement activism and the Sri 
Lankan Tamil diaspora in Canada. Athens, Ga.: The University of Georgia Press.

Anderson, B. (2016). Imagined communities: Reflections on the origin and spread of nationalism (Revised ed). London: Verso.

Andersson, P., \& Guo, S. (2009). Governing through non/recognition: The missing "R" in the PLAR for immigrant professionals in Canada and Sweden. International Journal of Lifelong Education, 28(4), 423-437.

Anisef, P., Brown, R. S., Phythian, K., Sweet, R., \& Walters, D. (2008). Early school leaving among immigrants in Toronto secondary schools (CERIS Working Paper Series No. 67). Toronto.

Aragón, M. (2017). "The Mexican" and "The cancer in the south": Discourses of race, nation and anti-blackness in early twentieth-century debates on Mexican immigration.

Immigrants \& Minorities. Historical Studies in Ethnicity, Migration and Diaspora, 35(1), 59-77.

Archibold, R. C., \& Schmitt, E. (2012, August 28). Americans shot in Mexico were C.I.A. operatives aiding in drug war. The New York Times. Mexico City. Retrieved from http://www.nytimes.com/2012/08/29/world/americas/americans-shot-in-mexico-were-ciaoperatives.html

Armony, V. (2014). Latin American communities in Canada: Trends in diversity and integration. Canadian Ethnic Studies, 46(3), 7-34.

Armony, V., Barriga, M., \& Schugurensky, D. (2004). Citizenship learning and political participation: The experience of Latin American immigrants in Canada. Canadian Journal of Latin American and Caribbean Studies, 29(57-58), 17-38.

Article 19, R3D, S. (2017). Gobierno espía. Vigilancia sistemática a periodistas y defensores de derechos humanos en México. Ciudad de México. Retrieved from https://r3d.mx/gobiernoespia/

Auditoría Superior de la Federación. (2017a). Evaluación núm. 1579-DE "Política pública de minería." México. Retrieved from https://www.asf.gob.mx/Trans/Informes/IR2015i/Documentos/Auditorias/2015_1579_a.p df

Auditoría Superior de la Federación. (2017b). Recaudación y aplicación de los derechos mineros. Auditoría financiera y de cumplimiento: 15-5-06E00-02-0085. Retrieved November 1, 2018, from https://www.asf.gob.mx/Trans/Informes/IR2015i/Documentos/Auditorias/2015_0085_a.p df

Balderas, O. (2016). Sobrevivió a 7 años como esclava sexual de Los Zetas y Cártel del Golfo, la historia de Daniela. Vanguardia. Ciudad de México. Retrieved from

http://www.vanguardia.com.mx/articulo/sobrevivio-7-anos-como-esclava-sexual-de-loszetas-y-cartel-del-golfo-la-historia-de

Balderas, O., \& Janowitz, N. (2016). Secretos de un jefe de Los Zetas: el gobierno nos abrió la puerta y hoy pacta con otro cártel. Vice News. Retrieved from

https://news.vice.com/es/article/secretos-jefe-los-zetas-gobierno-abrio-puerta-pacta-otrocartel

Balderrama, F. E., \& Rodríguez, R. (2006). Decade of betrayal: Mexican repatriation in the 1930s (Revised). Albuquerque: University of New Mexico Press.

Baluja, T. (2012, February 16). Tories unveil bill to thwart "bogus" refugees. The Globe and Mail. Ottawa. Retrieved from https://www.theglobeandmail.com/news/politics/toriesunveil-bill-to-thwart-bogus-refugees/article546604/

Banerjee, R. (2009). Income growth of new immigrants in Canada: Evidence from the Survey of Labour and Income Dynamics. Relations Industrielles, 64(3), 466-488. 
Bangarth, S. (2015). Canada's complicated history of refugee reception. Retrieved December 18, 2015, from http://activehistory.ca/2015/09/canadas-complicated-history-of-refugeereception/comment-page-1/

Barker, F. (2010). Learning to be a majority: Negotiating immigration, integration and national membership in Quebec. Political Science, 62(1), 11-36.

Barney, D. (2012). The truth of le printemps érable. Theory \& Event, 15(3).

Basch, L., Glick Schiller, N., \& Szanton Blanc, C. (1994). Nations unbound: Transnational projects, postcolonial predicaments, and deterritorialized nation-states. Abingdon, Oxfordshire: Taylor \& Francis.

Basok, T. (1999). Free to be unfree: Mexican guest workers in Canada. Labour, Capital and Society, 32(2), 192-221.

Basok, T. (2000a). He came, he saw, he... stayed. Guest worker programs and the issue of nonreturn. International Migration, 38(2), 215-238.

Basok, T. (2000b). Obstacles to productive investment: Mexican farm workers in Canada. International Migration Review, 34(1), 79-97.

Basok, T. (2002). Tortillas and tomatoes. Mexican transmigrant harvesters in Canada. Montréal and Kingston: McGill-Queen's Press.

Basok, T. (2003). Mexican seasonal migration to Canada and development: A communitybased comparison. International Migration, 41(2), 3-25.

Basok, T. (2004). Human rights and citizenship: The case of Mexican migrants in Canada. Citizenship Studies, 8(1), 47-64.

Bauböck, R. (2003). Towards a political theory of migrant transnationalism. International Migration Review, 37(3), 700-723.

BC Ministry of Justice. (2014). Findings and recommendations as a result of the Coroner's Inquest pursuant to Section 38 of the Coroners Act into the death of Vega Jiménez Lucía Dominga. Retrieved April 20, 2017, from http://www2.gov.bc.ca/assets/gov/birthadoption-death-marriage-and-divorce/deaths/coroners-service/inquest/2014/vegajimenez-lucia-dominga-2013-0380-0004-verdict.pdf

Beaudoin, J., Danch, J., \& Reehag, S. (2015). No refuge: Hungarian Romani refugee claimants in Canada (Legal Studies Research Paper Series No. 12). Toronto. Retrieved from https://papers.ssrn.com/sol3/papers.cfm?abstract_id=2588058

Beausoleil, J. (1998). Le travail d'établissement des réfugiés salvadoriens à Montréal. Université de Montréal.

Beausoleil, J. (2001). Travailler pour s'établir. Les expériences des réfugiés salvadoriens à Montréal. Les Cahiers Du Gres (Groupe de Recherche Ethnicité et Société), 2(1), 7-27.

Becerril, O. (2007). Transnational work and the gendered politics of labour: A study of male and female Mexican migrant farm workers in Canada. In L. Goldring \& S. Krishnamurti (Eds.), Organizing the transnational: Labour, politics, and social change (pp. 157-172). Vancouver, Toronto: UBC Press.

Becker, A. (2009). New migrant class flees Mexican drug war. Retrieved June 20, 2018, from https://www.revealnews.org/article/new-migrant-class-flees-mexican-drug-war/

Belmont, J. A. (2018). Equipo de AMLO se reúne con funcionarios de Canadá. Milenio. México. Retrieved from http://www.milenio.com/politica/equipo-de-amlo-se-reune-confuncionarios-de-canada

Bennett, B. (2014, April 1). High deportation figures are misleading. Los Angeles Times. Los Angeles. Retrieved from http://www.latimes.com/nation/la-na-obama-deportations20140402-story.html

Berdichewsky, B. (1985). Una nueva comunidad étnica: Los Latinoamericanos en la Colombia Británica, Canadá. Vancouver: Ediciones Futuro. 
Berdichewsky, B. (1990). La presencia hispánica en la Colombia Británica: Una visión histórica. Vancouver: Ediciones Futuro.

Berdichewsky, B. (2007). Latin American's integration into Canadian society in B.C. Vancouver: Canadian Hispanic Congress.

Bernhard, J. K., Landolt, P., \& Goldring, L. (2005). Transnational, multi-local motherhood: Experiences of separation and reunification among Latin American families in Canada (CERIS Working Paper No. 43). Toronto.

Bernhard, J. K., Landolt, P., \& Goldring, L. (2008). Transnationalizing families: Canadian immigration policy and the spatial fragmentation of care-giving among Latin American newcomers. International Migration, 47(2), 3-31.

Bernier, J., Dupuis, M.-J., Fontaine, L. L., \& Vultur, M. (2014). Les salariés d'agence de travail temporaire: Conditions de travail et pratiques des agences. Montréal.

Beserra, B. (2003). Brazilian immigrants in the United States: Cultural imperialism and social class. New York: LFB Scholarly Publishing.

Best, A. (2011). Youth identity formation: Contemporary identity work. Sociology Compas, 5(10), 908-922.

Betts, A. (2010). Survival migration: A new protection framework. Global Governance, 16(3), 361-382.

Bhattacharjee, K. (2003). The Ontario safe schools act. School discipline and discrimination. Research Report. Ontario Human Rights Commission.

Biles, J., \& Lafrance, L. (2009). Why identities matter: The critical importance of outcomes for first and second generation children and youth. In Multiple diversities: Child/youth identity and life outcomes. Toronto.

Black, J. H. (2011). Immigrant and minority political incorporation in Canada: A review with some reflections on Canadian-American comparison possibilities. American Behavioral Scientist, 55(9), 1160-1188.

Black, J. H., Niemi, R. G., \& Powell, G. B. (1987). Age, resistance, and political learning in a new environment: The case of Canadian immigrants. Comparative Politics, 20(1), 73-84.

Bloemraad, I. (2009). Invisible no more? Citizenship and politics among Portuguese Canadians. In C. Teixeira \& V. M. P. Da Rosa (Eds.), The Portuguese in Canada: Diasporic challenges and adjustment (2nd ed., pp. 161-188). Toronto, Buffalo, London: University of Toronto Press.

Bocking, P. (2012). Canadian mining and labour struggles in Mexico: The challenges of union organizing and the weaknesses of corporate social responsibility. McMaster University. Retrieved from https://macsphere.mcmaster.ca/handle/11375/12650

Bonilla Castro, V. E. (2014). El retorno de población desplazada en contexto con el conflicto armado y los actores en Colombia. Sociedad y Discurso, (26), 105-125. Retrieved from https://journals.aau.dk/index.php/sd/article/view/1095

Bonisteel, J. (2010). Ministerial influence at the Canadian Immigration and Refugee Board: The case for institutional bias. Refuge, 27(1), 103-109.

Boudarbat, B., \& Grenier, G. (2017). Immigration in Quebec: Labour market integration and contribution to economic growth. Canadian Ethnic Studies, 49(2), 13-32.

Bourdieu, P. (1978). La « jeunesse » n'est qu'un mot. In A.-M. Métailié \& J.-M. Thiveaud (Eds.), Les jeunes et le premier emploi (pp. 520-530). Paris: Association des âges.

Retrieved from http://www.hommemoderne.org/societe/socio/bourdieu/questions/jeuness.html

Bourdieu, P. (1983). The forms of capital. In S. J. Ball (Ed.), The Routledge Falmer reader in Sociology of Education (pp. 15-29). New York: Routledge Falmer.

Bourdieu, P. (1984). Distinction: A social critique of the judgment of taste. Cambridge, MA: 
Harvard University Press.

Bourdieu, P. (1990a). In other words. Essays towards a reflexive Sociology. Stanford, Calif.: Stanford University Press.

Bourdieu, P. (1990b). The logic of practice. Stanford: Stanford University Press.

Bourdieu, P. (1993). Sociology in question. Trowbridge: Sage Publications.

Bourdieu, P. (2001). Masculine domination. Stanford: Stanford University Press.

Boyd, M. (1984). At a disadvantage: The occupational attainments of foreign born women in Canada. International Migration Review, 18(4), 1091-1119.

Boyd, M. (1986). Immigrant Women in Canada. In R. J. Simon \& C. Brettell (Eds.), International migration: The female experience (pp. 45-61). Totowa, New Jersey: Rowman and Allanheld Publishers.

Boyd, M. (1990). Immigrant women: Socioeconomic inequalities and policy issues. In S. S. Halli, F. Trovato, \& L. Driedger (Eds.), Ethnic demography: Canadian immigrant, racial and cultural variations (pp. 275-296). Ottawa: Carleton University Press.

Boyd, M. (1992). Gender, visible minority, and immigrant earnings inequality: Reassessing an employment equity premise. In V. Satzewich (Ed.), Deconstructing a nation: Inmigration, multiculturalism and racism in '90s Canada (pp. 279-322). Halifax: Fernwood.

Boyd, M. (1997). Migration policy, female dependency, and family membership: Canada and Germany. In P. Evans \& G. Wekerle (Eds.), Women and the Canadian welfare state: Challenges and change (pp. 142-169). Toronto: University of Toronto Press.

Boyd, M., \& Nowak, J. (2013). A gender-blind approach in Canadian refugee processes. Mexican female claimants in the new refugee narrative. In M. Schrover \& D. M. Moloney (Eds.), Gender, migration and categorisation: Making distinctions between migrants in Western countries, 1945-2010 (pp. 105-125). Amsterdam: Amsterdam University Press.

Boyd, M., \& Pikkov, D. (2005). Gendering migration, livelihood and entitlements: Migrant women in Canada and the United States. Switzerland.

Brown, S. (2016). The instrumentalization of foreign aid under the Harper government. Studies in Political Economy, 97(1), 18-36.

Brown, T. (2012). Here and there: Hispanic heritage in Toronto. Retrieved February 5, 2018, from http://heritagetoronto.org/here-and-there-hispanic-heritage-in-toronto/

Brownell, P. (2017). Employer sanctions and the wages of Mexican immigrants. The Russell Sage Foundation Journal of the Social Sciences, 3(4), 70-96.

Burgmann, T. (2004, January 10). Lucía Vega Jiménez: Timeline of a tragedy. Vancouver Sun. Vancouver. Retrieved from http://www.vancouversun.com/health/Lucia+Vega+Jimenez+Timeline+tragedy/1025373 7/story.html

Burgueño, K. (2005). La migración latinoamericana en Québec. Revista Mexicana de Estudios Canadienses (Nueva Época), (9), 95-113.

Cachón, M. F. (2013). Embodied cartographies of Mexican-Canadian transnationalism. University of Windsor.

CAIR. (2011). Agricultural Fatalities in Canada 1990-2008. Edmonton. Retrieved from http://www.cair-sbac.ca/wp-content/uploads/2012/03/National-Report-1990-2008-FULLREPORT-FINAL-EN.pdf

Calgary Herald. (2000, June 6). Canadians don't want HIV-positive immigrants: Burden on health care too great, study says. Calgary Herald, p. A4. Calgary. Retrieved from http://search.proquest.com/docview/244805657

Calliste, A. (1993). Women of exceptional merit: Immigration of Caribbean nurses to Canada. Canadian Journal of Women and the Law, 6(1), 85-102. 
Calliste, A. (2000). Nurses and porters: Racism, sexism and resistance in segmented labour markets. In A. Calliste \& G. J. Sefa Dei (Eds.), Anti-racist feminism: Critical race and gender studies (pp. 143-164). Halifax: Fernwood.

Calva Sánchez, L. E., \& Alarcón, R. (2015). La integración laboral precaria de los migrantes mexicanos calificados en Estados Unidos al inicio del siglo XXI. Papeles de Población, 21(83), 9-39.

Canada. (1968). Immigration statistics. Ottawa. Retrieved from http://epe.lacbac.gc.ca/100/202/301/immigration_statistics-ef/mp22-1_1968.pdf

Canada. (1969). Immigration statistics. Ottawa. Retrieved from http://epe.lacbac.gc.ca/100/202/301/immigration_statistics-ef/mp22-1_1969.pdf

Canada. (1970). Immigration statistics. Ottawa. Retrieved from http://epe.lacbac.gc.ca/100/202/301/immigration_statistics-ef/mp22-1_1970.pdf

Canada. (2008). Canada Year Book historical collection by year. Retrieved May 25, 2017, from https://www66.statcan.gc.ca/acyb_000-eng.htm

Canada. Protecting Canada's Immigration System Act (2012). Ottawa: House of Commons. Retrieved from http://laws-lois.justice.gc.ca/PDF/2012_17.pdf

Canada. Instructions for managing certain permanent resident applications in the Economic Class (2014). Ottawa: Minister of Citizenship and Immigration. Retrieved from http://www.gazette.gc.ca/rp-pr/p1/2014/2014-12-01-x10/html/extra10-eng.html

Canada. (2015). Overhauling the Temporary Foreign Worker Program. Putting Canadians first. Gatineau. Retrieved from https://www.canada.ca/content/dam/canada/employmentsocial-

development/migration/documents/assets/portfolio/docs/en/foreign_workers/employers/o verhauling_TFW.pdf

Canada. (2016). Canada to lift visa requirements for Mexico. Retrieved July 1, 2016, from https://pm.gc.ca/eng/news/2016/06/28/canada-lift-visa-requirements-mexico

Canada. (2017a). Continuous Journey Regulation, 1908. Retrieved September 8, 2017, from https://pier21.ca/research/immigration-history/continuous-journey-regulation-1908

Canada. (2017b). Gentlemen's Agreement, 1908 (Hayashi-Lemieux Agreement). Retrieved September 8, 2017, from http://www.pier21.ca/research/immigration-history/gentlemensagreement-1908

Canada. (2017c). Immigration Act Amendment, 1919. Retrieved August 9, 2017, from https://pier21.ca/research/immigration-history/immigration-act-amendment-1919

Canada. (2017d). Order-in-Council PC 1911-1324. Retrieved September 7, 2017, from http://www.pier21.ca/research/immigration-history/order-in-council-pc-1911-1324

Canada. (2017e). The Chinese Immigration Act, 1885 (plus amendments: 1887, 1892, 1900, 1903). Retrieved September 7, 2017, from http:/www.pier21.ca/research/immigrationhistory/the-chinese-immigration-act-1885

Canada. (2017f). The Naturalization Act of 1914. Retrieved September 8, 2017, from https://pier21.ca/research/immigration-history/naturalization-act-1914

Canada. (2019). Quebec-selected skilled workers: About the process. Retrieved March 1, 2019, from https:/www.canada.ca/en/immigration-refugees-citizenship/services/immigratecanada/quebec-skilled-workers.html

Canada Dominion Bureau of Statistics. (1921). The Canada Year Book 1920. (R. H. Coats, Ed.). Ottawa: F. A. Acland. Retrieved from https://www66.statcan.gc.ca/eng/acyb_c1920eng.aspx

Canada Dominion Bureau of Statistics. (1924). The Canada Year Book 1922-23. (R. H. Coats, Ed.). Ottawa: F. A. Acland. Retrieved from https://www66.statcan.gc.ca/eng/acyb_c192223-eng.aspx 
Canada Mexico \& USA. (1994). Chapter 16: Temporary entry for business persons. Retrieved April 10, 2017, from https://www.nafta-sec-alena.org/Home/Texts-of-theAgreement/North-American-Free-Trade-Agreement?mvid=1\&secid=8fd98e3e-449543a8-ba47-4a6955d6b5db

Canales, A. I. (2012). La migración mexicana frente a la crisis económica actual: Crónica de un retorno moderado. Revista Interdisciplinar da Mobilidade Humana, 20(39), 117-134.

Cano, G., \& Délano, A. (2007). The Mexican government and organised Mexican immigrants in The United States: A historical analysis of political transnationalism (1848-2005). Journal of Ethnic and Migration Studies, 33(5), 695-725.

Caplan, H. (2001). "Integration" according to a group of young Salvadorans in Montreal. York University, North York. Retrieved from http://reel.utsc.utoronto.ca/relac/PDF/Caplan_01_integration.pdf

Carlaw, J. (2018). Authoritarian populism and Canada's conservative decade (2006-2015) in citizenship and immigration: The politics and practices of Kenneyism and neoconservative multiculturalism. Journal of Canadian Studies, 51(3), 782-816.

Carman, T., \& Elash, A. (2018, February 7). Gender persecution the top reason women seek asylum in Canada. CBC News. Toronto. Retrieved from http://www.cbc.ca/news/canada/asylum-seekers-data-gender-persecution-1.4506245

Carrigan, W. D., \& Webb, C. (2003). The lynching of persons of Mexican origin or descent in the United States, 1848 to 1928. Journal of Social History, 37(2), 411-438.

Castillo García, G. (2008). Armas robadas en EU, en poder de narcos. La Jornada. México. Retrieved from http://www.jornada.unam.mx/2008/01/23/index.php?section=politica\&article=006n1 pol

Castles, S. (2000). International migration at the beginning of the twenty-first century: Global trends and issues. International Social Science Journal, 52(165), 269-281.

Castles, S., \& Miller, M. J. (2009). The age of migration: International population movements in the modern world. New York: Palgrave Macmillan.

Castro, P. (2004). The "return" of the Mennonites from the Cuauhtémoc region to Canada: A perspective from Mexico. Journal of Mennonite Studies, 22, 25-38. Retrieved from http://jms.uwinnipeg.ca/index.php/jms/article/view/996

CBC News. (2013, July 26). Unaccompanied child refugees pouring into Canada. Toronto. Retrieved from http://www.cbc.ca/news/canada/unaccompanied-child-refugees-pouringinto-canada-1.1328888

CBC News. (2015a, October 2). Montreal's raw sewage to be dumped into St. Lawrence River as planned. $C B C$ News. Montreal. Retrieved from

https://www.cbc.ca/news/canada/montreal/montreal-sewage-decision-river-pollution1.3253800

CBC News. (2015b, November 14). Montreal sewage dump: Water treatment resumes in city's east end. CBC News. Montreal. Retrieved from

https://www.cbc.ca/news/canada/montreal/montreal-sewage-st-lawrence-river-watertreatment-east-end-1.3319099

CBC News. (2018, November 20). GM plant's closure effect on Windsor manufacturing suppliers still unknown. CBC News. Windsor. Retrieved from https://www.cbc.ca/news/canada/windsor/gm-plant-closure-oshawa-windsor-suppliermanufacturing-1.4921528

CCR. (2018). Permanent residents and criminal inadmissibility. Retrieved August 5, 2018, from http://ccrweb.ca/en/permanent-residents-and-criminal-inadmissibility

Cécile, R., Mekki-Berrada, A., \& Moreau, S. (2001). Trauma and extended separation from family among Latin American and African refugees in Montreal. Psychiatry, 64(1), 40- 
59.

Cervenan, A. (2009). Service class prosperity in Ontario (Ontario in the creative age No. 15). Retrieved from http://martinprosperity.org/media/pdfs/Service_Class_ProsperityACervenan.pdf

Chancer, L. S., \& Watkins, B. X. (2006). Gender, race, and class. An overview. Malden, Oxford, Carlton: Blackwell Publishing.

Chartier, J. (2019). Pauline Marois. Retrieved February 2, 2019, from https://www.thecanadianencyclopedia.ca/en/article/pauline-marois

Chávez, S., \& Ávalos, J. (2014, March 30). Los países que no lloran a sus muertos. La Prensa Gráfica. San Salvador. Retrieved from http://www.insightcrime.org/news-analysis/thenorthern-triangle-the-countries-that-dont-cry-for-their-dead

Cheran, R. (2007). Transnationalism, development, and social capital: Tammil community networks in Canada. In S. Krishnamurti \& L. Goldring (Eds.), Organizing the transnational: Labour, politics, and social change (pp. 129-144). Vancouver, Toronto: UBC Press.

Chiasson, M. (2002). A clarification of terms: Canadian multiculturalism and Quebec interculturalism. Montreal. Retrieved from http://canadianicon.org/wpcontent/uploads/2014/03/TMODPart1-Clarification.pdf

Chute, T. (2004). "Seguir luchando" The struggle continues: Salvadoran political participation in Toronto. A participatory action research project. University of Toronto.

CIC. (2008). Facts and figures 2007. Immigration overview: Permanent and temporary residents. Ottawa.

CIC. (2009). Backgrounder - The visa requirement for Mexico. Retrieved March 1, 2015, from http://www.cic.gc.ca/english/department/media/backgrounders/2009/2009-07-13.asp

CIC. (2012). Facts and figures 2012. Immigration overview. Permanent and temporary residents. Ottawa.

CIC. (2014a). Designated countries of origin. Retrieved March 1, 2015, from http://www.cic.gc.ca/english/refugees/reform-safe.asp

CIC. (2014b). Temporary Foreign Worker Program: Hiring foreign workers in occupations that require lower levels of formal training. Retrieved November 22, 2017, from http://www.cic.gc.ca/english/resources/tools/temp/work/pilot/training.asp

Clement, W. (1997). Whither the new Canadian Political Economy? In W. Clement (Ed.), Understanding Canada: Building on the new Canadian Political Economy (pp. 3-18). Montreal \& Kingston, London, Buffalo: McGill-Queen's University Press.

Cleveley, T., Gunderson, V., \& Nazarali, T. (2007). Chapala, Mexico - Twinning with the City of Edmonton. Retrieved July 23, 2019, from

https://webdocs.edmonton.ca/occtopusdocs/Public/Complete/Reports/Ex/CSAM/200711-07/2007CMC038.doc

Clinard, M. B. (1949). Secondary community influences and juvenile delinquency. The Annals of the American Academy of Political and Social Science, 261(2), 42-54.

Cloutier de Repentigny, P. (2015). Mexican queer refugees need not apply. Retrieved December 4, 2017, from http://canliiconnects.org/en/commentaries/37586

Cobas, J. A., \& Feagin, J. R. (2008). Language oppression and resistance: The case of middle class Latinos in the United States. Ethnic and Racial Studies, 31(2), 390-410.

Cohen, A. K. (1955). Delinquent boys: The culture of the gang. New York: Free Press.

Coletto, D., \& Kishchuk, O. (2019). Another youthquake? Exploring the concerns, priorities, and political engagement of Canadian youth aged 15 to 30. Ottawa. Retrieved from https://abacusdata.ca/wp-content/uploads/2019/05/NYS-YouthReport_April252019_FINAL.pdf 
Conapo. (2018). Anuario de migración y remesas México. Ciudad de México: Fundación BBVA Bancomer, Secretaría de Gobernación / Consejo Nacional de Población. Retrieved from https://www.gob.mx/conapo/documentos/anuario-de-migracion-y-remesas-mexico2018-173515

Contramuro. (2018, July 25). Funcionarios de Canadá se reunirán con AMLO. Contramuro. México. Retrieved from https://www.contramuro.com/funcionarios-de-canada-sereuniran-con-amlo/

Contreras Alcántara, J. (2018). \#YoSoy132, social media, and political organization. In Oxford Research Encyclopedia of Latin American History. Oxford University Press. Retrieved from http://oxfordre.com/latinamericanhistory/view/10.1093/acrefore/9780199366439.001.000 1/acrefore-9780199366439-e-484

Contreras Velasco, O. (2010). La evolución del narcotráfico en México. In ILASSA 30th Student Conference on Latin America. Austin: University of Texas at Austin. Retrieved from http://lanic.utexas.edu/project/etext/llilas/ilassa/2010/velasco.pdf

Cooper, A. F. (2012). Canada's engagement with the Americas in comparative perspective: Between declaratory thickness and operational thinness. International Journal: Canada's Journal of Global Policy Analysis, 67(3), 685-701.

Cornelissen, S. (2016). Canadian mining and Mexican economic development. Carleton University.

Cornelius, W. A. (2009). Migration from the Mexican Mixteca: A transnational community in Oaxaca and California. La Jolla, Calif.: University of California Press.

Corona-Cadena, R. I. (2008). El narco, estado paralelo. Análisis Plural, 20 semestre, 210-222. Retrieved from http://hdl.handle.net/11117/813

Correa-Cabrera, G. (2017). Los Zetas Inc. Criminal corporations, energy, and civil war in Mexico. Austin: University of Texas Press.

Correa-Cabrera, G., \& Gutiérrez-Mannix, C. D. (2019). Oil, gas, and guns: War, privatization, and violence in Tamaulipas, Mexico. In D. Paley \& S. Granovsky-Larsen (Eds.), Organized violence: Capitalist warfare in Latin America (pp. 135-161). Regina: University of Regina Press.

Corrigan, E. C. (2019). Canada-United States Safe Third Country Agreement under review. Retrieved March 27, 2019, from http://discuss.ilw.com/articles/articles/390379-articlecanada $\%$ E2\%80\%93united-states-safe-third-country-agreement-under-review-by-edwardc-corrigan

Côté, J. E., \& Allahar, A. L. (1996). Generation on hold: Coming of age in the late twentieth century. New York: New York University Press.

Côté, J. E., \& Allahar, A. L. (2006). Critical youth studies. A Canadian focus. Toronto: Pearson Prentice Hall.

Coyne, I. T. (1997). Sampling in qualitative research. Purposeful and theoretical sampling; merging or clear boundaries. Journal of Advanced Nursing, 26, 623-630.

CPA. (2018). About the Order. Retrieved March 13, 2018, from https://cpaquebec.ca/en/theorder/about-the-order/

Creese, G. (2011). The new African diaspora in Vancouver: Migration, exclusion and belonging. Toronto: University of Toronto Press.

Creese, G., Dyck, I., \& McLaren, A. (2008). The "flexible" immigrant? Human capital discourse, the family household and labour market strategies. Journal of International Migration and Integration / Revue de L'integration et de la migration internationale, 9(3), 269-288.

Creese, G., Ngene Kambere, E., \& Masinda, M. (2011). You have to stand up for yourself: 
African immigrant and refugee teens negotiate settlement in Vancouver (CERID Working Paper Series No. 11-16). Vancouver.

Currier, C., \& Franzblau, J. (2015). Mexican authorities implicated in violence, but U.S. security aid still flows. Retrieved April 15, 2017, from https:/theintercept.com/2015/05/08/ayotzinapa-mexico-u-s-security-aid-keeps-flowing/

Damasco, V. G. (2013). The recruitment of Filipino healthcare professionals to Canada in the 1960s. In R. Sintos Coloma, B. McElhinny, E. Tungohan, J. P. C. Catungal, \& L. M. Davidson (Eds.), Filipinos in Canada: Disturbing invisibility (pp. 97-122). Toronto, Buffalo, London: University of Toronto Press.

Daniel, Y., \& Bondy, K. (2008). Safe schools and zero tolerance, policy, program and practice in Ontario. Canadian Journal of Educational Administration and Policy, (70), 1-20.

Daudelin, J. (2013). Hamster wheel diplomacy. Retrieved March 24, 2017, from https://www.opencanada.org/features/hamster-wheel-diplomacy/

Dawson, L. (2014). Canada's trade with Mexico: Where we've been, where we're going and why it matters. Ottawa. Retrieved from http://www.ceocouncil.ca/wpcontent/uploads/2014/02/Canadas-trade-with-Mexico-Laura-Dawson-February-2014.pdf

de la O, M. E., \& Quintero, C. (2002). Globalización, trabajo y maquilas: Las nuevas y viejas fronteras en México. México: Plaza y Valdés, CIESAS, Fundación Friedrich Ebert, Centro Americano para la Solidaridad Sindical Internacional.

Délano, A. (2006). De la "no intervención" a la institucionalización: La evolución de las relaciones Estado-diáspora en el caso mexicano. In C. González Gutiérrez (Ed.), Relaciones estado-diáspora: perspectivas de América Latina y el Caribe (pp. 145-189). México: Miguel Ángel Porrúa.

Délano, A. (2009). From limited to active engagement: Mexico's emigration policies from a foreign policy perspective (2000-2006). International Migration Review, 43(4), 764-814.

Délano, A. (2010). El Instituto de los Mexicanos en el Exterior: ¿Un instrumento de política exterior? In Mexicanos en el exterior: Trayectoria y perspectivas (1990-2010) (pp. 8193). México: Secretaría de Relaciones Exteriores.

Délano, A. (2011). Mexico and its Diaspora in the United States: Policies of Emigration since 1848. New York: Cambridge University Press.

Délano, A. (2012). From "shared responsibility" to a migration agreement? The limits for cooperation in the Mexico-United States case (2000-2008). International Migration, $50(\mathrm{~s} 1), \mathrm{e} 41-\mathrm{e} 50$.

Delgado, D. J. (2016). “And you need me to be the token Mexican?”: Examining racial hierarchies and the complexities of racial identities for middle class Mexican Americans. Critical Sociology, 42(4-5), 679-698.

Deloitte. (2012). Mining industry in Mexico. Vancouver.

Demers, M. (2010). Pan-Americanism re-invented in uncle Sam's backyard: Catholic and Latin identity in French Canada and Mexico in the first half of the 20th century. York University.

DePalma, A. (2001). Here: A biography of the new American continent. New York: Public Affairs.

DFAIT. (2009). 2008-2009 Departmental performance report. Retrieved March 1, 2017, from https://www.tbs-sct.gc.ca/dpr-rmr/2008-2009/inst/ext/ext01-eng.asp

DFAIT. (2011). Evaluation of the Americas Strategy. Retrieved March 1, 2017, from http://www.international.gc.ca/gacamc/publications/evaluation/2011/tas_lsa11.aspx?lang=eng\&wbdisable=true

DHS. (2017a). Table 39. Aliens removed or returned: Fiscal years 1892 to 2016. Retrieved January 18, 2018, from https://www.dhs.gov/immigration- 
statistics/yearbook/2016/table39

DHS. (2017b). Table 41. Aliens removed by criminal status and region and country of nationality: Fiscal year 2016. Retrieved January 18, 2018, from

https://www.dhs.gov/immigration-statistics/yearbook/2016/table41

Díaz, H. (2011). Chileans. Retrieved from http://multiculturalcanada.ca/print/book/export/html/4147

Díaz Barrero, G. P. (2007). Dancing here, "living” there: Transnational lives and working conditions of Latina migrant exotic dancers. In L. Goldring \& S. Krishnamurti (Eds.), Organizing the transnational: Labour, politics, and social change (pp. 145-156). Vancouver, Toronto: UBC Press.

Dickinson, J., \& Young, B. (2008). A short history of Quebec (4th ed.). Collete: McGillQueen's University Press.

Dimbuene, Z. T., \& Turcotte, M. (2019). Study on international money transfers from Canada. Ottawa. Retrieved from https://www150.statcan.gc.ca/pub/89-657-x/89-657-x2019007eng.pdf

Dinges, J. (2005). The Condor years: How Pinochet and his allies brought terrorism to three continents. New York City: The New Press.

Doeringer, P., \& Piore, M. J. (1970). Internal labor markets and manpower analysis. Cambridge, Mass.: Harvard University.

Donato, K. M., Gabaccia, D., Holdaway, J., Manalansan IV, M., \& Pessar, P. R. (2006). A glass half full? Gender in migration studies. International Migration Review, 40(1), 3-26.

Doyle, K. (1996). El Salvador: War, peace, and human rights, 1980-1994. Retrieved March 1, 2016, from http://nsarchive.gwu.edu/nsa/publications/elsalvador2/\#DOCTY

Doyle, K., \& Osorio, C. (1999). U.S. policy in Guatemala, 1966-1996. Retrieved March 1, 2017, from http://nsarchive.gwu.edu/NSAEBB/NSAEBB11/docs/

Driedger, L. (1973). Impelled group migration: Minority struggle to maintain institutional completeness. International Migration Review, 7(3), 257-269.

Drotbohm, H. (2009). Deporting diaspora's future? Forced transnationalism and generational conflicts in the Haitian community of Montreal. Human Architecture: Journal of the Sociology of Self-Knowledge, 7(4), 69-84.

Durand, J. (1994). Más allá de la línea: Patrones migratorios entre México y Estados Unidos. México: Consejo Nacional para la Cultura y las Artes.

Durand, J. (2004). From traitors to heroes: 100 years of Mexican migration policies. Retrieved May 5, 2018, from https:/www.migrationpolicy.org/article/traitors-heroes-100-yearsmexican-migration-policies

Durand, J. (2007). Remesas y desarrollo. Las dos caras de la moneda. In P. Leite, S. Zamora, \& L. Acevedo (Eds.), Migración internacional y desarrollo en América Latina y el Caribe (pp. 221-236). México: Consejo Nacional de Población.

Durand, J., Kandel, W., Parrado, E. A., \& Massey, D. S. (1996). International migration and development in Mexican communities. Demography, 33(2), 249-264.

Durand, J., Massey, D. S., \& Zenteno, R. M. (2001). Mexican immigration to the United States: Continuities and changes. Latin American Research Review, 36(1), 107-127.

Durand, J., Parrado, E. A., \& Massey, D. S. (1996). Migradollars and development: A reconsideration of the Mexican case. International Migration Review, 30(2), 423-444.

Dyck, R. (2011). Canadian politics. Critical approaches (6th ed.). Toronto: Nelson Education.

Edwards, R. (2015). Segmented labor markets. In V. D. Lippit (Ed.), Radical political economy: Explorations in alternative economic analysis (2nd ed., pp. 60-85). New York: Routledge.

Egale Canada. (2013). LGBT persecution in Mexico and Canada's refugee program. Toronto. 
Retrieved from https://egale.ca/wp-content/uploads/2013/08/Backgrounder-Mexico-andBill-C-31.pdf

El Correo de Oaxaca. (2017, March 4). Detectan a 59 mineras presuntas evasoras de impuestos y obligaciones. El Correo de Oaxaca. Oaxaca. Retrieved from http://www.elcorreodeoaxaca.com/detectan-a-59-mineras-presuntas-evasoras-deimpuestos-y-obligaciones/

El País. (2016). El narcotráfico se infiltra en la contienda electoral en Tamaulipas. El País. Ciudad de México. Retrieved from https://internacional.elpais.com/internacional/2016/05/09/mexico/1462751826_825956.ht $\mathrm{ml}$

Elrick, J., \& Lightman, N. (2016). Sorting or shaping? The gendered economic outcomes of immigration policy in Canada. International Migration Review, 50(2), 352-384.

Embassy of Canada in Mexico. (2016). Canada-Mexico relations. A strategic partner for Canada. Retrieved April 1, 2017, from http://www.canadainternational.gc.ca/mexicomexique/canmex.aspx?lang=eng

Encalada Grez, E. (2007). Harvesting seeds of justice: The plight of migrant farm workers in Ontario. Women \& Environments International Magazine, 16-19.

Encalada Grez, E. (2017). Mexican migrant farmworker women organizing love and work across rural Canada and Mexico. University of Toronto.

Envisioning Global LGBT Human Rights. (2015). Envisioning LGBT refugee rights in Canada: Is Canada a safe haven? Toronto. Retrieved from http://yfile.news.yorku.ca/files/2015/09/Is-Canada-A-Safe-Haven-Report-2015.pdf

Erel, U. (2010). Migrating cultural capital: Bourdieu in migration studies. Sociology, 44(4), 642-660.

Escalante, S. (1998). Mexican refugees in 1990's Canada: Beyond the limits of repression. Carleton University.

Escalante, S. (2004). Disrupting Mexican refugee constructs: Women, gays, and lesbians in 1990s Canada. In B. J. Messamore (Ed.), Canadian migration patterns from Britain and North America (pp. 207-228). Ottawa: University of Ottawa Press.

Escobar, M. (2000). Exile and national identity: Chilean women in Canada. University of Toronto.

Escobar Latapí, A. (2009). Can migration foster development in Mexico? The case of poverty and inequality. International Migration, 47(5), 75-112.

Escobar Latapí, A. (2012). Migration vs. development? The case of poverty and inequality in Mexico. Migration Letters, 9(1), 65-74.

Escobar Latapí, A., \& Janssen, E. (2006). Migration, the diaspora and development: The case of Mexico (Decent Work Research Programme No. 167). Geneva.

ESDC. (2019a). Applicant guide for the Temporary Foreign Worker Program Global Talent Stream. Retrieved March 10, 2019, from https://www.canada.ca/en/employment-socialdevelopment/services/foreign-workers/global-talent/applicant-guide.html

ESDC. (2019b). Program requirements for the Global Talent Stream. Retrieved March 10, 2019, from https://www.canada.ca/en/employment-social-development/services/foreignworkers/global-talent/requirements.html\#h15

Estable, A. (1986). Immigrant women in Canada - Current issues. Toronto: Canadian Advisory Council on the Status of Women.

Esteinou, R. (2004). El surgimiento de la familia nuclear en México. Estudios de Historia Novohispana, 31(31), 99-136.

Estévez, A. (2015). La presunta falsedad de los casos de asilo de mexicanos en Canadá: Un análisis necropolítico. Con-Temporánea. Toda la historia en el presente, Julio- 
Diciembre(4). Retrieved from http://con-temporanea.inah.gob.mx/node/109

Estévez, A. (2016). Sexual and domestic violence: The hidden reasons why Mexican women flee their homes. Retrieved August 25, 2017, from https://theconversation.com/sexualand-domestic-violence-the-hidden-reasons-why-mexican-women-flee-their-homes-65352

Evans, M. (2015, January). Mexico's recurring nightmare. The Nation. Retrieved from https://www.thenation.com/article/mexicos-recurring-nightmare

Expansión. (2012). "El Sicario" revela cómo funciona el crimen organizado en México. Expansión. Retrieved from http://expansion.mx/nacional/2012/02/24/el-sicario-revelacomo-funciona-el-crimen-organizado-en-mexico

Faist, T. (2008). Migrants as transnational development agents: An inquiry into the newest round of the migration-development nexus. Population, Space and Place, 14(1), 21-42.

FBI. (2005a). How we're ganging up on MS-13 and what you can do to help. Retrieved January 20, 2018, from https://archives.fbi.gov/archives/news/stories/2005/july/ms13_071305

FBI. (2005b). Los Zetas: An emerging threat to the United States. San Antonio, Texas. Retrieved from https:/www.thenation.com/wp-content/uploads/2015/03/200507152.pdf

FBI. (2005c). Los Zetas - Violent gangs. Retrieved April 15, 2017, from http://nsarchive.gwu.edu/NSAEBB/NSAEBB499/DOCUMENT01-20050422.PDF

FBI. (2008). The MS-13 threat. A national assessment. Retrieved March 25, 2017, from https://archives.fbi.gov/archives/news/stories/2008/january/ms13_011408

FBI. (2009). United against MS-13. Our Central American partnerships. Retrieved January 20, 2018, from https://archives.fbi.gov/archives/news/stories/2009/november/calee_111009

FIDH \& OMCT. (2009). México: Defensores de derechos humanos frente a la mutación política y la violencia. París/Ginebra. Retrieved from http://www.omct.org/files/2009/02/5368/informe_mision_mexico.pdf

Fierro, J. O. (2017). Pegasus tuvo al menos seis responsables en PGR, entre 2014 y 2016. Retrieved July 3, 2017, from http://aristeguinoticias.com/0307/mexico/pegasus-tuvo-seisresponsables-en-pgr-entre-octubre-de-2014-y-2016/

Finn, M., \& Momani, B. (2019). Transnational citizenship mobilization among Canadian Arab youth: An engaged social movement for change in the Middle East. Canadian Ethnic Studies, 51(1), 25-68.

Fish Site Editor. (2011). US - Mexico tuna import restrictions violate fair trade. Retrieved June 20, 2017, from https://thefishsite.com/articles/us-mexico-tuna-import-restrictions-violatefair-trade

FitzGerald, D. (2009). A nation of emigrants: How Mexico manages its migration. Berkeley, Los Angeles, London: University of California Press.

Flores-Yeffal, N. Y., \& Aysa-Lastra, M. (2011). Place of origin, types of ties, and support networks in Mexico-U.S. migration. Rural Sociology, 76(4), 481-510.

Foner, N. (1997). What's new about transnationalism?: New York immigrants today and at the turn of the century. Diaspora: A Journal of Transnational Studies, 6(3), 355-375.

Foner, N. (2002). Second generation transnationalism. Then and now. In P. Levitt \& M. C. Waters (Eds.), The changing face of home: The transnational lives of the second generation (pp. 242-253). New York: Rusell Sage Foundation.

Foster, J. W. (2013). Canadians and the coup. In Remembering the coup: Canada and the Chilean dictatorship 40 years later (p. 8). Ottawa.

Fuller, S., \& Vosko, L. F. (2008). Temporary employment and social inequality in Canada: Exploring intersections of gender, race and immigration status. Social Indicators Research, 88(1), 31-50.

Fussell, E. (2010). The cumulative causation of international migration in Latin America. The 
Annals of the American Academy of Political and Social Science, 630(1), 162-177.

Fussell, E., \& Massey, D. S. (2004). The limits to cumulative causation: International migration from Mexican urban areas. Demography, 41(1), 151-171.

Gabriel, C., \& Macdonald, L. (2004). The hypermobile, the mobile, and the rest: Patterns of inclusion and exclusion in an emerging North American migration regime. Canadian Journal of Latin American and Caribbean Studies, 29(57), 67-91.

Gabriel, C., \& Macdonald, L. (2012). Debates on temporary agricultural worker migration in Canadian agriculture. In C. Straehle \& P. T. Lenard (Eds.), Legislated inequality: Temporary labour migration in Canada (pp. 95-118). Montréal: McGill-Queen's University Press.

Gamio, M. (1930/1969). Mexican immigration to the United States. A study of human migration and adjustment. New York: Arno Press and The New York Times.

Garay, E. (2000). Social, economic and demographic profile. Hispanic community. Toronto. Retrieved from http://atwork.settlement.org/downloads/Hispanic_Community_Profile.pdf

García, M. (2008a). Dimensiones simbólicas de la inmigración indocumentada. Rituales de paso de "norteños" y "norteñas" nahuas del sur de México hacia Estados Unidos. Norteamérica. Revista Académica Del CISAN-UNAM, 3(1), 121-151.

García, M. (2008b). Rituales de paso y categorías sociales en la migración internacional nahua del Alto Balsas, Guerrero. Cuicuilco, 15(42), 77-96.

García, M. T. (1981). Desert immigrants. The Mexicans of El Paso, 1880-1920. New Haven and London: Yale University Press.

García Zamora, R. (2007). Migración internacional, remesas y desarrollo en México al inicio del siglo XXI. In P. Leite, S. Zamora, \& L. Acevedo (Eds.), Migración internacional y desarrollo en América Latina y el Caribe (pp. 275-316). México: Consejo Nacional de Población.

Garciadiego, J. (2008). La revolución. In G. Jaramillo Herrera \& F. Gómez Ruiz (Eds.), Nueva historia mínima de México ilustrada. México: El Colegio de México.

Gariba, S. A. (2009). Race, ethnicity, immigration and jobs: Labour market access among Ghanaian and Somali youth in the Greater Toronto Area. University of Toronto, Toronto.

Gauthier, A. (2012). Canadian trade and investment activity: Canada-Mexico. Ottawa. Retrieved from http://www.lop.parl.gc.ca/Content/LOP/ResearchPublications/2012-60e.pdf

Gauthier, A., \& Meredith, K. (2011). Canadian trade and investment activity: CanadaMexico. Ottawa. Retrieved from http://www.lop.parl.gc.ca/Content/LOP/ResearchPublications/2011-136-e.pdf

Gaztambide-Fernández, R. A., \& Guerrero, C. (2011). Proyecto Latino. Year 1, exploratory research. Report to the Toronto District School Board. Toronto. Retrieved from https://www.oise.utoronto.ca/oise/UserFiles/File/ProyectoLatinoReportJan2011.pdf

GCIM. (2005). Migration in an interconnected world: New directions for action report of the global commission on international migration. Switzerland.

George, U. (2008). Mexican migration to Canada: Case study report. Journal of Immigrant \& Refugee Studies, 6(3), 463-474.

George, U., \& Young, J. (2006). Immigration to Canada: the case of Mexicans. Toronto. Retrieved from http://www.eliamep.gr/wpcontent/uploads/en/2009/04/migsys_canada_mexicans_july_06.pdf

Gilbert, E. (2007). Leaky borders and solid citizens: Governing security, prosperity and quality of life in a North American partnership. Antipode, 39(1), 77-98.

Gilbert, S. (2017). The political saga of avocados. How does such a nutritious fruit have such a contentious record? Retrieved May 14, 2017, from 
https://www.theatlantic.com/entertainment/archive/2017/02/a-brief-history-of-avocadocontroversy/514748/

Gillis, C. (2012, December). Why rich Mexicans are fleeing to Canada as refugees. Gangs target financially successful families in the country's ongoing drug war. Maclean's. Retrieved from http://www.macleans.ca/news/canada/wealth-asylum/

Ginieniewicz, J. (2007). The scope of political participation. International Migration and Integration, 8(3), 327-345.

Ginieniewicz, J. (2008a). Citizenship learning and political participation: The case of Latin American-Canadians. London Review of Education, 6(1), 71-85.

Ginieniewicz, J. (2008b). Citizenship learning and political participation of immigrants:The case of Latin Americans in Toronto. University of Toronto.

Ginieniewicz, J. (2010a). Identity politics and political representation of immigrants: The perceptions of Latin Americans in Toronto. Journal of Immigrant \& Refugee Studies, $8(3), 261-283$.

Ginieniewicz, J. (2010b). Latin American Canadians rethink their political spaces: Grass-roots or electoral participation? Political Studies, 58(3), 497-515.

Glenn, R. (1981, June 10). Bogus refugees "already serious problem." The Toronto Star, p. A7. Toronto. Retrieved from www.proquest.com/docview/1399353719

Glick Schiller, N., Basch, L., \& Szanton Blanc, C. (1995). From immigrant to transmigrant: Theorizing transnational migration. Anthropological Quarterly, 68(1), 48-63.

Glick Schiller, N., \& Fouron, G. E. (1999). Terrains of blood and nation: Haitian transnational social fields. Ethnic and Racial Studies, 22(2), 340-366.

Glick Schiller, N., \& Levitt, P. (2006). Haven't we heard this somewhere before? A substantive view of transnational migration studies by way of a reply to Waldinger and Fitzgerald (The Center for Migration and Development No. 6-1). Princeton N.J.

Global Rights, International Gay and Lesbian Human Rights Commission, Harvard Law School, \& Colectivo Binni Laanu A.C. (2010). The violations of the rights of lesbian, gay, bisexual and transgender persons in Mexico. A shadow report. New York. Retrieved from https://www.outrightinternational.org/sites/default/files/556-1.pdf

Goldring, L. (1992a). Diversity and community in transnational migration: A comparative study of two Mexico-U.S. migrant circuits. Cornell University.

Goldring, L. (1992b). La migración México-EUA y la transnacionalización del espacio político y social: perspectivas desde el México rural. Estudios Sociológicos de El Colegio de México, 10(29), 315-340.

Goldring, L. (1997). Difuminando fronteras: Construcción de la comunidad transnacional en el proceso migratorio México-Estados Unidos. In S. Macías Gamboa \& F. Herrera L. (Eds.), Migración laboral internacional: Transnacionalidad del espacio social (pp. 55-106). Puebla: Facultad de Economía de la Benemérita Universidad Autónoma de Puebla.

Goldring, L. (1999a). El Estado mexicano y las organizaciones trasmigrantes: ¿Reconfigurando la nación y las relaciones entre estado y sociedad civil? In G. Mummert (Ed.), Fronteras fragmentadas (1a ed., pp. 297-316). Morelia: El Colegio de Michoacán, Centro de Investigaciones y Desarrollo del Estado de Michoacán.

Goldring, L. (1999b). Mexicans. Retrieved from http://multiculturalcanada.ca/print/book/export/html/3677

Goldring, L. (1999c). Power and status in transnational social spaces. In L. Pries (Ed.), Migration and transnational social spaces (pp. 162-186). Aldershot, England; Brookfield, Vermont: Ashgate Publishing.

Goldring, L. (2002). The Mexican state and transmigrant organizations: Negotiating the 
boundaries of membership and participation. Latin American Research Review, 37(2), 55-99.

Goldring, L. (2003). Gender, status, and the state in transnational spaces: The gendering of political participation and Mexican hometown associations. In P. Hondagneu-Sotelo (Ed.), Gender and U.S. immigration: Contemporary trends (pp. 341-358). Berkeley: University of California Press.

Goldring, L. (2004). Family and collective remittances to Mexico: A multi-dimensional typology. Development and Change, 35(4), 799-840.

Goldring, L. (2006). Latin American transnationalism in Canada: Does it exist, what forms does it take, and where is it going? In V. Satzewich \& L. Wong (Eds.), Transnational identities and practices in Canada (pp. 180-201). Vancouver: UBC Press.

Goldring, L., Henders, S. J., \& Vandergeest, P. (2003). The politics of transnational ties: Implications for policy, research, and communities. North York: YCAR-CERLAC. Retrieved from www.yorku.ca/cohesion/LARG/PDF/Goldring_03_thepolitics.pdf

Goldring, L., \& Krishnamurti, S. (2007). Introduction: Contextualizing transnationalism in Canada. In L. Goldring \& S. Krishnamurti (Eds.), Organizing the transnational: Labour, politics, and social change (pp. 1-21). Vancouver, Toronto: UBC Press.

Goldring, L., \& Landolt, P. (2009a). Immigrants and precarious employment in the new economy (brief 2). Toronto. Retrieved from http://www.yorku.ca/ine/docs/2009_july/Brief 2.pdf

Goldring, L., \& Landolt, P. (2009b). Immigrants and precarious employment in the new economy (Introduction). Toronto. Retrieved from http://www.yorku.ca/ine/docs/2009_july/Introduction.pdf

Goldring, L., \& Landolt, P. (2011). Caught in the work-citizenship matrix: The lasting effects of precarious legal status on work for Toronto immigrants. Globalizations, 8(3), 325-341.

Goldring, L., \& Landolt, P. (2014). Transnational migration and the reformulation of analytical categories: Unpacking Latin American refugee dynamics in Toronto. In L. RiveraSánchez \& F. Lozano-Ascencio (Eds.), The practice of research on migration and mobilities. Mexico City: Springer, UNAM.

Gómez, L. E. (2007). Manifest destinies: The making of the Mexican American race. New York and London: New York University Press.

González, G. G. (2011). Mexican labor migration, 1876-1924. In Over (Ed.), Beyond la frontera: The history of Mexico-U.S. migration (pp. 28-50). New York: Oxford University Press.

González-Barrera, A., \& Krogstad, J. M. (2018). What we know about illegal immigration from Mexico. Retrieved December 3, 2018, from http://www.pewresearch.org/facttank/2018/12/03/what-we-know-about-illegal-immigration-from-mexico/

Gordon, M. M. (1978). Assimilation in American life: The role of race, religion, and national origins. New York: Oxford University Press.

Gordon, T., \& Webber, J. R. (2016). Blood of extraction. Canadian imperialism in Latin America. Halifax and Winnipeg: Fernwood.

Gortney, W. E. (2015). Posture statement of Admiral William E. Gortney, United States Navy Commander of the United States Northern Command and North American Aerospace Defense Command before the Senate Armed Services Committee. Retrieved April 4, 2017, from https://www.armed-services.senate.gov/imo/media/doc/Gortney_03-12-15.pdf

Gosselin, J.-P. (1984). Un immigration de la onzième heure : les Latino-Américains. Immigrants, 25(3), 393-420.

Government of Canada. (2009). Canada and the Americas: Priorities and Progress. Ottawa. Retrieved from http://publications.gc.ca/collections/collection_2009/maeci-dfait/FR5-41- 
1-2009E.pdf

Government of Canada. (2017). Travel advice and advisories for Mexico. Retrieved April 3, 2017, from https://travel.gc.ca/destinations-print/mexico

Gowans, D. (2015). Canadian trade and investment activity: Canada-Mexico. Ottawa. Retrieved from http://www.lop.parl.gc.ca/Content/LOP/ResearchPublications/2015-78e.pdf

Gowans, D. (2016). Canadian trade and investment activity: Canada-Mexico. Ottawa. Retrieved from http://www.lop.parl.gc.ca/Content/LOP/ResearchPublications/2016-58-e.pdf

Gowans, D. (2017). Canadian trade and investment activity: Canada-Mexico. Ottawa. Retrieved from https://lop.parl.ca/Content/LOP/ResearchPublications/2017-572-e.html

Grandin, G. (2007). Empire's workshop: Latin America, the United States, and the rise of the new imperialism. New York: Holt Paperbacks.

Grenfell, M. (2008). Pierre Bourdieu. Key concepts. Stocksfield: Acumen.

Griswold del Castillo, R. (2006). War's end. The Treaty of Guadalupe Hidalgo. Retrieved March 29, 2017, from http://www.pbs.org/kera/usmexicanwar/war/wars_end_guadalupe.html

Grundy, J., \& Smith, M. (2006). The politics of multiscalar citizenship: The case of lesbian and gay organizing in Canada. Citizenship Studies, 9(4), 389-404.

Guarnizo, L. E., Portes, A., \& Haller, W. (2003). Assimilation and transnationalism: Determinants of transnational political action among contemporary migrants. American Journal of Sociology, 108(6), 1211-1248.

Guarnizo, L. E., \& Smith, M. P. (1998). The locations of transnationalism. In M. P. Smith \& L. E. Guarnizo (Eds.), Transnationalism from below (pp. 1-31). New Brunswick, N.J: Transaction Publishers.

Guerrero, C. (2009). Latinidad and the high school experience: Working to curb early school leaving among Spanish speaking youth in Toronto's public school system. 2nd Annual Graduate Conference. Department of Ethnic and Pluralism Studies, University of Toronto.

Guerrero, V. M. G., Giorguli-Saucedo, S., \& Masferrer, C. (2019). Emerging demographic challenges and persistent trends in Mexico and the northern triangle of Central America. Governance in an Emerging New World. Retrieved from https://www.hoover.org/research/emerging-demographic-challenges-and-persistenttrends-mexico-and-northern-triangle-central

Gunderson, L. (2004). The language, literacy achievement, and social consequences of English-only programs for immigrant students. In J. Worthy, B. Malich, J. V. Hoffman, D. L. Schallert, \& C. M. Fairbanks (Eds.), 53rd National Reading Conference Yearbook (pp. 1-27). Wisconsin: National Reading Conference Inc.

Guo, S. (2009). Difference, deficiency, and devaluation: Tracing the roots of non-recognition of foreign credentials for immigrant professionals in Canada. Canadian Journal for the Study of Adult Education, 22(1), 37-52.

Guo, S. (2013). Economic integration of recent Chinese immigrants in Canada's second-tier cities: The triple glass effect and immigrants' downward social mobility. Canadian Ethnic Studies, 45(3), 95-115.

Gutiérrez, D. G. (1995). Walls and mirrors: Mexican Americans, Mexican immigrants, and the politics of ethnicity. Berkeley, Los Angeles, London: University of California Press.

Gutiérrez-Haces, M. T. (2015). Los vecinos del vecino. La continentalización de México y Canadá en América del Norte. México: Universidad Nacional Autónoma de México, Ariel. 
Halli, S. S., \& Vedanand. (2007). The problem of second-generation decline: Perspectives on integration in Canada. International Migration and Integration, 8, 277-287.

Handman, M. S. (1935). Economic reasons for the coming of the Mexican immigrant. American Journal of Sociology, 35(4), 601-611. Retrieved from http://www.jstor.org/stable/2765929

Harlow, S. (2016). Why Mexico's oil reform is a huge opportunity for investors. Retrieved January 2, 2019, from https://oilprice.com/Energy/Energy-General/Why-Mexicos-OilReform-Is-A-Huge-Opportunity-For-Investors.html

Harrigan, T. M. (2011). Statement of Thomas M. Harrigan, Assistant Administrator and Chief of Operations of Drug Enforcement Administration before the United States Senate Caucus on International Narcotics Control. Retrieved April 16, 2017, from http://www.drugcaucus.senate.gov/sites/default/files/HARRIGAN testimony.pdf

Harris, K., \& Payton, L. (2010). Mexico clamping down on bogus refugees to Canada: Calderon. Retrieved April 14, 2017, from http://www.torontosun.com/news/canada/2010/05/27/14147266.html

Harvesting Freedom. (2017). What's missing in media coverage of the new Auditor General report on the TFWP. Retrieved May 23, 2017, from https://harvestingfreedom.org/2017/05/23/whats-missing-in-media-coverage-of-the-newauditor-general-report-on-the-tfwp/

Harvey, D. (2005). A brief history of neoliberalism. New York: Oxford University Press.

Heinle, K., Molzahn, C., \& Shirk, D. A. (2015). Drug violence in Mexico. Data and analysis through 2014. San Diego.

Heinle, K., Rodríguez Ferreira, O., \& Shirk, D. A. (2017). Drug violence in Mexico: Data and analysis through 2016. San Diego.

Henderson, T. J. (2007). A glorious defeat: Mexico and its war with the United States. New York: Hill and Wang.

Hennebry, J. L. (2008). Bienvenidos a Canadá? Globalization and the migration industry surrounding temporary agricultural migration in Canada. Canadian Studies in Population, 35(2), 339-356.

Hennebry, J. L., \& McLaughlin, J. (2012). "The exception that proves the rule": Structural vulnerability, health risks, and consequences for temporary migrant farm workers in Canada. In C. Straehle \& P. T. Lenard (Eds.), Legislated inequality: Temporary labour migration in Canada (pp. 117-138). Montreal: McGill-Queen's University Press.

Hennebry, J. L., \& Preibisch, K. (2012). A model for managed migration? Re-examining best practices in Canada's Seasonal Agricultural Worker Program. International Migration, 50(s1), e19-e40.

Hernández, E. (2018). Canadá, preocupada por cambios en leyes mineras en México. El Sol de México. México. Retrieved from https://www.elsoldetijuana.com.mx/finanzas/canadapreocupada-por-cambios-en-leyes-mineras-en-mexico-2777291.html

Hernández, P. (1984). Understanding the lifeworlds of three Central American youth refugees in Vancouver. The University of British Columbia.

Hernández-Ramírez, A. (2008). Los jóvenes rurales: ¿nuevos actores de la migración a Estados Unidos? In A. Escobar Latapí (Ed.), Pobreza y migración internacional (pp. 173-222). México: CIESAS.

Hernández-Ramírez, A. (2012). Colombian and Mexican youth migration and acculturation experiences: The shaping of identities in Metropolitan Vancouver. Simon Fraser University, Vancouver.

Hernández-Ramírez, A. (2018). Our moral obligation to Central American migrants. Retrieved June 25, 2018, from https://theconversation.com/our-moral-obligation-to-central- 
american-migrants-98591

Hernández-Ramírez, A. (2019, in press). The political economy of immigration securitization: Nation-building and racialization in Canada. Studies in Political Economy. DOI:10.1080/07078552.2019.1646452

Hiebert, D. (2009). The economic integration of immigrants in Metro Vancouver (CERID Working Paper Series No. 9-8). Vancouver.

Hiebert, D. (2016). What's so special about Canada? Understanding the resilience of immigration and multiculturalism. Washington, D.C.

Hiebert, D., \& Ley, D. (2003a). Assimilation, cultural pluralism, and social exclusion among ethnocultural groups in Vancouver. Urban Geography, 24(1), 16-44.

Hiebert, D., \& Ley, D. (2003b). Characteristics of immigrant transnationalism in Vancouver (Research on Immigration and Integration in the Metropolis Working Paper Series No. 15). Vancouver.

Hiebert, D., \& Ley, D. (2006). Characteristics of immigrant transnationalism in Vancouver. In L. L. Wong \& V. Satzewich (Eds.), Transnational identities and practices in Canada (pp. 71-90). Vancouver: UBC Press.

Hiebert, D., \& Sherrell, K. (2009). The integration and inclusion of newcomers in British Columbia (Working Paper Series No. 09-11). Vancouver.

Hira-Friesen, P. (2018a). Does employment in precarious work lead to wage disparities for Canadian immigrants? Canadian Ethnic Studies, 50(1), 69-86.

Hira-Friesen, P. (2018b). Immigrants and Precarious Work in Canada: Trends, 2006-2012. International Migration and Integration, 19(1), 35-57.

Holden, M. (2010). Canadian trade and investment activity: Canada-Mexico. Ottawa. Retrieved from http://www.lop.parl.gc.ca/Content/LOP/ResearchPublications/2010-50e.pdf

Hollands, R. (2003). Towards a "cultural" political economy of Canadian youth. In W. Clement \& L. F. Vosko (Eds.), Changing Canada: Political economy as transformation (pp. 443-466). Montreal \& Kingston, London, Ithaca: McGill-Queen's University Press.

Hondagneu-Sotelo, P. (1992). Overcoming patriarchal constraints: The reconstruction of gender relations among Mexican immigrant women and men. Gender \& Society, 6(3), 393-415.

Hondagneu-Sotelo, P. (1994). Gendered transitions: Mexican experiences of immigration. Berkeley, Los Angeles, London: University of California Press.

Hondagneu-Sotelo, P. (2009). Families on the frontier: From Braceros in the fields to Braceras in the home. In M. M. Suárez-Orozco \& M. Páez (Eds.), Latinos: Remaking America (pp. 259-273). Berkeley, Los Angeles, London: University of California Press.

Hondagneu-Sotelo, P., \& Ávila, E. (1997). “I'm here, but I'm there.” The meanings of Latina transnational motherhood. Gender \& Society, 11(5), 548-571.

House, T. W. (2016). President Obama proposes $\$ 1.1$ billion in new funding to address the prescription opioid abuse and heroin use epidemic. Retrieved May 15, 2018, from https://obamawhitehouse.archives.gov/the-press-office/2016/02/02/president-obamaproposes-11-billion-new-funding-address-prescription

HRW. (2013). Mexico's disappeared. The enduring cost of a crisis ignored. New York. Retrieved from https://www.hrw.org/reports/2013/02/20/mexicos-disappeared

Huntington, S. (1996). The clash of civilizations and the remaking of world order. New York: Simon and Schuster.

Hussain, Y. (2014, November 1). Mexico, North America's last energy frontier is ready to dance. Financial Post. Toronto. Retrieved from 
https://business.financialpost.com/commodities/energy/mexico-north-americas-lastenergy-frontier-is-ready-to-dance

Hyndman, J., \& Walton-Roberts, M. (2000). Interrogating borders: A transnational approach to refugee research in Vancouver. The Canadian Geographer / Le Géographe Canadien, 44(3), 244-258.

Ibarra, I. (2004). Land sale still thorn to Mexico. Historians say U.S. imperialism behind treaty. Retrieved February 26, 2017, from https://web.archive.org/web/20070503064503/http:/www.azstarnet.com/sn/gadsden/9331

ICE. (2012). FY 2012: ICE announces year-end removal numbers, highlights focus on key priorities and issues new national detainer guidance to further focus resources. Retrieved January 18, 2018, from https://www.ice.gov/news/releases/fy-2012-ice-announces-yearend-removal-numbers-highlights-focus-key-priorities-and

ICE. (2014). Fiscal year 2014 ICE enforcement and removal operations report. Retrieved December 16, 2018, from https://www.ice.gov/doclib/about/offices/ero/pdf/2014-iceimmigration-removals.pdf

ICE. (2015a). DHS releases end of fiscal year 2015 statistics. Retrieved January 18, 2018, from https://www.ice.gov/news/releases/dhs-releases-end-fiscal-year-2015-statistics

ICE. (2015b). Fiscal year 2015 ICE enforcement and removal operations report. Retrieved December 16, 2018, from https://www.ice.gov/removal-statistics/2015

ICE. (2017a). Caso Pilato nets 53 MS-13 arrests. Retrieved January 18, 2018, from https://www.ice.gov/news/releases/caso-pilato-nets-53-ms-13-arrests

ICE. (2017b). HSI continues transnational gang fight in 2017. Retrieved January 18, 2018, from https://www.ice.gov/features/hpr-gangs

ICE. (2018). Fiscal year 2018 ICE enforcement and removal operations report. Retrieved December 16, 2018, from https://www.ice.gov/doclib/about/offices/ero/pdf/eroFY2018Report.pdf

IDMC. (2015a). Global overview 2015: People internally displaced by conflict and violence. Geneva. Retrieved from http://www.internaldisplacement.org/assets/library/Media/201505-Global-Overview-2015/20150506-globaloverview-2015-en.pdf

IDMC. (2015b). Mexico. Country information 2015. Retrieved April 1, 2017, from http://www.internal-displacement.org/database/country/?iso3=MEX

InSight Crime. (2017). MS13. Retrieved March 21, 2017, from http://www.insightcrime.org/el-salvador-organized-crime-news/mara-salvatrucha-ms-13profile

IRB. (2017). Immigration and refugee board of Canada announces new guideline on proceedings involving sexual orientation and gender identity and expression. Retrieved May 3, 2017, from https://www.canada.ca/en/immigrationrefugee/news/2017/05/immigration_and_refugeeboardofcanadaannouncesnewguidelineon proce.html

IRB. (2018). All RPD claims finalized from January 1, 2013 to September 30, 2017. All intake types (except cessation and vacation cases). Retrieved February 2, 2018, from https://github.com/taracarman/Refugee_Claim

IRB. (2019). Claims by country of alleged persecution, 2013-2018. Retrieved March 1, 2019, from https://irb-cisr.gc.ca/en/statistics/protection/Pages/index.aspx

IRCC. (2013a). Danger to public health or public safety. Retrieved June 12, 2017, from http://www.cic.gc.ca/english/resources/tools/medic/admiss/health.asp

IRCC. (2013b). Medical refusals and inadmissibility. Retrieved January 1, 2017, from http://www.cic.gc.ca/english/resources/tools/medic/admiss/index.asp 
IRCC. (2015a). International Mobility Program work permit holders with a valid permit on Dec 31 by program. Retrieved March 4, 2018, from http://www.cic.gc.ca/opendatadonneesouvertes/data/IRCC_FF_04_E.xls

IRCC. (2015b). Refugee claimants by top 50 countries of citizenship, 2006 to 2015. Retrieved April 4, 2017, from http://www.cic.gc.ca/opendatadonneesouvertes/data/IRCC_FF_39_E.xls

IRCC. (2016a). Admissions of permanent residents by country of citizenship, 1980 - Q2 2016. Retrieved May 1, 2017, from www.cic.gc.ca/opendatadonneesouvertes/data/IRCC_PRadmiss_0004_E.xls

IRCC. (2016b). Canada - Admissions of Permanent Residents by Immigration Category, 1980 - Q2 2016. Retrieved June 30, 2017, from http://www.cic.gc.ca/opendatadonneesouvertes/data/IRCC_PRadmiss_0002_E.xls

IRCC. (2017a). Fact Sheet - Temporary Foreign Worker Program. Retrieved May 17, 2017, from http://www.cic.gc.ca/english/resources/publications/employers/temp-foreignworker-program.asp

IRCC. (2017b). Temporary Foreign Worker Program work permit holders by program and sign year, 2006 to 2015. Retrieved May 17, 2017, from http://www.cic.gc.ca/opendatadonneesouvertes/data/IRCC_FF_14_E.xls

IRCC. (2018a). Find your NOC. Retrieved February 2, 2019, from https://www.canada.ca/en/immigration-refugees-citizenship/services/immigratecanada/express-entry/eligibility/find-national-occupation-code.html

IRCC. (2018b). International Mobility Program work permit holders by top 50 countries of citizenship and sign year, 2007 to 2016. Retrieved August 10, 2018, from http://www.cic.gc.ca/opendata-donneesouvertes/data/IRCC_FF_TR_2016_17_E.xls

IRCC. (2018c). Permanent resident landing cards of Mexican citizens, 1980-2015 (NonPersonal Permanent Resident Landing File, Special Access). Database of exclusive use for research purposes, Ottawa.

IRCC. (2018d). Permanent residents by country of citizenship as Mexico, 1980-1999 (NonPersonal Permanent Resident Landing File, Special Access). Database of exclusive use for research purposes, Ottawa, Canada.

IRCC. (2018e). Permanent residents by country of citizenship as Mexico, 2000-2015 (NonPersonal Permanent Resident Landing File, special access). Database of exclusive use for research purposes, Ottawa, Canada.

IRCC. (2018f). Sponsor your relatives: Who can sponsor. Retrieved November 1, 2018, from https://www.canada.ca/en/immigration-refugees-citizenship/services/immigratecanada/family-sponsorship/other-relatives/eligibility.html

IRCC. (2018g). Temporary Foreign Worker Program work permit holders by top 50 countries of citizenship and sign year, 2007 to 2016. Retrieved March 1, 2019, from http://www.cic.gc.ca/opendata-donneesouvertes/data/IRCC_FF_TR_2016_16_E.xls

IRCC. (2018h). Temporary Foreign Worker Program work permit holders with a valid permit on December 31st by top 50 countries of citizenship, 2007 to 2016. Retrieved March 1, 2019, from http://www.cic.gc.ca/opendatadonneesouvertes/data/IRCC_FF_TR_2016_05_E.xls

IRCC. (2018i). Who can apply to sponsor spouses, partners or children. Retrieved November 8, 2018, from https://www.canada.ca/en/immigration-refugeescitizenship/services/immigrate-canada/family-sponsorship/spouse-partnerchildren/eligibility.html

IRCC. (2019a). Canada ends the Designated Country of Origin practice. Retrieved May 17, 2019, from https://www.canada.ca/en/immigration-refugees- 
citizenship/news/2019/05/canada-ends-the-designated-country-of-origin-practice.html

IRCC. (2019b). Permanent residents by source country, 2008 - 2017. Retrieved May 1, 2019, from http://www.cic.gc.ca/opendata-donneesouvertes/data/IRCC_FF_PR_2017_15_E.xls IRCC. (2019c). Public policy concerning work permit restrictions for Designated Country of Origin asylum claimants. Retrieved May 17, 2019, from https://www.canada.ca/en/immigration-refugees-citizenship/corporate/mandate/policiesoperational-instructions-agreements/work-permit-designated-country-origin.html

Israelite, N. K., Herman, A., Khan, Y., Andino, R., \& Pacini-Ketchabaw, V. (2004). Voices of recent Latina immigrants and refugees: Effects of budget cuts on their settlement experiences. Toronto: CERIS. Retrieved from http://ceris.metropolis.net/Virtual Library/community/israekute1/israelite1.html

Itzigsohn, J., Cabral, C. D., Hernández Medina, E., \& Vázquez, O. (1999). Mapping Dominican transnationalism: Narrow and broad transnational practices. Ethnic and Racial Studies, 22(2), 316-339.

Itzigsohn, J., \& Giorguli Saucedo, S. (2002). Immigrant incorporation and sociocultural transnationalism. International Migration Review, 36(3), 766-798.

Itzigsohn, J., \& Giorguli-Saucedo, S. (2005). Incorporation, transnationalism, and gender: Immigrant incorporation and transnational participation as gendered processes. International Migration Review, 39(4), 895-920.

Jacobson, R. (2011). Testimony of Roberta Jacobson Principal Deputy Assistant Secretary of State. Bureau of Western Hemisphere Affairs (WHA) at the Department of State. Retrieved April 17, 2014, from http://www.drugcaucus.senate.gov/sites/default/files/JACOBSON testimony.pdf

Janzen, W. (2004). Welcoming the returning "Kanadier" Mennonites from Mexico. Journal of Mennonite Studies, 22, 11-24.

Jordan, S., \& Morrissey, C. (2013, May). “Por qué motivos?” Solicitudes de asilo de LGBT en Canadá. Revista Migraciones Forzadas, 13-15. Retrieved from http://rua.ua.es/dspace/handle/10045/28644

Juteau, F. (1989). Fréquentations, mariage et divorce chez les Salvadoriens de Montréal. Université de Montréal.

Kalleberg, A. L. (2009). Precarious work, insecure workers: Employment relations in transition. American Sociological Review, 74(1), 1-22.

Kamel, R., \& Anya, H. (1999). The maquiladora reader: Cross-border organizing since NAFTA. Philadelphia: American Friends Service Committee.

Kaplan, R. (2014, March 4). Obama is "deporter-in-chief," says prominent Latino group. $C B S$ News. New York. Retrieved from https:/www.cbsnews.com/news/obama-is-deporter-inchief-says-prominent-latino-group/

Katz, S. (2015). Presentation at the roundtable "Canadian engagement in the Americas: Policy, solidarity and impacts" at the 6th annual Ottawa-region conference on Latin America and the Caribbean: Mirrors and mirages (April 16-18). Ottawa: Carleton University.

Kazemipur, A. (2008). Social capital profiles: Immigrants and the native-born in Canada (PMC Working Paper Series No. WP02-08). Edmonton.

Kearney, M. (1995). The effects of trans-national culture, economy and migration on Mixtec identity in Oaxacalifornia. In M. P. Smith \& J. R. Feagin (Eds.), The bubbling cauldron: Race, ethnicity, and the urban crisis (pp. 226-243). Minneapolis: University of Minnesota Press.

Kelly, J. F. (2015). Posture statement of General John F. Kelly, United States Marine Corps Commander, United States Southern Command before the 114th Congress Senate Armed Services Committee. Retrieved April 4, 2017, from https://www.armed- 
services.senate.gov/download/kelly_03-12-15

Kelly, P. (2003). Canadian-Asian transnationalism. The Canadian Geographer / Le Géographe Canadien, 47(3), 209-218.

Kelly, P. (2012). Migration, transnationalism, and the spaces of class identity. Philippine Studies: Historical and Ethnographic Viewpoints, 60(2), 153-186.

Kelly, P. (2015). Transnationalism, emotion and second-generation social mobility in the Filipino-Canadian diaspora. Singapore Journal of Tropical Geography, 36, 280-299.

Kelly, P. (2007). Transnationalism and political participation among Filipinos in Canada. In L. Goldring \& S. Krishnamurti (Eds.), Organizing the transnational: Labour, politics, and social change (pp. 215-231). Vancouver, Toronto: UBC Press.

Kenney, J. (2009). Canada imposes a visa on Mexico. Retrieved April 15, 2017, from http://news.gc.ca/web/article-en.do?nid=466839

Kenney, J. (2012). Speaking notes for The Honourable Jason Kenney, P.C., M.P. Minister of Citizenship, Immigration and Multiculturalism at a news conference following the tabling of Bill C-31, Protecting Canada's Immigration System Act. Retrieved April 17, 2017, from http://www.cic.gc.ca/english/department/media/speeches/2012/2012-02-16.asp

Keung, N. (2009, October 23). Mexican woman deported to her death. The Toronto Star. Toronto. Retrieved from https://www.thestar.com/news/gta/2009/10/23/mexican_woman_deported_to_her_death.h tml

Keung, N. (2015, March 2). Canada's refugee acceptance rate up despite asylum restrictions. The Toronto Star. Toronto. Retrieved from https://www.thestar.com/news/immigration/2015/03/01/canadas-refugee-acceptance-rateup-despite-asylum-restrictions.html

Keung, N. (2019, July 18). Record number of Canada-bound visitors barred from flights on advice of Canada border agents. The Toronto Star. Toronto. Retrieved from https://www.thestar.com/news/canada/2019/07/17/record-number-of-canada-boundvisitors-barred-from-flights-on-advice-of-canada-border-agents.html

Kilbride, K. M., Tyyskä, V., Ali, M., \& Berman, R. (2008). Reclaiming voice: Challenges and opportunities for immigrant women for learning English (CERIS working paper No. 72). Toronto.

King, R., Christou, A., \& Teerling, J. (2010). "We took a bath with the chickens": Memories of childhood visits to the homeland by second-generation Greek and Greek Cypriot "returnees." Global Networks. A Journal of Transnational Affairs, 11(1), 1-23.

Klassen, D. H. (2008). "I wanted a life of my own": Creating a singlewoman Mennonite identity in Mexico. Journal of Mennonite Studies, 26, 49-68.

Klassen, J. (2015, September). Joining empire: Canadian foreign policy under Harper. Canadian Dimension. Retrieved from https:/canadiandimension.com/articles/view/joining-empire-canadian-foreign-policyunder-harper

Kobayashi, A. (2006). Multiculturalism, transnationalism, and immigrant integration: What can we learn from Hong Kong immigration diversity in the city? In L. D’Haenens, M. Hooghe, D. Vanheule, \& H. Gezduci (Eds.), "New” citizens, new policies? : Developments in diversity policy in Canada and Flanders (pp. 25-34). Gent: Academia Press.

Köhler, N. (2009, July). A crackdown on queue-jumpers. Will the Tories make bogus refugee claims an election issue? Maclean's. Retrieved from http://www.macleans.ca/news/canada/a-crackdown-on-queue-jumpers/

Konrad, V., \& Nicol, H. N. (2008). Beyond walls: Re-inventing the Canada-United States 
borderlands. Aldershot, Burlington: Routledge.

Kornbluh, P. (1987). Nicaragua: The price of intervention. Reagan's wars against the Sandinistas. Washington, D.C.: Institute for Policy Studies.

Kornbluh, P. (1998). Bay of Pigs declassified. The secret CIA report. New York City: The New Press.

Kornbluh, P. (2004a). Brazil marks 40th anniversary of military coup. Declassified documents shed light on U.S. role. Retrieved March 1, 2017, from http://nsarchive.gwu.edu/NSAEBB/NSAEBB118/index.htm

Kornbluh, P. (2004b). Nixon on Chile intervention. Retrieved February 4, 2015, from http://www2.gwu.edu/ nsarchiv/NSAEBB/NSAEBB110/

Kornbluh, P. (2009). Brazil conspired with U.S. to overthrow Allende. Retrieved March 1, 2017, from http://nsarchive.gwu.edu/NSAEBB/NSAEBB282/index.htm

Kornbluh, P. (2013). The Pinochet file: A declassified dossier on atrocity and accountability (2nd ed.). New York City: The New Press.

Kunz, R. (2008). "Remittances are beautiful"? Gender implications of the new global remittances trend. Third World Quarterly, 29(7), 1389-1409.

Labelle, M., Rocher, F., \& Field, A.-M. (2006). Contentious politics and transnationalism from below: The case of ethnic and racialized minorities in Quebec. In V. Satzewich \& L.

Wong (Eds.), Transnational identities and practices in Canada (pp. 111-129). Vancouver: UBC Press.

Lacey, M. (2009, November 15). Money trickles north as Mexicans help relatives. The New York Times. New York. Retrieved from https://www.nytimes.com/2009/11/16/world/americas/16mexico.html

Lalonde, M. (1970). Speak White. Retrieved February 2, 2018, from https://www.youtube.com/watch?v=0hsifsVi2po

Lambert-Racine, M., \& Benatuil, D. (2014). Canadian trade and investment activity: CanadaMexico. Ottawa. Retrieved from http://www.lop.parl.gc.ca/Content/LOP/ResearchPublications/2014-47-e.pdf

Landolt, P. (2007a). Nation-state building projects and the politics of transnational migration: Locating Salvadorans in Canada, the United States, and El Salvador. In G. Yurdakul \& Y. M. Bodemann (Eds.), Citizenship and immigrant incorporation. Comparative perspectives on North America and Western Europe (pp. 141-162). New York: Palgrave Macmillan.

Landolt, P. (2007b). The institutional landscapes of Salvadoran refugee migration: Transnational and local views from Los Angeles and Toronto. In L. Goldring \& S. Krishnamurti (Eds.), Organizing the transnational: Labour, politics, and social change (pp. 191-205). Vancouver, Toronto: UBC Press.

Landolt, P. (2008). The transnational geographies of immigrant politics: Insights from a comparative study of migrant grassroots organizing. The Sociological Quarterly, 49(1), 53-77.

Landolt, P., Autler, L., \& Baires, S. (1999). From hermano lejano to hermano mayor: The dialectics of Salvadoran transnationalism. Ethnic and Racial Studies, 22(2), 290-315.

Landolt, P., \& Goldring, L. (2009). Immigrant political socialization as bridging and boundary work: Mapping the multi-layered incorporation of Latin American immigrants in Toronto. Ethnic and Racial Studies, 32(7), 1226-1247.

Landolt, P., \& Goldring, L. (2010). Political cultures and transnational social fields: Chileans, Colombians and Canadian activists in Toronto. Global Networks. A Journal of Transnational Affairs, 10(4), 443-466.

Landolt, P., Goldring, L., \& Bernhard, J. K. (2011). Agenda setting and immigrant politics: 
The case of Latin Americans in Toronto. American Behavioral Scientist, 55(9), 12351266.

Lapalme, A. (2013). Citoyenneté, mondialisation et migration internationale: les réfugiés et demandeurs d'asile mexicains à Montréal. Université de Montréal.

Larouche, V. (2019). États-Unis : Explosion des passages clandestins depuis le Québec. La Presse. Montréal. Retrieved from https://www.lapresse.ca/actualites/201905/01/015224154-etats-unis-explosion-des-passages-clandestins-depuis-le-quebec.php

Lauer, S., Wilkinson, L., Yan, M. C., Sin, R., \& Tsang, A. K. T. (2012). Immigrant youth and employment: Lessons learned from the analysis of LSIC and 82 lived stories.

International Migration and Integration, 13, 1-19.

Lee, H. (2011). Rethinking transnationalism through the second generation. The Australian Journal of Anthropology, 22(3), 295-313.

LeFrançois, B. A. (2013). Adultism. In The Encyclopedia of Critical Psychology. Springer Reference.

Leibel, G. C. (2005). The changing face of farm labour in British Columbia: Exploring the experiences of migrant Quebecois and Mexican agricultural workers in the Okanagan Valley. University of Victoria. Retrieved from https://dspace.library.uvic.ca/handle/1828/975

Leavitt, S. (2019, June 16). Quebec passes bill to reform immigration system after government invokes closure. CBC News. Montreal. Retrieved from https://www.cbc.ca/news/canada/montreal/closure-bill-21-bill-9-national-assembly1.5177520

Levitt, P. (1998). Social remittances: Migration driven local-level forms of cultural diffusion. The International Migration Review, 32(4), 926-948.

Levitt, P. (2001a). The transnational villagers. Berkeley, Los Angeles, London: University of California Press.

Levitt, P. (2001b). Transnational migration: Taking stock and future directions. Global Networks. A Journal of Transnational Affairs, 1(3), 195-216.

Levitt, P. (2002). The ties that change: Relations to the ancestral home over the life cycle. In P. Levitt \& M. C. Waters (Eds.), The changing face of home: The transnational lives of the second generation (pp. 123-144). New York: Russell Sage Foundation.

Levitt, P. (2005). Social remittances: Culture as a development tool. Washington, D.C. Retrieved from https://publications.iadb.org/handle/11319/859

Levitt, P., DeWind, J., \& Vertovec, S. (2003). International perspectives on transnational migration: An introduction. International Migration Review, 37(3), 565-575.

Levitt, P., \& Glick Schiller, N. (2004). Conceptualizing simultaneity: A transnational social field perspective on society. International Migration Review, 38(3), 1002-1039.

Levitt, P., \& Jaworsky, B. N. (2007). Transnational migration studies: Past developments and future trends. Annual Review of Sociology, 33(1), 129-156.

Levitt, P., \& Lamba-Nieves, D. (2011). Social remittances revisited. Journal of Ethnic and Migration Studies, 37(1), 1-22. https://doi.org/10.1080/1369183X.2011.521361

Levitt, P., \& Lamba-Nieves, D. (2013). Rethinking social remittances and the migrationdevelopment nexus from the perspective of time. Migration Letters, 10(1), 11-22.

Levitt, P., \& Waters, M. C. (2002). The changing face of home: The transnational lives of the second generation. New York: Russell Sage Foundation.

Li, P. S., \& Xiaoling Li, E. (2013). Decomposing immigrants' economic integration in earnings disparity: Racial variations in unexpected returns. Canadian Ethnic Studies, 45(3), 81-94. 
Lightman, N., \& Good Gingrich, L. (2012). The intersecting dynamics of social exclusion: Age, gender, race and immigrant status in Canada's labour market. Canadian Ethnic Studies, 44(3), 121-145.

Linteau, P.-A., Durocher, R., Robert, J.-C., \& Ricard, F. (1989). Histoire du Québec contemporain. Tome II. Le Québec depuis 1930. Montréal: Les Éditions du Boréal.

Lizarzaburu, J. (2004, January). Mexican migrants' growing influence. BBC News. London. Retrieved from http://news.bbc.co.uk/2/hi/americas/3582881.stm

Ljunggren, D. (2017). Canada to Mexico on NAFTA: You might be on your own. Retrieved March 20, 2017, from https://www.reuters.com/article/us-usa-nafta-canada-mexicoidUSKBN1582MV

Llamoca, J. (2017). The kids who got "the Mexican Repatriation" of the 1930s into California textbooks. Retrieved March 31, 2017, from http://latinousa.org/2017/03/31/kids-gotmexican-repatriation-1930s-california-textbooks/

Loaiza, E. (1989). Socio-demographic characteristics and economic attainment of Latin American immigrants in Canada: A census data assessment, 1981, 1986. The University of Western Ontario.

Long, N. H. (2002). Conceptions of political participation among recent Latin-American newcomers to Canada: a phenomenographic examination. The University of New Brunswick.

Long, N. H., \& Hughes, A. S. (2003). The political integration of newcomers of Latin American origin to Canada: An examination of the role and relevance of prior knowledge. Encounters on Education, 4(Fall), 65-82.

López, R. J., Connell, R., \& Kraul, C. (2005, October 30). Gang uses deportation to its advantage to flourish in U.S. Los Angeles Times. Los Angeles. Retrieved from http://www.latimes.com/local/la-me-gang30oct30-story.html

López Salinas, A. (2016). Exploring transnational economic, social, and political participation of Mexican immigrants in Oregon. Portland State University.

Lu, Y., \& Hou, F. (2015). International students who become permanent residents in Canada. Ottawa.

Lugo, A. (2008). Fragmented lives, assembled parts: Culture, capitalism, and conquest at the U.S.-Mexico Border. Austin: University of Texas Press.

Luján, O. (2017). The “Other” Mexicans: Transnational citizenship and Mexican middle class migration in Toronto, Canada. Ryerson University.

Macdonald, L. (2003). Statement by Dr. Laura Macdonald to the Standing Senate Committee on Foreign Affairs and International Trade concerning the Canada-Mexico trade relationship. Retrieved March 23, 2017, from https://sencanada.ca/content/sen/committee/372/fore/witn/macdonald1-e.htm

Macdonald, L. (2016). Canada in the posthegemonic hemisphere: Evaluating the Harper government's Americas strategy. Studies in Political Economy, 97(1), 1-17. Retrieved from http://www.tandfonline.com/doi/full/10.1080/07078552.2016.1174460

Macdonald, L. (2017). Canadian development assistance to Latin America. Unpublished manuscript.

MacDougall, N. (n.d.). Foreign competitors in the US avocado Market. Retrieved June 21, 2017, from http://www.calpoly.edu/ nmacdoug/Avocado_Web_Project/Avocado_Web_Page04.htm

Mahler, S. J., \& Pessar, P. R. (2001). Gendered geographies of power: Analyzing gender across transnational spaces. Identities, 7(4), 441-459.

Maira, S., \& Soep, E. (2005). Introduction. In S. Maira \& E. Soep (Eds.), Youthscapes: The popular, the national, the global (p. 257). Philadelphia: University of Pennsylvania Press. 
Malkin, E. (2017, April 19). Corruption at a level of audacity "never seen in Mexico." The New York Times. Mexico City. Retrieved from

https://www.nytimes.com/2017/04/19/world/americas/in-mexico-mounting-misdeeds-butgovernors-escape-justice.html

Mansouri, F., \& Francis, S. (2009). Migrant youth, cultural adaptation and social policy. In F. Mansouri (Ed.), Youth identity and migration: Culture, values and social connectedness (pp. 11-23). Australia: Common Ground Book.

Marchand, M. H. (2006). Tlaxcala: ¿Migración o desarrollo local? Puebla: Universidad de las Américas Puebla.

Marchand, M. H. (2011). What kind of sustainability and for whom? Some reflections based on lived realities in the Mexican Mixteca. Development, 54(2), 247-249.

Marchand, M. H. (2014a). Engendering transnational movements: Transnationalizing women's and feminist movements in the Americas. Latin American Policy, 5(2), 180-192.

Marchand, M. H. (2014b). Mexican migrant transnationalism and imaginaries of temporary/permanent belonging. In L. F. Vosko, V. Preston, \& R. Latham (Eds.), Liberating temporariness? Migration, work, and citizenship in an age of insecurity (pp. 285-304). Montreal \& Kingston, London, Ithaca: McGill-Queen's University Press.

Marchand, M. H. (2015). Migrants as "experts" or "agents" of development? A postcolonial feminist critique. In T. van Naerssen, L. Smith, T. Davids, \& M. H. Marchand (Eds.), Women, gender, remittances and development in the global south (2nd ed., pp. 189-205). Abingdon, New York: Routledge.

Martin, P., Lapalme, A., \& Roffe Gutman, M. (2013). Réfugiés et demandeurs d'asile mexicains à Montréal : actes de citoyenneté au sein de l'espace nord-américain? ACME: An International Journal for Critical Geographies, 12(3), 603-628. Retrieved from https://ojs.unbc.ca/index.php/acme/article/view/982

Martin, P. M., \& Lapalme, A. (2012, August). Mexican mobility and Canada: Hardening boundaries and growing resistance. NACLA. Retrieved from http://nacla.org/blog/2012/8/8/mexican-mobility-and-canada-hardening-boundaries-andgrowing-resistance

Martin, P. M., \& Lapalme, A. (2014). Mexican asylum seekers to Canada: The door closes. Retrieved March 21, 2017, from https://nacla.org/article/mexican-asylum-seekers-canadadoor-closes

Martínez, J. R. (1957). Mexican emigration to the U.S., 1910-1930. University of California.

Masferrer, C., \& Rodríguez, O. (2019). Migración y violencia: Cambios en la migración interna e internacional en México. Otros Diálogos de El Colegio de México. Retrieved from https://otrosdialogos.colmex.mx/migracion-y-violencia-cambios-en-la-migracioninterna-e-internacional-en-mexico

Massey, D. S. (1986). The social organization of Mexican migration to the United States. The Annals of the American Academy of Political and Social Science, 487(1), 102-113.

Massey, D. S. (1990). Social structure, household strategies, and the cumulative causation of migration. Population Index, 56(1), 3-26.

Massey, D. S. (1999). Why does immigration occur? A theoretical synthesis. In C. Hirschman, P. Kasinitz, \& J. DeWind (Eds.), The handbook of international migration: The American experience (Vol. 1st, pp. 34-52). New York: Russell Sage Foundation.

Massey, D. S. (2007). Categorically unequal: The American stratification system. New York: Russell Sage Foundation.

Massey, D. S. (2009). Racial formation in theory and practice: The case of Mexicans in the United States. Race and Social Problems, 1(1), 12-26. 
Massey, D. S., Alarcón, R., Durand, J., \& González, H. (1987). Return to Aztlan: the social process of international migration from western Mexico. Berkeley: University of California Press.

Massey, D. S., \& Aysa, M. (2005). Social capital and international migration from Latin America. Mexico City.

Massey, D. S., \& Basem, L. C. (1992). Determinants of savings, remittances, and spending patterns among US migrants in four Mexican communities. Sociological Inquiry, 62(2), 185-207.

Massey, D. S., Durand, J., \& Malone, N. J. (2002). Beyond smoke and mirrors: Mexican immigration in an era of free trade. New York: Russell Sage Foundation.

Massey, D. S., Durand, J., \& Pren, K. A. (2016). The precarious position of Latino immigrants in the United States: A comparative analysis of ethnosurvey data. The Annals of the American Academy of Political and Social Science, 666(1), 91-109.

Massey, D. S., \& Gentsch, K. (2014). Undocumented migration to the United States and the wages of Mexican immigrants. International Migration Review, 48(2), 482-499.

Massey, D. S., Goldring, L., \& Durand, J. (1994). Continuities in transnational migration: An analysis of nineteen Mexican communities. American Journal of Sociology, 99(6), 14921533.

Massey, D. S., \& Parrado, E. (1994). Migradollars: The remittances and savings of Mexican migrants to the USA. Population Research and Policy Review, 13(1), 3-30.

Massey, D. S., \& Parrado, E. A. (1998). International migration and business formation in Mexico. Social Science Quarterly, 79(1), 1-20.

Massey, D. S., Riosmena, F., Garzón, L., Durand, J., \& Cachón, L. (2006). Capital social, política social y migración desde comunidades tradicionales y nuevas comunidades de origen en México. Reis, (116), 97-121.

Mata, F. (1985). Latin American immigration to Canada: Some reflections on the immigration statistics North-South. Canadian Journal of Latin American and Caribbean Studies, 20, $27-42$.

Maton, K. (2008). Habitus. In M. Grenfell (Ed.), Pierre Bourdieu. Key concepts (pp. 49-66). Stocksfield: Acumen.

McCaa, R. (2003). Missing millions: The demographic costs of the Mexican Revolution. Mexican Studies, 19(2), 367-400.

McCallum, J. (2016). Speaking notes for John McCallum, Minister of Immigration, Refugees and Citizenship at a luncheon hosted by the Halifax Chamber of Commerce. Retrieved January 22, 2018, from https://www.canada.ca/en/immigration-refugeescitizenship/news/2016/03/speaking-notes-for-john-mccallum-minister-of-immigrationrefugees-and-citizenship-at-a-luncheon-hosted-by-the-halifax-chamber-of-commerce.html

McCombs, V. M. (1925). From over the border. A study of the Mexicans in the United States. New York: Council of Women for Home Missions and Missionary Education Movement.

McCuaig-Boyd (Alberta Minister of Energy), M. (2017). Third session of the 29th legislature of the Legislative Assembly of Alberta. Edmonton, Canada: Hansard (Parliamentary Debates). Retrieved from http://www.assembly.ab.ca/ISYS/LADDAR_files/docs/hansards/han/legislature_29/sessi on_3/20170524_1330_01_han.pdf

McDougal, T., Shirk, D. A., Muggah, R., \& Patterson, J. H. (2013). The way of the gun: Estimating firearms traffic across the U.S.-Mexico border. San Diego. Retrieved from http://catcher.sandiego.edu/items/peacestudies/way_of_the_gun.pdf

McGregor, J. (2017, February 21). Canada isn't about to "throw Mexico under the bus," foreign ministers say. $C B C$ News. Ottawa. Retrieved from 
https://www.cbc.ca/news/politics/nafta-mulroney-guajardo-freeland-1.3992043

McIlwaine, C. (2012). Constructing transnational social spaces among Latin American migrants in Europe: Perspectives from the UK. Cambridge Journal of Regions, Economy and Society, 5(2), 289-303.

McLaughlin, J., \& Hennebry, J. L. (2013). Pathways to precarity: Structural vulnerabilities and lived consequences for migrant farmworkers in Canada. In L. Goldring \& P. Landolt (Eds.), Producing and negotiating non-citizenship: Precarious legal status in Canada (pp. 175-194). Toronto, Ont.: University of Toronto Press.

McLellan, J. (2004). Cambodian refugees in Ontario: Religious identities, social cohesion and transnational linkages. Canadian Ethnic Studies Journal, 36(2), 101-117.

McLellan, J. (2009). Cambodian refugees in Ontario: Resettlement, religion, and identity. Toronto: University of Toronto Press.

Medina, M. I. (1997). The criminalization of immigration law: Employer sanctions and marriage fraud. George Mason Law Review, 5(4), 669-732.

Melia, M. J. (2004). Transatlantic dialogue on integration of immigrant children and adolescents. International Migration, 42(4), 123-139.

Méndez Robles, R. (2018, July 25). AMLO recibe a funcionarios de alto nivel de Canadá. MVS Noticias. México. Retrieved from https:/mvsnoticias.com/\#!/noticias/amlo-recibe-afuncionarios-de-alto-nivel-de-canada-289

Menegus, M., \& Tortolero, A. (1999). Agricultura mexicana: Crecimiento e innovaciones. México: Instituto Mora / El Colegio de Michoacán / El Colegio de México / Instituto de Investigaciones Históricas-UNAM.

Meredith, D. (1992). Guatemalan refugees and their process of adjustment in Toronto. York University.

Merriam, J., \& Birchard, J. (2000, September 23). Crossfire: The issue: Should Canada deny entry to the HIV positive? Sun Times, p. A4. Owen Sound, Ontario. Retrieved from http://search.proquest.com/docview/349157618

Merriam-Webster Dictionary. (2018). Latinx. Retrieved December 12, 2018, from https://www.merriam-webster.com/dictionary/Latinx

Merry, R. W. (2011). A country of vast designs: James K. Polk, the Mexican War, and the conquest of the American continent. New York: Simon \& Schuster.

Meyers, D. W. (2002). Migrant remittances to Latin America: Reviewing the literature. In R. O. De la Garza \& B. L. Lowell (Eds.), Sending money home: Hispanic remittances and community development (pp. 53-81). Lanhalm, Boulder, New York, Oxford: Rowman and Littlefield Publishers.

Mezei, K. (1998). Bilingualism and translation in/of Michèle Lalonde's Speak White. The Translator, 4(2), 229-247.

Milenio Digital. (2018). Ebrard: Trudeau, con la mejor disposición para trabajar con AMLO. Milenio. México. Retrieved from http://www.milenio.com/politica/ebrard-trudeau-con-lamejor-disposicion-para-trabajar-con-amlo

Miller, R. J. (2006). Native America, discovered and conquered: Thomas Jefferson, Lewis \& Clark, and Manifest Destiny. Westport, Connecticut: Greenwood Publishing Group.

Mina, N. (2015). Homeland activism, public performance, and the construction of identity: An examination of Greek Canadian transnationalism, 1900s-1990s. University of Toronto. Retrieved from https://tspace.library.utoronto.ca/handle/1807/69412

Mines, R., \& Massey, D. S. (1985). Patterns of migration to the United States from two Mexican communities. Latin American Research Review, 20(2), 104-123.

Mitchell, B. A., Wister, A. V., \& Gee, E. M. (2002). "There's no place like home": An analysis of young adults' mature coresidency in Canada. The International Journal of Aging and 
Human Development, 54(1), 57-84.

Moore, J. (2015). Unearthing Canadian complicity: Excellon Resources, the Canadian embassy, and the violation of land and labour rights in Durango, Mexico. Ottawa. Retrieved from https://miningwatch.ca/sites/default/files/excellon_report_2015-02-23.pdf

Moore, J., \& Colgrove, G. (2013). Corruption, murder and Canadian mining in Mexico: The case of Blackfire exploration and the Canadian Embassy. Ottawa. Retrieved from $\mathrm{http} / / / \mathrm{m} 4$.mayfirst.org/wp-content/docs/blackfire_embassy_report_2013-05-02_ENG.pdf

Mora-Torres, J. (2011). "Los de casa se van, los de afuera no vienen." The first Mexican immigrants, 1848-1900. In M. Overmyer-Velázquez (Ed.), Beyond la frontera: The history of Mexico-U.S. migration (pp. 3-27). New York: Oxford University Press.

Morissette, R. (2016). Perspectives on the youth labour market in Canada. Ottawa. Retrieved from https://www150.statcan.gc.ca/n1/pub/11-631-x/11-631-x2016002-eng.htm

Moser, C. (1996). Confronting crisis: A comparative study of household responses to poverty and vulnerability in four poor urban communities. Washington, D.C.: World Bank.

Mueller, R. E. (2005). Mexican immigrants and temporary residents in Canada: Current knowledge and future research. Migraciones Internacionales, 3(1), 32-56.

Nájar, A. (2009). Narco S.A., una empresa global. Expansión. Retrieved from http://expansion.mx/expansion/2009/07/17/narco-sa

National Geographic. (2019). Día de los Muertos. Retrieved January 2, 2019, from https://www.nationalgeographic.org/media/dia-de-los-muertos/

National Interfaith Committee for Worker Justice. (1998). Cross border blues: A call for justice for maquiladora workers in Tehuacán. Chicago: National Interfaith Committee for Worker Justice.

$\mathrm{Ng}$, R. (1990). Immigrant women: The construction of a labour market category. Canadian Journal of Women and the Law, 40(1), 96-112.

Nieto, N. (2012). Political corruption and narcotrafficking in Mexico. Transcience, 3(2), 24 36.

Noble, G. (2013). "It is home but it is not home": Habitus, field and the migrant. Journal of Sociology, 49(2-3), 341-356.

Nolin Hanlon, C. (1997). Guatemalan refugees and returnees: Local geography and Maya identity (CERLAC Working Paper Series No. 11). North York, Ont.

Nolin Hanlon, C. (1999). Guatemalan refugees and returnees: Place and Maya identity. In L. L. North \& A. Simmons (Eds.), Journeys of fear: Refugee return and national transformation in Guatemala (1st ed., pp. 213-236). Montreal.

Nolin Hanlon, C. (2000). Transnational ruptures: Political violence and refugee and immigrant experiences in Guatemala and Canada. Queen's University, Kingston.

Nolin Hanlon, C. (2001). Transnational ruptures and sutures: Questions of identity and social relations among Guatemalans in Canada. GeoJournal, 56(1), 59-67.

Nolin Hanlon, C. (2004). Spatializing the immobility of Guatemalan transnationalism in Canada. Canadian Journal of Latin America and Caribbean Studies, 29(57-58), 267288.

Nolin Hanlon, C. (2006). Transnational ruptures: Gender and forced migration. Aldershot, England; Burlington, VT: Ashgate.

Notimex. (2015). Los mexicanos en Canadá son una migración calificada: investigador. Retrieved January 14, 2018, from http://www.lineadirectaportal.com/movil/publicacion.php?id=227211\&origen=s\&seccion $\mathrm{ID}=\&$ back $=$ seccion. php? seccionID $=9 \&$ seccion $=$

Notimex. (2018). Cerca de dos millones de canadienses visitaron México en 2017. Economíahoy.mx. Ciudad de México. Retrieved from 
https://www.economiahoy.mx/turismo-eAm-mx/noticias/8841965/01/18/Cerca-de-dosmillones-de-canadienses-visitaron-Mexico-en-2017.html

O’Donoghue, A. (2001). Okanagan Dreams. Canada: National Film Board of Canada. Retrieved from http://www.nfb.ca/film/okanagan_dreams/

Ogelsby, J. C. M. (1976). Canadian-Mexican trade relations: One common market between them. In Gringos from the far North (p. 346). Toronto: Macmillan of Canada/ MacleanHunter Press.

Olson-Raymer, G. (2014). Whose Manifest Destiny? The conquest of northern Mexico. Retrieved March 29, 2017, from http://users.humboldt.edu/ogayle/hist110/unit3/MexicanAmericanWar.html

Ontario. (2018). Ontario Immigrant Nominee Program: Human Capital. Retrieved March 9, 2017, from http://www.ontarioimmigration.ca/en/pnp/OI_PNPCAPITAL.html

Ontario. (2019). Learn about OSAP. Retrieved March 2, 2019, from https://www.ontario.ca/page/osap-ontario-student-assistance-program

Oreopoulos, P. (2011). Why do skilled immigrants struggle in the labor market? A field experiment with thirteen thousand resumes. American Economic Journal: Economic Policy, 3(4), 48-17.

Oreopoulos, P., \& Dechief, D. (2011). Why do some employers prefer to interview Matthew, but not Samir? New evidence from Toronto, Montreal, and Vancouver (CERID Working Paper Series No. 13). Vancouver.

Orozco, M. (2009). Migration and remittances in times of recession: Effects on Latin American economies. Paris. Retrieved from http://www.oecd.org/dev/americas/42753222.pdf

Osorno, D. E. (2011). ¿Por qué mataron al alcalde? Retrieved June 24, 2017, from https://cronicasperiodisticas.wordpress.com/2011/08/27/ipor-que-mataron-al-alcalde/

Paasche, E., \& Fangen, K. (2012). Transnational involvement: Reading quantitative studies in light of qualitative data. International Journal of Population Research, 1(580819), 12. Retrieved from http://www.hindawi.com/journals/ijpr/2012/580819/

Padgett, H. (2013). Yo maté con el Z-40: La historia de "Karen." SinEmbargo. Retrieved from http://www.sinembargo.mx/17-07-2013/689011

Painter, J., \& Jeffrey, A. (2012). Political geography: An introduction to space and power. London: Sage Publications.

Paley, D. (2015). Mexico one year after Ayotzinapa. In Drug war capitalism (2nd ed., pp. 216). Chico: AK Press. Retrieved from http://www.revolutionbythebook.akpress.org/wpcontent/uploads/2015/09/Pamphlet-to-read.pdf

Papp, L. (2000, September 20). Immigrants may face HIV test; Health Canada issues call for "safety first" policy. The Toronto Star, p. A01. Toronto. Retrieved from http://search.proquest.com/docview/438183069

Parliament of Canada. An Act to amend the Immigration and Refugee Protection Act, the Balanced Refugee Reform Act, the Marine Transportation Security Act and the Department of Citizenship and Immigration Act (2012). Ottawa: Parliament of Canada. Retrieved from https:/www.parl.ca/DocumentViewer/en/41-1/bill/C-31/royal-assent

Passel, J. S., \& Cohn, D. (2019). Mexicans decline to less than half the U.S. unauthorized immigrant population for the first time. Retrieved June 12, 2019, from https://www.pewresearch.org/fact-tank/2019/06/12/us-unauthorized-immigrantpopulation-2017

Paz Ramírez, A. G. (2013). Embodying and resisting labour apartheid: Racism and Mexican farm workers in Canada's seasonal agricultural workers program. The University of 
British Columbia.

Peddie, F. (2014). Young, well-educated, and adaptable: Chilean exiles in Ontario and Quebec, 1973-2010. Winnipeg: University of Manitoba Press.

PEN Canada. (2016). Can I be arrested for protesting? Retrieved November 2, 2018, from https://pencanada.ca/blog/canadians-right-to-protest/

Pendakur, K., \& Pendakur, R. (2016). Which child immigrants face earnings disparity? Age-atimmigration, ethnic minority status and labour market attainment in Canada.

International Migration, 54(5), 43-58.

Pérez-Armendáriz, C., \& Crow, D. (2010). Do migrants remit democracy? International migration, political beliefs, and behavior in Mexico. Comparative Political Studies, 43(1), 119-148.

Pessar, P. R. (1999). The role of gender, households, and social networks in the migration process: A review and appraisal. In C. Hirschman, P. Kasinitz, \& J. DeWind (Eds.), The handbook of international migration (pp. 53-70). New York: Russell Sage Foundation.

Pessar, P. R., \& Mahler, S. J. (2001). Gender and transnational migration (Transnational Communities Programme No. WPTC-01-20). Oxford.

Pessar, P. R., \& Mahler, S. J. (2003). Transnational migration: Bringing gender in. International Migration Review, 37(3), 812-846.

Phillips, J. A., \& Massey, D. S. (2000). Engines of immigration: Stocks of human and social capital in Mexico. Social Science Quarterly, 81(1), 33-48.

Pope, A. (2016). Partnering with Mexico to combat crime and secure our borders. Retrieved April 13, 2017, from https://obamawhitehouse.archives.gov/blog/2016/11/07/partneringmexico-combat-crime-and-secure-our-borders

Porter, I. (2019). Les travailleurs temporaires étrangers ont plus d'accidents que les autres. Le Devoir. Québec. Retrieved from https://www.ledevoir.com/politique/quebec/553286/titredeux-fois-plus-de-travailleurs-etrangers-morts-au-travail

Portes, A. (1999). Conclusions: Toward a new world - The origins and effects of transnational activities. Ethnic and Racial Studies, 22(2), 463-477.

Portes, A. (2001). Introduction: The debates and significance of immigrant transnationalism. Global Networks. A Journal of Transnational Affairs, 1(3), 181-193.

Portes, A. (2003). Conclusion: Theoretical convergences and empirical evidence in the study of immigrant transnationalism. International Migration Review, 37(3), 874-892.

Portes, A. (2008). Migration and development: A conceptual review of the evidence. In S. Castles \& R. Delgado-Wise (Eds.), Migration and development. Perspectives from the South (pp. 17-41). Geneva: International Organization for Migration.

Portes, A. (2015). Immigration, transnationalism, and development: The state of the question. In A. Portes \& P. Fernández-Kelly (Eds.), The state and the grassroots: Immigrant transnational organizations in four continents (pp. 1-24). New York, Oxford: Berghahn Books.

Portes, A., Guarnizo, L. E., \& Landolt, P. (1999). The study of transnationalism: Pitfalls and promise of an emergent research field. Ethnic and Racial Studies, 22(2), 217-237.

Portes, A., Guarnizo, L., \& Landolt, P. (2003). La globalización desde abajo: Transnacionalismo inmigrante y desarrollo: La experiencia de Estados Unidos y América Latina. México: Flacso-México, Miguel Angel Porrúa.

Portes, A., \& Rumbaut, R. G. (2001). Legacies: The story of the immigrant second generation. Berkeley, New York: University of California Press, Russell Sage Foundation.

Portes, A., \& Rumbaut, R. G. (2014). Immigrant America: A portrait (4th ed.). Oakland, London: University of California Press.

Pozniak, K. (2009). Talking the "immigrant talk": Immigration narratives and identity 
construction among Colombian newcomers. Canadian Ethnic Studies, 41(1/2), 173-190.

Pratt, G. (2002). Between homes: Displacement and belonging for second generation FilipinoCanadian youths (CERID Working Paper Series No. 02-13). Vancouver.

Pratt, G. (2010). Listening for spaces of ordinariness. Filipino-Canadian youths' transnational lives. Children's Geographies, 8(4), 343-352.

Pratt, G., Ugnayan ng Kabataang Pilipino sa Canada, \& Filipino-Canadian Youth Alliance. (2003). Between homes: Displacement and belonging for second generation FilipinoCanadian youths. B.C. Studies, 40, 41-68.

Preibisch, K. (2015). Los trabajadores migrantes y los cambios en los regímenes laborales en la producción agrícola contemporánea de Canadá. In S. M. Lara Flores, J. Pantaleón, \& M. J. Sánchez Gómez (Eds.), Hacia el otro norte. Mexicanos en Canadá (pp. 115-138). Buenos Aires: CLACSO.

Preibisch, K., \& Encalada Grez, E. (2010). The other side of el otro lado: Mexican migrant women and labor flexibility in Canadian agriculture. Signs: Journal of Women in Culture and Society, 35(2), 289-316.

Preibisch, K., \& Encalada Grez, E. (2013). Between hearts and pockets: Locating the outcomes of transnational homemaking practices among Mexican women in Canada's temporary migration programmes. Citizenship Studies, 17(6-7), 785-802.

Preibisch, K., \& Hennebry, J. L. (2012). Buy local, hire global: Temporary migration in Canadian agriculture. In C. Straehle \& P. T. Lenard (Eds.), Legislated inequality: Temporary labour migration in Canada (pp. 48-72). Montréal: McGill-Queen's University Press.

Preston, V., Kobayashi, A., \& Man, G. C. (2006). Transnationalism, gender, and civic participation: Canadian case studies of Hong Kong immigrants. Environment and Planning, 38(9), 1633-1651.

Proceso. (2016). Los Zetas tuvieron contratos del gobierno de Coahuila: San Antonio Express. Proceso. Retrieved from http://www.proceso.com.mx/448469/vinculan-a-humbertomoreira-los-zetas-en-juicio-a-lider-criminal-en-eu

Qadeer, M. A. (2003). Ethnic segregation in a multicultural city: The case of Toronto, Canada (CERIS Working Paper Series No. 28). Toronto.

Québec. (2010a). Portrait statistique de la population d'origine ethnique latino-américaine recensée au Québec en 2006. Montréal.

Québec. (2010b). Portrait statistique de la population d'origine ethnique mexicaine recensée au Québec en 2006. Montréal.

Québec. (2012). Sondage visant à évaluer les conditions de travail des salariés temporaires d'agences de placement de personnel et les pratiques de celles-ci. Montréal. Retrieved from https://www.cnt.gouv.qc.ca/publications/enquetes-etrecherches/enquetes/agences/index.html

Québec. (2015). Ensemble, nous sommes le Québec. Politique québécoise en matière d'immigration, de participation et d'inclusion. Montréal. Retrieved from http://www.midi.gouv.qc.ca/publications/fr/dossiers/Politique_ImmigrationParticipationI nclusion.pdf

Québec. (2016a). Les travailleurs invisibles: les risques pour la santé des travailleurs des agences de location de personnel. Montréal.

Québec. (2016b). Procedure for the sponsored person. Retrieved January 29, 2018, from http://www.immigration-quebec.gouv.qc.ca/en/immigrate-settle/familyreunification/apply/procedure-sponsored.html

Québec. (2016c). Programme de 1'expérience québécoise (PEQ - Québec experience program) Général. Retrieved January 6, 2018, from http://www.immigration- 
quebec.gouv.qc.ca/en/immigrate-settle/students/stay-quebec/application-csq/studentspeq/peq.html

Québec. (2016d). Programme de l'expérience québécoise (PEQ -Québec experience program) - Québec Graduate. Retrieved January 6, 2018, from http://www.immigrationquebec.gouv.qc.ca/en/immigrate-settle/students/stay-quebec/application-csq/studentspeq/index.html

Québec. (2017a). Délégation générale du Québec à Mexico. Retrieved July 25, 2017, from http://www.international.gouv.qc.ca/es/mexico

Québec. (2017b). Know the conditions of the regular Skilled Worker Program. Retrieved January 6, 2018, from http://www.immigration-quebec.gouv.qc.ca/en/immigratesettle/permanent-workers/requirements-programs/index.html

Québec. (2017c). Québec au Mexique. Pamphlet, Québec, Canada. Retrieved from http://www.mrif.gouv.qc.ca/content/documents/fr/Offre_service_Mexique_FRAN.pdf

Québec. (2018). Réseau des représentations du Québec à l'étranger. Retrieved November 9, 2018, from http://www.international.gouv.qc.ca/fr/general/representation-etranger

Québec. (2019). Arrima. Retrieved June 18, 2019, from https://www.immigrationquebec.gouv.qc.ca/en/informations/arrima/index.html

Québec and Canada. (1991). Canada-Québec accord relating to immigration and temporary admission of aliens. Retrieved January 8, 2018, from

https://www.canada.ca/en/immigration-refugees-citizenship/corporate/mandate/policiesoperational-instructions-agreements/agreements/federal-provincial-

territorial/quebec/canada-quebec-accord-relating-immigration-temporary-admissionaliens.html

Quirke, E., Potter, R. B., \& Conway, D. (2009). Transnationalism and the second-generation Caribbean community in Britain (Geographical Paper No. 187). Reading, UK, Bloomington, USA. Retrieved from https://www.reading.ac.uk/web/files/geographyandenvironmentalscience/GP187.pdf

Ramírez, B. (2001). Crossing the 49th Parallel: Migration from Canada to the United States, 1900-1930. Ithaca and London: Cornell University Press.

Ramírez, B. (2015). Mexicans, Canadians, and the reconfiguration of continental migrations, 1915-1965. In B. Bryce \& A. Freund (Eds.), Entangling migration history. Borderlands and transnationalism in the United States and Canada (pp. 77-99). Gainesville: University Press of Florida.

Ramírez, É. (2017). Señalan como evasoras fiscales a 12 mineras canadienses. Contralínea. Retrieved from https://www.contralinea.com.mx/archivo-revista/2017/07/04/senalancomo-evasoras-fiscales-a-12-mineras-canadienses/

Ramírez García, T., \& Meza González, L. (2011). Emigración México-Estados Unidos: Balance antes y después de la recesión económica estadounidense. In La situación demográfica de México 2011 (pp. 241-259). México: Consejo Nacional de Población. Retrieved from http://segob.gob.mx/work/models/SEGOB/swbpress_Content/3309/13_EMIGRACI_N_A .PDF

Raza, M., Beaujot, R., \& Woldemicael, G. (2013). Social capital and economic integration of visible minority immigrants in Canada. International Migration and Integration, 14(2), 263-285.

RBC. (2019). Parental paradox: Trying to save for retirement while supporting adult children. Retrieved February 28, 2019, from http://www.rbc.com/newsroom/news/2019/20190228parental-paradox.html

Redacción AN. (2017). Recibía Moreira de los Zetas 2 millones de dólares al mes, dice capo a 
la PGR. Retrieved May 21, 2017, from http://aristeguinoticias.com/1401/mexico/recibiamoreira-de-los-zetas-2-millones-de-dolares-al-mes-dice-capo-a-la-pgr/

Reehag, S. (2008). Troubling patterns in Canadian refugee adjudication. Ottawa Law Review, $39(2), 335-365$.

Reehag, S. (2011a). Do women refugee judges really make a difference? An empirical analysis of gender and outcomes in Canadian refugee determinations. Canadian Journal of Women and the Law, 23, 627-660.

Reehag, S. (2011b). The role of counsel in Canada's refugee determination system: An empirical assessment. Osgoode Hall Law Journal, 49(71), 71-116.

Reehag, S. (2017a). 2016 refugee claim data and IRB member recognition rates. Retrieved March 8, 2017, from http://ccrweb.ca/en/2016-refugee-claim-data

Reehag, S. (2017b). "I simply do not believe": A case study of credibility determinations in Canadian refugee ajudicator. Windsor Review of Legal and Social Issues, 38(28), 38-70.

Reguillo, R. (2000). Emergencia de culturas juveniles: Estrategias del desencanto. Bogotá: Grupo Editorial Norma.

Reguillo, R. (2005). La Mara: Contingencia y afiliación con el exceso. Nueva Sociedad, 70-84.

Reguillo, R. (2012). De las violencias: Caligrafía y gramática del horror. Desacatos, Septiembre(40), 33-46.

Rehaag, S. (2019). Closing the Canada-U.S. asylum border agreement loophole? Not so fast. Retrieved March 25, 2019, from https://theconversation.com/closing-the-canada-u-sasylum-border-agreement-loophole-not-so-fast-114116

Reitz, J. G. (1980). The survival of ethnic groups. Toronto: McGraw-Hill Ryerson.

Renwick, D. (2016). Central America's violent Northern Triangle. Retrieved March 21, 2017, from http://www.cfr.org/transnational-crime/central-americas-violent-northerntriangle/p37286

Reynolds, T., \& Zontini, E. (2016). Transnational and diasporic youth identities: Exploring conceptual themes and future research agendas. Identities: Global Studies in Culture and Power, 23(4), 379-391.

Riaño-Alcalá, P., \& Goldring, L. (2006). A Colombian diaspora? Characteristics, tensions and challenges in transnational engagements. In Expert forum on "Capacity building for peace and development: Roles of diaspora” (p. 23). Toronto: UN University for Peace.

Riaño-Alcalá, P., \& Goldring, L. (2014). Unpacking refugee community transnational organizing: The challenges and diverse experiences of Colombians in Canada. Refugee Survey Quarterly, 33(2), 84-111.

Ribando Seelke, C., \& Finklea, K. (2017). U.S.-Mexican security cooperation: The Mérida Initiative and beyond. Washington, D.C. Retrieved from http://www.crs.gov/

Roberts, B. R., Frank, R., \& Lozano-Ascencio, F. (1999). Transnational migrant communities and Mexican migration to the US. Ethnic and Racial Studies, 22(2), 238-266.

Robertson, D. C. (2017). Why is Canada only now accepting more LGBT asylum claims? Retrieved July 4, 2017, from https://www.dailyxtra.com/why-is-canada-only-nowaccepting-more-lgbt-asylum-claims-72932

Rodríguez, G. (2008). Mongrels, bastards, orphans, and vagabonds: Mexican immigration and the future of race in America. New York: Vintage Books.

Rodríguez Chávez, E., \& Cobo, S. (2012). Extranjeros residentes en México. Una aproximación cuantitativa con base en los registros administrativos del INM. México: Instituto Nacional de Migración.

Rodríguez Rodríguez, R. (2008). Convergence and divergence in United States and Canadian Cuba policy post-1959: A triangular comparative analysis. International Journal of Canadian Studies, 37, 115-138. 
Rogers, K. H. (1945). Street gangs in Toronto, a study of the forgotten boy. Toronto: Ryerson Press.

Ross, S. (2018, May 21). Canada puts asylum seekers to work as system feels pressure. The Star. Toronto. Retrieved from https://www.thestar.com/news/canada/2018/05/20/canadaputs-asylum-seekers-to-work-as-system-feels-pressure.html

Rouse, R. (1989). Mexican migration to the United States: Family relations in the development of a transnational migrant circuit. Stanford University.

Rouse, R. (1992). Making sense of settlement: Class transformation, cultural struggle, and transnationalism among Mexican migrants in the United States. Annals of the New York Academy of Sciences, 645, 25-52.

Ruíz Soto, A. G., \& Selee, A. (2019). A Profile of highly skilled Mexican immigrants in Texas and the United States. Washington, D.C. Retrieved from https://www.migrationpolicy.org/research/highly-skilled-mexican-immigrants-texasunited-states

Rumbaut, R. G. (2008). The coming of the second generation: Immigration and ethnic mobility in Southern California. The Annals of the American Academy of Political and Social Science, 620(1), 196-236.

Rummens, J. A., \& Sefa Dei, G. J. (2010). Including the excluded: De-marginalizing immigrant/refugee and racialized students. Education Canada, 50(6). Retrieved from https://www.edcan.ca/articles/including-the-excluded-de-marginalizingimmigrantrefugee-and-racialized-students/

Ryan, L. (2011). Migrants' social networks and weak ties: Accessing resources and constructing relationships post-migration. The Sociological Review, 59(4), 707-724.

Sadowski-Smith, C. (2008). Unskilled labor migration and the illegality spiral: Chinese, European, and Mexican indocumentados in the United States, 1882-2007. American Quarterly, 60(3), 779-804.

Samuel, T. J., Gutiérrez, R., \& Vázquez, G. (1995). International migration between Canada and Mexico: Retrospect and prospects. Canadian Studies in Population, 22(1), 49-65.

San Martín, R. M. (1998). Picking up the thread: An oral history of the Latin American women's collective in Toronto, 1983-1990. University of Toronto.

Sanchez, P. (2004). At home in two places: Second-generation Mexicanas and their lives as engaged transnationals. University of California, Berkeley.

Sarma-Debnath, K., \& Kutty, Y. (2006). Occupational accommodation for new immigrants and refugees in Newfoundland and Labrador: Understanding the roadblocks, challenges and barriers in labor market integration. Fredericton.

Sassen, S. (1995). Immigration and local labor markets. In A. Portes (Ed.), The economic sociology of immigration: Essays on networks, ethnicity, and entrepreneurship (pp. 87127). New York: Rusell Sage Foundation.

Sassen, S. (2001). The global city: New York, London, Tokyo. Princeton N.J.: Princeton University Press.

Sassen, S. (2018). Cities in a world economy (5th ed.). Thousand Oaks: Sage Publications.

Satzewich, V. (1991). Racism and the incorporation of foreign labour: Farm labour migration to Canada since 1945. London: Routledge.

Satzewich, V. (2015). Points of entry. How Canada's immigration officers decide who gets in. Vancouver, Toronto: UBC Press.

Schugurensky, D., Mantilla, D., \& Serrano, J. F. (2009). Four in ten. Spanish-speaking youth and early school leaving in Toronto. Toronto: LARED Latin American Research Education and Development Network Transformative Learning Centre, OISE/University of Toronto. 
SEGOB. (2017). Boletínes estadísticos anuales 2009-2017. Retrieved November 11, 2018, from http://politicamigratoria.gob.mx/es mx/SEGOB/Boletines_Estadisticos

SEGOB. (2018a). Estadísticas del fuero común. Retrieved November 18, 2018, from http://secretariadoejecutivo.gob.mx/rnped/estadisticas-fuerocomun.php

SEGOB. (2018b). Estadísticas del fuero federal. Retrieved November 18, 2018, from http://secretariadoejecutivo.gob.mx/rnped/estadisticas-fuerofederal.php

SEGOB. (2019). Documentación y condición de estancia en México, 2019. Ciudad de México: SEGOB. Retrieved from http://politicamigratoria.gob.mx/es_mx/SEGOB/Documentacion_y_condicion_estancia

Selee, A. (2019). Is U.S.-Mexico cooperation on migration possible? Retrieved April 16, 2019, from https://www.migrationpolicy.org/events/us-mexico-cooperation-migration-possible

Senate of Canada. (2003). Proceedings of the Standing Senate Committee on Foreign Affairs concerning the examination of the Canada-United States of America trade relationship and on the Canada-Mexico trade relationship. Ottawa. Retrieved from https://sencanada.ca/Content/SEN/Committee/372/fore/pdf/14issue.pdf

Senate of Canada. (2015). North American neighbours: Maximizing opportunities and strengthening cooperation for a more prosperous future. Ottawa. Retrieved from http://publications.gc.ca/collections/collection_2015/sen/yc23-0/YC23-0-412-10-eng.pdf

Senate of Canada. (2017). North American neighbours: Canada and Mexico cooperation in uncertain times. Ottawa. Retrieved from https://www.sencanada.ca/content/sen/committee/421/AEFA/Reports/Report-CanadaMexicoRelations_e.pdf

Shannon, T. A. (2009). Testimony of Thomas A. Shannon, Assistant Secretary of State, Bureau of Western Hemisphere Affairs, Department of State, before the Subcommittee on State, Foreign Operations, and Related Programs. Committee on Appropriations of the United States House of. Retrieved April 19, 2017, from https://web.archive.org/web/20100105234107/http://appropriations.house.gov/Witness_te stimony/SFOPS/Thomas_Shannon_03_10_09.pdf

Sheppard, M. (2012, April 24). Deported Mexican refugee claimant dies after beating. The life and death of Verónica Castro. CBC News. Ottawa. Retrieved from http://www.cbc.ca/news/canada/deported-mexican-refugee-claimant-dies-after-beating1.1166530

Shields, J., \& Rahi, K. S. (2002). Immigrant and refugee youth unemployment: A qualitative exploration of labour market exclusion. Toronto.

Shields, J., Rahi, K., \& Scholtz, A. (2006). Voices from the margins: Visible-minority immigrant and refugee youth experiences with employment exclusion in Toronto (CERIS Working Paper No. 47). Toronto.

Shik, A. W. Y. (2015). Transnational families: Chinese-Canadian youth between worlds. Journal of Ethnic and Cultural Diversity in Social Work, 24(1), 71-86.

Shipley, T. A. (2017). Ottawa and empire. Canada and the military coup in Honduras. Toronto: Between the Lines.

Shore, M. (2012). B. O. v. Canada (Citizenship and Immigration). Federal Court decisions. Calgary. Retrieved from http://decisions.fct-cf.gc.ca/fccf/decisions/en/item/61319/index.do?r=AAAAAQAIYmFsY29ydGEB

Silva Ávalos, H. (2013). Memos EUA: Los Zetas infiltraron ejércitos de C. A. Kaibiles se unieron a cartel. La Prensa Gráfica. El Salvador. Retrieved from http://www.laprensagrafica.com/2013/11/08/memos-eua-los-zetas-infiltraron-ejercitosde-c-a-kaibiles-se-unieron-a-cartel

Silver, J. (2014). About Canada: Poverty. Halifax and Winnipeg: Fernwood. 
Simard, M. (1996). La politique québécoise de régionalisation de l'immigration : enjeux et paradoxes. Dynamiques Territoriales, 3(37), 439-469.

Simmons, A. (1989). Trends and underlying forces in Latin American immigration to Canada. In A. R. M. Ritter (Ed.), Consultative symposium on Canadian relations with Latin America and Conference on Latin America and the Caribbean to the year 2000 (pp. $403-$ 417). Ottawa: CALACS.

Simmons, A. (1991). Explicando la migración: La teoría en la encrucijada. Estudios Demográficos y Urbanos, 6(1), 5-31. Retrieved from http://codex.colmex.mx:8991/exlibris/aleph/a18_1/apache_media/K2FHXRIVV5B2Q2V EC6BHRAXY9KM12C.pdf

Simmons, A. (1993). Latin American migration to Canada: New linkages in the hemispheric migration and refugee flow. International Journal, 48(2), 282-309.

Simmons, A. (2010). Immigration and Canada: Global and transnational perspectives. Toronto: Canadian Scholars' Press.

Simmons, A. (2015). Transformación de la política internacional de migración de Canadá. Implicaciones para México. In S. M. Lara Flores, J. Pantaleón, \& M. J. Sánchez Gómez (Eds.), Hacia el otro norte. Mexicanos en Canadá (pp. 17-42). Buenos Aires: CLACSO.

Simoes, A. (2007). Canada. Retrieved April 2, 2017, from http://atlas.media.mit.edu/en/profile/country/can/

SinEmbargo. (2014, September). Tlatlaya, primera gran masacre del gobierno de EPN, según HRW, se vuelve tema mundial. SinEmbargo. Retrieved from http://www.sinembargo.mx/19-09-2014/1121286

Slade, B. L. (2008). From high skill to high school: The social organization of Canadian work experience for immigrant professionals. University of Toronto. Retrieved from http://www.academia.edu/download/12107375/Slade_thesis.pdf

Smith, C. D. (1986). Trials and errors: The experience of Central American refugees in Montreal. Refuge, 5(4), 10-12.

Smith, R. C. (1992a). "Los ausentes siempre presentes": The imagining, making and politics of a transnational community between New York City and Ticuani, Puebla (Institute for Latin American and Iberian Studies). New York.

Smith, R. C. (1992b). Mixteca in New York; New York in Mixteca. NACLA Report on the Americas, 26(1), 39-49.

Smith, R. C. (2000). How durable and new is transnational life?: Historical retrieval through local comparison. Diaspora: A Journal of Transnational Studies, 9(2), 203-233.

Smith, R. C. (2002). Life course, generation, and social location as factors shaping secondgeneration transnational life. In P. Levitt \& M. C. Waters (Eds.), The changing face of home: The transnational lives of the second generation (pp. 145-167). New York: Russell Sage Foundation.

Smith, R. C. (2006a). Mexican New York: Transnational lives of new immigrants. Berkeley: University of California Press.

Smith, R. C. (2006b). Migrant membership as an instituted process: Transnationalization, the state and the extra-territorial conduct of Mexican politics. International Migration Review, 37(2), 297-343.

Snow, F. (2013). September Mo(u)rning. Chile: Chilean Canadian Cultural Society Casa Salvador Allende.

Sorensen, C. (2013, March). The future of jobs in Canada. Skills mismatch may mean 1.5 million vacancies by 2016. Maclean's. Retrieved from https://www.macleans.ca/work/jobs/the-future-of-jobs-in-canada/

Sorochan, C. (2012). The Quebec student strike - A chronology. Theory \& Event, 15(3). 
Project MUSE, muse.jhu.edu/article/484441

Sparks, H. (1997). Dissident citizenship: Democratic theory, political courage, and activist women. Hypatia, 12(4), 74-110.

Speckman Guerra, E. (2008). El Porfiriato. In G. Jaramillo Herrera \& F. Gómez Ruiz (Eds.), Nueva historia mínima de México ilustrada (pp. 337-392). México: El Colegio de México.

SRE. (2015). México y Canadá: Una relación amplia y profunda. Retrieved May 1, 2018, from https://www.gob.mx/sre/acciones-y-programas/mexico-y-canada-una-relacion-amplia-yprofunda-7990

Stanford, J. (2014). The staple theory@50: Reflections on the lasting significance of Mel Watkins' "A staple theory of economic growth." Ottawa: Canadian Centre for Policy Alternatives.

Stargardter, G., Díaz, L., \& Paperny, A. M. (2017, March 16). In Trump era, some Mexican migrants head north - to Canada. Reuters. Reynosa/Toronto. Retrieved from https://ca.reuters.com/article/topNews/idCAKBN16N15A-OCATP

Stasiulis, D. (1997). The political economy of race, ethnicity, and migration. In W. Clement (Ed.), Understanding Canada: Building on the new Canadian political economy (pp. 141-180). Montreal: McGill-Queen's University Press.

Stasiulis, D. (2013). Worrier nation: Quebec's value codes for immigrants. Politikon, 40(1), 183-209.

Stasiulis, D., Hughes, C., \& Amery, Z. (2011). From government to multilevel governance of immigrant settlement in Ontario's city-regions. In E. Tolley \& R. Young (Eds.), Immigrant settlement policy in Canadian municipalities (pp. 73-147). Montreal \& Kingston, London, Ithaca: McGill-Queen's University Press.

Stasiulis, D., \& Jhappan, R. (1995). The fractious politics of a settler society: Canada. In D. Stasiulis \& N. Yuva-Davis (Eds.), Unsettling settler societies. Articulations of gender, race, ethnicity and class (pp. 95-131). London: Sage Publications.

Statistics Canada. (2014). Citizenship, place of birth, immigrant status and period of immigration, age groups and sex for the population in private households of Canada. Retrieved March 3, 2015, from 99-010-X2011026

Statistics Canada. (2016). Longitudinal Survey of Immigrants to Canada. Retrieved January 15, 2019, from https://www12.statcan.gc.ca/census-recensement/2011/ref/92135/surveys-enquetes/longitudinalsurvey-enquetelongitudinale-eng.cfm

Statistics Canada. (2017a). Admission category and applicant type, period of immigration, age and sex for the immigrant population who landed between 1980 and 2016. Retrieved June 17, 2019, from 98-400-X2016201

Statistics Canada. (2017b). Census Profile, Canada. Retrieved January 12, 2018, from 98-316X2016001

Statistics Canada. (2017c). Immigration and ethnocultural diversity: Key results from the 2016 Census. Retrieved November 11, 2017, from http://www.statcan.gc.ca/dailyquotidien/171025/dq171025b-eng.htm

Statistics Canada. (2017d). Postsecondary enrolments, by student status, country of citizenship and sex, annual 1999-2015. Retrieved April 14, 2017, from Table 477-0031

Statistics Canada. (2018a). A portrait of Canadian youth. Ottawa. Retrieved from https://www150.statcan.gc.ca/n1/pub/11-631-x/11-631-x2018001-eng.htm

Statistics Canada. (2018b). Chapter 5 - Data quality assessment and indicators. Retrieved July 25, 2018, from http://www12.statcan.gc.ca/nhs-enm/2011/ref/nhs-enm_guide/99-001x2011001-eng.pdf 
Statistics Canada. (2018c). Ethnic origin, age, sex and selected demographic, cultural, labour force, educational and income characteristics for the population in private households of Canada. Retrieved August 3, 2018, from 98-400-X2016189

Statistics Canada. (2018d). Non-resident travellers entering Canada, by country of residence (excluding the United States) Table: 24-10-0003-01 (formerly CANSIM 427-0003). Retrieved November 11, 2018, from https://www150.statcan.gc.ca/t1/tbl1/en/cv.action?pid=2410000301

Statistics Canada. (2018e). Visible minority, age, sex and selected demographic, cultural, labour force, educational and income characteristics for the population in private households. Retrieved August 8, 2018, from 98-400-X2016192

Statistics Canada. (2019a). Family matters: Adults living with their parents. Retrieved February 20, 2019, from https://www150.statcan.gc.ca/n1/dailyquotidien/190215/dq190215a-eng.htm

Statistics Canada. (2019b). Visible minority, individual low-income status, low-income indicators, generation status, age and sex for the population in private households of Canada. Retrieved May 28, 2019, from 98-400-X2016211

Straehle, C., \& Lenard, P. T. (2012). Legislated inequality: Temporary labour migration in Canada. Montréal: McGill-Queen's University Press.

Subsecretaría de Minería. (2018). Prontuario. Industria minero metalúrgica. México. Retrieved from https://www.gob.mx/cms/uploads/attachment/file/292017/prontuario2018.pdf

Sultana, I. Z. (2013). Unaccompanied minors in Canada: How social and legal services affect their lives in Ontario. Brock University. Retrieved from https://dr.library.brocku.ca/bitstream/handle/10464/4975/Brock_Sultana_Ishrat_2013.pdf

Sydor, A. (2003).NAFTA@10. A preliminary report. Ottawa. Retrieved from http://www.international.gc.ca/economist-economiste/analysis-analyse/researchrecherche/10_pre.aspx?lang=eng

Taylor, J. E. (1987). Undocumented Mexico-U.S. migration and the returns to households in rural Mexico. American Journal of Agricultural Economics, 69(3), 626-638.

Taylor, J. E., Arango, J., Hugo, G., Kouaouci, A., Massey, D. S., \& Pellegrino, A. (1996). International migration and community development. International Migration and Community Development, 62(3), 397-418.

The Canadian Council for the Americas Alberta. (2019). Mexican oil \& gas industry: Overview on opportunities. Retrieved April 24, 2019, from https://cca-alberta.com/event3258440

The Globe and Mail. (1995, February 21). The Nation Refugee status in HIV case defended. The Globe and Mail, pp. A1, A4. Toronto. Retrieved from http://search.proquest.com/docview/385016538

The Globe and Mail. (1996, June 10). Mexico and Canada: An evolving partnership. The Globe and Mail, p. A12. Toronto.

The Griffin Centre. (2004). Jane Finch neighbourhood action plan report. Toronto. Retrieved from https://web.archive.org/web/20070331123541/http://www.twpcommunityministry.org/ho me/editorfiles/Jane_Finch_Neighbourhood_Action_Plan.pdf

The Library of Congress. (1848). Treaty of peace, friendship, limits, and settlement between the United States of America and the Republic of Mexico. Retrieved March 10, 2017, from https://memory.loc.gov/cgibin/ampage collId=1lsl\& fileName $=009 / 11$ s1009. $d b \&$ recNum $=975$

The Ottawa Citizen. (1997, October 11). The refugees go on vacation. The Ottawa Citizen, p. 
B4. Ottawa.

Thieme, S., \& Siegmann, K. A. (2010). Coping on women's backs: Social capital-vulnerability links through a gender lens. Current Sociology, 58(5), 715-737.

Thobani, S. (1998). Nationalizing citizens, bordering immigrant women: Globalization and the racialization of citizenship in late 20th century Canada. Simon Fraser University.

Thobani, S. (2000). Closing ranks: Racism and sexism in Canada's immigration policy. Race and Class, 42(1), 35-55.

Thompson, G. (2011, August 6). U.S. widens role in battle against Mexican drug cartels. The New York Times. Washington, D.C. Retrieved from http://www.nytimes.com/2011/08/07/world/07drugs.html

Thompson, G., \& Cohen, S. (2014, April 6). More deportations follow minor crimes, records show. The New York Times. New York. Retrieved from

https://www.nytimes.com/2014/04/07/us/more-deportations-follow-minor-crimes-datashows.html

Ticar, J. E. (2017). Investigating the transnational identities of Filipina/o/x youth in Toronto urban high schools: A critical ethnographic study of the impact of Canada's livein/caregiver program. The University of Western Ontario. Retrieved from https://ir.lib.uwo.ca/etd/4951

Tigau, C. (2011). Mexican migration to Canada. Statistical data and interview with Chona Iturralde, Citizenship and Immigration Canada (CIC). Norteamérica, 6(1), 189-203.

Tigau, C., \& Ucán Marín, F. (2013). La imagen de México en Canadá y de Canadá en México. Presentation at the VIII Congress of Mexican Students Federation in Canada (CEIMEXCAN), Gatineau, Canada.

Tiilikainen, M. (2017). "Whenever mom hands over the phone, then we talk": Transnational ties to the country of descent among Canadian Somali youth. Migration Letters, 14(1), 63-74.

Todaro, M. P. (1969). A model of labor migration and urban unemployment in less developed countries. American Economic Review, 59(1), 138-148.

Tomic, P., \& Trumper, R. (1994). Canada and the streaming of immigrants: A personal account of the Chilean case. In V. Satzewich (Ed.), Deconstructing a nation: Immigration, multiculturalism and racism in '90s Canada (pp. 163-182). Halifax: Fernwood.

Tonks, R. G., \& Paranjpe, A. C. (1999). Two sides of acculturation, attitudes toward multiculturalism and national identity amongst immigrant and Canadian born youth. In Metropolis National Congress, Vancouver 1999. Vancouver.

Tremblay, D.-G. (2003). Juggling youth unemployment and employment precariousness in Canada and Quebec: From a social to a more liberal approach to employment policies? In L. Roulleau-Berger (Ed.), Youth and work in the post-industrial city of North America and Europe (pp. 175-189). Leiden, Boston: Brill.

Tremblay, P. (2013). Canadian trade and investment activity: Canada-Mexico. Ottawa, Ont. Retrieved from http://www.lop.parl.gc.ca/Content/LOP/ResearchPublications/2013-46e.pdf

Tungohan, E. (2013). Debunking notions of migrant "victimhood": A critical assessment of temporary labour migration programs and Filipina migrant activism in Canada. In R.

Sintos Coloma, B. McElhinny, E. Tungohan, J. P. C. Catungal, \& L. M. Davidson (Eds.), Filipinos in Canada: Disturbing invisibility (pp. 161-180). Toronto, Buffalo, London: University of Toronto Press.

Turcotte, M. (2015). Political participation and civic engagement of youth. Ottawa. Retrieved from https://www150.statcan.gc.ca/pub/75-006-x/2015001/article/14232-eng.pdf 
UFCW Canada. (2011). Report on the status on migrant workers in Canada 2011. Toronto: UFCW Canada.

UFCW Canada. (2014). The great Canadian rip-off! An economic case for restoring full EI special benefits access to SAWP workers. Toronto: UFCW Canada.

Unger, K. (2007). El desarrollo económico y la migración mexicana: El TLCAN e impactos en las regiones. In P. Leite, S. Zamora, \& L. Acevedo (Eds.), Migración internacional y desarrollo en América Latina y el Caribe (pp. 359-412). México: Consejo Nacional de Población.

United Nations. (2015). Concluding observations on the report submitted by Mexico under article 29, paragraph 1, of the International Convention for the Protection of All Persons from Enforced Disappearance. New York. Retrieved from https://documents-ddsny.un.org/doc/UNDOC/GEN/G15/043/63/PDF/G1504363.pdf?OpenElement

Univision.com. (2013). Alcalde de Saltillo reveló que el narco infiltró al gobierno. Retrieved May 21, 2017, from http://www.univision.com/noticias/narcotrafico/alcalde-de-saltillorevelo-que-el-narco-infiltro-al-gobierno

US Census Bureau. (2016). 1870 Fast Facts. Retrieved March 27, 2017, from https://www.census.gov/history/www/through_the_decades/fast_facts/1870_fast_facts.ht $\mathrm{ml}$

US Department of Interior. (1992). Acquisition of the public domain, 1781-1867. Retrieved March 17, 2017, from

https://web.archive.org/web/20060929200726/http://www.blm.gov/natacq/pls02/pls11_02.pdf

US Department of State. (2013). Gadsden Purchase, 1853-1854. Retrieved March 15, 2017, from https://history.state.gov/milestones/1830-1860/gadsden-purchase

US Department of State. (2014). Human rights report 2013: Mexico. Washington, D.C. Retrieved from https://www.state.gov/documents/organization/220667.pdf

US Department of State. (2015). The Merida Initiative - An overview. Retrieved April 4, 2017, from https://photos.state.gov/libraries/mexico/310329/july15/MeridaInitiativeOverviewJul15.pdf

US Embassy in Mexico. (2015). Information paper on San Pedro Limón, Tlatlaya incident. Retrieved April 17, 2017, from https://www.documentcloud.org/documents/2073611tlatlaya-northcom.html

US Senate. (1975). Covert action in Chile 1963-1973. Staff report of the select committee to study governmental operations with respect to intelligence activities. Washington, D.C.

US Senate. (2015). Hearing to receive testimony on U.S. Northern Command and U.S. Southern Command in review of the defense authorization request for fiscal year 2016 and the future years defense program. Washington, D.C. Retrieved from https://www.armed-services.senate.gov/imo/media/doc/15-25 - 3-12-15.pdf

Vallejo, J. A. (2012). Barrios to burbs: The making of the Mexican American middle class. Stanford: Stanford University Press.

van Bochove, M. (2012). Truly transnational: The political practices of middle-class migrants. Journal of Ethnic and Migration Studies, 38(10), 1551-1568.

Van Hear, N. (2014). Reconsidering migration and class. International Migration Review, $48(\mathrm{~S} 1), \mathrm{S} 100-\mathrm{S} 121$.

Vargscarr, K. (2016). “Comrades! I am far from you, but I am with you!': Ukrainian working women, transnationalism, and the Soviet Cultural Revolution in Winnipeg, 1928.

University of Manitoba. Retrieved from https://mspace.lib.umanitoba.ca/handle/1993/31861

Veronis, L. (2006a). Rethinking transnationalism, citizenship and immigrant participation in 
neoliberal Toronto. University of Toronto, Toronto.

Veronis, L. (2006b). Rethinking transnationalism: Latin Americans' experiences of migration and participation in Toronto (CERIS Working Paper No. 51). Toronto.

Veronis, L. (2010). Immigrant participation in the transnational era: Latin Americans' experiences with collective organising in Toronto. International Migration and Integration, 11(2), 173-192.

Veronis, L. (2013). The border and immigrants in Ottawa-Gatineau: Governance practices and the (re)production of a dual Canadian citizenship. Journal of Borderlands Studies, 28(2), $257-271$.

Veronis, L. (2015). Immigrants' narratives of inclusion and belonging in the transborder city of Ottawa-Gatineau, Canada's National Capital Region. Canadian Ethnic Studies, 47(2), 45-65.

Veronis, L., \& McAloney, B. (2010). Latin American migration and the border: A preliminary report. Ottawa. Retrieved from http://artsites.uottawa.ca/ottawaproject/doc/LatinAmerican-2010-Feb.pdf

Vézina, C. (2019). ¿La Marcha al Mar como alternativa al Programa Bracero? El turismo como estrategia de control de la emigración mexicana. U.S.-Mexican-Canadian economic relations in transition: From Ruíz Cortinez to the present, Toronto, Canada: Canadian Association of Latin American and Caribbean Studies 2019 Conference.

Vicencio Miranda, A. (2007). La industria automotriz en México. Antecedentes, situación actual y perspectivas. Contaduría y Administración, 221(Enero/Abril), 209-246.

Vidal de la Rosa, G. (2009). Estado débil y estancamiento democrático en México. Obra en dos piezas. El Cotidiano, 57(Sept.-Oct.), 109-112. Retrieved from http://www.redalyc.org/articulo.oa?id=32512739013

Villegas, P. (2017, May 12). Gunmen kill Mexican activist for parents of missing children. The New York Times. Mexico City. Retrieved from https:/www.nytimes.com/2017/05/12/world/americas/mexico-mother-activist-murdereddaughter-tamaulipas.html

Viveros, A. (1997). Breaking the ice: The new Canadian-Mexican relationship. Carleton University.

Vosko, L. F. (2000). Temporary work: The gendered rise of a precarious employment relationship. Toronto, Buffalo, London: University of Toronto Press.

Vosko, L. F. (2006). Precarious employment: Understanding labour market insecurity in Canada. Montreal and Kingston: McGill-Queen's University Press.

Wacquant, L. (2018). Cuatro principios transversales para poner a trabajar a Bourdieu. Estudios Sociológicos de El Colegio de México, 36(102), 3-23.

Walters, W. (2008). Putting the migration-security complex in its place. In L. Amoore \& M. de Goede (Eds.), Risk and the war on terror (pp. 158-177). London: Routledge.

Walters, W. (2010). Migration and security. In J. P. Burgess (Ed.), The handbook of new security studies (pp. 217-228). London: Routledge.

Walton-Roberts, M. (2003). Transnational geographies: Indian immigration to Canada. The Canadian Geographer / Le Géographe Canadien, 47(3), 235-250.

Wang, L. A. S. (2013). "Of the law, but not its spirit": Immigration marriage fraud as legal fiction and violence against Asian immigrant women. UC Irvine Law Review, 3(4), 12211250 .

Watkins, M. (2007). Comment. Staples Redux. Studies in Political Economy, 79(Spring), 213226.

Wayland, S. V. (2003). Immigration and transnational political ties: Croatians and Sri Lankan Tamils in Canada. Canadian Ethnic Studies, 35(2), 61-85. 
Wessendorf, S. (2007). "Roots migrants": Transnationalism and "return" among secondgeneration Italians in Switzerland. Journal of Ethnic and Migration Studies, 33(7), 10831102.

Wessendorf, S. (2013). Second-generation transnationalism and roots migration: Crossborder lives. Burlington, VT, Farnham, Surrey: Ashgate.

West, C., \& Zimmerman, D. H. (1987). Doing gender. Gender and Society, 1(2), 125-151.

Wheelon, A. D., \& Graybeal, S. N. (1961). Intelligence for the space race. Studies in Intelligence (Central Intelligence Agency), 5(Fall).

Whitaker, R. (1987). Double standard: The secret history of Canadian immigration. Toronto: Lester \& Orpen Dennys.

Whitaker, R. (1998). Refugees: The security dimension. Citizenship Studies, 2(3), 413-434.

Whittaker, E. (1988). The Mexican presence in Canada: Liberality, uncertainty and nostalgia. Journal of Ethnic Studies, 16(2), 29-46.

Whyte, W. F. (1955). Street corner society: The social structure of an Italian slum (2nd ed.). Chicago: University of Chicago Press.

Wike, R., \& Castillo, A. (2018). Many around the world are disengaged from politics. Washington, D.C. Retrieved from http://www.pewglobal.org/2018/10/17/internationalpolitical-engagement/

Wilkinson, L., Lauer, S., Sin, R., Tsang, A. K. T., \& Yan, M. C. (2010). The labour market transitions of newly arrived immigrant youth: A tri-provincial study. Research Report of National Metropolis Secretariat.

Wilson, K. L., \& Portes, A. (1980). Immigrant enclaves: An analysis of the labor market experiences of Cubans in Miami. The American Journal of Sociology, 86(2), 295-319.

Wilson-Forsberg, S., \& Sethi, B. (2015). The volunteering dogma and Canadian work experience: Do recent immigrants volunteer voluntarily? Canadian Ethnic Studies, 47(3), 91-110.

Winland, D. N. (1995). "We are now an actual nation": The impact of national independence on the Croatian diaspora in Canada. Diaspora: A Journal of Transnational Studies, 4(1), $3-29$.

Winton, A. (2007). Youth gangs in North and Central America: From barrio gangs to transnational syndicates? workshop on Crime, Law, and Governance in Latin America and the United States, held at the Center for Latin American Studies, 29 April - 1 May, 2007, Florida: University of Florida.

Winton, A. (2012). Analysing the geographies of the "transnational" gangs of Central America: The changing spaces of violence. Investigaciones Geográficas, Boletín del Instituto de Geografía, UNAM, 79, 136-149.

Winton, A. (2014). Gangs in global perspective. Environment \& Urbanization, 26(2), 401416.

Winton, A. (2017a). Movilidad y supervivencia: Un estudio exploratorio sobre desplazamiento por violencia en el norte de Centroamérica y el sur de México. Tapachula.

Winton, A. (2017b). Violence, borders and boundaries: Reframing young people's mobility. In C. Ní Laoire, A. White, \& T. Skelton (Eds.), Movement, mobilities, and journeys. Geographies of children and young people (pp. 131-149). Singapore: Springer.

Wise, T. A. (2010a). Agricultural dumping under NAFTA: Estimating the costs of U.S. agricultural policies to Mexican producers. Washington, D.C.: Woodrow Wilson International Center Scholars. Retrieved from http://www.ase.tufts.edu/gdae/policy_research/AgNAFTA.html

Wise, T. A. (2010b). Who pays for agricultural dumping? Farmers in developing countries. Retrieved March 5, 2015, from http://triplecrisis.com/who-pays-for-agricultural-dumping- 
farmers-in-developing-countries-2/

Wong, L. L. (1995). Chinese capitalist migration to Canada: A sociological interpretation and its effect on Canada. Asian and Pacific Migration Journal, 4(4), 465-492.

Wong, L. L. (1997). Globalization and transnational migration: A study of recent Chinese capitalist migration from the Asia Pacific to Canada. International Sociology, 12(329351).

Wright, E. O. (2000). Class counts. Student edition. Cambridge, UK: Cambridge University Press.

WTO. (2011). Mexico etc. versus US: “tuna-dolphin.” Retrieved June 21, 2017, from https://www.wto.org/english/tratop_e/envir_e/edis04_e.htm

Wylie, L. (2019, June). Dark days for Canada-Cuba relations. Open Canada. Retrieved from https://www.opencanada.org/features/dark-days-canada-cuba-relations/

Yan, M. C., Lauer, S., \& Chan, S. (2009). Social capital and the labour market process among new generation youth from visible minority immigrant families (CERID Working Paper Series No. 9-1). Vancouver.

Yee, J. Y., Johns, C. M., Tam, S., \& Paul-Apputhurai, N. (2003). Apprenticeship opportunities and barriers for immigrant youth in the greater Toronto area (CERIS Working Paper Series No. 24). CERIS Working Paper. Toronto.

Young, J. G. (2009). Mexican emigration during the Cristero war, 1926-1929. The University of Chicago.

Young, J. G. (2015). Mexican exodus: Emigrants, exiles, and refugees of the Cristero War. New York: Oxford Scholarship Online.

Younge, E. R. (1944). Population movements and the assimilation of alien groups in Canada. The Canadian Journal of Economics and Political Science / Revue Canadienne d'Economique et de Science Politique, 10(3), 372-380.

Yssaad, L., \& Fields, A. (2018). The Canadian immigrant labour market: Recent trends from 2006 to 2017. Ottawa. Retrieved from https://www150.statcan.gc.ca/n1/pub/71-606-x/71606-x2018001-eng.htm

Zhang, S., \& Zuberi, D. (2017). Evening the keel: Measuring and responding to precarity in the Canadian labour economy. Canadian Public Administration / Administration Publique Du Canada, 60(1), 28-47.

Zhou, M. (2004). Revisiting ethnic entrepreneurship: Convergencies, controversies, and conceptual advancements. International Migration Review, 38(3), 1040-1074.

Zizys, T. (2010). An economy out of shape: Changing the hourglass. Toronto. Retrieved from http://workforceinnovation.ca/wp-content/uploads/2016/09/Hourglass2.pdf

Zong, J., \& Batalova, J. (2018). Mexican immigrants in the United States. Retrieved October 11, 2018, from https://www.migrationpolicy.org/article/mexican-immigrants-united-states

Zoraida Vázquez, J. (2008). De la Independencia a la consolidación republicana. In G. Jaramillo Herrera \& F. Gómez Ruiz (Eds.), Nueva historia mínima de México ilustrada (pp. 245-336). México: El Colegio de México. 


\section{Footnotes}

${ }^{1}$ The number of countries included in the Latin American 'label' is subject to change. I chose to include here 17 countries since these are located in the Latin American region, while the other four are located in the Caribbean region (i.e. Dominican Republic, Cuba, Haiti, and Puerto Rico). Some people do not count Puerto Rico because it is a territory of the United States, even if Puerto Ricans self-identify as Latinxs in sociocultural terms.

${ }^{2}$ For the 2011 National Household Survey, Statistics Canada did not use the Low-Income Cut-Offs After-Tax (LICO-AT), but only the Low-Income Measure After-Tax (LIM-AT). This despite the fact that LICO-AT is the most frequently used measure of low income or poverty in Canada, as Silver (2014) contends.

${ }^{3}$ Día de Muertos in Mexico "celebrates the lives of the deceased with food, drink, parties, and activities the dead enjoyed in life. [...] On Día de los Muertos, the dead are also a part of the community, awakened from their eternal sleep to share celebrations with their loved ones" (National Geographic 2019).

${ }^{4}$ On September 26, 2014, a group of Indigenous students from a Teachers College was attacked. 43 of them were abducted in a process that included police and military members.

5 'Latinx' is "used as a gender-neutral alternative to Latino or Latina" (Merriam-Webster Dictionary 2018). I apply the same linguistic pattern for other ethnic groups throughout the dissertation.

6 'Habitūs' designates the plural of the noun 'habitus' in Latin under the fourth declension.

${ }^{7}$ Perhaps the closest to a Latin American ethnic enclave was situated in Toronto, initially located along Bathurst Street, between College and Bloor Streets in the 1980s, which then expanded to the Jane and Finch area (Brown 2012). Their initial location in the Jane and Finch area, however, seems to be also related to economic integration issues, since "[t]he Jane-Finch community has one of the largest proportions of youth, sole support families, refugees and immigrants, low-income earners, and public housing tenants of any community in Toronto" (The Griffin Centre 2004:4). The ethnic clustering of Latin Americans in this area also seemed to have resulted from the third and fourth Latin American (im)migrant waves arriving at Canada in the 1980s, as mentioned in chapter 4. In Montreal, although they do not constitute an enclave, Latin Americans are mostly located by their demographic numbers in Villeray-Saint-Michel-Parc-Extension and Côte-des-Neiges, and Mexicans in Côte-desNeiges and Plateau-Mont-Royal (Quebec 2010a, 2010b). In Ottawa, their geographic location is dispersed.

${ }^{8}$ I also find that Edward's model offers the possibility of a more straightforward analysis to sort out the inherent complex dynamics of the labour market. For my economic integration analysis, I did not use industry division (e.g. manufacturing) or occupational categories (e.g. sales) to analyze the economic location and thus integration of my participants. This is because this indexing would not necessarily reflect the quality of the youth's jobs (Zizys 2010) and because my methodology was not only focusing on labour market outcomes, such as tracking the youth's entire employment history and earnings, but also on factors such as research participants' immigration motives and transnational practices. Other labour market incorporation analytical models, such as that of Zizys (2010) or Cervenan (2009) offer tri-partite or quadruple schemas that are essentially similar to that of Edwards. Nonetheless, I find Edward's model to be heuristically richer.

${ }^{9}$ For example, temporary migrants have participated not only in the Seasonal Agricultural Workers Program (SAWP), but also in other TFWP, such as the Low-Skill Pilot program. This program focuses on providing employment at the skill level C, which includes intermediate jobs that usually call for high school and/or jobspecific training, such as industrial butchers and food and beverage servers, and skill level D, which includes labour jobs that usually give on-the-job training, such as fruit pickers, cleaning staff, and oil field workers. These types of jobs only require a high school diploma at most or a maximum of two years of job-specific training (CIC 2014b; IRCC 2018a).

${ }^{10}$ The developments of the $23^{\text {rd }}$ meeting of the Standing Senate Committee on Foreign Affairs on the examination of the Canada-United States of America trade relationship and on the Canada-Mexico trade relationship (April 8, 2003) is a good example of the on-and-off relationship between Canada and Mexico. Mexico had not appeared on the Committee's research and work until their $23^{\text {rd }}$ meeting, signaling how the role of Mexico was not a priority for the Committee. Thus, Mexico and Latin America have largely remained terra incognita for the Canadian government and Canadians in general not only for many years in the past, as Macdonald signaled (2016), but still even today.

${ }^{11}$ This process was partly fueled by the Monroe doctrine of 1823 and the embedded ideology of Manifest Destiny. Manifest Destiny was the idea that Americans "virtue, mission, and divine ordination mandated the expansion" of 
the United States borders guided by three principles: 1) "The special virtues of the American people and their institutions;" 2) The United States "mission to redeem and remake the world in the image of America; and 3) "A divine destiny under god's direction to accomplish this wonderful task" (Miller 2006:120). Manifest Destiny also had a racial component. As Miller states, "America's self-defined Anglo-Saxons felt they held the leading role in educating, civilizing, and conquering the continent and dominating American Indians [sic] and Mexicans, whom they call the "inferior, savage, uncivilized, and with a hopeless future." "In 1847, for example, one writer stated that the Mexican destiny was the same as for Indians [sic], to assimilate into the "superior vigor of the AngloSaxon race, or they must utterly perish"” (ibid.).

${ }^{12}$ The Mexican Revolution, whose main purpose was to reverse the negative effects of the Porfiriato, ranked ninth out of 25 in a historical summary of the human costs of modern warfare (McCaa 2003).

${ }^{13}$ La Cristiada (1926-1929) or Cristero war was a guerrilla-style war fought by Catholic militants in central and western Mexican states, and supported transnationally by some Catholic immigrants from the United States, aimed at overthrowing the Mexican government and their rural supporters, the agraristas. Even when the conflict had deeper and previous roots due to a long history of tension between the Catholic church and the Mexican state, the war resulted from anti-Catholic, anticlerical, and secularist policies enacted by the post-revolutionary Mexican government as consigned in the Constitutional Convention of 1917, and later in the Ley Reglamentaria or Ley Calles of 1926, which reiterated and expanded the 1857 Reform Laws of President Benito Juárez. Although Catholic militants - called cristeros due to their battle cry of ; Viva Cristo Rey! or Long live Christ the King! provoked outbreaks of violence throughout Mexico, the warfare "was most intense in the densely populated, agriculturally productive west-central region, which included the states of Jalisco, Guanajuato, Michoacán, and others [the same region that had been affected by the Second French Invasion]. As a result, the conflict ravaged the Mexican heartland, destroying villages, disrupting agriculture, and claiming the lives of an estimated hundred thousand people" (Young 2009, 2015:5-6, 26).

${ }^{14}$ This was reflected in the emergence of actions and discourses such as the Brown Scare that differently characterized, threatened, and even put in danger Mexicans in the United States (Romo in Rodríguez 2008:137). For example, American mobsters attacked Mexicans who lived in El Paso in 1916 (Rodríguez 2008), and also unlawfully executed and lynched 597 Mexicans in Arizona, California, New Mexico, and Texas between 1848 and 1928 (Carrigan and Webb 2003). Carrigan and Webb (2003:418) noticed that these Anglo-American mobs also served to displace Mexicans from their land and access to natural resources, disenfranchise them, and further enhance their economic dependency, all useful factors for the consolidation and expansion of the Us industrial capitalist system. This dislocation strategy was also replicated at a large scale through the enforcement, coercion, and displacement of one million Mexicans and American citizens of Mexican descent to Mexico under the socalled 'Mexican Repatriation,' between 1929 and 1936 (Balderrama and Rodríguez 2006; Llamoca 2017).

${ }^{15}$ In the dissertation, I use the demonym 'Québécois' or 'Québécoise' considering the French gendered form, even if in the English language the word to use is 'Quebecois.' Similarly, I also followed the French grammar when using 'Québécois' or 'Québécoise' as adjective, even if the word was in English, because I live in between both English and French fields in Canada, and because I worked in Montreal for my research.

${ }^{16}$ Canada maintained a direct and commercial relationship with Cuba throughout the Cold War despite the United States’ pressure for Canada to align with its policies (Rodríguez Rodríguez 2008). Certainly, as Wylie (2019) contends, "Canada's Cuba policy became an important marker of Canadian sovereignty and independence from the United States. Of all the states in the hemisphere, only Mexico and Canada did not succumb to America pressure during the crisis." Moreover, Canada's position challenged the US hegemony in the western hemisphere and created a political irritant in the relationship between the two countries (Rodríguez Rodríguez 2008). However, Canada's independent international policy decision had an underlying economic goal. After the triumph of the Cuban Revolution in 1959 and the subsequent imposition of the US economic embargo, "Canadian companies then appeared as an option to fill the void left by US companies that had dominated the Cuban economy" (122), particularly in the job-generating manufacturing sector of the export-oriented Canadian economy (123). This allowed Cuba to circumvent the embargo (Rodríguez Rodríguez 2008), and also allowed Canada to keep its economic engines working. Overall, however, "[a]lthough Canada has historically prided itself on its independent stance on Cuba, Canada's relationship with Cuba has always had to carefully weigh the US factor" (Wylie 2019).

${ }^{17}$ The meeting was followed by a private meeting between then President-elect López Obrador's transition team and the Canadian team (Méndez Robles 2018). A second meeting occurred in Canada between the Canadian Ministers of Foreign Affairs and International Trade Diversification and Mexico's Secretaries-designate responsible for the most important governmental areas. This was followed by individual meetings between Canadian and Mexican 
counterparts, and a meeting between PM Justin Trudeau and then Foreign Affairs Secretary-designate Marcelo Ebrard (Belmont 2018; Milenio Digital 2018).

${ }^{18}$ Currently, Canada's immigration system is composed of four main streams: the economic stream, the sponsored family stream, the resettled refugee and protected person in Canada stream, and the so-called 'other immigration stream,' which includes the humanitarian and compassionate stream and other immigrants not included elsewhere, such as permit holders applying for permanent residence. The economic immigration stream is composed of three main programs: 1) the worker stream (which includes the Federal Skilled Worker, the Canadian Experience Class, the Caregiver, and the Skilled Trade programs), 2) the business stream (which may include the entrepreneur, the investor, the self-employed, and the start-up business programs), and 3) the various provincial nominee programs.

Canada presently uses the electronic system called Express Entry, which facilitates the processing of the economic immigration applications and is an updated version of the 1967 points processing immigration system. The economic immigration stream favours the immigration of people who demonstrate having so-called core human capital factors: age (with a maximum of 110 points allocated for people in the 20to-29 years of age range), education (a PhD degree offering the maximum of 150 points and a master's degree offering 135 points), language proficiency in one or the two official languages (with a maximum of 34 points given if assessed at level 10 of the Canadian Language Benchmarks for the first official language and 80 points for the second official language), and Canadian work experience (with a maximum of 80 points allocated for five or more years of Canadian work experience). Express Entry also considers so-called transferability factors, constituted by level of education (a combination of the applicant's highest level of education and their proficiency in their first official language and Canadian work experience) and years of foreign work experience under specific Canada's National Occupation Classification or NOC (with a maximum of three years work experience combined with level of proficiency in the first official language) or a certificate of qualification in a trade occupation.

The total number of points obtained in Express Entry can also be boosted, with a maximum of 600 points, for either having a provincial nomination or a qualifying offer of arranged employment. The candidate's accumulated points can also be increased by the points scored by an accompanying spouse or commonlaw partner's core human capital and transferability factors (Canada 2014).

There are other occasional programs that Canada implements focusing on the obtention of specific immigrants' skillsets or economic opportunities. These have included the international PhD students program (2011-2015), a subset of the Federal Skilled Workers Program that granted permanent residence to $500 \mathrm{PhD}$ students per year who had already been enrolled in their postgraduate program for two years (Rostin Consulting Group 2014).

Other programs are the Immigrant Investor Program (1987-2012/2014), internationally implemented by Canada for the first time under the Mulroney Conservative administration and under the Chrétien Liberal government (March 2014); the Investor Venture Capital program, implemented by the Harper Conservative government in 2015 to bring 60 millionaire immigrant investors and their families (March 2015), and the Start-Up Visa program, implemented by the Trudeau Liberal government in 2018. The latter focuses on bringing entrepreneurs who not only meet the immigration standard evaluation criteria, but who also can "secure a commitment from a designated Canadian angel investor group, venture capital fund or business incubator to support your business idea" (IRCC 2018). Another program is the Temporary Foreign Worker Program Global Talent Stream, a two-year pilot program (June 20172019) that allows employers to hire unique and specialized temporary foreign workers in order to scale-up and grow their businesses, such as information, software, and computer engineers and designers. These positions need to grant an annual salary of at least $\$ 80,000$ (ESDC 2019a, 2019b).

The province of Quebec has a special agreement on immigration with Canada. Quebec has its own rules for choosing immigrants based on the notion of interculturalism and immigrants' adaptation. The general mechanism to apply as an economic immigrant before June 2019 was composed of two stages. In the first stage, the person applied to the Government of Quebec for a Quebec Selection Certificate (Certificat de sélection du Québec) or CSQ. Then, the province assessed the application making use of its own criteria and rules. If the application was accepted, the granted CSQ indicated that Quebec accepted the person as an immigrant. In the second stage, the person had to apply to Immigration, Refugees and Citizenship Canada for permanent residence and undergo the health and security screening processes (Canada 2019).

On June 16, 2019, Quebec's National Assembly passed Bill 9, which cancelled approximately 16,000 immigration applications under the Skilled Worker Program and "set out the framework for a Quebec values test that would-be immigrants will need to pass in order to become a permanent resident” (Leavitt 2019). 
The new proposed immigration system, called Arrima, is very similar to Canada's economic immigration Express Entry system. Arrima is based on an expression of interest and follows a three-step process: 1) the interested party completes an expression of interest form online, indicating training, education, language skills, and work experience. 2) The Ministère de l'Immigration, de la Diversité et de l'Inclusion reviews the bank of expressions of interest and issues invitations to applicants who meet certain criteria, based on labour market needs in the different regions of Québec. These individuals can submit a permanent selection application (official immigration application) and pay the associated fees. And 3) applications are evaluated using the selection grid in effect (Québec 2019).

${ }^{19}$ For a first categorization of the 'Latin American' waves arriving in Canada, see the work of Fernando Mata (1985).

${ }^{20}$ Canada's evolving immigration policies targeted and prohibited the immigration of Chinese, Japanese, Indian, Blacks, Doukhobors, Mennonites and Hutterites (Canada 2017a, 2017b, 2017d, 2017e, 2017f), as well prohibited the entrance of any immigrant: "deemed unsuitable having regard to the climatic, industrial, social, educational, labour or other conditions or requirements of Canada or because such immigrants are deemed undesirable owing to their peculiar customs, habits, modes of life and methods of holding property, and because of their probable inability to become readily assimilated or to assume the duties and responsibilities of Canadian citizenship within a reasonable time after their entry" (Canada 2017c).

${ }^{21}$ Mata (1985:28-29) described the effects of these Us interventions as a collection of "social situations which made life and working conditions intolerable for large segments of the middle and working classes [in Latin America]. Labor unrest, political mobilization and even armed insurrection occurred as social responses to the obsolescence of the political control of traditional elites and generalized poverty in the cities and the countryside." More importantly, these interventions were followed by "[g]eneralized repression by the economic elites" and "a state of military control." Repression and military control in Latin America were, however, the main product of continued and usually covert US economic, political, military, and even cultural interventions in Central and South America (see Dinges 2005; Grandin 2007; Kornbluh 1987, 1998, 2004a, 2004b, 2009, 2013; US Senate 1975).

${ }^{22}$ It is important to note, however, that the acceptance of these refugees was not immediate or open-handedly authorized by the Canadian government. Rather, the sluggish approval of some of the refugee applications, since not all of them were accepted, constituted a big achievement obtained by internal and external political pressure exerted by human rights groups, diverse churches, and some Chileans already living or studying in Canada (Foster 2013). Moreover, the acceptance of South American refugees was shaped by the Cold War environment and its close, even if at times discreet, partnership with the United States (Whitaker 1987).

${ }^{23}$ The current numbers of Mexicans in Ottawa and Montreal are based on Statistics Canada's census divisions (\#2466 for Montreal and \#3506 for Ottawa), for which adjacent cities such as Laval in relation to Montreal are not included. Accordingly, numbers vary when the geographic unit is changed to, for instance, Census Metropolitan Areas, which in the case of Montreal include places such as Saint-Colomban or Lavaltrie. In the case of Ottawa, the census division includes smaller cities such as Kanata, Orleans, and Marlborough.

${ }^{24}$ If we add to the youth category (people aged 20 to 34 ) those who arrived between the ages of 0 and 19 , we note a strong demographic effect that produces a very youthful Mexican immigration to Canada. Thus, between 1980 and $1999,78 \%$ of Mexican immigrants landed between the ages of 0 and 34 (of which $55 \%$ were women and $45 \%$ men) and $71 \%$ between 2000 and 2015 (of which 52\% were women ad 48\% men) (IRCC 2018d, 2018e).

${ }^{25}$ Some of the key literature in this growing scholarly sub-area includes Basok 1999, 2000a, 2000b, 2002, 2003, 2004, Encalada Grez 2007, 2017; Gabriel and Macdonald 2012; Hennebry 2008; Hennebry and McLaughlin 2012; Hennebry and Preibisch 2012; McLaughlin and Hennebry 2013; Paz Ramírez 2013; Preibisch 2015; Preibisch and Encalada Grez 2010, 2013; Preibisch and Hennebry 2012; Satzewich 1991; Straehle and Lenard 2012; UFCW Canada 2011, 2014. For a detailed account of the day-to-day living conditions of Mexican migrant workers, see Leibel 2005.

${ }^{26}$ Alberta established a 'Mexico Office' in 2002. Currently, it has two offices, one in Mexico City and the other in Guadalajara (Alberta is a sister province to the state of Jalisco, Mexico) (Cleveley, Gunderson, and Nazarali 2007). Alberta Mexico Office's goal, however, is entirely devoted to support "export-ready Alberta companies and organizations in exploring the possibilities of the Mexican market for Alberta products and services," engage "in trade and investment advocacy activities to advance the government of Alberta's economic goals, and "[c]onnect Mexican companies with opportunities in Alberta" (Alberta 2019).

${ }^{27}$ The comparison I make between the National Household Survey (NHS) 2011 data and the 2016 Census needs to be considered carefully, since the quality of data significantly differs between both instruments due to the Harper's Conservative government's decision to change the NHS control of data. The NHS was turned into a voluntary rather than a mandatory survey in 2011 . This led to a low response rate of $68.6 \%$ or around $21 \%$ of the Canadian population. Moreover, the quality of the 2011 data differs due to variation in response rates from domain to domain. See more about data quality from this survey in Statistics Canada 2018a. 
${ }^{28}$ For comparison purposes, New York City, with a sizeable community of Mexican migrants, is located at a distance of 3,364 km from Mexico City, while Toronto is located at a distance of 3,243 km.

${ }^{29}$ Even when Chapter 16 of NAFTA has allowed for a relatively trouble-free, temporal inter-mobility of high-skilled migrants among Mexico, the United States, and Canada (i.e. intra-company transferees and professionals) (Canada, Mexico \& USA 1994), the temporal and permanent mobility of Mexicans to the other two countries has been highly regulated. This regulation has varied in intensity, degree, and scope through time depending on the regional and politico-economic needs, interests, and/or constraints of each country, but particularly those of the United States. In contrast, and even when there has also been a long history of migration across the United StatesCanada border, subject to different kinds of regulations (Konrad and Nicol 2008; Ramírez 2001), the mobility of Canadians and Americans was facilitated in 1988 with the signature of the Canada-US Free Trade Agreement. Chapter 16 of NAFTA establishes "the preferential trading relationship between the Parties, the desirability of facilitating temporary entry on a reciprocal basis and of establishing transparent criteria and procedures for temporary entry, and the need to ensure border security and to protect the domestic labor force and permanent employment in their respective territories." Article 1603, which deals with the grant of temporary entry, establishes that "Each Party shall grant temporary entry to business persons who are otherwise qualified for entry under applicable measures relating to public health and safety and national security" (Canada Mexico \& USA 1994).

${ }^{30}$ LGBTIQ+ stands for Lesbian, Gay, Bisexual, Transgender, Intersex, Queer, and other sexual orientations/identities.

${ }^{31}$ The stir did not last for too long among Canadians, since the IRB implemented HIV serological testing as part of the Immigration Medical Examination (IME) from January 2002 for all individuals aged 15 years and older who applied for permanent residence. The test implementation followed the new regulations of the 2001 Immigration and Refugee Protection Act (IRPA), which established that any foreign national would be banned from entry "on health grounds if their health condition (a) is likely to be a danger to public health; (b) is likely to be a danger to public safety; (c) [and/or] might reasonably be expected to cause excessive demand on health or social services." A posterior exception was made for "those who had applied for a permanent resident visa as a Convention refugee or a person in similar circumstances" (Minister of Justice, 2001, section 38.1). IME determines the conditions that are likely to be a danger to public health (i.e. tuberculosis and/or untreated syphilis, although HIV is not longer considered a danger to public health per se) or public safety (i.e. serious uncontrolled and/or uncontrollable mental health) (IRCC 2013a). Health Canada had suggested in the past, after some research and focus groups with Canadians, that the "best public health option" was to implement the results of a predictive computer model called Montebello Process, which suggested the screening of immigrants for HIV and excluding those who were infected (Papp 2000). Thus, although not every person who is HIV positive will be found inadmissible, IRPA guidelines will determine if the condition is "likely to be a danger to public health or public safety, or might reasonably be expected to cause excessive demand on health or social services" (IRCC 2013b).

32 This data, obtained by the newspaper Xtra, only includes Immigration and Refugee Board decisions on inland claims. It does not include Canada's intake of sponsored and non-sponsored refugees who arrive through the United Nations Refugee Agency.

${ }^{33}$ IRB (2018) data obtained by reporters Tara Carman and Anita Elashshows (2018), from CBC, show that between 2013 and September 2017, 8.35\% of all cases were filed due to gender violence against women ( $\mathrm{N}=$ $16,259, \mathrm{n}=1,105) \cdot{ }^{33}$ From these, only 22 cases of Mexican women and five cases of women from the Northern Triangle who alleged domestic violence or sexual harassment were heard (three in El Salvador, one in Guatemala, and one in Honduras). The numbers are, however, just indicative, since many claim categories and claim types in the database were left blank by the IRB. Moreover, there is more than one claim type in some cases, and "claim type categories are generic and are the 'best fit' for each case given the available categories" (IRB 2018). The accuracy of this data, then, needs to be carefully considered.

${ }^{34}$ Examples of this abound, such as the US ban on Mexican avocados (1914-1997), the US embargo on Mexican yellow fin tuna and tuna products under alleged environmental protection claims (2001), or the implementation of the post-NAFTA US Farm Bill (1996), which caused a price-depressing effect on most major crops in Mexico and generated devastating socio-economic effects, particularly among peasants. Moreover, these strategies were also implemented to protect and/or subsidized American producers (see Fish Site Editor 2011; Gilbert 2017; MacDougall n.d.; Wise 2010a, 2010b; WTO 2011).

${ }^{35}$ As part of the new multifaceted forms of violence, some people are being kidnapped not to sustain the 'traditional commerce' of sexual activities, but rather to cater to the degenerate desires of 'customers' who, for dearly sums of money, are allowed to rape and torture young women whilst "almost none of the victims stays alive" (Balderas 2016). 
${ }^{36}$ For example, from January 2007 to January 2013, in a single port of entry, that of Fort Erie, Ontario, 154 unaccompanied minors entered Canada: 28 from Colombia, 11 from El Salvador, and five from Honduras (Sultana 2013). And "[a]ccording to the Canada Border Services Agency, 1,937 children averaging 10 years old have arrived in Canada since 2008 with no parents and no documents, fleeing war, poverty and other adversity in their home countries. The biggest influx came in 2009 when 460 kids crossed the border" (CBC News 2013).

${ }^{37}$ The new 'architecture for bilateral security cooperation' consists of a strategic framework composed of "myriad" of activities and programs known as the Four Pillars: Pillar One: Disrupt capacity of organized crime to operate. Pillar Two: Institutionalize capacity to sustain the rule of law. Pillar Three: Create a twenty first century border structure. Pillar Four: Build strong and resilient communities (US Department of State 2015).

${ }^{38}$ Recent changes in the dynamic of Mexican migration to the United States signal the beginning of a shift in the composition of this migration stream, particularly in metropolitan areas closer to the US-Mexico border. As Ruíz Soto and Seele (2019) indicate, "[e]ducation levels are on the rise among Mexican immigrants, who now comprise the fourth largest group of college-educated immigrants in the United States, after those from India, China, and the Philippines. [...] Nearly one in six Mexicans arriving between 2013-17 had a college degree, compared to slightly more than one in 20 for those entering during the 1996-2000 period." Their employment sectors and levels, and despite their education, however, remain at the level of "a mix of more and less skilled work, ranging from primary/ secondary education and legal services to construction and food services" (1). Reasons for this migration shift, as established by the mentioned authors, are an increase in educational attainment in Mexico during the past two decades, more Mexicans taking advantage of the NAFTA visa, particularly after 2010, increased violence in Mexico, and the expansion of Mexican capital to the United States in the past decade, moving senior executives and key personnel to border cities (ibid.).

${ }^{39}$ All names used here are pseudonyms.

${ }^{40}$ My use of three dots in the form '...' means that the person made a pause in her/his speech. Conversely, the use of the form '[...]' implies that some text was omitted from the original speech."

${ }^{41}$ Under the Canada-Quebec Accord relating to Immigration and Temporary Admission of Aliens of 1991, which was instituted to preserve Quebec's demographic importance within Canada, "Quebec is responsible for the selection of immigrants destined to that province" and for their integration "in a manner that respects the distinct identity of Quebec.” This selection is done through various evaluation mechanisms that, if positive, grant a Certificat de sélection du Quebec to any prospective immigrant. Once a certificate is extended, Quebec refers the selected immigrant "to federal authorities for assessment relating to the admission" and the issuance of permanent residence (Quebec and Canada 1991). The Quebec Experience Program (QEP) "is an accelerated program for selecting skilled workers, which allows individuals to obtain a Certificat de sélection du Quebec. [...] The Programme de l'expérience Québécoise does not involve a selection grid, does not take into account the spouse's or de facto spouse's characteristics and does not require an interview" (Quebec 2016c).

${ }^{42}$ The Quebec Regular Skilled Worker Program (QRSWP) selection process is made based on a point grid for various factors, where each item is weighted differently. The main aspect it evaluates is the so-considered ability of the applicant's professional profile (as well as her/his spouse's, if applicable) to "easily adapt to the requirements and rapid development of the Quebec labour market." The factors considered in the evaluation are the applicant's schooling (i.e. level of education and area of training), work experience, age, knowledge of French and English, their residence in Quebec, and family relationship with a Canadian citizen or a permanent resident, having a valid employment offer, the characteristics regarding their accompanying spouse or common-law spouse if applicable, the number of children under the age of 22 who will be accompanying the applicant to Quebec if applicable, and their capacity for financial self-sufficiency (s/he must sign a contract confirming their commitment to provide for their needs and their family's needs for at least the first three months following their arrival in Quebec) (Quebec 2017).

${ }^{43}$ Currently, the Yukon and Northwest Territories are the only territories with nominee programs (Nunavut is missing).

${ }^{44}$ I am discounting here other immigration sub-programs in the Economic class such as Entrepreneur, Investor, SelfEmployed, Start-up Business, Skilled Trade, Skilled Worker, or Caregiver.

${ }^{45}$ Even in cases of sponsorship of a close relative in Quebec, applicants need to apply for a Certificat de sélection du Quebec-Family Class first. This application needs to be enclosed with the sponsor's undertaking application to the Quebec government. If the undertaking application is accepted, a CSQ will be issued to the sponsored person. The Ministère's decision will then be transmitted directly to the Canadian Visa Office of the sponsored person's country. The sponsored person will then submit their application for permanent residence to IRCC, since the final admission of candidates to Canadian territory falls under the jurisdiction of the Government of Canada. Finally, the sponsored person must satisfy the Government of Canada's health and security requirements to be granted PR (Quebec 2016a). 
${ }^{46}$ I use the official name of the governmental institution, CIC, respecting my respondents' historical account. This name was changed in 2015 to Immigration, Refugees and Citizenship Canada (IRCC).

${ }^{47}$ The physical demand and the seasonal, secondary market nature of picking fruit in the Okanagan Valley has shaped the profiles of the Québécois(es) who migrate to work there during the summer. Although picking fruit has been constituted as a rite du passage among some Québécois(es) since the mid-1970s, most of them belong to a working class rather than a middle-class background (Leibel 2005; O'Donoghue 2001).

${ }^{48}$ These numbers do not include FM2 and FM3 permits given in a Mexican embassy or consulates, but only in Mexico.

${ }^{49}$ For comparison purposes, there were approximately 732,000 Americans living in Mexico according to 2010 data.

This figure, however, can be as high as between 1.5 and 1.8 million people, and the figure is increasing (Selee 2019).

${ }^{50}$ It is estimated that there were 12.64 million of Mexican immigrants in the United States and 260,000 Mexican immigrants in other countries in 2017 (Conapo 2018).

51 "Removals are the compulsory and confirmed movement of an inadmissible or deportable alien out of the United States based on an order of removal. An alien who is removed has administrative or criminal consequences placed on subsequent re-entry owing to the fact of the removal. Returns are the confirmed movement of an inadmissible or deportable alien out of the United States not based on an order of removal" (DHS 2017a).

${ }^{52}$ Information collected by the US Immigration and Customs Enforcement does not make it possible to determine if there are repeated deportations of the same person. Thus, the numbers provided signal administrative procedures rather than individuals.

${ }^{53}$ Jaime is not identified as part of the petit bourgeoisie in Wright's (2000) scheme because he hired a labour force; thus he is identified as a capitalist.

${ }^{54}$ OSAP is a financial aid program in the province of Ontario that helps students to pay for college or university through a combination of grants and a student loan. OSAP is open to Ontario residents of any age who are Canadian citizens, permanent residents, or protected persons (Ontario 2019).

${ }^{55}$ The Order is a professional organization whose members practice a so-considered exclusive profession regulated by a Professional Code. Orders issue permits to new members, update the roll of the Order, monitor the practice of the profession, and detect illegal practice (CPA 2018).

${ }^{56}$ Their quantitative sub-sample for Latin Americans, however, was of 30 persons only.

${ }^{57}$ Garbage collectors in Mexico are usually minimum-wage workers employed by the municipality or by private companies. Some others are independent workers who make money out of collecting garbage and then selling the recyclable materials they find.

${ }^{58}$ However, it has also been demonstrated that the notion that women make a better use of remittances than men is sometimes a stereotype that is not always empirically validated, since women are subjected to, locally and transnationally, different kinds of social pressures regarding the use of remittances (Kunz 2008; Marchand 2006).

${ }^{59}$ For more details on the \#YoSoy132 movement, see Contreras Alcántara 2018.

${ }^{60}$ The printemps érable was a student social movement in Quebec. "In February 2012, after two years of protests, petitions, and occupations, students across Quebec voted to go on general unlimited strike against the Liberal government's plan to increase [post-secondary education] tuition fees. The months following the strike declaration have been the most politically intense time in Quebec or Canada in recent memory as the students' demand for a moratorium on tuition fees has for many become merely representative of a broader struggle against neoliberal policies, the failed logic of austerity, and the weakening of democratic institutions. This social movement declared itself le printemps érable (or Maple Spring)" (Sorochan 2012).

${ }^{61}$ Pauline Marois (Parti Québécois) was the first woman to be elected Premier of Québec. Under Marois' leadership, the Parti Québécois proposed a charter on secularism (i.e. the so-called Charter of Québec Values). "The purpose of the charter was to 'limit the wearing of overt and conspicuous religious symbols by state personnel in carrying out their duties' and to 'make it mandatory to have one's face uncovered when providing or receiving a state service.' The proposed charter sparked an impassioned debate in Québec. [...] However, the public debate was not settled, and no piece of legislation was passed. The Marois government was unable to garner enough votes in the National Assembly to push through its proposals on language, secularism, or the budget" (Chartier 2019).

${ }^{62}$ The City of Montreal dumped eight billion litres of raw sewage into the St. Lawrence River on November 2015 to empty a major sewer interceptor and allow construction work to be completed. The city rejected spending $\$ 1$ billion dollars to build a temporary diversion or storage area for wastewater, and the case was known as the "flushgate" (CBC News 2015a, 2015b).

${ }^{63}$ There are some (semi-institutional) professional, settlement support, or cultural organizations created as non-profits by Mexican immigrants, mainly adults, in various Canadian cities such as Toronto (Canadá nos une, Organización 
Multicultural, Casa Cultural Mexicana, Casa Maiz, Consejo Cultural Mexicano-Canadiense, Enlace, Fundación Social y Cultural Mexicana, Fundación Somos Jóvenes, Grupo de Profesionales Mexicanos en Canadá, Mexico Contemporáneo Foundation, Light your life, Extraordinary Agents Transforming and Enabling Change Ontario - Exatec Ontario, Dignidad Migrante), Montreal (Comunidad Mexicana de Quebec, Centre d'aide aux familles inmigrantes - CASA-CAFI, Mexicain.e.s uni.e.s pour la régularisation, Comunidad de Egresados del Instituto Tecnológico de Monterrey —Exatec, Communauté mexicaine du Québec_ComexQC, Club Riego Viejo),

Ottawa/Gatineau (Confederación de Estudiantes de Posgrado e Investigadores Mexicanos en Canadá and Asociacion Cultural Mexicana Canadiense Ottawa Gatineau), Victoria (Mexican Canadian Community Association of Victoria), Edmonton (Mex y Can Association of Manitoba), and Vancouver (Comunidad Mexicana en Vancouver Services Society). There are (have been) also a number of ballet folklórico or Mexican folk dance groups in various cities, including Ottawa, Montreal, Vancouver, and Toronto. In addition, there are five nodes of the Red Global de Mexicanos or Global Network of Mexicans in Toronto, Ottawa, Montreal, Metropolitan Vancouver, Alberta and Saskatchewan, and British Columbia. The red Global conglomerates Mexican professionals across the globe. 